\title{
RECREATION \\ AND THE AGING PROCESS
}

DISSERTATION

Presented in Partial Fulfillment of the Requirements

$$
\begin{gathered}
\text { for the Degree Doctor of Philosophy } \\
\text { in the Graduate School of } \\
\text { The Ohio State University }
\end{gathered}
$$

by
James Anton Baley, B.S., M.S.
The Ohio State University
June, 1952

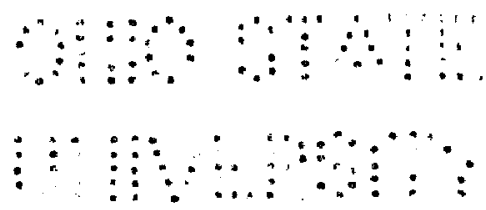

Approved by:

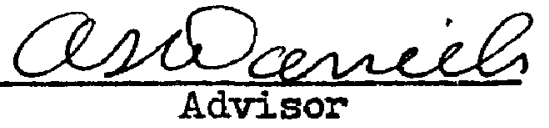




\section{Dedication}

This work is dedicated to the Grandparents of my children 


\section{Acknowledgments}

In a study of this type it is almost impossible to express appreciation to all people who assisted in some way. Literally thousands of men took time from their busy working day to answer the questions asked them regarding their recreational interests, habits, and problems. Although the writer cannot cite these men by name, he would like to express his sincere appreciation for their cooperation. He is deeply grateful to Mr. Ernest Molnar, Iabor Relations Counselor at the Cleveland Pneumatic Tool Company in Cleveland, Ohio for his generosity with his time and energies in assisting with mimeographing, distributing, and collecting two thousand of the questionnaires which were distributed to all the employees of the Cleveland Pneumatic Tool Company.

The writer is greatly indebted to his advisor, Dr. Arthur Daniels for his wise counsel and encouragement given not only with respect to the doctoral work but in all professional areas.

He is also indebted to Dr. Delbert Oberteuffer for his keen analysis and criticism of this dissertation, and to $\mathrm{Dr}$. Willard $\mathrm{P}$. Ashbrook for his examples of effective teaching procedures.

Last, but by no means least, the author must express his thanks to his wife, Estelle, for patiently tolerating, for the past three years, a husband who has been wedded to his desk, for assisting in making some 134,000 tabulations, and for numerous typings and re-typings of rough copies of the dissertation, the typing of numerous letters, and discussing with me and criticizing many of the ideas presented in this dissertation. 


\section{TABIE OF CONTENTS}

Chapter

Page

DEDICATION. . . . . . . . . . . . . . . . . i

AGKNONLEDGEMENTS. . . . . . .............. ii

I INTRODUCTION

Increasing Numbers of Older People. . . . . . . . . I

Necessity for Increasing Length of Productive Years . - 8

Unity of Man. . . . . . . . . . . . . . . 11

Conflicts Increase in Number and Severity With Age. . 13

The Relationship Between Chronic Ailments and Conflict. 15

Play Represents the Expression of Internal Stimuli. - 16

Play Iife Provides a Balancing Agent in Iife Organization. .................. 19

Activity and Health . . . . . . . . . . 22

Scope and Purpose of This Study . . . . . . . . 34

Methods of Procedure. . . . . . . . . . . . 36

The Questionnaire . . . . . . . . . . 37

Iimitations of the study. . . . . . . . . . 42

A Review of Related Studies . . . . . . . . . 44

II INFLUENCE OF AGE AND INCOME UPON RECREATIONAL INTERESTS 56

Influence of Age Upon Recreational Interests. . . . 56

Influence of Income Upon Recreational Interests . . . 64

III TNFLUENCE OF AGE AND INCOME UPON RECREATIONAI HABITS ' 72

Influence of Age Jpon Recreational Habits . . . . . 72

Influence of Income Upon Recreational Habits. . . . 78

IV RELATIONSHIP BETWEEN RECREATIONAL INTERESTS AND HABITS 85

Influence of Age Upon These Relationships . . . . 85 iii 
Influence of Income Upon These Relationships. . . . 95

$V$ REASONS OFFERED FOR UNSATISFACTORY PARTICIPATION

Influence of Age Upon Reasons Offered for. Unsatisfactory Participation. . . . . ....... 101

Poor Health . . . . . . . . . . 103

Lack of Time. . . . . . . . . . . 103

Lack of Money . . . . . . . . . . . 10L

Lack of Facilities. . . . . . . . . . 104

Lack of Knowledge or Skill. . . . . . . . . 105

Amount of Frustration Experienced in Satisfying Recreational Desires . . . . . . . . . . . J.12

Summary of the Questionnaire Findings . . . . . . 117

VI DISCUSSION AND RECOUMENDATIONS 123

Major Findings. . . . . . . . . . 124

A Recommended Personal Perspective. . . . . . . 125

A Recommended Social Point of View. . . . . . 129

Industrial Recreation ............ I48

Recommendations for Possible Contributions by Educational Institutions . . . . . . . . . 161

Suggestions for Further Research. . . . . . . 181 BIBLIOGRAPHY. .................. 183 APPENDIX. . . . . . . . . . . . . . 190 


\section{LIST OF TABLES}

Table

Page

1 PREDICTED CHANGE IN POPULATION DISTRIBUTION. • . . . . 1

2 PERSONS AGED SIXTY-FIVE TEARS OF AGE AND ABOVE . . . . 2

3 TMPEOVEMENT IN PHYSTCAL FITNESS ITEMIS AS A RESULT OF PHYSICAL ACTIVITY. . . . . . . . . . 28

4 NUMBER OF REN WHO PARTICIPATED IN THE SPCRT IISTED AT LEAST ONCE DURING THE YEAR 1940 (FROM HUSMAN). .... 4.5

5 PERCENTAGE OF MEN LIKING FIFTY-SEVEN AMUSEMENT ITEUS 51 (FROM STRONG)..................・

6 RANK ORDER OF DECRENENT IN NURBBER OF MEN FROM SUCCESSIVE

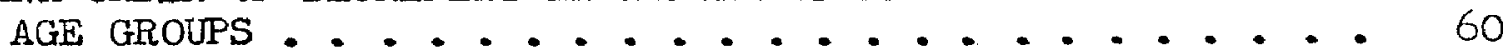

7 TWENTY MOST POPULAR ACTIVITIES IN EACH AGE GROUP . . . . 63

8 TWENTY MOST POPULAR ACTIVITIES IN EACH INCONE GROUP. . . 65

9 ACTIVITIES FOR WHICH THE PARTICULAR INCOIE CROUP SHOMED

A HIGHER PERCENTAGE OF ITKING THAN ANY OTHER INCOME

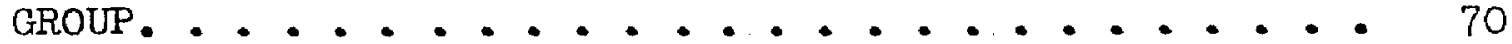

10 TWENTY ACTIVITIES PARTICIPATED IN MOST FREQUENTLY BY MEN OF EACH OF THE FIVE AGE GROUPS. . • •. •. •... 73

17 THE NINE ACTIVITIES IN WHICH FREQUENCY OF PARTICIPATION INCREASED WITH AGE •............. 78

12 THE TWENTY ACTIVITIES PARTICIPATED IN MOST FREQUENTLY BY MEN OF EACH INCONE GROUP .............. 79

13 EXTENT OF SELECTION OF ACTIVE FORMS OF RECREATION OVER SEDENTARY FORUS. ................

I4 DISCREPANCY SCCRES FOR AGL GROUPS. . . . . . . . 86

15 ACTIVITIES CLASSIFIED AS SEDENTARY AND MIIDLY ACTIVE • • 91

16 ACTIVITIES CLASSIFIED AS ACTIVE. . . . . . . . 92

17 DIFFERENCES BETWEEN TOTAL DISCREPANCIES FOR SEDENTARY AND MIIDLY ACTIVE AND ACTIVE FORAS OF RECREATION • • • 93

I8 DISCREPANCY SCORES FOR INCOME GROUPS . . . . . . . 96 
19 DISTRIBUTION OF REASONS FOR UNSATISFACTORY PARTICIPATION WITHIN EACH AGE GROUP. . . . . . . . . . . . . . IO3

20 COMPARISON IN NUMBER AND RELATIVE FREQUENCY OF REASONS FOR UNSATISFACTORY PARTICIPATION BETWEEN ACTIVE AND MIIDLY ACTIVE AND SEDENTARY TYPES OF RECREATIONAL ACTIVITIES FOR FOUR AGE GROUPS . . . . . . . . . . 108

21 THE TWENTY-FIVE ACTIVITIE'S SHOWING THE IARGEST NUMBER OF MEN LISTING REASONS FOR UNSATISFACTORY PARTICIPATION • - 11.3

22 SUGGESTED LIST OF ACTIVITIES APPROPRIATE TO EACH AGE GROUP. . . . . . . . . . . . . . . . . . 134 
RECREATION AND THE AGING PROCESS

CHAPTER I

Introduction

Increasing Numbers of Older People. Due principally to advances in medical science, public sanitation, and public health knowledge within recent years, length of life universally and particularly in the United States, has been steadily increasing. We can expect to see increasing numbers of older people in our society.

Studies of the 1940 Census reveal that while the population of the United States as a whole increased 7.21 per cent over 1930, the number of persons aged sixty-five or over increased 35.0 per cent. In 1940 there were approximately nine million people sixty-five or more years old in this country. The Census Bureau, by conservative estimate and assuming that there will be no increase in immigration, predicts that in another thirty years the structure of our population will be changed in the following ways: 1

Table I

Predicted Change in Population Distribution

Years of Age $\quad 1940$ 1980

$\begin{array}{ccc}9-19 & 34.5 \% & 25.8 \% \\ 20-54 & 50.7 \% & 47.0 \% \\ 55-64 & 8.0 \% & 12.8 \% \\ \text { Over 65 } & 6.8 \% & 114.4 \%\end{array}$

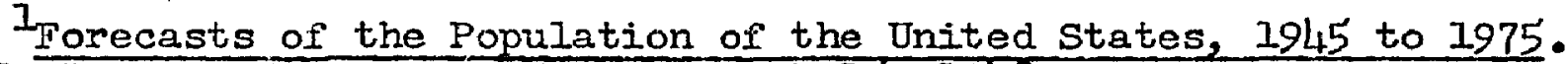

U. S. Bureau of Census. Issued March 15, 1948. 
It can be seen that there will be a substantial increase in the proportion of people over fifty-five and a decrease in the proportion under fifty-five.

The United States Bureau of Census presents still another point of view of the problem. The trend of those aged sixty-five and above in the United States, according to Census data and predictions based on median birth rate and median mortality rate and disregarding the influence of immigration, is as follows: 2

\section{Table 2}

Persons Aged Sixty-Five Years of Age and Above

\section{Year of Census \\ or}

Prediction

1900

1910

1920

1930

1940

1945

1950

1955

1960

1965

1970

1975
Number

$3,080,000$

$3,950,000$

$4,933,000$

$6,634,000$

$8,964,000$

$10,110,000$

$11,193,000$

$12,583,000$

$13,978,000$

$15,157,000$

$16,370,000$
Percentage

of Total

Population

$4.7 \%$

$4 \cdot 3 \%$

$4.7 \%$

$5.4 \%$

$6.8 \%$

$7.2 \%$

$7.7 \%$

$8.4 \%$

$9.1 \%$

$9.7 \%$

$10.2 \%$

$10.9 \%$

The above figures show an eighty-eight per cent increase from 1900 to 1950 in the number of people sixty-five years of age or more, with another forty-two per cent increase predicted in the next quarter century.

$$
\text { 2Tbid., p. } 11 \text {. }
$$


Stieglitz observes that the median age of the population increased from 26.4 in 1930 to 28.9 in 1940.3 This is an increase of 2.5 years in the average age of the population within a brief span of a decade. He estimates that the median age of our population will very probably be close to forty-five in another fifty years. Rate of Increase of Numbers of Elderly Poople May Accelerate. The predictions of the Census Bureau regarding the changes in the age distribution of the population were made without regard for the enormous strides being made by the relatively new branch of medicine called geriatrics.

It has been shown experimentally that length of life can be increased. Furthermore, many medical men believe, on the basis of empirical evidence, that man's life span can be increased. 4

Edward L. Bortz, past president of the American Medical Association, is quoted as saying that a dog is full grown at two years and lives to an average of twelve; a cat is full grown at one year and a half and lives to ten; a horse is full grown at four and lives to twenty-five. He reasoned that if a man is physicaliy mature at twenty-five, he should have a normal life span of one hundred and fifty years.

Henry S. Simms of Columbia Iniversity's College of Physicians and Surgeons has computed that if the human body could retain all

3Edward J. Stieglitz, The Second Forty Years, p. 17. 4"The 150 Year old Man," Time, December 29, 1947, p. 53. 
during life the ability to resist disease and repair breakdown that it possesses at the age of ten, ". . . man would have a life expectancy of eight hundred years and some individuals might survive twenty-two thousand years."

Henry Clegg Sherman, Professor-Emeritus of Columbia's Department of Chemistry, has increased the life span of rats by ten per cent by increasing intake of Vitamin A alone.

Australian scientist, T. B. Robertson, has increased the life span of mice seventeen per cent by feeding them nucleic acid, a component of yeast.

Anton J. Carlson of the University of Chicago added twenty per cent to the life span of rats simply by having them fast one day in every three or four days.

C. M. McCay of Cornell increased the life span of rats over fifty per cent by restricting caloric intake and adding minerals and vitamins.

T. S. Gardner, a graduate of Ohio State University, M.I.T., and Tennessee, has added ten per cent to the lives of laboratory mice by feeding them nucleic acid, while working with mice already old. Gardner, who is advisor to the National Foundation for Anti-Aging Research, and his associate Edward Wenis, have succeeded in prolonging the life of a guinea pig to the human equivalent of 148 years. This animal from birth had been fed a high-vitamin diet was already old at 700 days, corresponding to seventy years in human beings, when it was first fed nucleic acid. 
Due to research in the medical profession, the sciences of chemism try, nutrition, sanitation, and health education, people are living longer. They have succeeded in adding years to our lives. Now it is time to add Iife to our years. Perhaps recreational activities can help to accomplish this objective.

Large Number of Invalids Among Older People. A large and growing number of men from the older age groups are prematurely disabled by the so-called degenerative diseases. A characteristic of these degenerative diseases is their slow but inevitable progression and long periods of disability before the victim actually succumbs to the disease. A man in his forties or fifties, disabled for years by arthritis or cerebral, peripheral, or coronary arteriosclerosis, is a greater social loss and a heavier burden upon his immediate family and society as a whole than a man who dies immediately. The cost of these chronic diseases of middle and old age must be measured by more than the mortality tables.

Stieglitz points out. that, in the past, selective forces insured the operation of nature's law of survival of the fittest. Wars, famine, pestilence, droughts, and floods caused changes in population structure before, but always in the direction of a relative increase of youth. He believes that the problem of our day results from constructive forces; medical science and the diminished rigors of modern civilization have enabled many less vigorous youths to survive into full maturity. Wars will operate to accelerate these changes. He warns that the accumulating millions of the relatively unfit of all 
ages may ultimately jeopardize the survival of the fit. 5

Although life expectancy increased about fourteen years from 1910 to 1935, average Iife expectancy at 50 years of age increased by only 2.8 years. Why have the gains been so asymmetric? Obviously there is room for improvement in health, and therefore in Iife expectancy, after the age of fifty.

Many medical men suspect that these chronic ailments are due in part to the tensions and strains of modern life. Can recreational activities act as a counterbalance to these tensions and strains? Many physicians and psychiatrists believe they can. Family Relationships. Fanily relationships have changed greatly in recent years. This makes it more necessary now than formerly that the old develop and sustain the qualities of self-respect, mental alertness, and physical stamina in order to be able to maintain their economic independence for a longer period. Old people are no longer the recognized heads of households of three or four generations. This means that fewer older people than before can retire with prospects of aid from the children. This fact, coupled with that of the high mobility of our people, causes many older people to be without homes or close family ties. Much of the mutual interdependence between generations has disappeared. These changes, in addition to making more urgent the necessity for sustaining productivity and economic independence, make it more difficult for these people to secure those

5stieglitz, op. cit., p. 17 . 
basic needs such as affection, emotional security, companionship, recognition, and self-respect. These needs cry as loudly for satisfaction among the old as they do among the young. The Great Loss in Human Resources at the Mature End of Life. Industry is fullycognizant of the great loss in human resources which occurs at the mature end of Iife. It takes many years and the expenditure of large amounts of money to train men for specialized and technical positions. Too often, by the time a man has reached his peak in knowledge, skill, and productive efficiency, he is already well on the way down in stamina, energy, and health. If men could sustain these last qualities, qualities of youth, their productivity would be vastly increased. Their decreased stamina, energy, and health is a loss not only to themselves but to industry and society as well. A wealth of wisdom and potentially constructive work is permitted to waste away. Particularly during times of industrial expansion, industry would prefer not to release these older men. However, knowledge, skill, and experience which cannot be put to use is worthless. Older People Wish to Remain Useful. Not only does management desire to continue utilizing the particular abilities of older men but also the older people themselves show a desire to continue to be useful. In April of 1945, a year of high demand for labor, the Bureau of old Age and Survivors Insurance of the Old Age Security Board estimated that 70,000 old age beneficiaries had dropped benefits and returned to work. They further estimated that 750,000 wage earners who were entitled to benefits and could have retired had stayed on the job. At this time the number of men in the labor force 65 years of age and over 
was 25 per cent above normal. The excess over normal of men 45 to 64 was not so striking. The number of women in the labor force 65 years of age and over was 50 per cent above normal. The age group $55-64$ was almost as high, while that of 45 to 64 was $33-1 / 3$ per cent above norma1. 6 Between April 1945 and April 1947 there was a net withdrawal of over 3,000,000 women from the labor force. In the age groups 20-34 the outgo was so great that there was a deficit of over 1.4 million such women in the labor force. Despite these influences, the excess of women above normal 65 years and over exceeded 29 per cent in Apri.l 1947, and proportions in groups 55 to 64 and 45 to 64 remained high. The older women continued in the labor market. Among older men comparatively little change took place between April 1945 and April 1947. Those who obtained jobs under conditions of high wartime demand held on to them in the post war prosperity period irrespective of the age factor. 7

It would seem that the older workers want to continue on the job as long as they can and will not voluntarily withdraw from the labor force but will withdraw only when forced out.

Necessity for Increasing Length of Productive Years. It is necessary that industry spend considerable money in training its personnel. Whenever a company is forced to retire one of its employees it must train another man to take his place. This training represents a

6 Clarence Brown and Edwrin Ghiselli, "Oldsters Not So Slow," Science Digest, Vol. 27, No. 4, 1950, pp. 35-36.

7 Edwin Claque, "Employment Problems of the Older Worker," Monthly Labor Review, December, 1947, pp. 661-663. 
considerable expenditure of money. Industry should begin to investigate mothods of saving money by lengthening the period of productivity. It seems probable that a well organized industrial recreation program and intelligently planned personal recreation could make some substantial contributions in this direction. This is a problem which demands further study.

Edward J. Stieglitz points out the necessity for sustaining vitality and fitness into advanced age when he writes:

Industry and employers as a whole, must either increase the duration of employment of these increasing millions of older individuals or pay for their maintenance out of some system of dole or pensions or otherwise. I cannot conceive of a stable economy in which we have a large group of consumers who are not producers at all. We already have one large group like that--youth, with the increasing requirements of education-having to go to school much longer, etc. What about the other end? The middle group is getting smaller and smaller and is trying to carry a yolse at both ends with an increasing burden.

Can they save for their old age? I doubt it. In 1929, before the crash, five per cent of people reaching age 65 in New York State had sufficient funds to continue at their same standard of living; 28 per cent continued to work and 67 per cent were dependent on family or state or both. 8

If industry does not increase the duration of employment of the increasing millions of older individuals, it will be necessary to pay for their maintenance out of some system of dole or pension. A stable economy seems unlikely is there is a large group of consumers who do not produce some of the world's wealth. With the increasing educational requirements upon youth requiring them to go to school much

8, dward J. Stieglitz, "Health Problems of An Aging Population," The Ohio Citizen, June, 1949, p. 27. 
longer, the middle aged group is becoming smaller and smaller and is having to carry a yoke at both ends with an increasing burden at both ends.

Summary. The proportion of older people in our society is increasing at a rapid rate. If the predictions of geriatricians, biologists, and nutritionists prove true, this rate of increase will accelerate. The large number of chronic invalids among older people and their early retirement places a burden upon the wage earning group. This group has been growing proportionately smaller. It is being forced to carry a burden at both ends--the increasing numbers of retired and invalid older people at one end and the younger people whose productive period is being delayed due to increasing educational requirements at the other end. The early retirement of men with fifteen or twenty years of life remaining represents a great loss in human resources. Compulsory retirement often comes when a man still has many years of productive life remaining. The experience and knowledge this man possesses has taken many years to acquire. Often the man lacks the necessary physical stamina and vigor to continue worling. Other men may still be vigorous and healthy at age sixty-five. Biologic time is not the same as chronologic time and biologic age is not the same as chronologic age. Some men age more rapidly than others. For these reasons it is recommended that retirement at age sixty-five be made optional with the emplojee providing he can pass satisfactorily certain mental and physical examinations. 
In the next section an effort will be made to investigate the possible contributions of physical education and recreation to the solution of the problem discussed above. Can recreational activities, games, and sports be used to help slow down the biologic clock? There appears to be some evidence that it can. Present evidence indicates that it cannot be conclusively proven that recreational activities can accomplish this ambitious goal but there is sufficient evidence to lead us to believe that the topic is worthy of considerably more study than has been accomplished to date.

Can Recreation Contribute to Increased

Length of the Productive Years?

The Unity of Man. All living organisms, even the simple cell, start out in an integrated state. Integration is primary. Disorganizing influences may come along later but as the organism develops it strives to preserve an integrated state. The Whole is Greater Than the Sum of Its Parts. The human organism is not a collection of bones, muscles, a heart, and a brain. The interdependence and the relationship between the various parts of the organism make of them a living organism. That which is termed mental is really a derivative or special manifestation of the physical. 9 Mental and emotional attitudes influence not only athletic performance but can also influence detrimentally the various organs of the body and bring about ill health. Conversely, physical states, physical activity, and bodily development can influence the mind and the emotions. 
Influence of the Mind Upon the Body. Dunbar Flanders points out that a type of emotional development which prevents a person from practising "the hygiene of the quiet mind" may result in a number of unhygienic bodily consequences such as nervous indigestion, inability to swallow, constipation, backaches, tics, hypertension, and tendency towards accidents. 10 He goes on to cite a number of case studies which illustrate the association between the mind and the body.

S. H. Bartley and Eloise Chute emphasize that the condition known as fatigue which is usually thought of as physical is essentially a mental attitude. 11 They point out that since fatigue is experiential, and since "experiential" and "mental" are common synonyms, all fatigue is mental and fatigue can no longer be classified as either mental or physical.

Influence of the Body Upon the Mind. Rees and Eysench report results in which body build shows marked relationships to personality ratings. 12 The body build index was derived from a factor analysis of eighteen variables including height, weight, and various body dimensions. By means of this index, 389 neurotics were differentiated from 100 normal soldiers with a Critical Ratio of 2.3 . The findings showed that the neurotic population contains more extremes in body type than the

10 Dumbar Flanders, Mind and Body; Psychosomatic Medicine, p. 150. II. Howard Bartley and Eloise Chute, Fatigue and Impairment in Man, p. 303.

12W. L. Rees and H. J. Fysench, "A Factoral Study of Some Morphological and Psychological Aspects of Human Constitution, "Journal of Mental Science, Jan. 1945, pp. 8-21. 
normal population. They showed further that body types are an important factor predetermining the type of neurosis. The ectomorphic body types showed a larger percentage of obsessional, anxious types with narrow hobbies and interests. The endomorphs suffered from a greater amount of hysteria.

Malfunctioning of the endocrine organs provide another example of the close interrelationship between the mind and the bodiy. Mental and emotional life may be disastrously affected as a result of hypo or hyper-activity of the endocrine glands. 13

Conflicts Increase in Number and Severity With Age. The consideration of aging should take on the form of dealing with the individual's changing interests, purposes, attitudes, abilities, and experiences. The study of aging is an example of the genetic approach to behavior although it is not the only approach which should be used. It is not easy, if at all possible, to distinguish clearly between phenomena which may be attributed to aging and those which may be better understood in other terms. In many cases, it is profitable to avoid making this distinction. This is the point of view which has been taken in this study. The integrated, unified approach to the study of human problems is relatively new. For this reason, it has been found necessary at times to report studies which have taken the older segmented point of view. Where this has occurred, attempts will be made to show the necessary relationships.

\section{3 zoothout, Textbook of Physiology, p. 474 .}


Effects of Aging Upon the Human Organism. While many characteristics of behavior are premised upon inevitable changes that might be taken as a manifestation of organic aging, some of the characteristics studied are results of living in a social world. The effects of meeting conflicts on all levels over long periods of time accumulate and becom increasingly obvious as the individual grows older.

Conflict, in this case, refers to any clash or incompatibility occurring within the organism. Conflicts occur on all levels of organismic activity; and they lead directly to further disharmony and disorganization. 14

According to Sherman, a conflict may arise as "a result of an unsatisfied need or desire which the person regards as requisite for his we.ll-being." 15

Conflicts tend to increase with age until maturity. It is by no means true that conflicts are nonexistent in childhood or even infancy. It is true that the conflicts of adults are more complex and far reaching in their effects. The threat a conflict may mean to personality integration is greater when the personality is well formed than it is in the immature where personality integration is still 10ose. 16 As the individual grows older the opportunities, the difficulties, and the frustrations change. We usually expect the individual to become increasingly set in his ways of doing things and in his thinking. If

$\mathbb{1 4}_{\mathrm{S}}$. Howard Bartley and Eloise Chute, op. cit., p. 53.

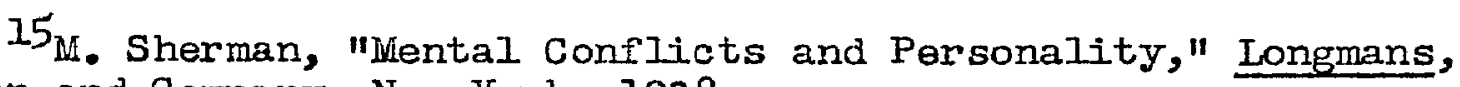
Green and Company, New York, 1938.

$16 \mathrm{~S}$. Howard Bartley and Eloise Chute, op. cit., p. 300. 
the individual builds up more and more aversions to situations he is bound to get into, old age can close in on him with considerable cruelty.

The Relationship Between Chronic Ailments and Conflict. Students of psychosomatic medicine have pointed out that conflict situations can and often do lead to chronic ailments such as ulcers, hypertension, tuberculosis, headaches, chronic fatigue, tics, allergies, and constipation. The incidence of these chronic ailments is known to increase with the age of the subjects surveyed. It has been pointed out that conflict situations increase both in frequency and in intensity with increasing age. There is great probability that the reason for the greater incidence of chronic ailments with increased age is the greater frequency and severity of the conflicts which come with increased age.

Dunbar Flanders indicates one of the reasons for the increasing frequency of the chronic ailments. He writes:

The advances of public health have banished epidemics, medical progress has taught new cures for once deadly diseases; millions are spared to an age when the most successfully buried mines of childhood are likely to explode, to an age when they are susceptible to the chronic and predominantly psychosomatic diseases. 17

Dissociative Character of Machine Work. As our social and economic structure becomes increasingly complex men are called upon to face an increasing number of situations which may lead to conflict. Kimball

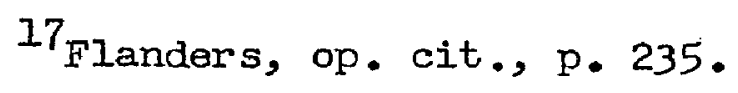


Young provides an illustration of this in one area--factory and machine work. 18 When men engaged in unified activities such as operating a farm, weaving a rug, or making completed articles of clothing or wood, the effects of these habits on personality organization were undoubtedly different from what they are today. A man's tools and the products of his work represented him. The inception and completion of an article constituted an integrated series of cycles of activities involving the entire personality. Today men operate machines which make only a small part of the complete article. It is difficult for men to find satisfaction in creation and in the pride of worlonanship, handicraft ability, and skill.

It seems highly probable that men can now secure this pride in accomplishment during their leisure time through various types of recreational activities. The type which they select will depend upon their own personality structure and ego needs. Some will find it in handicrafts, some through music, others through athletics, and still others through art. The selection of a recreational activity is and should be a highly individual and personal choice. Play Represents the Expression of Internal Stimuli. Kimball Young in discussing the impulsions to activity reminds his readers of the priority of internal stimuli over external stimuli.19 Although the exteroceptors are of importance, we must not forget that responses set

\footnotetext{
18 Kimball Young, Personality and Problems of Adjustment, p. 594. 19 Ibid., p. 60 .
} 
up by extrinsic factors are always greatly affected by the internal organism at that particular time. If, as Coghill points out, "the individual acts on its environment before it reacts to its environment," we must recognize that fundamental activity begins within the individual.20 In the course of growth and development, the activities of the human organism are initiated and conditioned more and more by extrinsic factors. It seems probable that this dictation by external factors and the submission of the internal stimuli will ultimately lead to varying degrees of personality disorganization.

Through recreational activities such as handicrafts, art, athletics, music, dancing, and to a lesser extent through the passive forms of recreation such as watching athletic contests, plays, and movies, an individual is afforded an cpportunity to give expression to these internal stimuli. This it seems would aid in lessening the extent of personality disorganization. Play is a spontaneous and pleasurable expenditure of energy for some immediate benefit. It is characterized by a spontaneity of action which is not found in the imposed task of the regularized and restricted movements of work which are directed toward a more remote goal. By its very definition, play is seen to give expression to the primary internal stimuli.

Play Satisfies Basic Human Needs. D. A. Prescott combined unlearned and acquired motives or needs into three large classes: physiological, social, and egoistic.21. The first has to do with the physical demands
20 G. E. Coghill, Anatomy and the Problem of Behavior, p. 47.
2ID. A. Prescott, Emotion and the Educative Process, p. 63. 
of bodily survival, air, food, elimination, shelter, avoidance of disease and danger, activity, and its counterpart rest and sexuality. The social needs are those of affection, participation or belonging, and likeness to others. The ego needs are concerned with the organization of selfhood such as effecting a fair balance between success and failure and an attainment of individuality which is efficient with reference to the obligations of others.

It seems probable that recreation can contribute to the satisfaction of all of the three great needs. With regard to the physiological needs, recreation can provide activity in a life which calls for little activity. Recreation can make substantial contributions to the social needs such as affection, participation, belonging, and"likeness to others." These needs are not easily satisfied at most occupations. Recreation can make great contributions to the ego needs by offering opportunities for success and attainment of individuality.

Dunbar Flanders indicates the need for an adequate recreational life when he writes:

widely spread diseases of our civilization, and one of
the most infrequently recognized. Most victims do not
suspect that they have it until it has been complicated
by some other ailment. Teaching them how to relax is
one of the most valuable of the psychosomatic techniques.22

Kimball Young believes that much of the problem of maladjusted personality rests in the failure of the basic organic tensions to find socially acceptable releases.23 Feelings of aggression can find outlet

22 Flanders, op. cit., p. 138.

${ }^{23}$ Young, op. cit., p. 65 . 
through a number of recreational activities. Competitive games and chopping wood, are examples of recreational activities which can provide socially acceptable release for feelings of aggression. Desires for affection and "belongingness" can be secured through membership on a team or in a social club.

According to William henninger, noted psychiatrist, recreational activity has a renewing effect psychologically. It is a re-creative experience. The rewards accruing, he contends are physical, mental, and psychological. He points out how recreation provides release for the basic organic tensions. He suggests three types of recreational. activity which effectively meet important psychological needs:

1. Competitive games which provide an unusually satisfactory social outlet for the feelings of aggression which do not have sufficient opportunity for expression in bther aspects of civilized living;

2. The opportunity to produce something-a rug, a chair, a poem, or a cake provides expression for the erotic, constructive, or creative drive; and

3. Relaxation through entertainment also satisfies important psychological needs through catering to passive desires as well 25 providing an opportunity for vicarious
participation. 24

Play Life Provides a Balancing Agent in Iife Organization. The variation in expression of interests is an involved matter. When most of one's fundamental drives are direvted toward an all-absorbing profession or job, the usefulness of hobbies or of religion or of art may not be very evident. In such individuals there is often a sort of hierarchy of interests, some dominant, others subsidiary, but all

$24_{\text {William Menninger, }}$ "Recreation and Mental Health," Recreation Magazine, November, 1938, p. 79. 
directed to the major aim or task or goaz. But few persons are fortunate enough to be in such circumstances. Hence, religion, artistic axpression, hobbies, or play life may provide balancing items in life organization.

W1Ima Donahue lists six needs which older people have in common with younger people. These are:

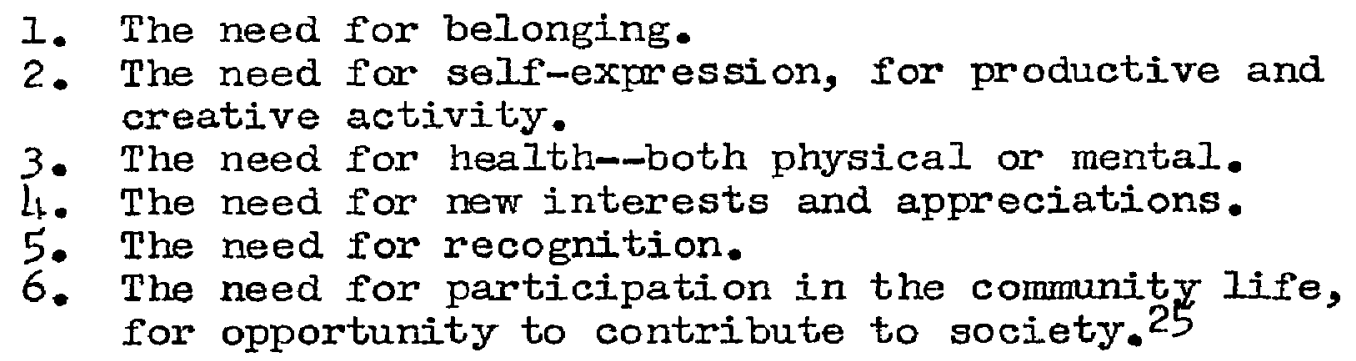

She writes further:

It seems clear that recreation has the possibility of playing a larger role in meeting any or all of these needs. The fact that, in the later years, usually a greater amount of leisure is available for doing things for the joy of doing them gives added importance to the role of recreation. 26

Gove Hambidge, a popular writer on the problems of aging, comments on the power of athletic activities to satisfy ego needs. He writes:

The experience of the spectator is mild compared with that of the player-which is the reason games should be played, not watched from a grandstand. At the risk of uttering a blasphemy, I wish to remark that catching a fast ping-pong ball and returning it with precision gives a pleasure not so far removed from that a painter feels when he makes a good stroke with his brush on canvas.

And that is one of the reasons why athletic games are so valuable for those of middle age and beyond. The game not only keeps the body supple and in good tone, which, after all, calisthenics would do; it subtly flatters the ego

\footnotetext{
25 Wilma Donahue, Planning the Older Years, p. 99. 26 Ibid., p. 99.
} 
with a sense of mastering new and difficult things. All of us need that kind of flattery, on occasion. We get it in games, no matter how modest the skill required. 27

The Expression of Neurosis in Older People. Social recognition and the assurance that they are useful members of society are just as essential for a well balanced personality for older people as they are for younger people. If this social recognition is not forthcoming, older people often resort to procedures to secure attention which are not entirely desirable. George Lawton makes the point that the demand of older people for increased old age assistance grants is based in part on a bid for social recognition sought as consolation for a person's frustrated ego. A neurotic unconsciously either exploits a genuine iliness or invents one in order to get attention, acting on the unverbalized feeling, "If you can't give me love, you can give me attention or sympathy." Lawton continues:

This same frustration expresses itself in other ways. Invariably older people have more physical ailments than younger ones. But these ailments, mostly chronic di.seases, are often difficult to distinguish from emotional disturbances. Louis Hammon, professor of internal medicine at Johns Hopkins says that of 500 patients consulting him on purely physical disorders, there were one-third without any discoverable organic cause for the symptoms of which they complained.' of the 500, 390 were over forty and 150 were over sixty. 28

He then suggests the need for some community agency to direct older people to recreational activities and courses for education, enjoyment, and social contacts.

27 Gove Hambidge, Time to Iive, Adventures in the Use of Leisixre, pp. 67-68.

${ }^{28}$ George Lawton, "You Cannot Demobilize Old People," Survey, April, 1946 . 
The "Golden Age Clubs" of Cleveland, Chicago, and Columbus have shown that interests of older men in various recreational activities can be aroused. Most of the members of these clubs found the needed social recognition trrough the hobby shows and various other activities. A large percentage of the members of these clubs are people who are senescent or already senile. Aging and middle aged men can secure this needed social recognition through sports and other recreational activities and at the same time sustain their physical efficiency.

Activity and Health. Iillian Martin, one of the pioneers in the psychiatric counseling of older people, in discussing the relationship between will power and muscular coordination in senescent and senile people writes:

We must also remember that wealmess of will is often a matter of muscular activity. That is, will is strong or weak in proportion to the degree and quality of muscular coordination in the person. Nuch can be comfortably done to strengthen the will by simple physical exercises of certain muscles and by occupations that develop muscular coordination, but these must never be exhausting or even cause overfatigue. 29

Edward J. Stieglitz, who is undoubtedly the foremost geriatrician in this country, feels that games, sports, and athletic activities are truly recreative in that they represent "deposits" in the bank balance of health while work and worry represent withdrawals. 30 He especially recommends then for those whose responsibilities are continuous and heavy and for the tired, serious, and responsible types

29 Lillian Martin, Salvaging Old Age, pp. 108-109. 30 Stieglitz, op. cit., p. 266. 
of individuals. We can borrow from ourselves by running on our nerve or relying on stimulants and mental whips and spurs, but such overdrafts must always be repaid.

Homer Kempfer, a student of the aging process, recommends exercise and physical activity for older people when he advises:

Since a reasonable amount of physical exercise seems to contribute to health, interests in such pursuits as housework, hunting, fishing, dancing, athletic sports, gardening, care of small children, and small scale farming can be encouraged to an advanced age if they do not run counter to physical limitations. $3 I^{\circ}$

The Organic Bases for Physical Activity. Phylogenetically, geneticalIy, and organically man is an active creature. Mian's organic health, growth, and development depend upon physical activity. The interdependence between the vital organs, between the organs and the skeletal muscles, and between the involuntary and the voluntary muscles dictates that man continue to keep himself physically active as long as he is able if he wishes to remain healthy and vigorous.

The coming of the industrial revolution has removed the necessity that man earn his living through the use of his muscles and the "sweat of his brow" Machinery now does almost all his physical work for him. This makes physical activity a personal choice. If an adult chooses to lead a completely sedentary life there is no one who will dictate that he do otherwise. The majority of adult men know, or at least feel, that they should secure this needed physical activity yet actually only a small percentage of them engage in some active form

3I Homer Kempfer, Education For a Long and Useful Iife, p. 22. 
of recreational activity regularly. Menke estimates that there are four or five million different people who play golf each year.32 How many of these play golf regularly? It appears that this is only a very small percentage of the total population of the United States. Perhaps there are another nineteen to twenty million bowlers but how many of these have been counted earlier as golfers? The statistical figures sound impressive, but to give us an idea of the proportional numbers of people who engage actively in sponts we need only to compart the number of adult television viewers, spectators at athletic contests, movie goers and night clubbers with the number of adults in attendance at the Young Mens: Christian Association, swimming at the beach or pool, hiking, cycling, or bowling. It can readily be seen that those in the first group far outnumber those in the second. Yet we often hear adult men say: "I need some exercise." This is an acknowledgement that they recognize the need for physical activity but lack the initiative, sufficient interest, or facilities to secure it. Undoubtedly, much remains to be accomplished in the direction. of increasing the frequency of participation in physical activities by adult men. The Need for Fitness in Modern Life. A study of the history of civilization will make apparent the importance of a high degree of physical efficiency for all men. Great strength and physical endurance were essential in building the Pyramids of Egypt. In all the wars of history,

32 Frank Menke, The Encyclopedia of Sports, p. 56. 
the nation which could produce the most agile, strongest, most enduring, and most courageous men was invariably the conquering nation. The men who created cities, farms, and homes out of the wilderness of the early North American continent undoubtedly needed excellent physical condition to sustain life under the adverse conditions.

Good physical condition is just as essential to progress and efficient living today as it has ever been. It is true that today there is not as high a premium placed on strength, agility, and physical endurance in and of themselves as there was in the past. However, the concomitants of physical fitness are more needed now than they have ever been. Nervous and emotional stability are prime requisites in modern life. Good health is no less important. Man is an indivisible unit. He acts and reacts as an integrated whole. He cannot be divided into separate compartments. Muscles, heart, blood, and mind function as a unit. The muscles of the greatest athlete in the world would remain impotent without the help of the heart, the liver, the nervous system, the thyroid, and all the other organs and glands of the body. All physical activities contain mental elements, and all mental activities are dependent upon organic functions. The use of the muscles stimulates the activity of other bodily organs and in that way improves their functions. For these reasons, good physical condition for men of all ages is important.

Efficient and successful living in the world of today does not demand strength to move boulders, muscular endurance, or agility, but it does demand great nervous energy, emotional stability, and the ability to think clearly. All of these are dependent upon good physical 
condition. Evidence will be presented in the following section which shows that regular and progressive exercise of sufficient dosage brings about improvement in all components of physical fitness. Regular daily exercise will result in improved physical condition which will produce greater nervous energy, better emotional stability, and improve the ability to think clearly. Strong muscles will be a byproduct of these daily exercise periods; they will not be a goal for adult men.

Technological progress has brought about great changes in our mode of life. These changes make necessary not only social adjustments, but also changes in our recreational life. The introduction of labor-saving machinery has herded people together in cities. The tempo of daily living has been speeded up making it more necessary than formerly that men secure release from the tensions and strains of daily living. Wlany men are engaged in monotonous work which does not require much physical exertion. Yet the biological need for activity is as great as ever. Since men no longer secure this necessary physical activity on their job, they must secure it elsewhere. The most logical and enjoyable places to secure this activity are the gymnasium, natatorium, or on the athletic field. Gardening, hiking, mountain climbing, hunting, rowin $\mathrm{E}^{\mathrm{r}}$ and other forms of outdoor recreation are also excellent means of securing physical activity.

It has been shown that the growing numbers of elderly people already present a serious economic problem and that this problem is destined to become more acute if the predictions of scientists, chemists, and gerontologists prove true. 
It is essential that the productive years of men be considerably increased. If they are not increased it is inevitable that our standard of living will be lowered unless the productivity of the wage earning age group is correspondingly increased. Middle Aged Men Can Improve Their Fitness Status. Several experiments have been conducted which demonstrate that middle-aged men can improve their fitmess level or put more life into their years by means of a program of regular and progressive exercise adapted to their condition. Physical improvement is not limited to the youthful. Good health can be achieved by all regardless of age. Improvements in organic condition and physical fitness resulting from a systematic physical conditioning program were demonstrated in a study conducted by D. E. Latham with a group of middle-aged men. This program consisted of an initial testing period followed by a sixmonth period during which the men met once each week to engage in such mildly vigorous activities as calisthenic movements, endurance activities, and elementary tumbling. At the end of this six month period, the men were given a repeat test on the items of physical fitness measured on the initial test. The following table from Latham's report indicates the resulting improvements in physical fitness as demonstrated by average scores: 33

33 Darrell E. Latham, "Report on the Physical Fitness Program for the University of Illinois Firemen," University of Illinois, Unpublished Report, 1945. 
Table 3

Improvement in Physical Fitness Items as a Result of Physical Activity

\begin{tabular}{|c|c|c|c|c|c|c|}
\hline $\begin{array}{c}\text { Physical Fitness } \\
\text { Items }\end{array}$ & \multicolumn{2}{|c|}{$\begin{array}{l}\text { Initial Test } \\
\text { Fal1-1945 }\end{array}$} & $\begin{array}{l}\text { Repeat } \\
\text { Spring }\end{array}$ & $\begin{array}{l}\text { Stand. } \\
\text { Score }\end{array}$ & \multicolumn{2}{|c|}{ 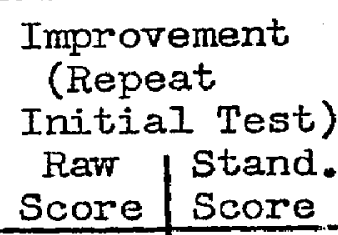 } \\
\hline $\begin{array}{l}\text { Total Fat Measure- } \\
\text { ments m. }\end{array}$ & 153 & 48 & $11,6.9$ & 52 & 6.1 & 4 \\
\hline Chest Expansion ins. & 3.1 & 52 & 3.4 & 55 & .3 & 3 \\
\hline $\begin{array}{l}\text { Chest-Abdomen } \\
\text { Girth ins. }\end{array}$ & 4.5 & 46 & 4.7 & 48 & .2 & 2 \\
\hline $\begin{array}{l}\text { Vital capacity Resi- } \\
\text { duals (actual-norm) } \\
\text { cu. ins. }\end{array}$ & -52 & 43 & -55 & 42 & -3 & -1 \\
\hline Expiratory Force $\underline{\mathrm{mm}}$. & $\Psi_{4}$ & 59 & 166 & 66 & 17 & 7 \\
\hline $\begin{array}{l}\text { Flarimeter Breath } \\
\text { Holding secs }\end{array}$ & 10.9 & 41 & 12.2 & 42 & 1.3 & 1 \\
\hline Schneider Test Score & 8.75 & 29 & 13 & 50 & 4.25 & 21 \\
\hline Heartogram Score & & 54.7 & & 63.7 & & 9 \\
\hline Step Test Score & 193 & 32 & 169.6 & 48 & 23.4 & 16 \\
\hline Chinning Times & 5.2 & 43 & 3.5 & 39 & -1.7 & -4 \\
\hline $\begin{array}{l}\text { Dips on Parallel } \\
\text { Bars No. }\end{array}$ & 4.4 & 46 & 4.9 & 48 & .5 & 2 \\
\hline Vertical Jump Ins. & 16.8 & 4 is & 17.2 & 46 & .14 & 2 \\
\hline Total Strength Lbs. & 1158 & 58 & 1339 & 71 & 181 & 13 \\
\hline Strength/Weight Lbs. & 6.2 & 47 & 7.49 & 59 & 1.29 & 12 \\
\hline
\end{tabular}


Medical science often uses rats as subjects to find the effects of various drugs, medicines, actions, and operations. Rats respond to these things very much as humans would and they can be dissected to be studied more fully. This type of study was conducted at the Wistar Institute to find the effects of exercise. Experiments at the Institute showed that rats placed in activity cages for a period corresponding to $U_{4}$ years in the human life span increased over confined rats by 6.8 per cent in body weight; 20 per cent in weight of heart, kidneys and liver; 4 per cent in brain weight; 34 per cent in ovaries; and 12 per cent in testes. In the absence of precise data for men, it is possible that corresponding organs in man may respond to long continued exercise in a like manner.

Opinions of Miedical and Psychiatric Authorities Regarding Physical Activity for Adults. A large number of medical authorities emphasize the importance of physical activity for men of middle age and beyond. Stieglitz, one of the outstanding geriatricians of the day, writes:

In the cultivation of our minds and bodies in anticipation of harvesting the fmuits of living in the second forty years, we must keep in mind that use retards decline and encourages development. Disuse leads to atrophy. Abuse too often is the forerunner of disease and consequently accelerated depreciation. There is less hazard in doing a little too much than not doing quite enough. For the senescent indulgence is bad medicine. To quit and sit back and let the world go by is the equivalent of introducing dry rot into the tree of 7 ife. 34

Another eminent medical authority, M. W. Thewlis writes:

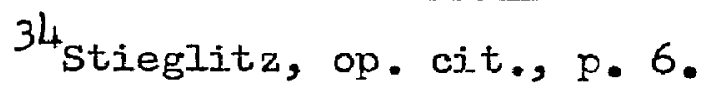


Lack of exercise is an important factor in premature aging. Exercise has a beneficial effect on circulation and appetite and a physiological value especially if it is directed toward a constructive end such as gardening or taking care of property. A forced rest may affect the number of coronary artery acclusions, which may result from overactivity. 35

Lewellys F. Barker, Emeritus Professor of liedicine at John Hophins University at Baltimore, Maryland, expresses his belief in the value of exercise for middle-aged men as well as for youth:

Undoubtedly a career of activity, rather than a life of idleness, predisposes to length of life, and no definite chronological age can be safely predicted as the time for retirement or for sudden and marked reduction of activities. Each person should carry on full activity as long as he can do so without over-fatigue or other injury to his constitution. The entire matter is individual and personal; no hard and fast rule can or should be laid down. $36^{\circ}$

Janet Baird, a psychiatrist specializing in counseling older

people, urges people of middle age and older to exercise and offers the following suggestions on the selection of sports:

Properly planned exercise brings the body to a condition resembling that of a trained athlete. Most of us become inexcusably soft with the passing years. In youth strenuous physical exercise is natural, but as one reaches middle life and has passed the age of forty, some modification in its form should be made. Tennis, handball, and such vigorous sports are best eliminated, in spite of the fact that there are some who can follow these games when well advanced in years. Golf, swiming, walking, riding, gardening, and work in the rood lot are excellent substitutes. For city dwellers, walking is of course, the exercise of choice and one that can be used to great advantage to the body.

35liark W. Thewlis, The Care of the Aged (Geriatrics), p. 160 . ${ }^{36}$ Iewellys F. Barker, The Clinical Diagnosis of Internal Diseases, p. 15 . 
In order to achieve and maintain harmonious function between the nervous system, the muscular, circulatory, and respiratory apparatus, exercise should be a daily habit and not just something to be indulged in occasionally. Daily exercise improves the efficiency of the body as a machine, increases its reserve strength to meet emergencies, and leads to a general sense of well-being. 37

The point of view recommended here with regard to the dual competitive sports such as handball, squash, and tennis, and team sports such as volleyball is that they can be engaged in with profit and enjoyment if men will learn to engage in them for the sociability, enjoyment, and physical activity which they provide rather than to give men an opportunity to prove their physical superiority over their opponents.

Summary. The mind and body are not separate entities but are one. What influences the mind influences the body and conversely, what influences the body influences the mind. Evidence has been accumulating in recent years that mental and emotional "stances" can cause chronic ailments such as ulcers, hypertension, migraine, asthma, visual deficiences, hemorrhoids, allergies, arteriosclerosis, tuberculosis, and other ailments. The complexities, tensions, and frustrations associated with modern Iife can and often do cause "conflicts" which predispose toward or cause many of the chronic ailments common to middle aged and older people. Through recreational activities adult men can give socially approved expression to many of the organic tensions and can satisfy the unsatisfied motives characteristic of modern life.

\section{Janet Baird, These Harvest Years, pp. 49-50.}


The relief of tensions and the satisfaction of motives, drives, and impulsions to activity may be of help in preventing the chronic ailments which are common among middle aged and older people. Recreational activities can provide this relief and satisfaction.

Chronic fatigue is a common complaint of middle aged people. A new interpretation of fatigue indicates that recreational activities may be of help in relieving this condition. 38 Fatigue is experiential and since "experiential" and mental are synonymous, fatigue is mental. Recreational activities can make Iife less boring, monotonous, and tedious. In this way, they help to allay the condition known as chronic fatigue. From the physiological standpoint, recreational activities can help to relieve fatigue through the "milking action" of the muscles upon venous blood thus helping to carry away lactic acid and other fatigue products from distal parts.

There has been some evidence gathered to show that middle aged men, like youth, can bring about substantial improvement in various aspects of their own fitness status by means of regular physical activity. This is further substantiated by medical opinion.

It has been pointed out that the increasing numbers of elderly people constitute a serious economic and social problem which is destined to become even more serious. The lack of ability of older people to produce is not only a problem to society but to the older people themselves. Doles of money and subsidies will place a heavy burden upon the wage earners and will not solve the problems of the older people themselves.

${ }^{38}$ S. Howard Bartley and Eloise Chute, op. cit., pp. 397-405. 
One approach to the problem under discussion is that of sustaining the productive efficiency of people for longer periods and making the retirement age optional with the employee rather than mandatory. By this is meant that an employee could retire at age sixty-five if he desired, but if he met satisfactorily certain health, fitness, and mental standards, he could continue working if he wished. Sustaining productive efficiency into advanced years by means of improving fitness through physical activity is one approach which should be investigated.

Also it has been pointed out that the fitness status of middle aged men can be improved through regular and systematic exercise. Calisthenic exercises and weight lifting will bring about improvement in fitness through increased strength, greater endurance, increased. power, and improved cardiovascular and respiratory condition but they do not contribute a great deal to mental health and furthermore, are boring and lacking in sufficient interest and challenge to many people to hold their interest over extended periods. Sports and sportslike activities, on the other hand, can offer men rewards in improved fitness as well as in improved mental efficiency. Sports offer relief from the tensions of work. They can offer a socially acceptable outlet for feelings of aggression.

It is apparent from the evidence presented that physical educators and recreation leaders have an opportunity to make contributions to improved national econony through helping to improve and sustain the fitness level of adult and aging men. Urging men to exercise has proven itself to be ineffective. The interest of men in sports should 
first be aroused and then these sports should be utilized as one medium of sustaining their fitness level. After a person has found a sport which interests and challenges him he is much more likely to continue physical activity than he is if he has had no such sports interest. Furthermore, sports and other forms of recreational activities will serve to relieve emotional tensions resulting from the complexities of modern life. They will serve to fulfill some of the psychological needs of adult men--the need for belonging to a group, for recognition, for self-expression, and for new interests and appreciations-and thereby make of these middle aged and older people better-adjusted, happier, and more useful members of our society.

It would be of help in arousing the interest and participation of men in sports, games, and other recreational activities to know what activities most men enjoy, in which they actually participate, and how frequently, and their reasons for not participating as frequently as they would like in those activities in which they desire more frequent participation. The questionnaire section of this study will deal with the answers to these questions.

The Scope and Purpose of This Study

The purposes of this study are:

1. To discover how adult mell spend their leisure time.

2. To discover how the recreational habits of adult men change with increasing age.

3. To discover the recreational interests of adult men.

4. To discover how recreational interests change with increasing age. 
5. To discover the discrepancies between recreational interests and habits.

6. To discover whether these discrepancies increase or decrease with increasing age.

7. To discover which, if any, recreational activities men enjoy at all ages.

8. To discover the relative constancy of participation in the various activities, i.e., to discover how the various activities compare with one another with respect to the number of years during which participation is carried on.

9. To discover the reasons men offer for failing to participate as frequently as they would like in various recreational activities.

10. To discover how these reasons change with increasing age.

11. To review Iiterature related to the problems of aging from the areas of gerontology, psychology, psychiatry, sociology, and economics and to draw implications from these to serve as guides for the conduct of recreational programs for adult men.

The scope of this study deals with the recreational habits, interests, and problems of adult men as they are related to the physiological, psychological, and social phenomena of aging. The emphasis will necessarily be principally upon the physiological aspects because the geriatricians have studied the problems of aging most thoroughly.

Problems of aging such as housing, education, medical care, and work will not be examined except as they are related to recreational 
practices.

Random samples of adult men in Ohio and Pennsylvania only will be included in the study. The income range of the men under consideration was from 0 to over $\$ 7,000$ annually. The age range of the men involved was from twenty to fifty-nine.

Methods of Procedure:

The procedures utilized in this study were those of:

1. Synthesizing the writings and studies of people in fields related to physical education and recreation (principally sociology, psychiatry, and gerontology) and adapting the principles discovered to the field of physical education and recreation in investigating the recreational problems of the aging and the aged. One mundred and twenty articles and eighty books were selected for review.

2. Discovering the recreational interests and habits of adult men between the ages of twenty and fifty-nine by means of a recreation questionnaire administered to approximately three thousand men residing in six cities of varying size (Cleveland, Ohio; Butler, Pennsylvania; Columbus, Ohio; New Castle, Pennsylvania; Slippery Rock, Pennsylvania; and Delaware, Ohio.) These unen are engaged in a variety of occupations and represent a wide income range.

3. Talks with retired and middle aged men concerning their leisure time and recreational interests and problems.

4. Correspondence with gerontologists and other professional people interested in the problems of aging. 
The Questionnaire. The questionnaire was the principal tool of this study. On this questionnaire men were asked to indicate their attitude towrard each of sixty-seven recreational items by placing a check mark in one of three columns headed: like, dislike, and indifferent. It is the feeling of the present writer that by finding which activities are most liked by men of various age groups, the physical education profession will be better able to interest adult men in physically stimulating and mentally relaxing activities. It will also be possible to help men to anticipate probable changes in their recreational interests. With this knowledge they can begin in advance, to develop recreational interests which are well adapted to the age group toward which they are moving.

When people say they like something they mean they are attracted to it. When people say they dislike a thing they feel aversion to it and will try to avoid it. People tend to do those things they like and to avoid those they dislike. Leaders of adult recreation programs would undoubtedly experience more success in trying to interest men in those activities which they like than in those which they dislike or toward which they feel indifferent. Iife itself is bound up with selection and exclusion. Men cannot be happy or continue long in a completely free-floating state. 'They soon decide which of life's activities they enjoy and wich they do not and can vote intelligentIy on their likes and dislikes. It is through a questionnaire of this type that certain facts, feelings, and attitudes which are locked up in the minds of men can be found. 
In addition to being asked to indicate their attitude toward each of the sixty-seven listed recreational activities, the men were asked to indicate the frequency of their participation in each. They were further asked to indicate the reason if they were prevented fron participating as frequently as they would like. If the limiting factor was a health reason, they wrote "health"; "time" if it was lack of time; "money" if it was due to lack of funds; "facilities" if local facilities were lacking, inadequate, or too distant; or "knowledge and skill" if lack of knowledge and skill limited their participation. Officials of the Cleveland Pneumatic mool Company, in Cleveland, Ohio were kind enough to cooperate in this study. The bulk of the questionnaires was secured from this company with the generous and untiring assistance of their labor relations counselor, Ernest Molnar. All 2,000 employees, both office and factory and at all echelons, were polled. From these, 350 useable questionnaires were secured. Sixtyone additional useable questionnaires were completed by means of personal interviews with friends, neighbors, colleagues, business people, and through visits to adult social organizations. Approximately one hour was spent in each personal interview.

In distributing the questionnaires at the cleveland Pneumatic Tool Company, the personnel depariment first found the number of employees in each department on each of the three shifts, by counting the number of time cards filed uncier that department. Then a corresponding number of questionmaires were counted out into departmental piles. Next the name of the foreman of each department was secured and a letter explaining the objectives of the study was taken to him, 
along with the questionnaires, by $\mathbb{M r}$. Molnar and the present writer. The method of marking the questionnaire and the objective of the study were explained to each foreman when the questionnaires were delivered. Each foreman was asked to explain to his men that the primary interest was in finding how the men felt about doing or participating in the activity rather than in watching someone else do it. The foremen then distributed the questionnaires to the men in their departrent and passed on the instructions to their men. The following day, the completed questionnaires were collected.

The remaining one hundred and sixty-two questionnaires were cormpleted by residents and business people of Slippery Rock, Pennsylvania; Cleveland, Ohio; Delaware, Ohio; Columbus, Ohio; Butler, Pennsylvania; and New Castle, Pennsylvania. These cities range in size from Slippery Rock, Pennsylvania with a population of approximately one thousand to Cleveland, Ohio with a population of nearly one million. Faculty of Ohio Wesleyan University and Slippery Rock State Teachers College were also polled. Nembers of the Golden Age Croups of the Central Community House in Columbus, Ohio were interviewed. The addresses of twenty-two participants in the Golden Age Hobby Show in Columbus, Ohio were secured from Mir. Pontious, Executive Secretary of the Recreation Division at United Appeals Headquarters. A letter explajning the study and a questionnaire was sent to each of these men. Three janitors at Edward's Gym of Ohio Wesleyar University were interviewed. Four retired men were found playing checkers at the Butler, Pennsylvania Young Niens' Christian Association. These men were interviewed as was one transient worker also found there. 
For tabulating purposes, the questionnaires were sorted into the following four age groups: 20-29 years, 30-39 years, $40-49$ years, and 50-59 years. After all useable questionnaires were tabulated for age groupings, they were re-sorted and then tabulated according to the following six annual income groupings: $0-\$ 2,000 ; \$ 2,000-\$ 3,000$; $\$ 3,000-\$ 4,000 ; \$ 4,000-\$ 5,000 ; \$ 5,000-\$ 7,000 ;$ and over $\$ 7,000$.

The total number of questionnaires tabulated for income groupings was smaller than that tabulated for age groupings. The reason for this was that colleagues, friends, and neighbors were not asked to indicate their income.

It was found necessary to discard some of the questionnaires which had not been filled out completely. Questionnaires which did not indicate frequency of participation or reasons for unsatisfactory participation were discarded.

Some men did not check like, dislike, or indifferent for one or sometimes more activities. It must be assumed that these men were unfamiliar with the particular activity or had difficulty in determining exactly how they felt about the particular activity. Since every person would have some feeling about each activity, these omissions were treated as an indication of a feeling of indifference toward the activity. If a person neither likes nor dislikes an activity or is unfamiliar with it, he feels indifferently toward it.

The total number of men indicating liking, disliking, or indifference toward each of the sixty-seven activities was then divided by the total number of used questionnaires for that age or income group to find the percentage of each group llking, disliking, or feeling 
indifferently toward each activity.

Reasons for unsatisfactory participation were tallied and totaled. These figures may appear low. The reason is that men checked these reasons only if they desired more frequent participation than they actually secured. When they indicated disliking or indifference toward an activity, they did not indicate a reason. The total number for all activities was computed to find the most common reason for insufficient participation for each age and income group.

All men did not indicate the frequency of participation in each activity. Many simply placed a check mark in the weekly, monthly, or annually column rather than the number of participations each week, month, or year. For this reason, the participation figure shall be called the participation index rather than the actual number of participations. Questionnaires which shoved neither check marks or actual frequency in the participation colums were discarded. If a man used check marks in indicating frequency of participation for one activity, he did the same for all activities. If he used a number for one activity, he followed this procedure tirroughout. For these reasons the participation index can be regarded as a fairly reliable index of the relative position of each activity with respect to the frequency with which men in each group engage in that activity. The following formula was used to find the participation index for each activity: (fifty-two times the total number of weekly participations) plus (twelve times the total number of monthly participations) plus (the total number of annual participations) divided by the total number of participants. Nany sports are of a seasonal 
nature and can be engaged in during only a portion of the year. For example, still fishing can be engaged in from approximately April lst to September 30th. This is equivalent to six months or one-half a year. In this case the formula used was as follows: $\triangle\left(52 \times\right.$ total no. of $\frac{w k-l}{2} y$-participations $) f$

$\frac{(12 \times \text { total no. mthly. participations })}{2}+\underset{\text { participations }}{\operatorname{total} \text { no. of } y r l y \cdot}=x$ $\frac{x}{\text { Total No. of men in the group }}=$ Participation Index.

This procedure was followed for each seasonal sport or activity to arrive at the participation index. If a man indicated that he bowls twenty times a year, he automatically took into consideration the seasonal aspect of the sport. If he indicated that he bowls twice each week he did not-mparticularly if he completed the questionnaire during the bowling season. The same was true when a man indicated he bowls three times each month. Did he bowl thee times each month for twelve months of the year or for three months of the year? It would seem reasonably safe to assume that he does not bowl for the three summer months. Therefore, it was necessary to compute the total number of times he bowled during the year and to divide this total by three-fourths, since nine months is equivalent to three-fourths of one year.

\section{Iiritations of the study}

People like and dislike activities in varying degrees. It was the original intent to request respondents to evaluate the extent of their like and dislike for each activity on a plus five to a minus five basis. A plus five would have indicated a great deal of liking; 
a plus four somewhat less; threo, average; two, less; and one, a minimal degree of liking. A zero would have indicated indifference or lack of familiarity with the activity. A minus five would indicate a great deal of dislike for an activity; a minus four, less dislike; etc. This method would have provided a more accurate measure of mens' attitudes torrard the various activities. It was found that the additional time necessary to make these evaluations was too great an imposition upon workers' time and the original plan was regretrully changed to the present more simple form.

Another limitation of this study was that the bulk of the responses came from one factory. Three hundred and fifty questionnaires of the four hundred and eleven used were responded to by employees of this company. It is believed that this is not as great a limitation as it would at first appear. The income range of these employees extended over the full scale represented--from "0-\$2,000" to "over $\$ 7,000 . "$ Both factory and office personnel were polled. The occupations ranged from janitor to attorney. This would seem, therefore, to be a fairly representative group.

The results might have been different had a company with a wellorganized recreation program been polled. A very small proportion of industrial companies have well-organized industrial recreation programs. (In Ohio there are three outstanding programs of which this writer has heard-The Goodyear Rubber Company in Akron, The Timken Roller Bearing Co., and the National Cash Register Co. in Dayton.) It is felt that because of this, this company is more representative than one which has a well-organized recreation program. 


\section{A Review of Related Studies}

Two studies were found which were related to this one. The first was an unpublished Naster's Thesis written by Burris F. Husman entitled "A Study of the Amount of Money Spent by Men Living in the State of Illinois Participating in and observing sports." 39 The second was made by Edward $\mathrm{K}$. Strong and is entitled Change of Interests With Age. 40

Husman's Study: Husman attempted to discover the amount of money men living in the state of Illinois spent participating in and observing sports. He also kept a record of the number of men who had participated at least once during the year previous to his study (1947) in each of fifty-two sports. He interviewed two hundred and forty-five men. The present writer is not interested in the amount of money spent by these men but is interested in the number of men who participated in each of the fifty-two sports listed.

The following table from Husman shows the number of men who participated in each sport at least once during the year for each age group:

39 Burris F. Husman, "A. Study of the Amount of Money Spent by Men Living in the State of IJlinois Participating in and Observing Sports," Unpublished Master's Thesis, University of IIlinois, 1941.

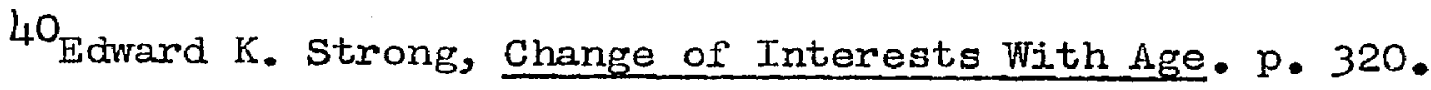


Table 4

Number of Men Who Participated in the Sport Listed at Least Once During the Year 1940 (From Husman)

\begin{tabular}{|c|c|c|c|c|c|}
\hline Activity & $21-30$ & $31-40$ & $41-50$ & $51-60$ & 61 Plus \\
\hline Baseba11 & $\mathrm{U}_{4}$ & 13 & 1 & 2 & 0 \\
\hline Badrinton & 7 & 6 & 1 & 1 & 0 \\
\hline Archery & 2 & 2 & 2 & 2 & 1 \\
\hline Basketbal1 & 26 & 10 & 2 & 1 & 0 \\
\hline Billiards & 38 & 19 & 12 & 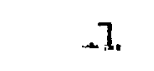 & 0 \\
\hline Bowling & 45 & 19 & 9 & 6 & 0 \\
\hline Camping & 8 & 8 & 3 & 5 & 1 \\
\hline Canoeing & 5 & 8 & 4 & 3 & 0 \\
\hline Bait \& Fly Casting & 6 & 5 & 4 & 2 & 1 \\
\hline Croquet & I6 & 8 & 4 & 5 & 0 \\
\hline Cycling & 16 & 8 & 1 & 0 & 0 \\
\hline Field Trials & 1 & 4 & 4 & 3 & 0 \\
\hline Fishing & 37 & 43 & 37 & 24 & 6 \\
\hline Football & $H_{4}$ & 5 & 1 & 0 & 0 \\
\hline Golf & 22 & 20 & 9 & 4 & 0 \\
\hline Handba 1.7 & 10 & 3 & 0 & 2 & 0 \\
\hline Hiking & 8 & 6 & 2 & 2 & 1 \\
\hline Horseshoes & 16 & 22 & 13 & 4 & 0 \\
\hline Hunting & 49 & 47 & 35 & 20 & 3 \\
\hline Ice Skating & 11 & 6 & 3 & 0 & 0 \\
\hline Motor Boating & 8 & 19 & 11 & 4 & 0 \\
\hline
\end{tabular}


Table 4

Number of Men Who Participated in the Sport Iisted at

Least Once During the Year 1940 (From Husman) (Cont'd.)

\begin{tabular}{|l|r|r|r|r|c|}
\hline Activity & $21-30$ & $31-40$ & $4 I-50$ & $51-60$ & 61 Plus \\
\hline Picnicing & 47 & 41 & 26 & 17 & 6 \\
Pistol Shooting & 17 & 18 & 7 & 1 & 0 \\
Riding (Horse) & 8 & 7 & 7 & 1 & 0 \\
Rifle Shooting & 28 & 29 & 14 & 2 & 2 \\
Shuffleboard & 5 & 6 & 2 & 0 & 0 \\
Skeet Trap Shooting & 11 & 12 & 12 & 4 & 0 \\
Roller Skating & 10 & 5 & 1 & 1 & 0 \\
Softball & 39 & 26 & 5 & 2 & 0 \\
Swimming & 42 & 27 & 14 & 5 & 2 \\
Table Tennis & 21 & 13 & 7 & 0 & 0 \\
Tennis & 14 & 6 & 0 & 1 & 0 \\
\hline
\end{tabular}

It can be seen from the preceding table that fewer men from each succeeding age group participated in each sport. The conclusion could be drawn that men participate in fewer sports as they grow older. Almost every activity shows a decrease in the number of participants for each succeeding age group after the age of forty. This decrease is greatest in baseball, basketball, bowling, cycling, football, golf, handball, roller skating, softball, swimming, table tennis, and tennis. This decrease could be expected in the more vigorous activities such as baseball, basketball, and football. However, there 
is no reason that men over forty could not profit from and enjoy such activities as bowling, cycling, golf, handball, swimming, and tennis if they engaged in them with the objective of enjoying themselves rather than that of proving their superiority over an opponent. Undoubtedly many men begin to think of themselves as too old for sports after they reach forty years of age. This idea should be dispelled. Following are some of Husman's conclusions which are pertinent to this study:

\section{Sports Participation and Attendance}

1. There is a definite tendency to participate less as age increases.

2. Conversely, men attend sports more as age increases.

3. Young men participate in the more active sports such as baseball and volleyball, while the older men participate more in the less active sports, i.e., billiards, camping, croquet, fishing, horseshoes, hunting, picnicing, and firearm shooting.

4. Both old and young are spectators at the more popular sports: baseball, basketball, football, and track and field events. Golf matches, motor boat races, and skeet-trap shooting matches seem to attract the middle age group more than they do the younger or older age groups.

\section{Related Sports and Participation}

1. To show the relationship between certain sports and the sportsman who participates in them, twelve or all, of the men who participated in field trials also hunted. Thirty-two of the thirty-nine sportsmen who participated in skeet or trap shooting also hunted. This could indicate that the three sports, field, trials, skeet-trap shooting, and hunting are closely related and if a sportsman participates in either skeet-trap shooting or field trials, he will also more than likely hunt.

2. One hundred and fourteen of the one hundred and fiftyfour men who hunted also reported that they fished. This could indicate that if a man engaged in either of these two activities, he will more than likely do both. 
3. Twenty-eight of the thirty-seven men who indicated that they participated in pistol shooting, also reported that they utilized part of their leisure time rifle shooting. Again, this could indicate that these two sports are related and that if a sportsman participated in one, he will probably participate in the other. 41

Strong's Study: A second related study was made by Edward K. Strong. He tried to discover the changing interests of men with increasing age. 42 The study was based on an examination of more than two thousand men between the ages of twenty and sixty representing eight occupations. He used a 420 item questionnaire to which he asked business and professional men to react by placing a check mark in one of three columns to indicate their attitude or feeling toward each item. The three colurms were headed: (1) like, (2) dislike, and (3) indifferent. These 420 items were grouped as follows: (1) one hundred occupational items, (2) fifty-four amusement items, (3) thirty-nine school subjects, (4) fifty-two activity items, (5) fiftythree peculiarities of people, (6) forty daily routine activities, (7) comparisons of interest between forty-two pairs of items, and (8) 'yes' and 'no' reactions to forty present abilities and characteristics. The results of this study give a fairly comprehensive and reliable picture of interest and attitude changes with age. For the purposes of the present study only the fifty-four amusement items will interest us. Therefore, a report will be made only on that section of the study.

$$
\begin{aligned}
& 4 I_{\text {Husman, op. cit., p. } 90 .} \\
& 42_{\text {Strong, op. cit., p. } 320 .}
\end{aligned}
$$


E. K. Strong employed a double classification with reference to amusements. The items were classified on the basis of cultural and non-cultural activities and also as to whether they were pursued usually alone, with a few persons, or with many persons. He arbitrarily classified such activities as art, music, and reading as cultural and sports and games as non-cultural. He found that cultural amusements increased in liking by 7.6 per cent but non-cultural items decreased in liking by 4.5 per cent. This, was one of the largest differences to be found among all his data between two groups of interest. He noted that among the cultural amusements, only two declined significantly, namely 'poetry' and 'playing a musical instrument.' Among the sixty-six non-cultural amusements he reported no such agreement. He noted twelve increased significantly in liking, and for the remaining twenty no change was indicated.

With regard to amusements pursued (a) usually alone, (b) with a few persons, and (c) with many persons, he found an increase in liking of one per cent for the first group, a decrease in liking of 2.6 per cent for amusements pursued with a few persons, and a decrease of 5.3 per cent in liking for amusements pursued with many persons. He concludes that evidently older men enjoy cultural amusements pursued largely alone more than do youngar men, whereas the reverse is the case with non-cultural amusements especially when pursued with a few or with many persons. Strong then comments on this data:

- . - it would appear that older men are not so much interested in people as are younger men, whether these people are associated with them in business or in amusement. - Clearly, there are many amusements of genuine interest to men of 55, for 50 per cent still like musical comedies, 72 per cent like to drive an auto, 63 
per cent like fishing, etc. Nevertheless the figures bear

out what is observed in almost every family, that to many amusements older men do not take kindly, particularly if they have not indulged in them from early life. Preparation for enjoyment of old age should seemingly include the development at an earlier age of interest in several cultural amusements which can be indulged in alone or with only a few others. Passibly, it should include development of other forms of interest, although our data do not support this view; and our data may reflect the interests of older men who did not learn to play tennis, golf, bridge, etc. and so today report that they are not interested in them. 43

With regard to that part of the questionnaire dealing with interests involving skill and daring he reports that all nineteen items show a decline in interest and that the group as a whole shows a very great decline--14.6 per cent. He points out that no other group approaches this one in the very decided drop in interest with increasing age. He makes the following observation:

But it is interesting to obtain a measure of how interest in physical skill and daring declines from 42.8 per cent at 25 to 28.2 per cent at 55 , and to contrast this decline with the increase or decrease in interest in other types of activity. 4

The following is strong's table presenting the percentage of men indicating like or dislike for each of the fity-four amusement items:

${ }^{43}$ Strong, op. cit., pp. 72-73.

Wistrong, op. cit., pp. 73-74. 
Table 5

Percentage of hen Liking Fifty-four Amusement Items (From Strong)

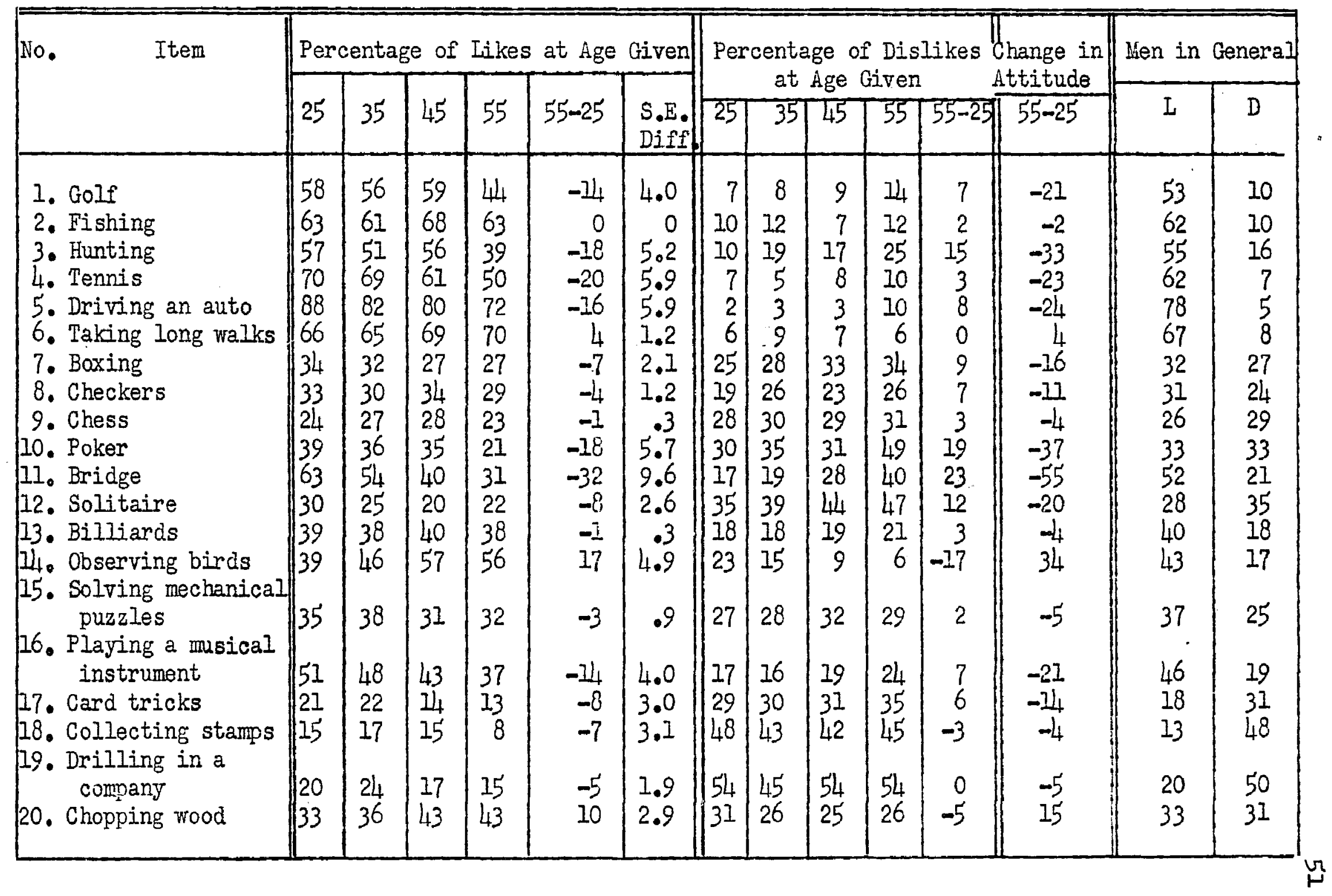


Table 5

Percentage of lien Iiking Fifty-four Amsement Items (From Strong) (Cont'd.)

\begin{tabular}{|c|c|c|c|c|c|c|c|c|c|c|c|c|c|c|}
\hline \multirow[b]{2}{*}{ No. Item } & \multicolumn{6}{|c|}{ Percentage of Likes at Age Given } & \multicolumn{5}{|c|}{$\begin{array}{c}\text { Percentage of Dislikes } \\
\text { at Age Given }\end{array}$} & \multirow{2}{*}{$\frac{\text { hange in }}{55-25}$} & \multicolumn{2}{|c|}{ Men in Genera] } \\
\hline & 25 & 35 & 45 & 55 & $55-25$ & $\begin{array}{l}\text { S.E. } \\
\text { Diff. }\end{array}$ & $\overline{25}$ & 25 & 45 & 55 & $55-25$ & & L & D \\
\hline $\begin{array}{l}\text { 21. Amusement parks } \\
\text { 22. Picnics } \\
\text { 23. Excursions } \\
\text { 24. Smokers } \\
\text { 25. "Rough House" } \\
\text { initiations } \\
\text { 26. Conventions } \\
\text { 27. Full Dress Affairs } \\
\text { 28. Auctions } \\
\text { 29. Fortune Tellers } \\
\text { 30. Animal Zoos } \\
\text { 31. Art Galleries } \\
\text { 32. Nuseums } \\
\text { 33. Vaudeville } \\
\text { 34. Musical Comedy } \\
\text { 35. Concerts } \\
\text { 36. Pet Canaries } \\
\text { 37. Pet Monkeys } \\
\text { 38. Snakes } \\
\text { 39. Sporting Page } \\
\text { 40. Poetry } \\
\text { 41. Detective Books } \\
\text { 42. "Literary Digest" }\end{array}$ & $\begin{array}{l}25 \\
54 \\
45 \\
36 \\
114 \\
27 \\
33 \\
15 \\
7 \\
53 \\
61 \\
66 \\
53 \\
79 \\
67 \\
12 \\
8 \\
6 \\
66 \\
57 \\
48 \\
64\end{array}$ & $\begin{array}{r}18 \\
49 \\
38 \\
33 \\
9 \\
93 \\
25 \\
14 \\
5 \\
60 \\
67 \\
71 \\
57 \\
72 \\
69 \\
15 \\
10 \\
6 \\
56 \\
49 \\
54 \\
69\end{array}$ & $\begin{array}{r}15 \\
51 \\
39 \\
28 \\
6 \\
65 \\
35 \\
21 \\
16 \\
4 \\
65 \\
75 \\
76 \\
50 \\
66 \\
69 \\
16 \\
5 \\
4 \\
45 \\
56 \\
59 \\
75\end{array}$ & $\begin{array}{r}17 \\
42 \\
37 \\
24 \\
5 \\
52 \\
17 \\
17 \\
3 \\
64 \\
78 \\
78 \\
41 \\
60 \\
66 \\
17 \\
8 \\
5 \\
34 \\
49 \\
55 \\
74\end{array}$ & $\begin{array}{r}-8 \\
-12 \\
-8 \\
-12 \\
-9 \\
5 \\
-16 \\
-4 \\
-4 \\
11 \\
17 \\
12 \\
-12 \\
19 \\
-1 \\
5 \\
0 \\
-1 \\
-32 \\
-3 \\
7 \\
10\end{array}$ & $\begin{array}{r}4.5 \\
1.6 \\
5.3 \\
1.7 \\
2.5 \\
3.2 \\
5.3 \\
3.8 \\
3.4 \\
6.0 \\
.3 \\
2.0 \\
0 \\
.6 \\
9.4 \\
2.3 \\
2.0 \\
3.1\end{array}$ & $\begin{array}{r}56 \\
30 \\
28 \\
47 \\
66 \\
13 \\
9 \\
8 \\
12 \\
5 \\
5 \\
40 \\
58 \\
69 \\
4 \\
14 \\
17 \\
5\end{array}$ & $\begin{array}{r}62 \\
25 \\
34 \\
50 \\
70 \\
17 \\
6 \\
4 \\
10 \\
5 \\
8 \\
40 \\
58 \\
71 \\
10 \\
12 \\
12 \\
5\end{array}$ & $\begin{array}{r}70 \\
30 \\
38 \\
47 \\
70 \\
10 \\
5 \\
5 \\
12 \\
6 \\
10 \\
34 \\
59 \\
73 \\
14 \\
11 \\
13 \\
4\end{array}$ & $\begin{array}{r}41 \\
20 \\
26 \\
45 \\
81 \\
28 \\
41 \\
53 \\
73 \\
8 \\
5 \\
4 \\
17 \\
9 \\
7 \\
35 \\
62 \\
74 \\
25 \\
10 \\
11 \\
5\end{array}$ & $\begin{array}{r}6 \\
3 \\
4 \\
20 \\
25 \\
-2 \\
-2 \\
13 \\
6 \\
7 \\
-5 \\
-4 \\
-4 \\
-5 \\
4 \\
2 \\
-5 \\
4 \\
5 \\
5 \\
21 \\
-4 \\
-6 \\
0\end{array}$ & $\begin{array}{r}-11 \\
-15 \\
-12 \\
-32 \\
-34 \\
7 \\
-29 \\
-10 \\
-11 \\
16 \\
21 \\
16 \\
-17 \\
-23 \\
-3 \\
10 \\
-4 \\
-6 \\
-53 \\
-4 \\
13 \\
10\end{array}$ & $\begin{array}{r}22 \\
48 \\
40 \\
37 \\
11 \\
32 \\
28 \\
15 \\
5 \\
54 \\
65 \\
70 \\
56 \\
74 \\
63 \\
20 \\
9 \\
5 \\
54 \\
444 \\
51 \\
71\end{array}$ & $\begin{array}{r}36 \\
16 \\
25 \\
26 \\
61 \\
61 \\
28 \\
32 \\
45 \\
66 \\
13 \\
7 \\
5 \\
11 \\
5 \\
10 \\
36 \\
61 \\
71 \\
13 \\
14 \\
15 \\
5\end{array}$ \\
\hline
\end{tabular}


Table 5

Percentage of lien Liking Fifty-four Amusement Items (Fron Strong) (Cont'd.)

\begin{tabular}{|c|c|c|c|c|c|c|c|c|c|c|c|c|c|c|}
\hline \multirow{2}{*}{ pio. Item } & \multicolumn{6}{|c|}{ Percentage of Likes at Age Civen } & \multicolumn{5}{|c|}{$\begin{array}{c}\text { Percentage of Dislikes } \\
\text { at Age Given }\end{array}$} & \multirow{2}{*}{$\begin{array}{l}\begin{array}{c}\text { Change in } \\
\text { Attitude }\end{array} \\
55-25\end{array}$} & \multicolumn{2}{|c|}{ Men in Genera] } \\
\hline & 25 & 35 & 45 & 55 & $55-25$ & $\begin{array}{l}\text { S.E. } \\
\text { Diff. }\end{array}$ & $25^{\circ}$ & 35 & 45 & 55 & $55-25$ & & I & D \\
\hline $\begin{array}{l}\text { 43. "Life" } \\
\text { 44. "New Republic" } \\
\text { 45. "System" } \\
\text { 46. "National Geographic } \\
\text { 47. "American Magazine" } \\
\text { 48. "Popular Mechanics" } \\
\text { 49."Atlantic lionthly" } \\
\text { 50."Arts \& Crafts" } \\
\text { 51. Cowboy Movie } \\
\text { 52. Educational Movies } \\
\text { 53. Travel Movies } \\
\text { 54. Social Problem } \\
\text { Movies }\end{array}$ & $\mid \begin{array}{l}59 \\
27 \\
22 \\
80 \\
46 \\
44 \\
55 \\
20 \\
15 \\
53 \\
68 \\
44\end{array}$ & $\begin{array}{l}55 \\
32 \\
28 \\
84 \\
52 \\
47 \\
58 \\
21 \\
17 \\
64 \\
77 \\
29\end{array}$ & $\begin{array}{l}55 \\
33 \\
32 \\
88 \\
54 \\
45 \\
63 \\
28 \\
25 \\
69 \\
83 \\
32\end{array}$ & $\begin{array}{l}45 \\
33 \\
29 \\
91 \\
48 \\
51 \\
65 \\
29 \\
21 \\
71 \\
83 \\
31\end{array}$ & $\begin{array}{r}-\frac{14}{6} \\
7 \\
11 \\
2 \\
7 \\
10 \\
9 \\
6 \\
18 \\
15 \\
-13\end{array}$ & $\begin{array}{l}4.0 \\
1.9 \\
2.3 \\
4.5 \\
.6 \\
2.0 \\
2.9 \\
3.0 \\
2.2 \\
5.4 \\
5.0 \\
3.8\end{array}$ & $\begin{array}{r}6 \\
9 \\
18 \\
2 \\
16 \\
17 \\
6 \\
17 \\
53 \\
12 \\
.8 \\
21\end{array}$ & $\begin{array}{r}9 \\
10 \\
16 \\
1 \\
11 \\
11 \\
4 \\
11 \\
39 \\
5 \\
3 \\
26\end{array}$ & $\begin{array}{r}12 \\
12 \\
16 \\
1 \\
10 \\
10 \\
3 \\
9 \\
33 \\
7 \\
2 \\
25\end{array}$ & $\begin{array}{r}10 \\
12 \\
14 \\
1 \\
8 \\
7 \\
2 \\
7 \\
31 \\
5 \\
2 \\
24\end{array}$ & $\begin{array}{r}4 \\
3 \\
-1 \\
-1 \\
-3 \\
-10 \\
-4 \\
-10 \\
-22 \\
-7 \\
-6 \\
3\end{array}$ & $\begin{array}{r}-18 \\
3 \\
11 \\
12 \\
10 \\
17 \\
114 \\
19 \\
28 \\
25 \\
21 \\
\\
-16\end{array}$ & $\begin{array}{l}61 \\
27 \\
34 \\
83 \\
51 \\
48 \\
55 \\
27 \\
23 \\
63 \\
76 \\
28\end{array}$ & $\begin{array}{r}6 \\
12 \\
114 \\
1 \\
13 \\
10 \\
5 \\
10 \\
36 \\
7 \\
4 \\
28\end{array}$ \\
\hline $\begin{array}{l}\text { Averages } \\
\text { Averages of Increases } \\
\text { Averages of Decreases } \\
\text { Average Change }\end{array}$ & $\begin{array}{l}42.7 \\
43.1 \\
42.4\end{array}$ & 2.6 & & $\begin{array}{l}39.7 \\
52.2 \\
31.9\end{array}$ & $\begin{array}{r}-3.0 \\
9.1 \\
-10.5 \\
10.0\end{array}$ & & $\begin{array}{l}22.5 \\
22.8 \\
21.8\end{array}$ & & 7.0 & $\begin{array}{l}25 . \\
30\end{array}$ & $\begin{array}{rl}1 & 2.6 \\
5 & 7.7 \\
4 & -6.4 \\
& 7.2\end{array}$ & $\begin{array}{l}-5.4 \\
15.3 \\
17.6 \\
16.8\end{array}$ & 42.2 & 22.4 \\
\hline
\end{tabular}


Strong contends that when you look at a group of interests, rather than only one at a time, relative interests tend to remain constant over the years.

Following are some of Strong's general conclusions which are pertinent to this study:

1. Iterns suggesting physical skill and daring, as in 'walking along the edge of a precipice' or tbeing an aviator' show the greatest change of all; older men do not like such activities as do younger men.

2. Many amusements are liked by large percentages of all ages. But there is a distinct tendency for all of them to decline except those that might be characterized as cultural. These increase in liking. Older men also prefer, more than younger men do, those amusements pursued largely alone in contrast to ones involving others. There is no question that older men are less interested in people associated with them whether in business or amusements. How much of the changes reported here are due to genuine changes in men with age and how much are a reflection of changes in social life is a question, undoubtedly not all of it is due to the latter.

3. Old people are likely to be lonely, as most of their lifelong friends are dead. Preparation for the enjoyment of old age should seemingly include the development of interest in activities that may be pursued largely alone. This our data clearly indicate. How far in addition older people can be trained in earlier life to enjoy activities wi.th others, so that in later life they will participate in them, is a question. For a generation or two the experiment should be tried in order that the limits of enjoyment in old age from such sources may be ascertained. 45

Though Strong's study gives a fairly comprehensive and reliable picture of the change in men's interests and attitudes with age, he includes only eight sports items among his list of amusement items. Golf showed a decline of $I_{4}$ per cent; fishing, 0 ; hunting, 18 per cent; tennis, 20 per cent; walks gained in interest 4 per cent; 
billiards 1 per cent; and chopping wood 10 per cent. These conclusions are in general agreement with those of Husman. 


\section{CHAPTER II \\ Influence of Age and Income Upon Recreational. \\ Interests}

The Questionnaire. In the present chapter, and also in Chapters III, IV, and $V$, the more important findings resulting from the present writer's questionnaire tabulation will be discussed. What happened with respect to liking for, participation in, and reasons for unsatisfactory participation in every one of the sixty-seven recreational activities being studied will not be discussed. To do so seems to the present writer to be repetitious inasmuch as anyone who is interested in a specific activity can refer to the tables in the appendix. In the following chapters it will be principally central tendencies which will be discussed. Influence of Age Upon Recreational Interests. As men grow older they like fewer recreational activities and feel indifferent toward an increasing number of them. This is unfortunate inasmuch as the amount of leisure time at a man's disposal increases with age. There were eight activities towards which an increasing number of men registered liking with increase in age. These were: checkers, still fishing, card playing, gardening, listening to the radio, watching $\mathrm{TV}$, reading, and stamp collecting. Fishing and gardening are desirable activities since they take men outdoors and provide some physical exercise. It is obvious that the remaining activities are all sedentary activities resulting in little if any growth either physically or mentally. Mental growth may or may not result from reading. Whether or not it does depends upon the types of reading material 
selected. Unfortunately, this study does not show what type of reading material is selected by the various age groups. Whether or not there is a more discriminating selection with increasing age is not known. It will be further noted that these are all activities which are solitary in nature with the exception of checkers and card playing. This is in agreement with the study made by strong in which he found that men's liking for solitary activities increases with age while their liking for group activities decreases sharply with age and their liking for activities engaged in with one or two people decreases somewhat less. It can be concluded from these data that men dislike extending thenselves more and more with increasing age. There were six activities in which the decline in interest with increasing age was insignificant. These were: bowling, bait casting, motoring, puttering and repairing, visiting friends, and watching sports events. Bowling for a middle aged man is a truly re-creative experience. It is both mentally and physically stimulating. It is mentally stimulating because of the friendly yet competitive spirit between himself and his partners. It is a mild physical activity appropriate to any age group. Bait casting is still another mild physical activity appropriate to any age group and one which takes men out of doors to enjoy the fresh air and to enjoy the tonic and relaxing atmosphere of the out-of-doors. Motoring provides new vistas and can broaden a person who is curious about the mores, problems, and points of view of people living in other sections of the country. Puttering and repairing can present new problems to solve and may result in some study. Watching sports is desirable if it will lead to 
participation in them. It is apparent from data presented further along in this study that this does not occur. Observing sports does not greatly increase participation in them, at least among adult men. The quality of elementary school, high school, and college physical education programs has been steadily improving over the years. Many of the men who are now in their forties, fifties, and sixties were not required to take any courses in physical education while they were in high school or college. A much larger number of those who did take physical education activities engaged in a very limited program consisting of mass calisthenics and gymnastic stunts. Few of the men, even those who are now in their twenties or thirties, participated in a diversified sports program where they were introduced to the rudiments of a large variety of sports. Mien are more likely to indicate a feeling of indifference toward those activities with which they are unfamiliar. They are more likely to indicate liking or disliking toward activities to which they have been introduced. This may account, in part, for the fact that in each succeeding age group a greater percentage of men indicated a feeling of indifference for each activity. However, the above reasons do not account entirely for the increasing number of men from successive age group indicating indifference. An increasing number uf men indicated a feeling of indifference toward activities such as: bicycling, boating, calisthenics, conversing, still fishing, hiking, horseshoes, music, movies, motoring, night clubbing, puttering and repairing, social drinking, social dancing, swimming, visiting friends; and walking. These are all activities which all men must have sampled at one time or another. At least, 
a substantial number of them must have done so. Strong's conclusions agree with the findings that men like fewer activities and feel indifferently toward an increasing number as they grow older.

Many of the activities listed can be participated in with profit and enjoyed by men of all age groups. Some of these activities are: archery, badminton, bicycling, boating, bowling, canoeing, chess, bait casting, still fishing, gardening, golf, handball, hiking, horseback riding, horseshoes, hunting, ice skating, music, metal craft, puttering and repairing, photography, painting, sailing, square dancing, swimming, tennis, volleyball, wood working, and wood carving. A liking for any of these activities is not simply inherited. It must be developed. Furthermore, it takes considerable time to develop a sustaining interest in an activity. A reasonable amount of proficiency in a particular activity must be developed if interest in the activity is to be sustained. People like and tend to do those things which they do reasonably well. It is also necessary to have some knowledge of the activity. An understanding of the techniques, strategies, past records, benefits accruing from the activity, and organizations and their locations where instruction and participation can be received will all help in bringing an increasing number of men to like and to enjoy any activity.

Following is a ranking of the activities according to the overall decrease in the percentage of men indicating liking for them. In successive age groups, table tennis showed the greatest decrease in liking while bait casting showed the least decrease in liking. 
Table 6

Rank Order of Decrement in Number of Men From Successive Age Groups Indicating Liking for the Activity Listed
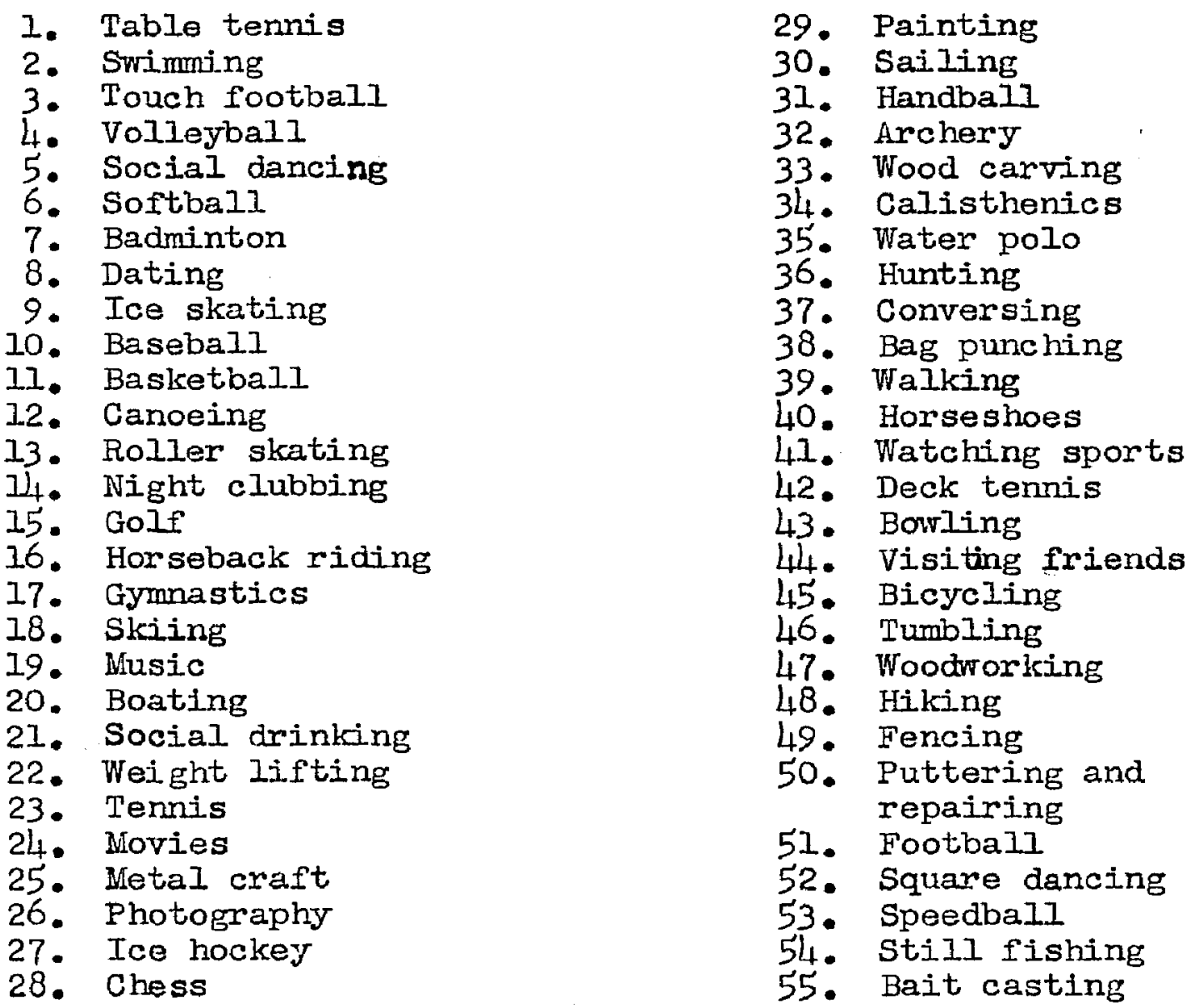

Note: Football and speedball did not show as large a decrement as would be expected because the percentage of men in the 20-29 age group who indicated liking for them was very small. This, of course, meant that there could not be a large decrement.

There are three types of activities which show the greatest decrease in liking. These are: (1) those which require quick reactions such as table tennis, volleyball, softball, badminton, baseball, skiing, tennis, etc; (2) those which require physical endurance such 
as swimming, touch football, basketball, ice skating, canoeing, gymnastics, water polo, etc.; and (3) those which satisfy the romantic and erotic impulses such as soctal dancing, dating, night clubbing, music, and movies.

Reaction time is known to decrease with age. As a result men are not likely to perform as well when they are older as they did when they were younger in those activities which require quick reaction time for success. If they compete against men their own age and develop the attitude of playing for the pleasure and the mental and physical relaxation provided rather than to prove their physical prowess, they are more apt to continue to enjoy this type of activity. The second type of activity which shows a marked decline in interest with increase in age is that requiring physical endurance and stamina. Another study shows that the muscular strength and endurance of men begins a sharp decline after the age of twenty-nine. I This study shows further that this decline is much greater than it need be. Studies were presented earlier which show that middleaged men can make great improvements in strength and in endurance (page 29). If men would set aside some time (two or three times weekly) to engage in fairly vigorous physical activity, they would help thernselves to sustain their endurance at higher levels. If they

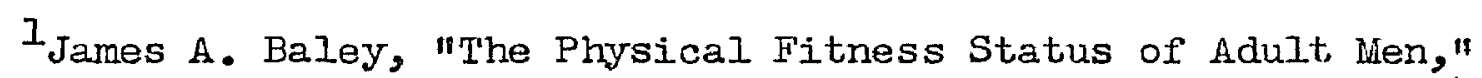
Unpublished Master's Thesis, University of Illinois, Urbana, 1948. 
would do this, it is certain that they could derive more satisfaction from those activities requiring a degree of physical endurance. They could then continue to enjoy activities such as swimming, canoeing, ice skating, roller skating, and gymnastics. Few adult men will participate in such activities as water polo, basketball, and touch football not only because they will prove too strenuous but also because it is very difficult for a person not in school or college to find enough men who are free at the same time to form two teams. The older the age group the greater the number of men in that age group who are married. The majority of married men do not require that their romantic and erotic impulses be satisfied outside their own home. This undoubtedly accounts in large part for the fact that each succeeding age group indicated less liking for activities such as social dancing, dating, night clubbing, music, and movies. With the exception of music and dancing, it is probably just as well that this is so.

The following table shows the twenty-most popular activities and the percentage of men indicating liking for them, for each age group: 
Table 7

Twenty Most Popular Activities

in Each Age Group

$20-29$

Baseball

Watching Sports

Swimming

Movies

Watching TV

Card Playing

Listening to Radio

Visiting Friends

Football

Hunting

Reading

Social Dancing

Softball

Motoring

Puttering and repairing

Bowling

Horseback Riding

Conversing

Social Drinking

Table Tennis

Horseshoes

$40-49$

Watching Sports

Watching TV

Card Playing

Reading

Visiting Friends

Baseball

Iistening to Radio

Movies

Bowling

Swimming

Puttering and repairing

Still Fishing

Hunting

Music

Gardening

lotoring

Horseshoes

Conversing

Football

Bait Casting

Social Dancing
$\%$ Liking

\% Iiking

92.6

91.2

87.9

84.6

83.5

79.1

78.0

78.0

73.6

72.5

71.4

70.3

70.3

70.3

67.0

67.0

67.0

65.8

64.8

63.6

63.6

87.0

86.0

85.0

82.0

82.0

77.0

75.0

73.0

68.0

67.0

65.0

65.0

65.0

63.0

61.0

58.0

53.0

50.0

48.0

47.0

47.0
$30-39$

\% Iiking

Watching Sports
Basebal1
Watching TV
Swimring
Reading
Bowling
Movies
Gardening
Softball
Visiting Friends
Card Playing
Listening to Radio
Puttering and repairing
Motoring
Horseshoes
Music
Football
Still Fishing
Converging
Social Dancing
Hunting

89.4

86.3

83.2

82.6

78.9

78.9

77.0

74.5

72.7

70.8

70.2

67.7

67.7

65.8

63.4

63.4

60.9

58.4

55.9

55.3

55.3

$50-59$

\% Iriking

Watching TV

88.1

Card Playing

88.1

Watching Sports

81.3

Iistening to Radio

79.6

Reading

72.8

69.5

67.8

64.4

Gardening

62.7

Notoring

59.3

Easebal1

59.3

Hunting

59.3

Puttering and repairing

57.6

Bowling

Conversing

52.5

52.5

52.5

47.4

44.1

44.2

40.7 
In the twenty to twenty-nine, thirty to thirty-nine, and forty to forty-nine age groups there were nine activities of a sports nature among the first twenty activities. In the fifty to fifty-nine age group there were eight activities of a sports nature among the twenty most popular activities. Gardening was regarded as an activity of: a sports nature because of its recreational aspects.

It is interesting to note that swimming declines in rank from third to fourth to tenth to twentieth in each succeeding age group. Gardening, which was not even included among the first twenty in the twenty to twenty-nine age group, ranked eighth in the thirty to thirtynine age group; fifteenth in the forty to forty-nine age group, and seventh in the fifty to fity-nine age group. Reading, which ranked eleventh in the twenty to twenty-nine age group, ranked among the first five after this age. Baseball continues to drop its position in each successive age grouping. Watching sports and watching IV rank high for all age groups. Social dancing, which ranked twelfth in the twenty to twenty-nine age group ranks nineteenth in the 30-39 age group, twentieth in the 40-49 age gioup, and is not even included among the first twenty activities by the time the fifty to fifty-nine age group is reached. The greatest decline in interest in recreational activities of a sports nature occurs after the age of forty. Influence of Income Upon Recreational Interests. The following table indicates the twenty recreational activities liked by the greatest percentage of men in each of the six income groups: 
Table 8

Twenty Most Popular Activities in Each Income Group $0-\$ 2,000$ \% Iiking $\$ 2,000-\$ 3,000$ of Liking

1. Reading

2. Puttering and repairing

3. Basebal1

4. Iistening to radio

91.7

91.7

91.7

91.7

83.3

83.3

75.0

75.0

75.0

75.0

75.0

66.7

66.6

66.6

66.6

66.6

66.6

58.3

58.3

58.3

58.3

58.3

58.3

58.3

58.3
Watching TV

Driving

Basebal1

Watching sports

listening to radio

Movies

Bowling

Mísic

Card Playing

Swimming

Visiting Friends

Motoring

Basketbal1

Reading

Football

SoItba 11

Hunting

Social Drinking

Boating

Puttering and repairing
88.0

84.0

80.0

78.0

78.0

76.0

72.0

72.0

70.0

70.0

70.0

64.0

62.0

60.0

60.0

58.0

58.0

54.0

54.0

19. Hunting

Dating

Gardening

Bait Casting

Badminton 
Table 8 (Cont'd.)

Twenty Most Popular Activities in Each Income Group $\$ 3,000-\$ 4,000$ \% Liking \$4,000-\$5,000 \% Liking

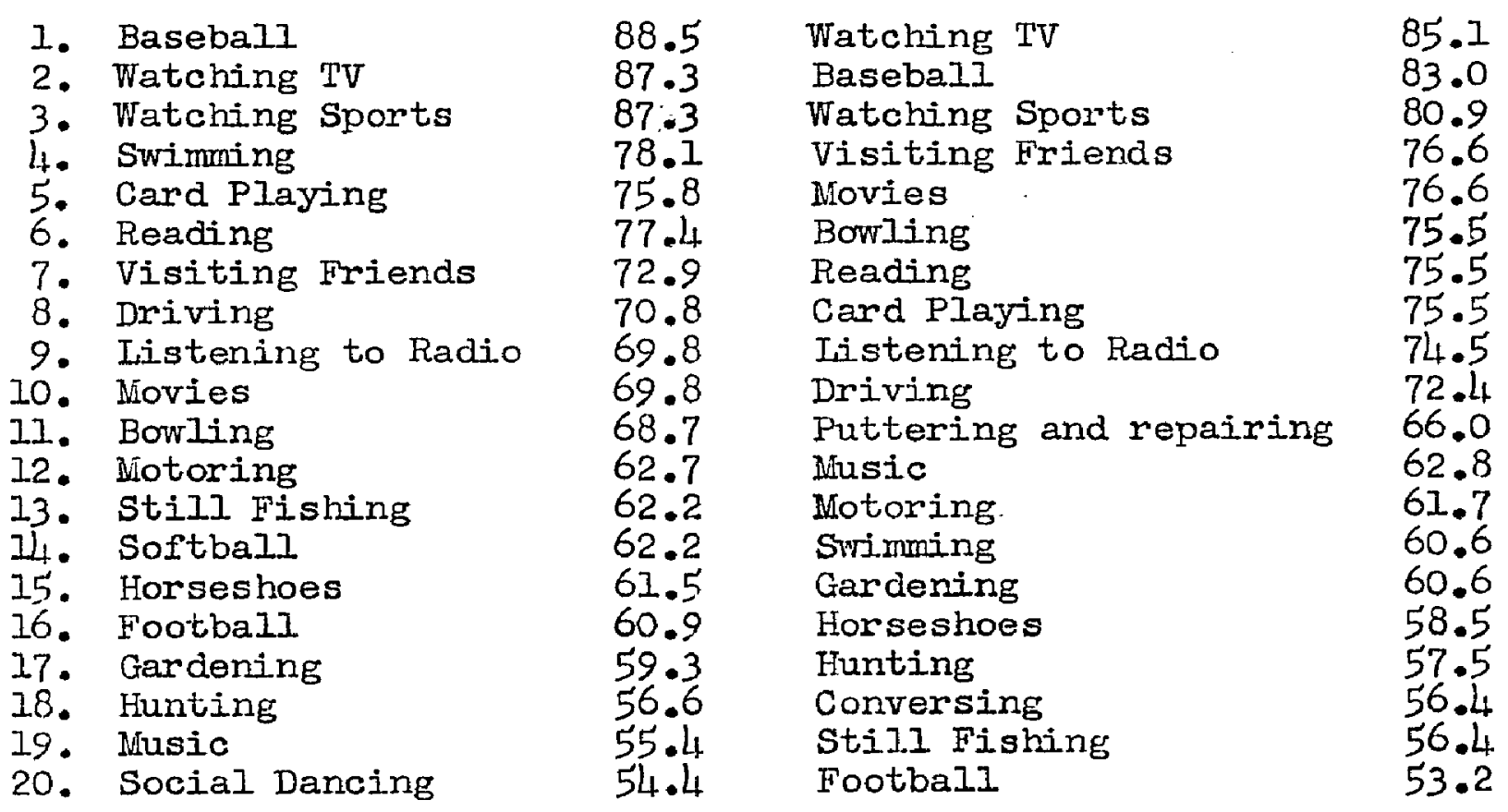


Table 8 (Cont'd.)

Twenty Most Popular Activities in Each Income Group $\$ 5,000-\$ 7,000 \%$ Liking Over $\$ 7,000$ of Liking

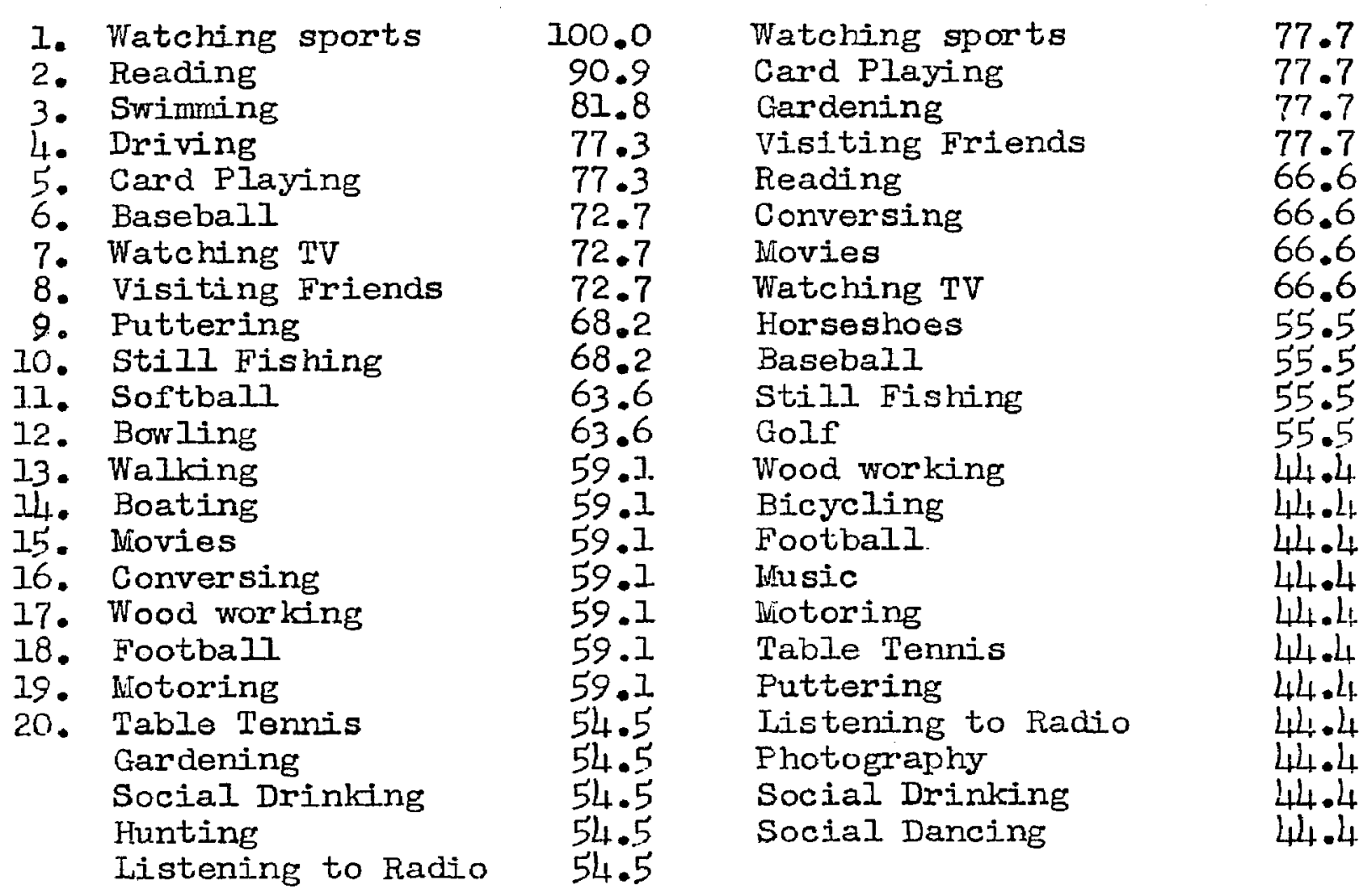

A consistent pattern was not shown as a result of the income grouping as was with the age grouping. The percentage of men liking an activity from each succeeding income group becomes progressively smaller. In the majority of cases whichever activity ranked third, fourth, fifth, etc. was liked by a smaller percentage of men in each succeeding income grouping. For example, the activity ranking tenth (this was a different activity for each income group) was liked by 75 per cent of the men in the 0-\$2,000 income group, 70 per cent of the men in the $\$ 2,000-\$ 3,000$ income group, 69.8 per cent of the men in the $\$ 3,000-\$ 4,000$ income group, 72.4 per cent of the men in the $\$ 4,000-\$ 5,000$ income group, 68.2 per cent of the men in the $\$ 5,000-$ $\$ 7,000$ income group, and 55.5 per cent of the men in the over $\$ 7,000$ 
income group. This general pattern was observed for almost every ranking. On the basis of this observation, it can be concluded that the higher a man's income, the fewer recreational activities he is apt to like and the more individualistic he is likely to become in his selection of recreational activities.

The majority of the activities did not change their position greatly or with any consistent pattern. Puttering and repairing, however, was one exception and did change its position but not with a consistent pattern. It ranked second in the $0-\$ 2,000$ income group, twentieth in the $\$ 2,000-\$ 3,000$ income group, was not among the first twenty in the $\$ 3,000-\$ 4,000$ income group, ranked eleventh in the \$4,000-\$5,000 income group, ninth in the $\$ 5,000-\$ 7,000$ income group, and nineteenth in the over $\$ 7,000$ income group.

Baseball ranked among the first ten in all age groups. Reading ranked high in all income groups with the exception of the $\$ 2,000-$ $\$ 3,000$ group. It should be kept in mind that few working men today earn less than $\$ 2,000$ annually. A majority of the men in the 0-\$2,000 income group were college students. This probably accounts for the high ranking of reading in this income group. The higher the income group, the more men of the group enjoy conversing. The $0-\$ 2,000$ group (mostly college students) ranked conversing sixth; it was not included among the first twenty activities by either the $\$ 2,000-\$ 3,000$ or the $\$ 3,000-\$ 4,000$ groups; it ranked eighteenth in the $\$ 4,000-\$ 5,000$ group; sixteenth in the $\$ 5,000-\$ 7,000$ group; and sixth in the over \$,000 group. Apparently, the greater a man's income, the more he enjoys exchanging ideas. The probability that a man will enjoy playing 
cards seems to be related to his income. The greater his income the more he is likely to enjoy playing cards. Card playing changed its position from twelfth to ninth, to fifth, to eighth, to fith, to second with each successive income grouping. Watching TV and watching sports ranked high in all income groups.

It will be noted that in the income groupings, as in the age groupings, recreational activities requiring physical movement did not rank very high. The most popular types of recreational activities were those of the passive or sedentary type.

The following table lists the activitj.es for which each particular income group showed a higher percentage of liking than any other income group. Badminton, for example, was liked by a greater percentage of men from the $0-\$ 2,000$ income group than any other income group. There were 58.3 per cent of the men from this group who liked badminton. No other income group showed as high a percentage of liking for this activity. This is true for each activity listed under each age group. All the activities listed under each income group are liked by a greater percentage of men from that income group than they are liked by men at any other income group. This listing follows: 
Table 9

Activities for Which the Particular Income Group

Showed a Higher Percentage of Liking Than Any other Income Group

\begin{tabular}{|c|c|c|}
\hline $0-\$ 2,000$ & $\$ 2,000-\$ 3,000$ & $\$ 3,000-\$ 4,000$ \\
\hline $\begin{array}{l}\text { Badminton } \\
\text { Baseball } \\
\text { Basketball } \\
\text { Calisthenics } \\
\text { Conversing } \\
\text { Deck Tennis } \\
\text { Dating } \\
\text { Fencing } \\
\text { Bait Casting } \\
\text { Still Fishing } \\
\text { Football } \\
\text { Gymnastics } \\
\text { Hiking } \\
\text { Horseback Riding } \\
\text { Hunting } \\
\text { Ice Skating } \\
\text { Puttering, etc. } \\
\text { Listening to radio } \\
\text { Reading } \\
\text { Painting } \\
\text { Sking } \\
\text { Social Dancing } \\
\text { Stamp Collecting } \\
\text { Tennis } \\
\text { Walking } \\
\text { Weight Iifting } \\
\text { Water Polo } \\
\text { Wrestling }\end{array}$ & $\begin{array}{l}\text { Archery } \\
\text { Bag Punching } \\
\text { Checkers } \\
\text { Driving } \\
\text { Ice Hockey } \\
\text { Music } \\
\text { Motoring } \\
\text { Night Clubbing } \\
\text { Watching TV } \\
\text { Photography } \\
\text { Roller Skating }\end{array}$ & $\begin{array}{l}\text { Track and Field } \\
\text { Horseshoes } \\
\text { Metal Craft } \\
\text { Speedball } \\
\text { Square Dancing }\end{array}$ \\
\hline$\$ 4,000-\$ 5,000$ & $\$ 5,000-\$ 7,000$ & Over $\$ 7,000$ \\
\hline $\begin{array}{l}\text { Bowling } \\
\text { Whovies } \\
\text { Wood Carving }\end{array}$ & $\begin{array}{l}\text { Boating } \\
\text { Boxing } \\
\text { Canoeing } \\
\text { Chess } \\
\text { Handball } \\
\text { Table Tennis } \\
\text { Social Drinking } \\
\text { Sailing } \\
\text { Softball } \\
\text { Swimming } \\
\text { Touch football } \\
\text { Tumbling } \\
\text { Volleyball } \\
\text { Watching Sports } \\
\text { Wood working }\end{array}$ & $\begin{array}{l}\text { Bicycling } \\
\text { Card Playing } \\
\text { Gardening } \\
\text { Golf } \\
\text { Visiting Friends }\end{array}$ \\
\hline
\end{tabular}


It can be seen that a greater percentage of men from the $0-\$ 2,000$ group like more activities than any other group. On the basis of these data, it can be concluded that the lower the income group, the more activities there are that a man will like. There is however, another important factor. That is, the $0-\$ 2,000$ income group is also the youngest age group. Recreational interests of younger persons: are generally more varied. The $\$ 2,000-\$ 3,000$ group liked most the sedentary or passive forms of recreation. The over $\$ 7,000$ income group liked most those activities which provide social contacts. Three of the five activities in which they ranked first provide social contacts. These were: card playing, golf, and visiting friends. Whether this is the result of moving into this income group or helped to bring about the move is not known. Increasing age may be a factor. The $0-\$ 2,000$ and the $\$ 5,000-\$ 7,000$ income groups indicated most liking for the active, sports type of recreational activities. 
CHAPTER III

The InfIuence of Age and Income Upon

Recreational Habits

The Influence of Age Upon Recreational Habits. In the preceding chapter the influence of the aging process and of income upon recreational interests as shown by the percentage of men indicating liking for an activity was discussed. In the present chapter the influence of age and income upon recreational habits will be discussed. The recreational interests and habits of men do not run parallel to one another. In certain areas substantial deviations are noted. Mien are often prevented from doing things they would like to do by various factors. Some of these restrictive factors are poor health, lack of adequate time, insufficient funds, lack or inaccessibility of facilities, or lack of knowledge and skill in the activity. For these reasons, it is not sufficient to study the recreational interests of men alone. It is also necessary to discover their recreational habits and to find how these habits relate to their recreational interests. Then it is necessary to discover their reasons for unsatisfactory participation in those activities in which they desire more frequent participation. In this chapter the recreational habits of adult men as they relate to age and income will be discussed.

The following table indicates the twenty recreational activities participated in most frequently by men of each of the four age groups. 
Twenty Activities Participated in Wost Frequently

by Men of the Five Age Groups

\begin{tabular}{|c|c|c|c|c|}
\hline \multicolumn{3}{|c|}{$20-29$} & \multicolumn{2}{|l|}{$30-39$} \\
\hline Rank & Activity & Part.Indexis & Activity & Part.Index: \\
\hline 1. & Driving & 108.7 & Watching TV & \\
\hline 2. & Conversing & 80 & Driving & \\
\hline & Listening to radio & 68 & Reading & 15 \\
\hline & Reading & 63 & Listening to radio & 92 \\
\hline 5. & Watching IV & 55 & Puttering, etc. & \\
\hline 6. & Wallcing & 45.45 & Conversing & \\
\hline 7. & Puttering, etc. & 40.82 & Watching sports & \\
\hline 8. & Social Drinking & 38.09 & Walking & .63 \\
\hline 9. & Watching sports & 11 & Visiting friends & .87 \\
\hline 10. & Visiting friends & 73 & Notoring & 17 \\
\hline 1]. & Music & 32 & Music & 21.19 \\
\hline 12. & Playing Cards & $29 \cdot 04$ & Playing Cards & 19.75 \\
\hline 13. & Dating & 26.25 & Movies & \\
\hline 14. & Motoring & 24.9 & Bowling & 13 \\
\hline 15. & Movies & $24 \cdot 23$ & Gardening & 13 \\
\hline 16. & Night clubbing & $15 \cdot 34$ & Social drinking & 12.39 \\
\hline 17 . & Bowling & 12.5 & SociaI dancing & \\
\hline 18. & Social Dancing & 11.96 & Woodworking & \\
\hline 19 . & Weight lifting & 10.78 & Checkers & \\
\hline 20 & Calisthenics & $\frac{10.60}{20.60}$ & Calisthenics & \\
\hline & TOTAL & 770.32 & TOTAL & \\
\hline & $40-49$ & & $50-59$ & \\
\hline 1. & Watching TV & 76.38 & Motoring & 65.56 \\
\hline 2 & Reading & 73.36 & Watching TV & 60 \\
\hline 3. & Listening to radio & 65.09 & Listening to radio & .00 \\
\hline 4. & Puttering, etc. & 42.09 & Reading & \\
\hline 5 . & Driving & 34.06 & Driving & \\
\hline 6. & Watching sports & 24.62 & Gardening & 31 \\
\hline 7. & Playing Cards & 23.72 & Puttering, etc. & $27 . . \amalg_{4}$ \\
\hline 8. & Conversing & 23 & Conversing & \\
\hline 9. & Visiting friends & 23.17 & Walking & 24.19 \\
\hline 10. & Walking & 20.1 .6 & Watching sports & 19 \\
\hline 11. & Wotoring & 28.78 & Playing cards & 39 \\
\hline 12. & Music & $17 . .77$ & Visiting friends & 15.41 \\
\hline 13. & Movies & 14.26 & Checkers & $1 \longdiv { 4 . 8 3 }$ \\
\hline 14. & Bowling & 12.32 & Music & 12.88 \\
\hline 15. & Gardening & 11.66 & inovies & 11.74 \\
\hline 16. & Checkers & 7.24 & Bowling & \\
\hline 17. & Still fishing & 7.21 & Still fishing & \\
\hline 18. & Woodworking & 5.38 & Woodworking & 12 \\
\hline 19. & Bait Casting & 4.81 & Metal Craft & 7.46 \\
\hline 20. & Social Dancing & 80 & Bait Casting & \\
\hline & & 510.10 & & \\
\hline
\end{tabular}

"The part. index is a measure of the frequency of participation in each activity: The method of deriving this figure is explained fully on pages $43-45$. 
It should be kept in mind that the participation index listed after each activity approaches but does not equal the average number of times each person in that age group participates in the activity in the course of one year. The reason for this, as was pointed out earlier, is that many men did not indicate the actual number of times they participated in the activity per week, month, or year, but merely placed a check mark in the weekly, monthly, or annually column. These questionnaires were treated as though the men participated once each week, month, or year, as the case might be. This should not have changed the relative positions of any activity since when a man used check marks for one activity, he used thern for all. Furthermore, the proportion of men following this procedure was approximately the same for all age groups.

It can be seen from the above table that with few exceptions most of the activities maintained their rank from one decade to the next and that they were in the main ron-vigorous in nature. Those activities that remained close to their first ranking from decade to decade were: driving, listening to the radio, reading, watching television, walking, puttering, watching sports, visiting friends, music, card playing, movies, and bowling. Apparently the recreational habits of younger men do not differ greatly in kind from those of older men.

There were a few activities which were participated in less frequently by older men than younger men. Conversing ranked second in the 20-29 age group, sixth in the 30-39 age group; and eighth in both 
the 40-49 age group and the 50-59 age group. On the basis of these data it can be concluded that as a man grows older he converses less. Social drinking ranked eighth in the 20-29 age group, seventeenth in the 30-39 age group, and did not rank among the first twenty thereafter. Night clubbing ranked sixteenth in the 20-29 age group, and did not rank among the first twenty in any other age group. Dating ranked thirteenth in the 20-29 age group but did not rank among the first twenty thereafter. Social drinking, night clubbing, and dating are activities most likely to be engaged in by young unmarried men in search of female companionship. This probably accounts for the sharp decline in participation in these activities after the age of thirty. A large proportion of men become married sometime during the third decade of Iife, and therefore do not desire to participate in such activities.

Weight lifting and calisthenics were two other activities which showed a large drop in frequency of participation after the age of thirty. They are the only two vigorous activities listed in any age group. They do not appear among the first twenty activities after the third decade. Even in the third decade they rank down on the bottom of the list-mineteenth and twentieth respectively. Such activities as archery, badminton, golf, gymnastics, handball, ice skating, skiing, softball, swimming, tennis, tumbling, and volleyball are taught in the school and college physical education programs with the hope that students will continue to participate in them after graduation. It can be seen from the low participation index for all these activities and at all age levels that these activities are not 
being continued after graduation to a considerable extent. There are probably several reasons for this. One is lack of opportunity. It requires considerable preparation to engage in these activities in the form of purchasing equipment, locating facilities, and finding friends interested in the same activity. It is much simpler to turn on the television set or radio, to pick up a magazine, to get into the car, to converse, to play cards, or to go to a night club. These require a minimum of preparation. It is necessary that facilities be easily accessible and that their location be known. All people are gregarious to various degrees. The sportslike activities require companionship for maximum enjoyment. Most of these types of activities require one or more partners. Reading, listening to the radio, watching television, and listening to music do not. Most men would not enjoy themselves engaging in archery, gymnastics, tumbling, or swimming alone. It is necessary that clubs, leagues, and tournaments be formed; that the programs be adequately publicized by community recreation associations and industries if any measure of success is to be achieved. Companionship is assured when a man is a member of a club playing in a tournament. It will be noted that bowling was the only sport which ranked fairly high from a participation standpoint. The reason for this probably lies in the fact that bowling is one of the most popular adult sports and industries have organized bowling leagues and tournaments on an extensive basis. It is the belief of the present writer that other activities such as archery, badminton, softball, handball, tennis, swiming, and volleyball could be made equally popular if leagues and tournaments were organized, 
if facilities were readily available, and if the programs were given adequate publicity. People who do not enjoy bowling could be almost certain of finding one activity among this list which they would enjoy.

The older a man becomes the less he participates in all recreational activities. The participation indices for all sixty-seven activities for each age group were totaled. It was found that these totals were as follows:

$$
\begin{aligned}
& 20-29-929.40 \\
& 30-39-703.36 \\
& 40-49-572.65 \\
& 50-59-559.59
\end{aligned}
$$

I'he greatest decrease in participation occurs after the third decade. There is also a large decrease after the fourth decade. The decrease between the third and fourth decade was 226.04 , between the fourth and fifth decade 130.71, and between the fifth and sixth decade 13.05. The fact that the drop is so great after the third decade is probably explained again by the fact of marriage during the third decade and the added responsibilities of marriage, a home, and a family. If men and women learned the co-educational sports and acquired the desire to participate in them together the decrease at this time would probably not be as great.

After the age of thirty, men begin to participate more frequently in activities such as gardening, woodworking, metal craft, bait casting, still fishing, and checkers. Gardening moves from sixteenth to fifteenth to sixth in the 30-39, 40-49, and 50-59 age groups respectively. Checkers moves up from twentieth to sixteenth, to thirteenth in each succeeding age group. Woodworking, bait casting, and metal 
craft also are participated in proportionately more frequently with increasing age.

There were nine activities whose participation index increased with each succeeding age group. This indicates that men participate in these activities more frequentIy with increasing age. These activities and their participation indices for each age group are given below:

Table 11

The Nine Activities in Which Frequency of Participation Increased with Age

$\begin{array}{lcccc}\text { Activity } & \begin{array}{c}20-29 \\ \text { Part. Index }\end{array} & \begin{array}{c}30-39 \\ \text { Part. Index }\end{array} & \begin{array}{c}40-49 \\ \text { Part. Index }\end{array} & \begin{array}{c}50-59 \\ \text { Part. Index }\end{array} \\ \text { Checkers } & 3.97 & 8.71 & 7.24 & 14.83 \\ \text { Bait Casting } & 5.84 & 5.37 & 4.81 & 6.80 \\ \text { Still Fishing } & 7.35 & 7.04 & 7.21 & 8.24 \\ \text { Gardening } & 8.80 & 13.40 & 11.66 & 31.83 \\ \text { Hiking } & 3.60 & 2.02 & 1.97 & 3.83 \\ \text { Metal Craft } & 5.17 & 7.35 & 2.36 & 7.46 \\ \text { Motoring } & 24.90 & 22.3 .7 & 18.76 & 65.56 \\ \text { Watching TV } & 55.50 & 57.27 & 76.38 & 60.63 \\ \text { Painting } & 1.48 & 3.44 & 1.90 & 2.02\end{array}$

The increase in frequency of participation in gardening and motoring is particularly great.

The Influence of Income Upon Recreational Habits. The following table shows the ranking of the twenty activities participated in most frequently by men of the several. income groupings: 
The Twenty Activities Participated in Most Frequently by Wen of Each Income Group

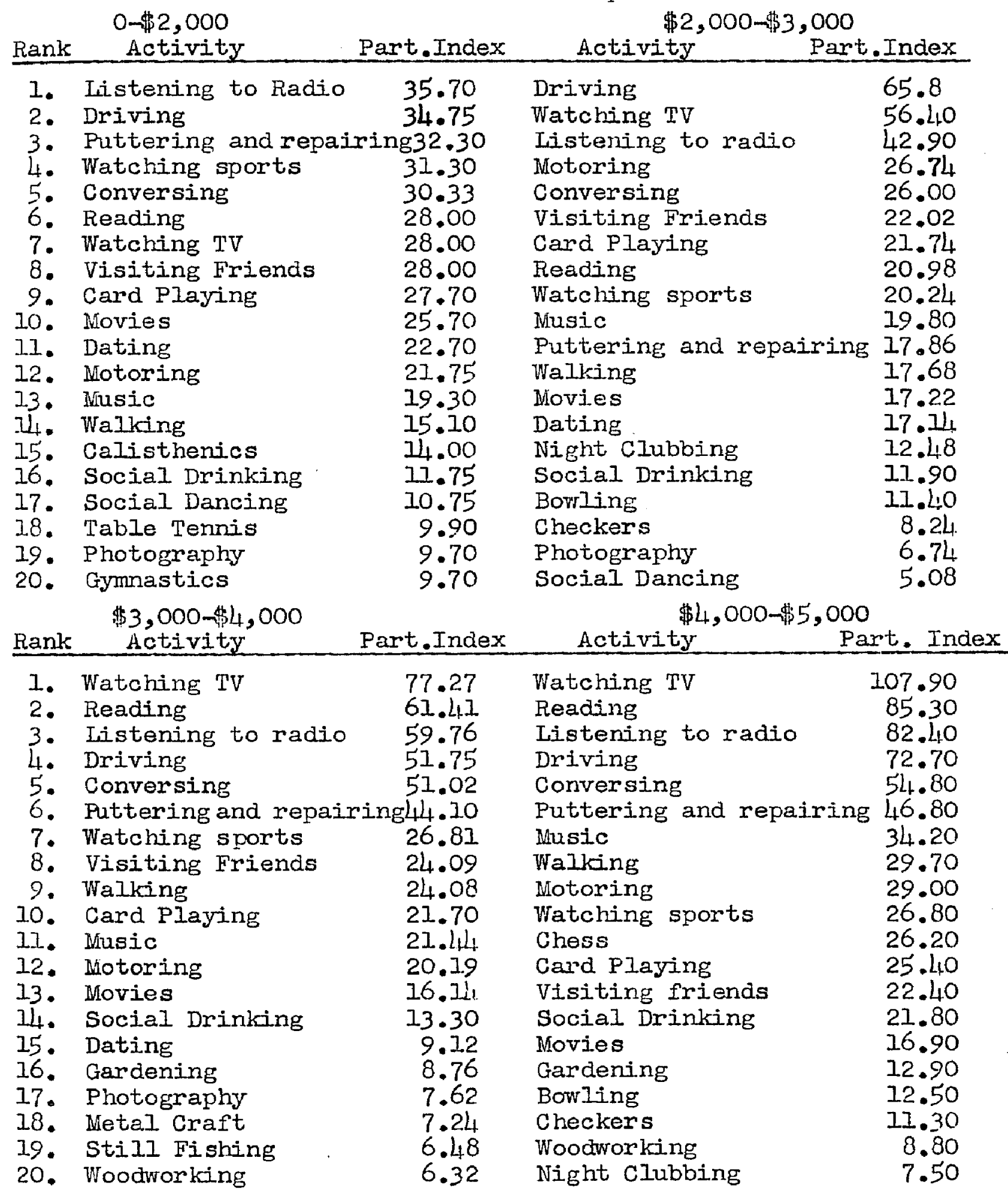


Table 12 (Cont'd.)

The Twenty Activities Participated in Miost Frequently by Wen of Each Income Group

\begin{tabular}{|c|c|c|c|c|}
\hline & $\$ 5,000-\$ 7,000$ & & Over $\$$ \$? & \\
\hline Rank & Activity & Part.Index & Activity & Part.Inde: \\
\hline 1. & Driving & 167.80 & Reading & 34.70 \\
\hline 2. & Watching TV & 94.50 & Conversing & 34.70 \\
\hline 3. & Conversing & 89.80 & Watching TV & 30.20 \\
\hline & Listening to radio & 63.80 & Visiting Friends & 27.10 \\
\hline & Puttering, etc. & 45.30 & Card Playing & 26.90 \\
\hline & Watching sports & 43.90 & Listening to radio & 26.40 \\
\hline & Card Playing & 40.40 & Puttering, etc. & 17.40 \\
\hline & Reading & 36.50 & Driving & 17.30 \\
\hline 9. & Walking & 35.60 & Movies & 14.40 \\
\hline 10. & Visiting Friends & 25.90 & Watching sports & 24.33 \\
\hline 11. & Motoring & 25.30 & Social Drinking & 12.90 \\
\hline 12. & Gardening & 18.90 & Woodworking & 12.90 \\
\hline & Movies & 16.20 & Music & 11.70 \\
\hline 14. & Bowling & 11.20 & Gardening & 9.70 \\
\hline & Music & 10.80 & Bowling & 8.70 \\
\hline 16. & Woodworking & 10.60 & Photography & 8.60 \\
\hline 17. & Night clubbing & 10.00 & Motoring & 8.40 \\
\hline 18. & Social Drinking & 9.60 & Night Clubbing & 7.10 \\
\hline 19. & Social Dancing & 9.20 & Wood Carving & 5.80 \\
\hline & Photography & 9.00 & Golf & 5.40 \\
\hline & & & & \\
\hline
\end{tabular}

It can be seen from the above table that few men participate in recreational activities of a sports nature or in those which require physical activity. In the 0-\$2,000 income group, there were only four activities of a sports nature included among the first twenty activities and these ranked on the bottom of the list. These activities and their rank were as fol.yows: walking, fourteenth; calisthenics, fifteenth; table tennis, eighteenth; and gymnastics, twentieth. The fact that calisthenics ranked ahead of such sports as golf, archery, badminton, volleyball, canoeing, boating, bait casting, still fishing, hunting, ice skating, roller skating, skiing, sailing, softball, srimming, tennis, and volleyball seens at first glance surprising. 
Upon making an analysis of the sports listed and of calisthenics it can be seen that the principal difference lies in the fact that calisthenics can be done in the home at any time with no equipment. Furthermore, no partners are required. Could not indistry help to increase participation in sportslike activities to some extent by organizing noon-hour and afterwork recreation programs similar to the high school intramural program? Equipment, facilities, and partners would then be readily available. The fact that this income group (0-\$2,000) participated in calisthenics to the extent they did seems to indicate they feel a need for physical activity. Why not make the physical activity more enjoyable by securing it in the form of sports?

In the $\$ 2,000-\$ 3,000$ income group, there were two physical activities included among the twenty recreational activities participated in most frequently. Walking ranked twelfth and bowling seventeenth. In the $\$ 3,000-\$ 4,000$ income group, walking ranked ninth, gardening sixteenth, and still fishing nineteenth. In the $\$ 4,000-$ \$5,000 income group, walking ranked eighth, gardening sixteenth, and bowling seventeenth. In the $\$ 5,000-\$ 7,000$ income group, walking ranked ninth, gardening twelfth, bowling fourteenth, and badminton tied for twentieth with photography. In the over $\$ 7,000$ income group gardening ranked fourteenth, bowling fifteenth, and golf twentieth. Lien of the 0-\$2,000 income group, which was made up mostly of college students and young men, participated in sports more frequently than any other incorne group. 
From the $\$ 2,000-\$ 3,000$ group to the $\$ 5,000-\$ 7,000$ income group the selection of sportslike recreational activities over other types seems to increase with income. The over $\$ 7,000$ income group prefers the sportslike activities somewhat less than the $\$ 5,000-\$ 7,000$ income group. Lien of this income group are undoubtedly older men. This may account for their infrequent participation in sports.

The relative extent to which the several income groups participated in sportslike activities was found in the following manner: Points on the basis of rank were awarded to each income group for any sportslike activity included among the first twenty activities. Twenty points were awarded if the activity ranked first; nineteen if it ranked second; eighteen if it ranked third, etc. The results of these computations follows:

\section{Table 13}

Extent of Selection of Active Forms of Recreation Over Sedentary Forms

\begin{tabular}{|c|c|c|c|c|c|}
\hline $0-\$ 2$ & & & & $00-\$ 3,0$ & Do \\
\hline Activity & Rank & Points & Activity & Rank & Points \\
\hline Walking & Ilth & 7 pts. & Walking & 12th & 9 pts. \\
\hline Calisthenics & $15 \mathrm{th}$ & - 6 pts. & Bowling & $17 \mathrm{th}$ & pts. \\
\hline Table Tennis & $18 \mathrm{th}$ & - 3 pts. & & TOTAL & $\overline{13}$ pts. \\
\hline Gymnastics & 20 th & - $\frac{1}{p t}$ pt. & & & \\
\hline & & 17 pts. & & & \\
\hline$\$ 3,000$ & $\$ 4,000$ & & & $00-\$ 5,0$ & \\
\hline Activity & Rank & Points & Activity & Rank & Points \\
\hline Walking & $9 \operatorname{th}$ & -12 pts. & Walking & $8 \operatorname{th}$ & $13 \mathrm{pts}$ \\
\hline Gardening & 16th & - 7 pts. & Gardening & 16 th & -5 pts. \\
\hline Still Fishing & $19 \mathrm{th}$ & -2 pts. & Bowling & 17 th & $-\frac{4}{4}$ pts. \\
\hline & DTAI & $\overline{21}$ pts. & & TOTAL & $\overline{20}$ \\
\hline$\$ 5,000$ & $\$ 7,000$ & & & er & \\
\hline Activity & Rank & Points & Activity & Rank & Points \\
\hline Walking & 9 th & - 12 pts. & Gardening & $I_{1}$ th & 7 pts. \\
\hline Gardening & I2th & - 9 pts. & Bowling & $15 \mathrm{th}$ & -6 pts. \\
\hline Bowling & I4th & $-\frac{7}{29}$ pts. & Golf & $\begin{array}{l}20 \text { th } \\
\text { TOTAL }\end{array}$ & $-\frac{1}{1} \mathrm{pt}$ \\
\hline & & 29 pts. & & & \\
\hline
\end{tabular}


The above table presents a measure of the degree of choice of participation in active forms of recreation over sedentary and mildly active activities within each age group and illustrates and compares the choice between the several income groups. It can be seen that men from the $\$ 5,000-\$ 7,000$ income group prefer the active forms of recreation more than do men of any other income group. Next in order were the $\$ 4,000-\$ 5,000 ; \$ 3,000-\$ 4,000 ; 0-\$ 2,000 ;$ over $\$ 7,000$; and the $\$ 2,000-\$ 3,000$ income groups.

The participation indices for all sixty-seven itens for each income group were totaled. The results of these computations were as follows:

$$
\begin{aligned}
& 0-\$ 2,000-549.98 \\
& \$ 2,000-\$ 3,000-532.73 \\
& \$ 3,000-\$ 4,000- \\
& \$ 4,000-\$ 5,000- \\
& \$ 5,000-\$ 7,000- \\
& \$ 74.49 \\
& \text { Over } \$ 7,000-867.80 \\
& \text { - } 357.78
\end{aligned}
$$

The results of these computations indicates that men of the $\$ 5,000-\$ 7,000$ income group participate most frequently in recreational activities. There is a steady increase in the frequency of participation from the $\$ 2,000-\$ 3,000$ income group to the $\$ 5,000-\$ 7,000$ income Eroup. When the over 7,000 incone group is reached there is a decided drop in the frequency of participation. The greatest increase in frequency of participation occurs betireen the $\$ 3,000-\$ 4,000$ and the $\$ 4,000-\$ 5,000$ income grouxs although that between the $\$ 2,000-$ $\$ 3,000$ and the $\$ 3,000-\$ 4,000$ income groups is also large. The men of the over $\$ 7,000$ income group participated in recreational activities less irequently than and other group. Possibly, they are so busy 
earning a living that they haven't time to enjoy the money they earn. Undoubtedly, the men of this income group are older men. This income level is not reached in a short time. It was shown earlier that older men participate in recreational activities less frequently than do younger men. The age of these men was without a doubt a factor in decreased participation of men of this income group. 
CHAPIER IV

\section{Relationship Between Recreation Interests \\ and Habits}

Influence of Age Upon These Relationships. The highest participation index found was 108.7. This was for driving for the 20-29 age group. It will be assumed that this represents maximum or perfect participation. This makes possible a comparison between the percentage of men liking an activity and the average frequency of participation. This comparison will provide a measure of the discrepancy between liking for and participation in each activity for each age and income group.

By subtracting the participation index for an activity from the percentage of men indicating liking for the activity, a measure of the discrepancy between men's desire to participate in an activity and their success in meeting this desire is provided. This procedure was followed for each of the sixty-seven activities for all four age groups. Following are listed the twenty activities which showed the greatest discrepancies: 
Table 가

Discrepancy Scores for Age Groups

$20-29$

1. Baseball

2. Swimning

84.89
83.0

3. Hunting

71.47

4. Football

5. Softbali.

70.75
67.09

6. Hor seback Riding

7. Movies

$$
65.20
$$

60.47

8. Ice Skating

60.34

9. Hor seshoes

$$
58.44
$$

10. Social Dancing 58.34

11. Basketball

12. 57.43

12. Table Tennis

13. Bowling

1. Boating

53.75
$30-39$

Baseball

Swimning

83.54

78.36

Softbal].

70.58

Bowling

65.40

Gardening

$$
61.10
$$

Football

Movies

59.66

57.79

Horseshoes 56.69

Watching Sports

$$
55.00
$$

Hunting

$$
53.80
$$

Boating

$$
52.19
$$

Still Fishing 51.36

Card Playing

$50.45^{\circ}$

Golf 46.39
$40-49$

Basebal1

Swimning

64.94

Hunting 62.73

Watching Sports 62.38

Card Playing 61.28

Visiting Friends 58.83

Movies

58.74

Still Fishing

Bowling 57.79

55.68

Horseshoes 49.49

Gardening

Football 49.34

Nusic 47.38

45.83

Social Dancing

$$
42.20
$$

$50-59$

Card Playing

68.71

Watching Sports 61.45

Hunting 58.89

Baseba17 56.89

Visiting Friends 54.09

Movies 52.65

Horseshoes

Bowling

$$
50.79
$$

Footbal

$$
48.02
$$

46.67

Still Fishing 44.26

Swimming 39.75

Hor seback Riding 37.68

Field Events 37.08

Gardening

35.97 
Table $\Psi_{4}$ (Cont'd.)

Discrepancy Scores for Age Groups

\section{$20-29$}

15. Touch Football

51.29

16. Card Playing

17. Golf

47.96

18. Still Fishing

19. Volleybali

47.47

20. Ice Hockey

45.80
$30-39$

Social Dancing

45.87

Ice Skating

45.47

Bait Casting

$$
45.43
$$

Basketball

44.33

Visiting Friends

43.93

Motoring

43.63

$$
\text { 40-49 }
$$

Bait Casting

$$
42.19
$$

Social Drinking

41.00

Softball

Motorin

40.20

Boating

39.22

38.65

Basketball

36.86
$50-59$

Boxing

$$
33.28
$$

Bait Casting

32.20

Puttering, etc. 32.16

Photography 31.89

Social Drinking 31.63

Wrestling 31.13 
It can be seen that the greatest discrepancy found was for the recreational activities of a sports nature. Seventeen of the first twenty activities for the 20-29 age group were sports. Thirteen of the first twenty for the 30-39 age group were sports. Eleven of the first twenty for the $40-49$ age group were sports. Twelve of the first twenty for the 50-59 age group were sports. This indicates that at all ages men are not participating in sports as frequently as they would like. It will be remembered that the twenty activities showing the highest participation index were principally of a mildly active and sedentary nature. (Pages 69, 89, and 90)

Men from the age of 20 to 49 would like to play baseball considerably more frequently than they do. From the standpoint of amount of discrepancy, baseball ranked first for the first three age groups. It ranked fourth for the 50-59 age group.

Swiming also showed great discrepancy between interests and habits. From this standpoint, it ranked second for all ages from 20 to 49 and eleventh from 50-59.

Hunting ranked third for the 20-29, 40-49, and 50-59 age groups, and tenth for the 30-39 age group. This is another activity which men would like to engage in considerably more frequently than they do. Movies is one of the few sedentary types of recreational activities in which men would like to participate more frequently than they do. It ranked seventh for the 20-29, 30-39 and the 40-49 age groups, and sixth for the 50-59 age group. 
The preceeding table points out the areas at which men's recreational habits begin to deviate from their interests. There were several activities which ranked among the first twenty for the 50-59 age group but not for any ot her age group. These were: track and field events, boxing, puttering and repairing, wrestling, and photography. Track and field events, boxing, and wrestling were more popular sports from a participation standpoint during the youth of the men who are now between 50 and 59 than they are at present. This plus the fact that they are activities which are too vigorous for men over fifty accounts for the fact that they ranked as high as they did. Puttering and repairing and photography were also included among the first twenty activities for the 50-59 age group but for no other age group. These are indications of the changes in the discrepancies between recreational habits and interests which come with increasing age.

The table also points out that after the age of forty men would like to participate in social drinking more frequently than they do. After the age of thirty, men would like to participate in bait casting, gardening, watching sports, and visiting friends more frequently than they do.

There were several activities which showed a discrepancy great enough to be included among the first twenty only in the 20-29 age group. These were: ice hockey, table tennis, touch football, and volleyball. Volleyball is an activity which men of all ages could enjoy. Interest in volleyball was stimulated at service camps throughout the world during World War II and it became one of the most popular 
of sports activities. World War II veterans are likely to have had experienced this activity. On the other hand, it is probable that only a small proportion of men from the upper age groups have had experience with this game. Since they are not familiar with the game, they are not as likely to indicate liking for it. The amount of participation in volleyball at all ages was almost negligible for all age groups.

Ice hockey and table tennis are sports which require quick reactions. Younger men enjoy this type of activity. Reaction time is known to become slower with age. As a result, older men are not as likely to be successful in these activities and therefore do not enjoy them. Participation in both activities was small at all ages. These factors account for the fact that the discrepancy figure for these activities for the 20-29 age group was high while it was low for other age groups.

Liking for golf and ice skating remains fairly high until the age of thirty-nine and then drops off quite sharply. The amount of participation remains approximately the same at all ages in both activities. Although the number of men playing golf is no greater after the age of thirty-nine, a greater proportion of them satisfy their desire to play this game since the proportion liking the activity is smaller.

There were several activities whose discrepancy between per cent liking and amount of participation was great enough to be included among the first twenty activities for the first three age groups, 20-29, 30-39, and 40-49 respectively, but not among the first twenty 
for the 50-59 age group. These activities were: basketball, boating, social dancing, and softball. For all of these, with the exception of softball, there was a steady decrease in the percentage of men indicating liking for the activity from age group to age group as well as a steady decrease in the amount of participation. The decrease in the amount of participation was not as great as the decrease in the percentage liking these activities. This indicates that of the men who enjoy these activities, a greater proportion of them satisfy their desire to engage in these activities as they grow older.

A check was made upon the extent to which men meet two types of recreational desires. This was done in the following manner: The sixty-seven activities were classified into two groups, sedentary and mildly active, and active. There was a total of twenty-four activities listed which were classified as sedentary and mildly active. These were as follows:

$$
\text { Table } 75
$$

Activities Classif'ied as Sedentary and Mildly Active

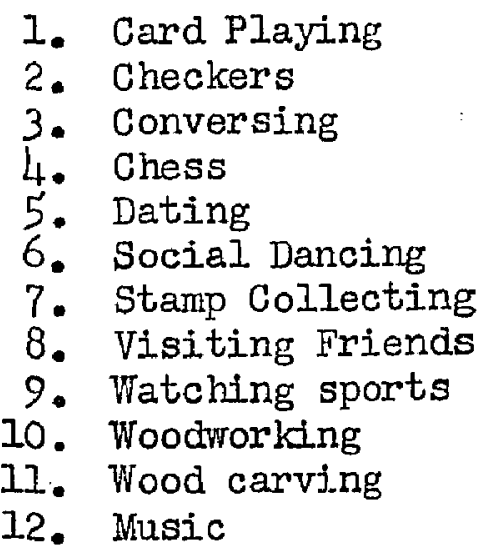

13. WetaI Craft

14. Movies

15. Motoring

16. Night Clubbing

17. Futtering and Repairing

18. Tistening to Radio

19. Watching television

20. Reading

21. Photography

22. Painting

23. Social Drinking

24. Driving

There was a total of forty-two sports, sporslike or active forms of recreation listed. In order to provide a fair comparison, only the 
first twenty-four active forms of recreation listed were used. These were as follows:

Table 16

Activities Classified as Active

1. Archery
2. Badminton
3. Bag Punching
4. Baseball
5. Basketball
6: Bicycling
7. Boating
8. Bowling
9. Boxing
10. Calisthenics
17. Canoeing
12. Deck Tennis

13. Fencing

I1. Irack and Field Events

15. Bait Casting

16. Still Fishing

17. Football

18. Gardening

19. Golf

20. Gymnastics

21. HandbalI

22. Hiking

23. Horseback Riding

24. Horseshoes

The difference between the percentage of men indicating liking for an activity and the participation index has been called, for the sake of simplicity, the discrepancy. The discrepancies for all twenty-four sedentary activities for each age group were totaled. The same was done for the twenty-four active forms for each of the four age groups. 'These totals were then compared. This procedure furnishes a measure of the extent to which men satisfy desires for recreational activities of an active form as compared to the extent to which they satisfy desires for recreational activities of a passive or sedentary form.

The following table presents the results of these computations: 


\section{Table 17}

Differences Between Total Discrepancies for Sedentary and Mildly Active and Active Forms of Recreation

\begin{tabular}{llllll} 
& $20-29$ & $30-39$ & $40-49$ & $50-59$ & Total \\
\cline { 2 - 6 } & & & & & \\
Active forms & 992.31 & 932.10 & 738.17 & 636.98 & 3299.56 \\
Sedentary forms & 686.10 & 758.82 & $\frac{702.54}{35.63}$ & $\frac{650.63}{-13.65}$ & $\frac{2798.09}{501.47}$ \\
\cline { 2 - 3 } & 313.21 & $\frac{173.28}{173}$ &
\end{tabular}

Since the discrepancy figures decrease from decade to decade, as can be seen from the above table, and since men participate less as they grow older, they must have learned to linit their desires to those things which they can do.

Iiking for the various activities must have decreased more rapidly than participation in them.

the figures also show that until the age of fifty is reached, men az'e not satisfying their desire to participate in the active forms of recreational activities as often as they are their desire to participate in the sedentary and mildly active forms. After the age of fifty they are less successful in satisfying their desire to participate in the sedentary and mildly active forms than they are in satisfying their desire to participate in the active forms. Apparently men find it more difficult to satisfy their desire to engage in the active forms than they do in the sedentary or mildly active forms. The difference between the total discrepancies for active and sedentary forms is shown to become progressively smaller and for the 50-59 age group this difference is reversed. This indicates that the decrement in participation in the active forms is greater from decade to decade than is the decrement in participation in the 
sedentary and mildly active forms and the decrement in liking for the active forms is greater than the decrement in liking for the sedentary or mildly active forms. However, the extent of participation and interest in the active forms approach one another more rapidly than they do in the sedentary forms. As men grow older they become increasingly successful in satisfying waning desires for participation in active forms of recreation. They also become increasingly successful in satisfying desires for participation in sedentary and mildly active forms of recreation but not as rapidly or to as great an extent as in the active forms.

One of the factors which limits men's participation in the active forms is physiologic change. If physiologic change is one of the main factors involved in changing habits of recreational participation, the evidence presented seems to indicate that these physiologic changes are preceded at a faster rate by mental, psychological, or sociological changes. What these changes are, the evidence does not indicate. The conjecture might be made that one of the sociologic factors is that older men are not expected by society to like and to enjoy such things as boxing, wrestling, and football. Another surmise might be that older men do not gain social prestige as readily as do younger men, through athletic ability. As has been pointed out earlier, men need to learn to enjoy sports for the mental and physical relaxation provided rather than to derive enjoyment only from proving their physical superiority. Lillian J. Martin, has pointed out that society's attitude toward babies and children has 
changed greatly in the past fifty years. 1 she predicts that a similar change will occur in our attitude toward older people. We may also change our atti.tude regarding physical activity by adult men. Acceptance of older men's swimming for hours imply for the physical activity, mental relaxation, and enjoyment provided may become one manifestation of this changing attitude. Influence of Income Upon the Relationship Between Recreational Interests and Habits. In the previous section the influence of age upon the relationship between recreational interests and habits was discussed. In the present section the influence of income upon the relationship between recreational interests and habits will be discussed. Income is related to age but not directly. It is a factor which should be taken into consideration in planning recreational programs for adult men. On the following page are listed the twenty recreational activities showing the greatest discrepancy between interest and participation for income groupings:

${ }^{I_{\text {Lillian }}}$ J. Martin, and C. de Gruchy, Salvaging Old Age, p.27. 
Table 18

Discrepancy Scores for Income Groups

\begin{tabular}{|c|c|c|c|c|}
\hline Rank & $\begin{array}{l}0-\$ 2,000 \\
\text { Activity }\end{array}$ & Discrepancy & $\begin{array}{l}\$ 2,000-\$ \\
\text { Activity }\end{array}$ & $\begin{array}{l}\text {,000 } \\
\text { Discrepancy }\end{array}$ \\
\hline 1. & Baseball & 88.45 & Basebal1 & 75.14 \\
\hline 2. & Football & 72.58 & Swimming & 67.18 \\
\hline 3. & Still Fishing & 69.00 & Bowling & 60.60 \\
\hline 4. & Reading & 63.70 & Movies & 58.78 \\
\hline 5. & Swimming & 62.20 & Basketball & 58.18 \\
\hline 6. & Basketball & 59.90 & Footba17 & 57.80 \\
\hline 7. & Puttering, etc. & 59.40 & Watching sports & 57.76 \\
\hline 8. & Hunting & 57.55 & Hunting & 57.30 \\
\hline 9. & Horseback riding & 56.63 & Softball & 56.40 \\
\hline 10. & Visiting friends & 55.30 & Boating & 52.27 \\
\hline 11. & Gardening & 54.26 & Music & 52.20 \\
\hline 12. & Badminton & 54.05 & Horseback riding & 51.24 \\
\hline 13. & Bait Casting & 52.47 & Card Playing & 48.26 \\
\hline 14. & Walking & 51.50 & Visiting friends & 47.98 \\
\hline 15. & Tennis & 49.75 & Social Dancing & 46.92 \\
\hline 16. & Ice skating & 49.50 & Still Fishing & 43.60 \\
\hline 17. & Driving & 48.55 & Social Drinking & 42.10 \\
\hline 18. & Softbaiz & 48.40 & Horseshoes & 41.92 \\
\hline 19. & Listening to radic & 47.60 & Roller skating & 40.72 \\
\hline 20 . & Social dancing & 47.55 & Ice skating & 39.72 \\
\hline & $\$ 3,000-\$ 4,000$ & & $\$ 4,000-$ &, 000 \\
\hline Rank & Activity & Discrepancy & Activity & Discrepancy \\
\hline I. & Baseball & 84.18 & Baseball & 80.30 \\
\hline 2. & Swimming & 74.76 & Bowling & 63.00 \\
\hline 3. & Bowling & 64.19 & Movies & 59.70 \\
\hline 4. & Watching sports & 60.49 & Swimming & 57.47 \\
\hline 5. & Softbali & 59.77 & Hunting & 56.30 \\
\hline 6. & FootbalI & 59.53 & Visiting Friends & 54.20 \\
\hline 7. & Horseshoes & & Watching sports & 54.10 \\
\hline 8. & Hunting & 55.74 & Horseshoes & 52.70 \\
\hline 9. & Still fishing & 55.72 & FootbalI & 52.45 \\
\hline 10. & Card Playing & 54.10 & Card Playing & 50.10 \\
\hline 11. & Social Dancing & 53.72 & Still fishing & 49.42 \\
\hline 12. & Movies & 53.66 & Softbal1 & 48.50 \\
\hline 13. & Gardening & 50.54 & Gardening & 47.70 \\
\hline I4. & Visiting friends & 48.81 & Boating & 46.00 \\
\hline 15. & Ice skating & 43.96 & Golf & 42.57 \\
\hline 16. & Bait casting & 43.60 & Bait casting & 38.80 \\
\hline 17. & Basketball & 43.61 & Social Dancing & 38.30 \\
\hline 18. & Boating & 42.98 & Horseback Riding & 35.25 \\
\hline 19. & Motoring & 42.51 & Boxing & 34.80 \\
\hline 20. & Hor'seback Riding & & Woodworking & 34.80 \\
\hline
\end{tabular}


Table 18 (Cont'd.)

\begin{tabular}{|c|c|c|c|c|}
\hline & $\$ 5,000-\$ 7,000$ & & Over 非7,000 & \\
\hline Rank & Activity & Discrepancy & Activity & Discrepancy \\
\hline 1. & Swimming & 75.40 & Gardening & 68.00 \\
\hline 2. & Baseball & 70.15 & Watching sports & 63.37 \\
\hline 3. & Softbali & 62.40 & Horseshoes & 55.28 \\
\hline 4. & Still fishing & 59.90 & Baseball & 55.06 \\
\hline 5. & Football & 58.74 & Still Fishing & 53.39 \\
\hline 6. & Watching Sports & 56.10 & Movies & 52.20 \\
\hline 7. & Boating & 56.10 & Golf & 51.10 \\
\hline 8. & Reading & 54.40 & Card Playing & 50.80 \\
\hline 9. & Hunting & 52.80 & Visiting Friends & 50.60 \\
\hline 10. & Bowling & 52.40 & Footbali & 44.40 \\
\hline 11. & Table Tennis & 50.40 & Table Tennis & 43.96 \\
\hline 12. & Woodworking & 48.50 & Social Dancing & 42.70 \\
\hline 13. & Visiting Friends & 46.80 & Bicycling & 40.45 \\
\hline If. & Social Dancing & 45.30 & Watching television & 36.110 \\
\hline 15. & Social Drinking & 44.90 & Motoring & 36.00 \\
\hline 16. & Bait Casting & 44.40 & Photography & 35.80 \\
\hline 17. & Volleyball & 44.20 & Dating & 33.30 \\
\hline 18. & Movies & 42.90 & Ice Skating & 32.97 \\
\hline 19. & Ice Skating & 40.55 & Hunting & 32.97 \\
\hline 20. & Horseback Riding & 40.40 & Minsic & 32.70 \\
\hline & Touch Football & 40.40 & & \\
\hline & Sailing & 40.40 & & \\
\hline
\end{tabular}

For income groupings, as for age groupings, it was found that the greatest discrepancies between recreational interests and habits were for sports activities. It is apparent that at all income levels men find it more difficult to satisfy sports interests than they do other recreational interests. Thirteen of the twenty recreational activities with the greatest discrepancy were sports. This was true of five of the six income groups. The sixth, the over $\$$;,000 income group included nine sports activities among the twenty recreational activities showing greatest discrepancy.

Men from all income groups would like to participate much more frequently than they do in baseball, football, still fishing, hunting, visiting friends, and social dancing. These activities ranked among 
the twenty highest for all income groups. It would take a considerable outlay of time for most adult men to bring themselves to the level of physical condition or physical fitness required to play football or baseball. Men of almost any age, however, can enjoy throwing and catching a football or a baseball. Could not industries provide footballs, baseballs, and gloves for their employees? Employees could then utilize the equipment during their Iunch hour.

Swimming, horseback riding, and softball ranked among the first twenty activities for all income groups with the exception of the over $\$ 7,000$ group. Obviously, industry could not provide horses for its employees. More of the larger companies might build swimming pools. They might also organize softball tour naments.

The following activities were included among the first twenty for only the 0-\$2,000 income group: puttering and repairing, badminton, walking, tennis, driving, and listening to the radio. All of these activities showed a sharp decrease from one income group to the succeeding one in discrepancy score. Wen from this income group cannot afford homes and so are not provided as much of an opportunity to putter or repair. This would account for the large discrepancy between their interest in these activities and their participation in thern.

There were three activities which ranked among the first twenty on the discrepancy score for the over $\$$; 7,000 income group but not for any other income group. These were: watching TV, photography, and dating. The percentage of men from this income group indicating liking for dating was not unusually high $(33.3$ per cent as compared with 
58.3 per cent, 46.0 per cent, 35.7 per cent, 31.9 per cent, and 27.3 per cent.) Since the participation index was zero, these men apparently do not "date" as often as the other men.

The discrepancy between participation in and liking for basketball was large enough to place it among the first twenty activites in the $0-\$ 2,000, \$ 2,000-\$ 3,000$, and $\$ 3,000-\$ 4,000$ income groups. Both liking for and participation in basketball decrease with increasing income.

The discrepancy score for bowling was high for all income groups with the exception of the lowest and the highest groups. It may be that men earning between $0-\$ 2,000$ annually cannot afford bowling and therefore have not discovered its pleasures and consequently do not indicate liking for it. There is undoubtedly a hierarchy of sports. Some sports are the exclurive property of the wealthy, such as pony polo, and as golf and tennis were in past years. Others, such as bowling, are the property of the masses. This may account for the small number of men earning over $\$ 7,000$ who indicated liking for this sport.

The discrepancy score for gardening was hi.gh for all income groups with the exception of the $\$ 2,000-\$ 3,000$ and the $\$ 5,000-\$ 7,000$ groups. The percentage of men from the $\$ \$ \$ 5,000-\$ 7,000$ income group indicating liking for gardening was high. The participation index was also high. This accounts for the low discrepancy score. A substantially greater number of men from the $\$ 2,000-\$ 3,000$ income group 
indicated dislike or indifference towards gardening. They neither liked nor participated extensively in gardening.

The discrepancy score for bait casting was high for all income groups with the exception of the $\$ 2,000-\frac{1}{\$ 3}, 000$ and the over $\$ 7,000$ income groups. The participation index for this activity was approximately the same for all income groups. The per cent liking bait casting from the above two income groups was small. This accounts for the low discrepancy score for these groups.

For the majority of the activities, there was no consistent pattern in the discrepancy score from one income group to the succeeding groups. This was not true for age groupings. There the djscrepancy score was shown to decrease from decade to decade indicating that men's desire to participate in recreational activities decreases more rapidly with increasing age than does their actual frequency of participation. 
CHAPTER V

Reasons Offered for Unsatisfactory Participation

The Influence of Age Upon Reasons Offered for Unsatisfactory Participation. In column three of the questionnaire men were asked to state their reason for insurficient participation in any of the sixty-seven activities in which they desired more frequent participation. Five reasons were suggested which might limit their participation. These were: health, time, money, facilities, and knowledge and skill. They wrote "health" in this column if poor health limited their participation; "time" if lack of time was the limiting factor; "money" if they lacked sufficient funds to engage in the activity as frequently as they would like; "facilities" if local facilities were lacking, inadequate, or too distant; or "knowledge and skill" if lack of knowledge or skill prevented or limited their participation. Obviously, men stated a reason only for those activities which they liked and in which they did not participate as frequently as they would like. If they liked the activity and did not desire more frequent participation, they did not state a reason. This explains why the number of times a reason was stated for any activity was as small as it was.

The table following presents the distribution of reasons for unsatisfactory participation for each age group. This was found in the following manner: first the total number of times health was listed as a factor limiting participation was determined by adding the number of times health was listed by all men of each age group 
for all sixty-seven activities. The same procedure was followed for each of the other four categories; namely, time, money, facilities, and knowledge and skill for each age group. The total number of times any reason was given was found by adding the totals of each of the five categories of reasons for each age group. The total number of times a specific reason appeared in the particular age group was divided by the total number of times all fi ve reasons were offered. This figure indicates the percentage each reason represents of the total number of reasons within a specific age group. The percentage figures are a measure of the relative frequency with which each of the five reasons was offered.

For example in the 20-29 age group, twelve men stated lack of time prevented satisfactory participation in archery. Twelve men stated time limited their participation in badminton. Seven men would like to punch a bag more frequently but were prevented from doing so because of lack of time. These numbers and all the number of times men of this age group listed "time" for all the remaining sixty-four activities were added. This was also done, as has been explained, for the "health," "money, "facilities," and "knowledge and skill" categories. Finally, the se totals were added and this grand total was divided into the total for each category of reason to secure the percentage flgure. This table follows = 
Table 19

Distribution of Reasons for Unsatisfactory Participation Within Each Age Group

\begin{tabular}{|c|c|c|c|c|c|c|c|}
\hline $\begin{array}{l}\text { Age } \\
\text { Group }\end{array}$ & & Health & Time & Woney & Facilities & $\begin{array}{l}\text { Knowledge } \\
\text { and Skili }\end{array}$ & $\begin{array}{c}\text { Total } \\
\% \\
\%\end{array}$ \\
\hline $20-29$ & No. & 5 & $\begin{array}{c}699 \\
56.2 \%\end{array}$ & $\begin{array}{c}157 \\
12.6 \%\end{array}$ & $\begin{array}{c}268 \\
21.6 \%\end{array}$ & $\begin{array}{l}17 y_{4} \\
9.2^{\circ}\end{array}$ & 100.0 \\
\hline $30-39$ & $\underset{\%}{\text { No. }}$ & $\begin{array}{c}90 \\
5.3 \%\end{array}$ & $\begin{array}{c}995 \\
58.3 \%\end{array}$ & $\begin{array}{c}269 \\
15.8 \%\end{array}$ & $\begin{array}{c}274 \\
16.0 \%\end{array}$ & $\begin{array}{c}80 \\
4.7 \%\end{array}$ & 100.1 \\
\hline $40-49$ & No. & $\begin{array}{c}42 \\
5.2 \%\end{array}$ & $\begin{array}{c}483 \\
59.9 \%\end{array}$ & $\begin{array}{c}184 \\
22.8 \%\end{array}$ & $\begin{array}{c}71 \\
8.8 \%\end{array}$ & $\begin{array}{c}27 \\
3.3 \%\end{array}$ & 100.0 \\
\hline $50-59$ & No. & $\begin{array}{r}94 \\
20.6 \% \\
\end{array}$ & $\begin{array}{r}227 \\
49.8 \% \\
\end{array}$ & $\begin{array}{r}70 \\
15.4 \% \\
\end{array}$ & $\begin{array}{c}36 \\
7.9 \% \\
\end{array}$ & $6.29 \%$ & 100.1 \\
\hline Total & $\%$ & $31.5 \%$ & $224.2 \%$ & $66.6 \%$ & $54.3 \%$ & $23.6 \%$ & $400.2 \%$ \\
\hline
\end{tabular}

Poor Health. It can be seen from the above table that as men grow older their participation in recreational activities is increasingly limited by poor or failing health. Only five, or .4 per cent of the men in the 20-29 age group stated poor health limited their participation. Ninety or 5.3 per cent of the men in the 30-39 age group listed health as a limiting factor. The percentage for the $40-49$ age group was approximately the same as for the 30-39 age group. The biggest increase in the proportion of men listing health as a limiting factor came in the 50-59 age group. Ninety-four, or 20.6 per cent of men of this age group stated poor health or some physical deficiency prevented them from participating in recreational activities as frequently as they would like.

Lack of Time. The percentage of men who stated Lack of time prevented satisfactory participation was as great or greater than the percentages 
for all other categories combined. One-half or more of the men from every age group who listed a reason for unsatisfactory participation listed lack of time. The proportion of men who listed time was approximately the same for all age groups until the 50-59 age group was reached. There the percentage indicating time as a reason dropped 10.1 per cent below that of the preceeding age group. Lack of Mioney. The proportion of men who stated lack of money limited their participation increased from decade to decade until the sixth decade was reached, when there occurred a substantial decline in the proportion of men listing this reason for limited participation. It was during the sixth decade that a large increase in the proportion of men stating poor health limited their participation occurred. Apparently some men do not permit themselves to enjoy life during the first five decades of their lives because they want to earn more money and after the fifth decade they cannot enjoy themselves because of failing health. One of the reasons for the smaller proportion of men of the 50-59 age group listing lack of money as a limiting factor may be that it is at about this time that children marry and leave home, mortgages have been paid, and family costs decrease, leaving more money for recreational purposes.

Lack of Facilities. The proportion of men who stated lack of accessible facilities limited their participation decreased from one decade to the next. One reason for this may be that as men grow older they have more money remaining after the necessities of life have been taken care of and so can spend more money to buy the facilities needed for their leisure time pursuits. Another reason may be that as men 
grow older they learn to limit their recreational desires to those which may be satisfied. Accessibility of facilities is one of the factors which make for ease in satisfying recreational desires. Lack of Knowledge or Skill. The proportion of men who stated lack of knowledge or skill limited their participation decreased from one decade to the next until the sixth decade was reached. The proportion of men in the 50-59 age group who indicated lack of knowledge or skill was a limiting factor was greater than that for the 40-49 or the 30-39 age groups. This may be true because men at fifty years of age or above find themselves with increasing amounts of leisure time and with sufficient money and at that time begin to try various new recreational activities. They would then be likely to discover their lack of knowledge or skill.

It was felt it would be desirable as well as interesting to find whether there is a difference between the reasons men give for unsatisfactory participation in the sedentary or mildly active and the active types of activity. This was done. There were twentyfour mildly active types of recreational activities listed. These were compared with respect to reasons for unsatisfactory participation with twenty-four active types of recreation. The total number of men who indicated health was tine limiting factor in participation in the mildly active types of recreational activities was found. The same procedure was followed to find the total number of men who indicated time, money, facilities, and knowledge or skill was the limiting factor. This procedure was followed for both the sedentary or mildly active and active types of recreation. The results provide 
a picture of the distribution of reasons offered within each age group. The results further provide a comparison within each age group of the differences between the number of times reasons were offered for unsatisfactory participation in the active and in the mildly active forms of recreational activity.

Since the total number of men in the several age groups differs, it would not be a fair comparison to compare the number of times each reason appeared in one group with the number of times that reason appeared in another group. To accomplish this it is necessary to first change the figures into percentages. This was done by finding the total number of men who checked each of the five reasons for unsatisfactory participation for both sedentary or mildly active and active forms in one age group. This total was then divided into the total number in each of the five categories of reasons for the active forms and then into each of the five categories of reasons for the sedentary or mildly active forms. An illustration of the steps followed should clarify the procedure. For this purpose the 20-29 age group will be selected. 
An Illustration of the Steps Followed to Secure The

Percentage of Men Indicating a Reason for limited

Participation

Total Number of

Times Reason Appeared:

for Active for Mildly Active

Reason and Sedentary

Total

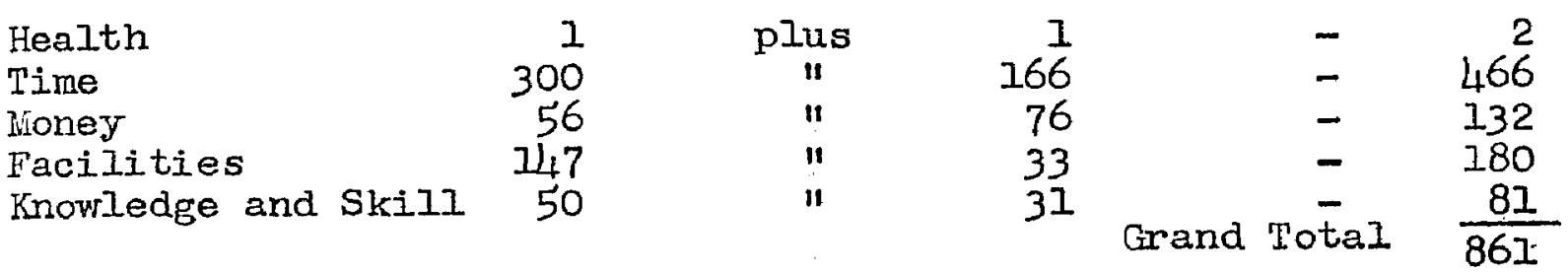

$.1 \%$ of all reasons for restricted participation $861 / 1.000$ listed in the 20-29 age group were for reason of poor health for the active forms.

This procedure was followed for each of the five categories of reasons for both active and mildly active or sedentary forms and for all five age groups. A total of forty computations identical to the above were made to arrive at Table 20 on the following page.

The table illustrating the difference in percentage between reasons for insufficient participation in active and sedentary types of recreational activities follows: 
Table 20

Comparison Between Number and Relative

Frequency of Reasons for Insufficient

Participation in Active and Mildly Active and Sedentary Types of Recreational Activities for Four

Age Groups

$\begin{array}{rlll}\text { Health } & \text { Time } & \text { Money Facili- } & \text { Knowledge } \\ \text { No. } \% & \text { No. } \% & \text { No. } \% \text { ties } & \text { and Skill }\end{array}$ No. $\%$ No. $\%$

Total \%

Age Group $(20-29)$

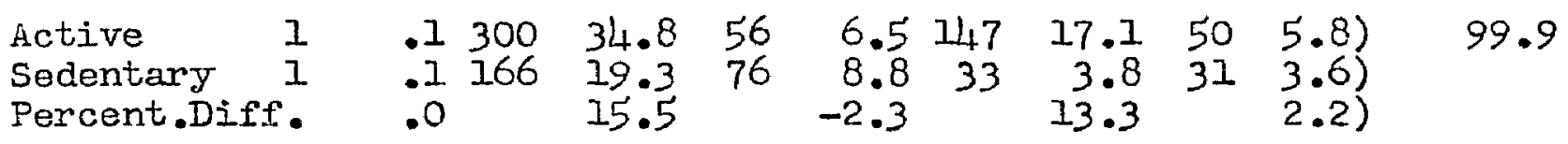

Age Group

$(30-39)$

Active

$54 \quad 4.2500$

Sedentary

Percent.Diff.

.2208

31.9131

10.2155

$\left.\begin{array}{rrr}12.1 & 27 & 2.1 \\ 3.0 & 38 & 3.0 \\ 9.1 & & -.9\end{array}\right)$

99.9

Age Group

$(40-49)$

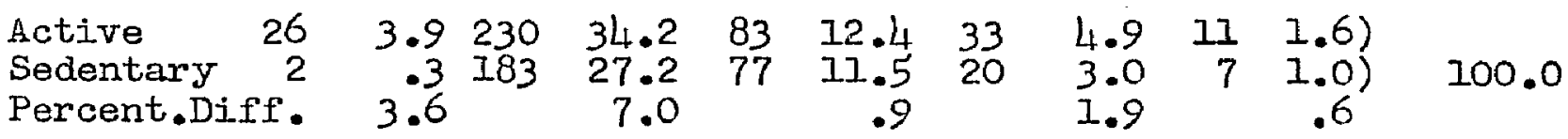

Age Group

$(50-59)$

Active

$\begin{array}{lllll}61 & 16.2 & 123 & 32.7 & 35\end{array}$

Sedentary

$18.6 \quad 30$

9.318

4.810

8.09

$2.4 \quad 13$

2.7)

Percent.Diff. $14.3 \quad 14.1$

1.3

2.4

100.1 
It can be seen that the proportions of men indicating reasons for unsatisfactory participation in the active forms are with but three exceptions, greater than the proportion of men indicating reasons for unsatisfactory participation in the sedentary forms. In the 20-29 age group there were more men who found they did not have enough money to engage in the sedentary forms often enough to be satisfied than there were who did not have enough money to satisfy their desires for participation in the active forms. Lack of lonowledge and skill in both the 30-39 age group and the 50-59 age group limited participation in the sedentary forms more than it did in the active forms. Few men in all age groups feel that lack of knowledge or skill in an activity prevents them from participating in it. Whether they felt they already possessed the knowledge and skill or felt that they could gain it in a short time, the questionnaire unfortunately does not show. The difference between the number of men listing lack of knowledge or skill as a limiting factor in active and sedentary forms is insignificant. If the men appraised their situation accurately, lack of knowledge or skill does not deter them from participating in the active forms any more than it does the sedentary forms.

Lack of Facilities. The proportion of men who indjcated that lack of facilities prevented them from participating in the sedentary or mildIy active forms remained approximately the same from one age group to the next. Few men were prevented from participating in the sedentary or mildly active forms for this reason at all ages. There was a decrease from one age group to the next in the proportion of men whose partici- 
pation in the active forms was restricted by lack of facilities. Of al1 the reasons listed, 17.1 per cent of those in the 20-29 age group for the active forms were for lack of facilities. This percentage drops rapidly until in the 50-59 age group only 4.8 per cent of the reasons listed were for lack of facilities for active forms of recreation. Younger men more than do older men attribute failure to participate as frequently as they would like to lack of facilities. Ihey also feel that it is a greater deterant to participation in the active forms than it is to participation in the sedentary or mildly active forms.

Lack of Money. With increasing age an increasing number of men state that lack of money prevents them from participating in both the active and the sedentary and mildly active forms of recreation. After the age of fifty, however, there is a small decrease in the proportion of men who feel that lack of money limits their participation in recreational activities. One of the reasons for this may be that family expenses are considerably greater before the age of fifty than they are after this age. Iack of money is a greater deterant to participation in the active forms than it is to participation in the sedentary and mildIy active forms in all age groups except the 20-29 age group.

Lack of Time. Lack of time in the minds of men, is the factor which most frequently limits the extent of their participation in both forms of recreational activity. Almost twice as many men feel they are denied full participation because of lack of time in the active forms as are in the sedentary or mildly active forms. These figures probably 
indicate the universality of the process of rationalizing. It takes approximately three hours to attend a movie. It takes approximately the same amount of time to take a swim at the Young lien's Christian Association. As an example of this rationalizing consider the following: In the 20-29 age group fifteen men listed lack of time as a reason for not swimming as frequently as they would like. Only ten listed time as a factor limiting attendance at a movie. Yet both activities are liked by approximately the same percentage of men. Miovies are liked by 84.6 per cent of men at this age group and swimming by 87.9 per cent. The participation index for swimming was 4.85 . For movies it was 24.13. Men believe they would like to go swimming more frequently but excuse themselves this opportunity by saying they do not have time. Yet they do have time to attend movies. A factor may be that taking a girl friend or wife to the movies is considered a more appropriate expenditure of leisure time.

Approximately the same proportion of men from all age groups felt that lack of time limited the frequency of their participation in recreational activities.

Poor Health. Only a small proportion of men from all age groups feel that poor health limits the frequency of their participation in the mildly active forms. The proportion of men whose participation in the active forms is limited by reason of poor health increases rapidly after the age of thirty. Only. .I per cent of reasons for limited participation in the 20-29 age group were for poor health. This proportion increases to 4.2 per cent in the 30-39 age group and remains approximately the same (3.9 per cent in the 40-49 age group). After 
the age of fifty a much larger proportion of men find they cannot satisfy desires for active recreation because of poor health. In the 50-59 age group, 16.2 per cent of the reasons for limited participation in the active forms were for reason of poor health. Amount of Frustration Experienced in Satisfying Recreational Desires.

In column three of the questionnaire men were aslced to indicate their reason for insufficient participation in those activities in which they desired more frequent participation. When men stated a reason in this column they were indicating they would like to participate in the activity more frequently but were prevented from doing so, or felt they were prevented from doing so, by some real or imagined reason. The total number of men who stated a reason for unsatisfactory participation in each activity provides a measure of the relative amounts of frustration men experience in satisfying their desire to participate in the activities listed. Table 21 on the following page presents the twenty-five recreational activities in which the greatest number of men listed reasons for unsatisfactory participation. After each activity is listed the total number of men who listed a reason for limited participation--this tabulation is the total of all reasons: poor health, lack of time, money, facilities, and knowledge or skill. This table follows: 
Table 21

The Twenty-Five Activities Showing the Largest Number of Men Iisting Reasons for Insufficient Participation

$\underline{20-29}$

No. of times

a reason

Rank Activity

1. Horseback Riding

2. Basketball

3. Archery

4. Baseball

5. Hunting

6. Canoeing

7. Golf

8. Boating

9. Badminton

10. Swimming

11. Sailing

12. Ice Skating

13. Softball

I1. Football

15. Bicycling

16. Bowling

17. Table Tennis

18. Volleyball

19. Card Playing

20. Woodworliing

21. Ice Hockey

22. Still Fishing

23. Skiing

24. Watching Sports

25. Niovies

was listed
30-39

No. of times

a reason

Rank Activity

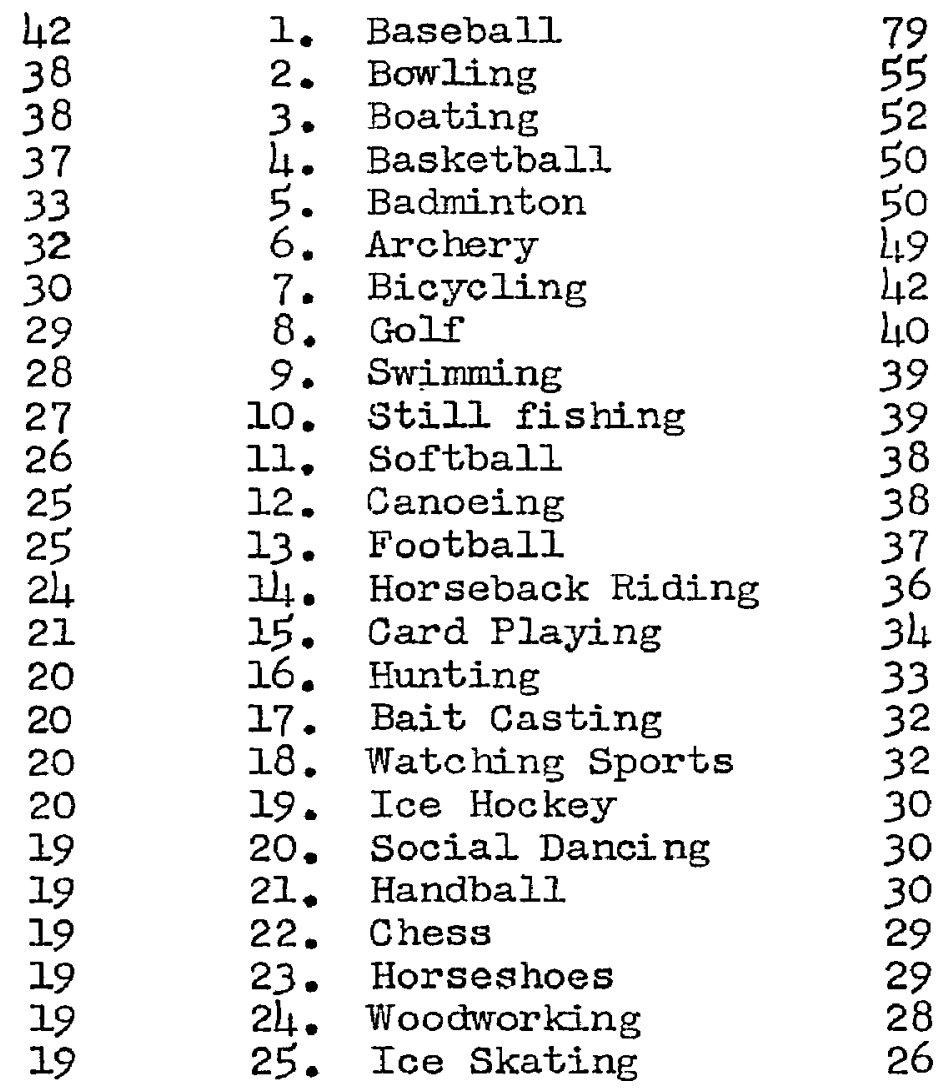


Table $2 I$ (Cont'd.)

The Twenty-Five Activities Showing the Largest Number of Mien Listing Reasons for Insufficient Participation

$40-49$

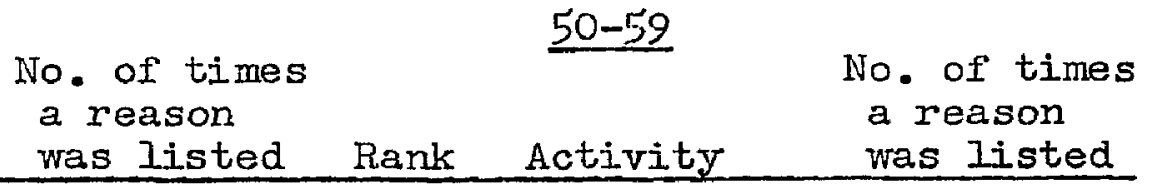

Rank Activity

34

1. Baseball

2. Bowling

3. Golf

4. Still fishing

5. Boating

6. Card Playing

7. Hunting

8. Horseback Riding

9. Movies

10. Bait Casting

11. Basketball

12. Watching sports

13. Horseshoes

1). Checkers

15. Watching TV

16. Footbal1

17. Reading

18. Softball

19. Woodworking

20. Motoring

21. Swimming

22. Ice Skating

23. Music

24. Social Dancing

25. Roller Skating
1. Basketball

2. Baseball

3. Bowling

4. Card Playing

5. Calisthenics

6. Bag Punching

7. Still Fishing

8. Bicycling

9. Canoeing

10. Boxing

11. Boating

12. Movies

13. Bait Casting

I4. Wrestling

15. Driving

16. Horseback Riding

17. Track and Field

18. Woodworking

19. Archery

20. Badminton

21. Handball

22. Ice Hockey

23. Hunting

24. Conversing

25. Swimming
19

18

17

15

15

13

13

13

12

12

11

10

10

10

10

9

9

9

9

8

8

8

8

8

7 
Apparently men can satisfy their desire to participate in the mildly active forms of recreational activity more easily than they can their desire to participate in the active forms of recreation. In the 20-29 age group, only four mildly active or sedentary types of recreational activities were included among the first twenty-five activities listed. These were: card playing, woodworking, watching sports, and movies. In the 30-39 age group there were five activities of a mildly active or sedentary type listed. These were: card playing, watching sports, social dancing, chess, and woodworlking. In the 40-49 age group there were ten activities of a mildly active or sedentary nature listed. These were: card playing, movies, watching sports, checkers, watching television, reading, woodworking, motoring, music, and social dancing. In the 50-59 age group there were five activities of a mildly active or sedentary nature listed. These were: card playing, movies, driving, woodworking, and conversing.

It may seem strange that men who are over fifty years of age express a desire to participate more frequently in such vigorous sports as baseball, basketball, bag punching, boxing, wrestling, track and field events, and ice hockey. The writer interviewed personally a number of men in their sixties and seventies. Many of these men expressed a desire to participate in vigorous activities which they had enjoyed in their youth but stated they were too old or their state of health prevented them from participating in the activities. Not all the older men admitted, even to themselves, to being too old for such vigorous activities as swimming and calisthenics. 
In the 50-59 age group, only one man listed health as a factor limiting his participation in swimning while five listed lack of time and one lack of knowledge or skill as the limiting factor. Only three men listed health as a factor limiting their participation in calisthenics while ten listed time as the limiting factor. (When a man wrote "too old" in column three, it was tabulated under "health.") Older men, men over fifty, should be made to understand that sports such as baseball, basketball, wrestling, track and field events, boxing, and ice hockey are too vigorous for older men. They should also be made familiar with the less vigorous sports, proper "warmup" procedures, and the importance of including some physical activity in every day's schedule. 
Summary of the Questionnaire Findings

I. As men grow older they like fewer recreational activities, feel indifferent towards an increasing mumber, and dislike an increasing number.

A. There are seven sedentary activities which are liked by an increasing number of men from each succeeding age group.

These are:

1. Checkers

2. Still fishing

3. Card Playing

4. Listening to the radio

5. Watching television

6. Reading

7. Stamp collecting

B. It should be noted that the activities which show an increasing number of men liking them with increasing age are of a sedentary nature and are done either alone or with only a few people.

C. There were six activities which showred an insignificant decline in interest with increasing age.

These were:

1. Bowling

2. Bait casting

3. Motoring

4. Puttering and repairing

5. Visiting friends

6. Watching sports events

D. The following is a ranking of the activities according to the overall decrease in the percentage of men indicating liking for them. (It should be kept in mind that some of these activities show a high proportion of men from the 20-29 age 
group liking them while others show only a small proportion of men from the 20-29 age group liking them. This means that the former group can show a greater decrease over the total age span and yet be liked by a greater proportion of men in the 50-59 age group.) The listing follows:

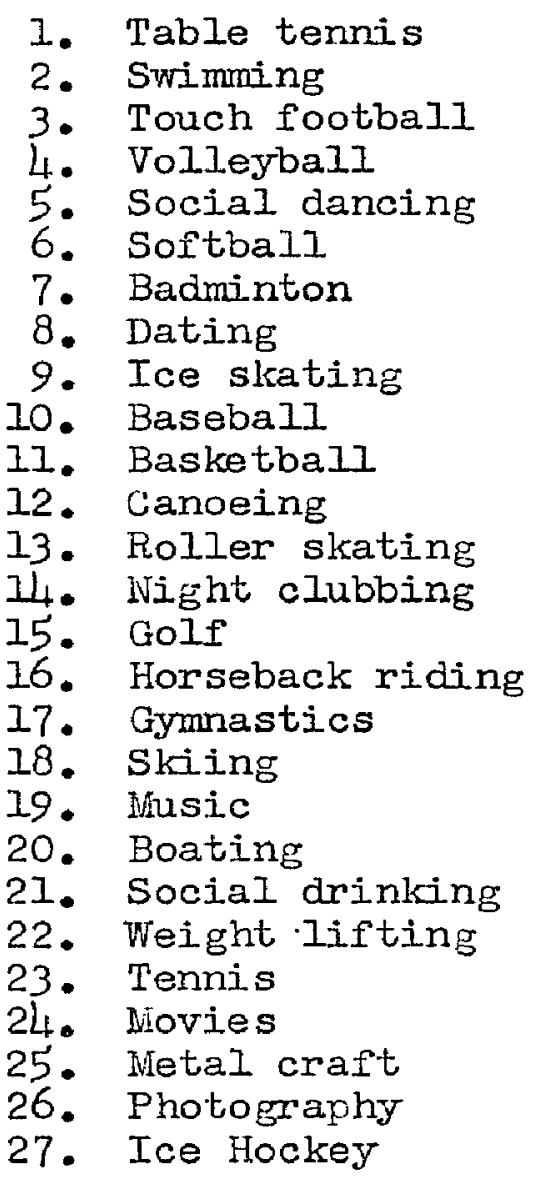

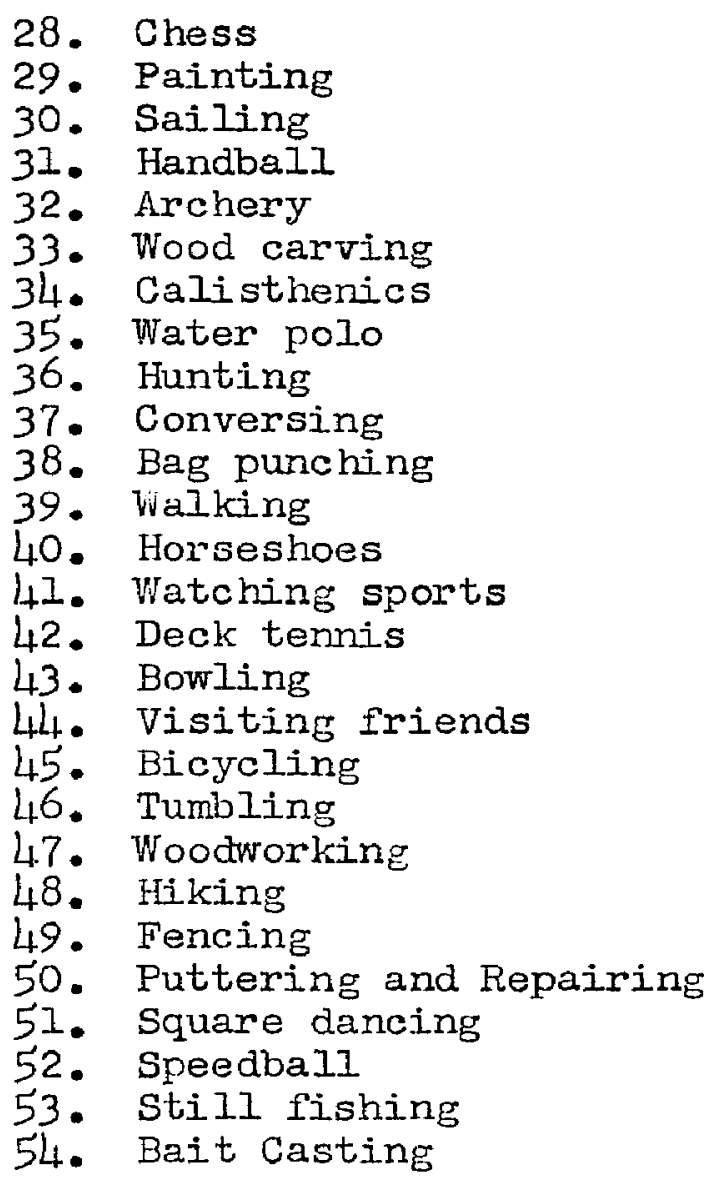

Note: Tumbling, fencing, and speedball show little decline in liking principa.lly because they start with few men indicating liking for them.

The three types of activities which show the greatest dection decrease in liking are: (1) those which require quick reaction time; (2) those which require physical stamina and endurance; (3) those which satisfy the romantic and erotic impulses. 
II. The rank of activities according to the proportion of men liking them is approximately the same for all six income groups.

A. Apparently men become more individualistic in their recreational likes and dislikes as their income increases since the percentage of men liking each activity ranking first, second, third, or twentieth becomes smaller for each succeeding income grouping.

B. Liking for a few activities seems to be related to income. 1. The percentage of men from each income group who enjoy conversing increases wi.th each succeeding income grouping.

2. The probability that a man will enjoy card playing increases with income.

3. Activities which provide social contacts are liked most by men from the highest income grouping, the over $\$ 7,000$ income group.

4. Wien of the $\$ 5,000-\$ 7,000$ income group, like the sports types of recreational activities more than do men of any other income group.

III. With respect to frequency of participation, the majority of the sixty-seven recreational activities maintained their rank from one age grouping to the succeeding grouping. Apparently, the recreational habits of younger men do not differ greatly in kind from thos of older men.

A. There were a few activities which showed a decline in frequency of participation with increasing age. These were: 
1. Conversing

2. Social drinking

3. Night clubbing

4. Dating

5. Weight lifting

6. Calisthenics

B. Participation in recreational activities of a sports type is meager at all age levels.

1. Bowling, still fishing, and bait casting were the only sports listed among the first twenty activities for all four age groupings with respect to frequency of participation.

C. As men grow older they participate less frequently in all forms of recreational activity.

D. The proportion of their leisure time which men spend on gardening, motoring, hiking, metal craft, bait casting, still fishing, and checkers increases slightly with age.

IV. Mien of all income groups participate very little in sports during their leisure time.

A. Men of the $\$ 5,000-\$ 7,000$ income group participate in sports more frequently than men of any other income group.

B. ilen of the $\$ 2,000-\$ 33,000$ income group participate in sports less frequently than men of any other income group.

C. Participation in sports increases in frequency from the $\$ 2,000-\$ 3,000$ income group with each succeeding income group until the $\$ 5,000-\$ 7,000$ income group is reached. However, men of the over $\$ 7,000$ income group participate in sports somewhat less than men of the $\$ 5,000-\$ 7,000$ income group. 
This is accounted for in part by the fact that men of the over $\$ 7,000$ income group are older men.

V. With respect to frequency of participation in all forms of recreational activity, men of the $\$ 5,000-\$ 7,000$ income group participate most frequently. Next in order of frequency of participation are the $\$ 4,000-\$ 5,000 ; \$ 3,000-\$ 4,000 ; 0-\$ 2,000 ; \$ 2,000-43,000 ;$ and the over \$,000 income groups.

VI. Men of all age and income groups do not satisfy their desire to participate in recreational activities of an active or sports nature as frequently as they do those of a mildly active or sedentary nature.

A. Baseball, swimming, hunting, and movies showed high discrepancy between the proportion of men liking the activity and the frequency of participation.

B. Track and field events, boxing, wrestling, photography, and puttering and repairing ranked among the first twenty in discrepancy score for the 50-59 age group but for no other group.

C. The discrepancy score decreases more rapidly for the active forms of recreation than it does for the sedentary or mildly active forms.

1. As men grow older they limit their recreational desires more and more and are increasingly successful in satisfying them.

2. Men's liking for the active forms of recreational activity decreases more rapidly than their liking for the mildly active or sedentary forms.

VII. For income groupings, as for age groupings, the discrepancy between the interest in an activity and the frequency of participation 
in it was greater for the active forms of recreation than it was for the sedentary forms.

A. For the majority of activities, there was no consistent pattern in the discrepancy score from one income group to the succeeding groups.

VIII. The reason for unsatisfactory participation most frequently listed by men of all age groups was lack of time.

A. The proportion of men who state poor health limits their participation increases with age.

B. The proportion of men who state lack of money limits their participation increases until the age of $40-49$ and then drops rather sharply after this age.

C. The proportion of men who state lack of facilities limits their participation decreases with age.

D. A greater proportion of men list reasons for unsatisfactory participation for the active forms of recreation than do for the sedentary or mildiy active forms. 
CHAPTER VI

Discussion and Recommendations

In Chapter I it was shown that because of the increasing numbers of older people in our society it is important that the productive years of men be increased. This is necessary if our standard of living is to remain high.

It was shown that chronic ailments often cut down men's productive years. The association between mental health, a "relaxed mind", and physical health was pointed out. Evidence was presented showing the probability that an adequate recreational life can be of help in developing a "relaxed mind," in relieving the tensions due to the frustrations arising from the complexities of modern life, and in providing socially acceptable outlets for feelings of aggression. Evidence was presented showing that adult men can and have made improvements in measurable aspects of fitness through regular physical exercise. It was pointed out that men feel they should "exercise" and know that it will "do them good" but that they do during their leisure time those things which they enjoy. The participation of men in recreational activities can be better encouraged if what men like and enjoy is known. In this study of men it would also be desirable to know their recreational habits and problems.

In chapters II, III, IV, and $V$ a study of men's recreational likes and dislikes, recreational habits, and recreational problems was reported on.

In the present chapter the major findings will be discussed and 
some recommendations will be made regarding methods of helping adult men select their recreational activities wisely. Methods of encouraging, promoting, and making possible more universal participation in the more desirable recreational activities will also be discussed. Major Findings. In Table 7, Chapter II, page 63, showing the percentage of men indicating liking for the various activities, it was shown that nine sports or sportslike activities ranked among the twenty activities liked by the greatest proportion of men in the first three age groups and eight by men in the last age group. In Table 10, Chapter III, page 73 , showing average frequency of participation, only four sports or sportslike activities ranked among the twenty activities showing the highest frequency of participation in the first age group, three in the second age group, and five in the last two age groups. These two facts taken together are an indication that men do not participate in the active forms of recreation to the extent they would like. Further, the total discrepancy between the percentage of men indicating liking for an activity, and the average frequency of participation was found to be considerably greater for the active forms of recreation than it was for the mildly active and sedentary forms. In addition to this, it was found that almost twice as many men stated raasons for insufficient participation where more frequent participation was desired, for the active forms as did for the sedentary or mildly active forms. All this evidence points to the fact that men find it more difficult to satisfy their desires to participate in sports and sportslike activities than they do in the mildly active and sedentary forms of recreation. 
The most commonly offered reason for unsatisfactory participation was lack of time. The second most common reason was that facilities were lacking, inadequate, or too distant. Next in order of the number of men indicating the reason were lack of money, lack of knowledge or skill, and finally health. In the 50-59 age group, poor health limited participation more than any other reason with the exception of time.

In Chapter I a number of reasons, from the personal, social, and economic point of view, were presented for increasing the frequency of men's participation in active sports or sportslike forms of recreation. In this chapter some recommendations for bringing this about will be made. The problem will be approached from the personal, social, economic, and educational point of view. These recommendations are drawn not only from the data but also from the writings of psychologists, gerontologists, psychiatrists, and social workers specializing in the problems of aging or recreation.

\section{A Recommended Personal Perspective.}

The First Step. Mental attitudes toward one's self and toward external objects are undoubtedly important factors in determining the course of action men will follow. If success is to be achieved in educating adult, men to use their leisure time more wisely, it is necessary that first the attitude many of these men hold about themselves and recreational activities be changed. Often it is a question of relative values. Many men are totally engrossed in the effort to make more money, taking little time to live each day and deferring their pleasures until after they have achieved economic security. If 
men valued material wealth less and a satisfying, enjoyable life more, perhaps they would not have offered lack of time as a reason for insufficient participation in recreational activities which they enjoy, as frequently as they did. The first problem then is to convince these men that an outlay of time to pursue recreational activities is worth both the time and the money. They must be convinced that planning the use of their leisure time for years ahead is just as essential to a happy, satisfying, and successful life as is planning their professional or business life. Needless to say, this is no small job. It is one which will demand the combined efforts of the public schools, colleges, universities, and industrial plants as well as the mediums of adult education such as magazines, newspapers, and public talks.

Planning the Recreational life. In planning their day to day and yearly schedules, men should include time in this schedule for the three important aspects of life--work, rest, and recreation. This planning for the recreational facet of a man's life should take due consideration of the probable changes in his physiological, mental, and emotional make-up. This is not to say that men should always be preparing for the future years because then they could never enjoy the present, but on the other hand they should not hang on to recreational activities from thich they are receiving diminishing pleasures. For example, a man whose recreational activity is fancy diving will realize that the physiology of the aging process will prevent him from continuing this activity for the rest of his life. Sometime before this activity begins to become too difficult for him he should set 
aside some time to learn another activity which does not make such demands on fast reaction time and neuro-muscular coordination-characteristics of youth. Tennis or golf might be good interests for him to acquire at this time. The preferential interests of the individual should of course be the most important factor in the selection of activities. From the fitness standpoint, he should not try to move too rapidly toward the more sedentary activities but should try to maintain his physical condition at such a level as to be able to enjoy the more vigorous activities for as long as possible.

Clare de Gruchy writing on the problems of preparation for the retirement years, contends that a person should begin early in preparing for retirement. Her comments follow:

A life ideally lived develops from one period to another, thus making a continuous whole rather than one composed of a series of water-tight compartments, each isolated from the others and each requiring a new set of mental adjustments and makeshifts.

The reason old people today rarely present such continuous living throughout their life span is the materialistic creed which emphasized the need for survival, to the sacrifice of the need for self-fulfillment.

The growing human being requires that both needs be met concurrently. Once the physical satisfactions have been gained, the ascending spiral of growth works towards the social need for participation in broader fields than the mere preservation of life.

Were this realized, we should appreciate the fact that the daily life of the individual, from babyhood to death, should be divided between periods of work, play, and rest: work for survival, play for self-fulfillment, and rest for recuperation. A growing consciousness of the unhappy results of this past concept of the aim of life, as exemplified in the bored, idle, useless old of today, is evidenced by the aroused interest in their plight, in the growing realization that they have gained or are receiving economic security, but at the price of 
remaining immobilized, thus losing their hold on life today, and suffering premature death of mind and spirit. I

Building Up Health Deposits. People set aside a portion of their earnings in Social Security, insurance, pension funds, and savings accounts to take care of their material needs during their old age. Following the same principle, a man should spend a portion of his time and energy to build up health reserves and to create a program of creative interests and activities which will provide for his future mental, emotional, and social needs.

The point of view advocated in this study is that of preparing not only for recreational life during retirement but for each succeeding period in life. In order to do this, it is necessary that men be able to anticipate the inevitable mental, emotional, and physiologic changes which will come.

It has been pointed out that from a fitness standpoint men depreciate first in such qualities as muscular strength, endurance, and power, and later in circulatory and respiratory fitness. The respiratory and circulatory systerns are more enduring than the skeletal muscles and do not show the effects of lack of stimulation as soon as do the skeletal muscles. If men could sustain at a high level the qualities of muscular strength, endurance, and power, the onset of circulatory and respiravory deficiencies would probably be delayed.

Men are not likely to list as a reason for insufficient participation lack of muscular strength or endurance. Yet this should be listed as a health reason. They will list as a health reason however

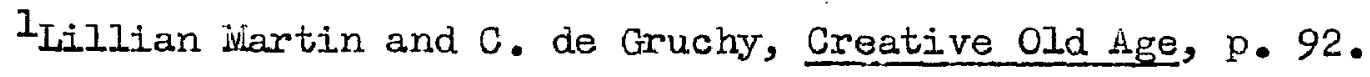


such things as circulatory or respiratory unfitness. It will be recalled that of the reasons offered for unsatisfactory participation in the $40-49$ age group, 5.2 per cent were for health. In the 50-59 age group, however, 20.6 per cent of the reasons were for health. The number of men who had offered health as a reason limiting participation had almost quadrupled in a ten-year span. The majority of health complaints of older men are for chronic ailments. A characteristic of the chronic ailments is their slow progression over many years. It is probable that the health of these men had been depreciating over the years butdid not reach a level low enough to be considered a reason for limiting participation until after the age of fifty or more was reached. It is also probable that a greater proportion of men from the age groups under fifty should have listed health as a limiting factor. It is likely that many men in their forties, thirties, and even twenties did not participate in sports activities which they said they like, not so much because of lack of time, but because of the undue fatigue which resulted from their last participation in the sports.

Once physical condition has regressed to the point where exertion is felt on climbing the stairs, it is unlikely that a feeling of enjoyment and satisfaction will be experienced in swimning, bowling, or golf. Under these conditions it is difficult for a man to really enjoy any sport. When a man, once fit and interested in sports, allows himself to get out of condition, he finds sports less pleasurable, engages in them less frequently and so falls further toward physical unfitness. The vicious circle begins! 
Hen Ore Society the Responsibility for Keeping Themselves Fit. If men are to be held on this world for more years by medical and scientific progress, they must maintain themselves in such condition that they are capable of doing their share of the world's work. The privilege of longevity directly entails the obligation to endeavor to prevent long and premature disability, and to maintain health and continued usefulness into true senility. Full, rich, and fruitful lives in later maturity are not fortuitous; they result from planned effort. There must be enough desire to enrich our later years to justify the effort and enough knowledge to direct it. Preparation and planning are required. The obligation to make such efforts is not purely a personal question. Efforts to sustain fitness and usefulness into the later years are obligations due the family, the community, and the nation. Iife has depth and breadth as well as length. A person's usefulness is measured more by the depth and breadth of his life than by its length. Years of existence after premature disability is more a hinderance than a help to society. We need more to add life to our years than years to our lives. One of the better ways of adding life to our years is through participation in sports and sportslike activities.

The Capacity to Tolerate Vigorous Exercise. The capacity to tolerate vigorous physical effort depreciates with age. This depreciation need not be as great as usually is the case. In an earlier study by the present writer, it was reported that twelve chin-ups represented an average (61.8 percentile) score for the 20-29 age group. 2 There

$$
\text { 2Baley, op. cit., pp. } 85-92 \text {. }
$$


were men in the 50-59 age group who served as subjects in this study who could still do twelve chin-ups although this performance placed them in the 99.87 percentile for their age group. It is apparent that there are some men who expend the effort and are successful in sustaining their fitness level. If there were a few who sustained their fitness, there probably could have been more. There were men in the 50-59 age group who indicated, on the questionnaire used in the present study, that they still participated in such vigorous activities as bag punching, roller skating, weight lifting, gymnastics, bicycling, calisthenics, handball, ice skating, softball, swimming, and tennis. It is true that the number of men from this age group participating in these activities was small; yet, if some of the men participated in them, it is likely that many more could have if they had kept thernselves in good physical condition.

Evidence has been presented showing that middle-aged men not only can sustain their level of fitness but can also make improvements. Darrel Latham's study reported on earlier, showed that middleaged men who participated in a mildly vigorous prozram only once each week for nine months made substantial improvements in fitness. 3 Men who participate regularly can continue the sport of their choice for many years. Some men are forced, by reason of marital and financial responsibilities, to discontinue participation for several years. These men, particularly if they are of a strong competitive

3Latham, op. cit., p. 5. 
nature, should avoid those highly competitive games where their activity depends directly upon that of their adversary until they have brought themselves to the necessary level of fitness. Since golf, archery, bowling, hiking, hunting, volleyball, swimming, horseback riding, walking, gardening, fishing, boating, sailing, and skating are not directly competitive, they may well be the preferred activities of these men until they improve in fitness. Those directly competitive games such as squash, handball, tennis, fencing, and badminton can be participated in by men of all ages who sustain or improve their fitness level if they develop the attitude of playing for the mental and physical relaxation and the enjoyment provided rather than to prove their physical superiority over their opponent. The Amount and Intensity of Exercise to be Prescribed. The amount of exercise which a person should take is a highly individual matter. The amount required to derive maximum health benefits varies greatly with individuals. Some men require far more than the usual sedentary occupations can afford; others require but a minimum. Therefore, no hard and fast rules are justified; the specific problems of each individual must be considered separately. It is important to avoid excesses in either direction. Obviously, physical indolence for fifty weeks is no sort of preparation for two weeks of violent and excessive exertion during vacation time. This is tantamount to inviting disaster. For most men, one hour of activity, two or three times each week will bring about decided improvements in fitness. Activities Most Appropriate for Fach Age Group. There is a steady decline in almost all aspects of fitness of adult men from one decade 
to the next. 4 Just hov much of this decline is due to lack of sufficient physical activity and how much is due to the aging process itself is unknown. It is known that a considerable part of this decline is due to lack of sufficient physical exercise. It is also known that middle aged men can make substantial improvements in fitness by engaging in regular and progressive physical activity.

On the basis of the observed decline in fitness of adult men, his knowledge of the sports, and the evidence presented earlier, the present writer has set up the following suggested list of sports and recreational activities appropriate for each age group. This is a device which might be utilized to discourage men from ceasjng all physical activity when they find themselves becoming less proficient in the activity of their choice. Many collegiate and high school athletes stop all physical activity upon graduation or a few years later because facilities or personnel are not available or because they cannot perform their sport as proficiently as they had. A listing of this type could serve to remind these men that there are many other activi.ties in which they could engage with profit and pleasure. It is to be understood, of course, that a few men will be able to engage with benefit in some of the sports listed for the $20-29$ age group until they are forty or fifty years of age. A few others may find those listed for their age group too strenuous. The selection of activities is a highly individual matter. Several factors bear upon the selection of an activity: the level of fitness, time avail-

$$
\text { 4Baley, op. cit., p. 85-92. }
$$


able, facilities available, and the preferential interests of the individual. Some activities such as archery, bait casting, fly casting, bowling, golf, and sailing may carry over a span of several decades. The list does not imply that a man should linnit his activities to those proposed for his age group. It merely offers a starting point. It offers a starting point for men who feel the need for physical activity and improved fitness. It is suggested that men contimually experinent with activities listed for the succeding age group in order to select one or more which will give them the greatest satisfaction and pleasure. Another reason for this is that some skill in an activity is prerequisite to enjoyment of the activity. Through this experimenting a man can develop a minimal level of skill and is helped in selecting the activity best suited to him. This listing follows:

Table 22

Suggested List of Activities Appropriate to Each Age Croup

$\begin{array}{lll}\text { 20-29 } & \text { 30-39 } & \text { 40-49 } \\ \text { Baseball } & \text { Badminton } & \text { Bowling } \\ \text { Basketball } & \text { Bag Punching } & \text { Canoeing } \\ \text { Boxing } & \text { Bicycling } & \text { Golf } \\ \text { Diving } & \text { Bowling } & \text { Hiking } \\ \text { Football } & \text { Fencing } & \text { Horsebacis Riding } \\ \text { Golf } & \text { Golf } & \text { Hunting } \\ \text { Gymnastics } & \text { Handball } & \text { Table Tennis } \\ \text { Ice Hockey } & \text { Ice Skating } & \text { Volleyball } \\ \text { Lacrosse } & \text { Ijfe Saving } & \text { Weight Lifting } \\ \text { Sking } & \text { Softball } & \\ \text { Soccer } & \text { Squash } & \\ \text { Speedball } & \text { Swinuing } & \\ \text { Tumbling } & \text { Tennis } & \\ \text { Water Polo } & & \\ \text { Wrestling } & & \end{array}$


Suggested Iist of Activities Appropriate to Each Age Group

$\underline{50-59}$

Archery

Billiards

Bowling

Gardening

Horseshoes

Square Dancing
$60-69$

Bait Casting
Boating
Checkers
Chess
Metal Craft
Pottery
Reading
Shuffleboard
Still Fishing
Weaving
Woodworking
Writing

Attitudes Toward Aging and Recreation. Most men want to live Iong but they do not want to become old. Miedical science, improved num trition, and better sanitation are enabling men to live longer. Sports and other recreational activities properly used can help to keep men young in mind and body. They can add more life to the years. Men do not enjoy being reminded of their depreciating abilities. This is more likely to occur in the natatorium, on the athletic field, or in the gymnasium than it is in the sedentary activities such as reading, watching sports, or listening to the radio. Mien must learn to accept this loss gracefully. They should contimue trying to retard this loss as much as is consistent with their interests and their situation. A desirable point of view in this regard would be that of engaging in the sport not to prove one's physical superiority over an opponent but rather for the sociability which is provided, for the healthful benefits which one knows will accrue, and for the sheer enjoyment of the game. This attitude should begin its formation during childhood. 
Men must realize that chronologic age and biologic age are not the same. Man has no control over chronologic age. He does have some control over biologic age. Further, the various organs age at differing rates. Some age more rapidly than others. Physiologic age is a composite of the various ages of different organs of the body. The placenta at birth shows all the symptoms of old age. The female ovaries become old, wither, and die at menopause. Man's hair falls out along with his teeth. These are not indications that he must settle back into a vegetative stupor. They are not indications that men must stop all vigorous physical activity. We have all seen some fine physical specimens who had no teeth or hair. The results of the questionnaire indicated that few men listed age as a factor limiting participation. Wen may rationalize their indolence to their friends by saying they are too old but when they are not identified (men were asked not to sign the questionnaire) they indicate that they do not believe they are too old. To themselves, they rationalize that they haven't time to keep themselves physically fit.

Health Problems of Older People Often Due to Their Indolence. That many of the difficulties and health problems of older people are due to their lack of fitness and their love of the soft and cornfortable life was the experience of $\mathrm{Dr}$. Whonroe who conducted a geriatric clinic in Boston. These were people older than those studied in this dissertation but they are undoubtedly representative, in this respect, of the people being studied here. Thomas C. Desmond summarizes the results of $\mathrm{Dr}$. Monroe's findings in the following words: 
At his geriatric clinic in Boston, one of the first such clinics in the world, Dr. Robert $T$. Monroe has found that much that passes for senility turns out to be merely physical or mental unfitness. This is true of much feebleness, frailty, unsteadiness, askwardness, and undue fatigue and shortmess of breath.

He has found that regular exercise and play (such as simple games and dancing, to restore the sense of timing and coordination) have beneficial effects on patients with high blood pressure, hypertensiye heart disease, arthritis, tremors, and partiai paralysis. 5

Summary of Recommendations. If adult men are to utilize sports as one medium to maintain physical, mental, and emotional fitness they should:

1. Know what physiological, mental, and emotional changes can be expected as one grows older and realize that ohronological age and biological age are not the same; that sone individuals age more rapidly than others; that we have some control over the rate of aging; and that various organs age at differing rates, some beginning to age at birth.

2. Develop the attitude to accept these changes gracefully knowing that there are always many other beneficial, interesting, and challenging recreational activities which can be learned to take the place of those which have served their usefulness.

3. Possess the interest, desire, and determination to continue leaming new sports and sportslike activities.

\footnotetext{
5Thomas C. Desmond, "The Promise of Geriatrics," Today's Health, June, 1950.
} 
4. Possess the desire and determination to keep themselves mentally and physically fit knowing that this is their obligation to society in return for having been given more years in which to live.

5. Possessthe desire and determination to maintain a wholesome balance betwreen work, rest and play, realizing that all three are essential to a happy, satisfying, and successful life.

6. Possess the determination to plan their recreational life for years ahead rather than to take on recreational interests haphazardly.

7. Engage in a minimum of two sports or sportslike activities at the same time--one or more representing their current interest and the others representing interests which are in the process of development for major enjoyment in coming years.

8. Know where local facilities for the various recreational activities are located.

9. Know where information can be secured about recreational activities in which they might become interested.

10. Possess the desire to interest and instruct others in the sports with which they are familiar.

11. Be willing to serve on community committees and to contribute in other ways to the maintenance of mental and physical fitness. 
12. Engage in recreational activities throughout the year. Golf is a fine and popular sport but in most sections of the United States can be played only during the warm months. Nen who play golf or engage in other warm weather sports should also learn and engage in one or more winter sports such as bowling, ice skating, badminton, handball, or squash. A Recommended Social Point of View The lihreat of Leisure. The abuse of leisure has marked and initiated the decadence of cultures throughout history. Few men look for physical activity. Unless they are prodded by some urgent necessity, most men are likely to spend their leisure in physical confort. Peoples become soft when excess of leisure leads to indolence. The fall of ancient Rome, the cultural absorption of the Manchus in China, and the decline of the early Egyptian civilization all serve to illustrate this. Stieglitz points out that such decadence threatened America before World War II: ${ }^{6}$ It was abated by the urgent demands for manpower during the war, in the postwar period of adjustment, and at the present time by the rearmament program and the Korean war. He states that a great wave of dangerously soft living can be expected after things return to normal. He advises:

The threat is insidious and deceitful in that it is so thoroughly sugar-coated with pleasures. With leisure and privilege constantly increasing as a result of technological advances changed social trends, and the luxurious comforts of modern civilization there has accumulated a tremendous surplus of time, energy, and capabilities which

6Edward J. Stieglitz, op. cit., p. 262. 
we as a nation must learn to use in peace as well as war. The physical conquest of the land is largely accomplished; the intellectual conquest of human capabilities is just beginning. 7

In reviewing the history of Greek sports, Deschner comments on the relationship between physical education (he uses this word in the inclusive sense to mean all sports) and civilization:

But physical education, as a moving force in Greek life, can best be established by a consideration of the rise and decline of physical culture and athletic activity in Greece and the corresponding rise and decline of Greek civilization--two phenomena so closely related that it is difficult to say which constituted cause, and which effect. 8

Neumeyer and Neumeyer point out that civilizations of the world have been made and unmade by the way in which people used their free time and that the tone of any society is conditioned by the quantity and quality of its leisure. 9

The results of poorly used leisure do not manifest themselves immediately. Many decades may pass before the results are seen and then the connection between the cause and the result is obscure. In addition, people feel that the way in which they use their leisure time is their own affair and they will not tolerate any interference. For these reasons, local, state, and national governments do not devote the attention to recreation that the subject warrants.

\section{Ibid., p. 62 .}

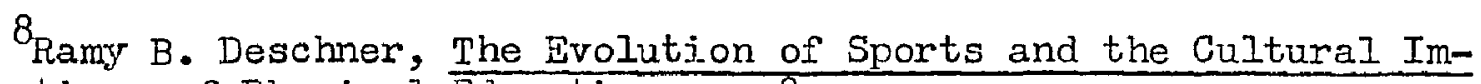
plications of Physical Education, p. 8 .

QMartin H. Neumeyer and Ester $s$. Neumeyer, Ieisure and Recreation, p. 13 . 
Changing Peoples' Recreational Habits. Changing and improving people's recreational habits is an educational process. It cannot be done by edict. Educational processes are slow and require a great deal of concerted effort to initiate movements. After the movements have been initiated however, they gain momentum. The first step then is to educate people to profitable use of leisure time. Lectures on the evils of indolent leisure and the benefits of physical and mental activity will not be nearly as productive as will demonstrating that the pleasures of constructive recreational activity over the long run are superior to the pleasures of destructive recreational activity. Need for Wore Community Facilities. Community facilities and leadership are far from adequate at the present time for adult recreation programs. Many more facilities and more leaders are needed. The most commonly offered reason for unsatisfactory participation it was found, was lack of time.. Lack of facilities came next as a factor limiting participation. If community recreation centers for adults were conveniently located and conducted well-organized programs for adults, men could not offer the reason of lack of time and facilities as a factor limiting their participation. It then would not take mich longer to go to the community gymnasium for a game of volleyball than to tune in a television program.

If all adult people should suddenly become convinced of their need for recreative activity, it would become apparent that we would be ill-equipped to meet the demand. The need for recreational facilities for older people is particularly great. Wilma Donahue points out that figures from the national community chests and councils show a 
meager 1.6 per cent of the total budgets of communities devoted to programs for the aged. 10 Few community agencies give any attention to the recreational needs of older people. If this is not sufficient evidence, one need only glance at the number of older people sitting in parks, public libraries, in hotel lobbies, residential hotels, Young Mien's Christian Associations and Young Women's Christian Associations to know that the recreational needs of our older population are not being met. It is unlikely that recreation organizations will include adult men in their program planning to any great extent until these men demand that they be included in the planning. Few older men indicate a desire to join a Young Men's Christian Association or to belong to a sports group even though they do indicate that they like sports. The first step then is to translate the desire for sports participation into action or at least to secure expression of this desire.

Procedures Recommended for Organizing Adult Recreation Programs. In setting out to organize community recreation facilities for adults, it is first necessary to stimulate enough interest to arouse action on the part of the citizens. When adults are convinced of their need for these services some of them will initiate action. These leaders can assume the primary responsibility for seeing that adequate community facilities and programs are provided and that they are used to best advantage by all. It is the responsibility of people themselves

$10_{W i}$ ma Donahue, PJ.anning The Older Years, pp. 101-102. 
to discover and to develop their own interests and to aid in the development of recreational facilities in their community which can enrich their lives and that of the entire community. The major portion of the leadership should come from the people themselves. In many cases where they have had little opportunity to develop recreational skills, skilled professional leadership will be required, at least to get the program under way. Where possible, every effort should be made to develop and to use volunteer leaders from among the participants.

Wilma Donahue points out that there are five steps which need to be taken in order to provide recreational facilities and leadership. These are:

1. To get together the people interested in doing something about the situation.

2. To gather facts.

3. To locate facilities and to acquire money to finance the program.

4. To provide expert leadership and training.

5. To let people know of the possibilities. 11 Getting the People Together. To meet the first requirement, a recreation committee of interested people should be formed. The membership of this comittee could be made lip of physical education teachers, members of the city department of recreation or physical welfare, Young Men's Christian Association, Young Women's Christian Association, Young Men's Hebrew Association, Bureau of Public Welfare, psychiatrists, psychologists, occupational therapists, librarians, artists, musicians,

II Ibid., pp. 105-108. 
dramatists, persons skilled in public relations, representatives of labor and of any sizable nationality and racial groups in the community and an interested number of a nearby college or university. Gathering Facts. The facts which should be gathered should include:

1. The number, sex, marital status, occupation, education, time available, and recreational interests of people who would participate in the program.

2. The nationality and cultural background of the population.

3. A compilation of information about all existing recreational groups or activities in which adults are participating in appreciable numbers.

Locating Facilities. In considering possible facilities and activities, nothing should be overlooked. Community institutions no Ionger required for their original purpose may provide excellent recreation centers. Summer centers or outdoor senior day camps may be developed in public parks or on college campuses. Camps may be useful as holiday centers for a larger part of the year if made available to the adults. Homes for the aged, libraries, and youth recreation organizations may also be investigated for their possible use as adult recreation facilities. Other facilities which could be used would include: facilities of public schools which are not being used during the evening hours, facilities of the Young Men's Christian Associations, Young Women's Christian Associations, Young Men's Hebrew Associations, and church buildings.

Financing the Program. The program could be financed in any one of a number of methods or combinations of methods. One of the more 
common methods is through a small membership fee supplemented by voluntary contributions from the merabers thernselves. Usually the program is supported principally by a mill tax levy. Providing Leadership. In developing leaders for adult recreation programs, it should be kept in mind that though the knowledges and skills required of them will be similar in some respects to those required of school physical education people, they will be different in other respects.

Since the personality characteristics and the psychological needs of the individual provide the basis for the appeal of specific types of recreation, the recreation worker should have a working knowledge of the structure of the personality and the way it functions. The recreation leader should also make a study of the scientific data regarding leadership methods. He should possess a knowledge of the social forces operating in groups which may greatly enhance or detract from the effectiveness of a recreational program. He should have an understanding of the physiology of exercise, especially in the case of middle aged and older people. Fie should understand the physical capabilities and limitations of middle aged and senescent people. He should understand the aging process and have knowledge and some skill in the recreational activities in which older people are likely to engage.

It is not unlikely that there will soon be some demand for recreation leaders for adult and middle aged or senescent groups. Schools of health and physical education should begin now to prepare their graduates so that they will be qualified to serve these groups. 
It would not be necessary to modify curriculums a great deal. Students wishing to go into this work could substitute some courses for others. They should take courses in the physiology and hygiene of the aging process in addition to the usual physiology and hygiene courses. The hygiene course should emphasize the chronic rather than the infectious ailments. They should take more courses in the individual and dual sports and fewer in the coaching techniques of such vigorous team sports as football, basketball, and baseball, for it is unlikely that sufficient numbers of adult people in any one situation wiIl want to play these games to warrant forming a team. They should possess a working knowledge and skill in many of the following activities:

$\begin{array}{ll}\text { Badminton } & \text { Volleytull } \\ \text { Handball } & \text { Weight Lifting } \\ \text { Squash } & \text { Borling } \\ \text { Square Dancing } & \text { Horseshoes } \\ \text { Folk Dancing } & \text { Billiards } \\ \text { Softball } & \text { Archery } \\ \text { Fencing } & \text { Shuffleboard } \\ \text { Tennis } & \text { Tumbling } \\ \text { Swinming } & \text { Gymnastics } \\ \text { Boating } & \text { Exhibitional Activities } \\ \text { Canoeing } & \text { Soccer } \\ \text { Bait and Fly Casting } & \text { Chess } \\ \text { Golf } & \text { Checkers }\end{array}$

They should also possess as large a working knowledge as possible of such things as weaving, pottery, metal craft, woodworking, leather craft, basketry, painting, bookkinding, wickerwork, home repairing, etc. Perhaps the industrial arts, the physical education, and adult education departments coulc cooperate in preparing adult recreation leaders. These students should also take courses in the psychology of aging, adult camping, group dynamics, and publicity methods. Student teaching experience could be gained in adult recreation situations. 
Summary of Recommendations for Social Agencies. The following are principles for the organization and administration of recreational clubs for middle aged and older people:

1. The number of men and women in the club shoulcl be kept as nearly equal as possible. Experience has shown that where this procedure has been followed members attended more regularly, seemed to enjoy themselves more, and the membership grew. Husbands and wives should be encouraged to participate together. This incidentally, is another recommendation for including co-educational recreation activities in our public school and college physical education programs.

2. Develop an esprit de corps. Every member should consider himself as one of the welcoming conmi.ttee. The group leader should maintain a friendly relationship with the members.

3. Provide opportunity for as many individuals as possible to exercise leadership and thereby to gain needed recognition.

4. Select a convenient location.

5. The club should meet at least once every week.

6. Encourage members to adopt a hobby if they do not already have one. A hobby show has proven an excellent method of achieving this objective. Hobby shows afford the opportunity to gain recognition from associates and to develop an interest in the activities of other people.

7. The latter part of the evening of the club meeting should be devoted to free play. Activities should be utilized which permit a maximum of interaction yet make it easy for the in- 
dividual to assume the role of a passive observer. Humor should be given ful]. expression. In dancing games, those who do not dance can be encouraged to participate by singing or clapping hands.

8. In setting up an adult recreation program follow the five steps cited earlier.

9. Endeavor to think with, rather than for, or about these older people.

10. In addition to relaxation, play, and recreation, stated objectives of the club should also be to bring about community improvements and to make civic contributions.

Industrial Recreation

Technology Has Increased Need for Industrial Recreation.

Technology has brought about radical changes in man's way of life. These changes call for new adjustments in the interests of individual and social well-being. Such factors as specialization, monotony in work, health, and early retirement have caused industrial recreation to assume an increasingly important, if not immediately discernible, part in helping to alleviate some of these problems.

In talks with Industrial Relations men and through reading industrial recreation journals it became obvious to the writer that current emphasis in industrial recreation programs is upon using organized recreation to promote better employer-employee relationships. Evidence presented earlier in this study points out that recreational programs can also be used to sustain mental and physical health and thereby increase the span of productivity. If industrial management understood 
and accepted this evidence, it undoubtedly would expend greater efforts toward setting up better recreational programs because it could then utilize the training and experience of its older employees for longer periods. It also seems probable that industrial recreation would be more carefully organized and administered than it is at present. Management must learn to regard the objectives of industrial recreation as more than that of paternalistically providing relaxation and enjoyment for its employees. A well-organized recreation program can be an important factor in strengthening the mental and physical health of the workers, in creatine good esprit de corps and morale in plants, in improving effjciency of production, in bringing about better employer-employee relationships and cooperation, in lessening absenteeism and labor turnovers, and in providing opportunities for creative expression and the development of leadership abilities. Creat Loss in Human Resources. Industry is fully cognizant of the great loss in human resources which occurs at the mature end of life. This is a loss to society, to the older people themselves, and to industry. A wealth of wisdom, energy, and potentially constructive work is allowed to waste away because we have not yet become wise enough to use it to the maximum. Particularly during times of industrial expansion, such as these inaustry would prefer not to release older men. However, not only current practise and philosophy, but also the chronic fatigue, irritability, and chronic ailments characteristic of older men dictate that industry release or retire older men. When industry recognizes recreation as one means of increasing its employees' productive years, it undoubtedly will devote an 
increasing amount of attention to this phase of the industrial relations program.

Wen in Positions of Responsibility Particularly lieed Recreational Activity. It is particularly the conscientious, driving type of executive, supervisors and foremen whom the company should induce to participate in recreational activities of an active type. Because of their constant stimulation and emotional drive, these individuals are often not aware how seriously fatigued they are. Very often they offer no complaint or will admit only to insomnia or a moderate loss of appetite. Stieglitz shows that critical observation and questioning usually reveals an intense and continuous restlessness, an inability to concentrate the attention on one subject until it is finished, and a decided impairment in logical, intellectual analysis. He writes:

The greater the cumulative nervous tension and fatigue, the greater is their difficulty. These individuals must be told that they will feel much wor se before they can expect to feel better. When relaxation is finally achieved, they become aware of their depletion. Until relaxation is established, fatigue is not being neutralized. The induction of relaxation and the duration and character of the rest required are individual problems requiring considerable medical acumen for wise solution. Frequently, mental. rest is enhanced by physical activity; this too must be individually prescribed. 12

These driving types of personalitios are frequently the company's most useful employees. It would seem that a minimal recreational program would be one set up for those personnel in positions of leadership. If these ren would set aside a portion of each day for healthful recreational activity they would be less likely to experience physical and nervous bankruptcy. Physical activity would give them at least 
temporary relief from their emotional and nervous tensions. The muscular fatigue following would enable them to relax more completely. Wien who are physically fit and who have an opportunity to work off emotional and nervous tensions through recreational activity are less likely to experience chronic fatigue. A poorly considered decision by an executive or foreman might cost a company thousands of dollars or involve someone's health or safety. An adequate recreational program participated in by the executives, foremen, and superintendents, by lowering the incidence and severity of this type of fatigue, might save a company considerable money over a long period of time.

It has been pointed out that older men can make substantial contributions to a company's productivity, that these older men want to continue to work, and that some einployers would like to retain them. It has also been shown that the deterents to continued employnent of older men are their low physical fitness level, their irritability, and the high incidence of chronic ailments common to older age groups. An adequate personal, community, or industrial recreation program could help delay the onset of these undesirable characteristics. Types of Industrial Recreation Programs. There are seven principal ways in which industrial recreation prograns can be administered: (I) the program can be sponsored entirely by the management which provides all areas and facilities and operates the program at little or no cost to the worker; (2) management may provide the capital outlay for areas and facilities while the program is operated jointly by the employer and the employees; (3) the employer may provide the areas and 
the facilities while the employees maintain and operate the program; (4) the program may be planned, financed, and operated entirely by the employees; (5) an industrial recreation program may be of the association type where the public recreation department or the Young Wien's Christian Association operates the recreation program for all members of the association; (6) in cases where the industry and the living quarters of the workers are segregated, the industrial recreation program is the community program; here the community recreation program is utilized by the industry which neither provides areas or facilities but makes liberal contiributions to the community program and expects its workers to participate in the overall community program; (7) several smaller industries may pool resources to bring about joint action for the building of areas and facilities and for the operation of the program. 13

The first five types of programs are frequently located in company towns, where the industrial plant forms the large block of the community and greatly influences the pattern of living.

Experience shows that the first type in which the industry provides all areas and facilities and operates the program, is regarded as paternalistic by the employees and does not evoke as enthusiastic a response from them as do most of the other types of programs. Factors Influencing the Industrial Recreation Program. The situations in no two industries are identical. Various factors alter the conditions under which an industrial recreation program will function

13 Harold D. Meyer and Charles K. Brightbill, Community Recreation, pp. 248-249. 
most effectively. If the workers live in company-built houses, an industry-centered program may be most appropriate. If workers commute and are widely scattered, a different type of program may be considered. Company policy and the size of the company are factors which influence the type of program offered. A few companies feel responsibility for the employees' recreational life while others feel. the workers should provide their own leisure-time outlets. Small firms often find that the expense involved in purchasing, operating, and staffing areas and facilities is prohibitive. Several small companies often successfully operate joint programs. Where there is a large and successful community program a careful study should be made to determine whether an industrial recreation program would merely duplicate the existing community program.

Leadership. The majority of industries have no recreational program. Where they do have one, it is often conducted in a haphazard and an incidental manner. This is usually the situation where the recreational program is regarded as an incidental responsibility of the personnel manager. It is not wise for a personnel manager to be required, in addition to his many other heavy responsibilities, to operate the industrial recreation program. When it is possible, the industry should have a recreation department directed and staffed by professional recreation leaders who are capable and qualified. In small companies, it may be necessary that the personnel manager include recreation as one of his many responsibilities. If this is the case he should not attempt to operate the recreation program unassisted. He should make wide use of committees of employees, groups of 
volunteers, cormittees of employers and employees, and trade union committees. 'The combined efforts of all these volunteers is desirable. There is a need for personnel trained specifically to assume leadership in industrial recreation. Where industrial recreation is under the part-time leadership of a member of the industrial relations departments, a need might be expressed for a short intensive course for these men at colleges and universities located nearby.

While employees should be encouraged to help organize their own activities, full-time paid leadership is essential for effective operation. Part-time paid leaders are the next best substitute. Often community recreation programs serve industries. Private agencies can and often do assist industrial groups. Meyers and Brightbill point out that studies show that companies which employ full-time paid leaders have larger and generally more effective programs. If Financing the Recreation Program. There are many methods of financing industrial recreation programs. Each company should have a fixed financial policy. Experience shows that the most successful programs are those where all who are interested in the program and benefit by it share in the financial burden. Activities which are expensive to operate or which require special supervision or instruction should be made as self-supporting as possibie. Funds should be budgeted on an equitable basis and proper accounting and auditing principles should be followed.

Most companies supply both equipment and facilities. The facili-

$\Psi_{\text {Ibid., p. } 251 .}$ 
ties which some companies supply include skating rinks, bowling alleys, dance halls, fields, tracks, swimming pools, and camps. Often company areas and facilities are supplemented by the public and private facilities of the community. Sometimes a facility or an area is a gift or is bujlt as a menorial with funds derived from contributions and drives. In other situations it is purchased with earnings from concessions or from admissions receipts.

Preferred Activities. The industrial recreation propram should be based principally upon the preferential interests of the participants. However, the recreation director should attempt to stimulate interest in activities which result in physical and mental growth. Interest in the se types of activities continues to increase with length of participation. Interest in those activities which are continualiy challenging and wich bring ego satisfaction should be stimulated in preference to the sedentary types of activity. The recreation director should anid people into activities not only on the basis of their interests but also on the basis of the requirements of the activity and the capacities of the individual. The individual's capacities are determined in large part by his age, physical condition, and mental abilities. In most situations the recreation director will not; have sufficient time at his disposal to give individual counseling. However, he can enable people to prescribe for themselves trough the nedia of mass education such as pamphlets, mimeographed material, and articles in the company paper. Activities which should be included in the program are athletics and sports of all types, musical activities, 
arts and crafts, outing activities, camping picnics, and social, folk, and square dancing. Within plant, inter-and-intra-league events, tournaments, and contests should be sponsored. Company plays and variety shows should also be a part of the program. Steps in Organizing an Industrial Recreation Program. Mieyer and Brightbill list thirteen steps which are useful in organizing an industrial recreation program. These are as follows:

1. A group of employees have some ideas about recreation activities; the president of the industry or some other officer becomes interested, or the personnel director senses needs--the idea is planted.

2. A small group of interested people meet and "talk things over." Plans are made to "look into" the idea.

3. Committees are formed to (a) survey the situation and discover needs, (b) investigate programs in other places, (c) formulate a skeleton plan of action, and (d) explore ways of financing the program.

4. A permanent organization is established, and definite steps are taken to proceed on the basis of predetermined objectives.

5. A publicity campaign is initiated. Facts, plans, and information are presented to everyone conerned.

6. Funds are raised and budgeted for capital improvements and operation.

7. Areas and facilities are obtained, developed, or located.

8. A recreation director and stafe are employed.

9. A broad program based on workers' jnterests and needs is established

10. A "talent survey" is made to obtain volunteer helpers. (The Industrial Recreation Association has a good "Recreation Interest Finder.")

11. Long-range plans are made. 
12. Cooperation of community recreation departinents, private agencies, and conmercial interests is sought.

13. The program is constantly interpreted to the workers and their families, the comnunity, and the management. 1.5

Summer Camps. A number of industries operate summer camps for their employees and the children of the employees. Some camps provide a weekend retreat for the employees. Others are within walking distance of the industry and the homes of the employees, and are in daily use. Some camps are company owned while others are leased by the company for weekends during the summer. There are three general types of employee camps: (1) for the entire family; (2) for men or women employees; (3) for youth and children of employees. Canping periods provide an excellent opportunity for introducing, or re-introducing middle aged men and women to the pleasures of sports and sportslike activities. Industries which are planning to add or expand their recreation programs should seriously consider the camp as a medium for educating their employees to use their leisure time as a means for increasing their productive years. Causes of Inadequate Programs. Seven principal causes of inadequate programs of recreation are: (1) lack of company equipment and facilities; (2) the lack of a diversified program to meet the needs of employees, (3) insufficient numbers of employees, (4) employees living too far away from the plant, (5) inadequate financing of the program,

$$
{ }^{15} \text { Ibid., p. } 253 .
$$


(6) lack of good leadership, and (7) attitude of employers, employees, or labor unions.

The Recreation Programs of Labor Organizations. The labor organizations of the country do not sponsor recreation on a national basis. However, many local branches do. They include recreation as an important part of regular meetings; they conduct feature activities such as picnics, play days, excursions, parties and dances; they encourage the promotion of well-rounded community programs; they serve as representatives on recreation commissions, boards, councils, and advisory committees; they cooperate with local recreation authorities; and they participate in training institutes, conferences, and workshops. If labor organizations recognized recreation programs as a medium for increasing the length of the productive years of their members, they undoubtedly would promote recreational programs more enthusiastically. The Industrial Recreation Association. The Industrial Recreation Association was formed in 1941 to promote and assist industrial recreation programs. Its main services to the members include: providing reports of new developrents and ideas on all phases of industrial recreation; sponsoring conferences in various sections of the country; conducting research, providing information service; producing manuals of procedure for establishing industrial recreation programs, and issuing monthly and special bulletins. The Association lists its objectives as follows:

1. To acquaint management with the importance of industrial recreation as a part of sound industrial relations. 
2. To emphasize industrial recreation in periods of national emergency, to achieve industrial unity, improve morale, skill, and production.

3. To develop industrial recreation as a benefit to the community and improvement of industrial, labor, and government understanding.

4. To study methods of improving industrial recreation programs.

5. To provide a clearing house for ideas and dissemination of information on industrial recreation programs through bulletins and other media.

6. To aid members in the solution of recreation problems.

7. To encourage further study and research on industrial recreation.

8. To function in any manner beneficial to the industrial recreation movement. 1.6

If the Industrial Recreation Association can convince management that sports and sportslike activities can increase the length of an employee's productive years, they would be even more successful than they have been in promoting industrial recreation. Characteristics of a Good Industrial Recreation Program. What would be some of the characteristics desirable in an industrial recreation program? First, it should have as its aim not only that of promoting and organizing a variety of recreational activities but should include that of educating the participants in various aspects of mental and physical health as related to recreational activities and particularly with regard to the physiological and psychological changes associated with the aging process. This educational job should be designed for

16 Harold D. Meyer and Charles K. Brightbill, p. cit., pp.265-266. 
the aging--not the aged--before retirement rather than after. The best possible preparation for age is the habit of learning to adjust at all ages. If preparation for the later vears is postponed until old age, an educational program can be expected to achieve orly a fraction of the desired results. The age of thirty is not too soon for a man to decide that at the age of sixty he will be as young and vigorous as most men are at forty. The objective of education for aging is not to prepare for old age prematurely but to help adjust and to get the most out of the present with due regard for the years ahead. Such education should help people to make the necessary behavioral changes, both general and specific, whenever they should be made.

Second, the program should provide for participation in a wide variety of activities for recreational interests of men change from one decade to the next. Further, an activity which is recreative and interesting to one man may be boring and monotonous labor to another. Third, it would be highly desirable to guide men into activities on the basis of their emotional make-up and their physical limitations. Perhaps it might be simpler to enable men to prescribe for themselves by acquainting them with the requirements of the various activities.

Fourth, highly competitive activities for men over forty should be de-emphasized. This would include such directly competitive activities as boxing, wrestling, racing, basketball, and football. These are all activities where the outcome depends directly on the relative speed, strength, skill, and endurance of the opponents. The interest of men in such activities as golf, archery, bowling, hunting, fishing, 
hiling, handball, and squash, should be stimulated. These are all activities where the men compete first of all against themselves and secondly against their opponent. They are less directly competitive. Recommendations for Possible Contributions by Educational Institutions

Educators Should Devote More Attention to Adult Education. Educators have been well aware of various states of development such as infancy, pre-school, pre-adolescence, and young adulthood. Only passing recognition has been given to the existence of later stages such as middle age, later maturity, and old age. This has been especially true in the case of people in the area of physical education.

These states or life periods have been identified and studied because each represents a different phase in the life of the individual. These successive life periods arise out of the continuous changes in the biological organization and functioning of the individual and out of his changing mental capacities and processes. They also arise out of the fact that as the individual grows up and then grows older, society changes the demands it makes upon him. In a sense, life represents a series of roles imposed upon the individual. by the cultural group of which he is a meraber.

Education is a process which aids human beings to adapt to other human beings and to the demands of society. Until the present, education has been used primarily in the formal school systems to prepare youth for adulthood. Very little has been done to use education to help adults adjust to the changing pattern of their environment and to help them to continue to grow as individuals. Enough is known about 
adult education to assure us that great changes can be made in an adult person's vocational, avocational, and cultural equipment through the proper methods.

The Iater Stages in the Life Cycle Have Received Little Attention.

Stieglitz comments that our life cycle consists of a series of consecutive stages although the lines of division between these phases are not sharp and distinct. His scheme of classification follows: 17

Biologic Average Chronologic Age Period Landmarks at Onset of Period.

Conception

Birth

9 months plus or minus two weeks

Embryonic)

Fetal

Newborn -Pediatrics

Infantile)

Childhood)

Puberty

Fertility

Climacterium

old Age
12 years plus or rninus two years

19 years plus or minus three years

45 years plus or minus five years

70 years plus or minus ten years
Adolescence Youth

Young adult vlaturity

Later maturity) Senescence -Geriatrics

The branch of medicine called Pediatrics has specialized in the health problems of young children while the newer branch of medicine called Geriatrics is specializing in the health problems of older people. The general field of education has until only recently con${ }^{17}$ Stieglitz, op. cit., p. 103. 
cerned itself exclusively with the younger age groups. The unfortunate implications of this to many people has been that learning is restricted to the years before twenty or twenty-five. It must be admitted that considerable work and research has been accomplished in the area of adult education in recent years. In the area of physical education, little research has been done as to the possible contributions to increased health and happiness during middle and older life arising from participation in recreational activities. There is need to determine what is the best content and method in activity programs for the adult and aging members of our society to discover what activities adults enjoy, in which activities they participate, the adequacy of the facilities, and the effects of participation in recreational activities upon nen of various ages. Growth and Involution. Gerontologists tell us that life is aging-all living things age. Between the ages of 20 and 25 the growth processes begin to play a less important role while those of involution begin to play an increasingly important role. Desirable habits of living whether they be in the areas of diet, health, sanitation, or recreation are not simply acquired. They must be developed. Adult men by anticipating the probable extent of their approaching limitations and capacities and by antisipating the probable changes in their interests can begin to prepare for them in advance. Physical educators and recreation leaders can help them in this objective if they are faniliar with the approaching changes. The entire educational system operates on this principle. Children are continually being prepared for the next highest level. But learning, growth, and prepara- 
tion should not stop abruptly with graduation from high school or college. If a rich harvest is to be produced in succeeding years the soil must be prepared ahead of time. Aging is a dynamic, on-going process.

Adaptation to Old Age. Frances Conley reports the results of an investigation into the factors making for good adaptation in old age. Adaptation in this case being defined as $1 \mathrm{~A}$ modification of the individual' which will fit him to live under the conditions of his environment. She placed highest on the list of factors making for good adaptation to old age, interests which were strong or varied or both. 18 Certainly, properly guided recreation can lead people to strong or varied interests. The implication here is that we guide people to those recreational pastimes which continue to grow in interest and challenge with the years, as opposed to the passive forms of recreation. Education Should Continue Throughout the Individual's Life. Education should be a process which continues throughout the life of the individual. It is necessary to living fully at every phase of life. Further, education is just as essential for middle aged people in preparing for old age and retirement as it is for children in preparing for adulthood. Education for middle aged people should aim to produce the mental hygiene which makes for intellectual and emotional vigor and enables people to make adjustments to the inevitable changes which will modify their way of life. As men age it will be necessary that

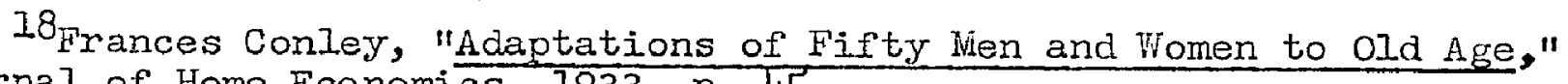
Journal of Home Economics, 1933, p. 45. 
they learn how to adjust to an increased amount of leisure, to changes in interest, to alterations in their capacities to work, and to a changing attitude of society. More Research and Study of the Fitness Problems of Adult wen is Needed. Considerable research and experimentation in the fitness problems of youth and young men has been accomplished. Which activities are best adapted to their emotional, mental, and physical peculiarities are reasonably well known. liany methods of stimzlating their interest in sports and physical activities are known. Considerable success has been achieved in stimulating the interest of boys and young men in sports and in physical fitness. Such success has not been achieved with the fitness problems of the senior members of our society. It is highly desirable that this same information be secured for older men.

One of the reasons for this lag is that interest in human aging is of very recent origin. Until recently there was no practical reason for great concern over elderly people or for enabling people to continue to serve themselves and the community until relatively advanced age. Though the ancient Greeks delighted in the philosophic discussions of their aged seers, in those days the old were revered largely as objects of curiosity because of their rarity. Though the processes of aging are as old as time, interest in senescence is very recent. The aging of men and women, as individuals, has until recently received but scant attention. What is actually know of the basic mechanism of aging, as a biologic process is very limited. That part of aging which is youth and is exemplified by growth has 
received vastly more attention than that part of aging which is concerned with life after the age of twenty.

Emphasis in the past has been upon subsidizing older people. A few gerontologists and old age counselors (psychiatrists) are beginning to point out the need for showing people how they can extend their productive years. The emphasis is just beginning to swing from the corrective toward the preventive approach in dealing with the aging process in man. Federal funds to the amount of more than ॠ400,000,000 are annually allocated to old age assistance, but not one cent of this is used to study the disabilities which prevent the elderly people from continuing to earn their own way.19 It might be added that money should be spent to study methods of preventing the disabilities from occurring.

Robert J. Havighurst predicts that public opinion will put pressure on industry, business, and labor unions to find ways of holding older workers on the job to a later age. He also predicts that emphasis in recreation will swing toward the recreational needs and problems of older people. 20

Adult Education Most Effective When it is a Part of the Recreation Program. Homer Kempfer points out that adult education can be most effective if it is tied in with the activities of recreation centers,

\section{Stieglitz, op. cit., p. 12 .}

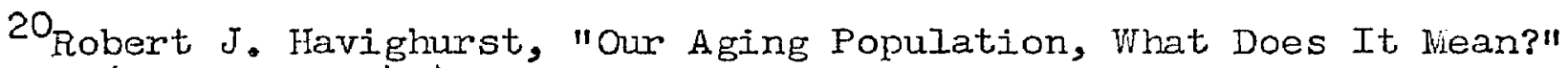
Hygeia, (October, 1947), p. 102 . 
social agencies, health departments, and industrial and business firms. 21 He states that health education is most effective when it is planned as an incidental part of recreation and leisure-time activity because relatively few adults, especially younger ones, are likely to be interested in joining classes for the formal study of health problems of the aging. Schools Should Furnish Initiating Leadership. The same author urges the local schools to take primary responsibility for initiating community-ride planning for the aging. 22 He does not want the school to take up noneducational functions but rather that they furnish initiating leadership. A major service of the school can be to provide building space and work-shop equipment for the practice of hobbies, handicrafts, and related interests. Inasmuch as recreation departments often do not exist in small communities, the school can serve as the center for many activities of an educational-recreational character. Older people should be given ample opportunities to learn new ways of self-expression and to do what they have always wanted to do. New forms of creativity can come at any age.

An adult education program should build a wide range of leisuretime skills for people of all ages. It is then likely to be providing educational opportunities for olcier people. Efforts should be made to

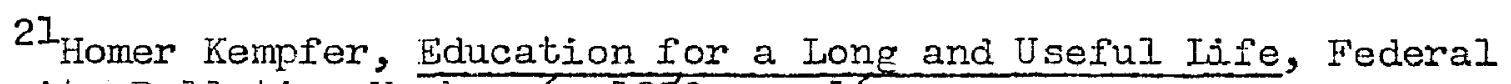
Security Bulletin, Number 6, 1950. p. 16.

22 Ibid., p. 9 . 
times--that is, continuing to learn."23

"Hell is an endless holiday--an everlasting state of having nothing to do and plenty of money to spend doing it." George Bernard Shaw.

Public Relations. The most effective way of changing peoples: behavior is to change their ideas. To change their ideas it is necessary to present considerable and valid evidence that it is advisable that they do this. This evidence must be brought to their attention repeatedly. The evidence that play is beneficial to adult men as well as to youth is beginning to accumulate. Fealth, physical education, and recreation people should utilize all media to make this evidence known to the Eeneral public. Some of the media which could be utilized are the following:

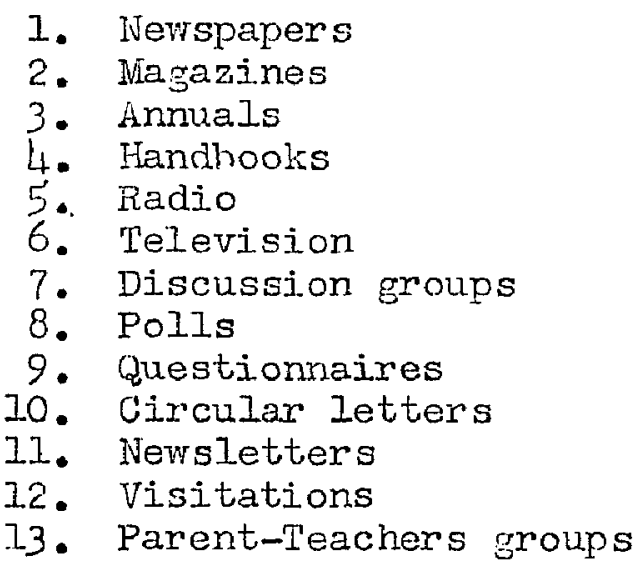
Newspapers and Magazines. Newspaper articles would probably be the most effective media because trey reach many people and they are current. iragazine articles should also prove userul. In addition to articles on the rules, strategies, and techniques of the various

${ }^{23}$ Lyman Bryson, "Iife Long Learning," Educational News Bulletin, (February, 1936) pp. 14-19. 
sports and other recreational activities, articles should be written presenting scientific evidence from the fields of physiology, psychology, and sociology which indicate the criteria for selecting recreational activities. Articles should be written proving the importance to adults of participating in sports and recreational activities. As a profession, we spend a great deal of time writing to ourselves and allow sportswriters to interpret our program to the public. Then we are surprised that there exists so nuch misunderstanding of our objectives. That is needed, particularly for adult education-recreation programs, are articles written for popular magazines. The medical profession has been doing this for a number of years. This undoubtedly is one of the important factors contributing to the excellent relations between the medical profession and the general public.

Radio and Television. Radio and television are two excellent media. for interpreting the adult education-recreation programs to the public. The physical education profession has made little use of the se media. I'hey have been used to interpret the varsity sports program to a large extent in order to increase spectator interest and attendance and because of public demand. They have not been used to an appreciable extent to increase participation. Observing a sport does not increase participation in that sport, at least among adult men. This has been shown by the data presented earlier in this study. On page 70 "watching sports," which usually means such sports as football, baseball, basketball, and hockey, ranked among the first three in percentage of men liking them. In the table on page 80 showing the twenty activi- 
3. To show the objectives of the program.

4. To promote the scientific method.

5. To build a sound philosophy of adult education and recreation. Wobile Units. Still another device which could be used by the physical education department in improving public relations is that of sending mobile units to outlying districts to teach physical education activities, simple forms of family recreation, school and home health practices, and farm and home safety to the members of the comminity. Visitations. When the college or university wishes to help in startm ing a community program certain members of the adult education or physical education department should visit the same community several times each year. These members should become acquainted with the people in a natural, informal manner. They should not emphasize that they are university professors because many people would tend to feel a social and educational distance and to "freeze up." Students should accompany the professor. A folder should be kept on the important events, persons, and problems of the community. In the master folder, an individual folder on the particular events and people should be kept to help to know and to understand the people the college will be working with. Obviously, the members of the commmity should never have access to these folders.

Emphasize Social Activities. In conducting adult recreation programs, it should be kept in mind that man is primarily a social being. For this reason, social activities such as folk and square dancing, folk lore, festivals, and pageantry should be prominent in the program. 
Friendly Attitude. If adult recreational leaders are to get the "feel" of the community, they should associate with the typical citizens as well as with people with educational background similar to their own. If they do this, they will be more likely to understand and to represent the majority point of view. Empathy and rapport are as important when working with adults as when working with children. They are an important part of a "growth climate." However, skill in organizing and conducting the activities is even more important when worling with adults than is a friendly attitude. Community Leadership. Leadership should be developed from within the community. Not only does this relieve the person in charge of many responsibilities thereby freeing him to expand the program but it also insures that the program will continue should the leader be called away. In addition, the program is more likely to succeed inasmuch as the participants will feel that the program is their own. Volunteer leaders can be effective in three principal ways:

1. By helping to get the facts.

2. By informing people of the facts in such a way as to elicit their interest.

3. By mustering the community resources for action.

The first successful commity endeavor will spur it on to new and greater efforts. Therefore, it is highly desirable that its first tasks prove successful. Their first undertaking should be one at which they are reasonably certain of success.

In securing data to serve as guides in the construction of a commity recreation program, it will be necessary to make a number of 
4. Democracy is a growth process and often slow. Patience is required.

5. When they cooperate, the more agencies which are participating in the program, the greater are the probabilities of having a successful program.

6. Keep the people informed in such a way that they will want to take action themselves.

7. Help everyone in the community feel his contribution is needed and wanted.

8. Believe in the efficiency of the democratic process.

9. Know how to organize democratic group processes so that people share in making decisions.

Training Adult Recreation-Education Leaders. As industries, communities, and educational institutions become increasingly aware of the need for starting adult recreation programs or for enlarging existing programs, the need for trained and qualified adult education-recreation leaders will be felt more strongly. Colleges and universities have both the facilities and qualified personnel to train these people. If they don't assume the responsibility for training adult recreation personnel, it is almost inevitable that they will be asked to do so. With some modifications, the orgenization of the better teacher training departments can be used for training adult education-recreation leaders. The organization of this department will be discussed briefly here because it is thoroughly covered in a recent study. 25 inch of the ${ }^{25}$ Richardson, Edwin, op. cit. 
material following on the training of adult education recreation leaders is adapted from Richardson.

Objectives of the Program. The objectives of the program will be:

1. To prepare physical educators to "teach" the associated learnings which are peculiar to their field and are integrated in the unity of the "whole man."

2. To prepare prospective teachers in indirect leadership so that after they have left, their programs will continue for the betterment of the community.

3. To assist future teachers in developing respect for human personality, a value of morality, a sense of objectivity, a capacity to do reflective thinking, and a desire for continuous education.

4. To assist the futme recreation leaders in developing teaching skills, improving their supervision, increasing their professional competency, and developing their organizational ability.

5. To prepare health, physical, recreation, and safety educators, and to interpret their services to the community.

6. To prepare the future adult education-recreation leaders to participate in the commuity activities and to become an integral part of the community.

7. To equip the prospective teachers with the necessary organizational ability so they will be able to plan in-service training programs for voluntary leaders. 
8. To prepare the students to cooperate with other agencies actively concerned with the welfare of adults.

9. To show the students how to encourage 100 per cent participation.

Selection. Selection of candidates for degrees in adult educationrecreation should be a careful and continuous process. There should be definite points at which qualifications of candidates should be summarized and the decision made as to whether the student should continue in the field or be urged to select some other area for which he might be better qualified. These summaries should be made at entrance, at admittance to junior standing, and approval for practise teaching. Referral Agencies. Adequate use should be made of referral agencies such as the Psychological Clinic, Speech Clinic, Health Service, and the Miarriage Counseling Clinic to assist in evaluating the students' potentialities and as referral agencies when the student needs help. Basis of Selection. Evaluations of the following student characteristics should be made at the initial selection:

1. Intelligence--by means of intelligence tests.

2. Scholarship--by records.

3. Special aptitudes--by records.

4. Physical and mental heaith--evaluation made by the Health Service.

5. Personality.

6. Character.

7. Attitudes.

8. Interest. 
General Recommendations. In the area of adult education-recreation, educational institutions are in a position which is favorable for providing guidance and leadership. Education is primarily guidance. Educational institutions can provide guidance for aging in the following ways:

1. By developing a wide range of recreational interests and ski.lls while children are in school as well as through the adult education program, some of which they can use now and others which they can use later as they become older and lose some of their youthful vigor. Interests in recreational activities which were once started and then discontinued in the hustle to earn a living are easily aroused when in later years leisure is often obligatory. It is much harder to become interested in something entirely new after fifty years of age than it is to pick up an activity discontinued because of lack of time.

2. By preventing unnecessary or premature physical depreciation through educating men to the need for maintaining fitness, showing them how to accomplish this goal, providing the opportunities, and stimulating their interest in recreational. activities which will help them to achieve this goal.

3. By orienting school children to aging and developing a more rational attitude toward older people. This might be accomplished through a unit on aging or in an incidental fashion in the way health education is being taught in some schools. A minimum requirement would be that some comments 
on the aging process be made in textbooks.

4. Developing health habits based on medical knowledge, which may influence the individual throughout life.

5. Developing mental hygiene practices and increased mental and emotional maturity.

Sumnary. Educational institutions--schools, colleges, and universities-are in a favorable position to make substantial contributions to the growing problem which the increasing numbers of older people pose for us. They can make contributions in four principal ways: First, by educating and orienting students and the general public with regard to the aging process and by developing the skills, knowledges, techniques, and attitudes which will make possible a useful and productive older age. Second, by making their facilities and personnel available for the use of comnunity education-recreation programs in cooperation with other social agencies. Third, by training adult education-recreation leaders. Fourth, by doing research in the problems of aging.

Tradition dictates that educational institutions continue dealing with youth. There is a great need that educational institutions devote more attention to the adu.t members of the population. Will the educational institutions be strong enough to break away from traditional practices? The present writer believes they will. Public pressure will require that they give more attention to adults and the aging population. Since it is the acults who pay the taxes, school systems and educational institutions which serve adults will secure their cooperation more easily. Educational institutions have already 
begun to assume leadership in the study of the aging problem and in organizing adult education-recreation programs.

\section{Suggestions for Further Research}

1. Does regular exercise have any influence upon the rate of deposition of cholesterol in the arteries? Cholesterol, a mineral-like substance deposited in the arteries causes their internal diameter to becorne smaller. It is responsible for the condition commonly known as hardening of the arteries. A few geriatricians suspect that regular exercise might influence the rate of this deposition. The rate of this deposition can be measured by taking measurements of the arterial wall diameter at regular intervals. It is suggested that a control group of twenty-five rabbits leading a sedentary life and an experimental group of twenty-five rabbits excercised daily in rotating cages be used.

2. A study of the recreational habits and interests of men over sixty years of age is needed. The study could be similar to this one. Since it is extremely difficult to find significant numbers of men over sixty who could be polled the study would require considerable time.

3. A study of the physiological and psychological effects of exercise on adult men over at least a ten-year period should be conducted by one of the recreation or physical education associations. A control group of men who do not engage in sports and an experimental group of men who have established habits of regular sports participation could be used. The tests of fitness used should 
include tests of muscular endurance such as chinning, dipping, and sit-ups; tests of muscular power such as the Sargeant vertical jump and medicine ball put or the standing broad jump; tests of muscular strength such as dynamameter tests; tests of functional cardiovascular efficiency such as the Heartograph, Snyder test, step tests, and tests of respiratory fitness. A medical record should be kept and various psychological tests could also be used.

4. Studies should be made to find the most effective methods of organizing adult recreation programs. Other studies should be made

- to discover methods of stimulating interest in sports on the part of adult men.

5. All the above studies could also be made regarding women.

6. A study should be made to discover whether the incidence of neurosis is greater among people who have not allowed themselves time for recreational activities than among those who have.

7. The above comparison should be made between those who have participated in the active recreational activities, as against those who have participated in the sedentary forms.

8. As a result of having read Bartley and Chute's Fatigue and Impairment in Man, the present writer has been contemplating the relationship between mental attituces or "stances" and posture. A study could be made to discover whether certain postural deficiencies such as lordosis, Iryphosis, scoliosis, or "fatigue slump" show a relationship to certain mental attitudes. 
SELECTED BIBIIOGRAPHY

(BOOKS)

Baird, Janet. These Harvest Years.

Bartley, S. Howard, and Eloise Chute. Fatigue and Irmpairment in Nian. New York and London: MicGraw-Hill Book Company, Inc., 1947.

Barker, Lewellys F. The Clinical Diagnosis of Internal Diseases. New York and London: D. Appleton and Co., 1923.

Collins, S. D. How to Ride Your Hobby. New York: Appleton-Century, 1935.

Cowdry, E. V. and Others. Problems of Aging: Biological and liedical Aspects. Baltimore: Williams and Wilkins, 1942 .

de Gruchy, Clare. Creative Old Age. San Francisco: 1946.

Deschner, Ramy B. The Evolution of Sports and the Cultiral Inplications of Physical Education. St. Louis: Fred livedart Co., 1946.

Donahue, Wilma. Planning the Older Years. University of Wichigan: Ann Arbor Press, 1950.

Dublin, Louis I. Length of Iife. New York: Ronald Press Co., 1936.

- . - . - - Medical Problems of Old Age. Philadelphia: University of Pennsylvania Press, . .9Ll.

Dunbar, Flanders. Ijind and Body: Esychosomatic kiedicine. New York: Random House, 1947.

Giles, Ray. How to Retire and Enjoy It. New York: Liccraw-Hill, 1949.

Hambridge, Gove. Tine to Live; Adventures in the Use of Leisure. New York: Michraw-IIilI Book Co., 1933.

Hollingworth, H. L. Mental Growh and Decline. New York: Appleton and Company, 1927.

Irwin, Leslie $W$. The Curriculum in Health and Physical Education. St. Louis: The C. V. hosby Company, 1944 .

Josselyn, D. W. Live Up to Yourself; How to ihake the liost of Your Energy. New York: Longmans, I94I.

Koffka, K. Principles of Gestalt Psychology. New York: Harcourt, Brace and Company, 1935. 
Kluckhohn, Clyde and Henry A. Hiurray. Personality in liature, Society, and Culture. Fiew York: Alfred A. Knopf, 1949.

Kozman, Hilda Chute, Rosalind Cassidy, and Chester Jackson. Miethods in Physical Education. Philadelphia and London: W. B. Saunders Company, 1948.

Lawton, George. Aging Successfully. Columbia University Press, 1946. Jartin, Lillian J. and C, de Gruchy. Salvaging Old Age. New York: liacmillan Company, 1930.

Wartin, Lillian J. Creative Old Age. San Franci sco: Old Äge Counseling Center, $\overline{1946 .}$

liearns, Hughes, The Creative Adult. INew York: Doubleday, Doran and Company, Inc., 1940.

ilenke, Frank. The Encyclopedia of Sports. New York: A. S. Barnes and Company, 1946.

Leyer, Harold D. and Charles K. Bri ghtbill. Cormunity Recreation. Boston: D. C. Heath and Company, 1948 .

National Recreation Association. The Leisure Hours of 50,000 People. New York: National Recreation Association, 1935.

iveumeyer, Martin H. and Ester S. Neumeyer. Leisure and Recreation. New York: A. S. Barnes and Company, 1949.

Oberteuffer, Delbert. Plhysical Education. New York: Harper and Brothers, 1951.

Pitkin, walter B. Life Begins at Forty. New York: NicGraw-HiIl, 1937.

- . . - . - Careers After Forty. New York: NicGraw-Hill, 1937. - - - - - - The Best Years. New York: Current Books, Inc.,

Society for the Psychological Study of Social Issues. Readings in Social Psychology. New York: Henry Holt and Conpany, 1947.

Sokoloff, Boris. Widdle Age is What You Wiake It. Richmond: William Byrd Press, 1938.

Stafford, George T. Preventive and Corrective Physical Education. New York: A. S. Barnes and Company, 1950.

Steincrohn, P. J. Forget Your Age. Blue Ribbon Books, 1947. 
Stieglitz, Edward J. and Others. Geriatric Medicine. Philadelphia: W. B. Saunders Co., 1943.

Stieglitz, Edward J. The Second Forty Years. Philadelphia and New York: J. B. Lippincott Company, 1946.

Strong, E. K., Jr. Change of Interests With Age. Stanford University: Stanford University Press, 1931.

Tibbits, Clark. Iiving Through the Older Years. University of Michigan: Ann Arbor Press, 1949.

Therlis, M. W. Care of the Aged (Geriatrics). St. Louis: C. V. Mosby Company, 1942.

Ioung, Kimball. Personality and Problems of Adjustment. New York: F. S. Crofts and Company, 1946.

Zoethout, William D. and W. W. Tuttle. Textbook of Physiology. St. Louis: C. V. Mosby Company, 1949 .

\section{(PERIODICALS)}

Babcock, Harriet, "An Experiment in the Measurement of Wiental Deterioration," Archives of Psychology, (1930), Vol. 18: No. 117, p. 105.

Barkin, Solomon, "The Employment of the Older Worker: The Economically iitddle-Aged," Journal of the American Statistical Association, (karch 1933 supplement), Vol. 27: No. 177-A, pp. 102-108.

Blai, Boris, "It's In Your Hands," American Magazine, (1940), pp.51-53. Bond, C., "Age, the Great Adventure," Hygeia, (19/40), pp. 14-16.

Bortz, E. L., "Geriatrics--New Light on Old Folks," Clinics, (19l.2), Vol. 1, pp. 386-405.

Brown, Clarence and Edwin Ghiselii, "Oldsters Not So Slow," Science Digest, Vol. 27, Iro. 4, (1950).

Brown, Ralph, "Effects of Age on the Speed-Power Relationship with Reference to Tests of Intelligence," Journal of Educational Psychology, (Sept., 1938), pp. 413-418.

Bryan, Alice I., "Can There be a Science of Bibliotherapy?" Iibrary Journal, (1939), pp. 773-776. 
Carlson, A. J., "The Older Worker," Scientific Honthly, (July, 19l43), $\mathrm{pp}$. 5-II.

Claque, Edwin, "Employment Problems of the Older Worker, " ionthly Labor Review, (December, 1947), pp. 661-663.

Conley, F., "Adaptations of Fifty iren and Fifty Women to Old Age," Journal of Fome Economics, (1933), pp. 387-389.

Cowdry, E. V., WWe Crow Old," Scientific lionthly, (Jan., 1940), pp. $51-58$.

- - - - - "Factors in Aging," Scientific lionthly, (1943), Vol. 56, pp. $370-374$.

Crampton, C. Ward, "Postponjing Old Age," Science Digest, (August, 1948), Vol. 24, No. 2, pp. 62-66.

Dawson, Percy M., "The Influence of Aging on Power and Endurance in lian," Research Quarterly, Vol. 16, No. 2, (May, 1945), pp. 95-101.

Desmond, "1. C., "i ivew Idea for ivew jobs at 65," rotarian, (lway, 1950), p. 21.

- . - . - - "The Promise of Geriatrics," Today's Health, (June, $194.0), \mathrm{p} .35$.

Drucher, Peter, "The liirage of Pensions," Reader's Digest, (April, 1950), p. 26.

Franklin, Z. C., "Iittle-Known Facts About Grandparents," Parents Wagazine, (1934), Fp. 16-17.

Franz, S. I., "Rehabilitation and Reeducation--Fhysical, ivental, and Social," Miental Hygiene, (1919), pp. 33-47.

Gavigan, A. J., "Senescent Efficiency and Employability," Journal of Applied Psychology, (1936), pp. 266-272.

Goldfarb, W., "An Investigation oi Reaction Time in Older Adults, and Its Relationship to Certain Observed Mental I'est Patterns," Columbia University, Teachers College Contributions to Education, (19LI): No. 83I, pp. 8-76.

Greifer, Julian L., "Time to Kill," Recreation, (1937), pp. 345-48.

Havighurst, Robert. "Our Aging Population: What Does It liean," Hygeia, (October, 1947), pp. 53-58.

Helton, Roy, "Old People: A Rising ivatíonal Problem," Harpers, (October, 1939), pp. 103-110. 
Hubbell, R. A., "Men and Women Who Have Performed Distinctive Service After the Age of 74," Wilson Bulletin, (1935), pp. 297-304.

Kenpfer, Homer, "Education for a Long and Useful Life," Bulletin No. 6, Office of Education, Government Printing Office, (1950).

Kossoris, H. D., "Relation of Age to Industrial Injuries," Monthly Iabor Review, (1940), pp. 789-804.

Landis, J. T., "What is the Happiest Period in Life," School and Society, (1942), pp. 643-645.

Lawrence, William L., "You're Going to Live Longer Than You Think," Saturday Evening Post, (April 29, 1950), pp. 28-29.

Lawton, George, "After 65?" ivental Hygiene, (July, 19l11), pp. 81-88.

- - - - - - " will Your Old Timers Be Ready to Retire?" Factory Management and Maintenance, (Jan., 1950).

- - - - - - "Happiness in Old Age," Miental Hygiene, (April, 1943), pp. 231-237.

- - - - - - - "You Carnot Demobilize Old People," Survey ilidNonthly, (April 19, 194.6), pp. 97-103.

- - - - - - - "Mental Hygiene at Senescence," iiental Hygiene, (1930), pp. 67-74.

- - - - - - - "Not Quite Heaven; the Story of the Colony for the Aged at Millvil1, N. J.," Saturday Evening Post, (Iidy 9, 1942), pp. 91-99.

- - - - - - - "Man's Most Creative Years," Scientific MonthIy, $(1944), \operatorname{Vol} .58, \mathrm{pp} \cdot 384-393$.

Levitt, G., "Electrocardiogram in the Aged; Study of 100 Iien and Women Over 70 With Apparently Normal Hearts," American Heart Journal, (1939), pp. 692-696.

- - - . - - - "Never Too Late to Learn," Journal of the American Association of University Women, (Oct., 1937), pp. 27-32.

- - - - - - - "Psychological Bases for Hdult Learning," Teachers College Record, (Oct., 1939), pp. It-12.

IheCloy, Charles H., "Forgotten objectives of Physical Education," Journal of Health and Physical Education, (October, 1937), pp. $75-78$. 
Nienninger, Williarn, "Recreation and Wental Health," Recreation Magazine, (November, 1948), p. 79 .

Hiles, Walter R., "Age and Iuman Ability," Psychological Review, (1933), pp. 99-123.

- - - - $-{ }_{-}-$"What Makes Old People Happy?" Survey, (Dec.,1935), pp. 360-361.

Phillips, Narjorie, "Problems of Questionnaire Investigations," Research Quarterly, Vol. 12, (October, 1941), pp. 75-88.

Randal. 1, Ollie A., "Need of Recreation for the Aged," Journal of Health, Physical Education, and Recreation, (Feb., 1951), pp.
2h-25.

Rees, W. L., and H. J. Ensench, "A Factoral Study of Some liorphological and Psychological ispects of Human Constitution," Journal of Mental Science, (Jan., 1945), pp. 8-21.

Robson, R. B., "Experiment in Education of the Older Workers," Industrial diedicine, Vol. 18, (Jept., 19/49), pp. 365-367.

Schartz, George and Harvey J., "Coronary Artery Disease in a Financial Area," inedical Kecord, (ivay 7, 19/41), pp. 121-133.

Stevens, $A$. F., Jr., "Accidents of Older Workers: Relation of Age to Extent of Disability," Personnel Journal, (1934), pp. 138-1.5.

- - - - - - - "Aging as an Industrial Health Program," Journal of the American Hedical Association, (Narch 29, 1941), pp. 1383-

- - - - - - - Mise Investment of Leisure," Scientiric Honthly, $(1940), p .147$.

Stieglitz, Edward J., "Health Problerns of an Aging Population," The Oliio Citizen, (June, 1949), pp. 77-91.

- - - - - - - "Pertinent Problems of Geriatric liedicine," Annals of Internal Medicine, (I943), Vol. 18, pp. 89-93.

Tyson, ${ }^{7 \pi T}$. J., "The Danger of Putting old People to Bed," Olinical Journal, (1923), pp. 384-407.

Wagner, hargaret, "Meet Yourself at Sixty-ive," Survey, (April, 1946), p. 122.

Warner, Frances L., "How to be Loved When Old," Atlantic Monthly, (Feb., 1942), pp. 103-110. 
Wolfe, Joseph B., and Victor A. Digilio, "The Heart in the Athlete," Joumal of Health and Physical Education, (Jan., 1945), p. 8.

_. - . . . _ " "The 150 Year Old Vian," Time, Vol. I, No. 26, (December 29, 1947), p. 53.

\section{(BUILETINS)}

Bryson, Iyman. "Life Long Learning," Educational ivews Bulletin, Feb. 1936.

Collins, S. D. A General View of the Causes of Illness and Death at Specific Aces. Washington: U. S. Public Health Service, 1935. Jnited States Public Health Reports, pp. 237-255.

Forecasts of the Population of the United States, 1945 to 1974 . U. S. Bureau of Census. March 15, 1948.

Kemper, Homer, Education for a Long and Useful Life. Federal Security Bulletin, ivo. 6, 1950.

Kessler, G. O., "The Determinati on of Physical Fitness," Journal of the American Wedical Association, (Nov. 9, 1940).

"Longevity of American People," Metropolitan Life Insurance Company, (1938).

Sinith, Elliott Dunlap, What are the Psychological Factors of the Obsolescence of Workers in Middle Age," Wew York, American lianagement Association, 1931, Personnel Series No. 9.

\section{(UNPUBIISHED MATERIAL)}

Baley, James A., "Physical Fitness of Adult lien, "Unpublished liaster's Thesis, University of IIIinois, 1948.

Husman, Burris F., "A Study in the Amount of Money Spent by Mien Living in the State of Illinois Participating in and Observing Sports," Unpublished Master's Thesis, University of Illinois, 1941.

Latham, Darrell E., "Report on the Physical Fitness Program for University of Illinois Firemen," University of Illinois, Unpublished Iieport, 1945 .

Richardson, Edwin, "Adult Education in the Physical Education CurricuIum, "Unpublished Doctoral Dissertation, The Ohio State University, 1951. 
APPEINDIX 
APPENDIX

Page

A Copy of the Questionnaire. . . . . . . . . . 193

Table

23 RELATIVE POPULARITY OF RECREATIONAL ACTIVITIES BY AGE GROUPS. . . . . . . . . . . . . . 195

24 REIATIVE POPULARTTY OF RECREATIONAL ACTIVITTES BY INCORE GROUPS ............... 203

25 DISCREPAICY BETWEEN LITING AND PARTICIPATION IN RECREATIONAL ACTIVILIES BY AGE GROUPS. •. • . • • • 217

26 DISCREPANCY BETWEEIN LIKTNG AND PARTICIPATION IN RECREATIONAL ACPIVITIES BY INCONI GROUPS . . . . . . 225

27 NUIMBERS AND PERCEIVTAGES OF MEIN LIKING, DISINKIIVG, AND INDIFHERELVIT THACH OH SIXTY-SEVEIV RECREATIONAL ACTIVITIES, EXTEIT OF PARTICIPATION IN EACH, AIND INUIBBER OF IUEUV LISTIING IACH OF FIVA RWASOISS FOI UNSATISFACTORY PARTICIPATION IN THE 20-29 AGE GROUP. . . . . . 239

28 INUMBERS AND PERCENTAGES OF MEN LIKING, DISIIKING, AND INDIFFERENT TO EACH OF STXTY-SEVEN RECREATIONAL ACTIVI'IIES, EXTENT OF PAR'PICIPATIOIN IN EACH, AIND INURBR OF INEN LISTIING EACH OF FIVE REASOIS FOR UINSATISFACTORY PARTICIPATION IN THE 30-39 AGI CROUP . . . . . 262

29 INUNBERS AIND PERCENTAGES OF WEN LIK工NG, DISLIKING, AND INDIFFELRENT TO EACH OF SIXTY-SEVEN RECREATIONAL ACTIVITIES, EXTENT OF PARTICIPATION IN EACH, AIND NUMBEH OF INEN IISTING EACH OF ITIV REASONS FOR UNSATISFACTORY PARTICIPATION IN THE 40-49 AGE GROUP .

30 INUWBERS AIVD PERCEITAGES OF IVEN LIKIING, DISLIKING, AND IIDTFFEREITT TO EACH OF SIXTY-SEVEN RECREATIONAL ACTIVITIES, EXTENIT OF PAITICIPATION IN EACH, AIND INUMBER OF MEN LISTING EACH OF FIVE REASONS FOR UNSATISTACTORY PARTICIPATION IN THE 50-59 AGE GROUP

31 NUMBERS AIND PEIZCENTAGES OF REN LIKING, DISLIKIIVG, AND INDIFFERENT TO EACH OF SIXTY-SEVEN RECREATIONAL ACTIVIIIES, EXTENI OF PARTICIPATION IN EACH, AND INULEER OF WEIV LISTING EACH OF FIVE REASONS FOR UNSATISFACTORY PARTICIPATION IN THE O- \$2,000 INCOAE GROUP ..................... 
32 NUMBERS AND PERCEITAGES OF MEN LTKING, DISIIKING, AND INDIFFEREINT TO EACH OF SIXTY-SEVEN RECREATIONAL ACTIVITIES, EXTENT OF PARTICIPATION IN EACH, AND NUMBER OF MEN LISTING EACH OF FIVE REASONS FOR UNSATISFACTORY PARTICIPAIION IN THE $\$ 2,000-\$ 3,000$ INCONE GROUP. . - 354

33 NUIMERS AND PERCENTAGES OF MEN ITKING, DISLTKING, AND INDIFFERENT TO EACH OF SIXTY-SEVEN RECREATIONAL ACTIVITIES, EXTEIVT OF PAR'LICIPATION IN EACH, AND NUMBEZ OF MEN IISTING EACH OF ET VE REASONS FOR UNSATISEACTORY PARIICIPATION IN THE $\$ 3$ 3,000-\$4,000 INGORE GROUP. • • 376

34 INUMBERS AND PERCENTAGES OF MEN LIKING, DISLTKTING, AND INDIFFEREINT IO EACH OF SIXTY-SEVEN RECREATIONAL ACTIVITIES, EXTEINT OF PARTICTPATT ON IN EACH, AND NUMBER OF MEN IISTING EACH OF FIVE REASONS FOR UNSATISFACTORY PARTICIPATION IN THE $\$ 4,000-\$ 5,000$ INCONE GROUP. . - 399

35 NUIBERS AIND PERCEINTAGES OF HUN LIKING, DISLTKIIVG, AND INDIFFEREINT TO EACH OF SIXIY-SEVEN REGREATIONAL ACIIVITIES, EXTEIVT OF PARTICIPATION IN EACH, AND NUIBER OF. INEN LISTING EACH OF FIVE. REASONS FOR UNSATISFACTORY PARTICIPATION IN THE $\$ 5,000-\$ 7,000$ INCONNE GROUP. : . - 422

36 INIMBERS AND PERCENTAGES OF WEN LTKING, DISTIKING, AND INDIFFERENT TO EACH OF SIXTY-SEVEN RECREATIONAL ACTIVITIES, EXTEIVT OF PARTICIPATION IN EACH, AND INUMBER OF INEN LISTING EACH OF FIVE REASONS FOR UNSATISFACTORY PARTICIPATI ON IN IHE OVER \$7,00O INCOME GROUP. . . . 1,45 
The material on pages 193-194

is poor copy. Filmed as received

from The Ohio State UnIversity.

UNIVERSITY MICROFIIMS 
This questionneire is part of a studr, tine rurpose of rinien is tw discover the recreational habits, needs, and interests of aduits. It is hoped that the results of this study will point out to school shysical educetion people, procedures thereby the physical educetion curricul wi night be improved so as to better meet the needs of you and your chiloren. It is also noped that community adult recreational rroups inil be able to utilize the fesults as a guide in planning their progran. Persons using this questionnaire are not required to shoin their name.

\section{IHSTRICTIONS}

1. In Column I after each activity indicate ycur feeling toriard the activity by placing a check inark in the appropriate colum. Please make some appraisal for each activity.

2. In Colurn II indicate the frecuenoy of your perticipation by miting in the amount per week, month, or year.

3. In Colum III indicate the reson for your not participating nore frequently in those activities in ihich you desire more frequent participation. Frite "health" If the limiting factor is a heaitin reason: "tine" if it is lack of time "noney" if It is aue to lack of funds; "facilities" if iocal faciltties are locking, fnadequate, or too distant; "knowledge and rikly" if lack of knowledge end shill prevent your participation.

\section{Check one:}

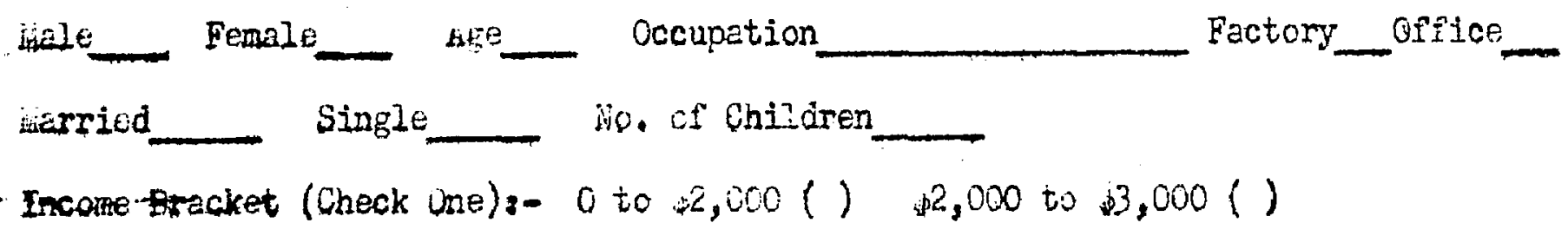



TABLE 23

Relative Popularity of Recreational Activities by Age Groups

\begin{tabular}{|c|c|c|c|c|}
\hline Age Group & $20-29$ & $30-39$ & $40-49$ & $50-59$ \\
\hline Total No. in Group & 91 & 161 & 100 & 59 \\
\hline \multicolumn{5}{|l|}{ Archery } \\
\hline Percent. Liking & 28.5 & 26.7 & 12.0 & 13.6 \\
\hline Percent. Disliking & 13.2 & 21.7 & 16.0 & 16.9 \\
\hline Percent. Indifferent & 58.3 & 51.6 & 72.0 & 69.5 \\
\hline \multicolumn{5}{|l|}{ Badminton } \\
\hline Percent. Liking & 46.2 & 50.3 & 25.0 & 8.5 \\
\hline Percent. Disliking & i4. 3 & 18.0 & $I_{1.0} .0$ & 11.9 \\
\hline Percent. Indifferent & 39.5 & 31.7 & 61.0 & 79.6 \\
\hline \multicolumn{5}{|l|}{ Bag Punching } \\
\hline Percent. Liking & 30.8 & 19.3 & 12.0 & 18.6 \\
\hline Percent. Disliking & 25.3 & 33.5 & 19.0 & 13.6 \\
\hline Percent. Indifferent & 43.9 & 47.2 & 69.0 & 67.8 \\
\hline \multicolumn{5}{|l|}{ Baseball } \\
\hline Percent. Liking & 92.6 & 86.3 & 77.0 & 59.3 \\
\hline Percent. Disliking & 0.0 & 1.2 & 4.0 & 1.7 \\
\hline Percent. Indifferent & 7.7 & 12.4 & 19.0 & 39.0 \\
\hline \multicolumn{5}{|l|}{ Basketball } \\
\hline Percent. Iiking & 62.6 & 46.0 & 38.0 & 30.5 \\
\hline Fercent. Disliking & 7.7 & 19.2 & 9.0 & 3.4 \\
\hline Percent. Indifferent & 29.7 & 34.8 & 53.0 & 66.1 \\
\hline \multicolumn{5}{|l|}{ Bicycling } \\
\hline Percent. Liking & 31.9 & 46.0 & 26.0 & 22.0 \\
\hline Percent. Disliking & 12.1 & 10.6 & 8.0 & 8.5 \\
\hline Percent. Indifferent & 56.0 & 43.4 & 66.0 & 69.5 \\
\hline \multicolumn{5}{|l|}{ Boating } \\
\hline Percent. Liking & 57.0 & 54.7 & 42.0 & 32.2 \\
\hline Percent. Disliking & 6.7 & 11.8 & 6.0 & 8.5 \\
\hline Percent. Indifferent & 36.3 & 33.5 & 52.0 & 59.3 \\
\hline \multicolumn{5}{|l|}{ Bowling } \\
\hline Percent. Iiking & 67.0 & 78.9 & 68.0 & 57.6 \\
\hline Percent. Disliking & 8.8 & 11.2 & 12.0 & 0.0 \\
\hline Percent. Indifferent & 24.2 & 9.9 & 20.0 & 42.4 \\
\hline \multicolumn{5}{|l|}{ Boxing } \\
\hline Percent. Liking & 31.9 & 25.5 & 28.0 & 35.5 \\
\hline Percent. Disliking & 24.2 & 30.4 & 20.0 & $\begin{array}{r}6.8 \\
57.7\end{array}$ \\
\hline & 4207 & 44.1 & $3<.0$ & \\
\hline
\end{tabular}


TABIE 23 (Continued)

Relative Popularity of Recreational Activities by Age Groups

\begin{tabular}{|c|c|c|c|c|}
\hline Age Group & $20-29$ & $30-39$ & $40-49$ & $50-59$ \\
\hline $\begin{array}{l}\text { Calisthenics } \\
\text { Percent. Liking } \\
\text { Percent. Disliking } \\
\text { Percent. Indifferent }\end{array}$ & $\begin{array}{l}31.9 \\
25.3 \\
42.9\end{array}$ & $\begin{array}{l}28.6 \\
28.0 \\
43.4\end{array}$ & $\begin{array}{l}20.0 \\
17.0 \\
63.0\end{array}$ & $\begin{array}{l}16.9 \\
15.3 \\
67.8\end{array}$ \\
\hline $\begin{array}{l}\text { Canoeing } \\
\text { Percent. Liking } \\
\text { Percent. Disliking } \\
\text { Percent. Indifferent }\end{array}$ & $\begin{array}{r}46.2 \\
7.7 \\
46.2\end{array}$ & $\begin{array}{l}42.3 \\
11.9 \\
42.8\end{array}$ & $\begin{array}{l}19.0 \\
18.0 \\
63.0\end{array}$ & $\begin{array}{l}15.3 \\
16.9 \\
67.8\end{array}$ \\
\hline $\begin{array}{l}\text { Card Playing } \\
\text { Percent. Iiking } \\
\text { Percent. Disliking } \\
\text { Percent. Indifferent }\end{array}$ & $\begin{array}{r}79.1 \\
11.0 \\
9.9\end{array}$ & $\begin{array}{l}70.2 \\
16.1 \\
13.7\end{array}$ & $\begin{array}{r}85.0 \\
7.0 \\
8.0\end{array}$ & $\begin{array}{r}88.1 \\
1.7 \\
10.2\end{array}$ \\
\hline $\begin{array}{l}\text { Checkers } \\
\text { Percent. Liking } \\
\text { Percent. Disliking } \\
\text { Percent. Indifferent }\end{array}$ & $\begin{array}{l}35.1 \\
19.9 \\
45.0\end{array}$ & $\begin{array}{l}41.0 \\
16.2 \\
42.8\end{array}$ & $\begin{array}{l}38.0 \\
13.0 \\
49.0\end{array}$ & $\begin{array}{r}4.4 .1 \\
8.5 \\
47.5\end{array}$ \\
\hline $\begin{array}{l}\text { Conversing } \\
\text { Percent. Liking } \\
\text { Percent. Disliking } \\
\text { Percent. Indifferent }\end{array}$ & $\begin{array}{r}65.8 \\
7.7 \\
26.5\end{array}$ & $\begin{array}{l}55.9 \\
11.8 \\
32.3\end{array}$ & $\begin{array}{r}50.0 \\
8.0 \\
42.0\end{array}$ & $\begin{array}{r}52.5 \\
3.4 \\
44.1\end{array}$ \\
\hline $\begin{array}{l}\text { Chess } \\
\text { Percent. Liking } \\
\text { Percent. Disliking } \\
\text { Percent. Indifferent }\end{array}$ & $\begin{array}{l}28.5 \\
25.3 \\
46.2\end{array}$ & $\begin{array}{l}20.5 \\
29.8 \\
49.7\end{array}$ & $\begin{array}{r}9.0 \\
26.0 \\
65.0\end{array}$ & $\begin{array}{l}10.2 \\
22.0 \\
67.8\end{array}$ \\
\hline $\begin{array}{l}\text { Deck Tennis } \\
\text { Percent. Iiking } \\
\text { Percent. Disliking } \\
\text { Percent. Indifferent }\end{array}$ & $\begin{array}{l}17.0 \\
27.5 \\
61.5\end{array}$ & $\begin{array}{r}8.1 \\
31.0 \\
60.9\end{array}$ & $\begin{array}{r}3.0 \\
25.0 \\
72.0\end{array}$ & $\begin{array}{r}1.7 \\
15.3 \\
83.0\end{array}$ \\
\hline $\begin{array}{l}\text { Dating } \\
\text { Percent Liking } \\
\text { Percent Disliking } \\
\text { Percent Indifferent }\end{array}$ & $\begin{array}{r}52.7 \\
3.3 \\
43.9\end{array}$ & $\begin{array}{l}37.9 \\
11.2 \\
50.9\end{array}$ & $\begin{array}{l}15.0 \\
10.0 \\
75.0\end{array}$ & $\begin{array}{r}18.6 \\
5.1 \\
76.3\end{array}$ \\
\hline $\begin{array}{l}\text { Fencing } \\
\text { Percent. Liking } \\
\text { Percent. Disliking } \\
\text { Percent. Indifferent }\end{array}$ & $\begin{array}{l}\frac{11}{27.3} \\
58.5 \\
58.2\end{array}$ & $\begin{array}{l}17.8 \\
33.5 \\
54.7\end{array}$ & $\begin{array}{r}3.0 \\
25.0 \\
72.0\end{array}$ & $\begin{array}{r}6.8 \\
13.6 \\
79.6\end{array}$ \\
\hline
\end{tabular}


TABLE 23 (Continued)

Relative Popularity of Recreational Activities by Age Groups.

Age Croup

Track and Field

Percent. Liking

Percent. Disliking

Percent. Indifferent

Bait Casting

Percent. Liking

Percent. Disliking

Percent. Indifferent

Still Fishing

Percent. Iiking

Percent. Disliking

Percent. Indifferent

Football

Percent. Liking

Percent, Disliking

Percent. Indifferent

Gardening

Percent. Liking

Percent. Disliking

Percent. Indifferent

Golf

Percent. Liking

Percent. Disliking

Percent. Indifferent

Gymnastics

Percent. Liking

Percent. Disliking

Percent. Indifferent

Handball

Percent. Liking

Percent. Disliking

Percent. Indifferent

Hiking

Percent. Liking

Percent. Disliking

Percent. Indifferent
$20-29$

$30-39$

$40-49$

$50-59$

$\begin{array}{llll}27.5 & 23.0 & 22.0 & 37.3 \\ 20.7 & 20.5 & 12.0 & 1.7 \\ 51.8 & 56.6 & 66.0 & 61.0\end{array}$

42.9

26.5

50.8

30.8

19.9

29.3

47.0

9.0

39.0

44.0

6.8

54.2

$\begin{array}{rrrr}55.0 & 58.4 & 65.0 & 52.5 \\ 21.9 & 16.1 & 6.0 & 8.5 \\ 23.1 & 25.5 & 29.0 & 39.0\end{array}$

73.6
5.6

$60.9 \quad 48.0$

47.4

$10.0 \quad 5.1$

$\begin{array}{llll}20.9 & 30.4 & 42.0 & 47.4\end{array}$

42.9

19.1

74.5

6.2

61.0

12.0

67.8

38.0

19.3

27.0

3.4

28.8

51.8

50.3

13.7

36.0

34.0

16.0

22.0

16.5

50.0

11.9

66.1

40.6

21.1

21.1

57.8

20.0

13.6

16.5

42.9

16.0

13.6

64.0

72.8

37.0

28.6

17.4

23.0

15.3

19.1

54.0

17.0

11.9

43.9

60.0

72.8

41.7

16.5

34.8

16.8

24.0

32.2

$41.8 \quad 48.4$

13.0

10.2

57.6 
TABLE 23 (Continued)

Relative Popularity of Recreational Activities by Age Groups

Age Group

Hor seback Riding

Percent. Liking

Percent. Disliking

Percent. Indifferent

Horseshoes

Percent. Liking

Percent. Disliking

Percent. Indifferent

Hunting

Percent, Liking

Percent. Disliking

Percent. Indifferent

Ice Hockey

Percent. Liking

Percent. Disliking

Percent. Indifferent

Ice Skating

Percent. Liking

Percent. Disliking

Percent. Indifferent

Lusic

Percent. Iiking

Percent. Disliking

Percent. Indifferent

Metal Craft

Percent. Liking

Percent. Disliking

Percent. Indifferent

Ríovies

Percent. Liking

Percent. Disliking

Percent. Indifferent

Motoring

Percent. Liking

Percent. Disliking

Percent. Indifferent
$20-29$

$30-39$

67.0

12.1

20.9

38.5

11. 2

50.3

$40-49$

$50-59$

63.

6.7

29.7

63.4

3.7

32.9

36.0

14.0

50.0

39.0

8.5

52.5

72.5

11.0

16.5

55.3

17.4

27.3

53.0

8.0

39.0

52.5

5.1

42.4

46.

12.1

41.7

32.9

$\mathrm{IH}_{4} .3$

52.8

65.0

59.3

3.0

32.0

10.2

30.5

61.5

9.9

28.6

46.6

13.0

40.4

22.0

16.0

28.8

62.0

10.2

61.0

61.5

2.2

36.3

63.4

2.5

34.1

30.0

15.0

28.8

55.0

10.2

61.0

36.3

13.2

50.5

34.2

14.9

50.9

63.0

35.6

1.0

5.1

36.0

59.3

84.6

1.1

77.0

79.7

73.0

4.0

18.0

12.0

16.9

70.0

11.9

71.2

14.3

19.3

23.0

64.4

1.7

33.9

70.3

3.3

65.8

5.0

29.2

58.0

4.0

38.0
62.7

1.7

35.6 
TABLE 23 (Continued)

Relative Popularity of Recreational Activities by Age Groups

Age Group

Night Clubbing

Percent. Liking

Percent. Disliking

Percent. Indifferent

Table Tennis

Percent. Iiking

Percent. Disliking

Percent. Indifferent

Puttering and Repairing

Percent. Liking

Percent. Disliking

Percent. Indifferent

Iistening to the Radio

Percent. Liking

Percent. Disliking

Percent. Indifferent

Watching TV

Percent. Liking

Percent. Disliking

Percent. Indifferent

Reading

Percent. Iiking

Percent. Disliking

Percent. Indifferent

Photography

Percent. Liking

Percent. Disliking

Percent. Indifferent

Roller Skating

Percent. Liking

Percent. Disliking

Percent. Indifferent

Painting

Percent. Liking

Percent. Disliking

Percent. Indifferent
$20-29$

$30-39$

$40-49$

50.5

8.8

40.7

34.7

20.5

45.4

21.0

20.0

59.0

20.3

18.6

61.0

63.6

9.9

44.7

24.0

21.0

8.5

26.5

47.2

55.0

10.2

81.3

67.0

9.9

67.7

65.0

59.3

23.1

8.1

8.0

8.5

32.2

$\begin{array}{rrrr}78.0 & 67.7 & 75.0 & 79.6 \\ 1.1 & 3.7 & 2.0 & 1.7 \\ 20.9 & 28.6 & 23.0 & 18.6\end{array}$

83.5

83.2

86.0

1.0

15.4

2.5

14. 3

13.0

88.1

3.4

8.5

71.

7.7

20.9

78.9

82.0

72.8

4.3

16.8

2.0

16.0

3.4

23.8

53.8

8.8

41.0

9.9

28.0

35.6

37.4

49.1

10.0

5.1

62.0

59.3

43.9

12.1

32.9

13.7

25.0

$\mathrm{IH}_{1} \mathrm{O}$

13.6

$4+.0$

53.4

61.0

13.6

72.8
33.0

22.0

45.0
23.0

23.0

54.0
23.0

15.0

62.0
15.3

1.7

83.0 
TABLE 23 (Continued)

Relative Popularity of Recreational Activities by Age Groups

\begin{tabular}{|c|c|c|c|c|}
\hline Age Group & $20-29$ & $30-39$ & $40-49$ & $50-59$ \\
\hline $\begin{array}{l}\text { Social Drinking } \\
\text { Percent. Liking } \\
\text { Percent. Disliking } \\
\text { Percent. Indifferent }\end{array}$ & $\begin{array}{r}64.8 \\
7.7 \\
27.5\end{array}$ & $\begin{array}{l}52.2 \\
16.1 \\
31.7\end{array}$ & $\begin{array}{l}41.0 \\
15.0 \\
44.0\end{array}$ & $\begin{array}{l}39.0 \\
11.9 \\
49.1\end{array}$ \\
\hline $\begin{array}{l}\text { Sailing } \\
\text { Percent. Iiking } \\
\text { Percent. Disliking } \\
\text { Percent. Indifferent }\end{array}$ & $\begin{array}{l}31.9 \\
12.1 \\
56.0\end{array}$ & $\begin{array}{l}23.0 \\
20.5 \\
56.6\end{array}$ & $\begin{array}{l}15.0 \\
15.0 \\
70.0\end{array}$ & $\begin{array}{r}13.6 \\
5.1 \\
81.3\end{array}$ \\
\hline $\begin{array}{l}\text { Skiing } \\
\text { Percent. Iiking } \\
\text { Percent. Disliking } \\
\text { Percent. Indifferent }\end{array}$ & $\begin{array}{l}35.2 \\
17.6 \\
47.2\end{array}$ & $\begin{array}{l}21.1 \\
23.6 \\
55.3\end{array}$ & $\begin{array}{r}9.0 \\
24.0 \\
67.0\end{array}$ & $\begin{array}{r}8.5 \\
1.7 \\
89.8\end{array}$ \\
\hline $\begin{array}{l}\text { Social Dancing } \\
\text { Percent. Liking } \\
\text { Percent. Disliking } \\
\text { Percent. Indifferent }\end{array}$ & $\begin{array}{l}70.3 \\
13.2 \\
16.5\end{array}$ & $\begin{array}{l}55.3 \\
13.7 \\
31.0\end{array}$ & $\begin{array}{l}47.0 \\
17.0 \\
36.0\end{array}$ & $\begin{array}{r}27.1 \\
6.8 \\
66.1\end{array}$ \\
\hline $\begin{array}{l}\text { Softball } \\
\text { Percent. Liking } \\
\text { Percent. Disliking } \\
\text { Percent. Indifferent }\end{array}$ & $\begin{array}{r}70.3 \\
6.6 \\
23.1\end{array}$ & $\begin{array}{r}72.7 \\
8.1 \\
19.2\end{array}$ & $\begin{array}{l}41.0 \\
12.0 \\
47.0\end{array}$ & $\begin{array}{r}28.8 \\
3.4 \\
67.8\end{array}$ \\
\hline $\begin{array}{l}\text { SpeedbalI } \\
\text { Percent. Liking } \\
\text { Percent. Disliking } \\
\text { Percent. Indifferent }\end{array}$ & $\begin{array}{l}17.6 \\
\frac{11}{68.3} \\
68.1\end{array}$ & $\begin{array}{l}16.8 \\
17.1_{4} \\
65.8\end{array}$ & $\begin{array}{r}7.0 \\
17.0 \\
76.0\end{array}$ & $\begin{array}{r}17.9 \\
5.1 \\
83.0\end{array}$ \\
\hline $\begin{array}{l}\text { Square Dancing } \\
\text { Percent. Liking } \\
\text { Percent. Disliking } \\
\text { Percent. Indifferent }\end{array}$ & $\begin{array}{l}26.5 \\
23.1 \\
50.4\end{array}$ & $\begin{array}{l}21.7 \\
25.5 \\
52.8\end{array}$ & $\begin{array}{l}26.0 \\
17.0 \\
57.0\end{array}$ & $\begin{array}{l}18.6 \\
13.6 \\
67.8\end{array}$ \\
\hline $\begin{array}{l}\text { Stamp Collecting } \\
\text { Percent. Iiking } \\
\text { Percent. Disliking } \\
\text { Percent. Indifferent }\end{array}$ & $\begin{array}{r}3.3 \\
42.9 \\
53.8\end{array}$ & $\begin{array}{r}5.6 \\
36.6 \\
57.8\end{array}$ & $\begin{array}{l}10.0 \\
25.0 \\
65.0\end{array}$ & $\begin{array}{r}5.1 \\
15.3 \\
79.6\end{array}$ \\
\hline $\begin{array}{l}\text { Swimming } \\
\text { Percent. Liking } \\
\text { Percent. Disliking } \\
\text { Percent. Indifferent }\end{array}$ & $\begin{array}{r}87.9 \\
2.2 \\
9.9\end{array}$ & $\begin{array}{r}82.6 \\
4.4 \\
13.0\end{array}$ & $\begin{array}{r}67.0 \\
3.0 \\
30.0\end{array}$ & $\begin{array}{r}40.7 \\
3.4 \\
55.9\end{array}$ \\
\hline
\end{tabular}


TABLE 23 (Continued)

Relative Popularity of Recreational Activities by Age Groups

Age Group

Temis

Percent. Liking

Percent. Disliking

Percent. Indifferent

Touch Football

Percent. Liking

Percent. Disliking

Percent. Indifferent

Tumbling

Percent. Liking

Percent. Disliking

Percent. Indifferent

Visiting Friends

Percent. Liking

Percent. Disliking

Percent. Indifferent

Volleyball

Percent. Liking

Percent. Indifferent

Watching Sports Events

Percent. Liking
Percent. Disliking
Percent. Indifferent

Walking

Percent. Liking

Percent. Disliking

Percent. Indifferent

Weight lifting

Percent. Liking

Percent. Disliking

Percent. Indifferent

Water Polo

Percent. Iiking

Percent. Disliking

Percent. Indifferent
$20-29$

$30-39$

$40-49$

31.7

19.3

48.4

16.0

14.0

70.0

11.9

6.8

81.3

52.7

11.0

36.3

24.8

17.4

57.8

11.0

20.0

69.0

8.5

10.2

81.3

19.9

29.7

50.4

11.8

26.1

62.1

7.0

25.0

68.0

10.2

10.2

79.6

78.0

1.1

20.9

70.8

8.7

20.5

82.0

4.0

11.0

69.5

1.7

28.8

49.5

12.5

38.0

39.1

16.2

44.7

21.0

12.0

67.0

6.8

6.8

86.4

91.2

1.1

7.7

89.4

6.2

87.0

3.0

10.0

81.3

$1 . ?$

17.0

56.0

16.5

27.5

52.8

15.5

31.7

46.0

10.0

44.0

44.1

0.0

55.9

27.5

25.3

47.2

13.7

33.5

52.8

4.0

31.0

65.0

5.1

15.3

79.6

20.0

21.3

57.0

10.0

25.4

64.6

4.0

6.8

28.0

68.0

10.2

83.0 


\section{TABLE 23 (Continued)}

Relative Popularity of Recreational Activities by Age Groups

\begin{tabular}{lllll} 
Age Group & $20-29$ & $30-39$ & $40-49$ & $50-59$ \\
\hline Wood Working & & & & \\
\hline Fercent. Iiking & 48.4 & 52.2 & 38.0 & 39.0 \\
Percent. Disliking & 13.2 & 9.3 & 13.0 & 5.1 \\
Percent. Indifferent & 38.4 & 38.5 & 49.0 & 55.9 \\
& & & & \\
Wood Carving & 28.5 & 21.7 & 12.0 & 13.6 \\
\hline Percent. Iiking & 16.5 & 15.0 & 19.0 & 8.5 \\
Percent. Disliking & 55.0 & 63.3 & 69.0 & 77.9 \\
Percent. Indifferent & & & & \\
Wrestling & & & & \\
Percent. Iiking & 27.5 & 26.7 & 21.0 & 37.3 \\
Percent. Disliking & 27.5 & 28.0 & 23.0 & 10.2 \\
Percent. Indifferent & 45.0 & 45.3 & 56.0 & 52.5
\end{tabular}


TABIE 24

Relative Popularity of Recreational Activities by Income Groups

\begin{tabular}{|c|c|c|c|c|c|c|}
\hline Inc ome & $0-\$ 2,000$ & $\begin{array}{l}\$ 2,000- \\
\$ 2,000 \\
\$ 3\end{array}$ & $\begin{array}{l}\$ 3,000- \\
\$ 4,000 \\
\end{array}$ & $\begin{array}{l}44,000- \\
\$ 5,000\end{array}$ & $\begin{array}{l}\$ 5,000- \\
\$ 7,000\end{array}$ & $\begin{array}{l}\text { Over } \\
\$ 7,000\end{array}$ \\
\hline \multicolumn{7}{|l|}{ Archery } \\
\hline Percentage Iiking & 16.7 & 30.0 & 21.0 & 18.1 & 13.6 & 22.2 \\
\hline Percentage Disliking & 25.0 & 20.0 & 18.1 & 12.8 & 9.1 & 0.0 \\
\hline Percentage Indifferent & 58.3 & 50.0 & 60.9 & 69.2 & 77.3 & 77.7 \\
\hline \multicolumn{7}{|l|}{ Badninton } \\
\hline Percentage Iiking & 58.3 & 36.0 & 37.4 & 29.8 & 45.5 & 11.1 \\
\hline Percentage Disliking & 8.3 & 24.0 & 11.4 & 16.0 & 9.1 & 22.1 \\
\hline Percentage Indifferent & 33.3 & 40.0 & 51.2 & $54 \cdot 3$ & 45.5 & 66.6 \\
\hline \multicolumn{7}{|l|}{ Bag Punching } \\
\hline Percentage Iiking & 25.0 & 206.0 & 15.4 & 19.1 & 18.2 & 0.0 \\
\hline Percentage Disliking & 25.0 & 30.0 & 21.3 & 21.3 & 36.4 & 44.4 \\
\hline Percentage Indifferent & 50.0 & 44.0 & 63.3 & 59.6 & 45.5 & 55.5 \\
\hline \multicolumn{7}{|l|}{ Basebal1 } \\
\hline Percentäge Iiking & 91.7 & 80.0 & 88.5 & 83.0 & 72.7 & 55.5 \\
\hline Percentage Disliking & 0.0 & 4.0 & 1.1 & 1.1 & 0.0 & 11.1 \\
\hline Percentage Indifferent & 8.3 & 26.0 & 10.4 & 16.0 & 27.3 & 33.3 \\
\hline \multicolumn{7}{|l|}{ BasketbalI } \\
\hline Percentage Liking & 66.7 & 62.0 & 45.1 & 35.1 & 31.8 & 22.2 \\
\hline Percentage Disliking & 0.0 & 6.0 & 11.0 & 13.8 & 13.6 & 11.1 \\
\hline Percentage Indifferent & 33.3 & 32.0 & 43.9 & 51.1 & $5 \longdiv { 4 \cdot 5 }$ & 66.6 \\
\hline
\end{tabular}


TABIE 24 (Continued)

Relative Popularity of Recreational Activities by Income Groups

\begin{tabular}{|c|c|c|c|c|c|c|}
\hline Income & $0-$ 需2,000 & 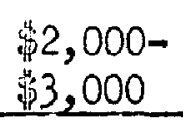 & $\begin{array}{l}\$ 3,000- \\
\$ 4,000 \\
\end{array}$ & $\begin{array}{l}\$ 4,000- \\
\$ 5,000 \\
\end{array}$ & $\begin{array}{l}\$ 5,000- \\
37,000 \\
\end{array}$ & $\begin{array}{l}\text { Over } \\
\$ 7,000\end{array}$ \\
\hline \multicolumn{7}{|l|}{ Bicycling } \\
\hline Percentage Iiking & 33.3 & 38.0 & 30.3 & 30.9 & 22.7 & 44.4 \\
\hline Percentage Disliking & 16.7 & 12.0 & $9 \cdot 3$ & 10.6 & 9.1 & 11.1 \\
\hline Percentage Indifferent & 50.0 & 50.0 & 60.4 & 58.5 & 68.2 & 44.4 \\
\hline \multicolumn{7}{|l|}{ Boating } \\
\hline Percentage Liking & 41.7 & 54.0 & 46.2 & 47.9 & 59.1 & 22.2 \\
\hline Percentage Disliking & 8.3 & 10.0 & 7.1 & 9.6 & $4 \cdot 5$ & 11.1 \\
\hline Percentage Indifferent & 50.0 & 36.0 & 46.7 & 42.6 & 36.4 & 66.6 \\
\hline \multicolumn{7}{|l|}{ Bowling } \\
\hline Percentage Iiking & 33.3 & 72.0 & 68.7 & 75.5 & 63.6 & 33.3 \\
\hline Percentage Disliking & 16.7 & 10.0 & 8.8 & 9.6 & $4 \cdot 5$ & 22.2 \\
\hline Percentage Indifferent & 50.0 & 18.0 & 22.5 & $14 \cdot 9$ & 31.8 & 44.4 \\
\hline \multicolumn{7}{|l|}{ Boxing } \\
\hline Percentage Liking & 16.7 & 38.0 & $24 \cdot 8$ & 37.2 & 40.9 & 11.1 \\
\hline Percentage Disliking & 25.0 & $24 \cdot 0$ & 20.8 & 13.8 & 22.7 & 55.5 \\
\hline Percentage Indifferent & 58.3 & 38.0 & $54 \cdot 4$ & 48.9 & 36.4 & 33.3 \\
\hline \multicolumn{7}{|l|}{ Calistnenics } \\
\hline Percentage Iiking & 41.7 & 28.0 & 22.5 & 22.3 & 18.2 & 11.1 \\
\hline Percentage Disliking & 16.7 & 24.0 & 22.5 & 13.8 & 36.4 & 44.4 \\
\hline Percentage Indifferent & 41.7 & 48.0 & 55.0 & 63.8 & 45.4 & \\
\hline
\end{tabular}


TABIE 24 (Continued)

Relatjve Popularity of Recreational Activities by Income Groups

\begin{tabular}{|c|c|c|c|c|c|c|c|}
\hline \multicolumn{2}{|l|}{ Inc ome } & $0-\$ 2,000$ & $\begin{array}{l}\$ 2,000- \\
\$ 3,000\end{array}$ & $\begin{array}{l}\$ 3,000- \\
\$ 4,000 \\
\end{array}$ & $\begin{array}{l}\$ 4,000- \\
\$ 5,000\end{array}$ & $\begin{array}{l}\$ 5,000- \\
\$ 7,000 \\
\end{array}$ & $\begin{array}{l}\text { Over } \\
\$ 7,000\end{array}$ \\
\hline \multicolumn{8}{|c|}{ Canoeing } \\
\hline Percentage & Iiking & 25.0 & 38.0 & 30.3 & 29.8 & 40.9 & 33.3 \\
\hline Percentage & Disliking & 0.0 & 22.0 & 14.7 & 13.8 & 13.6 & 22.2 \\
\hline Percentage & Indifferent & 75.0 & 40.0 & 55.0 & 56.4 & 45.5 & $44 \cdot 4$ \\
\hline \multicolumn{8}{|c|}{ Card Playing } \\
\hline Percentage & Liking & 66.6 & 70.0 & 75.8 & 75.5 & 77.3 & 77.7 \\
\hline Percentage & Disliking & 8.3 & 12.0 & 6.6 & 13.8 & $4 \cdot 5$ & 0.0 \\
\hline Percentage & Indifferent & 25.0 & 18.0 & 17.6 & 10.6 & 18.2 & 22.2 \\
\hline \multicolumn{8}{|c|}{ Checkers } \\
\hline Percentage & liking & 33.3 & 40.0 & 38.5 & 33.0 & 31.8 & 22.2 \\
\hline Percentage & Disliking & 8.3 & 22.0 & 11.5 & 27.0 & $27 \cdot 3$ & $44 \cdot 4$ \\
\hline Percentage & Indifferent & 58.3 & 38.0 & 50.0 & 50.0 & 40.9 & 33.3 \\
\hline \multicolumn{8}{|c|}{ Conversing } \\
\hline Percentage & Liking & 75.0 & 48.0 & 50.0 & 56.4 & 59.1 & 66.6 \\
\hline Percentage & Disliking & 0.0 & 18.0 & 6.6 & 3.2 & 13.6 & 0.0 \\
\hline Percentage & Indifferent & 25.0 & $34 \cdot 0$ & 43.4 & 40.4 & $27 \cdot 3$ & 33.3 \\
\hline \multicolumn{8}{|c|}{ Chess } \\
\hline Percentage & Iiking & 16.7 & 16.0 & 18.1 & 12.8 & 31.8 & 22.2 \\
\hline Percentage & Disliking & 8.3 & 40.0 & $25 \cdot 3$ & 25.5 & 31.8 & 22.2 \\
\hline Percentage & Indifferent & 75.0 & 44.0 & 56.6 & 61.7 & 36.4 & 55.5 \\
\hline
\end{tabular}


TABLE 24 (Continued)

Relative Popularity of Recreational Activities By Income Groups

\begin{tabular}{|c|c|c|c|c|c|c|}
\hline Income & 0 - 2,000 & $\begin{array}{l}\$ 2,000- \\
\$ 3,000\end{array}$ & $\begin{array}{l}\$ 3,000- \\
\$ 4,000\end{array}$ & $\begin{array}{l}4,000- \\
\$ 5,000 \\
\$ \$ \$ 5\end{array}$ & $\begin{array}{l}\$ 5,000- \\
\$ 7,000 \\
\$ 7\end{array}$ & $\begin{array}{l}\text { Over } \\
\$ 7,000 \\
\$ 71,00\end{array}$ \\
\hline \multicolumn{7}{|l|}{ Deck Tennis } \\
\hline Percentage Iiking & 8.3 & 6.0 & $5 \cdot 5$ & 3.2 & 4.5 & 0.0 \\
\hline Percentage Disliking & 16.7 & 32.0 & 28.0 & 18.1 & 31.8 & 22.2 \\
\hline Percentage Indifferent & 75.0 & 62.0 & 66.5 & 78.7 & 63.6 & 77.7 \\
\hline \multicolumn{7}{|l|}{ Dating } \\
\hline Percentage Iiking & 58.3 & 46.0 & 35.7 & 31.9 & $27 \cdot 3$ & 33.3 \\
\hline Percentage Disliking & 0.0 & 8.0 & 7.7 & 8.5 & 9.1 & 0.0 \\
\hline Percentage Indifferent & 41.7 & 46.0 & 56.6 & 59.6 & 63.6 & 66.6 \\
\hline \multicolumn{7}{|l|}{ Driving } \\
\hline Percentage Liking & 83.3 & 84.0 & 70.8 & 72.4 & $77 \cdot 3$ & 22.2 \\
\hline Percentage Disliking & 0.0 & 6.0 & 3.3 & 7.4 & 13.6 & 22.2 \\
\hline Percentage Indifferent & 16.7 & 10.0 & 25.9 & 20.2 & 9.1 & 55.5 \\
\hline \multicolumn{7}{|l|}{ Fencing } \\
\hline Percentage Iiking & 16.7 & 8.0 & 8.8 & 9.6 & 4.5 & 0.0 \\
\hline Percentage Disliking & 16.7 & 40.0 & 28.5 & 20.2 & 31.8 & 33.3 \\
\hline Percentage Indifferent & 66.6 & 52.0 & 62.7 & 70.3 & 63.6 & 66.6 \\
\hline \multicolumn{7}{|l|}{ Track and Field } \\
\hline Percentage Iiking & 25.0 & $24 \cdot 0$ & 27.5 & 23.4 & 18.2 & 11.1 \\
\hline Percentage Disliking & 25.0 & 26.0 & 13.2 & 0.0 & 22.7 & 33.3 \\
\hline Percentage Indifferent & 50.0 & 50.0 & 59.3 & 76.6 & 59.1 & 55.5 \\
\hline
\end{tabular}


TABLE 24 (Continued)

Relative Popularity of Recreational Activities by Income Groups

\begin{tabular}{|c|c|c|c|c|c|c|}
\hline Inc ome & $0-\$ 2,000$ & $\begin{array}{l}\$ 2,000- \\
\$ 13,000 \\
\end{array}$ & $\begin{array}{l}\$ 3,000- \\
\$ 4,000\end{array}$ & $\begin{array}{l}\$ 4,000- \\
\$ 5,000 \\
\$ 5\end{array}$ & $\begin{array}{l}\$ 5,000- \\
\$ 7,000\end{array}$ & $\begin{array}{l}\text { Over } \\
\$ 7,000\end{array}$ \\
\hline \multicolumn{7}{|l|}{ Bait Casting } \\
\hline Percentage Iiking & 58.3 & 36.0 & 49.0 & 43.6 & 50.0 & 33.3 \\
\hline Percentage Disliking & 16.7 & 32.0 & 14.2 & 10.6 & 18.2 & 22.2 \\
\hline Percentage Indifferent & 25.0 & 32.0 & 36.8 & 45.8 & 31.8 & $44 \cdot 4$ \\
\hline \multicolumn{7}{|l|}{ Still Fishing } \\
\hline Percentage Liking & 75.0 & 48.0 & 62.2 & 56.4 & 68.2 & 55.5 \\
\hline Percentage Disliking & 16.7 & 20.0 & 11.9 & $7 \cdot 4$ & 9.1 & 22.2 \\
\hline Percentage Indifferent & 8.3 & 32.0 & 25.9 & 36.2 & 22.7 & 22.2 \\
\hline \multicolumn{7}{|l|}{ Football } \\
\hline Percentage Iiking & 75.0 & 60.0 & 60.9 & 53.2 & 59.1 & $44 \cdot 4$ \\
\hline Percentage Disliking & 0.0 & 12.0 & $4 \cdot 4$ & 8.5 & $4 \cdot 5$ & 22.2 \\
\hline Percentage Indifferent & 25.0 & 28.0 & 34.7 & 38.3 & 36.4 & 33.3 \\
\hline \multicolumn{7}{|l|}{ Gardening } \\
\hline Percentage Iiking & 58.3 & 40.0 & 59.3 & 60.6 & 54.5 & 77.7 \\
\hline Percentage Disliking & 8.3 & 22.0 & 11.0 & 10.6 & 0.0 & 11.1 \\
\hline Percentage Indifferent & 33.3 & 38.0 & 29.7 & 28.7 & $44 \cdot 5$ & 11.1 \\
\hline \multicolumn{7}{|l|}{ Golf } \\
\hline Percentage Liking & $33 \cdot 3$ & 30.0 & 39.6 & 45.7 & 40.9 & 55.5 \\
\hline Percentage Disliking & 0.0 & 24.0 & 14.2 & 14.9 & 22.7 & 22.2 \\
\hline Percentage Indifferent & 66.6 & 46.0 & 46.2 & 39.4 & 36.4 & 22.2 \\
\hline
\end{tabular}


TABLE 24 (Continued)

Relative Popularity of Recreational Activities by Income Groups

\begin{tabular}{|c|c|c|c|c|c|c|}
\hline Inc one & $0-62,000$ & $\begin{array}{l}\$ 2,000- \\
\$ 3,000 \\
\$ 3\end{array}$ & $\begin{array}{l}\$ 3,000- \\
\$ 4,000 \\
\$ 4\end{array}$ & $\begin{array}{l}\$ 4,000- \\
\$ 5,000\end{array}$ & $\begin{array}{l}\$ 5,000- \\
\$ 7,000 \\
\end{array}$ & $\begin{array}{l}\text { Over } \\
\$ 7,000\end{array}$ \\
\hline \multicolumn{7}{|l|}{ Gymnastics } \\
\hline Fercentage Iiking & 33.3 & 26.0 & 28.5 & 16.0 & 9.1 & 11.1 \\
\hline Percentage Disliking & 25.0 & 20.0 & 16.1 & 17.0 & 40.9 & 33.3 \\
\hline Percentage Indifferent & 41.7 & 54.0 & 55.4 & 67.0 & 50.0 & 55.5 \\
\hline \multicolumn{7}{|l|}{ HandbalI } \\
\hline Percentage Iiking & 16.7 & 26.0 & 26.4 & 21.3 & 27.3 & 11.1 \\
\hline Percentage Disliking & 16.7 & 24.0 & 15.4 & 16.0 & 22.7 & 22.2 \\
\hline Percentage Indifferent & 66.6 & 50.0 & 58.2 & 62.8 & 50.0 & 66.6 \\
\hline \multicolumn{7}{|l|}{ Hiking } \\
\hline Percentage Liking & 50.0 & 32.0 & 33.5 & 23.4 & 40.9 & 22.2 \\
\hline Percentage Disllking & 8.3 & 24.0 & 15.4 & 10.6 & 22.7 & 23.3 \\
\hline Fercentage Indifferent & 41.7 & 44.0 & 51.1 & 66.0 & 36.4 & 44.4 \\
\hline \multicolumn{7}{|l|}{ Horseback Riding } \\
\hline Percentage Liking & 58.3 & 52.0 & 41.2 & 37.2 & $1,0.9$ & 11.1 \\
\hline Percentage Disliking & 8.3 & 18.0 & 11.4 & 9.6 & 18.2 & 33.3 \\
\hline Percentage Indifferent & 33.3 & 30.0 & 47.4 & 53.2 & 40.9 & 55.5 \\
\hline \multicolumn{7}{|l|}{ Horseshoes } \\
\hline Percentage Liking & 33.3 & 46.0 & 61.5 & 50.5 & 40.9 & 55.5 \\
\hline Percentage Disliking & 8.3 & 10.0 & 15.0 & 9.6 & 9.1 & 11.1 \\
\hline Percentage Indifferent & 58.3 & 44.0 & 33.5 & 31.9 & 50.0 & 33.3 \\
\hline
\end{tabular}


TABIE 24 (Continued)

Relative Popularity of Recreational Activities by Income Groups

\begin{tabular}{|c|c|c|c|c|c|c|}
\hline Inc ome & $0-{ }^{2} 2,000$ & $\begin{array}{l}\$ 2,000- \\
\$ 3,000-\end{array}$ & $\begin{array}{l}\$ 3,000- \\
\$ 4,000 \\
44\end{array}$ & $\begin{array}{l}34,000- \\
\$ 45,000 \\
\$ 4\end{array}$ & $\begin{array}{l}\$ 5,000- \\
\$ 7,000 \\
\end{array}$ & $\begin{array}{l}\text { Over } \\
\$ 7,000\end{array}$ \\
\hline \multicolumn{7}{|l|}{ Hunting } \\
\hline Percentage Liking & 58.3 & 58.0 & 56.6 & 57.5 & $54 \cdot 5$ & 33.3 \\
\hline Eercentage Disliking & 16.7 & 10.0 & 12.6 & 13.8 & 13.6 & 22.2 \\
\hline Percentage Indifferent & 25.0 & 32.0 & 30.8 & 28.7 & 31.8 & 44.4 \\
\hline \multicolumn{7}{|l|}{ Ice Hockey } \\
\hline Percentage Liking & 16.7 & 38.0 & $34: 1$ & 20.2 & 36.4 & 22.2 \\
\hline Percentage Disliking & 16.7 & 18.0 & 13.2 & 14.9 & 9.1 & 11.1 \\
\hline Percentage Indifferent & 66.6 & 44.0 & 52.7 & 64.9 & 54.5 & 66.6 \\
\hline \multicolumn{7}{|l|}{ Ice Skating } \\
\hline Percentage Liking & 50.0 & 40.0 & $44 \cdot 5$ & 30.9 & 45.5 & 33.3 \\
\hline Percentage Disliking & 8.3 & 12.0 & 12.6 & 13.8 & 22.7 & 11.1 \\
\hline Percentage Indifferent & $41 . ?$ & 48.0 & 42.9 & 55.3 & 31.8 & 55.5 \\
\hline \multicolumn{7}{|l|}{ Metal Craft } \\
\hline Percentage Iiking & 25.0 & 18.0 & 25.9 & 23.4 & 18.2 & 11.1 \\
\hline Percentage Disliking & 16.7 & 18.0 & 13.7 & 10.6 & 13.6 & 22.2 \\
\hline Percentage Indifferent & 58.3 & 64.0 & 60.4 & 66.0 & 68.2 & 66.6 \\
\hline \multicolumn{7}{|l|}{ Ifovies } \\
\hline Percentage Iiking & 66.6 & 76.0 & 69.8 & 76.6 & 59.1 & 66.6 \\
\hline Percentage Disliking & 0.0 & 6.0 & $4 \cdot 9$ & 2.1 & $4 \cdot 5$ & 0.0 \\
\hline Percentage Indifferent & 33.3 & 18.0 & 25.3 & 21.3 & 36.4 & 33.3 \\
\hline
\end{tabular}


TABLE 24 (Continued)

Relative Popularity of Recreational Activities by Income Groups

\begin{tabular}{|c|c|c|c|c|c|c|}
\hline Inc ome & $0-\$ 2,000$ & $\begin{array}{l}\$ 2,000- \\
\$ 3,000 \\
\end{array}$ & $\begin{array}{l}\$ 3,000- \\
\$ 4,000 \\
\$ \$ 25\end{array}$ & $\begin{array}{l}\$ 4,000- \\
\$ 5,000 \\
\end{array}$ & $\begin{array}{l}\text { 缡, } 000- \\
\$ 7,000 \\
\$\end{array}$ & $\begin{array}{l}\text { Over } \\
\$ 7,000 \\
\end{array}$ \\
\hline \multicolumn{7}{|l|}{ Music } \\
\hline Percentage Liking & 66.6 & 72.0 & 55.4 & 62.8 & 50.0 & 44.4 \\
\hline Percentage Disliking & 0.0 & 2.0 & 2.2 & 3.2 & 4.5 & 11.1 \\
\hline Percentage Indifferent & 33.3 & 26.0 & 42.4 & 34.0 & 45.5 & 44.4 \\
\hline \multicolumn{7}{|l|}{ Motoring } \\
\hline Percentage Liking & 58.3 & 64.0 & 62.7 & 61.7 & 59.1 & $44 \cdot 4$ \\
\hline Percentage Disliking & 0.0 & 8.0 & 3.8 & 4.3 & 13.6 & 0.0 \\
\hline Percentage Indifferent & 41.7 & 28.0 & 33.5 & 34.0 & 27.3 & 55.5 \\
\hline \multicolumn{7}{|l|}{ Night Cluboing } \\
\hline Percentage Iiking & 41.7 & 48.0 & 30.3 & 33.0 & 22.7 & 22.2 \\
\hline Percentage Disliking & 8.3 & 8.0 & 15.4 & 13.8 & 18.2 & 55.5 \\
\hline Percentage Indifferent & 50.0 & 44.0 & 54.4 & 53.2 & 59.1 & 22.2 \\
\hline \multicolumn{7}{|l|}{ Ping-Pong } \\
\hline Percentage Liking & 50.0 & 32.0 & 41.8 & 35.1 & 54.5 & 44.4 \\
\hline Percentage Disliking & 0.0 & 18.0 & 9.8 & 16.0 & 18.2 & 22.2 \\
\hline Percentage Indifferent & 50.0 & 50.0 & 48.4 & 48.9 & $27 \cdot 3$ & 33.3 \\
\hline \multicolumn{7}{|l|}{ Puttering, Repairing, etc. } \\
\hline Percentage Iiking & $91 . ?$ & 54.0 & 67.6 & 66.0 & 68.2 & 44.4 \\
\hline Percentage Disliking & 0.0 & 8.0 & 11.4 & 4.3 & 4.5 & 22.2 \\
\hline Percentage Indifferent & 8.3 & 38.0 & 21.0 & 29.8 & 27.3 & 33.3 \\
\hline
\end{tabular}


TABIE 24 (Continued)

Relative Popularity of Recreational Activities by Income Groups

\begin{tabular}{|c|c|c|c|c|c|c|}
\hline Inc ome & $0-\$ 2,000$ & $\begin{array}{l}\$ 2,000 m \\
\$ 3,000 \\
\$ \$\end{array}$ & $\begin{array}{l}\$ 3,000- \\
\$ 4,000 \\
\end{array}$ & $\begin{array}{l}\$ 4,000- \\
\$ 5,000 \\
\$ 5\end{array}$ & $\begin{array}{l}\$ 5,000- \\
\$ 7,000 \\
\end{array}$ & $\begin{array}{l}\text { Over } \\
\$ 7,000\end{array}$ \\
\hline \multicolumn{7}{|l|}{ Listening to Radio } \\
\hline Percentage Liking & 83.3 & 78.0 & 69.8 & 74.5 & 54.4 & 44.4 \\
\hline Percentage Disliking & 0.0 & 2.0 & 2.2 & 0.0 & 4.5 & 22.2 \\
\hline Percentage Indifierent & 16.7 & 20.0 & 28.0 & 25.5 & 40.9 & 33.3 \\
\hline \multicolumn{7}{|l|}{ Watching TV } \\
\hline Percentage Liking & 75.0 & 88.0 & 87.3 & 85.1 & 72.7 & 66.6 \\
\hline Percentage Disliking & 8.3 & 2.0 & 1.7 & 3.2 & 0.0 & 11.1 \\
\hline Percentage Indifferent & 16.7 & 10.0 & 11.0 & 11.7 & 27.3 & 22.2 \\
\hline \multicolumn{7}{|l|}{ Reading } \\
\hline Percentage Liking & 91.7 & 60.0 & 77.4 & 75.5 & 90.9 & 66.6 \\
\hline Percentage Disliking & 8.3 & 10.0 & 2.7 & 4.3 & 4.5 & 22.2 \\
\hline Percentage Indifferent & 0.0 & 30.0 & 19.9 & 20.2 & 4.5 & 11.1 \\
\hline \multicolumn{7}{|l|}{ Photography } \\
\hline Percentage Liking & 33.3 & 46.0 & 39.0 & 29.8 & 40.9 & 44.4 \\
\hline Percentage Disliking & 8.3 & 8.0 & 7.1 & 10.6 & 9.1 & 22.2 \\
\hline Percentage Indifierent & 58.3 & 46.0 & 63.9 & 59.6 & 50.0 & 33.3 \\
\hline \multicolumn{7}{|l|}{ Roller Skating } \\
\hline Percentage Liking & 25.0 & 44.0 & 33.5 & 23.4 & 13.6 & 22.2 \\
\hline Percentage Disliking & 8.3 & 8.0 & 16.1 & 9.6 & 31.8 & 22.2 \\
\hline Percentage Indifferent & 66.6 & 48.0 & 50.6 & 67.0 & 54.5 & 55.4 \\
\hline
\end{tabular}


TABIE 24 (Continued)

Relative Popularity of Recreational Activities by Income Groups

\begin{tabular}{|c|c|c|c|c|c|c|}
\hline Inc ome & $0-\$ 2,000$ & $\begin{array}{l}32,000- \\
43,000 \\
433,0\end{array}$ & $\begin{array}{l}\$ 3,000- \\
\$ 4,000 \\
\$ 4\end{array}$ & $\begin{array}{l}34,000- \\
\$ 5,000 \\
\end{array}$ & $\begin{array}{l}\$ 5,000- \\
\$ 27,000 \\
\end{array}$ & $\begin{array}{l}\text { Over } \\
\$ 7,000 \\
\end{array}$ \\
\hline \multicolumn{7}{|l|}{ Painting } \\
\hline Percentage Iiking & 41.7 & 10.0 & 25.9 & 22.3 & 9.1 & 11.1 \\
\hline Percentage Disliking & 10.7 & 28.0 & 18.1 & 12.8 & 18.2 & 55.5 \\
\hline Percentage Indifferent & $41 . \dot{7}$ & 56.0 & 56.0 & $64 \cdot 9$ & 72.7 & 33.3 \\
\hline \multicolumn{7}{|l|}{ Social Drinking } \\
\hline Percentage Iiking & 41.7 & 54.0 & 48.4 & 50.0 & 54.5 & 44.4 \\
\hline Percentage Disliking & 16.7 & 10.0 & 11.0 & 11.7 & 18.2 & 33.3 \\
\hline Percentage Indifferent & 41.7 & 36.0 & 40.6 & 38.3 & $27 \cdot 3$ & 22.2 \\
\hline \multicolumn{7}{|l|}{ Sailing } \\
\hline Percentage Liking & 33.3 & 20.0 & 22.5 & 14.9 & 40.9 & 11.1 \\
\hline Percentage Disliking & 16.7 & 16.0 & 15.4 & 11.7 & 18.2 & 33.3 \\
\hline Fercentage Indifferent & 50.0 & 64.0 & 62.2 & 73.4 & 40.9 & 55.5 \\
\hline \multicolumn{7}{|l|}{ Skiing } \\
\hline Percentage Liking & 41.7 & 18.0 & 18.1 & 12.8 & 22.7 & 11.1 \\
\hline Percentage Disliking & 8.3 & 24.0 & 18.6 & 18.1 & 27.3 & 33.3 \\
\hline Percentage Indifferent & 50.0 & 58.0 & 63.3 & 69.1 & 50.0 & 55.5 \\
\hline \multicolumn{7}{|l|}{ Social Dancing } \\
\hline Percentage Liking & 58.3 & 52.0 & $54 \cdot 4$ & 43.6 & 54.5 & $44 \cdot 4$ \\
\hline Percentage Disliking & 8.3 & 8.0 & 11.5 & 13.8 & 22.7 & $44 \cdot 4$ \\
\hline Percentage Indifierent & 33.3 & 40.0 & 34.1 & 42.6 & 22.7 & 11.1 \\
\hline
\end{tabular}


TABIE 24 (Continued)

Relative Popularity of Recreational Activities by Income Groups

Inc one

$0-\$ 2,000$

\$2,000-

$\$ 3,000-$

$\$ 4,000$

$\$ 4,000-$

$\$ 5,000-$

Over

$\$ 3,000$

$\$ 5,000$

$\$ 7,000$

$\$ 7,000$

Softball

Percentage Liking

Percentage Disliking

Percentage Indifferent

$\begin{array}{rrrrrr}50.0 & 58.0 & 62.2 & 50.0 & 63.6 & 11.1 \\ 8.3 & 8.0 & 4.9 & 12.8 & 0.0 & 22.2 \\ 41.7 & 34.0 & 32.9 & 37.2 & 36.4 & 66.6\end{array}$

Speedball

Percentage Liking Percentage Disliking

Percentage Indifferent

16.7

16.7

16.0

16.0

68.0

18.1

15.1

65.8

$11 . ?$

19.2

69.2

9.1

18.2

72.7

0.0

22.2

77.7

Square Dancing

Percentage Liking

Percentage Disliking

Percentage Indifferent

Stamp Collecting

Percentage Liking

Percentage Disliking

Percentage Indifierent

Swimming

Percentage Liking

Percentage Disliking

Percentage Indifferent

$\begin{array}{rrrrrr}8.3 & 20.0 & 27.5 & 20.2 & 18.2 & 11.1 \\ 25.0 & 24.0 & 17.6 & 19.2 & 31.8 & 55.5 \\ 66.6 & 56.0 & 54.9 & 60.6 & 50.0 & 33.3\end{array}$

16.7

2.0

8.2

26.9

64.9

4.3

36.2

59.6

$0.0^{\circ}$

11.1

50.0

64.0

50.0

33.3

50.0

55.5

66.6

70.0

4.0

78.1

60.6

81.8

0.0

7.4
31.9

4.9
17.0

33.3

26.0

18.2

33.3

0.0

66.6 
TABIE 24 (Continued)

Relative Popularity of Recreational Activities by Income Groups

\begin{tabular}{|c|c|c|c|c|c|c|}
\hline Inc ome & $0-\$ 2,000$ & $\begin{array}{l}\$ 2,000- \\
\$ 3,000\end{array}$ & $\begin{array}{l}\$ 3,000- \\
\$ 4,000\end{array}$ & $\begin{array}{l}\$ 4,000- \\
\$ 5,000\end{array}$ & $\begin{array}{l}\$ 5,000- \\
\$ 7,000 \\
19\end{array}$ & $\begin{array}{l}\text { Over } \\
\$ 7,000 \\
\end{array}$ \\
\hline \multicolumn{7}{|l|}{ Tennis } \\
\hline Percentage Liking & 50.0 & 26.0 & 25.3 & 20.2 & 22.7 & 11.1 \\
\hline Percentage Disliking & 8.3 & 22.0 & 13.7 & 17.0 & 36.8 & 33.3 \\
\hline Percentage Indifferent & 41.7 & 52.0 & 60.9 & 62.8 & 45.5 & 55.5 \\
\hline \multicolumn{7}{|l|}{ Touch Football } \\
\hline Percentage Liking & 33.3 & 30.0 & 24.8 & 17.0 & 40.9 & 11.1 \\
\hline Percentage Disliking & 0.0 & 18.0 & 12.6 & 24.5 & 18.2 & 33.3 \\
\hline Percentage Indifferent & 66.6 & 52.0 & 62.7 & 58.5 & 40.9 & 55.5 \\
\hline \multicolumn{7}{|l|}{ Tumbling } \\
\hline Percentage Iiking & 8.3 & 6.0 & 8.8 & $7 \cdot 4$ & 13.6 & 0.0 \\
\hline Percentage Disliking & 16.7 & 24.0 & 21.9 & 20.7 & 36.4 & 33.3 \\
\hline Percentage Indifferent & 75.0 & 70.0 & 69.3 & 63.8 & 50.0 & 66.6 \\
\hline \multicolumn{7}{|l|}{ Visiting Friends } \\
\hline Percentage Iiking & & 70.0 & 72.9 & 76.6 & 72.7 & 77.7 \\
\hline Percentage Disliking & & 2.0 & 6.6 & 6.4 & 4,5 & 0.0 \\
\hline Percentage Indifferent & & 28.0 & 20.5 & 17.0 & 22.7 & 22.2 \\
\hline \multicolumn{7}{|l|}{ Volleyball } \\
\hline Percentage Liking & 33.3 & 28.0 & 30.3 & 17.0 & 45.4 & 11.1 \\
\hline Percentage Disliking & 8.3 & 14.0 & 12.0 & 18.8 & 18.2 & 33.3 \\
\hline Percentage Indifference & 58.3 & 58.0 & 57.7 & 64.9 & 36.4 & 55.5 \\
\hline
\end{tabular}


TABIE 24 (Continued)

Relative Popularity of Recreational Activities by Income Groups

\begin{tabular}{|c|c|c|c|c|c|c|}
\hline Income & $0-42,000$ & $\begin{array}{l}6^{2} 2,000- \\
\$ 3,000\end{array}$ & $\begin{array}{l}\$ 3,000- \\
\quad 34,000 \\
54\end{array}$ & $\begin{array}{l}\$ \$ 2,000- \\
\$ 5,000 \\
\$ 2\end{array}$ & $\begin{array}{l}\$ 5,000- \\
\$ 7,000 \\
\end{array}$ & $\begin{array}{l}\text { Over } \\
\$ 7,000 \\
\end{array}$ \\
\hline \multicolumn{7}{|l|}{ Watching Sports Events } \\
\hline Percentage Liking & 75.0 & 78.0 & 87.3 & 80.9 & 100.0 & 77.7 \\
\hline Percentage Disliking & 0.0 & 2.0 & 2.7 & 4.3 & 0.0 & 11.1 \\
\hline Percentage Indifferent & 25.0 & 20.0 & 9.9 & 14.9 & 0.0 & 11.1 \\
\hline \multicolumn{7}{|l|}{ Walking } \\
\hline Percentage Liking & 66.6 & 46.0 & 51.2 & 42.5 & 59.1 & 33.3 \\
\hline Percentage Disliking & 8.3 & 14.0 & 9.9 & 12.8 & 13.6 & 11.1 \\
\hline Percentage Indifferent & 25.0 & 40.0 & 39.0 & 45.7 & 27.3 & 55.5 \\
\hline \multicolumn{7}{|l|}{ Weight Lifting } \\
\hline Percentage Liking & 33.3 & 10.0 & 13.2 & 11.7 & 4.5 & 0.0 \\
\hline Percentage Disliking & 8.3 & 30.0 & 25.3 & 29.8 & 45.5 & 55.5 \\
\hline Percentage Indifferent & 58.3 & 60.0 & 61.5 & 58.5 & 50.0 & 44.4 \\
\hline \multicolumn{7}{|l|}{ Water Polo } \\
\hline Percentage Iiking & 16.7 & 2.0 & 13.2 & 6.4 & 4.5 & 11.1 \\
\hline Percentage Disliking & 16.7 & 26.0 & 19.9 & 24.5 & 40.9 & $44 . \overline{4}$ \\
\hline Percentage Indifferent & 66.6 & 72.0 & 66.9 & 69.1 & 54.5 & 44.4 \\
\hline \multicolumn{7}{|l|}{ Wood Working } \\
\hline Percentage Liking & 33.3 & 32.0 & 42.4 & 43.6 & 59.1 & 44.4 \\
\hline Percentage Disliking & 25.0 & 16.0 & 9.3 & 10.6 & 9.1 & 22.2 \\
\hline Percentage Indifferent & 41.7 & 52.0 & $48 . \bar{L}$ & 45.6 & 31.8 & 33.3 \\
\hline
\end{tabular}


TABIE 24 (Continued)

Relative Popularity of Recreational Activities by Income Groups

\begin{tabular}{|c|c|c|c|c|c|c|}
\hline Inc ome & $0-\$ 2,000$ & $\begin{array}{l}\$ 2,000- \\
\$ 3,000 \\
\$\end{array}$ & $\begin{array}{l}\$ 3,000- \\
\$ 4,000 \\
\$ \$ 4\end{array}$ & $\begin{array}{l}54,000- \\
\$ 5,000\end{array}$ & $\begin{array}{l}\$ 5,000- \\
\$ 7,000\end{array}$ & $\begin{array}{l}\text { Over } \\
\$ 7,000\end{array}$ \\
\hline \multicolumn{7}{|l|}{ Wood Carving } \\
\hline Percentage Liking & 8.3 & 10.0 & 22.5 & 25.5 & 18.2 & 11.1 \\
\hline Percentage Disliking & 25.0 . & 22.0 & 12.6 & 12.8 & 18.2 & 22.2 \\
\hline Percentage Indifferent & $66.6^{\circ}$ & 68.0 & 64.9 & 61.7 & 63.6 & 66.6 \\
\hline \multicolumn{7}{|l|}{ Wrestling } \\
\hline Percentage Iiking & 41.7 & 10.0 & 25.3 & $24 \cdot 5$ & 31.8 & 11.1 \\
\hline Percentage Disliking & 16.7 & 28.0 & 22.5 & 24.5 & 22.7 & 44.4 \\
\hline Percentage Indifferent & 41.7 & 62.0 & 52.2 & 51.1 & 45.5 & 44.4 \\
\hline
\end{tabular}


TABLE 25

Discrepany Between Liking and Participation in Recreational Activities by Age Groups

\begin{tabular}{|c|c|c|c|c|}
\hline Age Croup & $20-29$ & $30-39$ & $40-49$ & $50-59$ \\
\hline Archery & & & & \\
\hline Percentage Liking & 28.50 & 26.70 & 12.00 & 13.60 \\
\hline $\begin{array}{l}\text { Participation Index } \\
\text { Difference }\end{array}$ & $\begin{array}{r}2.60 \\
25.90\end{array}$ & $\begin{array}{r}2.10 \\
24.60\end{array}$ & $\begin{array}{r}.80 \\
17.20\end{array}$ & 13.27 \\
\hline \multicolumn{5}{|l|}{ Badminton } \\
\hline Percentage Iiking & 46.20 & 50.30 & 25.00 & 8.50 \\
\hline Participation Index & 2.96 & 6.77 & 3.50 & \\
\hline Difference & $43 \cdot 24$ & 43.53 & 21.50 & 8.30 \\
\hline \multicolumn{5}{|l|}{ Bag Punching } \\
\hline Percentage Iiking & 30.80 & $19 \cdot 30$ & 12.00 & 18.60 \\
\hline Participation Index & 2.00 & 3.89 & .40 & 1.79 \\
\hline Difference & 28.80 & 25.41 & 11.60 & 16.81 \\
\hline \multicolumn{5}{|l|}{ Basebal1 } \\
\hline Percentage Lilcing & 92.60 & 86.30 & 77.00 & 59.30 \\
\hline Participation Index & 7.71 & 2.76 & 3.89 & 2.41 \\
\hline Difference & 84.89 & 83.54 & 73.11 & 56.89 \\
\hline \multicolumn{5}{|l|}{ Basketbal1 } \\
\hline Percentage Liking & 62.60 & 45.97 & 38.00 & 30.50 \\
\hline Participation Index & 5.17 & 1.64 & 1.14 & .00 \\
\hline Difference & 57.43 & 44.33 & 36.86 & 30.50 \\
\hline \multicolumn{5}{|l|}{ Bicycling } \\
\hline Percentage Iiking & 31.90 & 45.97 & 26.00 & 22.00 \\
\hline Participation Index & 1.96 & 4.93 & 1.20 & .66 \\
\hline Difference & 29.94 & 41.04 & 24.80 & 21.34 \\
\hline \multicolumn{5}{|l|}{ Boating } \\
\hline Percentage Iiking & 57.00 & 54.70 & 42.00 & 32.20 \\
\hline Participation Index & $\begin{array}{r}3.25 \\
53.75\end{array}$ & $2 \cdot 51$ & $3 \cdot 35$ & 2.19 \\
\hline DLIIErence & 53.15 & 52.19 & 38.05 & 30.01 \\
\hline \multicolumn{5}{|l|}{ Bowling } \\
\hline Percentage Iiking & 67.00 & 78.90 & 68.00 & 57.60 \\
\hline Participation Index & 12.50 & $13 \cdot 50$ & $12 \cdot 32$ & 9.58 \\
\hline Difference & 54.50 & 65.40 & 55.68 & 48.02 \\
\hline \multicolumn{5}{|l|}{ Boxing } \\
\hline Percentage Iiking & 31.90 & 25.50 & 28.00 & 35.50 \\
\hline $\begin{array}{l}\text { Participation Index } \\
\text { Difference }\end{array}$ & $\begin{array}{r}2.73 \\
29.17\end{array}$ & $\begin{array}{r}3.00 \\
22.50\end{array}$ & $\begin{array}{r}1.29 \\
26.71\end{array}$ & $\begin{array}{r}2.22 \\
33.28\end{array}$ \\
\hline
\end{tabular}


TABLE 25 (Continued)

Discrepancy Between liking and Participation in Recreational Activities by Age Groups

\begin{tabular}{|c|c|c|c|c|}
\hline Age Group & $20-29$ & $30-39$ & $40-49$ & $50-59$ \\
\hline \multicolumn{5}{|l|}{ Calisthenics } \\
\hline Percentage Liking & 31.90 & 28.60 & 20.00 & 16.90 \\
\hline Participation Index & 10.60 & 8.63 & 4.45 & 1.79 \\
\hline Difference & 21.30 & 19.97 & 15.55 & 15.11 \\
\hline \multicolumn{5}{|l|}{ Canoeing } \\
\hline Percentage Iiking & 46.20 & $42 \cdot 30$ & 19.00 & 15.30 \\
\hline Participation Index & & .99 & .77 & \\
\hline Difference & 45 & 41.31 & 18.23 & 15.18 \\
\hline \multicolumn{5}{|l|}{ Card Playing } \\
\hline Percentage Iiking & 79.10 & $70 \cdot 20$ & 85.00 & 88.10 \\
\hline Participation Index & 29.04 & 19.75 & 23.72 & 19.39 \\
\hline Difference & 50.06 & 50.45 & 61.28 & 68.71 \\
\hline \multicolumn{5}{|l|}{ Checkers } \\
\hline Percentage Liking & 35.10 & 41.00 & 38.00 & 44.10 \\
\hline Participation Index & 3.97 & 8.71 & $7 \cdot 24$ & 14.83 \\
\hline Difference & 31.13 & 32.29 & 30.76 & 29.27 \\
\hline \multicolumn{5}{|l|}{ Conversing } \\
\hline Percentage Liking & 65.80 & 55.90 & 50.00 & 52.50 \\
\hline Participation Index & 80.70 & 42.96 & 23.52 & 26.29 \\
\hline Difference & -14.90 & 12.94 & 26.48 & 26.21 \\
\hline \multicolumn{5}{|l|}{ Chess } \\
\hline Percentage Iiking & 28.50 & $20 \cdot 50$ & 9.00 & 10.20 \\
\hline Participation Index & 1.22 & 3.57 & .18 & 1.17 \\
\hline Difference & 27.28 & 16.93 & 8.82 & 9.03 \\
\hline \multicolumn{5}{|l|}{ Deck Tennis } \\
\hline Percentage Iiking & 11.00 & 8.10 & 3.00 & 1.70 \\
\hline Participation Index & 1.47 & .09 & .01 & .00 \\
\hline Difference & 9.53 & 8.01 & 2.99 & 1.70 \\
\hline \multicolumn{5}{|l|}{ Dating } \\
\hline Percentage Liking & 52.70 & 37.90 & 15.00 & 18.60 \\
\hline Participation Index & 26.25 & 7.03 & 1.56 & 3.53 \\
\hline Difference & 26.45 & 30.87 & 13.44 & 15.07 \\
\hline \multicolumn{5}{|l|}{ Driving } \\
\hline Percentage Liking & $82 \cdot 30$ & $73 \cdot 90$ & 66.00 & 57.60 \\
\hline Participation Index & 108.70 & 56.50 & 34.06 & 36.05 \\
\hline Difference & -26.40 & 17.40 & 31.94 & 21.55 \\
\hline
\end{tabular}


TABLE 25 (Contimued)

Discrepancy Between Liking and Participation in Recreational Activities by Age Groups

Age Group

Fencing

Percentage Iiking

Participation Index

Difference

Field Events

Percentage Liking

Participation Index

Difference

Bait Casting

Percentage Liking

Participation Index

Difference

Still Fishing

Percentage Liking

Participation Index

Difference

Football

Percentage Liking

Participation Index

Difference

Gardening

Percentage Ifiking

Participation Index

Difference

Golf

Percentage Liking

Participation Index

Difference

Gymastics

Percentage Liling
Participation Index
Difference

Handball

Percentage liking

Participation Index

Difference
$20-29$

$30-39$

114.30

.63

11.80

.36

3.00
.12
2.88

6.80

11.44

2.80

6.60

$\begin{array}{rrrr}27.50 & 22.98 & 22.00 & 37.30 \\ 27.35 . & .69 & .11 & .22 \\ 22.15 & 22.29 & 21.89 & 37.08\end{array}$

42.90

5.84

50.80

37.06

5.37

47.00

4.81

39.00

45.43

42.19

6.80

32.20

55.00
7.35

58.40

7.04

65.00

7.21

57.79

52.50

8.24

51.36

44.26

47.65

73.60
2.85

60.90

1.24

48.00

.62

59.66

47.38

47.40

.73

70.75

42.90

74.50

61.00

11.66

49.34

34.10

61.10

51.80

50.30

34.00

2.47

31.59

46.67

3.84

3.91

46.39

31.83

35.97

40.60
6.65
33.95

21.10

2.43

18.67

20.00

.63

19.37

13.60

1.86

11.74

37.00

28.60

1.65

26.95

23.00

15.30

2.60

.95

22.05

.02

15.28 
TABLE 25 (Continued)

Discrepancy Between Liking and Participation in Recreational Activities by Age Groups

Age Group

Hiking

Percentage Iiking
Participation Index
Difference

Horseback Riding

Percentage Iiking

Participation Index

Difference

Horseshoes

Percentage Iiking

Participation Index

Difference

Hunting

Percentage Liking
Participation Index
Difference

Ice Hockey

Percentage Liking

Participation Index

Difference

Ice Skating

Percentage Iiking

Participation Index

Difference

Music

Percentage Liking

Participation Index

Difference

Metal Craft

Percentage Iiling

Difference

Kiovies

Percentage Iiking

Participation Index

Difference
$20-29$

$30-39$

41.70

3.60

38.10

34.80

2.02

32.78

$40-49$

$50-59$

67.00

1.80

65.20

38.50

.99

37.51

24.00
1.97
22.03

32.20

3.83

28.37

63.60

5.16

58.44

63.40

6.71

56.69

36.00

.71

35.29

39.00

1.32

37.68

$\begin{array}{rrrr}72.50 & 55.30 & 65.00 & 59.30 \\ 1.03 & 1.50 & 2.28 & .41 \\ 71.47 & 53.80 & 62.72 & 58.89\end{array}$

46.20

.40

45.80

32.90
.65

32.25

53.00

3.51

49.49

52.50

1.71

50.79

58.89

61.50

1.16

46.60

1.13

60.34

45.47

22.00

.13

21.87

28.80

.32

28.48

61.50

32.32

63.40

21.19

42.21

30.00
.36
29.64

28.80

.19

28.61

29.16

63.00

17.17

45.83

35.60

12.88

22.72

36.30

34.20

7.35

18.00

2.36

16.90

5.17

26.85

15.64

7.46

9.44

84.60

77.02

73.00

64.40

24.13

60.47

19.23

57.79

14.23

58.74

11.75

52.65 
TABLE 25 (Continued)

Discrepancy Between Liking and Participation in Becreational Activities by Age Groups

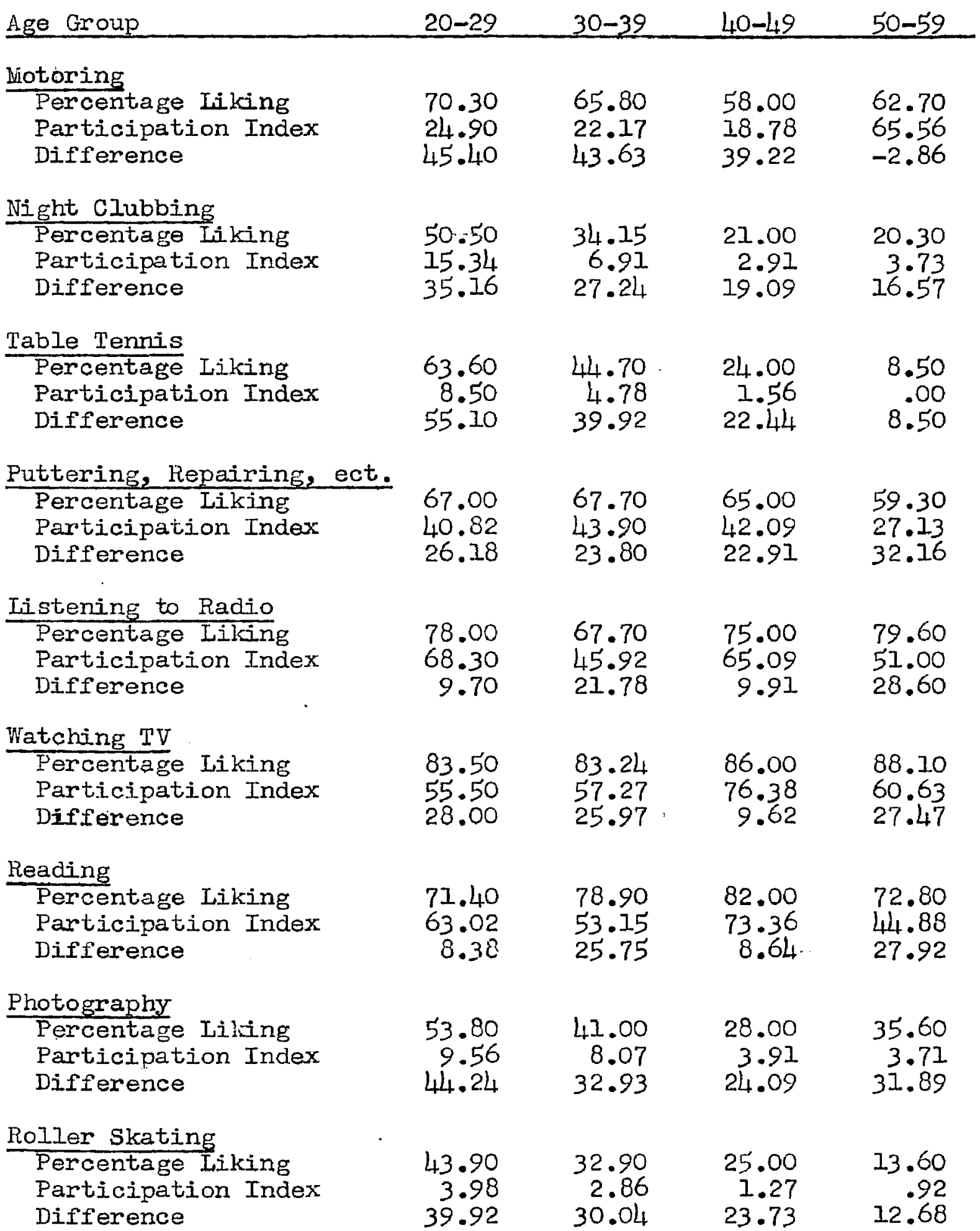


TABLE 25 (Continued)

Discrepancy Between Liking and Participation in Recreational Activities by Age Groups

\begin{tabular}{|c|c|c|c|c|}
\hline Age Group & $20-29$ & $30-39$ & $40-49$ & $50-59$ \\
\hline $\begin{array}{l}\text { Painting } \\
\text { Percentage Liking } \\
\text { Participation Index } \\
\text { Difference }\end{array}$ & $\begin{array}{r}33.00 \\
1.48 \\
31.52\end{array}$ & $\begin{array}{r}22.98 \\
3.44 \\
19.54\end{array}$ & $\begin{array}{r}23.00 \\
1.90 \\
21.10\end{array}$ & $\begin{array}{r}15.30 \\
2.02 \\
13.28\end{array}$ \\
\hline $\begin{array}{l}\text { Social Drinking } \\
\text { Percentage Iiking } \\
\text { Participation Index } \\
\text { Difference }\end{array}$ & $\begin{array}{l}64.80 \\
38.09 \\
26.71\end{array}$ & $\begin{array}{l}52.20 \\
12.39 \\
39.81\end{array}$ & $\begin{array}{r}41.00 \\
.00 \\
41.00\end{array}$ & $\begin{array}{r}39.00 \\
7.37 \\
31.63\end{array}$ \\
\hline $\begin{array}{l}\text { Sailing } \\
\text { Percentage Liking } \\
\text { Participation Index } \\
\text { Difference }\end{array}$ & $\begin{array}{r}31.90 \\
.99 \\
30.91\end{array}$ & $\begin{array}{r}22.98 \\
.25 \\
22.23\end{array}$ & $\begin{array}{r}15.00 \\
.15 \\
14.85\end{array}$ & $\begin{array}{r}13.60 \\
.05 \\
13.55\end{array}$ \\
\hline $\begin{array}{l}\frac{\text { Skiing }}{\text { Percentage Liking }} \\
\text { Participation Index } \\
\text { Difference }\end{array}$ & $\begin{array}{r}35.20 \\
.27 \\
34 . .93\end{array}$ & $\begin{array}{r}21.10 \\
.31 \\
20.79\end{array}$ & $\begin{array}{r}9.00 \\
.12 \\
8.88\end{array}$ & $\begin{array}{r}8.50 \\
.00 \\
8.50\end{array}$ \\
\hline $\begin{array}{l}\text { Social Dancing } \\
\text { Percentage Liking } \\
\text { Participation Index } \\
\text { Difference }\end{array}$ & $\begin{array}{l}70.30 \\
11.96 \\
58.34\end{array}$ & $\begin{array}{r}55.30 \\
9.43 \\
45.87\end{array}$ & $\begin{array}{l}47.00 \\
4.80 \\
42.20\end{array}$ & $\begin{array}{r}27.10 \\
1.49 \\
25.61\end{array}$ \\
\hline $\begin{array}{l}\text { Softball } \\
\text { Percentage Liling } \\
\text { Particlpation Index } \\
\text { Difference }\end{array}$ & $\begin{array}{r}70.30 \\
3.21 \\
67.09\end{array}$ & $\begin{array}{r}72.70 \\
2.12 \\
70.58\end{array}$ & $\begin{array}{r}41.00 \\
.80 \\
40.20\end{array}$ & $\begin{array}{r}28.80 \\
.22 \\
28.58\end{array}$ \\
\hline $\begin{array}{l}\text { Speedbal1 } \\
\text { Percentage Iiking } \\
\text { Participation Index } \\
\text { Difference }\end{array}$ & $\begin{array}{r}17.60 \\
.29 \\
17.31\end{array}$ & $\begin{array}{r}16.80 \\
.25 \\
16.55\end{array}$ & $\begin{array}{r}7.00 \\
.73 \\
6.87\end{array}$ & $\begin{array}{r}11.90 \\
.22 \\
11.68\end{array}$ \\
\hline $\begin{array}{l}\text { Square Dancing } \\
\text { Percentage Iiking } \\
\text { Participation Index } \\
\text { Difference. }\end{array}$ & $\begin{array}{r}26.50 \\
1.92 \\
24.58\end{array}$ & $\begin{array}{r}21.70 \\
1.98 \\
19.72\end{array}$ & $\begin{array}{r}26.00 \\
1.47 \\
24.53\end{array}$ & $\begin{array}{r}18.60 \\
1.10 \\
17.50\end{array}$ \\
\hline $\begin{array}{l}\text { Stamp Collecting } \\
\text { Percentage Ijking } \\
\text { Participation Index } \\
\text { Difference }\end{array}$ & $\begin{array}{r}3.30 \\
2.90 \\
.40\end{array}$ & $\begin{array}{r}5.60 \\
.98 \\
4.62\end{array}$ & $\begin{array}{r}10.00 \\
2.87 \\
7.13\end{array}$ & $\begin{array}{r}5.10 \\
.22 \\
4.88\end{array}$ \\
\hline
\end{tabular}


TABLE 25 (Continued)

Discrepancy Between Liking and Participation in Recreational Activities by Age Groups

\begin{tabular}{|c|c|c|c|c|}
\hline Age Group & $20-29$ & $30-39$ & $40-49$ & $50-59$ \\
\hline \multicolumn{5}{|l|}{ Swimming } \\
\hline Percentage Liking & 87.90 & 82.60 & 67.00 & 40.70 \\
\hline Participation Index & 4.85 & 4.24 & 2.06 & \\
\hline Difference & 83.05 & 78.36 & 64.94 & 39.75 \\
\hline \multicolumn{5}{|l|}{ Tennis } \\
\hline Percentage Liking & 33.00 & 31.70 & 16.00 & 11.90 \\
\hline Participation Index & 1.00 & & & \\
\hline Difference & 32.00 & 30.98 & 15.51 & 11.77 \\
\hline \multicolumn{5}{|l|}{ Touch Football } \\
\hline Percentage Iiking & 52.70 & 24.80 & 11.00 & 8.50 \\
\hline Participation Index & 1.41 & & .30 & \\
\hline Difference & 51.29 & $24 \cdot 55$ & 10.70 & 8.50 \\
\hline \multicolumn{5}{|l|}{ Tumbling } \\
\hline Percentage Liking & 19.90 & 11.80 & 7.00 & 10.20 \\
\hline Participation Index & 5.62 & 2.69 & .26 & .00 \\
\hline Difference & 14.28 & 9.11 & 6.74 & 10.20 \\
\hline \multicolumn{5}{|l|}{ Visiting Friends } \\
\hline Percentage Liking & 78.00 & 70.80 & 82.00 & 69.50 \\
\hline Participation Index & 36.73 & 26.87 & 23.17 & 15.41 \\
\hline Difference & 41.27 & 43.93 & 58.83 & 54.09 \\
\hline \multicolumn{5}{|l|}{ Volleyball. } \\
\hline Percentage Iiking & $49 \cdot 50$ & 39.20 & 21.00 & 6.80 \\
\hline Participation Index & 2.03 & 6.19 & 1.80 & .00 \\
\hline Difference & 47.47 & 33.01 & 19.20 & 6.80 \\
\hline \multicolumn{5}{|l|}{ Watching Sports } \\
\hline Percentage Iiking & 91.20 & 89.40 & 87.00 & 81.30 \\
\hline Participation Index & 37.11 & 34.40 & 24.62 & 19.85 \\
\hline Difference & $54 \cdot 69$ & 55.00 & 62.38 & 61.45 \\
\hline \multicolumn{5}{|l|}{ Walking } \\
\hline Percentage Liking & 56.00 & 52.79 & 46.00 & 44.10 \\
\hline Participation Index & 45.45 & 28.63 & 20.46 & 24.19 \\
\hline Difference & 10.55 & 24.16 & 25.54 & 19.91 \\
\hline \multicolumn{5}{|l|}{ Weight Iifting } \\
\hline Eercentage liking & 27.50 & 13.70 & 4.00 & 5.10 \\
\hline $\begin{array}{l}\text { Participation Index } \\
\text { Difference }\end{array}$ & $\begin{array}{l}10.78 \\
16.72\end{array}$ & $\begin{array}{r}3.45 \\
10.25\end{array}$ & .52 & .05 \\
\hline Difference & $10 \cdot 12$ & 10.25 & 3.40 & \\
\hline
\end{tabular}


TABLE 25 (Continued)

Discrepancy Between Liking and Participation in Recreational Activities by Age Groups

\begin{tabular}{|c|c|c|c|c|}
\hline Age Group & $20-29$ & $30-39$ & $40-49$ & $50-59$ \\
\hline Water Polo & & & & \\
\hline $\begin{array}{l}\text { Percentage Liking } \\
\text { Participation Index } \\
\text { Difference }\end{array}$ & $\begin{array}{r}19.90 \\
1.63 \\
18.27\end{array}$ & $\begin{array}{r}9.90 \\
.29 \\
9.61\end{array}$ & $\begin{array}{r}4.00 \\
.00 \\
4.00\end{array}$ & $\begin{array}{r}6.80 \\
.24 \\
6.56\end{array}$ \\
\hline \multicolumn{5}{|l|}{ Woodworking } \\
\hline $\begin{array}{l}\text { Percentage Irking } \\
\text { Participation Index } \\
\text { Difference }\end{array}$ & $\begin{array}{l}48.40 \\
10.37 \\
38.03\end{array}$ & $\begin{array}{r}52.20 \\
8.99 \\
43.21\end{array}$ & $\begin{array}{r}38.00 \\
5.38 \\
32.62\end{array}$ & $\begin{array}{r}39.00 \\
8.12 \\
30.88\end{array}$ \\
\hline \multicolumn{5}{|l|}{ Wood Carving } \\
\hline $\begin{array}{l}\text { Percentage Iiking } \\
\text { Participation Index } \\
\text { Difference }\end{array}$ & $\begin{array}{r}28 \cdot .50 \\
4 \cdot 22 \\
24 \cdot 28\end{array}$ & $\begin{array}{r}21.70 \\
3.69 \\
18.01\end{array}$ & $\begin{array}{r}12.00 \\
1.13 \\
10.87\end{array}$ & $\begin{array}{r}13.60 \\
1.19 \\
12.41\end{array}$ \\
\hline \multicolumn{5}{|l|}{ Wrestling } \\
\hline $\begin{array}{l}\text { Percentage Iiking } \\
\text { Participation Index } \\
\text { Difference }\end{array}$ & $\begin{array}{r}27.50 \\
1.91 \\
25 \cdot 59\end{array}$ & $\begin{array}{r}26.70 \\
3 \cdot 32 \\
23.38\end{array}$ & $\begin{array}{r}21.00 \\
.19 \\
20.81\end{array}$ & $\begin{array}{r}37.30 \\
6.17 \\
31.13\end{array}$ \\
\hline
\end{tabular}


TABLE 26

Discrepancy Between Liking and Participation in Recreational

Activities by Income Groups

\begin{tabular}{|c|c|c|c|c|c|c|}
\hline Income Group & $0-\$ 2,000$ & $\begin{array}{r}\$ 2,000- \\
\$ 3,000 \\
\end{array}$ & $\begin{array}{l}\$ 3,000- \\
\$ 4,000 \\
\end{array}$ & $\begin{array}{l}\$ 4,000- \\
\$ 5,000 \\
\end{array}$ & $\begin{array}{l}\$ 5,000- \\
\$ 7,000\end{array}$ & $\begin{array}{l}\text { Over } \\
\$ 7,000 \\
\end{array}$ \\
\hline \multicolumn{7}{|l|}{ Archery } \\
\hline Percentage Liking & 16.70 & 30.00 & 21.00 & 18.10 & 13.60 & 22.20 \\
\hline Participation Index & .17 & 3.56 & .62 & 1,20 & .18 & .22 \\
\hline Difference & 16.53 & 26.44 & 20.38 & 16.00 & 13.42 & 21.98 \\
\hline \multicolumn{7}{|l|}{ Badminton } \\
\hline Percentage Liking & 58.30 & 36.00 & 37.40 & 29.80 & 45.50 & 11.10 \\
\hline Participa tion Index & 4.25 & 3.70 & 5.03 & 3.40 & 9.00 & 1.44 \\
\hline Difference & 54.05 & 32.30 & 32.37 & 26.50 & 36.50 & 9.66 \\
\hline \multicolumn{7}{|l|}{ Bag Punching } \\
\hline Percentage Liking & 25.00 & 26.00 & 15.40 & 19.10 & 18.20 & 0.00 \\
\hline Participation Index & 2.09 & 2.90 & 1.02 & 1.70 & .55 & 0.00 \\
\hline Difference & 22.91 & 23.10 & 14.31 & 17.40 & 17.65 & 0.00 \\
\hline \multicolumn{7}{|l|}{ Baseball } \\
\hline Percentage Liking & 91.70 & 00.00 & 88.50 & 83.00 & 72.70 & 55.50 \\
\hline Participation Index & 3.25 & 4.86 & 4.32 & 2.70 & 2.55 & .44 \\
\hline Difference & 88.45 & $75.14 !$ & 84.18 & 80.30 & 70.15 & 55.06 \\
\hline \multicolumn{7}{|l|}{ Basketball } \\
\hline Percentage Iiking & 66.60 & 62.00 & 45.10 & 35.10 & 31.80 & 22.20 \\
\hline Participation Index & 6.70 & 3.82 & 1.49 & .84 & .41 & .06 \\
\hline Difference & 59.90 & 58.18 & 43.61 & 34.26 & 31.39 & 22.14 \\
\hline
\end{tabular}




\section{TABLE 26 (Continued)}

Discrepancy Between Liking and Participation in Recreational

Activities by Income Groups

\begin{tabular}{|c|c|c|c|c|c|c|}
\hline Income Group & $0-m_{\$} 2,000$ & $\begin{array}{l}2,000- \\
\$ 3,000\end{array}$ & $\begin{array}{l}\$ 3,000- \\
\$ 4,000 \\
\end{array}$ & $\begin{array}{l}\$ 4,000- \\
\$ 5,000 \\
\end{array}$ & $\begin{array}{l}\$ 5,000- \\
\$ 7,000 \\
7\end{array}$ & $\begin{array}{l}\text { Over } \\
\$ 7,000 \\
\end{array}$ \\
\hline \multicolumn{7}{|l|}{ Bicycling } \\
\hline Percentage Liking & $33.30^{\circ}$ & 38.00 & 30.30 & 30.90 & 22.70 & $44 \cdot 40$ \\
\hline Participation Index & 3.60 & 1.17 & 2.30 & 1.70 & .91 & 3.95 \\
\hline Difference & 29.70 & 36.83 & 28.00 & 29.20 & 21.79 & 40.45 \\
\hline \multicolumn{7}{|l|}{ Boating } \\
\hline Percentage Liking & 41.70 & 54.00 & 46.20 & 47.90 & 59.10 & 22.20 \\
\hline Participation Index & 2.70 & 1.73 & 3.22 & 1.90 & 3.00 & .11 \\
\hline Difference & 39.00 & 52.27 & 42.98 & 46.00 & 56.10 & 22.09 \\
\hline \multicolumn{7}{|l|}{ Bowling } \\
\hline Fercentage Liking & 33.30 & 72.00 & 68.70 & 75.50 & 63.60 & 33.30 \\
\hline Participation Index & $4 \cdot 17$ & 11.40 & 4.51 & 13.50 & 11.20 & 8.70 \\
\hline Difference & 29.13 & 60.60 & 64.79 & 63.00 & 52.40 & 24.60 \\
\hline \multicolumn{7}{|l|}{ Boxing } \\
\hline Percentage Iiking & 16.70 & 38.00 & 24.80 & 37.20 & 40.90 & 11.10 \\
\hline Participation Index & 1.08 & 3.44 & 2.32 & 2.40 & .60 & .00 \\
\hline Difference & 15.62 & 34.56 & 22.48 & 34.80 & 40.30 & 11.10 \\
\hline \multicolumn{7}{|l|}{ Calisthenics } \\
\hline Percentage Liking & 41.70 & 28.00 & 22.50 & 22.30 & 18.20 & 11.10 \\
\hline Participation Index & 14.00 & 3.86 & 5.60 & 7.20 & 5.30 & .11 \\
\hline Difference & 27.70 & 24.14 & 16.90 & 15.10 & 12.90 & 10.99 \\
\hline
\end{tabular}


TABIE 26 (Continued)

Discrepancy Between Liking and Participation in Recreational Activities by Income Groups

\begin{tabular}{|c|c|c|c|c|c|c|}
\hline Income Group & $0-\$ 2,000$ & $\begin{array}{l}\$ 2,000- \\
\$ 3,000 \\
\end{array}$ & $\begin{array}{l}\$ 3,000- \\
\$ 4,000 \\
\end{array}$ & $\begin{array}{l}\$ 4,000- \\
\$ 5,000\end{array}$ & $\begin{array}{l}\$ 5,000- \\
\$ 57,000\end{array}$ & $\begin{array}{l}\text { Over } \\
\$ 7,000\end{array}$ \\
\hline \multicolumn{7}{|l|}{ Canoeing } \\
\hline Percentage Iiking & 25.00 & 38.00 & 30.30 & 29.80 & 40.90 & 33.30 \\
\hline Participation Index & .42 & .28 & .34 & .45 & .59 & 2.50 \\
\hline Difference & $24 \cdot 58$ & $37 \cdot 72$ & 29.96 & 29.35 & 40.31 & 30.80 \\
\hline \multicolumn{7}{|l|}{ Card Playing } \\
\hline Percentage Liking & 66.60 & 70.00 & 75.80 & 75.50 & 77.30 & 77.70 \\
\hline Participation Index & 23.70 & 21.74 & 21.70 & 25.40 & 40.40 & 26.90 \\
\hline Difference & 42.90 & 48.26 & 54.10 & 50.10 & 36.90 & 50.80 \\
\hline \multicolumn{7}{|l|}{ Checkers } \\
\hline Percentage Liking & 33.30 & 40.00 & 38.50 & 33.00 & 31.80 & 22.20 \\
\hline Participation Index & 2.09 & 8.24 & 4.66 & 11.30 & 5.90 & .11 \\
\hline Difference & 31.21 & 31.76 & 33.84 & 21.70 & 25.90 & 22.09 \\
\hline \multicolumn{7}{|l|}{ Conversing } \\
\hline Percentage Iiking & 75.00 & 48.00 & 50.00 & 56.40 & 59.10 & 66.60 \\
\hline Participation Index & 30.33 & 26.00 & 51.02 & 54.80 & 89.80 & 34.70 \\
\hline Difference & 44.67 & 22.00 & -1.02 & 1.60 & -30.70 & 31.90 \\
\hline \multicolumn{7}{|l|}{ Chess } \\
\hline Percentage Liking & 16.70 & 16.00 & 18.10 & 12.80 & 31.80 & 22.20 \\
\hline Participation Index & .17 & 1.32 & 1.70 & 26.20 & 1.70 & 1.44 \\
\hline Difference & 16.53 & 14.68 & 16.40 & -13.40 & 30.10 & 20.76 \\
\hline
\end{tabular}


TADLE 26 (Continued)

Discrepancy Between Iiking and Participation in Recreational

Activities by Income Groups

\begin{tabular}{|c|c|c|c|c|c|c|}
\hline Income Group & $0-\$ 2,000$ & $\begin{array}{l}\$ 2,000- \\
\$ 3,000 \\
\end{array}$ & $\begin{array}{l}\$ 3,000- \\
\$ 4,000 \\
\$ 4\end{array}$ & $\begin{array}{l}\$ 4,000- \\
\$ 5,000 \\
\$\end{array}$ & $\begin{array}{l}\$ 5,000- \\
\$ 7,000\end{array}$ & $\begin{array}{l}\text { Over } \\
\$ 7,000 \\
\end{array}$ \\
\hline \multicolumn{7}{|l|}{ Deck Tennis } \\
\hline Percentage Liking & $8.30^{\circ}-1-1-1-1$ & 6.00 & 5.50 & 3.20 & 4.50 & 0.00 \\
\hline Participation Index & .17 & 1.04 & .09 & -.56 & .55 & 0.00 \\
\hline Difference & 8.13 & 4.96 & 5.41 & 2.63 & 3.95 & 0.00 \\
\hline \multicolumn{7}{|l|}{ Dating } \\
\hline Percentage Iiking & 58.30 & 46.00 & 35.70 & 31.90 & 27.30 & 33.30 \\
\hline Participation Index & 22.70 & 17.14 & 9.12 & -2.00 & 7.60 & 0.00 \\
\hline Difference & 35.60 & 28.86 & 26.58 & 29.90 & 19.70 & 33.30 \\
\hline \multicolumn{7}{|l|}{ Driving } \\
\hline Percentage Iiking & 83.30 & 84.00 & 70.80 & 72.40 & 77.30 & 22.20 \\
\hline Participation Index & 34.75 & 65.80 & 51.75 & -72.70 & 167.80 & 17.30 \\
\hline Difference & 48.55 & 18.20 & 19.05 & -.30 & -90.50 & 4.90 \\
\hline \multicolumn{7}{|l|}{ Fencing } \\
\hline Fercentage Liking & 16.70 & 8.00 & 8.80 & 9.60 & 4.50 & 0.00 \\
\hline Participation Index & .08 & 1.08 & .08 & .18 & .00 & 0.00 \\
\hline Difference & 16.62 & 6.92 & 8.72 & $9 \cdot 42$ & 4.50 & 0.00 \\
\hline \multicolumn{7}{|l|}{ Field Events (Irack) } \\
\hline Percentage Liking & 25.00 & 24.00 & 27.50 & 23.40 & 18.20 & 11.10 \\
\hline Participation Index & .67 & .57 & .28 & -.33 & .18 & .00 \\
\hline Difference & $24 \cdot 33$ & $23.4 ! 3$ & 27.22 & 23.07 & 18.02 & 11.10 \\
\hline
\end{tabular}


TABIE 26(Continued)

Discrepancy Between Liking and Participation in Recreational Activities by Income Groups

\begin{tabular}{|c|c|c|c|c|c|c|}
\hline Income Group & $0-\$ 2,000$ & $\begin{array}{l}\$ 2,000- \\
\$ 3,000 \\
\end{array}$ & $\begin{array}{l}\$ 3,000- \\
\$ 4,000\end{array}$ & $\begin{array}{l}\$ 4,000- \\
\$ 5,000 \\
\end{array}$ & $\begin{array}{l}\$ 5,000- \\
\$ 7,000\end{array}$ & $\begin{array}{l}\text { Over } \\
\$ 7,000 \\
\end{array}$ \\
\hline \multicolumn{7}{|l|}{ Bait Casting } \\
\hline $\begin{array}{l}\text { Percentage Iiking } \\
\text { Participation Index } \\
\text { Difference }\end{array}$ & $\begin{array}{r}58.30 \\
5.83 \\
52.47\end{array}$ & $\begin{array}{r}36.00 \\
3.36 \\
32.64\end{array}$ & $\begin{array}{r}49.00 \\
5.40 \\
43.60\end{array}$ & $\begin{array}{r}43.60 \\
4.80 \\
38.80\end{array}$ & $\begin{array}{r}50.00 \\
5.60 \\
44.40\end{array}$ & $\begin{array}{r}33.30 \\
32.49\end{array}$ \\
\hline \multicolumn{7}{|l|}{ Still Fishing } \\
\hline $\begin{array}{l}\text { Percentage Liking } \\
\text { Participation Index } \\
\text { Difference }\end{array}$ & $\begin{array}{r}75.00 \\
6.00 \\
69.00\end{array}$ & $\begin{array}{r}48.00 \\
4.40 \\
43.60\end{array}$ & $\begin{array}{r}62.20 \\
6.48 \\
55.72\end{array}$ & $\begin{array}{r}56.40 \\
6.98 \\
49.42\end{array}$ & $\begin{array}{l}68.20 \\
8.30 \\
59.90\end{array}$ & $\begin{array}{r}55.50 \\
2.11 \\
53.39\end{array}$ \\
\hline \multicolumn{7}{|l|}{ Football } \\
\hline $\begin{array}{l}\text { Percentage Iiking } \\
\text { Participation Index } \\
\text { Difference }\end{array}$ & $\begin{array}{r}75.00 \\
2.42 \\
72.58\end{array}$ & $\begin{array}{r}60.00 \\
2.20 \\
57.80\end{array}$ & $\begin{array}{r}60.90 \\
1.37 \\
59.53\end{array}$ & $\begin{array}{r}53.20 \\
-.75 \\
52.45\end{array}$ & $\begin{array}{r}59.10 \\
.36 \\
58.74\end{array}$ & $\begin{array}{r}44.40 \\
.00 \\
44.40\end{array}$ \\
\hline \multicolumn{7}{|l|}{ Gardening } \\
\hline $\begin{array}{l}\text { Percentage Liking } \\
\text { Participation Index } \\
\text { Difference }\end{array}$ & $\begin{array}{r}58.30 \\
4.04 \\
54.26\end{array}$ & $\begin{array}{r}40.00 \\
1.70 \\
38.30\end{array}$ & $\begin{array}{r}59.30 \\
8.76 \\
50.54\end{array}$ & $\begin{array}{l}60.60 \\
12.90 \\
47 \cdot 70\end{array}$ & $\begin{array}{l}54.50 \\
18.90 \\
35.60\end{array}$ & $\begin{array}{r}77.70 \\
9.70 \\
68.00\end{array}$ \\
\hline \multicolumn{7}{|l|}{ Golf } \\
\hline $\begin{array}{l}\text { Percentage Liking } \\
\text { Participation Index } \\
\text { Difference }\end{array}$ & $\begin{array}{r}33.30 \\
2.97 \\
30.33\end{array}$ & $\begin{array}{r}30.00 \\
1.15 \\
28.85\end{array}$ & $\begin{array}{r}39.60 \\
2.57 \\
37.03\end{array}$ & $\begin{array}{r}45.70 \\
3.73 \\
42.57\end{array}$ & $\begin{array}{r}40.90 \\
3.40 \\
37.50\end{array}$ & $\begin{array}{r}55.50 \\
4.40 \\
51.10\end{array}$ \\
\hline
\end{tabular}


TABLE 26 (Continued)

Discrepancy Between Liking and Participation in Recreational Activities by Income Group

\begin{tabular}{|c|c|c|c|c|c|c|}
\hline Income Group & $0-$ p 2,000 & $\begin{array}{l}\$ 2,000- \\
\$ 3,000 \\
\end{array}$ & $\begin{array}{l}\$ 3,000- \\
\$ 4,000 \\
\$ 3\end{array}$ & $\begin{array}{l}\$ 4,000- \\
\$ 5,000 \\
\$ 5\end{array}$ & $\begin{array}{l}\$ 5,000- \\
\$ 7,000 \\
\end{array}$ & $\begin{array}{l}\text { Over } \\
\$ 7,000\end{array}$ \\
\hline \multicolumn{7}{|l|}{ Gymnastics } \\
\hline Percentage Liking & 33.30 & 26.00 & 28.50 & 16.00 & 9.10 & 11.10 \\
\hline Participation Index & 9.70 & 3.54 & 2.59 & 2.10 & .82 & .00 \\
\hline Difference & 23.60 & 22.46 & 25.91 & 13.90 & 8.28 & 11.10 \\
\hline \multicolumn{7}{|l|}{ HandbaII } \\
\hline Percentage Liking & 16.70 & 26.00 & 26.40 & 21.30 & 27.30 & 11.10 \\
\hline Participation index & 1.50 & 3.10 & .71 & 2.03 & .09 & .90 \\
\hline Difference & 15.20 & 22.90 & 25.69 & 19.27 & 27.21 & 11.10 \\
\hline \multicolumn{7}{|l|}{ Hiking } \\
\hline Percentage Liking & 50.00 & 32.00 & 33.50 & 23.40 & 40.90 & 22.20 \\
\hline Participation Index & 5.00 & 1.44 & 2.38 & 1.80 & 3.80 & 1.11 \\
\hline Difference & 45.00 & 30.56 & 31.12 & 21.60 & 37.10 & 21.09 \\
\hline \multicolumn{7}{|l|}{ Hor seback Riding } \\
\hline Fercentage Liking & 58.30 & 52.00 & 41.20 & 37.20 & 40.90 & 11.10 \\
\hline Participation Index & 1.67 & .76 & 1.39 & 1.95 & .50 & .11 \\
\hline Difference & 56.63 & 51.34 & 39.81 & 35.25 & 40.40 & 10.99 \\
\hline \multicolumn{7}{|l|}{ Horseshoes } \\
\hline Percentage Liking & 33.30 & 46.00 & 61.50 & 58.50 & 40.90 & 55.50 \\
\hline Participation Index & 6.67 & 4.08 & 3.90 & -5.80 & 1.00 & .22 \\
\hline Difference & 26.63 & 41.92 & 57.60 & 52.70 & 39.90 & 55.28 \\
\hline
\end{tabular}


TABIE 26 (Continued)

Discrepancy Between Liking and Participation In Recreational Activities by Income Groups

\begin{tabular}{|c|c|c|c|c|c|c|}
\hline Income Group & $0-\$ 2,000$ & $\begin{array}{l}\$ 2,000 \\
\$ 3,000 \\
\end{array}$ & $\begin{array}{l}\$ 3,000- \\
\$ 4,000 \\
\$ 4\end{array}$ & $\begin{array}{l}\$ 4,000- \\
\$ 5,000 \\
\end{array}$ & $\begin{array}{l}\$ 5,000- \\
\$ 7,000 \\
\end{array}$ & $\begin{array}{l}\text { Over } \\
\$ 7,000\end{array}$ \\
\hline \multicolumn{7}{|l|}{ Hunting } \\
\hline Percentage Liking & 58.30 & 58.00 & 56.60 & 57.50 & 54.50 & 33.30 \\
\hline Participation Index & .75 & .70 & .86 & 1.20 & 1.70 & .33 \\
\hline Difference & 57.55 & 57.30 & 55.74 & 56.30 & 52.80 & 32.97 \\
\hline \multicolumn{7}{|l|}{ Ice Hockey } \\
\hline Percentage Liking & 16.70 & 38.00 & 34.10 & 20.20 & 36.40 & 22.20 \\
\hline Participation Index & 1.33 & .36 & .56 & .160 & .17 & .11 \\
\hline Difference & 15.37 & 37.64 & 33.54 & 20.01 & 36.23 . & 22.09 \\
\hline \multicolumn{7}{|l|}{ Ice Skating } \\
\hline Percentage Liking & 50.00 & 40.00 & 44.50 & 30.90 & 45.50 & 33.30 \\
\hline Participation Index & .50 & .28 & .54 & .47 & 4.95 & .33 \\
\hline Difference & 59.50 & 39.72 & 43.96 & 30.43 & 40.55 & 32.97 \\
\hline \multicolumn{7}{|l|}{ Metal Craft } \\
\hline Percentace Liking & 25.00 & 18.00 & 25.90 & 23.40 & 18.20 & 11.10 \\
\hline Participation Index & 1.17 & 1.06 & 7.24 & 4.10 & 1.10 & .90 \\
\hline Difference & 23.83 & 16.94 & 18.66 & 19.30 & 17.10 & 11.10 \\
\hline \multicolumn{7}{|l|}{ Movies } \\
\hline Percentage Liking & 66.60 & 76.00 & 69.80 & 76.50 & 59.10 & 66.60 \\
\hline Participation Index & 25.70 & 17.22 & $16 . \frac{14}{66}$ & 16.90 & 16.20 & 14,40 \\
\hline Difference & 40.90 & 58.78 & 53.66 & 59.70 & 42.90 & 52.20 \\
\hline
\end{tabular}


TABLE 26 (Continued)

Discrepancy Between Liking and Participation In Recreational Activities by Income Groups

\begin{tabular}{|c|c|c|c|c|c|c|}
\hline Income Group & $0-\$ 2,000$ & $\begin{array}{l}\$ 2,000- \\
\$ 3,000 \\
\end{array}$ & $\begin{array}{l}\$ 3,000- \\
\$ 4,000\end{array}$ & $\begin{array}{l}\$ 4,000- \\
\$ 5,000 \\
\$\end{array}$ & $\begin{array}{l}\$ 5,000- \\
\$ 7,000 \\
\end{array}$ & $\begin{array}{l}\text { Over } \\
\$ 7,000\end{array}$ \\
\hline \multicolumn{7}{|l|}{ Wusic } \\
\hline Percentage Liking & 66.60 & 72.00 & 55.40 & 62.80 & 50.00 & 44.40 \\
\hline Participation Index & $19 \cdot 30$ & 19.80 & 21.44 & 34.20 & 10.80 & 11.70 \\
\hline Difrerence & 47.30 & 52.20 & 33.96 & 28.60 & 39.20 & 32.70 \\
\hline \multicolumn{7}{|l|}{ Motoring } \\
\hline Percentage Iiking & 58.30 & 64.00 & 62.70 & 61.70 & 59.10 & 44.40 \\
\hline Participation Index & 21.75 & $26.74_{4}$ & 20.19 & 29.00 & 25.30 & 8.40 \\
\hline Difference & 36.55 & 37.26 & 42.51 & 32.70 & 33.80 & 36.00 \\
\hline \multicolumn{7}{|l|}{ Night Clubjing } \\
\hline Percentage Liking & 41.70 & 48.00 & 30.30 & 33.00 & 22.70 & 22.20 \\
\hline Participation Index & 8.40 & 12.48 & 5.71 & 7.50 & 10.00 & 7.10 \\
\hline Difference & 33.30 & 35.52 & 24.59 & 25.50 & 12.70 & 15.10 \\
\hline \multicolumn{7}{|l|}{ Table Tennis } \\
\hline Percentage Liking & 50.00 & 32.00 & 41.80 & 35.10 & 54.50 & 44.40 \\
\hline Participation Index & 9.90 & 3.60 & 4.84 & 3.40 & 4.10 & .44 \\
\hline Difference & 40.10 & 28.40 & 36.96 & 31.70 & 50.40 & 43.96 \\
\hline \multicolumn{7}{|l|}{ Puttering, ect. } \\
\hline Percentage Liking & 91.70 & 54.00 & 67.60 & 66.00 & 68.20 & 44.40 \\
\hline $\begin{array}{l}\text { Participation Index } \\
\text { Difference }\end{array}$ & 32.30 & 17.86 & $4.4 \cdot 10$ & 46.80 & 45.30 & 17.40 \\
\hline Difference & 59.40 & 36.14 & 23.50 & 19.20 & 22.90 & 27.00 \\
\hline
\end{tabular}


TABIE 26 (Continued)

Discrepancy Between Iiking and Participation in Recreational

Activities by Income Groups

\begin{tabular}{|c|c|c|c|c|c|c|}
\hline Income Groups & $0-42,000$ & $\begin{array}{l}\$ 2,000- \\
\$ 3,000\end{array}$ & $\begin{array}{l}\$ 3,000- \\
\$ 4,000\end{array}$ & $\begin{array}{l}\$ 4,000- \\
\$ 5,000\end{array}$ & $\begin{array}{l}\$ 5,000- \\
\$ 7,000\end{array}$ & $\begin{array}{l}\text { Over } \\
\$ 7,000\end{array}$ \\
\hline \multicolumn{7}{|l|}{ Painting } \\
\hline Percentage Iiking & 41.70 & 16.00 & 25.90 & 22.30 & 9.10 & 11.10 \\
\hline Participation Index & 1.08 & .10 & 2.89 & 1.70 & 2.40 & .11 \\
\hline Difference & 40.62 & 15.90 & 23.01 & 20.60 & 6.70 & 10.99 \\
\hline \multicolumn{7}{|l|}{ Social Drinizing } \\
\hline Percentage Ijiking & 41.70 & 54.00 & 48.40 & 50.00 & 54.50 & $44 \cdot 40$ \\
\hline Participation Index & 11.75 & 11.90 & 13.30 & 21.80 & 9.60 & 12.90 \\
\hline Difference & 29.95 & 42.10 & 35.10 & 28.20 & 44.90 & 31.50 \\
\hline \multicolumn{7}{|l|}{ Sailing } \\
\hline Percentage Iiking & 33.30 & 20.00 & 22.50 & 14.90 & 40.90 & 11.10 \\
\hline Participation Index & .08 & .63 & .39 & .10 & .50 & .11 \\
\hline Difference & 33.22 & 19.37 & 22.11 & 14.80 & 40.40 & 10.99 \\
\hline \multicolumn{7}{|l|}{ Skiing } \\
\hline Percentage Iiking & 41.70 & 13.00 & 18.10 & 12.80 & 22.70 & 11.10 \\
\hline Participation Index & .17 & .20 & .10 & .06 & .14 & .00 \\
\hline Difference & 41.53 & 17.80 & 18.00 & 12.74 & 22.56 & 11.10 \\
\hline \multicolumn{7}{|l|}{ Social Dancing } \\
\hline Percentage Liking & 58.30 & 52.00 & $54 \cdot 40$ & 43.60 & 54.50 & 44.40 \\
\hline Participation Index & 10.75 & 5.08 & .68 & 5.30 & 9.20 & 1.70 \\
\hline Difference & 47.55 & 46.92 & 53.72 & 38.30 & 45.30 & 42.70 \\
\hline
\end{tabular}




\section{TABLE 26 (Continued)}

Discrepancy Between Liking and Participation in Recreational Activities by Income Groups

\begin{tabular}{|c|c|c|c|c|c|c|}
\hline Income Group & $0-\$ 2,000$ & $\begin{array}{l}\dddot{p}_{2}, 000- \\
\$ 3,000 \\
\$ 3\end{array}$ & $\begin{array}{l}3,000- \\
\$ 4,000 \\
\$ 4\end{array}$ & $\begin{array}{l}\$ 4,000- \\
\$ 5,000\end{array}$ & $\begin{array}{l}\$ 5,000- \\
\$ 7,000\end{array}$ & $\begin{array}{l}\text { Over } \\
\$ 7,000\end{array}$ \\
\hline \multicolumn{7}{|l|}{ Wood Carving } \\
\hline $\begin{array}{l}\text { Percentage Liking } \\
\text { Participation Index } \\
\text { Difference }\end{array}$ & $\begin{array}{l}8.30 \\
0.00 \\
8.30\end{array}$ & $\begin{array}{r}10.00 \\
1.28 \\
8.72\end{array}$ & $\begin{array}{r}22.50 \\
2.64 \\
19.86\end{array}$ & $\begin{array}{r}25.50 \\
2.70 \\
22.80\end{array}$ & $\begin{array}{r}18.20 \\
.27 \\
17.93\end{array}$ & $\begin{array}{r}11.10 \\
5.80 \\
5.30\end{array}$ \\
\hline \multicolumn{7}{|l|}{ Wrestling } \\
\hline $\begin{array}{l}\text { Percentage Iiking } \\
\text { Participation Index } \\
\text { Difference }\end{array}$ & $\begin{array}{r}41.70 \\
5.50 \\
36.20\end{array}$ & $\begin{array}{r}10.00 \\
.50 \\
9.50\end{array}$ & $\begin{array}{r}25.30 \\
2.48 \\
22.82\end{array}$ & $\begin{array}{r}24.50 \\
1.40 \\
23.10\end{array}$ & $\begin{array}{r}31.80 \\
1.70 \\
30.10\end{array}$ & $\begin{array}{r}11.10 \\
0.00 \\
11.10\end{array}$ \\
\hline
\end{tabular}




\section{TABLE 27}

Numbers and Percentages of Ken Iiking, Disliking, and Indifferent to Each of Sixty-Seven Recreational Activities, Extent of Participation in Each, and Number of Men Listing Each of Five Reasons for Unsatisfactory Participation in the 20-29 Age Group

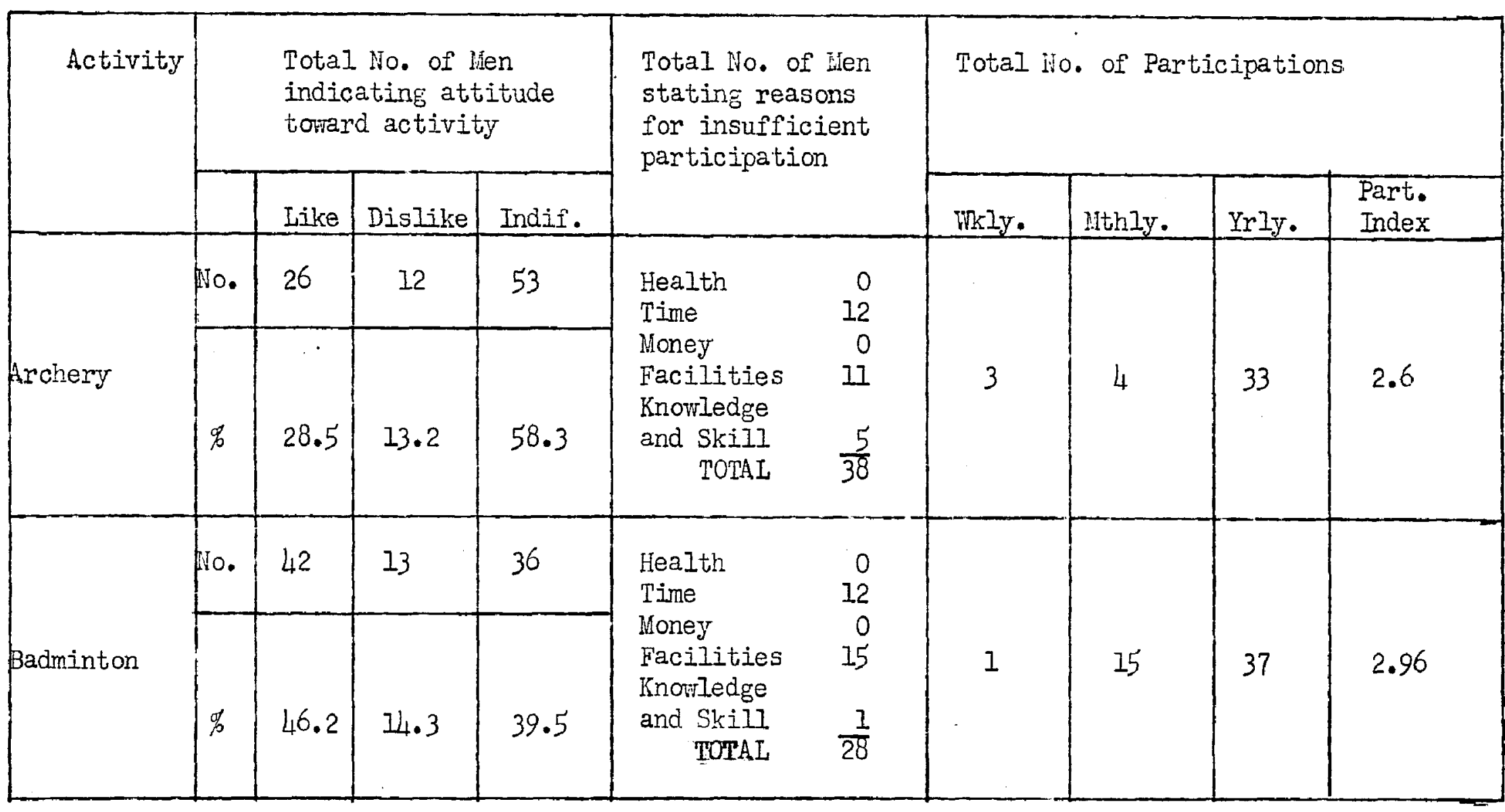


TABLE 27 (Continued)

20-29 Age Group

\begin{tabular}{|c|c|c|c|c|c|c|c|c|c|c|}
\hline \multirow[t]{2}{*}{ Activity } & \multicolumn{4}{|c|}{$\begin{array}{l}\text { Total No. of Men } \\
\text { indicating attitude } \\
\text { toward activity }\end{array}$} & \multirow{2}{*}{\multicolumn{2}{|c|}{$\begin{array}{l}\text { Total lio. of Men } \\
\text { stating reasons } \\
\text { for insufficient } \\
\text { participation }\end{array}$}} & \multicolumn{4}{|c|}{ Total No. of Participations } \\
\hline & & Like & Dislike & Indif. & & & Wkly. & nthly. & Yrly, & $\begin{array}{l}\text { Part. } \\
\text { Index }\end{array}$ \\
\hline \multirow[b]{2}{*}{$\begin{array}{l}\text { Bag } \\
\text { Punching }\end{array}$} & No. & 28 & 23 & 40 & \multirow[b]{2}{*}{$\begin{array}{l}\text { Health } \\
\text { Time } \\
\text { Money } \\
\text { Facilities } \\
\text { Knowledge } \\
\text { and Skill } \\
\text { TOTAL } \\
\end{array}$} & 0 & \multirow[b]{2}{*}{0} & \multirow[b]{2}{*}{14} & \multirow[b]{2}{*}{14} & \multirow[b]{2}{*}{2.0} \\
\hline & 若 & 30.8 & 25.3 & 43.9 & & $\begin{array}{r}7 \\
0 \\
7 \\
\frac{2}{16} \\
\end{array}$ & & & & \\
\hline \multirow[b]{2}{*}{$\begin{array}{l}\text { Baseball } \\
\text { (3 Months) }\end{array}$} & ino. & 84 & 0 & 7 & \multirow{2}{*}{$\begin{array}{l}\text { Health } \\
\text { Time } \\
\text { Money } \\
\text { Facilities } \\
\text { Knowledge } \\
\text { and Skill } \\
\quad \text { TOTAL } \\
\end{array}$} & 0 & \multirow[b]{2}{*}{33} & \multirow[b]{2}{*}{7} & \multirow[b]{2}{*}{222} & \multirow[b]{2}{*}{7.71} \\
\hline & $\%$ & 92.6 & 0 & 7.7 & & $\begin{array}{r}27 \\
0 \\
7 \\
\frac{3}{37} \\
\end{array}$ & & & & \\
\hline \multirow[b]{2}{*}{$\begin{array}{l}\text { Basketball } \\
\text { (6 Ionths) }\end{array}$} & No. & 57 & 7 & 27 & \multirow{2}{*}{$\begin{array}{l}\text { Health } \\
\text { Time } \\
\text { Money } \\
\text { Facilities } \\
\text { Knowledze } \\
\text { and Skill } \\
\text { TOTAL }\end{array}$} & 0 & \multirow[b]{2}{*}{12} & \multirow[b]{2}{*}{13} & \multirow[b]{2}{*}{81} & \multirow[b]{2}{*}{5.17} \\
\hline & $\%$ & 62.6 & 7.7 & 29.7 & & $\begin{array}{r}0 \\
7 \\
4 \\
\frac{4}{38}\end{array}$ & & & & \\
\hline
\end{tabular}


TABEE 27 (Continued)

20-29 Age Group

\begin{tabular}{|c|c|c|c|c|c|c|c|c|c|c|}
\hline \multirow[t]{2}{*}{ Activity } & \multicolumn{4}{|c|}{$\begin{array}{l}\text { Total No. of wen } \\
\text { indicating attitude } \\
\text { toward activity }\end{array}$} & \multirow{2}{*}{\multicolumn{2}{|c|}{$\begin{array}{l}\text { Total No. of Men } \\
\text { stating reasons } \\
\text { for insufficient } \\
\text { participation }\end{array}$}} & \multicolumn{4}{|c|}{ Total No. of Participations } \\
\hline & & Like & Dislike & Indif. & & & Wkly. & Mthly. & Yrly. & $\begin{array}{l}\text { Part. } \\
\text { Index }\end{array}$ \\
\hline \multirow[b]{2}{*}{$\begin{array}{l}\text { Boating } \\
\text { ( } 5 \text { Honths) }\end{array}$} & No. & 52 & 6 & 33 & \multirow{2}{*}{$\begin{array}{l}\text { Health } \\
\text { Time } \\
\text { Money } \\
\text { Facilities } \\
\text { Knowledge } \\
\text { and Skill } \\
\quad \text { TOTAI }\end{array}$} & \multirow{2}{*}{$\begin{array}{r}0 \\
12 \\
8 \\
8 \\
\\
\frac{1}{29} \\
\end{array}$} & \multirow[t]{2}{*}{9} & \multirow[t]{2}{*}{15} & \multirow[t]{2}{*}{26} & \multirow[t]{2}{*}{3.25} \\
\hline & 君 & 57.0 & 6.7 & 36.3 & & & & & & \\
\hline \multirow[b]{2}{*}{$\begin{array}{l}\text { Bowling } \\
\text { (9 Months) }\end{array}$} & No. & 61 & 8 & 22 & \multirow{2}{*}{$\begin{array}{l}\text { Health } \\
\text { Time } \\
\text { Uloney } \\
\text { Facilities } \\
\text { Knowledge } \\
\text { and Skill } \\
\quad \text { TOTAL } \\
\end{array}$} & \multirow{2}{*}{$\begin{array}{r}0 \\
15 \\
4 \\
0 \\
\frac{1}{20} \\
\end{array}$} & \multirow[t]{2}{*}{25} & \multirow[t]{2}{*}{15} & \multirow[t]{2}{*}{27} & \multirow[t]{2}{*}{12.5} \\
\hline & $\%$ & 6.70 & 8.8 & 24.2 & & & & & & \\
\hline \multirow[b]{2}{*}{ Boxing } & No. & 29 & 22 & 40 & \multirow{2}{*}{$\begin{array}{l}\text { Health } \\
\text { Time } \\
\text { Honey } \\
\text { Facilities } \\
\text { Knowledge } \\
\text { and Skill } \\
\quad \text { Total }\end{array}$} & \multirow{2}{*}{$\begin{array}{r}0 \\
9 \\
2 \\
5 \\
\frac{2}{18}\end{array}$} & \multirow[t]{2}{*}{4} & \multirow[t]{2}{*}{2} & \multirow[t]{2}{*}{16} & \multirow[t]{2}{*}{2.73} \\
\hline & $\%$ & 31.0 & 24.2 & 43.9 & & & & & & \\
\hline
\end{tabular}


TABIE 27 (Continued)

20-29 Age Group

\begin{tabular}{|c|c|c|c|c|c|c|c|c|c|c|}
\hline \multirow[t]{2}{*}{ Activity } & \multicolumn{4}{|c|}{$\begin{array}{l}\text { Total No. of lien } \\
\text { indicating attitude } \\
\text { toward activity }\end{array}$} & \multirow{2}{*}{\multicolumn{2}{|c|}{$\begin{array}{l}\text { Total Ho. of Wen } \\
\text { stating reasons } \\
\text { for insufficient } \\
\text { participation }\end{array}$}} & \multicolumn{4}{|c|}{ Total No. of Participations } \\
\hline & & Iike & Dislike & Indif: & & & Wkly. & Withly. & Yrly. & $\begin{array}{l}\text { Part. } \\
\text { Index }\end{array}$ \\
\hline \multirow[b]{2}{*}{ Calisthenic } & No. & 29 & 23 & 39 & \multirow[b]{2}{*}{$\begin{array}{l}\text { Health } \\
\text { Time } \\
\text { Inoney } \\
\text { Facilities } \\
\text { Knowledge } \\
\text { and Skill }\end{array}$} & \multirow[b]{2}{*}{$\begin{array}{r}0 \\
7 \\
0 \\
3 \\
0 \\
10 \\
\end{array}$} & \multirow[t]{2}{*}{17} & \multirow[t]{2}{*}{6} & \multirow[t]{2}{*}{8} & \multirow[t]{2}{*}{10.6} \\
\hline & 鼻 & 31.9 & 25.3 & 42.9 & & & & & & \\
\hline \multirow[b]{2}{*}{$\begin{array}{l}\text { Canoeing } \\
\text { (5 Honths) }\end{array}$} & No. & 42 & 7 & 42 & \multirow{2}{*}{$\begin{array}{l}\text { Health } \\
\text { Time } \\
\text { Honey } \\
\text { Facilities } \\
\text { Knowledge } \\
\text { and Skill } \\
\quad \text { Total } \\
\end{array}$} & \multirow{2}{*}{$\begin{array}{r}0 \\
17 \\
5 \\
14 \\
\frac{2}{32} \\
\end{array}$} & \multirow[t]{2}{*}{1} & \multirow[t]{2}{*}{5} & \multirow[t]{2}{*}{24} & \multirow[t]{2}{*}{.77} \\
\hline & $\%$ & 46.2 & 7.7 & 46.2 & & & & & & \\
\hline \multirow[b]{2}{*}{$\begin{array}{l}\text { Card } \\
\text { Playing }\end{array}$} & No. & 72 & 10 & 9 & \multirow[b]{2}{*}{$\begin{array}{l}\text { Health } \\
\text { Time } \\
\text { Woney } \\
\text { Facilities } \\
\text { Knowledge } \\
\text { and Skill } \\
\quad \text { TOTAL }\end{array}$} & \multirow[b]{2}{*}{$\begin{array}{r}0 \\
11 \\
5 \\
3 \\
\frac{1}{20}\end{array}$} & \multirow[t]{2}{*}{46} & \multirow[t]{2}{*}{20} & \multirow[t]{2}{*}{11} & \multirow[t]{2}{*}{29.04} \\
\hline & $\mathscr{0}$ & 79.1 & 11.0 & 9.9 & & & & & & \\
\hline
\end{tabular}


TABIE 27 (Continued)

20-29 Age Group

\begin{tabular}{|c|c|c|c|c|c|c|c|c|c|c|}
\hline \multirow[t]{2}{*}{ Activity } & & \multicolumn{3}{|c|}{$\begin{array}{l}\text { Total No. of Hen } \\
\text { indicating attitude } \\
\text { toward activity }\end{array}$} & \multirow{2}{*}{\multicolumn{2}{|c|}{$\begin{array}{l}\text { Total No. of lien } \\
\text { stating reasons } \\
\text { for insufficient } \\
\text { participation }\end{array}$}} & \multicolumn{4}{|c|}{ Total No. of Participations } \\
\hline & & Like & Dislike & Indif. & & & Wkly. & Wthly. & Yrly. & $\begin{array}{l}\text { Part. } \\
\text { Index }\end{array}$ \\
\hline \multirow[b]{2}{*}{ Checkers } & No. & 32 & 18 & 41 & \multirow{2}{*}{$\begin{array}{l}\text { Health } \\
\text { Time } \\
\text { Money } \\
\text { Facilities } \\
\text { Knowledge } \\
\text { and Skill } \\
\quad \text { TOTAL } \\
\end{array}$} & \multirow[b]{2}{*}{$\begin{array}{r}0 \\
11 \\
0 \\
1 \\
\frac{0}{12} \\
\end{array}$} & \multirow[t]{2}{*}{3} & \multirow[t]{2}{*}{16} & \multirow[t]{2}{*}{13} & \multirow[t]{2}{*}{3.97} \\
\hline & : & 35.1 & 19.9 & 45.0 & & & & & & \\
\hline \multirow[b]{2}{*}{ Conversing } & Ho. & 60 & 7 & 24 & \multirow{2}{*}{$\begin{array}{l}\text { Health } \\
\text { Time } \\
\text { Money } \\
\text { Facilities } \\
\text { Knowledge } \\
\text { and Skill } \\
\text { TOTAL } \\
\end{array}$} & 0 & \multirow[t]{2}{*}{137} & \multirow[t]{2}{*}{1} & \multirow[t]{2}{*}{207} & \multirow[t]{2}{*}{80.7} \\
\hline & $\%$ & 65.8 & 7.7 & 26.5 & & $\begin{array}{l}3 \\
0 \\
0 \\
0 \\
\\
\end{array}$ & & & & \\
\hline \multirow[b]{2}{*}{ Chess } & 通。. & 26 & 23 & 42 & \multirow{2}{*}{$\begin{array}{l}\text { Health } \\
\text { Time } \\
\text { Money } \\
\text { Facilities } \\
\text { Knowledge } \\
\text { and Skill } \\
\text { TOTAL }\end{array}$} & 0 & \multirow[t]{2}{*}{0} & \multirow[t]{2}{*}{8} & \multirow[t]{2}{*}{15} & \multirow[t]{2}{*}{1.22} \\
\hline & $\%$ & 28.5 & 25.3 & 46.2 & & $\begin{array}{c}7 \\
0 \\
4 \\
\frac{6}{17}\end{array}$ & & & & \\
\hline
\end{tabular}


TABLE 27 (Continued)

20-29 Age Group

\begin{tabular}{|c|c|c|c|c|c|c|c|c|c|c|}
\hline \multirow[t]{2}{*}{ Activity } & \multicolumn{4}{|c|}{$\begin{array}{l}\text { Total No. of Hen } \\
\text { indicating attitude } \\
\text { toward activity }\end{array}$} & \multirow{2}{*}{\multicolumn{2}{|c|}{$\begin{array}{l}\text { Total No. of Men } \\
\text { stating reasons } \\
\text { for insufficient } \\
\text { Participation }\end{array}$}} & \multicolumn{4}{|c|}{ Total No. of Participations } \\
\hline & & Like & Dislike & Indif. & & & Wkly. & Mthly. & Yrly. & $\begin{array}{l}\text { Part. } \\
\text { Index }\end{array}$ \\
\hline \multirow[b]{2}{*}{ Deck Tennis } & Wo. & 10 & 25 & 56 & \multirow[b]{2}{*}{$\begin{array}{l}\text { Health } \\
\text { Tine } \\
\text { Money } \\
\text { Facilities } \\
\text { Knowledge } \\
\text { and Skill } \\
\quad \text { TOTAL } \\
\end{array}$} & \multirow[b]{2}{*}{$\begin{array}{l}0 \\
4 \\
0 \\
2 \\
\frac{4}{10}\end{array}$} & \multirow[t]{2}{*}{2} & \multirow[t]{2}{*}{2} & \multirow[t]{2}{*}{6} & \multirow[t]{2}{*}{1.47} \\
\hline & 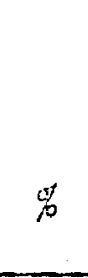 & 17.0 & 27.5 & 61.5 & & & & & & \\
\hline \multirow[b]{2}{*}{ Dating } & Nio. & 48 & 3 & 40 & \multirow{2}{*}{$\begin{array}{l}\text { Health } \\
\text { Time } \\
\text { Honey } \\
\text { Hacilities } \\
\text { Knowledge } \\
\text { and Skill }\end{array}$} & 0 & \multirow[t]{2}{*}{45} & \multirow[t]{2}{*}{4} & \multirow[t]{2}{*}{$I$} & \multirow[t]{2}{*}{26.25} \\
\hline & \% & 52.7 & 3.3 & 43.9 & & $\begin{array}{l}3 \\
3 \\
2 \\
0 \\
\frac{0}{8}\end{array}$ & & & & \\
\hline \multirow[b]{2}{*}{ Driving } & Iro. & 75 & 6 & 10 & \multirow{2}{*}{$\begin{array}{l}\text { Health } \\
\text { Time } \\
\text { Money } \\
\text { Facilities } \\
\text { Knowledge } \\
\text { and Skill }\end{array}$} & 0 & \multirow[t]{2}{*}{190} & \multirow[t]{2}{*}{1} & \multirow[t]{2}{*}{0} & \multirow[t]{2}{*}{108.7} \\
\hline & of & 82.3 & 6.7 & 11.0 & & $\begin{array}{l}4 \\
0 \\
0 \\
\frac{0}{4}\end{array}$ & & & & \\
\hline
\end{tabular}




\section{TABIE 27 (Continued)}

20-29 Age Group

\begin{tabular}{|c|c|c|c|c|c|c|c|c|c|c|}
\hline \multirow[t]{2}{*}{ Activity } & & \multicolumn{3}{|c|}{$\begin{array}{l}\text { Total No. of lien } \\
\text { indicating attitude } \\
\text { toward activity }\end{array}$} & \multicolumn{2}{|c|}{$\begin{array}{l}\text { Total No. of Men } \\
\text { stating reasons } \\
\text { for insufficient } \\
\text { participation }\end{array}$} & \multicolumn{4}{|c|}{ Total ivo. of Participations } \\
\hline & & Iike & Dislike & Indif. & & & Wkly. & Mthly. & YrIy. & $\begin{array}{l}\text { Part. } \\
\text { Index }\end{array}$ \\
\hline \multirow[b]{2}{*}{ Fencing } & No. & 13 & 25 & 53 & \multirow{2}{*}{$\begin{array}{l}\text { Health } \\
\text { Time } \\
\text { Honey } \\
\text { Facilities } \\
\text { Knowledge } \\
\text { and Skill } \\
\quad \text { TOIAI } \\
\end{array}$} & \multirow{2}{*}{$\begin{array}{r}0 \\
3 \\
1 \\
7 \\
5 \\
\frac{5}{16}\end{array}$} & \multirow[t]{2}{*}{1} & \multirow[t]{2}{*}{0} & \multirow[t]{2}{*}{5} & \multirow[t]{2}{*}{.63} \\
\hline & $\%$ & 山. 3 & 27.5 & 58.2 & & & & & & \\
\hline \multirow[b]{2}{*}{$\begin{array}{l}\text { Field } \\
\text { Events } \\
\text { (Track) } \\
\text { (4 Wonths) }\end{array}$} & No. & 25 & 19 & 47 & \multirow{2}{*}{$\begin{array}{l}\text { Health } \\
\text { Time } \\
\text { Money } \\
\text { Facilities } \\
\text { Knowledge } \\
\text { and Skill } \\
\quad \text { TOTAL } \\
\end{array}$} & \multirow{2}{*}{$\begin{array}{r}0 \\
7 \\
0 \\
4 \\
-2 \\
\end{array}$} & \multirow[t]{2}{*}{0} & \multirow[t]{2}{*}{4} & \multirow[t]{2}{*}{16} & \multirow[t]{2}{*}{.35} \\
\hline & $\%$ & 27.5 & 20.7 & 51.8 & & & & & & \\
\hline \multirow[b]{2}{*}{$\begin{array}{l}\text { Bait } \\
\text { Casting } \\
\text { (6 Months) }\end{array}$} & No. & 39 & 24 & 28 & \multirow{2}{*}{$\begin{array}{l}\text { Health } \\
\text { Time } \\
\text { Woney } \\
\text { Facilities } \\
\text { Knowledge } \\
\text { and Skill }\end{array}$} & 0 & \multirow[t]{2}{*}{16} & \multirow[t]{2}{*}{16} & \multirow[t]{2}{*}{19} & \multirow[t]{2}{*}{5.84} \\
\hline & of & 42.9 & 26.5 & 30.8 & & $\begin{array}{r}0 \\
1 \\
\frac{1}{12}\end{array}$ & & & & \\
\hline
\end{tabular}


TABIE 27 (Continued)

20-29 Age Group

\begin{tabular}{|c|c|c|c|c|c|c|c|c|c|c|}
\hline \multirow[t]{2}{*}{ Activity } & \multicolumn{4}{|c|}{$\begin{array}{l}\text { Total No. of hen } \\
\text { indicating attitude } \\
\text { toward activity }\end{array}$} & \multirow{2}{*}{\multicolumn{2}{|c|}{$\begin{array}{l}\text { Total No. of Men } \\
\text { stating reasons } \\
\text { for insufficient } \\
\text { participation }\end{array}$}} & \multicolumn{4}{|c|}{ Total No. of Participations } \\
\hline & & Like & Dislike & Indif. & & & Wkly. & Wthly. & Yrly. & $\begin{array}{l}\text { Part. } \\
\text { Index }\end{array}$ \\
\hline \multirow[b]{2}{*}{$\begin{array}{l}\text { Still } \\
\text { Fishing } \\
\text { (6 Iionths) }\end{array}$} & No. & 50 & 20 & 21 & \multirow{2}{*}{$\begin{array}{l}\text { Health } \\
\text { Time } \\
\text { Money } \\
\text { Facilities } \\
\text { Knowledge } \\
\text { and Skill } \\
\quad \text { TOTAI }\end{array}$} & \multirow{2}{*}{$\begin{array}{r}0 \\
15 \\
1 \\
2 \\
\\
\frac{1}{19} \\
\end{array}$} & \multirow[t]{2}{*}{16} & \multirow[t]{2}{*}{38} & \multirow[t]{2}{*}{25} & \multirow[t]{2}{*}{7.35} \\
\hline & 8 & 55.0 & 21.9 & 23.1 & & & & & & \\
\hline \multirow[b]{2}{*}{$\begin{array}{l}\text { Football } \\
\text { (3 ilonths) }\end{array}$} & No. & 67 & 5 & 19 & \multirow{2}{*}{$\begin{array}{l}\text { Health } \\
\text { Time } \\
\text { loney } \\
\text { Facilities } \\
\text { Knovledge } \\
\text { and Skill } \\
\quad \text { TOTAL } \\
\end{array}$} & \multirow{2}{*}{$\begin{array}{r}0 \\
17 \\
1 \\
4 \\
\frac{2}{24} \\
\end{array}$} & \multirow[t]{2}{*}{13} & \multirow[t]{2}{*}{13} & \multirow[t]{2}{*}{49} & \multirow[t]{2}{*}{2.85} \\
\hline & $\%$ & 73.6 & 5.6 & 20.9 & & & & & & \\
\hline \multirow[b]{2}{*}{$\begin{array}{l}\text { Gardening } \\
\text { ( } 5 \text { Months) }\end{array}$} & No. & 39 & 17 & 35 & \multirow{2}{*}{$\begin{array}{l}\text { Health } \\
\text { Tine } \\
\text { Money } \\
\text { Facilities } \\
\text { Knowledge } \\
\text { and Skills } \\
\quad \text { TOPAI }\end{array}$} & 0 & \multirow[t]{2}{*}{$35^{\prime}$} & \multirow[t]{2}{*}{5} & \multirow[t]{2}{*}{17} & \multirow[t]{2}{*}{8.8} \\
\hline & 落 & 42.9 & 19.1 & 38.0 & & $\frac{0}{16}$ & & & & \\
\hline
\end{tabular}


TABLE 27 (Continued)

20-29 Age Group

\begin{tabular}{|c|c|c|c|c|c|c|c|c|c|c|}
\hline \multirow[t]{2}{*}{ Activity } & & \multicolumn{3}{|c|}{$\begin{array}{l}\text { Total No. of lien } \\
\text { indicating attitude } \\
\text { toward activity }\end{array}$} & \multirow{2}{*}{\multicolumn{2}{|c|}{$\begin{array}{l}\text { Total No. of Wen } \\
\text { stating reasons } \\
\text { for insufficient } \\
\text { participation }\end{array}$}} & \multicolumn{4}{|c|}{ Total No. of Participations } \\
\hline & & Like & Dislike & Indif. & & & Wkly. & Mthly. & Yrly. & $\begin{array}{l}\text { Part. } \\
\text { Index }\end{array}$ \\
\hline \multirow[b]{2}{*}{ (4 Months) } & No. & 47 & 15 & 29 & \multirow[b]{2}{*}{$\begin{array}{l}\text { Health } \\
\text { Tine } \\
\text { Money } \\
\text { Facilities } \\
\text { Knowledge } \\
\text { and Skill } \\
\quad \text { TOTAL }\end{array}$} & \multirow[b]{2}{*}{$\begin{array}{r}0 \\
12 \\
7 \\
2 \\
\frac{9}{30} \\
\end{array}$} & \multirow[t]{2}{*}{15} & \multirow[t]{2}{*}{15} & \multirow[t]{2}{*}{29} & \multirow[t]{2}{*}{3.84} \\
\hline & 曽 & 51.8 & 16.5 & 31.7 & & & & & & \\
\hline \multirow[b]{2}{*}{ Gymnastics } & No. & 37 & 15 & 39 & \multirow[b]{2}{*}{$\begin{array}{l}\text { Health } \\
\text { Time } \\
\text { Money } \\
\text { Facilities } \\
\text { Knowledge } \\
\text { and Skill } \\
\quad \text { TOTAL } \\
\end{array}$} & 0 & \multirow[t]{2}{*}{9} & \multirow[t]{2}{*}{11} & \multirow[t]{2}{*}{6} & \multirow[t]{2}{*}{6.65} \\
\hline & $\ddot{\%}$ & 40.6 & 16.5 & 42.9 & & $\begin{array}{r}10 \\
1 \\
6 \\
\frac{1}{18} \\
\end{array}$ & & & & \\
\hline \multirow[b]{2}{*}{$\begin{array}{l}\text { Handball } \\
\text { (9 Months) }\end{array}$} & No. & 34 & 17 & 40 & \multirow[b]{2}{*}{$\begin{array}{l}\text { Health } \\
\text { Time } \\
\text { ivoney } \\
\text { Facilities } \\
\text { Knowledge } \\
\text { and Skill } \\
\quad \text { TOTAI }\end{array}$} & 1 & \multirow[t]{2}{*}{3} & \multirow[t]{2}{*}{12} & \multirow[t]{2}{*}{11} & \multirow[t]{2}{*}{2.6} \\
\hline & $\stackrel{d}{10}$ & 37.0 & 19.1 & 43.9 & & $\begin{array}{r}9 \\
1 \\
5 \\
\frac{1}{17}\end{array}$ & & & & \\
\hline
\end{tabular}


TABIE 27 (Continued)

20-29 Age Group

\begin{tabular}{|c|c|c|c|c|c|c|c|c|c|c|}
\hline \multirow[t]{2}{*}{ Activity } & \multicolumn{4}{|c|}{$\begin{array}{l}\text { Total Ho. of Men } \\
\text { indicating attitude } \\
\text { toward activity }\end{array}$} & \multirow{2}{*}{\multicolumn{2}{|c|}{$\begin{array}{l}\text { Total No. of inen } \\
\text { stating reasons } \\
\text { for insufficient } \\
\text { participation }\end{array}$}} & \multicolumn{4}{|c|}{ Total No. of Participations } \\
\hline & & Like & Dislike & Indif. & & & Wkly. & inthly. & Yrly. & $\begin{array}{l}\text { Part. } \\
\text { Index }\end{array}$ \\
\hline \multirow[b]{2}{*}{$\begin{array}{l}\text { Hiking } \\
\text { (9 Months) }\end{array}$} & No. & 38 & 15 & 38. & \multirow{2}{*}{$\begin{array}{l}\text { Health } \\
\text { Time } \\
\text { Nioney } \\
\text { Facilities } \\
\text { Knowledge } \\
\text { and Skill } \\
\quad \text { TOTAL } \\
\end{array}$} & \multirow{2}{*}{$\begin{array}{r}0 \\
12 \\
0 \\
1 \\
\frac{0}{13} \\
\end{array}$} & \multirow[t]{2}{*}{5} & \multirow[t]{2}{*}{12} & \multirow[t]{2}{*}{24} & \multirow[t]{2}{*}{3.6} \\
\hline & $\%$ & 41.75 & 16.5 & 41.75 & & & & & & \\
\hline \multirow[b]{2}{*}{$\begin{array}{l}\text { Horseback } \\
\text { Riding } \\
\text { ( } 9 \text { Months) }\end{array}$} & ino. & 61 & 11 & 19 & \multirow[b]{2}{*}{$\begin{array}{l}\text { Health } \\
\text { Time } \\
\text { woney } \\
\text { Facilities } \\
\text { Knowledge } \\
\text { and Skill } \\
\text {. TomAI } \\
\end{array}$} & \multirow[b]{2}{*}{$\begin{array}{r}0 \\
16 \\
15 \\
10 \\
1 \\
42 \\
\end{array}$} & \multirow[t]{2}{*}{0} & \multirow[t]{2}{*}{13} & \multirow[t]{2}{*}{47} & \multirow[t]{2}{*}{1.8} \\
\hline & $\%$ & 67.0 & 12.1 & 20.9 & & & & & & \\
\hline \multirow[b]{2}{*}{$\begin{array}{l}\text { Horseshoes } \\
\text { (9 Months) }\end{array}$} & No. & 58 & 6 & 27 & \multirow[b]{2}{*}{$\begin{array}{l}\text { Health } \\
\text { Time } \\
\text { Money } \\
\text { Facilities } \\
\text { Knowledge } \\
\text { and Skill } \\
\text { TOTAL }\end{array}$} & \multirow[b]{2}{*}{$\begin{array}{l}0 \\
6 \\
2 \\
6 \\
\frac{0}{1} \\
\end{array}$} & \multirow[t]{2}{*}{6} & \multirow[t]{2}{*}{22} & \multirow[t]{2}{*}{38} & \multirow[t]{2}{*}{5.16} \\
\hline & $\%$ & 63.6 & 6.7 & 29.7 & & & & & & \\
\hline
\end{tabular}


TABIE 2? (Continued)

20-29 Age Group

\begin{tabular}{|c|c|c|c|c|c|c|c|c|c|c|}
\hline \multirow[t]{2}{*}{ Activity } & & \multicolumn{3}{|c|}{$\begin{array}{l}\text { Total No. of Hen } \\
\text { indicating attitude } \\
\text { toward activity }\end{array}$} & \multirow{2}{*}{\multicolumn{2}{|c|}{$\begin{array}{l}\text { Total ilo. of lien } \\
\text { stating reasons } \\
\text { for insurficient } \\
\text { participation }\end{array}$}} & \multicolumn{4}{|c|}{ Total No. of Participations } \\
\hline & & Like & Dislike & Indif. & & & TKKIV. & Mthly. & Yrly. & $\begin{array}{l}\text { Part. } \\
\text { Index }\end{array}$ \\
\hline \multirow[b]{2}{*}{ Hunting } & No. & 66 & 10 & 15 & \multirow{2}{*}{$\begin{array}{l}\text { Health } \\
\text { Time } \\
\text { Honey } \\
\text { Facilities } \\
\text { Knowledge } \\
\text { and Skill } \\
\text { TOTAI }\end{array}$} & \multirow{2}{*}{$\begin{array}{r}0 \\
16 \\
7 \\
8 \\
\\
2 \\
33 \\
\end{array}$} & \multirow[t]{2}{*}{1} & \multirow[t]{2}{*}{4} & \multirow[t]{2}{*}{69} & \multirow[t]{2}{*}{1.03} \\
\hline & 落 & 72.5 & 11.0 & 16.5 & & & & & & \\
\hline \multirow[b]{2}{*}{$\begin{array}{l}\text { Ice Hocliey } \\
\text { (3 Wonths) }\end{array}$} & No. & 42 & 11 & 38 & \multirow{2}{*}{$\begin{array}{l}\text { Health } \\
\text { Time } \\
\text { Woney } \\
\text { Facilities } \\
\text { Knowledge } \\
\text { and Skill } \\
\quad \text { TOTAI } \\
\end{array}$} & \multirow{2}{*}{$\begin{array}{r}0 \\
9 \\
1 \\
5 \\
4 \\
19 \\
\end{array}$} & \multirow[t]{2}{*}{0} & \multirow[t]{2}{*}{1} & \multirow[t]{2}{*}{33} & \multirow[t]{2}{*}{.40} \\
\hline & $\%$ & 46.2 & 12.1 & 41.7 & & & & & & \\
\hline \multirow[b]{2}{*}{$\begin{array}{l}\text { Ice } \\
\text { Skating } \\
\text { ( } 3 \text { Honths) }\end{array}$} & No. & 56 & 9 & 26 & \multirow{2}{*}{$\begin{array}{l}\text { Health } \\
\text { Time } \\
\text { lioney } \\
\text { Facilities } \\
\text { Knowledge } \\
\text { and Skill } \\
\quad \text { TOPAI }\end{array}$} & \multirow[b]{2}{*}{$\begin{array}{r}0 \\
12 \\
1 \\
9 \\
\\
3 \\
25\end{array}$} & \multirow[t]{2}{*}{2} & \multirow[t]{2}{*}{3} & \multirow[t]{2}{*}{71} & \multirow[t]{2}{*}{1.16} \\
\hline & $\ddot{p}$ & 61.5 & 9.9 & 28.6 & & & & & & \\
\hline
\end{tabular}


TABLE 27 (Continued)

20-29 Age Group

\begin{tabular}{|c|c|c|c|c|c|c|c|c|c|c|}
\hline \multirow[t]{2}{*}{ Activity } & \multicolumn{4}{|c|}{$\begin{array}{l}\text { Total No. of Wen } \\
\text { indicating attitude } \\
\text { toward activity }\end{array}$} & \multirow{2}{*}{\multicolumn{2}{|c|}{$\begin{array}{l}\text { Total No. of hen } \\
\text { stating reasons } \\
\text { for insufficient } \\
\text { participation }\end{array}$}} & \multicolumn{4}{|c|}{ Total No. of Participations } \\
\hline & & $\overline{\text { Like }}$ & jislike & Indif: & & & Wkly. & Fithly. & Yrly. & $\begin{array}{l}\text { Part. } \\
\text { Index }\end{array}$ \\
\hline \multirow[b]{2}{*}{ Music } & No. & 56 & 2 & 33 & \multirow{2}{*}{$\begin{array}{l}\text { Health } \\
\text { Time } \\
\text { Koney } \\
\text { Facilities } \\
\text { Knowledge } \\
\text { and Skill } \\
\quad \text { TOTAL } \\
\end{array}$} & \multirow{2}{*}{$\begin{array}{l}0 \\
6 \\
2 \\
0 \\
\frac{3}{111} \\
\end{array}$} & \multirow[t]{2}{*}{54} & \multirow[t]{2}{*}{11} & \multirow[t]{2}{*}{1} & \multirow[t]{2}{*}{32.32} \\
\hline & $\stackrel{\leftrightarrow}{\infty}$ & 61.5 & 2.2 & 36.3 & & & & & & \\
\hline \multirow[b]{2}{*}{$\begin{array}{l}\text { Wetal } \\
\text { Craft }\end{array}$} & No. & 33. & 12 & 46 & \multirow{2}{*}{$\begin{array}{l}\text { Health } \\
\text { Time } \\
\text { Woney } \\
\text { Facilities } \\
\text { Knowledge } \\
\text { and Skill } \\
\quad \text { TOTAL } \\
\end{array}$} & 0 & \multirow[t]{2}{*}{8} & \multirow[t]{2}{*}{4} & \multirow[t]{2}{*}{7} & \multirow[t]{2}{*}{5.17} \\
\hline & \% & 36.3 & 13.2 & 50.5 & & $\begin{array}{r}0 \\
4 \\
\frac{3}{15} \\
\end{array}$ & & & & \\
\hline \multirow[b]{2}{*}{ Hovies } & No. & 77 & 1 & 13 & \multirow{2}{*}{$\begin{array}{l}\text { Health } \\
\text { Time } \\
\text { Money } \\
\text { Facilities } \\
\text { Knowledge } \\
\text { and Skill } \\
\quad \text { TOTAL } \\
\end{array}$} & 0 & \multirow[t]{2}{*}{33} & \multirow[t]{2}{*}{38} & \multirow[t]{2}{*}{24} & \multirow[t]{2}{*}{24.13} \\
\hline & 名 & 84.6 & 1.1 & 14.3 & & $\begin{array}{r}9 \\
0 \\
0 \\
\frac{0}{19}\end{array}$ & & & & \\
\hline
\end{tabular}


TABIE 27 (Continued)

20-29 Age Group

\begin{tabular}{|c|c|c|c|c|c|c|c|c|c|c|}
\hline \multirow[t]{2}{*}{ Activity } & \multicolumn{4}{|c|}{$\begin{array}{l}\text { Total No. of lien } \\
\text { indicating attitude } \\
\text { toward activity }\end{array}$} & \multirow{2}{*}{\multicolumn{2}{|c|}{$\begin{array}{l}\text { Total No. of hien } \\
\text { stating reasons } \\
\text { for insufficient } \\
\text { participation }\end{array}$}} & \multicolumn{4}{|c|}{ Total No. of Participations } \\
\hline & & Like & Dislike & Indif. & & & Wkly. & Mthly. & Yrly. & $\begin{array}{l}\text { Part. } \\
\text { Index }\end{array}$ \\
\hline \multirow[b]{2}{*}{ Hotoring } & No. & 64 & 3 & 24 & \multirow{2}{*}{$\begin{array}{l}\text { Health } \\
\text { Time } \\
\text { líoney } \\
\text { Facilities } \\
\text { Knowledge } \\
\text { and Skill } \\
\quad \text { TOTAI } \\
\end{array}$} & \multirow{2}{*}{$\begin{array}{r}0 \\
6 \\
9 \\
1 \\
0 \\
16\end{array}$} & \multirow[t]{2}{*}{46} & \multirow[t]{2}{*}{5} & \multirow[t]{2}{*}{17} & \multirow[t]{2}{*}{24.90} \\
\hline & $\not \partial$ & 70.3 & 3.3 & 26.4 & & & & & & \\
\hline \multirow[b]{2}{*}{$\begin{array}{l}\text { Night } \\
\text { Clubbing }\end{array}$} & No. & 46 & 8 & 37 & \multirow[b]{2}{*}{$\begin{array}{l}\text { Health } \\
\text { Time } \\
\text { Ironey } \\
\text { Facilities } \\
\text { Knowledge } \\
\text { and Skill } \\
\quad \text { TOIAI }\end{array}$} & 0 & \multirow[t]{2}{*}{22} & \multirow[t]{2}{*}{20} & \multirow[t]{2}{*}{12} & \multirow[t]{2}{*}{15.34} \\
\hline & $g$ & 50.5 & 8.8 & 40.7 & & $\begin{array}{r}3 \\
8 \\
0 \\
0 \\
11 \\
\end{array}$ & & & & \\
\hline \multirow[b]{2}{*}{ Ping-Pong } & No. & 58 & 9 & 24 & \multirow{2}{*}{$\begin{array}{l}\text { Health } \\
\text { Time } \\
\text { Money } \\
\text { Facilities } \\
\text { Knowledge } \\
\text { and SkilI } \\
\quad \text { TOIAI }\end{array}$} & 0 & \multirow[t]{2}{*}{9} & \multirow[t]{2}{*}{24} & \multirow[t]{2}{*}{18} & \multirow[t]{2}{*}{8.50} \\
\hline & $c_{p}^{\prime}$ & 63.6 & 9.9 & 26.5 & & $\begin{array}{r}0 \\
14 \\
\frac{0}{20}\end{array}$ & & & & \\
\hline
\end{tabular}


TABIE 27 (Continued)

20-29 Age Group

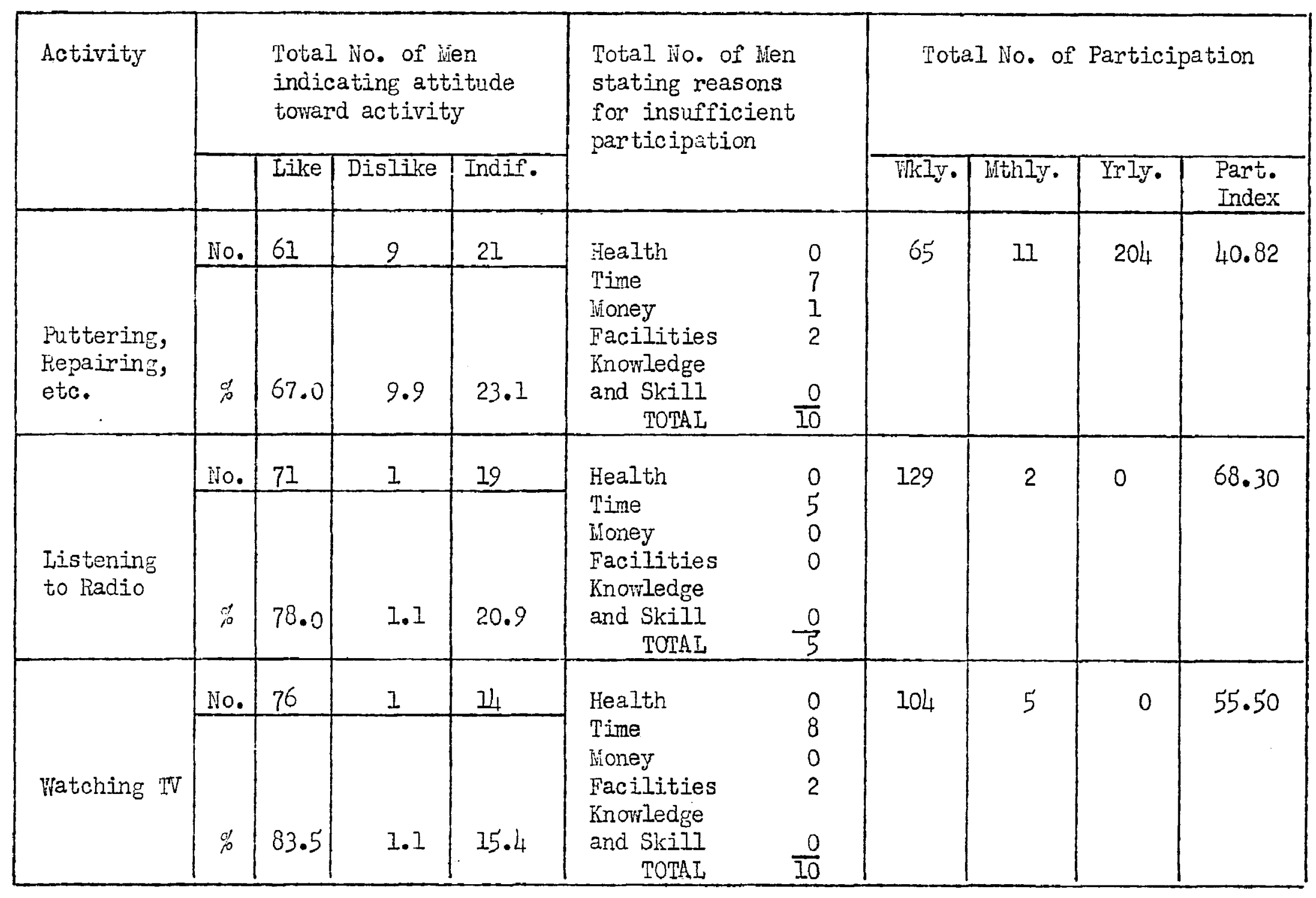


TIBIE 27 (Continued)

20-29 Age Group

\begin{tabular}{|c|c|c|c|c|c|c|c|c|c|c|}
\hline \multirow[t]{2}{*}{ Activity } & & \multicolumn{3}{|c|}{$\begin{array}{l}\text { Total lo. of Men } \\
\text { indicatins attitude } \\
\text { toward activity }\end{array}$} & \multirow{2}{*}{\multicolumn{2}{|c|}{$\begin{array}{l}\text { Total No. of lien } \\
\text { stating reasons } \\
\text { for insufficient } \\
\text { participation }\end{array}$}} & \multicolumn{4}{|c|}{ Total No. of Participation } \\
\hline & & Like & Dislike & Indif. & & & WkII- & inthly. & Yrly. & $\begin{array}{l}\text { Part. } \\
\text { Index }\end{array}$ \\
\hline \multirow[b]{2}{*}{ Reading } & No. & 65 & 7 & 19 & \multirow{2}{*}{$\begin{array}{l}\text { Health } \\
\text { Time } \\
\text { Money } \\
\text { Facilities } \\
\text { Knowledge } \\
\text { and Skill } \\
\quad \text { TOTAL } \\
\end{array}$} & \multirow{2}{*}{$\begin{array}{r}0 \\
12 \\
0 \\
0 \\
\frac{0}{12}\end{array}$} & \multirow[t]{2}{*}{107} & \multirow[t]{2}{*}{14} & \multirow[t]{2}{*}{3} & \multirow[t]{2}{*}{63.02} \\
\hline & 8 & 71.4 & 7.7 & 20.9 & & & & & & \\
\hline \multirow[b]{2}{*}{ Photography } & No. & 49 & 8 & 34 & \multirow{2}{*}{$\begin{array}{l}\text { Health } \\
\text { Tine } \\
\text { Honey } \\
\text { Facilities } \\
\text { Knowledge } \\
\text { and Skill } \\
\quad \text { TOMAI } \\
\end{array}$} & 0 & \multirow[t]{2}{*}{1.1} & \multirow[t]{2}{*}{20} & \multirow[t]{2}{*}{58} & \multirow[t]{2}{*}{9.56} \\
\hline & of & 53.9 & 8.8 & $37 \cdot 4$ & & $\begin{array}{r}6 \\
4 \\
\frac{1}{18}\end{array}$ & & & & \\
\hline \multirow[b]{2}{*}{$\begin{array}{l}\text { Roller } \\
\text { Skating }\end{array}$} & $\mathrm{Ho}$ & 40 & 17 & 40 & \multirow{2}{*}{$\begin{array}{l}\text { Health } \\
\text { Time } \\
\text { Woney } \\
\text { Facilities } \\
\text { Knowledge } \\
\text { and Skill } \\
\text { TOPAL }\end{array}$} & 1 & \multirow[t]{2}{*}{4} & \multirow[t]{2}{*}{11} & \multirow[t]{2}{*}{22} & \multirow[t]{2}{*}{3.98} \\
\hline & $\%$ & 43.9 & 12.1 & 44.0 & & $\begin{array}{r}10 \\
0 \\
1 \\
\frac{2}{1 I_{4}}\end{array}$ & & & & \\
\hline
\end{tabular}


TABLE 27 (Continued)

20-29 Age Group

\begin{tabular}{|c|c|c|c|c|c|c|c|c|c|c|}
\hline \multirow[t]{2}{*}{ Activity } & \multicolumn{4}{|c|}{$\begin{array}{l}\text { Total No. of Men } \\
\text { indicating attitude } \\
\text { toward activity }\end{array}$} & \multirow{2}{*}{\multicolumn{2}{|c|}{$\begin{array}{l}\text { Total No. of Men } \\
\text { stating reasons } \\
\text { for insufficient } \\
\text { participation }\end{array}$}} & \multicolumn{4}{|c|}{ Total No. of Participation } \\
\hline & & Like & Dislike & Indif. & & & WKIJ. & Mthly. & $\operatorname{Irly.}$ & $\begin{array}{l}\text { Part. } \\
\text { Index }\end{array}$ \\
\hline \multirow[b]{2}{*}{ Painting } & No. & 30 & 20 & 41 & \multirow{2}{*}{$\begin{array}{l}\text { Health } \\
\text { Time } \\
\text { Noney } \\
\text { Facilities } \\
\text { Knowledge } \\
\text { and Skill } \\
\quad \text { TOTAL } \\
\end{array}$} & \multirow{2}{*}{$\begin{array}{l}0 \\
4 \\
0 \\
0 \\
\frac{1}{5}\end{array}$} & \multirow[t]{2}{*}{1} & \multirow[t]{2}{*}{5} & \multirow[t]{2}{*}{23} & \multirow[t]{2}{*}{1.48} \\
\hline & $\%$ & 33.0 & 22.0 & 45.0 & & & & & & \\
\hline \multirow[b]{2}{*}{$\begin{array}{l}\text { Social } \\
\text { Drinking }\end{array}$} & No. & 59 & 7 & 25 & \multirow{2}{*}{$\begin{array}{l}\text { Health } \\
\text { Time } \\
\text { Money } \\
\text { Facilities } \\
\text { Knowledge } \\
\text { and Skill } \\
\quad \text { TOMAL } \\
\end{array}$} & \multirow{2}{*}{$\begin{array}{r}0 \\
5 \\
12 \\
0 \\
0 \\
\frac{0}{17}\end{array}$} & \multirow[t]{2}{*}{39} & \multirow[t]{2}{*}{119} & \multirow[t]{2}{*}{10} & \multirow[t]{2}{*}{38.09} \\
\hline & $\mathscr{p}$ & 63.8 & 7.7 & 28.5 & & & & & & \\
\hline \multirow[b]{2}{*}{$\begin{array}{l}\text { Sailing } \\
\text { (5 nonths) }\end{array}$} & No. & 29 & 11 & 51 & \multirow{2}{*}{$\begin{array}{l}\text { Health } \\
\text { Time } \\
\text { Money } \\
\text { Facilities } \\
\text { Knowledge } \\
\text { and Skill } \\
\quad \text { TOTAL }\end{array}$} & 0 & \multirow[t]{2}{*}{3} & \multirow[t]{2}{*}{1} & \multirow[t]{2}{*}{20} & \multirow[t]{2}{*}{.99} \\
\hline & 名 & 31.9 & 12.1 & 56.0 & & $\begin{array}{r}8 \\
12 \\
\frac{2}{26}\end{array}$ & & & & \\
\hline
\end{tabular}


TABIE 27 (Continued)

20-29 Age Group

\begin{tabular}{|c|c|c|c|c|c|c|c|c|c|c|}
\hline \multirow[t]{2}{*}{ Activity } & & \multicolumn{3}{|c|}{$\begin{array}{l}\text { Total No. of Men } \\
\text { indicating attitude } \\
\text { toward activity }\end{array}$} & \multirow{2}{*}{\multicolumn{2}{|c|}{$\begin{array}{l}\text { Total No. of lien } \\
\text { stating reasons } \\
\text { for insufficient } \\
\text { participation }\end{array}$}} & \multicolumn{4}{|c|}{ Total No. of Participation } \\
\hline & & Iike & Dislike & Indif. & & & WkIy. & Withly. & Yrly. & $\begin{array}{l}\text { Part. } \\
\text { Index }\end{array}$ \\
\hline & No. & 32 & 16 & 43 & \multirow[b]{2}{*}{$\begin{array}{l}\text { Health } \\
\text { Time } \\
\text { Money } \\
\text { Facilities } \\
\text { Knowledge } \\
\text { and SkilI } \\
\quad \text { TOTAI } \\
\end{array}$} & \multirow[b]{2}{*}{$\begin{array}{l}0 \\
2 \\
1 \\
9 \\
\frac{7}{19}\end{array}$} & \multirow[t]{2}{*}{0} & \multirow[t]{2}{*}{0} & \multirow[t]{2}{*}{25} & \multirow[t]{2}{*}{.27} \\
\hline $\begin{array}{l}\text { Skiing } \\
\text { ( } 3 \text { Nonths) }\end{array}$ & $\mathscr{0}$ & 35.2 & 17.6 & 47.2 & & & & & & \\
\hline \multirow[b]{2}{*}{$\begin{array}{l}\text { Social } \\
\text { Dancing }\end{array}$} & No. & 64 & 12 & 15 & \multirow{2}{*}{$\begin{array}{l}\text { Health } \\
\text { Time } \\
\text { lioney } \\
\text { Facilities } \\
\text { Knowledge } \\
\text { and Skill } \\
\text { TOIAI } \\
\end{array}$} & \multirow[b]{2}{*}{$\begin{array}{l}0 \\
7 \\
4 \\
1 \\
\frac{5}{16} \\
\end{array}$} & \multirow[t]{2}{*}{15} & \multirow[t]{2}{*}{23} & \multirow[t]{2}{*}{32} & \multirow[t]{2}{*}{11.96} \\
\hline & $\stackrel{0}{10}$ & 70.3 & 13.2 & 16.5 & & & & & & \\
\hline & ino. & 64 & 6 & 21 & \multirow[b]{2}{*}{$\begin{array}{l}\text { Health } \\
\text { Time } \\
\text { lloney } \\
\text { Facilities } \\
\text { Knowledge } \\
\text { and Skill } \\
\quad \text { TOTAI }\end{array}$} & 0 & \multirow[t]{2}{*}{$I_{4}$} & \multirow[t]{2}{*}{18} & \multirow[t]{2}{*}{56} & \multirow[t]{2}{*}{3.21} \\
\hline $\begin{array}{l}\text { Softball } \\
\text { (3 Nonths) }\end{array}$ & 吕 & 70.3 & 6.6 & 21 & & $\begin{array}{l}17 \\
\frac{1}{6} \\
\frac{1}{25}\end{array}$ & & & & \\
\hline
\end{tabular}


TABLE 27 (Continued)

20-29 Age Group

\begin{tabular}{|c|c|c|c|c|c|c|c|c|c|c|}
\hline \multirow[t]{2}{*}{ Activity } & & \multicolumn{3}{|c|}{$\begin{array}{l}\text { Total No, of Men } \\
\text { indicating attitude } \\
\text { toward activity }\end{array}$} & \multirow{2}{*}{\multicolumn{2}{|c|}{$\begin{array}{l}\text { Total io. of iien } \\
\text { stating reasons } \\
\text { for insufficient } \\
\text { participation }\end{array}$}} & \multicolumn{4}{|c|}{ Total No. of Participation } \\
\hline & & Fike & Dislike & Indif. & & & wely. & Mthly. & Yrly. & $\begin{array}{l}\text { Part } \\
\text { Index }\end{array}$ \\
\hline \multirow[b]{2}{*}{$\begin{array}{l}\text { Speedball } \\
\text { (3 ironths) }\end{array}$} & No. & 16 & 13 & 62 & \multirow{2}{*}{$\begin{array}{l}\text { Health } \\
\text { Time } \\
\text { Honey } \\
\text { Facilities } \\
\text { Knowledge } \\
\text { and Skill } \\
\quad \text { TOTAL } \\
\end{array}$} & \multirow{2}{*}{$\begin{array}{l}0 \\
4 \\
0 \\
1 \\
\\
2 \\
\end{array}$} & \multirow[t]{2}{*}{0} & \multirow[t]{2}{*}{7} & \multirow[t]{2}{*}{5} & \multirow[t]{2}{*}{.29} \\
\hline & $\%$ & 17.6 & 14.3 & 68.1 & & & & & & \\
\hline \multirow{2}{*}{$\begin{array}{l}\cdots \\
\text { Square } \\
\text { Dancing }\end{array}$} & No. & 24 & 21 & 46 & \multirow{2}{*}{$\begin{array}{l}\text { Health } \\
\text { Time } \\
\text { Honey } \\
\text { Facilities } \\
\text { Knowledge } \\
\text { and Skill } \\
\quad \text { TOTAL } \\
\end{array}$} & \multirow{2}{*}{$\begin{array}{l}0 \\
5 \\
1 \\
3 \\
5 \\
5 \\
\end{array}$} & \multirow[t]{2}{*}{2} & \multirow[t]{2}{*}{5} & \multirow[t]{2}{*}{11} & \multirow[t]{2}{*}{1.92} \\
\hline & of & 26.5 & 23.1 & 50.4 & & & & & & \\
\hline \multirow[b]{2}{*}{$\begin{array}{l}\text { Stamp } \\
\text { Collecting }\end{array}$} & ivo. & 3 & 39 & 49 & \multirow{2}{*}{$\begin{array}{l}\text { Health } \\
\text { Time } \\
\text { Nioney } \\
\text { Facilities } \\
\text { Knowledge } \\
\text { and Skill } \\
\text { TOTAL } \\
\end{array}$} & 0 & \multirow[t]{2}{*}{5} & \multirow[t]{2}{*}{0} & \multirow[t]{2}{*}{4} & \multirow[t]{2}{*}{2.90} \\
\hline & $\not \partial$ & 3.3 & 42.9 & 53.8 & & $\begin{array}{l}2 \\
1 \\
0\end{array}$ & & & & \\
\hline
\end{tabular}


TABIE 27 (Continued)

20-29 Age Group

\begin{tabular}{|c|c|c|c|c|c|c|c|c|c|c|}
\hline \multirow[t]{2}{*}{ Activity } & \multicolumn{4}{|c|}{$\begin{array}{l}\text { Total ivo. of lien } \\
\text { indicating attitude } \\
\text { toward activity }\end{array}$} & \multirow{2}{*}{\multicolumn{2}{|c|}{$\begin{array}{l}\text { Total No. of Men } \\
\text { stating reasons } \\
\text { for insufficient } \\
\text { participation }\end{array}$}} & \multicolumn{4}{|c|}{ Total No. of Participation } \\
\hline & & Like & Dislike & Indif. & & & Wkly. & Mthly. & Irly. & $\begin{array}{l}\text { Part. } \\
\text { Index }\end{array}$ \\
\hline \multirow[b]{2}{*}{$\begin{array}{l}\text { Swimning } \\
\text { (3 Honths) }\end{array}$} & No. & 80 & 2 & 9 & \multirow{2}{*}{$\begin{array}{l}\text { Health } \\
\text { Time } \\
\text { Money } \\
\text { Facilities } \\
\text { inowledge } \\
\text { and Skill } \\
\text { TOTAI } \\
\end{array}$} & \multirow{2}{*}{$\begin{array}{r}0 \\
15 \\
1 \\
7 \\
\frac{4}{27} \\
\end{array}$} & \multirow[t]{2}{*}{22} & \multirow[t]{2}{*}{21} & \multirow[t]{2}{*}{92} & \multirow[t]{2}{*}{4.85} \\
\hline & $\not 8$ & 87.9 & 2.2 & 9.9 & & & & & & \\
\hline \multirow[b]{2}{*}{$\begin{array}{l}\text { Tennis } \\
\text { (5 Jonths) }\end{array}$} & No. & 30 & 20 & 41 & \multirow{2}{*}{$\begin{array}{l}\text { Health } \\
\text { Time } \\
\text { Money } \\
\text { Facilities } \\
\text { Knowledge } \\
\text { and Skill } \\
\text { TOTAL } \\
\end{array}$} & \multirow[b]{2}{*}{$\begin{array}{l}1 \\
9 \\
1 \\
4 \\
\frac{2}{17} \\
\end{array}$} & \multirow[t]{2}{*}{2} & \multirow[t]{2}{*}{5} & \multirow[t]{2}{*}{23} & \multirow[t]{2}{*}{1.00} \\
\hline & $\%$ & 33.0 & 22.0 & 45.0 & & & & & & \\
\hline \multirow[b]{2}{*}{$\begin{array}{l}\text { Touch } \\
\text { Football } \\
\text { (3 Months) }\end{array}$} & No. & 48 & 10 & 33 & \multirow{2}{*}{$\begin{array}{l}\text { Health } \\
\text { Time } \\
\text { Woney } \\
\text { Facilities } \\
\text { Knowledge } \\
\text { and Skill } \\
\quad \text { TOTAL } \\
\end{array}$} & \multirow{2}{*}{$\begin{array}{r}0 \\
12 \\
1 \\
2 \\
0 \\
\frac{15}{15}\end{array}$} & \multirow[t]{2}{*}{5} & \multirow[t]{2}{*}{14} & \multirow[t]{2}{*}{21} & \multirow[t]{2}{*}{1.41} \\
\hline & $\%$ & 52.7 & 17.0 & 36.3 & & & & & & \\
\hline
\end{tabular}


TABIE 27 (Continued)

20-29 Age Group

\begin{tabular}{|c|c|c|c|c|c|c|c|c|c|c|}
\hline \multirow[t]{2}{*}{ Activity } & & \multicolumn{3}{|c|}{$\begin{array}{l}\text { Total ivo. of Men } \\
\text { indicating attitude } \\
\text { toward activity }\end{array}$} & \multirow{2}{*}{\multicolumn{2}{|c|}{$\begin{array}{l}\text { Total No. of Wen } \\
\text { stauing reasons } \\
\text { for insufficient } \\
\text { participation }\end{array}$}} & \multicolumn{4}{|c|}{ Total No. of Participations } \\
\hline & & Iike & Dislike & Indif. & & & Wkig. & Wthly. & Irly. & $\begin{array}{l}\text { Part. } \\
\text { Index }\end{array}$ \\
\hline \multirow[b]{2}{*}{ Tumbling } & No. & 18 & 27 & 46 & \multirow[b]{2}{*}{$\begin{array}{l}\text { Health } \\
\text { Time } \\
\text { inoney } \\
\text { Facilities } \\
\text { Knowledge } \\
\text { and Skill } \\
\quad \text { TOTAL } \\
\end{array}$} & \multirow[b]{2}{*}{$\begin{array}{l}0 \\
5 \\
0 \\
5 \\
\frac{0}{10} \\
\end{array}$} & \multirow[t]{2}{*}{9} & \multirow[t]{2}{*}{3} & \multirow[t]{2}{*}{7} & \multirow[t]{2}{*}{5.62} \\
\hline & 8 & 19.9 & 29.7 & 50.4 & & & & & & \\
\hline \multirow[b]{2}{*}{$\begin{array}{l}\text { Visiting } \\
\text { Friends }\end{array}$} & Ho. & 71. & 1 & 19 & \multirow{2}{*}{$\begin{array}{l}\text { Health } \\
\text { Time } \\
\text { Money } \\
\text { Facilities } \\
\text { Knowledge } \\
\text { and Skill } \\
\quad \text { TOTAL } \\
\end{array}$} & \multirow{2}{*}{$\begin{array}{r}0 \\
11 \\
0 \\
0 \\
0 \\
\frac{0}{11}\end{array}$} & \multirow[t]{2}{*}{58} & \multirow[t]{2}{*}{27} & \multirow[t]{2}{*}{2.} & \multirow[t]{2}{*}{36.73} \\
\hline & $\%$ & 78.0 & 1.1 & 20.9 & & & & & & \\
\hline \multirow[b]{2}{*}{ Volleyball } & No. & 45 & 11 & 35 & \multirow{2}{*}{$\begin{array}{l}\text { Health } \\
\text { Time } \\
\text { Money } \\
\text { Facilities } \\
\text { Knowledge } \\
\text { and SkilI } \\
\text { TOTAI }\end{array}$} & 0 & \multirow[t]{2}{*}{1} & \multirow[t]{2}{*}{9} & \multirow[t]{2}{*}{25} & \multirow[t]{2}{*}{2.03} \\
\hline & o & 49.5 & 12.5 & 38.0 & & $\begin{array}{c}0 \\
9 \\
\frac{0}{20}\end{array}$ & & & & \\
\hline
\end{tabular}


TA3IE 27 (Continued)

20-29 Age Group

\begin{tabular}{|c|c|c|c|c|c|c|c|c|c|c|}
\hline \multirow[t]{2}{*}{ Activity } & \multicolumn{4}{|c|}{$\begin{array}{l}\text { Total No. of Men } \\
\text { indicating attitude } \\
\text { toward activity }\end{array}$} & \multirow{2}{*}{\multicolumn{2}{|c|}{$\begin{array}{l}\text { Total Wo. of Men } \\
\text { stating reasons } \\
\text { for insufficient } \\
\text { participation }\end{array}$}} & \multicolumn{4}{|c|}{ Total No. of Farticipations } \\
\hline & & Like & Dislike & Indif. & & & Whly. & Mthly. & Yrly. & $\begin{array}{l}\text { Part. } \\
\text { Index }\end{array}$ \\
\hline \multirow[b]{2}{*}{$\begin{array}{l}\text { Watching } \\
\text { Sports Event }\end{array}$} & Ho: & 83 & 1 & 7 & \multirow[b]{2}{*}{$\begin{array}{l}\text { Health } \\
\text { Time } \\
\text { Money } \\
\text { Facilities } \\
\text { Knowledge } \\
\text { and Skill } \\
\quad \text { TOTAL } \\
\end{array}$} & \multirow[b]{2}{*}{$\begin{array}{r}0 \\
10 \\
7 \\
2 \\
\\
0 \\
19\end{array}$} & \multirow[t]{2}{*}{59} & \multirow[t]{2}{*}{20} & \multirow[t]{2}{*}{69} & \multirow[t]{2}{*}{37.11} \\
\hline & 5 & 91.2 & 1.1 & 7.7 & & & & & & \\
\hline \multirow[b]{2}{*}{ Walking } & No. & 51 & 15 & 25 & \multirow[b]{2}{*}{$\begin{array}{l}\text { Health } \\
\text { Tine } \\
\text { Money } \\
\text { Facilities } \\
\text { Knowledge } \\
\text { and Skill } \\
\text { TOTAL } \\
\end{array}$} & 0 & \multirow[t]{2}{*}{79} & \multirow[t]{2}{*}{2} & \multirow[t]{2}{*}{4} & \multirow[t]{2}{*}{45.45} \\
\hline & $\not s$ & 56.0 & 16.5 & 27.5 & & $\begin{array}{l}6 \\
0 \\
0 \\
0 \\
\frac{0}{6} \\
\end{array}$ & & & & \\
\hline \multirow[b]{2}{*}{$\begin{array}{l}\text { Weight } \\
\text { Lifting }\end{array}$} & No. & 25 & 23 & 43 & \multirow{2}{*}{$\begin{array}{l}\text { Health } \\
\text { Time } \\
\text { Money } \\
\text { Facilities } \\
\text { Knowledge } \\
\text { and Skill } \\
\text { TOTAL }\end{array}$} & 1 & \multirow[t]{2}{*}{17} & \multirow[t]{2}{*}{7} & \multirow[t]{2}{*}{13} & \multirow[t]{2}{*}{10.78} \\
\hline & $\not t$ & 27.5 & 25.3 & 47.2 & & $\begin{array}{r}y \\
0 \\
4 \\
0 \\
\frac{0}{I_{4}}\end{array}$ & & & & \\
\hline
\end{tabular}


TABIE 27 (Continued)

20-29 Age Group

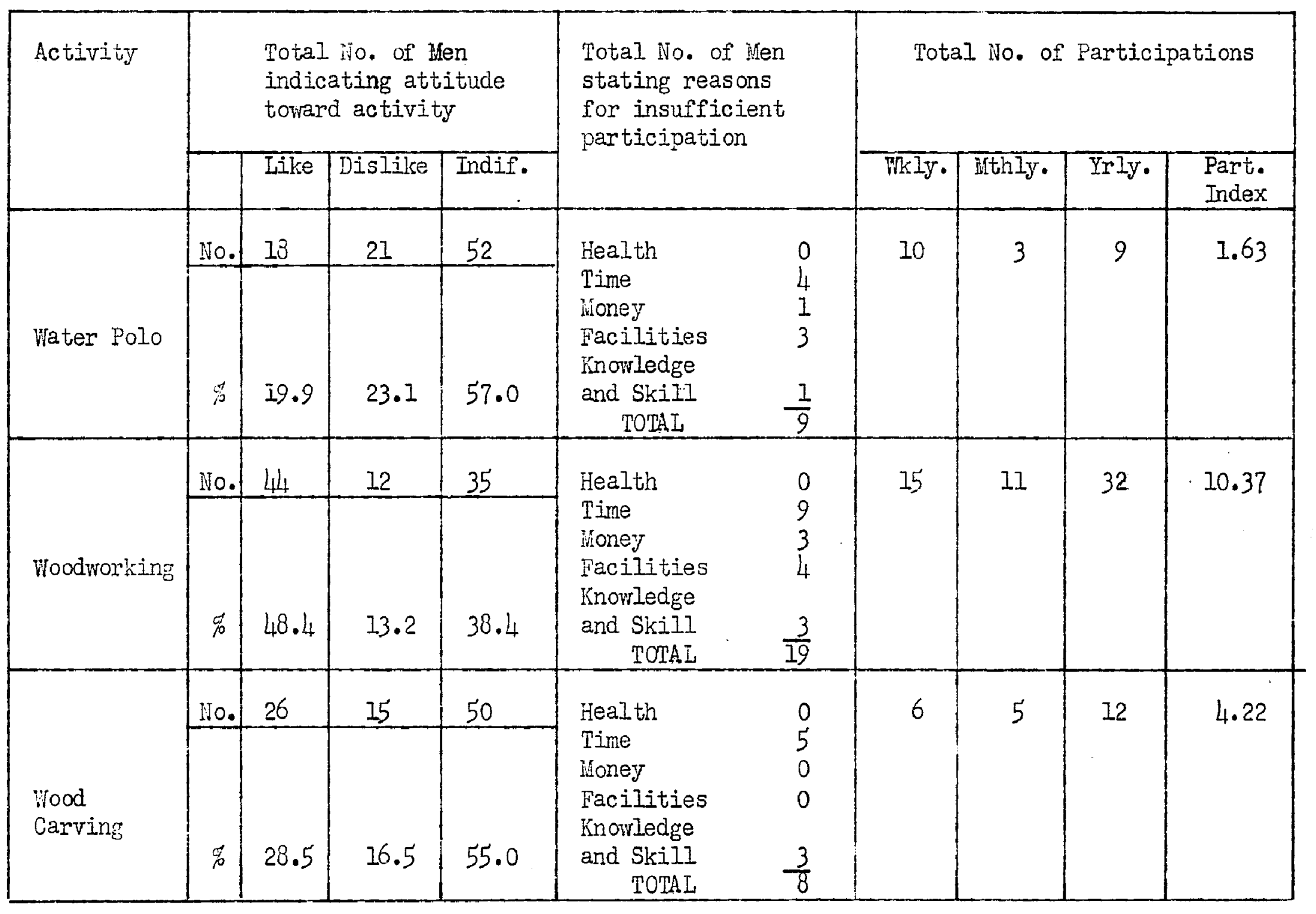


TABLE 27 (Continued)

20-29 Age Group

\begin{tabular}{|c|c|c|c|c|c|c|c|c|c|c|}
\hline \multirow[t]{2}{*}{ Activity } & & \multicolumn{3}{|c|}{$\begin{array}{l}\text { Total iNo. of lien } \\
\text { indicating attitude } \\
\text { toward activity }\end{array}$} & \multirow{2}{*}{\multicolumn{2}{|c|}{$\begin{array}{l}\text { Total No. of Men } \\
\text { stating reasons } \\
\text { for insufficient } \\
\text { participation }\end{array}$}} & \multicolumn{4}{|c|}{ Total No. of Participations } \\
\hline & & Like & Dislike & Indif. & & & WkIy. & Nthly. & Yrly. & $\begin{array}{l}\text { Fart. } \\
\text { Index }\end{array}$ \\
\hline \multirow[b]{2}{*}{ Wrestling } & No. & 25 & 25 & $4 I$ & \multirow{2}{*}{$\begin{array}{l}\text { Health } \\
\text { Time } \\
\text { Bloney } \\
\text { Facilities } \\
\text { Knowledge } \\
\text { and Skill } \\
\quad \text { TOTAL }\end{array}$} & 1 & \multirow[t]{2}{*}{1} & \multirow[t]{2}{*}{9} & \multirow[t]{2}{*}{ 工 } & \multirow[t]{2}{*}{1.91} \\
\hline & $\not 1$ & 27.5 & 27.5 & 45.0 & & $\begin{array}{l}1 \\
1 \\
\frac{1}{10} \\
\end{array}$ & & & & \\
\hline
\end{tabular}

REASOIN :

$\begin{array}{lrrr}\text { Health } & 5 & - & .4 \% \\ \text { Time } & 699 & -56.2 \% \\ \text { Money } & 157 & -12.6 \% \\ \text { Facilities } & 268 & -21.6 \% \\ \text { Knowledge and Skill } & 11 l_{4} & -9.2 \%\end{array}$




\section{TABLE 28}

Numbers and Percentages of lien Liking, Disliking, and Indifferent to Each of Sixty-Seven Recreational Activities, Extent of Participation in Each, and Number of Nen Listing Each of Five Reasons for Unsatisfactory Participation in the 30-39 Age Group

\begin{tabular}{|c|c|c|c|c|c|c|c|c|c|c|}
\hline \multirow[t]{2}{*}{ Activity } & & \multicolumn{3}{|c|}{$\begin{array}{l}\text { Total No. of Men } \\
\text { indicating attitude } \\
\text { toward activity }\end{array}$} & \multirow{2}{*}{\multicolumn{2}{|c|}{$\begin{array}{l}\text { Total io. of len } \\
\text { stating reasons } \\
\text { for insufficient } \\
\text { participation }\end{array}$}} & \multicolumn{4}{|c|}{ Total No. of Participations } \\
\hline & & Iike & Dislike & Indif. & & & Thly. & Inthly. & Irly. & $\begin{array}{l}\text { Part. } \\
\text { Index }\end{array}$ \\
\hline \multirow[b]{2}{*}{ Archery } & No. & 43 & 35 & 83 & \multirow{2}{*}{$\begin{array}{l}\text { Health } \\
\text { Time } \\
\text { Money } \\
\text { Facilities } \\
\text { Knowledge } \\
\text { and Skill } \\
\quad \text { TOTAL } \\
\end{array}$} & \multirow{2}{*}{$\begin{array}{r}0 \\
25 \\
8 \\
17 \\
\frac{5}{49}\end{array}$} & \multirow[t]{2}{*}{3} & \multirow[t]{2}{*}{11} & \multirow[t]{2}{*}{51} & \multirow[t]{2}{*}{2.1} \\
\hline & $\%$ & 26.7 & 21.7 & 51.6 & & & & & & \\
\hline \multirow[b]{2}{*}{ Badminton } & No. & 81 & 29 & 51 & \multirow{2}{*}{$\begin{array}{l}\text { Health } \\
\text { Time } \\
\text { loney } \\
\text { Facilities } \\
\text { Knowledge } \\
\text { and Skill } \\
\quad \text { TOTAL }\end{array}$} & 0 & \multirow[t]{2}{*}{12} & \multirow[t]{2}{*}{27} & \multirow[t]{2}{*}{152} & \multirow[t]{2}{*}{6.77} \\
\hline & $\%$ & 50.3 & 10.0 & 31.7 & & $\begin{array}{r}5 \\
12 \\
\frac{2}{50}\end{array}$ & & & & \\
\hline
\end{tabular}


TABIE 28 (Continued)

30-39 Age Group

\begin{tabular}{|c|c|c|c|c|c|c|c|c|c|c|}
\hline \multirow[t]{2}{*}{ Activity } & \multicolumn{4}{|c|}{$\begin{array}{l}\text { Total lo. of lien } \\
\text { indicating attitude } \\
\text { toward activity }\end{array}$} & \multirow{2}{*}{\multicolumn{2}{|c|}{$\begin{array}{l}\text { Total No. of lien } \\
\text { stating reasons } \\
\text { for insufficient } \\
\text { participation }\end{array}$}} & \multicolumn{4}{|c|}{ Total No. of Participations } \\
\hline & & Like & Dislike & Indif. & & & Tik $l_{y} \cdot$ & Ifthly. & Yrly. & $\begin{array}{l}\text { Part. } \\
\text { Index }\end{array}$ \\
\hline \multirow[b]{2}{*}{$\begin{array}{l}\text { Bag } \\
\text { Punching }\end{array}$} & No. & $3 I$ & 54 & 76 & \multirow{2}{*}{$\begin{array}{l}\text { Health } \\
\text { Time } \\
\text { Money } \\
\text { Facilities } \\
\text { Knowledge } \\
\text { and Skill } \\
\quad \text { TOTAL } \\
\end{array}$} & \multirow{2}{*}{$\begin{array}{r}1 \\
13 \\
2 \\
4 \\
\frac{2}{22} \\
\end{array}$} & \multirow[t]{2}{*}{10} & \multirow[t]{2}{*}{7} & \multirow[t]{2}{*}{22} & \multirow[t]{2}{*}{3.89} \\
\hline & \% & 19.3 & 33.5 & 47.2 & & & & & & \\
\hline \multirow[b]{2}{*}{$\begin{array}{l}\text { Baseball } \\
\text { (3 inths) }\end{array}$} & No. & 139 & 2 & 20 & \multirow{2}{*}{$\begin{array}{l}\text { Health } \\
\text { Time } \\
\text { Money } \\
\text { Facilities } \\
\text { Knowiedge } \\
\text { and Skill } \\
\quad \text { TOTAL } \\
\end{array}$} & \multirow{2}{*}{$\begin{array}{r}8 \\
55 \\
9 \\
6 \\
\frac{1}{79}\end{array}$} & \multirow[t]{2}{*}{23} & \multirow[t]{2}{*}{24} & \multirow[t]{2}{*}{73} & \multirow[t]{2}{*}{2.76} \\
\hline & $\%$ & 86.34 & 1.24 & 12.42 & & & & & & \\
\hline \multirow[b]{2}{*}{$\begin{array}{l}\text { Basketball } \\
\text { (6 Hionths) }\end{array}$} & IIo. & 74 & 31 & 56 & \multirow{2}{*}{$\begin{array}{l}\text { Health } \\
\text { Tina } \\
\text { Hiney } \\
\text { Facilities } \\
\text { Knowledge } \\
\text { and Skill } \\
\quad \text { TOTAL }\end{array}$} & \multirow{2}{*}{$\begin{array}{r}6 \\
32 \\
5 \\
7 \\
0 \\
50 \\
\end{array}$} & \multirow[t]{2}{*}{8} & \multirow[t]{2}{*}{3} & \multirow[t]{2}{*}{38} & \multirow[t]{2}{*}{1.62} \\
\hline & $\%$ & 45.97 & 19.25 & 34.78 & & & & & & \\
\hline
\end{tabular}


TABLE 28 (Continued)

30-39 Age Group

\begin{tabular}{|c|c|c|c|c|c|c|c|c|c|c|}
\hline \multirow[t]{2}{*}{ Activity } & & \multicolumn{3}{|c|}{$\begin{array}{l}\text { Total No, of Men } \\
\text { indicating attitude } \\
\text { toward activity }\end{array}$} & \multirow{2}{*}{\multicolumn{2}{|c|}{$\begin{array}{l}\text { Total No. of lien } \\
\text { stating reasons } \\
\text { for insufficient } \\
\text { participation }\end{array}$}} & \multicolumn{4}{|c|}{ Total No. of Participations } \\
\hline & & Iike & Dislike & Indif. & & & Thly. & Nthly. & Yrly. & Part. Index \\
\hline & No. & 88 & 19 & 54 & \multirow[b]{2}{*}{$\begin{array}{l}\text { Health } \\
\text { Time } \\
\text { Money } \\
\text { Facilities } \\
\text { Knowledge } \\
\text { and Skill } \\
\quad \text { TOTAL } \\
\end{array}$} & \multirow[b]{2}{*}{$\begin{array}{r}1 \\
29 \\
13 \\
9 \\
0 \\
52 \\
\end{array}$} & \multirow[t]{2}{*}{10} & \multirow[t]{2}{*}{21} & \multirow[t]{2}{*}{83} & \multirow[t]{2}{*}{2.51} \\
\hline $\begin{array}{l}\text { Boating } \\
\text { ( } 5 \text { Months) }\end{array}$ & g & 54.69 & 11.78 & 33.53 & & & & & & \\
\hline \multirow[b]{2}{*}{$\begin{array}{l}\text { Bowling } \\
\text { (9 Nonths) }\end{array}$} & No. & 127 & 18 & 16 & \multirow{2}{*}{$\begin{array}{l}\text { Health } \\
\text { Pine } \\
\text { Money } \\
\text { Facilities } \\
\text { Knowledge } \\
\text { and Skill } \\
\quad \text { TOTAI } \\
\end{array}$} & \multirow{2}{*}{$\begin{array}{r}1 \\
30 \\
19 \\
3 \\
2 \\
55 \\
\end{array}$} & \multirow[t]{2}{*}{$44_{4}$} & \multirow[t]{2}{*}{22} & \multirow[t]{2}{*}{259} & \multirow[t]{2}{*}{13.50} \\
\hline & $\%$ & 78.88 & 11.13 & 9.94 & & & & & & \\
\hline \multirow[b]{2}{*}{ Boxing } & INo. & 41 & 49 & 71 & \multirow{2}{*}{$\begin{array}{l}\text { Health } \\
\text { Time } \\
\text { Whoney } \\
\text { Facilities } \\
\text { Knowledge } \\
\text { and Skili } \\
\quad \text { TOTAL }\end{array}$} & 4 & \multirow[t]{2}{*}{8} & \multirow[t]{2}{*}{5} & \multirow[t]{2}{*}{8} & \multirow[t]{2}{*}{3.00} \\
\hline & $\mathscr{p}^{\prime \prime}$ & 25.46 & 30.43 & 44.11 & & $\begin{array}{r}7 \\
3 \\
\frac{7}{24}\end{array}$ & & & & \\
\hline
\end{tabular}


ThSLE 28 (Continued)

30-39 Age Group

\begin{tabular}{|c|c|c|c|c|c|c|c|c|c|c|}
\hline \multirow[t]{2}{*}{ Activity } & & \multicolumn{3}{|c|}{$\begin{array}{l}\text { Total No. of Men } \\
\text { indicating attitude } \\
\text { toward activity }\end{array}$} & \multirow{2}{*}{\multicolumn{2}{|c|}{$\begin{array}{l}\text { Total No. of lien } \\
\text { stating reasons } \\
\text { for insufficient } \\
\text { participation }\end{array}$}} & \multicolumn{4}{|c|}{ Total No. of Participations } \\
\hline & & Like & Dislike & Indif. & & & Tk $\overline{l y}$ & inthly. & Yrly. & $\begin{array}{l}\text { Part. } \\
\text { Index }\end{array}$ \\
\hline \multirow[b]{2}{*}{ Calisthenics } & No. & 46 & 45 & 70 & \multirow{2}{*}{$\begin{array}{l}\text { Health } \\
\text { Time } \\
\text { Money } \\
\text { Facilities } \\
\text { Knowledge } \\
\text { and Skill } \\
\quad \text { TOTAI } \\
\end{array}$} & \multirow{2}{*}{$\begin{array}{r}2 \\
20 \\
1 \\
1 \\
\frac{1}{24} \\
\end{array}$} & \multirow[t]{2}{*}{25} & \multirow[t]{2}{*}{4} & \multirow[t]{2}{*}{41} & \multirow[t]{2}{*}{8.63} \\
\hline & of & 28.57 & 27.95 & 43.47 & & & & & & \\
\hline \multirow[b]{2}{*}{$\begin{array}{l}\text { Canoeing } \\
\text { (5 Months) }\end{array}$} & No. & 68 & 24 & 69 & \multirow{2}{*}{$\begin{array}{l}\text { Heal th } \\
\text { Time } \\
\text { Money } \\
\text { Facilities } \\
\text { Knowledge } \\
\text { and Skill } \\
\text { TOTAL }\end{array}$} & \multirow{2}{*}{$\begin{array}{r}1 \\
16 \\
6 \\
14 \\
\frac{1}{38}\end{array}$} & \multirow[t]{2}{*}{4} & \multirow[t]{2}{*}{8} & \multirow[t]{2}{*}{33} & \multirow[t]{2}{*}{.99} \\
\hline & $\%$ & $42.2 \$$ & 14.90 & 42.85 & & & & & & \\
\hline \multirow[b]{2}{*}{$\begin{array}{l}\text { Card } \\
\text { Playing }\end{array}$} & No. & 113 & 26 & 22 & \multirow{2}{*}{$\begin{array}{l}\text { Health } \\
\text { Time } \\
\text { Wioney } \\
\text { Facilities } \\
\text { Knowledge } \\
\text { and Skill } \\
\text { TOTAL }\end{array}$} & 0 & \multirow[t]{2}{*}{50} & \multirow[t]{2}{*}{38} & \multirow[t]{2}{*}{128} & \multirow[t]{2}{*}{19.75} \\
\hline & $\%$ & 70.1 & 16.15 & 13.66 & & $\begin{array}{c}10 \\
0 \\
\frac{2}{34}\end{array}$ & & & & \\
\hline
\end{tabular}


TABLE 28 (Continued)

30-39 Age Group

\begin{tabular}{|c|c|c|c|c|c|c|c|c|c|c|}
\hline \multirow[t]{2}{*}{ Activity } & \multicolumn{4}{|c|}{$\begin{array}{l}\text { Total ivo. of Men } \\
\text { indicating attitude } \\
\text { toward activity }\end{array}$} & \multirow{2}{*}{\multicolumn{2}{|c|}{$\begin{array}{l}\text { Total No. of Men } \\
\text { stating reasons } \\
\text { for insufficient } \\
\text { participation }\end{array}$}} & \multicolumn{4}{|c|}{ Total No. of Participation } \\
\hline & & Like & Dislike & Indif. & & & Whly. & ithiy. & YrIy. & $\begin{array}{l}\text { Part. } \\
\text { Index }\end{array}$ \\
\hline \multirow[b]{2}{*}{ Checkers } & No. & 66 & 26 & 69 & \multirow{2}{*}{$\begin{array}{l}\text { Health } \\
\text { Time } \\
\text { loney } \\
\text { Facilities } \\
\text { Knowledge } \\
\text { and Skill } \\
\quad \text { TOTAI } \\
\end{array}$} & \multirow{2}{*}{$\begin{array}{r}0 \\
19 \\
4 \\
0 \\
\frac{1}{24}\end{array}$} & \multirow[t]{2}{*}{22} & \multirow[t]{2}{*}{15} & \multirow[t]{2}{*}{79} & \multirow[t]{2}{*}{8.71} \\
\hline & $\%$ & 41.00 & 16.15 & 42.85 & & & & & & \\
\hline \multirow[b]{2}{*}{ Conversing } & No. & 90 & 19 & 52 & \multirow{2}{*}{$\begin{array}{l}\text { Health } \\
\text { Time } \\
\text { Ioneyr } \\
\text { Facilities } \\
\text { Knowledge } \\
\text { and Skill } \\
\quad \text { TOTAL } \\
\end{array}$} & \multirow{2}{*}{$\begin{array}{r}0 \\
16 \\
0 \\
0 \\
\\
\frac{3}{19} \\
\end{array}$} & \multirow[t]{2}{*}{117} & \multirow[t]{2}{*}{1} & \multirow[t]{2}{*}{821} & \multirow[t]{2}{*}{42.96} \\
\hline & $\%$ & 55.93 & 11.78 & 32.29 & & & & & & \\
\hline \multirow[b]{2}{*}{ Chess } & No. & 34 & 48 & 79 & \multirow{2}{*}{$\begin{array}{l}\text { Health } \\
\text { Time } \\
\text { Money } \\
\text { Facilities } \\
\text { Knowledge } \\
\text { and Skill } \\
\text { TOTAL }\end{array}$} & 0 & \multirow[t]{2}{*}{9} & \multirow[t]{2}{*}{8} & \multirow[t]{2}{*}{11} & \multirow[t]{2}{*}{3.57} \\
\hline & $\%$ & 20.50 & 29.80 & 49.70 & & $\begin{array}{r}0 \\
4 \\
\frac{11}{29}\end{array}$ & & & & \\
\hline
\end{tabular}


TABIE 28 (Continued)

30-39 Age Group

\begin{tabular}{|c|c|c|c|c|c|c|c|c|c|c|}
\hline \multirow[t]{2}{*}{ Activity } & \multicolumn{4}{|c|}{$\begin{array}{l}\text { Total ijo. of len } \\
\text { indicating attitude } \\
\text { toward activity }\end{array}$} & \multirow{2}{*}{\multicolumn{2}{|c|}{$\begin{array}{l}\text { Total No. of Hen } \\
\text { stating reasons } \\
\text { for insufficient } \\
\text { participation }\end{array}$}} & \multicolumn{4}{|c|}{ Total No. of Participations } \\
\hline & & Iike & Dislike & Indif. & & & WkIy. & Wthly. & Yrly. & $\begin{array}{l}\text { Part. } \\
\text { Index }\end{array}$ \\
\hline \multirow[b]{2}{*}{ Deck Tennis } & No. & 34 & 48 & 79 & \multirow{2}{*}{$\begin{array}{l}\text { Health } \\
\text { Tine } \\
\text { Money } \\
\text { Facilities } \\
\text { Knowledge } \\
\text { and Skill } \\
\quad \text { TOTAL } \\
\end{array}$} & \multirow{2}{*}{$\begin{array}{r}0 \\
4 \\
2 \\
7 \\
\frac{1}{12} \\
\end{array}$} & \multirow[t]{2}{*}{0} & \multirow[t]{2}{*}{1} & \multirow[t]{2}{*}{2} & \multirow[t]{2}{*}{.09} \\
\hline & 若 & 8.07 & 31.05 & 60.88 & & & & & & \\
\hline \multirow[b]{2}{*}{ Dating } & No. & 61 & 18 & 82 & \multirow{2}{*}{$\begin{array}{l}\text { Heal th } \\
\text { Time } \\
\text { iNoney } \\
\text { Facilities } \\
\text { Knowledge } \\
\text { and Skill } \\
\quad \text { TOTAL } \\
\end{array}$} & \multirow{2}{*}{$\begin{array}{r}0 \\
y_{4} \\
9 \\
2 \\
\\
\frac{0}{25} \\
\end{array}$} & \multirow[t]{2}{*}{20} & \multirow[t]{2}{*}{6} & \multirow[t]{2}{*}{20} & \multirow[t]{2}{*}{7.03} \\
\hline & $\%$ & 37.90 & 11.18 & 50.92 & & & & & & \\
\hline \multirow[b]{2}{*}{ Driving } & No, & 118 & 17 & 32 & \multirow{2}{*}{\multicolumn{2}{|c|}{$\begin{array}{lr}\text { Health } & 0 \\
\text { Time } & 13 \\
\text { Money } & 8 \\
\text { Facilities } & 3 \\
\text { Knowledge } & \\
\text { and Skill } & \quad \frac{1}{25} \\
\end{array}$}} & \multirow[t]{2}{*}{153} & \multirow[t]{2}{*}{4} & \multirow[t]{2}{*}{1097} & \multirow[t]{2}{*}{56.53} \\
\hline & $\not t$ & 73.91 & 6.83 & 19.26 & & & & & & \\
\hline
\end{tabular}


TABLE, 28 (Contimued)

30-39 Age Group

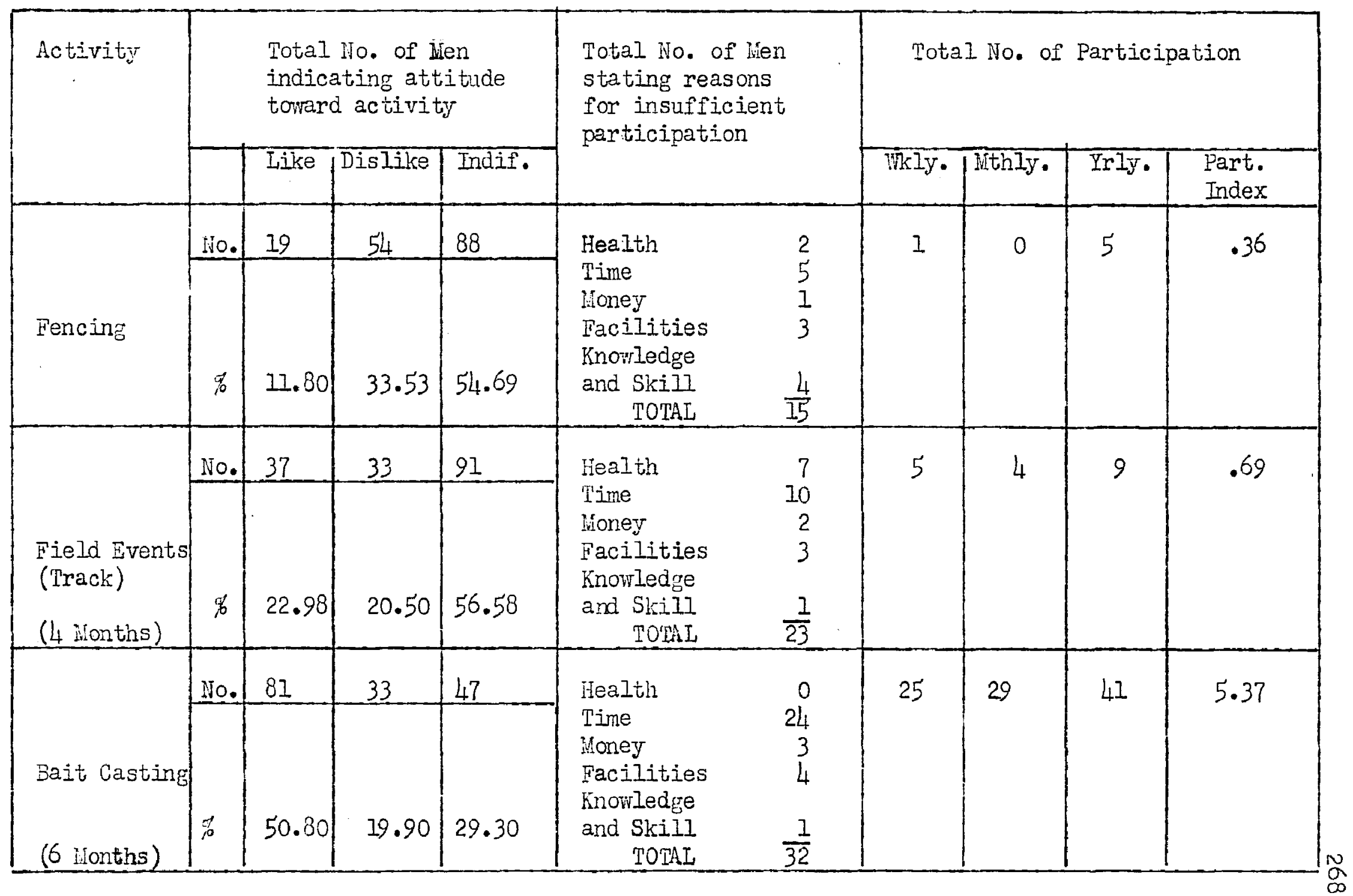


TABIF 28 (Continued)

30-39 Age Group

\begin{tabular}{|c|c|c|c|c|c|c|c|c|c|c|}
\hline \multirow[t]{2}{*}{ Activity } & \multicolumn{4}{|c|}{$\begin{array}{l}\text { Total No. of Pien } \\
\text { indicating attitude } \\
\text { toward activitiy }\end{array}$} & \multirow{2}{*}{\multicolumn{2}{|c|}{$\begin{array}{l}\text { Total No. of Wen } \\
\text { stating reasons } \\
\text { for insufficient } \\
\text { participation }\end{array}$}} & \multicolumn{4}{|c|}{ Total iNo. of Participations } \\
\hline & & Like & Dislike & Indif. & & & Whiy. & fithly. & Yrly. & $\begin{array}{l}\text { Part. } \\
\text { Index }\end{array}$ \\
\hline \multirow[b]{2}{*}{$\begin{array}{l}\text { Still } \\
\text { Fishin: } \\
\text { (6 lionths) }\end{array}$} & No. & 94 & 26 & 41 & \multirow{2}{*}{$\begin{array}{l}\text { Health } \\
\text { Tine } \\
\text { Money } \\
\text { Facilities } \\
\text { Knowledge } \\
\text { and Skill } \\
\quad \text { TOTAL } \\
\end{array}$} & \multirow{2}{*}{$\begin{array}{r}0 \\
24 \\
2 \\
5 \\
0 \\
\frac{0}{39} \\
\end{array}$} & \multirow[t]{2}{*}{35} & \multirow[t]{2}{*}{27} & \multirow[t]{2}{*}{61} & \multirow[t]{2}{*}{7.04} \\
\hline & $\%$ & 58.38 & 16.15 & 25.47 & & & & & & \\
\hline \multirow[b]{2}{*}{$\begin{array}{l}\text { Footiball } \\
\text { (3 lionths) }\end{array}$} & No. & 98 & 14 & 49 & \multirow{2}{*}{$\begin{array}{l}\text { Health } \\
\text { Time } \\
\text { Mioney } \\
\text { Facilities } \\
\text { Knowledge } \\
\text { and Skill } \\
\quad \text { TOTAI } \\
\end{array}$} & \multirow{2}{*}{$\begin{array}{r}17 \\
15 \\
6 \\
5 \\
0 \\
\frac{0}{37} \\
\end{array}$} & \multirow[t]{2}{*}{10} & \multirow[t]{2}{*}{13} & \multirow[t]{2}{*}{30} & \multirow[t]{2}{*}{1.24} \\
\hline & $\%$ & 60.88 & 8.69 & 30.43 & & & & & & \\
\hline \multirow[b]{2}{*}{$\begin{array}{l}\text { Gardening } \\
\text { (5 lionths) }\end{array}$} & No. & 119 & 10 & 32 & \multirow{2}{*}{$\begin{array}{l}\text { Health } \\
\text { Time } \\
\text { Money } \\
\text { Facilities } \\
\text { hnowledge } \\
\text { and Skill } \\
\text { TOTAL }\end{array}$} & \multirow{2}{*}{$\begin{array}{c}0 \\
8 \\
2 \\
6 \\
\\
\frac{1}{17}\end{array}$} & \multirow[t]{2}{*}{73} & \multirow[t]{2}{*}{7} & \multirow[t]{2}{*}{548} & \multirow[t]{2}{*}{13.44} \\
\hline & $\not 0^{\circ}$ & 74.53 & 6.21 & 19.26 & & & & & & \\
\hline
\end{tabular}


TABLE 28 (continued)

30-39 Age Group

\begin{tabular}{|c|c|c|c|c|c|c|c|c|c|c|}
\hline \multirow[t]{2}{*}{ Activity } & \multicolumn{4}{|c|}{$\begin{array}{l}\text { Total No. of inen } \\
\text { indicating attitude } \\
\text { toward activity }\end{array}$} & \multirow{2}{*}{\multicolumn{2}{|c|}{$\begin{array}{l}\text { Total No. of ifen } \\
\text { stating reasons } \\
\text { for insufficient } \\
\text { participation }\end{array}$}} & \multicolumn{4}{|c|}{ Total No. of Participations } \\
\hline & & Like & Dislike & Indif. & & & Wkly. & Mthly. & Yrly. & $\begin{array}{l}\text { Part. } \\
\text { Index }\end{array}$ \\
\hline \multirow[b]{2}{*}{$\begin{array}{l}\text { Golf } \\
\text { (4 Months) }\end{array}$} & No. & 81 & 22 & 58 & \multirow{2}{*}{$\begin{array}{l}\text { Health } \\
\text { Time } \\
\text { Honey } \\
\text { Facilities } \\
\text { Knowledge } \\
\text { and Skill } \\
\text { TOTAL } \\
\end{array}$} & \multirow{2}{*}{$\begin{array}{r}0 \\
18 \\
12 \\
7 \\
\frac{3}{40} \\
\end{array}$} & \multirow[t]{2}{*}{30} & \multirow[t]{2}{*}{19} & \multirow[t]{2}{*}{33} & \multirow[t]{2}{*}{3.91} \\
\hline & $\tilde{r}^{*}$ & 50.30 & -13.66 & 36.02 & & & & & & \\
\hline \multirow[b]{2}{*}{ Gymnastics } & No. & 34 & 34 & 93 & \multirow{2}{*}{$\begin{array}{l}\text { Health } \\
\text { Time } \\
\text { Money } \\
\text { Facilities } \\
\text { Knowledge } \\
\text { and Skill } \\
\quad \text { Total } \\
\end{array}$} & \multirow{2}{*}{$\begin{array}{r}2 \\
9 \\
1 \\
3 \\
0 \\
15 \\
\end{array}$} & \multirow[t]{2}{*}{ ó } & \multirow[t]{2}{*}{4} & \multirow[t]{2}{*}{31} & \multirow[t]{2}{*}{2.43} \\
\hline & 落 & 21.10 & 21.10 & 57.76 & & & & & & \\
\hline \multirow[b]{2}{*}{$\begin{array}{l}\text { Handball } \\
\text { (9 Months) }\end{array}$} & No. & 46 & 28 & 87 & \multirow{2}{*}{$\begin{array}{l}\text { Health } \\
\text { Tine } \\
\text { Money } \\
\text { Facilities } \\
\text { Knowledge } \\
\text { and Skril } \\
\text { TOTAL }\end{array}$} & 1 & \multirow[t]{2}{*}{5} & \multirow[t]{2}{*}{5} & \multirow[t]{2}{*}{25} & \multirow[t]{2}{*}{1.65} \\
\hline & $f_{j}^{f}$ & 28.57 & 17.39 & 54.07 & & $\begin{array}{r}11 \\
2 \\
9 \\
\frac{1}{30} \\
\end{array}$ & & & & \\
\hline
\end{tabular}


TABLF 28 (Continued)

30-39 Age Group

\begin{tabular}{|c|c|c|c|c|c|c|c|c|c|c|}
\hline \multirow[t]{2}{*}{ Activity } & & \multicolumn{3}{|c|}{$\begin{array}{l}\text { Total No. of Hen } \\
\text { indicating attitude } \\
\text { toward activity }\end{array}$} & \multirow{2}{*}{\multicolumn{2}{|c|}{$\begin{array}{l}\text { Total No. of lien } \\
\text { stating reasons } \\
\text { for insufficient } \\
\text { participation }\end{array}$}} & \multicolumn{4}{|c|}{ Total No. of Participations } \\
\hline & & Like & Dislike & Indif. & & & $\mathrm{HkIY}$ & lithly. & Irly. & $\begin{array}{l}\text { Part. } \\
\text { Index }\end{array}$ \\
\hline & No. & 56 & 27 & 78 & \multirow[b]{2}{*}{$\begin{array}{l}\text { Health } \\
\text { Time } \\
\text { Honey } \\
\text { Facilities } \\
\text { Knowledge } \\
\text { and Skill } \\
\quad \text { TOTAI } \\
\end{array}$} & \multirow[b]{2}{*}{$\begin{array}{r}0 \\
20 \\
2 \\
0 \\
0 \\
\frac{0}{22} \\
\end{array}$} & \multirow[t]{2}{*}{6} & \multirow[t]{2}{*}{8} & \multirow[t]{2}{*}{19} & \multirow[t]{2}{*}{2.02} \\
\hline $\begin{array}{l}\text { Hiking } \\
\text { ( } 9 \text { Months) }\end{array}$ & 晜 & 34.78 & 16.77 & 48.44 & & & & & & \\
\hline \multirow[b]{2}{*}{$\begin{array}{l}\text { Horseback } \\
\text { Riding } \\
\text { (9 Montins) }\end{array}$} & No. & 62 & 18 & 81 & \multirow{2}{*}{$\begin{array}{l}\text { Health } \\
\text { Time } \\
\text { Money } \\
\text { Facilities } \\
\text { Knowledge } \\
\text { and Skill } \\
\text { TOTAL }\end{array}$} & \multirow{2}{*}{$\begin{array}{r}3 \\
17 \\
11 \\
5 \\
\frac{0}{36}\end{array}$} & \multirow[t]{2}{*}{2} & \multirow[t]{2}{*}{7} & \multirow[t]{2}{*}{17} & \multirow[t]{2}{*}{.99} \\
\hline & $y_{0}^{*}$ & 38.52 & 11.18 & 50.30 & & & & & & \\
\hline \multirow[b]{2}{*}{ Horseshoes } & No. & 102 & 6 & 53 & \multirow[b]{2}{*}{$\begin{array}{l}\text { Health } \\
\text { Time } \\
\text { Woney } \\
\text { Facilities } \\
\text { Knowledge } \\
\text { and Skill } \\
\text { TOTAL }\end{array}$} & \multirow[b]{2}{*}{$\begin{array}{r}1 \\
14 \\
0 \\
14 \\
\frac{0}{29}\end{array}$} & \multirow[t]{2}{*}{20} & \multirow[t]{2}{*}{27} & \multirow[t]{2}{*}{57} & \multirow[t]{2}{*}{6.71} \\
\hline & of & 13.36 & 3.73 & 32.91 & & & & & & \\
\hline
\end{tabular}


TABLE 28 (Continued)

30-39 Age Group

\begin{tabular}{|c|c|c|c|c|c|c|c|c|c|c|}
\hline \multirow[t]{2}{*}{ Activity } & & \multicolumn{3}{|c|}{$\begin{array}{l}\text { Total No. of ien } \\
\text { indicating attitude } \\
\text { toward activity }\end{array}$} & \multirow{2}{*}{\multicolumn{2}{|c|}{$\begin{array}{l}\text { Total No. of Men } \\
\text { stating reasons } \\
\text { for insufficient } \\
\text { participation }\end{array}$}} & \multicolumn{4}{|c|}{ Total No. of Participations } \\
\hline & & Iike & Dislike & Indif. & & & Tikly. & Mthly. & Yrly. & $\begin{array}{l}\text { Part. } \\
\text { Index }\end{array}$ \\
\hline \multirow[b]{2}{*}{$\begin{array}{l}\text { Hunting } \\
\text { (3 Ionths) }\end{array}$} & Ho. & 89 & 28 & 44 & \multirow{2}{*}{$\begin{array}{l}\text { Health } \\
\text { Time } \\
\text { Money } \\
\text { Facilities } \\
\text { Knowledge } \\
\text { and Skill } \\
\quad \text { TOTAL } \\
\end{array}$} & \multirow{2}{*}{$\begin{array}{r}1 \\
20 \\
3 \\
8 \\
\\
1 \\
33 \\
\end{array}$} & \multirow[t]{2}{*}{4} & \multirow[t]{2}{*}{15} & \multirow[t]{2}{*}{145} & \multirow[t]{2}{*}{1.50} \\
\hline & $\%$ & 55.37 & 17.39 & 27.32 & & & & & & \\
\hline \multirow[b]{2}{*}{$\begin{array}{l}\text { Ice Hockey } \\
\text { (3 Honths) }\end{array}$} & No. & 53 & 23 & 85 & \multirow{2}{*}{$\begin{array}{l}\text { Health } \\
\text { Time } \\
\text { Honey } \\
\text { Facilities } \\
\text { Knomledge } \\
\text { and Skill } \\
\quad \text { TOTAL } \\
\end{array}$} & \multirow{2}{*}{$\begin{array}{r}5 \\
\frac{14}{6} \\
5 \\
\frac{0}{30} \\
\end{array}$} & \multirow[t]{2}{*}{5} & \multirow[t]{2}{*}{6} & \multirow[t]{2}{*}{22} & \multirow[t]{2}{*}{.65} \\
\hline & $\%$ & 32.91 & $\Psi_{1} .28$ & 52.79 & & & & & & \\
\hline \multirow[b]{2}{*}{$\begin{array}{l}\text { Ice Skating } \\
\text { (3 ironths) }\end{array}$} & No. & 75 & 21 & 65 & \multirow{2}{*}{$\begin{array}{l}\text { Health } \\
\text { Time } \\
\text { Honey } \\
\text { Facilities } \\
\text { Knowledge } \\
\text { and Skili } \\
\quad \text { TOTAL } \\
\end{array}$} & \multirow{2}{*}{$\begin{array}{r}1 \\
18 \\
1 \\
4 \\
\\
\frac{2}{26} \\
\end{array}$} & \multirow[t]{2}{*}{7} & \multirow[t]{2}{*}{$I_{4}$} & \multirow[t]{2}{*}{49} & \multirow[t]{2}{*}{1.13} \\
\hline & $\mathscr{O}_{0}^{\circ}$ & 46.59 & 13.04 & 40.39 & & & & & & \\
\hline
\end{tabular}


TABIE 28 (Continued)

30-39 Age Group

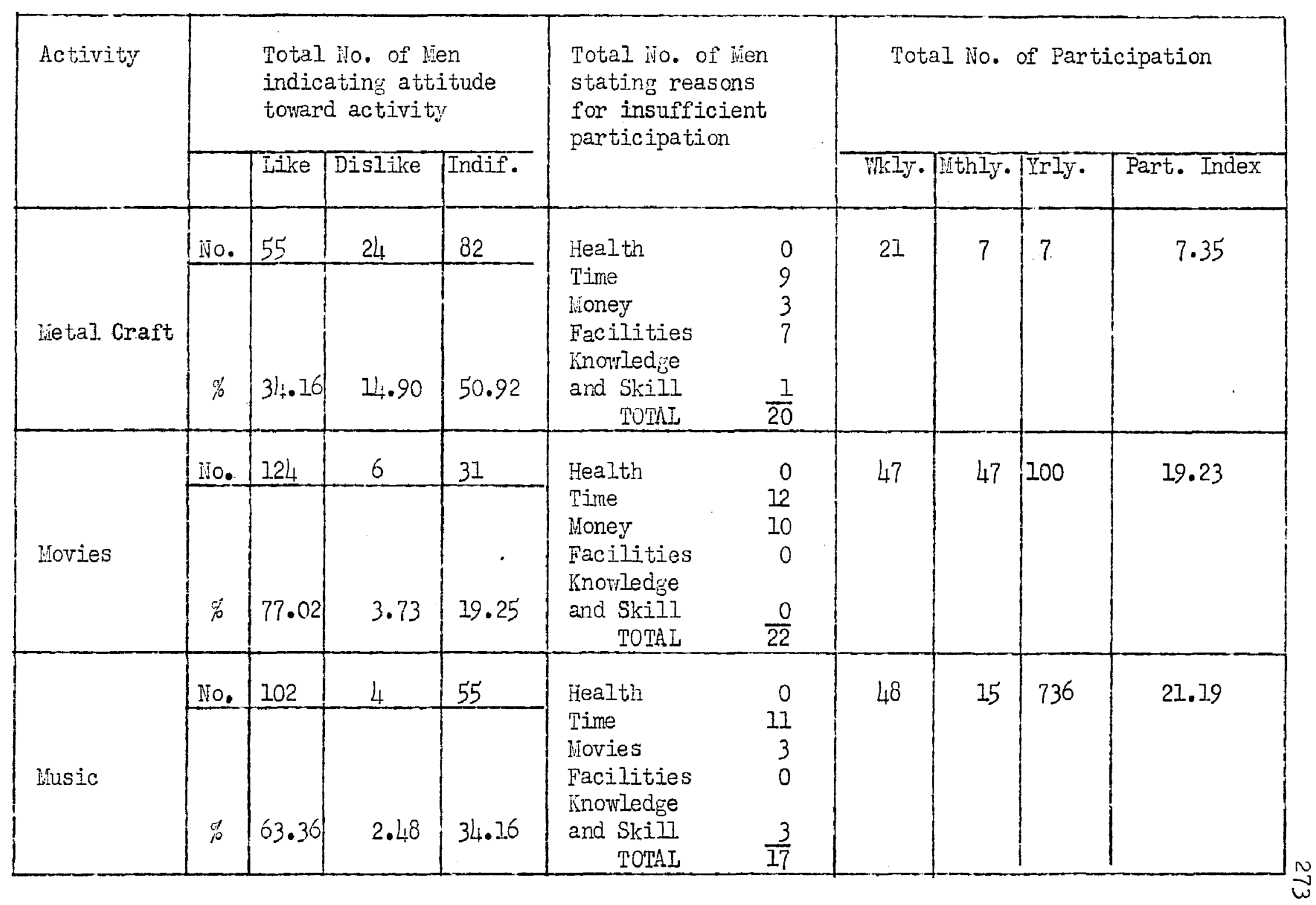


TAEIE 28 (Continued)

30-39 Age Group

\begin{tabular}{|c|c|c|c|c|c|c|c|c|c|c|}
\hline \multirow[t]{2}{*}{ Activity } & & \multicolumn{3}{|c|}{$\begin{array}{l}\text { Total No. of len } \\
\text { indicating attitude } \\
\text { toward activity }\end{array}$} & \multirow{2}{*}{\multicolumn{2}{|c|}{$\begin{array}{l}\text { Total No. of Hen } \\
\text { stating reasons } \\
\text { for insufficient } \\
\text { participation }\end{array}$}} & \multicolumn{4}{|c|}{ Total No. of Participations } \\
\hline & & Like & Dislike & Indif. & & & Whiy. & wthly. & Yrly. & $\begin{array}{l}\text { Part. } \\
\text { Index }\end{array}$ \\
\hline \multirow[b]{2}{*}{ lotoring } & No. & 106 & 8 & 47 & \multirow[b]{2}{*}{$\begin{array}{l}\text { Health } \\
\text { Time } \\
\text { lioney } \\
\text { Facilities } \\
\text { Inowledge } \\
\text { and Skill } \\
\quad \text { TOIAI } \\
\end{array}$} & \multirow{2}{*}{$\begin{array}{l}1 \\
\frac{14}{6} \\
1 \\
\frac{0}{22}\end{array}$} & \multirow[t]{2}{*}{65} & \multirow[t]{2}{*}{10} & \multirow[t]{2}{*}{70} & \multirow[t]{2}{*}{22.17} \\
\hline & $\%$ & 65.84 & 4.97 & 29.19 & & & & & & \\
\hline \multirow[b]{2}{*}{$\begin{array}{l}\text { Night } \\
\text { Clubbing }\end{array}$} & No. & 55 & 33 & 73 & \multirow[b]{2}{*}{$\begin{array}{l}\text { Health } \\
\text { Time } \\
\text { Honey } \\
\text { Facilities } \\
\text { Knowledge } \\
\text { and Skill } \\
\quad \text { TOTAL } \\
\end{array}$} & \multirow[b]{2}{*}{$\begin{array}{r}0 \\
5 \\
13 \\
1 \\
0 \\
\frac{0}{19}\end{array}$} & \multirow[t]{2}{*}{15} & \multirow[t]{2}{*}{16} & \multirow[t]{2}{*}{11} & \multirow[t]{2}{*}{6.91} \\
\hline & $\ddot{8}$ & 34.15 & 20.50 & 45.35 & & & & & & \\
\hline \multirow[b]{2}{*}{ Ping-pong } & No. & 72 & 13 & 76 & \multirow{2}{*}{$\begin{array}{l}\text { Health } \\
\text { Time } \\
\text { Jisoney } \\
\text { Facilities } \\
\text { Knowledge } \\
\text { and Skill } \\
\quad \text { TOTAL }\end{array}$} & 0 & \multirow[t]{2}{*}{8} & \multirow[t]{2}{*}{27} & \multirow[t]{2}{*}{30} & \multirow[t]{2}{*}{4.78} \\
\hline & 8 & 44.73 & 8.07 & 47.20 & & $\begin{array}{r}3 \\
y_{1}^{3} \\
\frac{0}{23}\end{array}$ & & & & \\
\hline
\end{tabular}


TABLE 28 (Continued)

30-39 Age Group

\begin{tabular}{|c|c|c|c|c|c|c|c|c|c|c|}
\hline \multirow[t]{2}{*}{ Activity } & & \multicolumn{3}{|c|}{$\begin{array}{l}\text { TotaI No. of lien } \\
\text { Indicating attitude } \\
\text { toward activity }\end{array}$} & \multirow{2}{*}{\multicolumn{2}{|c|}{$\begin{array}{l}\text { Total No. of Hen } \\
\text { stating reasons } \\
\text { for insufficient } \\
\text { participation }\end{array}$}} & \multicolumn{4}{|c|}{ Total No. of Participations } \\
\hline & & Iilke & Dislike & Indif. & & & wriy. & methly. & Irly. & $\begin{array}{l}\text { Part. } \\
\text { Index }\end{array}$ \\
\hline \multirow[b]{2}{*}{$\begin{array}{l}\text { Puttering, } \\
\text { Repairing, } \\
\text { etc. }\end{array}$} & No. & 109 & 13 & 39 & \multirow{2}{*}{$\begin{array}{l}\text { Health } \\
\text { Time } \\
\text { Money } \\
\text { Facilities } \\
\text { Knowledge } \\
\text { and Skill } \\
\quad \text { TOTAL } \\
\end{array}$} & \multirow{2}{*}{$\begin{array}{r}0 \\
13 \\
4 \\
0 \\
0 \\
17 \\
\end{array}$} & \multirow[t]{2}{*}{106} & \multirow[t]{2}{*}{5} & \multirow[t]{2}{*}{1496} & \multirow[t]{2}{*}{43.90} \\
\hline & $\stackrel{c}{p}$ & 67.70 & 3.07 & 24.22 & & & & & & \\
\hline \multirow[b]{2}{*}{$\begin{array}{l}\text { Listening } \\
\text { to Radio }\end{array}$} & ino. & 109 & 6 & 46 & \multirow{2}{*}{$\begin{array}{l}\text { Health } \\
\text { Time } \\
\text { Money } \\
\text { Facilities } \\
\text { Knowledge } \\
\text { and Skill } \\
\quad \text { TOmi } \\
\end{array}$} & \multirow{2}{*}{$\begin{array}{c}0 \\
8 \\
3 \\
0 \\
\\
\\
11 \\
\end{array}$} & \multirow[t]{2}{*}{119} & \multirow[t]{2}{*}{5} & \multirow[t]{2}{*}{$1 u_{4} 5$} & \multirow[t]{2}{*}{45.92} \\
\hline & $\%$ & 67.70 & 3.73 & 28.60 & & & & & & \\
\hline \multirow[b]{2}{*}{ Watching TV } & No. & 134 & 4 & 23 & \multirow{2}{*}{$\begin{array}{l}\text { Health } \\
\text { Time } \\
\text { Money } \\
\text { Facilities } \\
\text { Knowledge } \\
\text { and Skill } \\
\quad \text { TOTAI } \\
\end{array}$} & 0 & \multirow[t]{2}{*}{160} & \multirow[t]{2}{*}{4} & \multirow[t]{2}{*}{852} & \multirow[t]{2}{*}{57.27} \\
\hline & $\%$ & 83.24 & 2.48 & 14.28 & & $\begin{array}{r}11 \\
1 \\
1 \\
0 \\
\frac{0}{19} \\
\end{array}$ & & & & \\
\hline
\end{tabular}


TABIE 28 (Continued)

30-39 Age Group

\begin{tabular}{|c|c|c|c|c|c|c|c|c|c|c|}
\hline \multirow[t]{2}{*}{ Activity } & \multicolumn{4}{|c|}{$\begin{array}{l}\text { Total No. of Hen } \\
\text { indicating attitude } \\
\text { toward activity }\end{array}$} & \multirow{2}{*}{\multicolumn{2}{|c|}{$\begin{array}{l}\text { Total No. of ifen } \\
\text { stating reasons } \\
\text { for insufficent } \\
\text { participation }\end{array}$}} & \multicolumn{4}{|c|}{ Total Ho. of Participations } \\
\hline & & Iike & Dislike & Indif. & & & why. & ifthly. & Yrly. & $\begin{array}{l}\text { Part } \\
\text { Index }\end{array}$ \\
\hline \multirow[b]{2}{*}{ Reading } & No. & 127 & 7 & 27 & \multirow{2}{*}{$\begin{array}{l}\text { Health } \\
\text { Time } \\
\text { Money } \\
\text { Facilities } \\
\text { Knowledge } \\
\text { and Skill } \\
\quad \text { TorAI }\end{array}$} & \multirow{2}{*}{$\begin{array}{r}0 \\
16 \\
2 \\
0 \\
0 \\
0 \\
18\end{array}$} & \multirow[t]{2}{*}{158} & \multirow[t]{2}{*}{5} & \multirow[t]{2}{*}{281} & \multirow[t]{2}{*}{52.15} \\
\hline & 落 & 78.88 & $4 \cdot 35$ & 16.77 & & & & & & \\
\hline \multirow[b]{2}{*}{ Photography } & No. & 66 & 16 & 79 & \multirow{2}{*}{$\begin{array}{l}\text { Health } \\
\text { Time } \\
\text { Woney } \\
\text { Facilities } \\
\text { Knowledge } \\
\text { and Skill } \\
\quad \text { TOTAI } \\
\end{array}$} & \multirow{2}{*}{$\begin{array}{r}0 \\
11 \\
9 \\
1 \\
0 \\
\frac{0}{21} \\
\end{array}$} & \multirow[t]{2}{*}{18} & \multirow[t]{2}{*}{22} & \multirow[t]{2}{*}{99} & \multirow[t]{2}{*}{8.07} \\
\hline & t & 4.00 & 9.94 & 49.10 & & & & & & \\
\hline \multirow[b]{2}{*}{$\begin{array}{l}\text { Roller } \\
\text { Skatinge }\end{array}$} & No. & 53 & 22 & 86 & \multirow{2}{*}{$\begin{array}{l}\text { Heal th } \\
\text { Tine } \\
\text { linoney } \\
\text { Facilities } \\
\text { Knowledge } \\
\text { and Skill } \\
\text { TUTAL }\end{array}$} & \multirow{2}{*}{$\begin{array}{r}2 \\
12 \\
3 \\
0 \\
1 \\
\frac{1}{18}\end{array}$} & \multirow[t]{2}{*}{6} & \multirow[t]{2}{*}{9} & \multirow[t]{2}{*}{41} & \multirow[t]{2}{*}{2.86} \\
\hline & 楛 & 32.91 & 13.66 & 53.43 & & & & & & \\
\hline
\end{tabular}


TABLE 28 (Continued)

30-39 Age Group

\begin{tabular}{|c|c|c|c|c|c|c|c|c|c|c|}
\hline \multirow[t]{2}{*}{ Activity } & & \multicolumn{3}{|c|}{$\begin{array}{l}\text { Total No. of wen } \\
\text { indicating attitude } \\
\text { toward activity }\end{array}$} & \multirow{2}{*}{\multicolumn{2}{|c|}{$\begin{array}{l}\text { Total No. of iren } \\
\text { stating reasons } \\
\text { for insufficient } \\
\text { participation }\end{array}$}} & \multicolumn{4}{|c|}{ Total No. of Participations } \\
\hline & & Like & Dislike & Indif. & & & Wh $l y$. & Mthly. & Yrly. & $\begin{array}{l}\text { Part. } \\
\text { Index }\end{array}$ \\
\hline \multirow[b]{2}{*}{ Painting } & No. & 37 & 37 & 87 & \multirow[b]{2}{*}{$\begin{array}{l}\text { Healih } \\
\text { Tine } \\
\text { Inoney } \\
\text { Facilities } \\
\text { Knowledge } \\
\text { and Skill } \\
\quad \text { TOTAL } \\
\end{array}$} & \multirow[b]{2}{*}{$\begin{array}{l}0 \\
4 \\
1 \\
1 \\
3 \\
\frac{3}{9}\end{array}$} & \multirow[t]{2}{*}{7} & \multirow[t]{2}{*}{10} & \multirow[t]{2}{*}{70} & \multirow[t]{2}{*}{3.44} \\
\hline & $\ddot{p}$ & 22.98 & 22.98 & 54.04 & & & & & & \\
\hline \multirow[b]{2}{*}{$\begin{array}{l}\text { Sailing } \\
\text { (5 Months) }\end{array}$} & No. & 37 & 33 & 91 & \multirow[b]{2}{*}{$\begin{array}{l}\text { Health } \\
\text { Time } \\
\text { Honey } \\
\text { Facilities } \\
\text { Knowledge } \\
\text { and Skill } \\
\quad \text { TOTAL } \\
\end{array}$} & \multirow[b]{2}{*}{$\begin{array}{r}0 \\
7 \\
6 \\
9 \\
\frac{3}{25} \\
\end{array}$} & \multirow[t]{2}{*}{1} & \multirow[t]{2}{*}{1} & \multirow[t]{2}{*}{14} & \multirow[t]{2}{*}{.25} \\
\hline & $\%$ & 22.98 & 20.50 & 56.53 & & & & & & \\
\hline \multirow[b]{2}{*}{$\begin{array}{l}\text { Social } \\
\text { Drinking }\end{array}$} & No. & 84 & 26 & 51 & \multirow{2}{*}{$\begin{array}{l}\text { Health } \\
\text { Time } \\
\text { Honey } \\
\text { Facilities } \\
\text { Knowledge } \\
\text { and Skill } \\
\quad \text { TOTAI }\end{array}$} & \multirow{2}{*}{$\begin{array}{c}0 \\
8 \\
6 \\
0 \\
0 \\
\frac{0}{I_{4}}\end{array}$} & \multirow[t]{2}{*}{27} & \multirow[t]{2}{*}{32} & \multirow[t]{2}{*}{207} & \multirow[t]{2}{*}{12.39} \\
\hline & : & 52.16 & 16.15 & 31.67 & & & & & & \\
\hline
\end{tabular}


TABIE 28 (Continued)

30-39 Age Group

\begin{tabular}{|c|c|c|c|c|c|c|c|c|c|c|}
\hline \multirow[t]{2}{*}{ Activity } & \multicolumn{4}{|c|}{$\begin{array}{l}\text { Total ivo. of hen } \\
\text { indicating attitude } \\
\text { toward activity }\end{array}$} & \multirow{2}{*}{\multicolumn{2}{|c|}{$\begin{array}{l}\text { Total No. of lien } \\
\text { stating reasons } \\
\text { for insufîicient } \\
\text { participation }\end{array}$}} & \multicolumn{4}{|c|}{ Total No. of Participations } \\
\hline & & Like & Dislike & Indif. & & & Wily. & Jthly. & $\operatorname{Yrly} \cdot$ & $\begin{array}{l}\text { Part. } \\
\text { Index }\end{array}$ \\
\hline $\begin{array}{l}\text { Skiing } \\
\text { (3 Bonths) }\end{array}$ & No. & 21.10 & 23.60 & 55.31 & $\begin{array}{l}\text { Health } \\
\text { Time } \\
\text { Ionejy } \\
\text { Facilities } \\
\text { Knowledge } \\
\text { and Skill } \\
\text { TOTALI } \\
\end{array}$ & $\begin{array}{r}1 \\
7 \\
2 \\
11 \\
\frac{2}{23} \\
\end{array}$ & 1 & 4 & 25 & 3.44 \\
\hline $\begin{array}{l}\text { Social } \\
\text { Dancing }\end{array}$ & No. & 55.31 & 13.66 & 31.05 & $\begin{array}{l}\text { Health } \\
\text { Time } \\
\text { ifoney } \\
\text { Facilities } \\
\text { Knowledge } \\
\text { and Skill } \\
\quad \text { TOTAL } \\
\end{array}$ & $\begin{array}{r}0 \\
13 \\
7 \\
2 \\
\\
3 \\
30\end{array}$ & 21 & 33 & 31 & 9.43 \\
\hline $\begin{array}{l}\text { Softball } \\
\text { (3 riontils) }\end{array}$ & ivo. & 72.67 & 8.07 & 19.26 & $\begin{array}{l}\text { Health } \\
\text { Time } \\
\text { Noney } \\
\text { Facilities } \\
\text { Knowledge } \\
\text { and Skill } \\
\quad \text { TOTAI } \\
\end{array}$ & $\begin{array}{r}3 \\
28 \\
4 \\
3 \\
0 \\
38 \\
\end{array}$ & 15 & 25 & 69 & 2.12 \\
\hline
\end{tabular}


TABLE 28 (Continued)

30-39 Age Group

\begin{tabular}{|c|c|c|c|c|c|c|c|c|c|c|}
\hline \multirow[t]{2}{*}{ Activity } & \multicolumn{4}{|c|}{$\begin{array}{l}\text { Total ivo. of ien } \\
\text { indicating attitude } \\
\text { towara activity }\end{array}$} & \multirow{2}{*}{\multicolumn{2}{|c|}{$\begin{array}{l}\text { Total No. of lien } \\
\text { stating reasons } \\
\text { for insufficient } \\
\text { participation }\end{array}$}} & \multicolumn{4}{|c|}{ Total No. of Participations } \\
\hline & & Like & Dislike & Indif. & & & Wiry. & Wth.ly. & Yrly. & $\begin{array}{l}\text { Part. } \\
\text { Tndex }\end{array}$ \\
\hline \multirow[b]{2}{*}{$\begin{array}{l}\text { Speedball } \\
\text { ( } 3 \text { Months) }\end{array}$} & No. & 27 & 28 & 106 & \multirow{2}{*}{$\begin{array}{l}\text { Health } \\
\text { Time } \\
\text { Money } \\
\text { Facilities } \\
\text { Knowledge } \\
\text { and Skill } \\
\text { TOTAL } \\
\end{array}$} & \multirow{2}{*}{$\begin{array}{r}0 \\
12 \\
0 \\
1 \\
0 \\
\frac{0}{13}\end{array}$} & \multirow[t]{2}{*}{1} & \multirow[t]{2}{*}{4} & \multirow[t]{2}{*}{15} & \multirow[t]{2}{*}{.25} \\
\hline & $\not$ & 16.77 & 17.39 & 65.84 & & & & & & \\
\hline \multirow[b]{2}{*}{$\begin{array}{l}\text { Square } \\
\text { Dancing }\end{array}$} & No. & 35 & 41 & 85 & \multirow{2}{*}{ 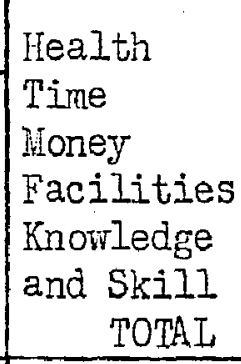 } & 0 & \multirow[t]{2}{*}{4} & \multirow[t]{2}{*}{8} & \multirow[t]{2}{*}{15} & \multirow[t]{2}{*}{1.98} \\
\hline & $\%$ & 21.74 & 25.46 & 52.79 & & $\begin{array}{r}9 \\
1 \\
1 \\
4 \\
15 \\
\end{array}$ & & & & \\
\hline \multirow[b]{2}{*}{$\begin{array}{l}\text { Stamp } \\
\text { Collecting }\end{array}$} & No. & 9 & 59 & 93 & \multirow{2}{*}{$\begin{array}{l}\text { Health } \\
\text { Time } \\
\text { Money } \\
\text { Facilities } \\
\text { Knowledse } \\
\text { and Skill } \\
\quad \text { ToraL } \\
\end{array}$} & 0 & \multirow[t]{2}{*}{3} & \multirow[t]{2}{*}{0} & \multirow[t]{2}{*}{2} & \multirow[t]{2}{*}{.98} \\
\hline & $c_{\rho}^{\prime}$ & 5.59 & 36.65 & 57.76 & & $\begin{array}{l}2 \\
1 \\
0 \\
\frac{1}{4}\end{array}$ & & & & \\
\hline
\end{tabular}


TABLE 28 (Continued)

30-39 Age Group

\begin{tabular}{|c|c|c|c|c|c|c|c|c|c|c|}
\hline \multirow[t]{2}{*}{ Activity } & \multicolumn{4}{|c|}{$\begin{array}{l}\text { Total No. of ifen } \\
\text { indicating attitude } \\
\text { toward activity }\end{array}$} & \multirow{2}{*}{\multicolumn{2}{|c|}{$\begin{array}{l}\text { Total Ho. of ien } \\
\text { stating reasons } \\
\text { for insufficient } \\
\text { participation }\end{array}$}} & \multicolumn{4}{|c|}{ Total No. of Participations } \\
\hline & & Like & Dislike & Indif. & & & Wkly. & Nithly.1 & Irly. & $\begin{array}{l}\text { Part. } \\
\text { Index }\end{array}$ \\
\hline \multirow[b]{2}{*}{$\begin{array}{l}\text { Swimninz } \\
\text { (3) Months) }\end{array}$} & No. & 133 & 7 & 21 & \multirow{2}{*}{$\begin{array}{l}\text { Health } \\
\text { Time } \\
\text { Money } \\
\text { Facilities } \\
\text { Knowledge } \\
\text { and Skill } \\
\quad \text { TOMAL } \\
\end{array}$} & \multirow[b]{2}{*}{$\begin{array}{r}3 \\
23 \\
1 \\
9 \\
\frac{3}{39} \\
\end{array}$} & \multirow[t]{2}{*}{29} & \multirow[t]{2}{*}{28} & \multirow[t]{2}{*}{221} & \multirow[t]{2}{*}{4.24} \\
\hline & $\not 8$ & 82.61 & 4.35 & 13.04 & & & & & & \\
\hline \multirow[b]{2}{*}{$\begin{array}{l}\text { Tennis } \\
\text { (5 wionths) }\end{array}$} & No. & $5 I$ & 32 & 78 & \multirow[b]{2}{*}{$\begin{array}{l}\text { Health } \\
\text { Time } \\
\text { Money } \\
\text { Facilities } \\
\text { Knowledge } \\
\text { and Skill } \\
\text { TOTAL } \\
\end{array}$} & \multirow[b]{2}{*}{$\begin{array}{r}\frac{2}{14} \\
\frac{1}{6} \\
\frac{1}{24}\end{array}$} & \multirow[t]{2}{*}{1} & \multirow[t]{2}{*}{9} & \multirow[t]{2}{*}{49} & \multirow[t]{2}{*}{.72} \\
\hline & $\%$ & 31.67 & 19.32 & 48.40 & & & & & & \\
\hline \multirow[b]{2}{*}{$\begin{array}{l}\text { Touch } \\
\text { FootbalI } \\
\text { (3 Months) }\end{array}$} & No. & 40 & 28 & 93 & \multirow{2}{*}{$\begin{array}{l}\text { Health } \\
\text { Time } \\
\text { Money } \\
\text { Facilities } \\
\text { Knowledge } \\
\text { and Skill } \\
\text { TUTAL }\end{array}$} & 3 & \multirow[t]{2}{*}{1} & \multirow[t]{2}{*}{4} & \multirow[t]{2}{*}{16} & \multirow[t]{2}{*}{.25} \\
\hline & $\stackrel{9}{p}$ & 24.84 & 17.39 & 57.77 & & $\begin{array}{l}0 \\
4\end{array}$ & & & & \\
\hline
\end{tabular}


TABIE 28 (Continued)

30-39 Age Group

\begin{tabular}{|c|c|c|c|c|c|c|c|c|c|c|}
\hline \multirow[t]{2}{*}{ Activity } & \multicolumn{4}{|c|}{$\begin{array}{l}\text { Total No. of lifen } \\
\text { indicating attitude } \\
\text { toward activity }\end{array}$} & \multirow{2}{*}{\multicolumn{2}{|c|}{$\begin{array}{l}\text { Total No. of hen } \\
\text { stating reasons } \\
\text { for insufficient } \\
\text { participation }\end{array}$}} & \multicolumn{4}{|c|}{ Total Ho. of Participations } \\
\hline & & Like & Dislike & Indif. & & & Wixly. & lithly. & Irly. & $\begin{array}{l}\text { Part. } \\
\text { Index }\end{array}$ \\
\hline \multirow[b]{2}{*}{ Tumbling } & INo. & 19 & 42 & 100 & \multirow[b]{2}{*}{$\begin{array}{l}\text { Health } \\
\text { Time } \\
\text { lioney } \\
\text { Facilities } \\
\text { Inowledge } \\
\text { and Skill } \\
\text { TOTAL }\end{array}$} & \multirow[b]{2}{*}{$\begin{array}{l}1 \\
3 \\
0 \\
3 \\
0 \\
7\end{array}$} & \multirow[t]{2}{*}{3} & \multirow[t]{2}{*}{2} & \multirow[t]{2}{*}{253} & \multirow[t]{2}{*}{2.69} \\
\hline & $\%$ & 11.89 & 26.08 & 62.12 & & & & & & \\
\hline \multirow[b]{2}{*}{$\begin{array}{l}\text { Visiting } \\
\text { Friends }\end{array}$} & No. & 1114 & $\underline{14}$ & 33 & \multirow[b]{2}{*}{$\begin{array}{l}\text { Health } \\
\text { Time } \\
\text { Money } \\
\text { Facilities } \\
\text { Knowledge } \\
\text { and Skill } \\
\text { TOTSI }\end{array}$} & \multirow[b]{2}{*}{$\begin{array}{r}0 \\
15 \\
0 \\
0 \\
\frac{0}{15}\end{array}$} & \multirow[t]{2}{*}{72} & \multirow[t]{2}{*}{21} & \multirow[t]{2}{*}{330} & \multirow[t]{2}{*}{26.87} \\
\hline & $g^{\prime}$ & 70.81 & 8.70 & 20.50 & & & & & & \\
\hline \multirow[b]{2}{*}{ Volleyball } & No. & 63 & 26 & 72 & \multirow{2}{*}{$\begin{array}{l}\text { Health } \\
\text { Time } \\
\text { Money } \\
\text { Facilities } \\
\text { Knowledge } \\
\text { and Skill } \\
\text { TOTAL }\end{array}$} & 0 & \multirow[t]{2}{*}{16} & \multirow[t]{2}{*}{12} & \multirow[t]{2}{*}{21} & \multirow[t]{2}{*}{6.19} \\
\hline & 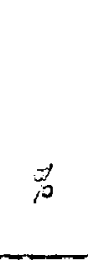 & 39.15 & 16.15 & 44.73 & & $\begin{array}{r}0 \\
6 \\
\frac{0}{18}\end{array}$ & & & & \\
\hline
\end{tabular}


TABIE 20 (Continued)

30-39 Age Group

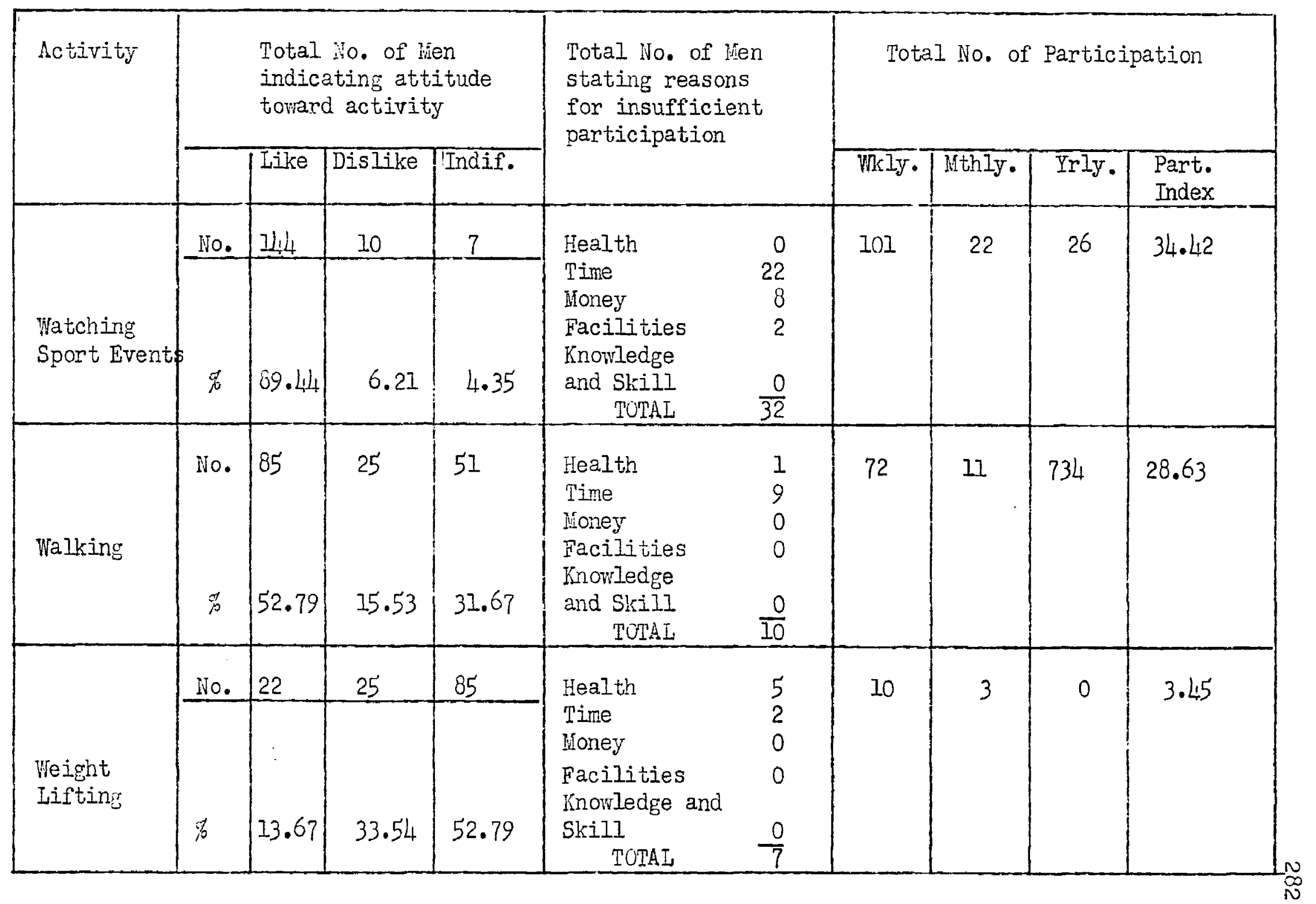


TABIE 28 (Continued)

30-39 Age Group

\begin{tabular}{|c|c|c|c|c|c|c|c|c|c|c|}
\hline \multirow[t]{2}{*}{ Activity } & \multicolumn{4}{|c|}{$\begin{array}{l}\text { Total yo. of Men } \\
\text { indicating attitude } \\
\text { toward activity }\end{array}$} & \multirow{2}{*}{\multicolumn{2}{|c|}{$\begin{array}{l}\text { Total No. of Hen } \\
\text { stating reasons } \\
\text { for insufficient } \\
\text { participation }\end{array}$}} & \multicolumn{4}{|c|}{ Total No. of Participations } \\
\hline & & Like & Dislike & Indif. & & & Wkly. & Mithly. & Yrly. & $\begin{array}{l}\text { Part. } \\
\text { Index }\end{array}$ \\
\hline \multirow[b]{2}{*}{$\begin{array}{l}\text { Water Polo } \\
\text { (3 Honths) }\end{array}$} & No. & 16 & 47 & 85 & \multirow[b]{2}{*}{$\begin{array}{l}\text { Health } \\
\text { Time } \\
\text { Noney } \\
\text { Facilities } \\
\text { Knowledge } \\
\text { and Skill } \\
\quad \text { TOTAL } \\
\end{array}$} & \multirow[b]{2}{*}{$\begin{array}{l}0 \\
3 \\
0 \\
4 \\
0 \\
7\end{array}$} & \multirow[t]{2}{*}{2} & \multirow[t]{2}{*}{5} & \multirow[t]{2}{*}{5} & \multirow[t]{2}{*}{.29} \\
\hline & $\%$ & 9.94 & 25.46 & 64.60 & & & & & & \\
\hline \multirow[b]{2}{*}{ Woodworking } & No. & 84 & 15 & 62 & \multirow[b]{2}{*}{$\begin{array}{l}\text { Health } \\
\text { Time } \\
\text { Honey } \\
\text { Facilities } \\
\text { Knorledge } \\
\text { and Skill } \\
\quad \text { TOTAL } \\
\end{array}$} & \multirow[b]{2}{*}{$\begin{array}{r}0 \\
13 \\
5 \\
8 \\
\\
0 \\
28 \\
\end{array}$} & \multirow[t]{2}{*}{22} & \multirow[t]{2}{*}{11} & \multirow[t]{2}{*}{169} & \multirow[t]{2}{*}{8.99} \\
\hline & $\mathscr{8}$ & 52.16 & 9.32 & 38.52 & & & & & & \\
\hline \multirow[b]{2}{*}{$\begin{array}{l}\text { Wood } \\
\text { Carving }\end{array}$} & ĩo. & 35 & 24 & 102 & \multirow[b]{2}{*}{$\begin{array}{l}\text { lealth } \\
\text { Time } \\
\text { lioney } \\
\text { Facilities } \\
\text { Knowledge } \\
\text { and Skill } \\
\quad \text { TOIAL } \\
\end{array}$} & 0 & \multirow[t]{2}{*}{10} & \multirow[t]{2}{*}{6} & \multirow[t]{2}{*}{2} & \multirow[t]{2}{*}{3.69} \\
\hline & $\%$ & 21.74 & 14.90 & 63.36 & & $\begin{array}{r}7 \\
0 \\
5 \\
\frac{2}{14}\end{array}$ & & & & \\
\hline
\end{tabular}


TABLE 28 (Continued)

30-39 Age Group

\begin{tabular}{|c|c|c|c|c|c|c|c|c|c|c|}
\hline \multirow[t]{2}{*}{ Activity } & \multicolumn{4}{|c|}{$\begin{array}{l}\text { Total No. of Wen } \\
\text { indicating attitude } \\
\text { toward activity }\end{array}$} & \multirow{2}{*}{\multicolumn{2}{|c|}{$\begin{array}{l}\text { Total No. of lien } \\
\text { stating reasons } \\
\text { for insufficient } \\
\text { participation }\end{array}$}} & \multicolumn{4}{|c|}{ Total No. of Participations } \\
\hline & & Like & Dislike & Indif. & & & WhIy. & Ifthly. & Yrly. & $\begin{array}{l}\text { Part. } \\
\text { Index }\end{array}$ \\
\hline \multirow[b]{2}{*}{ Wrestling } & No & 43 & 45 & 73 & \multirow{2}{*}{$\begin{array}{l}\text { Health } \\
\text { Time } \\
\text { Money } \\
\text { Facilities } \\
\text { Knowledge } \\
\text { and Skill } \\
\text { TOTAL }\end{array}$} & 7 & \multirow[t]{2}{*}{9} & \multirow[t]{2}{*}{5} & \multirow[t]{2}{*}{6} & \multirow[t]{2}{*}{3.32} \\
\hline & 点. & 26.70 & 27.95 & 45.35 & & $\begin{array}{r}2 \\
1 \\
\frac{1}{20}\end{array}$ & & & & \\
\hline
\end{tabular}

REASONS :

$\begin{array}{lcc}\text { Healti } & 90 & 5.3 \% \\ \text { Time } & 995 & 58.3 \% \\ \text { Honey } & 269 & 15.8 \% \\ \text { Facilities } & 274 & 16.0 \% \\ \text { Knowledge and Skill } & 80 & -4.7 \%\end{array}$


Numbers and Percentages of en Iiking, Disliking, and Indifferent to Each of Sixty-Seven Recreational Activities, Extent of Participation in Each, and Number of Men Listing Each of Five Feasons for Unsatisfactory Participation in the 40-49 Age Group

\begin{tabular}{|c|c|c|c|c|c|c|c|c|c|c|}
\hline \multirow[t]{2}{*}{ Activity } & \multicolumn{4}{|c|}{$\begin{array}{l}\text { Total Wo. of hen } \\
\text { indicating attitude } \\
\text { toward activity }\end{array}$} & \multirow{2}{*}{\multicolumn{2}{|c|}{$\begin{array}{l}\text { Total No. of ifen } \\
\text { stating reasons } \\
\text { for insufficient } \\
\text { participation }\end{array}$}} & \multicolumn{4}{|c|}{ Total No. of Participations } \\
\hline & & Iike & Dislike & Indif. & & & WI 1 . & inthIy. & Irly. & $\begin{array}{l}\text { Part. } \\
\text { Index }\end{array}$ \\
\hline \multirow[b]{2}{*}{ Archery } & No. & 12 & 16 & 72 & \multirow[b]{2}{*}{$\begin{array}{l}\text { Health } \\
\text { Time } \\
\text { Money } \\
\text { Facilities } \\
\text { Knowledge } \\
\text { and Skill } \\
\quad \text { TOTAL }\end{array}$} & 0 & \multirow[t]{2}{*}{1} & \multirow[t]{2}{*}{2} & \multirow[t]{2}{*}{4} & \multirow[t]{2}{*}{.80} \\
\hline & $\frac{1}{10}$ & 12 & 16 & 72 & & $\begin{array}{r}8 \\
2 \\
1 \\
\frac{1}{I_{4}} \\
\end{array}$ & & & & \\
\hline \multirow[b]{2}{*}{ Badminton } & No. & 25 & 내 & 61 & \multirow{2}{*}{$\begin{array}{l}\text { Health } \\
\text { Time } \\
\text { Honey } \\
\text { Facilities } \\
\text { Knowledge } \\
\text { and SkilI } \\
\quad \text { TOTAI }\end{array}$} & 0 & \multirow[t]{2}{*}{5} & \multirow[t]{2}{*}{6} & \multirow[t]{2}{*}{18} & \multirow[t]{2}{*}{3.50} \\
\hline & 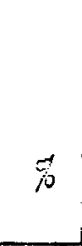 & 25 & 出 & 61. & & $\begin{array}{r}1 \\
1 \\
\frac{0}{12}\end{array}$ & & & & \\
\hline
\end{tabular}


TABLE 29 (Continued)

40-49 Age Group

\begin{tabular}{|c|c|c|c|c|c|c|c|c|c|c|}
\hline \multirow[t]{2}{*}{ Activity } & & \multicolumn{3}{|c|}{$\begin{array}{l}\text { Total No. of wen } \\
\text { indicating attitude } \\
\text { toward activity }\end{array}$} & \multirow{2}{*}{\multicolumn{2}{|c|}{$\begin{array}{l}\text { Total No. of Len } \\
\text { stating reasons } \\
\text { for insufficient } \\
\text { participation }\end{array}$}} & \multicolumn{4}{|c|}{ Total No. of Participations } \\
\hline & & Like & Dislike & Indif. & & & Tikly. & WthIy. & Irly. & $\begin{array}{l}\text { Part. } \\
\text { Index }\end{array}$ \\
\hline \multirow[b]{2}{*}{$\begin{array}{l}\text { Bag } \\
\text { Punching }\end{array}$} & No. & 12 & 19 & 69 & \multirow[b]{2}{*}{$\begin{array}{l}\text { Health } \\
\text { Time } \\
\text { Money } \\
\text { Facilities } \\
\text { Knowledge } \\
\text { and Skill } \\
\quad \text { TOMAL } \\
\end{array}$} & \multirow[b]{2}{*}{$\begin{array}{l}0 \\
4 \\
2 \\
0 \\
\frac{1}{7}\end{array}$} & \multirow[t]{2}{*}{0} & \multirow[t]{2}{*}{3} & \multirow[t]{2}{*}{4} & \multirow[t]{2}{*}{.40} \\
\hline & $\mathscr{8}$ & 12 & 19 & 69 & & & & & & \\
\hline \multirow[b]{2}{*}{$\begin{array}{l}\text { Baseball } \\
\text { (3 Months) }\end{array}$} & No. & 77 & 4 & 19 & \multirow{2}{*}{$\begin{array}{l}\text { Health } \\
\text { Time } \\
\text { Money } \\
\text { Facilities } \\
\text { Knowledge } \\
\text { and Skill } \\
\quad \text { TOTAL } \\
\end{array}$} & \multirow[b]{2}{*}{$\begin{array}{r}6 \\
23 \\
4 \\
1 \\
\\
0 \\
\frac{0}{34}\end{array}$} & \multirow[t]{2}{*}{25} & \multirow[t]{2}{*}{10} & \multirow[t]{2}{*}{34} & \multirow[t]{2}{*}{3.89} \\
\hline & $\%$ & 77 & 4 & 19 & & & & & & \\
\hline \multirow[b]{2}{*}{ Basketball } & No. & 30 & 9 & 53 & \multirow{2}{*}{$\begin{array}{l}\text { Health } \\
\text { Time } \\
\text { Money } \\
\text { Facilities } \\
\text { Knowledge } \\
\text { and Skill } \\
\quad \text { TOTAL }\end{array}$} & \multirow{2}{*}{$\begin{array}{r}3 \\
11 \\
2 \\
1 \\
\frac{1}{18}\end{array}$} & \multirow[t]{2}{*}{3} & \multirow[t]{2}{*}{2} & \multirow[t]{2}{*}{24} & \multirow[t]{2}{*}{1.14} \\
\hline & $\%$ & 38 & 9 & 53 & & & & & & \\
\hline
\end{tabular}


TABIE 29 (Continued)

40-49 Age Group

\begin{tabular}{|c|c|c|c|c|c|c|c|c|c|c|}
\hline \multirow[t]{2}{*}{ Activity } & \multicolumn{4}{|c|}{$\begin{array}{l}\text { Total Ho. of lien } \\
\text { indicating attitude } \\
\text { toward activity }\end{array}$} & \multirow{2}{*}{\multicolumn{2}{|c|}{$\begin{array}{l}\text { Total Ho. of wen } \\
\text { stating reasons } \\
\text { for insufficient } \\
\text { participation }\end{array}$}} & \multicolumn{4}{|c|}{ Total No. of Participations } \\
\hline & & Like & Dislike & Indif. & & & WK $1 y$ & NethIy. & Yrly. & $\begin{array}{l}\text { Part. } \\
\text { Index }\end{array}$ \\
\hline \multirow[b]{2}{*}{ Boating } & No. & 42 & 6 & 52 & \multirow{2}{*}{$\begin{array}{l}\text { Health } \\
\text { Time } \\
\text { Honey } \\
\text { Facilities } \\
\text { Hnowledge } \\
\text { and Skill }\end{array}$} & \multirow{2}{*}{$\begin{array}{r}0 \\
12 \\
5 \\
5 \\
\frac{0}{22}\end{array}$} & \multirow[t]{2}{*}{3} & \multirow[t]{2}{*}{2} & \multirow[t]{2}{*}{151} & \multirow[t]{2}{*}{3.35} \\
\hline & $\stackrel{t}{p}$ & 42 & 6 & 52 & & & & & & \\
\hline \multirow[b]{2}{*}{$\begin{array}{l}\text { Bowling } \\
\text { (9 Honths) }\end{array}$} & INo. & 68 & 12 & 20 & \multirow{2}{*}{$\begin{array}{l}\text { Health } \\
\text { Time } \\
\text { Money } \\
\text { Facilities } \\
\text { Knowledge } \\
\text { and Skill } \\
\quad \text { TOTAI } \\
\end{array}$} & \multirow{2}{*}{$\begin{array}{r}0 \\
20 \\
6 \\
0 \\
\\
0 \\
26 \\
\end{array}$} & \multirow[t]{2}{*}{24} & \multirow[t]{2}{*}{26} & \multirow[t]{2}{*}{62} & \multirow[t]{2}{*}{$12 \cdot 32$} \\
\hline & $\not 8$ & 68 & 12 & 20 & & & & & & \\
\hline \multirow[b]{2}{*}{ Boxing } & Ho. & 28 & 20 & 52 & \multirow{2}{*}{$\begin{array}{l}\text { Health } \\
\text { Time } \\
\text { Honey } \\
\text { Facilities } \\
\text { Knowledge } \\
\text { and Skill } \\
\quad \text { TOTAL } \\
\end{array}$} & 4 & \multirow[t]{2}{*}{2} & \multirow[t]{2}{*}{2} & \multirow[t]{2}{*}{1} & \multirow[t]{2}{*}{1.29} \\
\hline & $\mathscr{o f}$ & 28 & 20 & 52 & & $\begin{array}{c}0 \\
2 \\
\frac{1}{10}\end{array}$ & & & & \\
\hline
\end{tabular}


TASIE 29 (Continued)

40-49 Age Group

\begin{tabular}{|c|c|c|c|c|c|c|c|c|c|c|}
\hline \multirow[t]{2}{*}{ Activity } & & \multicolumn{3}{|c|}{$\begin{array}{l}\text { Total No. ổ lien } \\
\text { indicating attitude } \\
\text { toward activity }\end{array}$} & \multirow{2}{*}{\multicolumn{2}{|c|}{$\begin{array}{l}\text { Total No. of hien } \\
\text { stating reasons } \\
\text { for insufficient } \\
\text { participation }\end{array}$}} & \multicolumn{4}{|c|}{ Total No. of Participations } \\
\hline & & Like & Dislike & Indif. & & & Wkly. & Mthly 1 & $\operatorname{Irly\cdot 1}$ & $\begin{array}{l}\text { Part. } \\
\text { Index }\end{array}$ \\
\hline \multirow[b]{2}{*}{ Calisthenics } & No. & 20 & 17 & 63 & \multirow{2}{*}{$\begin{array}{l}\text { Health } \\
\text { Time } \\
\text { Honey } \\
\text { Facilities } \\
\text { Knowledge } \\
\text { and Skill } \\
\quad \text { TOTAL } \\
\end{array}$} & \multirow[b]{2}{*}{$\begin{array}{c}2 \\
9 \\
0 \\
0 \\
\frac{0}{11} \\
\end{array}$} & \multirow[t]{2}{*}{8} & \multirow[t]{2}{*}{2} & \multirow[t]{2}{*}{5} & \multirow[t]{2}{*}{$4 \cdot 45$} \\
\hline & $\frac{9}{30}$ & 20 & 17 & 63 & & & & & & \\
\hline \multirow[b]{2}{*}{$\begin{array}{l}\text { Canoeing } \\
\text { (5 Months) }\end{array}$} & No. & 19 & 18 & 63 & \multirow{2}{*}{$\begin{array}{l}\text { Health } \\
\text { Time } \\
\text { lioney } \\
\text { Facilities } \\
\text { Knowledge } \\
\text { and Skill } \\
\quad \text { TOTA I } \\
\end{array}$} & \multirow{2}{*}{$\begin{array}{l}0 \\
5 \\
4 \\
2 \\
\frac{0}{17}\end{array}$} & \multirow[t]{2}{*}{1} & \multirow[t]{2}{*}{9} & \multirow[t]{2}{*}{10} & \multirow[t]{2}{*}{.77} \\
\hline & of & 19 & 18 & 63 & & & & & & \\
\hline \multirow[b]{2}{*}{ Card Playing } & INo. & 85 & 7 & 8 & \multirow{2}{*}{$\begin{array}{l}\text { Health } \\
\text { Time } \\
\text { Money } \\
\text { Facilities } \\
\text { Knowledge } \\
\text { and Skill } \\
\quad \text { TOTAI }\end{array}$} & 0 & \multirow[t]{2}{*}{35} & \multirow[t]{2}{*}{35} & \multirow[t]{2}{*}{132} & \multirow[t]{2}{*}{23.72} \\
\hline & f & 85 & 7 & 8 & & $\begin{array}{r}15 \\
6 \\
1 \\
\frac{0}{22}\end{array}$ & & & & \\
\hline
\end{tabular}


TABIE 29 (Continued)

40-49 Age Group

\begin{tabular}{|c|c|c|c|c|c|c|c|c|c|c|}
\hline \multirow[t]{2}{*}{ Activity } & \multicolumn{4}{|c|}{$\begin{array}{l}\text { Total No. of ivien } \\
\text { indicating attitude } \\
\text { toward activity }\end{array}$} & \multirow{2}{*}{\multicolumn{2}{|c|}{$\begin{array}{l}\text { Total Ho. of Jien } \\
\text { stating reasons } \\
\text { for insufficient } \\
\text { participation }\end{array}$}} & \multicolumn{4}{|c|}{ Total To. of Participations } \\
\hline & & Like & Dislike & Indif. & & & Wkly. & Mthly. & Irly.1 & Part. Index \\
\hline \multirow[b]{2}{*}{ Checkers } & No. & 38 & 13 & 49 & \multirow{2}{*}{$\begin{array}{l}\text { Health } \\
\text { Time } \\
\text { Money } \\
\text { Fracilities } \\
\text { Knowledge } \\
\text { and Skill } \\
\quad \text { TOTAI } \\
\end{array}$} & \multirow{2}{*}{$\begin{array}{r}0 \\
14 \\
1 \\
1 \\
\frac{1}{17}\end{array}$} & \multirow[t]{2}{*}{11} & \multirow[t]{2}{*}{11} & \multirow[t]{2}{*}{20} & \multirow[t]{2}{*}{7.24} \\
\hline & $\%$ & 33 & 13 & 49 & & & & & & \\
\hline \multirow[b]{2}{*}{ Conversing } & No. & 50 & 8 & 42 & \multirow{2}{*}{$\begin{array}{l}\text { Health } \\
\text { Time } \\
\text { lioney } \\
\text { Pacilities } \\
\text { Knowledge } \\
\text { and Skill } \\
\quad \text { TOTAI } \\
\end{array}$} & 0 & \multirow[t]{2}{*}{45} & \multirow[t]{2}{*}{0} & \multirow[t]{2}{*}{12} & \multirow[t]{2}{*}{23.52} \\
\hline & $\%$ & 50 & 8 & 42 & & $\begin{array}{l}1 \\
0 \\
1 \\
\frac{1}{4}\end{array}$ & & & & \\
\hline \multirow[b]{2}{*}{ Chess } & No. & 9 & 26 & 65 & \multirow{2}{*}{$\begin{array}{l}\text { Health } \\
\text { Time } \\
\text { linoney } \\
\text { Facilities } \\
\text { Finowledge } \\
\text { and Skill } \\
\text { TOTAL }\end{array}$} & 0 & \multirow[t]{2}{*}{0} & \multirow[t]{2}{*}{1} & \multirow[t]{2}{*}{6} & \multirow[t]{2}{*}{.18} \\
\hline & $\not b$ & 9 & 26 & 65 & & $\begin{array}{l}1 \\
3 \\
\frac{1}{7}\end{array}$ & & & & \\
\hline
\end{tabular}


TABIF 29 (Continued)

40-49 Age Group

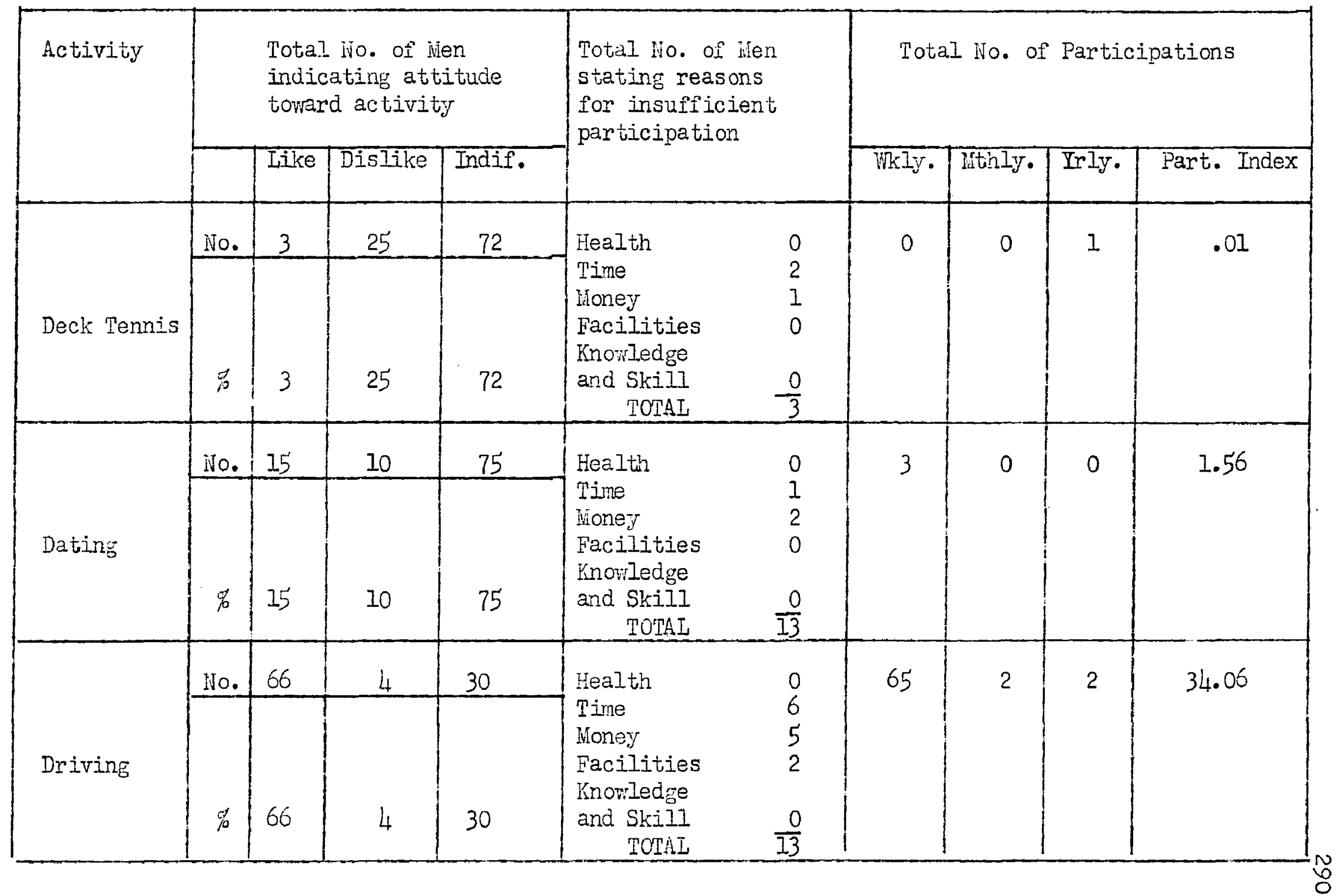


TASIE 29 (Continued)

40-49 Age Group

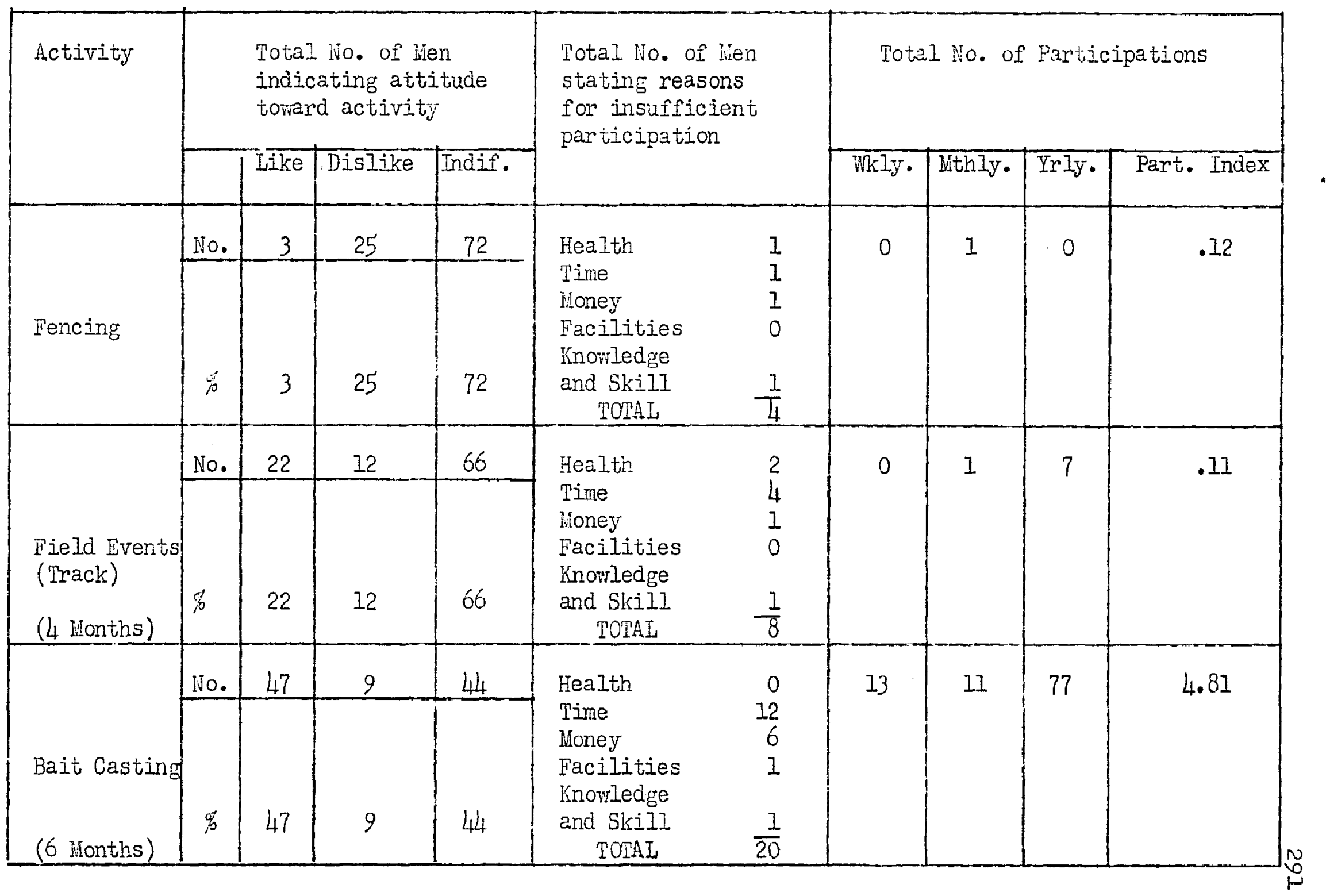


TABLE 29 (Continued)

40-49 Age Group

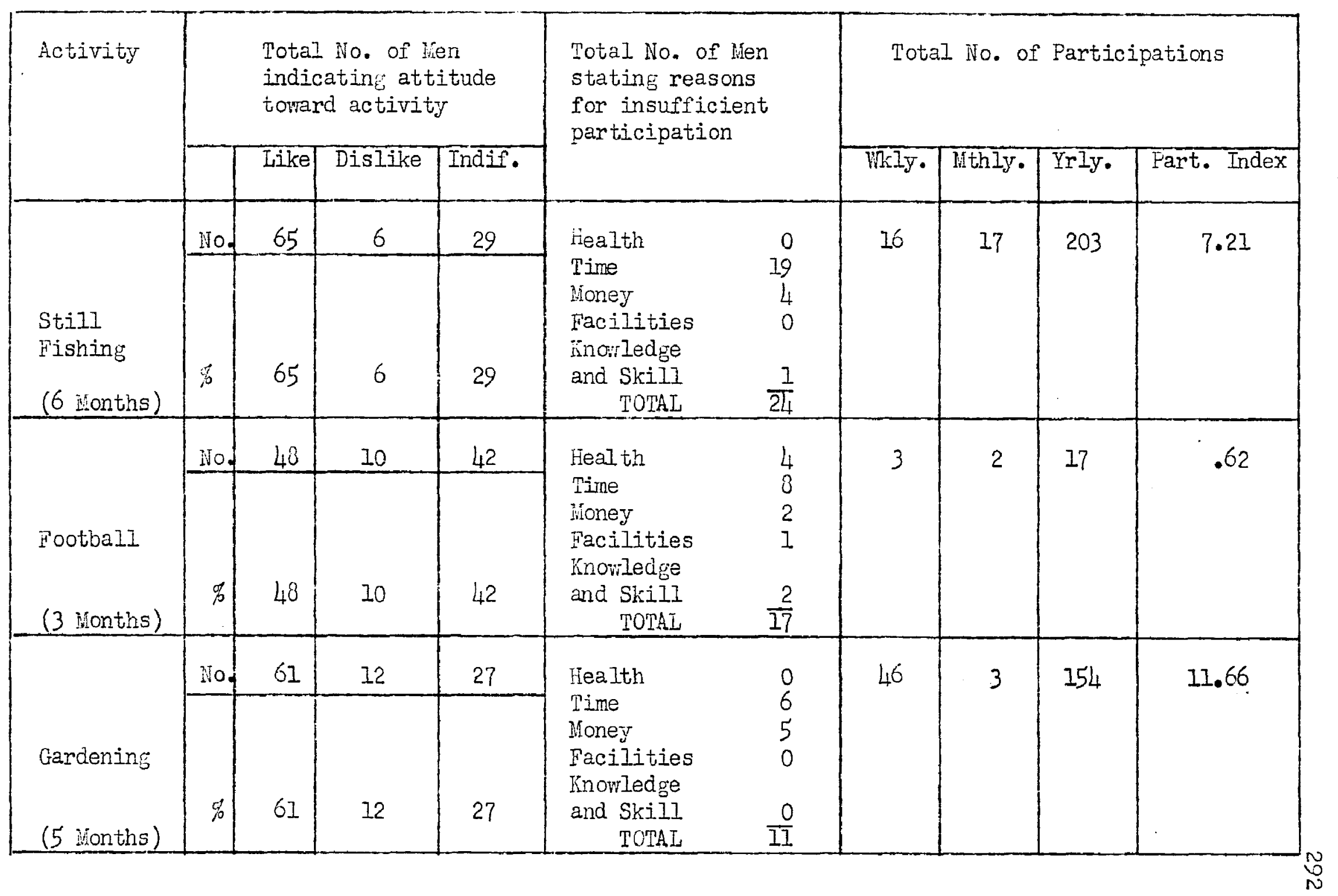


TABIE 29 (Continued)

40-49 Age Group

\begin{tabular}{|c|c|c|c|c|c|c|c|c|c|c|}
\hline \multirow[t]{2}{*}{ Activity } & \multicolumn{4}{|c|}{$\begin{array}{l}\text { Total ivo. of Men } \\
\text { indicating attitude } \\
\text { toward activity }\end{array}$} & \multirow{2}{*}{\multicolumn{2}{|c|}{$\begin{array}{l}\text { Total No. of lien } \\
\text { stating reasons } \\
\text { for insufficient } \\
\text { participation }\end{array}$}} & \multicolumn{4}{|c|}{ Total No. of Participations } \\
\hline & & Like & Dislike & Indif. & & & Wly. & Kthly. & Yrly. & Part. Index \\
\hline \multirow[b]{2}{*}{ (4 lifonths) } & No. & 34 & 16 & 50 & \multirow{2}{*}{$\begin{array}{l}\text { Healthi } \\
\text { Time } \\
\text { !ioney } \\
\text { Facilities } \\
\text { Knowledge } \\
\text { and Skill } \\
\quad \text { TOTAL } \\
\end{array}$} & \multirow{2}{*}{$\begin{array}{r}0 \\
15 \\
10 \\
0 \\
0 \\
\frac{0}{25} \\
\end{array}$} & \multirow[t]{2}{*}{10} & \multirow[t]{2}{*}{6} & \multirow[t]{2}{*}{44} & \multirow[t]{2}{*}{2.41} \\
\hline & $\ddot{s}$ & 34 & 16 & 50 & & & & & & \\
\hline \multirow[b]{2}{*}{ Gymnastics } & No. & 20 & 16 & 64 & \multirow{2}{*}{$\begin{array}{l}\text { Health } \\
\text { Time } \\
\text { Woney } \\
\text { Facilities } \\
\text { Knowledge } \\
\text { and Skill } \\
\quad \text { TOTAL } \\
\end{array}$} & 2 & \multirow[t]{2}{*}{1} & \multirow[t]{2}{*}{0} & \multirow[t]{2}{*}{11} & \multirow[t]{2}{*}{.63} \\
\hline & $\%$ & 20 & 16 & 64 & & $\begin{array}{r}2 \\
2 \\
1 \\
0 \\
10 \\
\end{array}$ & & & & \\
\hline \multirow[b]{2}{*}{ Handball } & No. & 23 & 17 & 60 & \multirow{2}{*}{$\begin{array}{l}\text { Health } \\
\text { Time } \\
\text { Noney } \\
\text { Facilities } \\
\text { Knowledge } \\
\text { and Skill } \\
\text { rOTAI }\end{array}$} & 1 & \multirow[t]{2}{*}{2} & \multirow[t]{2}{*}{1} & \multirow[t]{2}{*}{8} & \multirow[t]{2}{*}{.95} \\
\hline & $\%$ & 23 & 17 & 60 & & $\begin{array}{r}2 \\
2 \\
0 \\
\frac{0}{13}\end{array}$ & & & & \\
\hline
\end{tabular}


TABIE 29 (Continued)

40-49 Age Group

\begin{tabular}{|c|c|c|c|c|c|c|c|c|c|c|}
\hline \multirow[t]{2}{*}{ Activity } & & \multicolumn{3}{|c|}{$\begin{array}{l}\text { Total No. of wen } \\
\text { indicating attitude } \\
\text { toward activity }\end{array}$} & \multirow{2}{*}{\multicolumn{2}{|c|}{$\begin{array}{l}\text { Total ivo. of Men } \\
\text { stating reasons } \\
\text { for insufficient } \\
\text { participation }\end{array}$}} & \multicolumn{4}{|c|}{ Total No. of Participations } \\
\hline & & Like & Dislike & Indif. & & & WhIy. & jithly. & Irly. & Part. Index \\
\hline \multirow[b]{2}{*}{ Hiking } & No. & 24 & 13 & 63 & \multirow{2}{*}{$\begin{array}{l}\text { Health } \\
\text { Time } \\
\text { Money } \\
\text { Facilities } \\
\text { Knowledge } \\
\text { and Skill } \\
\quad \text { TORAI } \\
\end{array}$} & \multirow[b]{2}{*}{$\begin{array}{l}0 \\
7 \\
2 \\
0 \\
0 \\
9 \\
\end{array}$} & \multirow[t]{2}{*}{4} & \multirow[t]{2}{*}{4} & \multirow[t]{2}{*}{5} & \multirow[t]{2}{*}{1.97} \\
\hline & $\%$ & 24 & 13 & 63 & & & & & & \\
\hline \multirow[b]{2}{*}{$\begin{array}{l}\text { Horseback } \\
\text { Riding } \\
\text { (9 lionths) }\end{array}$} & iNo. & 36 & $\underline{14}$ & 50 & \multirow{2}{*}{$\begin{array}{l}\text { Health } \\
\text { Time } \\
\text { Money } \\
\text { Facilities } \\
\text { Hinowledge } \\
\text { and Skill } \\
\quad \text { TOTAL }\end{array}$} & \multirow{2}{*}{$\begin{array}{r}0 \\
10 \\
6 \\
5 \\
1 \\
\frac{1}{22} \\
\end{array}$} & \multirow[t]{2}{*}{1} & \multirow[t]{2}{*}{2} & \multirow[t]{2}{*}{14} & \multirow[t]{2}{*}{.71} \\
\hline & 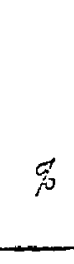 & 36 & $\mathrm{IH}_{4}$ & 50 & & & & & & \\
\hline \multirow[b]{2}{*}{$\begin{array}{l}\text { Horseshoes } \\
\text { (9 Fonths) }\end{array}$} & IYo. & 53 & 8 & 39 & \multirow[b]{2}{*}{$\begin{array}{l}\text { Health } \\
\text { Time } \\
\text { Money } \\
\text { Facilities } \\
\text { Knowledge } \\
\text { and Skill } \\
\quad \text { TOTAL } \\
\end{array}$} & \multirow[b]{2}{*}{$\begin{array}{r}0 \\
12 \\
1 \\
4 \\
0 \\
\frac{0}{17}\end{array}$} & \multirow[t]{2}{*}{6} & \multirow[t]{2}{*}{8} & \multirow[t]{2}{*}{45} & \multirow[t]{2}{*}{3.51} \\
\hline & $\not{B}$ & 53 & 8 & 39 & & & & & & \\
\hline
\end{tabular}


TABLE 29 (Continued)

40-49 Age Group

\begin{tabular}{|c|c|c|c|c|c|c|c|c|c|c|}
\hline \multirow[t]{2}{*}{ Activity } & & \multicolumn{3}{|c|}{$\begin{array}{l}\text { Total io. of lien } \\
\text { indicating attitude } \\
\text { toward activity }\end{array}$} & \multirow{2}{*}{\multicolumn{2}{|c|}{$\begin{array}{l}\text { Total No. of lien } \\
\text { stating reasons } \\
\text { for insufficient } \\
\text { participation }\end{array}$}} & \multicolumn{4}{|c|}{ Total No. of Farticipations } \\
\hline & & Iike & Dislike & Indif. & & & Wely. & Mthly. & Yrly. & Part. Index \\
\hline \multirow[b]{2}{*}{$\begin{array}{l}\text { Hunting } \\
\text { (3 Honths) }\end{array}$} & No. & 65 & 3 & 32 & \multirow{2}{*}{$\begin{array}{l}\text { Health } \\
\text { Time } \\
\text { Woney } \\
\text { Facilities } \\
\text { Knowledge } \\
\text { and Skill } \\
\text { ToTiL } \\
\end{array}$} & \multirow{2}{*}{$\begin{array}{r}0 \\
11 \\
7 \\
4 \\
0 \\
\frac{0}{22} \\
\end{array}$} & \multirow[t]{2}{*}{6} & \multirow[t]{2}{*}{9} & \multirow[t]{2}{*}{123} & \multirow[t]{2}{*}{2.28} \\
\hline & $\%$ & 65 & 3 & 32 & & & & & & \\
\hline \multirow[b]{2}{*}{$\begin{array}{l}\text { Ice Hockey } \\
\text { (3 Months) }\end{array}$} & No. & 22 & 16 & 62 & \multirow{2}{*}{$\begin{array}{l}\text { Iiealth } \\
\text { Time } \\
\text { inoney } \\
\text { Facilities } \\
\text { Knowledge } \\
\text { and Skill } \\
\quad \text { TOTAL } \\
\end{array}$} & \multirow{2}{*}{$\begin{array}{l}0 \\
5 \\
4 \\
0 \\
0 \\
9\end{array}$} & \multirow[t]{2}{*}{0} & \multirow[t]{2}{*}{1} & \multirow[t]{2}{*}{10} & \multirow[t]{2}{*}{.13} \\
\hline & $\%$ & 22 & 16 & 62 & & & & & & \\
\hline \multirow[b]{2}{*}{$\begin{array}{l}\text { Ice Skating } \\
\text { (3 Jonths) }\end{array}$} & No. & 30 & 15 & 55 & \multirow{2}{*}{$\begin{array}{l}\text { Health } \\
\text { Time } \\
\text { Money } \\
\text { Facilities } \\
\text { Knowledge } \\
\text { and Skill } \\
\text { TOTAL }\end{array}$} & 0 & \multirow[t]{2}{*}{0} & \multirow[t]{2}{*}{6} & \multirow[t]{2}{*}{18} & \multirow[t]{2}{*}{.36} \\
\hline & $\%$ & 30 & 15 & 55 & & $\begin{array}{r}8 \\
3 \\
2 \\
1 \\
15\end{array}$ & & & & \\
\hline
\end{tabular}


TABLE 29 (Continued)

40-49 Age Group

\begin{tabular}{|c|c|c|c|c|c|c|c|c|c|c|}
\hline \multirow[t]{2}{*}{ Activity } & \multicolumn{4}{|c|}{$\begin{array}{l}\text { Total No. of Men } \\
\text { indicating attitude } \\
\text { toward activity }\end{array}$} & \multirow{2}{*}{\multicolumn{2}{|c|}{$\begin{array}{l}\text { Total No. of lien } \\
\text { stating reasons } \\
\text { for insufficient } \\
\text { participation }\end{array}$}} & \multicolumn{4}{|c|}{ Total No. of Participations } \\
\hline & & Like & Dislike & Indif. & & & Thk ly. & dinly. & YrIy. & Part. Index \\
\hline \multirow[b]{2}{*}{ Movies } & No. & 73 & 4 & 23 & \multirow{2}{*}{$\begin{array}{l}\text { Health } \\
\text { Time } \\
\text { Honey } \\
\text { Facilities } \\
\text { Knowledje } \\
\text { and Skill } \\
\quad \text { TOTAL } \\
\end{array}$} & \multirow{2}{*}{$\begin{array}{r}0 \\
14 \\
7 \\
0 \\
0 \\
\frac{0}{21} \\
\end{array}$} & \multirow[t]{2}{*}{20} & \multirow[t]{2}{*}{26} & \multirow[t]{2}{*}{74} & \multirow[t]{2}{*}{14.26} \\
\hline & $L_{0}^{\circ}$ & 73 & 4 & 23 & & & & & & \\
\hline \multirow[b]{2}{*}{ Ijetal Craft } & No. & 18 & 12 & 70 & \multirow{2}{*}{$\begin{array}{l}\text { Health } \\
\text { Time } \\
\text { lioney } \\
\text { Facilities } \\
\text { Knowledge } \\
\text { and Skill } \\
\quad \text { TOTAI } \\
\end{array}$} & 0 & \multirow[t]{2}{*}{4} & \multirow[t]{2}{*}{1} & \multirow[t]{2}{*}{16} & \multirow[t]{2}{*}{2.36} \\
\hline & $\not 8$ & 18 & 12 & 70 & & $\begin{array}{r}4 \\
0 \\
\frac{1}{10}\end{array}$ & & & & \\
\hline \multirow[b]{2}{*}{ Iusic. } & No. & 63 & 1 & 36 & \multirow{2}{*}{$\begin{array}{l}\text { Health } \\
\text { Time } \\
\text { Woney } \\
\text { Facilities } \\
\text { Knowledge } \\
\text { and Skill } \\
\quad \text { TOTAL }\end{array}$} & 0 & \multirow[t]{2}{*}{32} & \multirow[t]{2}{*}{3} & \multirow[t]{2}{*}{17} & \multirow[t]{2}{*}{17.17} \\
\hline & $\%$ & 63 & 1 & 36 & & $\begin{array}{l}4 \\
4 \\
0 \\
\frac{1}{I_{4}}\end{array}$ & & & & \\
\hline
\end{tabular}


TABIE 29 (Continued)

40-49 Age Group

\begin{tabular}{|c|c|c|c|c|c|c|c|c|c|c|}
\hline \multirow[t]{2}{*}{ Activity } & \multicolumn{4}{|c|}{$\begin{array}{l}\text { Total No. of Wen } \\
\text { indicating attitude } \\
\text { toward activity }\end{array}$} & \multirow{2}{*}{\multicolumn{2}{|c|}{$\begin{array}{l}\text { Total Wo. of llen } \\
\text { stating reasons } \\
\text { for insuficicient } \\
\text { participation }\end{array}$}} & \multicolumn{4}{|c|}{ Total iNo. of Participations } \\
\hline & & Like & Dislike & Indif. & & & Wkly. & lithly. & Yrly. & Part. Index \\
\hline \multirow[b]{2}{*}{ Motoring } & No. & 50 & 4 & 38 & \multirow{2}{*}{$\begin{array}{l}\text { Health } \\
\text { Time } \\
\text { Money } \\
\text { Facilities } \\
\text { Knowledge } \\
\text { and Skill } \\
\quad \text { TOTAL } \\
\end{array}$} & \multirow{2}{*}{$\begin{array}{r}0 \\
7 \\
6 \\
2 \\
0 \\
15\end{array}$} & \multirow[t]{2}{*}{34} & \multirow[t]{2}{*}{5} & \multirow[t]{2}{*}{50} & \multirow[t]{2}{*}{18.78} \\
\hline & $g$ & 58 & 4 & 38 & & & & & & \\
\hline \multirow[b]{2}{*}{$\begin{array}{l}\text { Night } \\
\text { Clubbing }\end{array}$} & No. & 21 & 20 & 59 & \multirow{2}{*}{$\begin{array}{l}\text { Iealth } \\
\text { Time } \\
\text { Money } \\
\text { Facilities } \\
\text { Knorledge } \\
\text { and SkilI } \\
\quad \text { TOTAL }\end{array}$} & 0 & \multirow[t]{2}{*}{4} & \multirow[t]{2}{*}{5} & \multirow[t]{2}{*}{23} & \multirow[t]{2}{*}{2.91} \\
\hline & of & 21 & 20 & 59 & & $\begin{array}{l}7 \\
0 \\
0 \\
9\end{array}$ & & & & \\
\hline \multirow[b]{2}{*}{ Ping-Pong } & No. & 24 & 21 & 55 & \multirow{2}{*}{$\begin{array}{l}\text { Fiealth } \\
\text { Tine } \\
\text { Honey } \\
\text { Facilities } \\
\text { Knowledge } \\
\text { and Skill } \\
\quad \text { TOTAL }\end{array}$} & 0 & \multirow[t]{2}{*}{2} & \multirow[t]{2}{*}{3} & \multirow[t]{2}{*}{16} & \multirow[t]{2}{*}{1.56} \\
\hline & $\%$ & 24 & 21 & 55 & & $\begin{array}{l}\frac{1}{4} \\
\frac{1}{9}\end{array}$ & & & & \\
\hline
\end{tabular}


TABIP 29 (Continued)

40-49 Age Group

\begin{tabular}{|c|c|c|c|c|c|c|c|c|c|c|}
\hline \multirow[t]{2}{*}{ Activity } & & \multicolumn{3}{|c|}{$\begin{array}{l}\text { Total io. of ien } \\
\text { indicating attitude } \\
\text { toward activity }\end{array}$} & \multirow{2}{*}{\multicolumn{2}{|c|}{$\begin{array}{l}\text { Total iro. of ilen } \\
\text { stating reasons } \\
\text { for insuficicient } \\
\text { participation }\end{array}$}} & \multicolumn{4}{|c|}{ Total No. of Participations } \\
\hline & & Like & Dislike & Indif. & & & mkly. & jicthly. & Yrly. & Part. Index \\
\hline $\begin{array}{l}\text { Puttering, } \\
\text { Repairing, } \\
\text { etc. }\end{array}$ & No. & 65 & 8 & 27 & $\begin{array}{l}\text { Heal th } \\
\text { Time } \\
\text { Money } \\
\text { Facilities } \\
\text { Knowledge } \\
\text { and Skill } \\
\quad \text { TOTAL } \\
\end{array}$ & $\begin{array}{r}0 \\
7 \\
3 \\
0 \\
\frac{0}{10} \\
\end{array}$ & 78 & 10 & 33 & 42.09 \\
\hline $\begin{array}{l}\text { Iristening } \\
\text { to Radio }\end{array}$ & No. & 72 & 2 & 23 & $\begin{array}{l}\text { Health } \\
\text { Time } \\
\text { iloney } \\
\text { Tacilities } \\
\text { Knowledge } \\
\text { and Skill } \\
\quad \text { TOTAL }\end{array}$ & $\begin{array}{l}0 \\
5 \\
1 \\
0 \\
0 \\
\end{array}$ & 116 & 1 & 465 & 65.09 \\
\hline Watching $\mathrm{TV}$ & No. & 86 & 1 & 13 & $\begin{array}{l}\text { Heal th } \\
\text { Time } \\
\text { I. } \\
\text { Faney } \\
\text { Knowledies } \\
\text { and Skill } \\
\quad \text { TOTAL } \\
\end{array}$ & $\begin{array}{r}0 \\
12 \\
2 \\
3 \\
0 \\
\frac{0}{17}\end{array}$ & 125 & 2 & $11]_{4}$ & 76.38 \\
\hline
\end{tabular}


TABL 29 (Continued)

40-49 Age Group

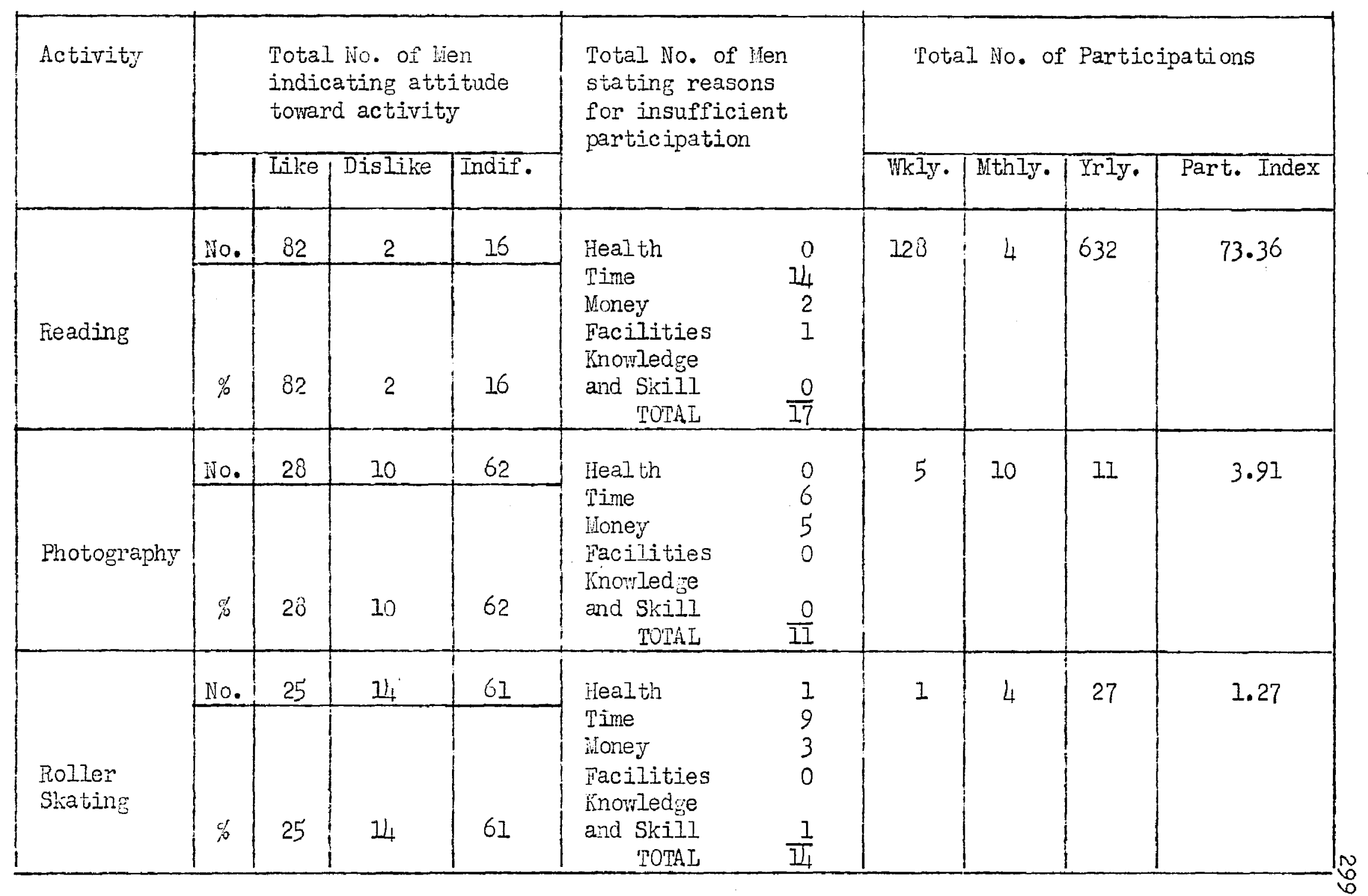


TABIE 29 (Continued)

40-49 Age Group

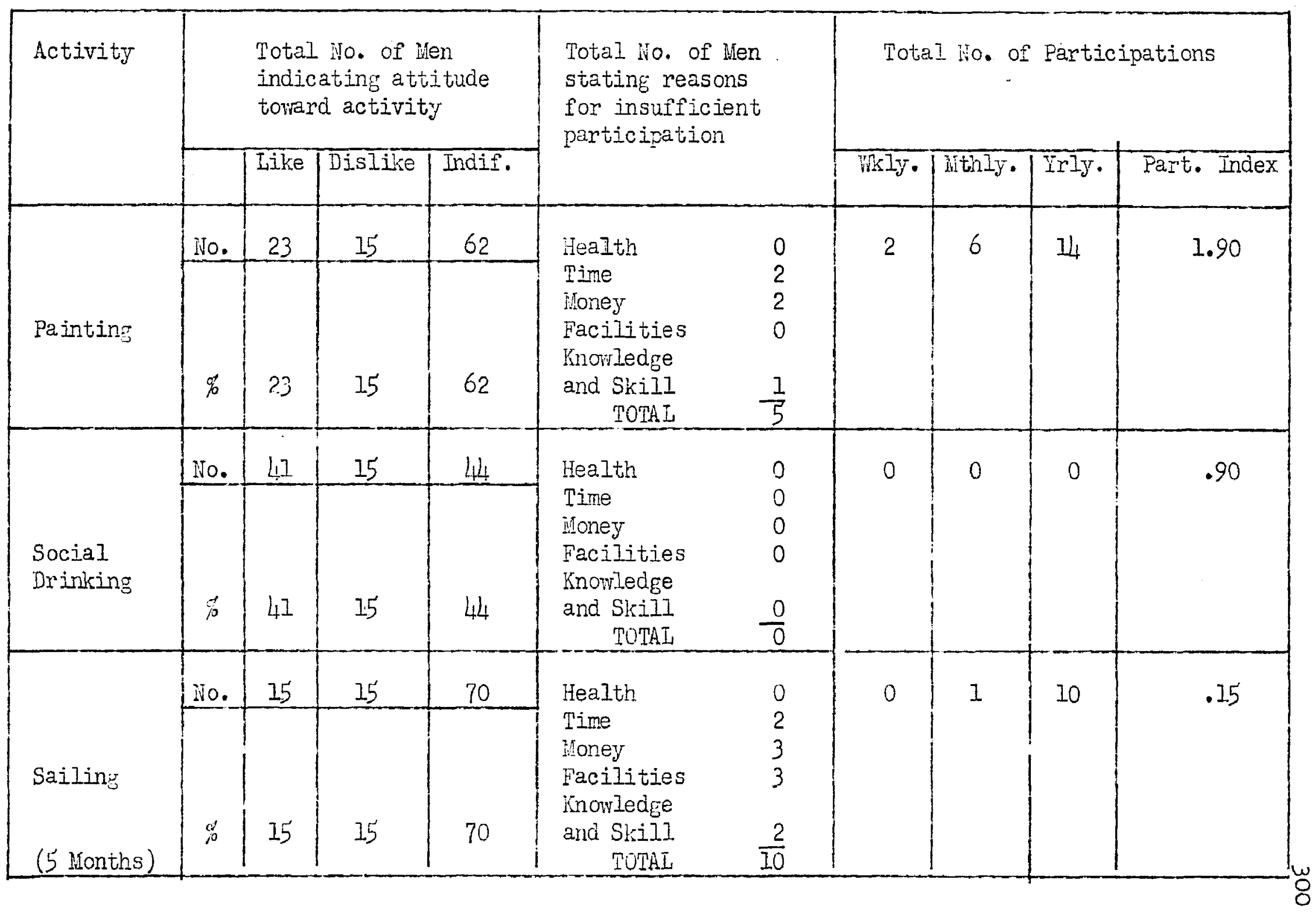


TABLE 29 (Continued)

40-49 Age Group

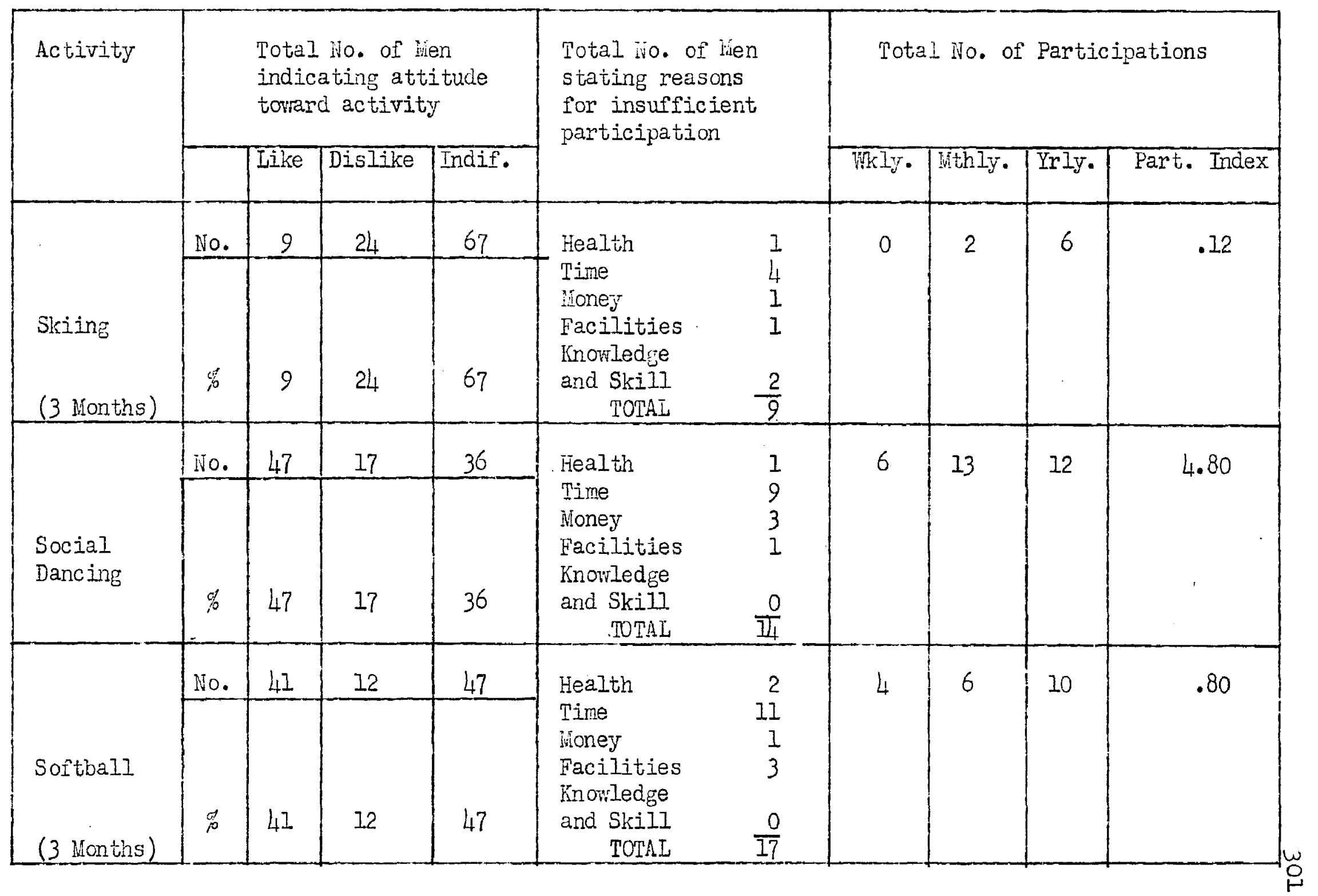


TABIE 29 (Continued)

40-49 Age Group

\begin{tabular}{|c|c|c|c|c|c|c|c|c|c|c|}
\hline \multirow[t]{2}{*}{ Activity } & \multicolumn{4}{|c|}{$\begin{array}{l}\text { Total io. of len } \\
\text { indicating attitude } \\
\text { toward activity }\end{array}$} & \multirow{2}{*}{\multicolumn{2}{|c|}{$\begin{array}{l}\text { Total No. of lien } \\
\text { stating reasons } \\
\text { for insufficient } \\
\text { participation }\end{array}$}} & \multicolumn{4}{|c|}{ Total No. of Participations } \\
\hline & & Like & Dislike & Indif. & & & WkIy. & Wthly. & YrIy. & Part. Index \\
\hline $\begin{array}{l}\text { Speedball } \\
\text { (3 Honths) }\end{array}$ & ivo. & 7 & 17 & 76 & $\begin{array}{l}\text { Health } \\
\text { Time } \\
\text { Money } \\
\text { Facilities } \\
\text { Knowledge } \\
\text { and SkilI } \\
\quad \text { TOTAL } \\
\end{array}$ & $\begin{array}{l}1 \\
2 \\
1 \\
0 \\
0 \\
\\
\end{array}$ & 1 & 0 & 0 & .13 \\
\hline $\begin{array}{l}\text { Square } \\
\text { Dancing }\end{array}$ & iNo. & 26 & 17 & 57 & $\begin{array}{l}\text { Health } \\
\text { Time } \\
\text { Money } \\
\text { Facilities } \\
\text { Knowledge } \\
\text { and Skill } \\
\text { TuTAL } \\
\end{array}$ & $\begin{array}{l}0 \\
8 \\
2 \\
1 \\
1 \\
1 \\
\end{array}$ & 2 & 3 & 7 & 1.47 \\
\hline $\begin{array}{l}\text { Stamp } \\
\text { Collecting }\end{array}$ & No. & 10 & 25 & 65 & $\begin{array}{l}\text { Health } \\
\text { Time } \\
\text { Money } \\
\text { Facilities } \\
\text { Knowledge } \\
\text { and Skill } \\
\text { TOTAL }\end{array}$ & $\begin{array}{l}1 \\
4 \\
1 \\
1 \\
0 \\
7\end{array}$ & 5 & 2 & 3 & 2.87 \\
\hline
\end{tabular}


TABLE 29 (Continued)

40-49 Age Group

\begin{tabular}{|c|c|c|c|c|c|c|c|c|c|c|}
\hline \multirow[t]{2}{*}{ Activity } & & \multicolumn{3}{|c|}{$\begin{array}{l}\text { Total No. of Hen } \\
\text { indicating attitude } \\
\text { toward activity }\end{array}$} & \multirow{2}{*}{\multicolumn{2}{|c|}{$\begin{array}{l}\text { Total No. of Men } \\
\text { stating reasons } \\
\text { for insufficient } \\
\text { participation }\end{array}$}} & \multicolumn{4}{|c|}{ Total iNo. of Participations } \\
\hline & & Like & Dislike & Indif. & & & Wkly. & Nhly. & Yrly. & Part. Index \\
\hline \multirow[b]{2}{*}{$\begin{array}{l}\text { Swiming } \\
\text { (3 Ironths) }\end{array}$} & iNo. & 67 & 3 & 30 & \multirow{2}{*}{$\begin{array}{l}\text { Ilealth } \\
\text { Time } \\
\text { Money } \\
\text { Facilities } \\
\text { Knowledge } \\
\text { and Skill } \\
\quad \text { TOTAL } \\
\end{array}$} & \multirow{2}{*}{$\begin{array}{r}0 \\
10 \\
2 \\
3 \\
0 \\
\frac{0}{15} \\
\end{array}$} & \multirow[t]{2}{*}{9} & \multirow[t]{2}{*}{20} & \multirow[t]{2}{*}{29} & \multirow[t]{2}{*}{2.06} \\
\hline & $g^{t}$ & $6 ?$ & 3 & 30 & & & & & & \\
\hline \multirow[b]{2}{*}{$\begin{array}{l}\text { Tennis } \\
\text { (5 Honths) }\end{array}$} & No. & 16 & $I_{4}$ & 70 & \multirow{2}{*}{$\begin{array}{l}\text { Health } \\
\text { Time } \\
\text { IIoney } \\
\text { Facilities } \\
\text { Knowledge } \\
\text { and Skill } \\
\quad \text { TOTAL } \\
\end{array}$} & \multirow{2}{*}{$\begin{array}{l}1 \\
3 \\
3 \\
0 \\
0 \\
7 \\
\end{array}$} & \multirow[t]{2}{*}{2} & \multirow[t]{2}{*}{1} & \multirow[t]{2}{*}{1} & \multirow[t]{2}{*}{.495} \\
\hline & $\%$ & 16 & 14 & 70 & & & & & & \\
\hline \multirow[b]{2}{*}{$\begin{array}{l}\text { Touch } \\
\text { Football } \\
\text { (3 Months) }\end{array}$} & No. & 11 & 20 & 69 & \multirow{2}{*}{$\begin{array}{l}\text { Health } \\
\text { Time } \\
\text { Money } \\
\text { Facilities } \\
\text { Knowledge } \\
\text { and Skill } \\
\quad \text { TOTAL } \\
\end{array}$} & 2 & \multirow[t]{2}{*}{2} & \multirow[t]{2}{*}{1} & \multirow[t]{2}{*}{1} & \multirow[t]{2}{*}{.30} \\
\hline & of & 11 & 20 & 69 & & $\begin{array}{l}1 \\
0 \\
\frac{0}{T}\end{array}$ & & & & \\
\hline
\end{tabular}


TA3LE 29 (Continued)

40-49 Age Group

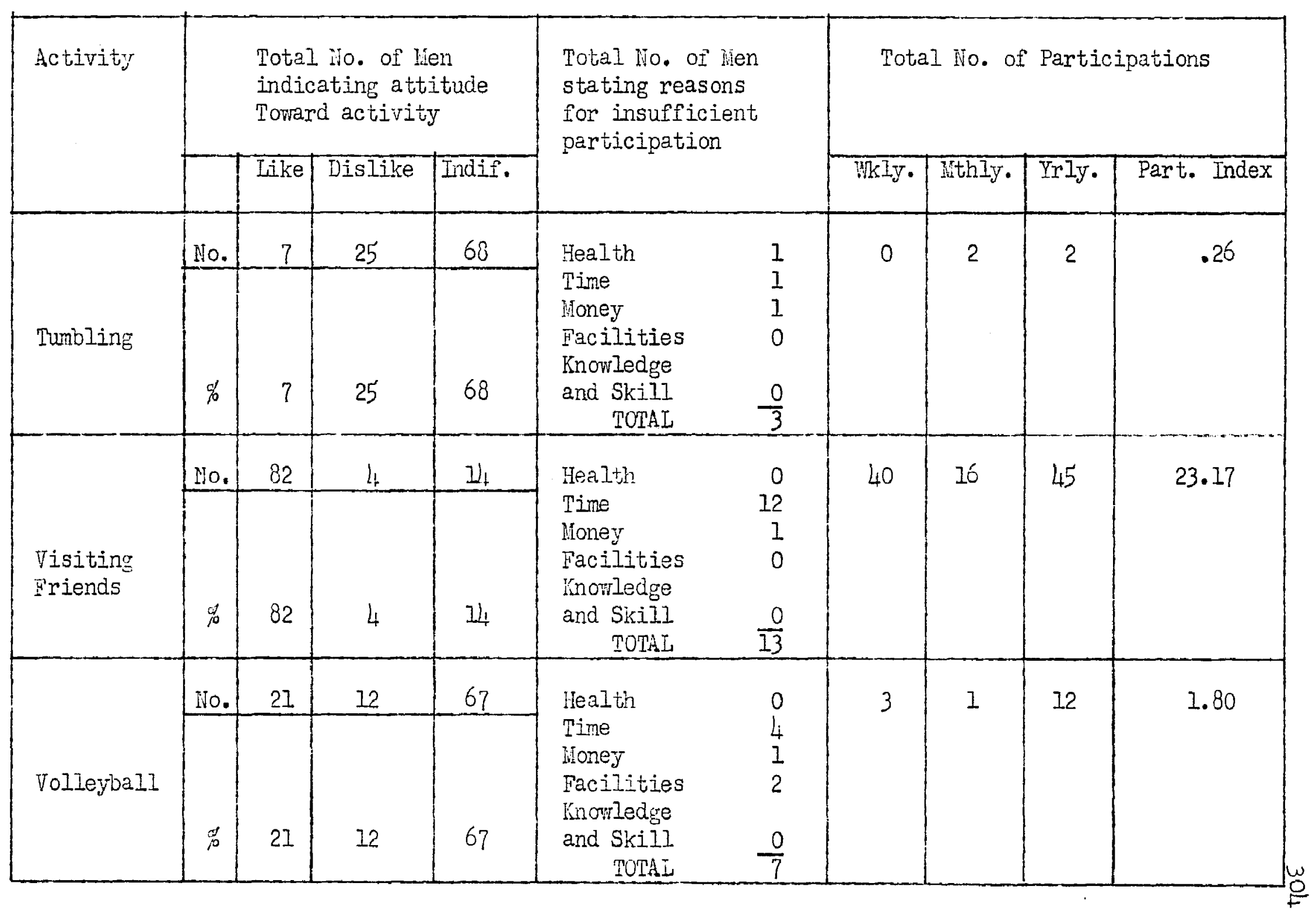


TABIF 29 (Continued)

40-49 Age Group

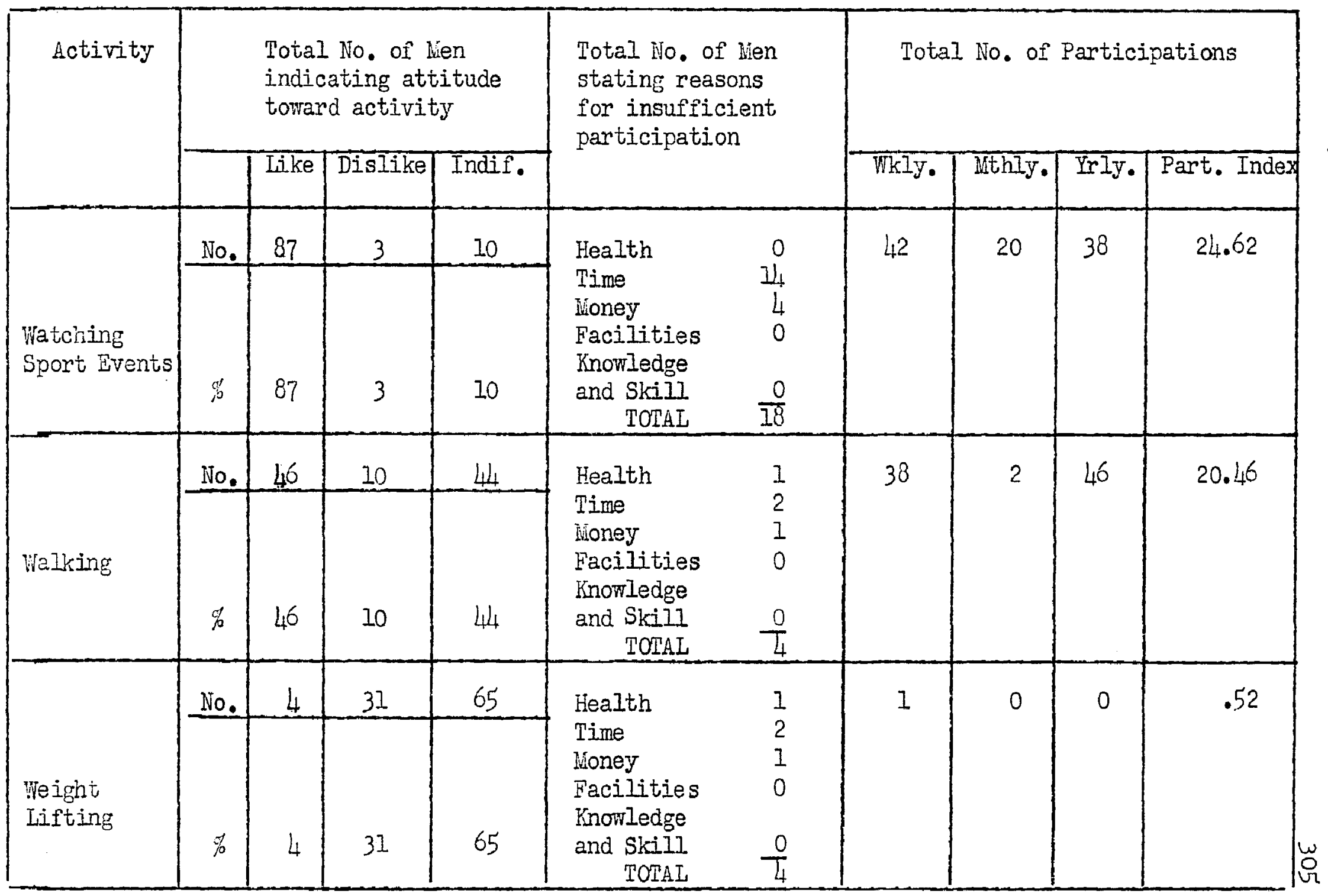


TABLE 29 (Continued)

40-49 Age Group

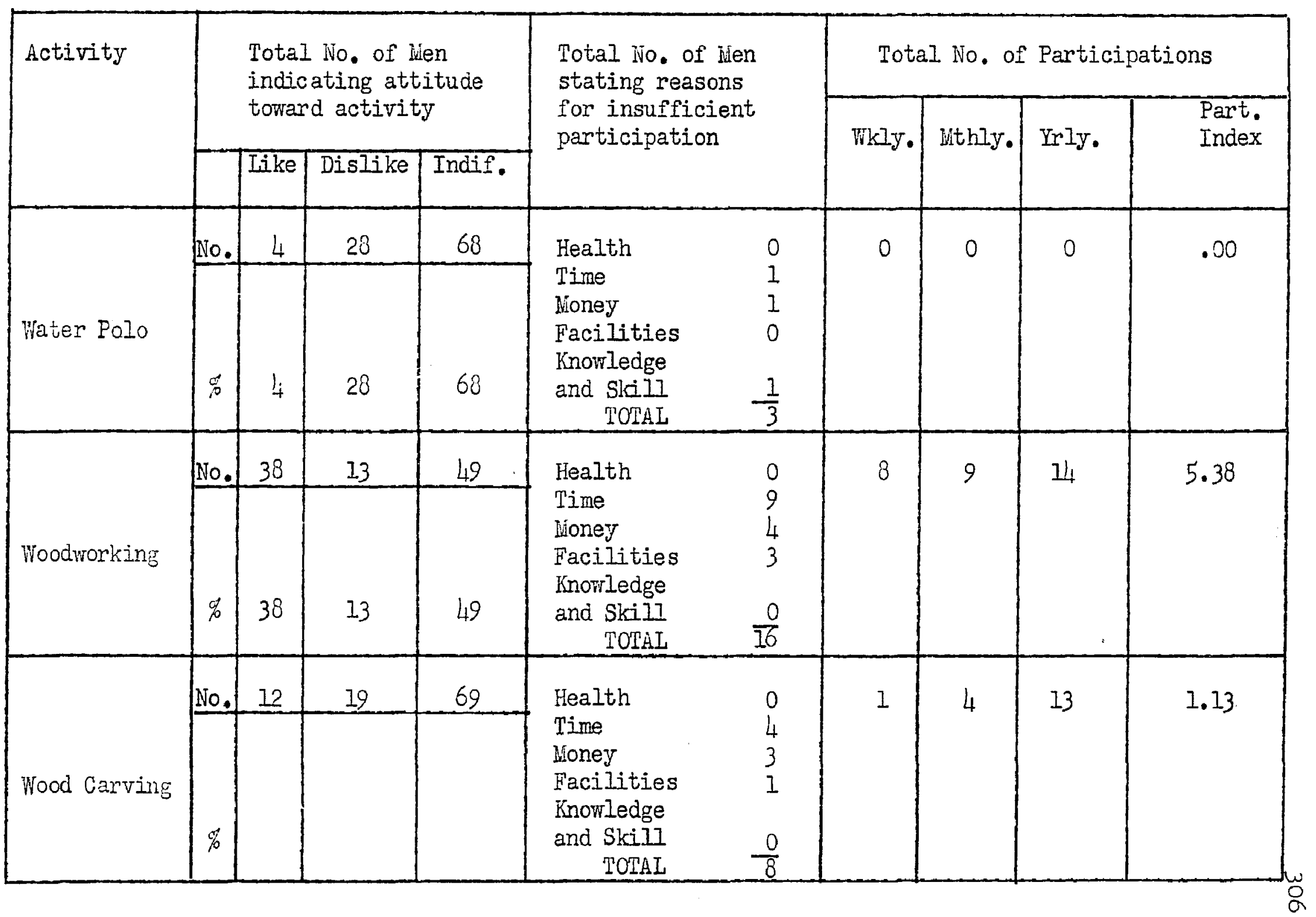


TABLE 29 (Continued)

40-49 Age Group

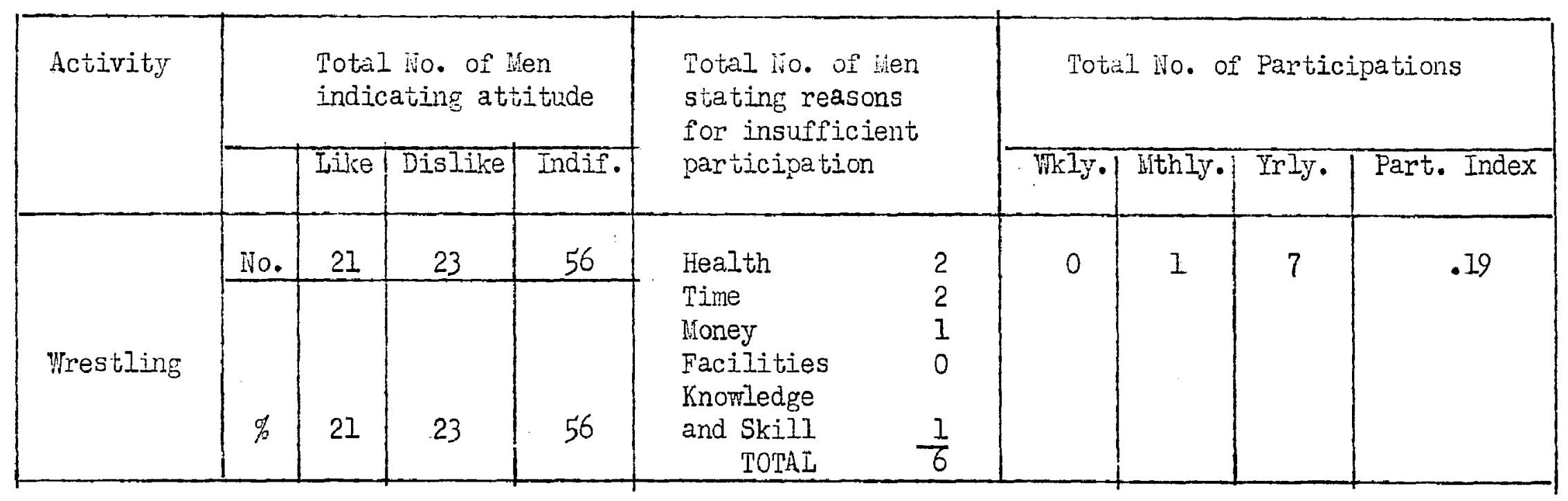

REASONS :

$\begin{array}{lcc}\text { Health } & 42 & -5.2 \% \\ \text { Time } & 483 & -59.9 \% \\ \text { Honey } & 184 & -22.8 \% \\ \text { Facilities } & 71 & -8.8 \% \\ \text { Knowledge and Skill } & 27 & -3.3 \%\end{array}$


TABIE 30

Numbers and Percentages of Wen Liking, Disliking, and Indifferent to wach of Sixty-Seven Recreational Activities, Extent of Participation in Each, and Humber of Men Listining Each of Five Reasons for Unsatisfactory Participation in the 50-59 Age Group

\begin{tabular}{|c|c|c|c|c|c|c|c|c|c|c|}
\hline \multirow[t]{2}{*}{ Activity } & \multicolumn{4}{|c|}{$\begin{array}{l}\text { Total Ho, of Men } \\
\text { indicating attitude } \\
\text { ionard activity }\end{array}$} & \multirow{2}{*}{\multicolumn{2}{|c|}{$\begin{array}{l}\text { Total } 1 \text { of of hen } \\
\text { stating reasons } \\
\text { for insufficient } \\
\text { participation }\end{array}$}} & \multicolumn{4}{|c|}{ Total No. of Participations } \\
\hline & & Like & Dislike & Indif. & & & Wkly. & uthly. & Yrly. & Part. Index \\
\hline \multirow[b]{2}{*}{ Archery } & No. & 8 & 10 & 41 & \multirow{2}{*}{$\begin{array}{l}\text { Health } \\
\text { Time } \\
\text { ifoney } \\
\text { Facilities } \\
\text { Knowledge } \\
\text { and Skill } \\
\text { TOTAI }\end{array}$} & \multirow{2}{*}{$\begin{array}{l}1 \\
5 \\
1 \\
2 \\
0 \\
\frac{0}{9}\end{array}$} & \multirow[t]{2}{*}{0} & \multirow[t]{2}{*}{1} & \multirow[t]{2}{*}{3} & \multirow[t]{2}{*}{.27} \\
\hline & $\not 0$ & 13.6 & 16.9 & 69.5 & & & & & & \\
\hline \multirow[b]{2}{*}{ Badminton } & Iio. & 5 & 7 & 47 & \multirow{2}{*}{$\begin{array}{l}\text { Health } \\
\text { Time } \\
\text { lioney } \\
\text { Facilities } \\
\text { Knowledge } \\
\text { and Skill } \\
\quad \text { TOTAI }\end{array}$} & 0 & \multirow[t]{2}{*}{0} & \multirow[t]{2}{*}{1} & \multirow[t]{2}{*}{0} & \multirow[t]{2}{*}{.20} \\
\hline & 幕 & 8.5 & 11.9 & 79.6 & & $\frac{1}{2}$ & & & & \\
\hline
\end{tabular}


TABLE 30 (Continued)

50-59 Age Group

\begin{tabular}{|c|c|c|c|c|c|c|c|c|c|c|}
\hline \multirow[t]{2}{*}{ Activity } & \multicolumn{4}{|c|}{$\begin{array}{l}\text { Total No. of lien } \\
\text { indicating attitude } \\
\text { toward activity }\end{array}$} & \multirow{2}{*}{\multicolumn{2}{|c|}{$\begin{array}{l}\text { Total No. of lien } \\
\text { stating reasoris } \\
\text { for insufficient } \\
\text { participation }\end{array}$}} & \multicolumn{4}{|c|}{ Total No. of Participations } \\
\hline & & Iike & Dislike & Indif. & & & Tikly. & Mthy. & Yrly. & Part. Index \\
\hline Bag Punching & No. & 18.6 & 13.6 & 67.8 & $\begin{array}{l}\text { Health } \\
\text { Time } \\
\text { Money } \\
\text { Eacilities } \\
\text { Knowledge } \\
\text { and Skill } \\
\text { TOIAL } \\
\end{array}$ & $\begin{array}{l}5 \\
6 \\
1 \\
1 \\
0 \\
13\end{array}$ & 2 & 0 & 0 & 1.79 \\
\hline & No. & 35 & 1 & 23 & \multirow[b]{2}{*}{$\begin{array}{l}\text { Health } \\
\text { Time } \\
\text { Noney } \\
\text { Facilities } \\
\text { Knowledge } \\
\text { and Skill } \\
\quad \text { TOTAL } \\
\end{array}$} & 6 & \multirow[t]{2}{*}{7} & \multirow[t]{2}{*}{8} & \multirow[t]{2}{*}{27} & \multirow[t]{2}{*}{2.41} \\
\hline $\begin{array}{l}\text { Baseball } \\
\text { (3) Fonths) }\end{array}$ & $\%$ & 59.3 & 1.7 & 39.0 & & $\begin{array}{r}21 \\
1 \\
0 \\
\frac{0}{10}\end{array}$ & & & & \\
\hline & No. & 13 & 2 & 32 & \multirow{2}{*}{$\begin{array}{l}\text { Health } \\
\text { Time } \\
\text { lioney } \\
\text { Facilities } \\
\text { Knowledge } \\
\text { and Skill } \\
\quad \text { TOTAL }\end{array}$} & 6 & \multirow[t]{2}{*}{0} & \multirow[t]{2}{*}{0} & \multirow[t]{2}{*}{0} & \multirow[t]{2}{*}{.00} \\
\hline $\begin{array}{l}\text { Basketball } \\
\text { (6 inonths) }\end{array}$ & of & 30.5 & 3.4 & 66.1 & & $\begin{array}{l}11 \\
1 \\
0 \\
\frac{1}{19}\end{array}$ & & & & \\
\hline
\end{tabular}


TABLE 30 (Continued)

50-59 Age Croup

\begin{tabular}{|c|c|c|c|c|c|c|c|c|c|c|}
\hline \multirow[t]{2}{*}{ Activity } & \multicolumn{4}{|c|}{$\begin{array}{l}\text { Total No, of lien } \\
\text { indicating attitude } \\
\text { toward activity }\end{array}$} & \multirow{2}{*}{\multicolumn{2}{|c|}{$\begin{array}{l}\text { Total No. of lien } \\
\text { stating reasons } \\
\text { for insufficient } \\
\text { participation }\end{array}$}} & \multicolumn{4}{|c|}{ Total No. of Participations } \\
\hline & & Iike & Dislike & Indif. & & & $\mathrm{Wk} I \mathrm{y} \cdot$ & Bithly. & Irly. & Part. Index \\
\hline $\begin{array}{l}\text { Boating } \\
\text { (5 Iionths) }\end{array}$ & No. & 32.2 & 8.5 & 59.3 & $\begin{array}{l}\text { Health } \\
\text { Time } \\
\text { hioney } \\
\text { Facilities } \\
\text { Knowledge } \\
\text { and Skill } \\
\text { TOTAL } \\
\end{array}$ & $\begin{array}{l}2 \\
6 \\
1 \\
1 \\
\frac{1}{11}\end{array}$ & 3 & 1 & 59 & 2.19 \\
\hline $\begin{array}{l}\text { Bowling } \\
\text { (9 Honths) }\end{array}$ & No. & 57.7 & 0 & 42.3 & $\begin{array}{l}\text { Health } \\
\text { Time } \\
\text { Iloney } \\
\text { Facilities } \\
\text { Knowledge } \\
\text { and Skill } \\
\quad \text { ToTAL } \\
\end{array}$ & $\begin{array}{c}6 \\
8 \\
3 \\
0 \\
0 \\
17\end{array}$ & $1_{4}$ & 2 & 1 & 9.58 \\
\hline Boxing & No. & 35.6 & 6.8 & 57.7 & $\begin{array}{l}\text { Health } \\
\text { Time } \\
\text { Money } \\
\text { Facilities } \\
\text { Knowledge } \\
\text { and Skill } \\
\text { ToTAL }\end{array}$ & $\begin{array}{c}2 \\
6 \\
2 \\
1 \\
\frac{1}{12}\end{array}$ & 2 & 2 & 3 & 2.22 \\
\hline
\end{tabular}


TABLE 30 (Continued)

50-59 Age Group

\begin{tabular}{|c|c|c|c|c|c|c|c|c|c|c|}
\hline \multirow[t]{2}{*}{ Activity } & \multicolumn{4}{|c|}{$\begin{array}{l}\text { Total No. of Men } \\
\text { indicating attitude } \\
\text { toward activity }\end{array}$} & \multirow{2}{*}{\multicolumn{2}{|c|}{$\begin{array}{l}\text { Total No. of Men } \\
\text { stating reasons } \\
\text { for insufficient } \\
\text { Participation }\end{array}$}} & \multicolumn{4}{|c|}{ Total No. of Participations } \\
\hline & & Iike & Dislike & Indif. & & & Wkly. & wthly. & Irly. & Part.Index \\
\hline Calisthenics & No. & 10 & 15.3 & 40 & $\begin{array}{l}\text { Health } \\
\text { Time } \\
\text { Woney } \\
\text { Facilities } \\
\text { Knowledge } \\
\text { and Skill } \\
\quad \text { TOTAL } \\
\end{array}$ & $\begin{array}{r}3 \\
10 \\
1 \\
0 \\
\frac{1}{15} \\
\end{array}$ & 2 & 0 & 0 & 1.79 \\
\hline Canoeing & No. & 15.3 & 16.9 & 67.8 & $\begin{array}{l}\text { Health } \\
\text { Time } \\
\text { Money } \\
\text { Facilities } \\
\text { Knomledge } \\
\text { and Skill } \\
\quad \text { TOTAL } \\
\end{array}$ & $\begin{array}{l}1 \\
8 \\
1 \\
2 \\
\frac{0}{12} \\
\end{array}$ & 0 & 0 & 7 & .12 \\
\hline Card Playing & No. & 88.1 & 1.7 & 10.2 & $\begin{array}{l}\text { Health } \\
\text { Time } \\
\text { líoney } \\
\text { Facilities } \\
\text { Knorledge } \\
\text { and Skill } \\
\quad \text { TOTAL }\end{array}$ & $\begin{array}{r}1 \\
10 \\
2 \\
1 \\
\frac{1}{15}\end{array}$ & 16 & 11 & 180 & 19.39 \\
\hline
\end{tabular}


TABIE 30 (Contimed)

50-59 Age Group

\begin{tabular}{|c|c|c|c|c|c|c|c|c|c|c|}
\hline \multirow[t]{2}{*}{ Activity } & \multicolumn{4}{|c|}{$\begin{array}{l}\text { Total No. of len } \\
\text { indicating attitude } \\
\text { toward activity }\end{array}$} & \multirow{2}{*}{\multicolumn{2}{|c|}{$\begin{array}{l}\text { Total No. of lien } \\
\text { stating reasons } \\
\text { for insufficient } \\
\text { participation }\end{array}$}} & \multicolumn{4}{|c|}{ Total No. of Participations } \\
\hline & & Iike & Dislike & Indif. & & & Wkly. & lithly. & Irly. & Part.Index \\
\hline \multirow[b]{2}{*}{ Checkers } & No. & 44.7 & 8.5 & 47.4 & \multirow{2}{*}{$\begin{array}{l}\text { Health } \\
\text { Time } \\
\text { Honey } \\
\text { Facilities } \\
\text { Knowledge } \\
\text { and Skill } \\
\quad \text { TOTAL } \\
\end{array}$} & \multirow{2}{*}{$\begin{array}{l}0 \\
5 \\
1 \\
0 \\
0 \\
\frac{0}{6}\end{array}$} & \multirow[t]{2}{*}{13} & \multirow[t]{2}{*}{8} & \multirow[t]{2}{*}{103} & \multirow[t]{2}{*}{14.83} \\
\hline & $\%$ & $4: 4.1$ & 8.5 & 47.4 & & & & & & \\
\hline \multirow[b]{2}{*}{ Conversing } & No. & 31 & 2 & 26 & \multirow{2}{*}{$\begin{array}{l}\text { Health } \\
\text { Time } \\
\text { Honey } \\
\text { Facilities } \\
\text { Knowledge } \\
\text { and Skill } \\
\quad \text { TOTAL }\end{array}$} & \multirow{2}{*}{$\begin{array}{l}0 \\
6 \\
0 \\
0 \\
\frac{2}{8} \\
\end{array}$} & \multirow[t]{2}{*}{18} & \multirow[t]{2}{*}{0} & \multirow[t]{2}{*}{615} & \multirow[t]{2}{*}{26.29} \\
\hline & $\%$ & 52.5 & 3.4 & 44.1 & & & & & & \\
\hline \multirow[b]{2}{*}{ Chess } & No. & 6 & 13 & 40 & \multirow{2}{*}{$\begin{array}{l}\text { Health } \\
\text { Time } \\
\text { Woney } \\
\text { Facilities } \\
\text { Knowledge and } \\
\quad \text { Skill } \\
\quad \text { TOTAL }\end{array}$} & \multirow{2}{*}{$\begin{array}{l}0 \\
4 \\
1 \\
0 \\
\frac{2}{7}\end{array}$} & \multirow[t]{2}{*}{1} & \multirow[t]{2}{*}{1} & \multirow[t]{2}{*}{5} & \multirow[t]{2}{*}{1.17} \\
\hline & $\%$ & 10.2 & 22.0 & 67.8 & & & & & & \\
\hline
\end{tabular}


TABIE 30 (Continued)

50-59 Age Group

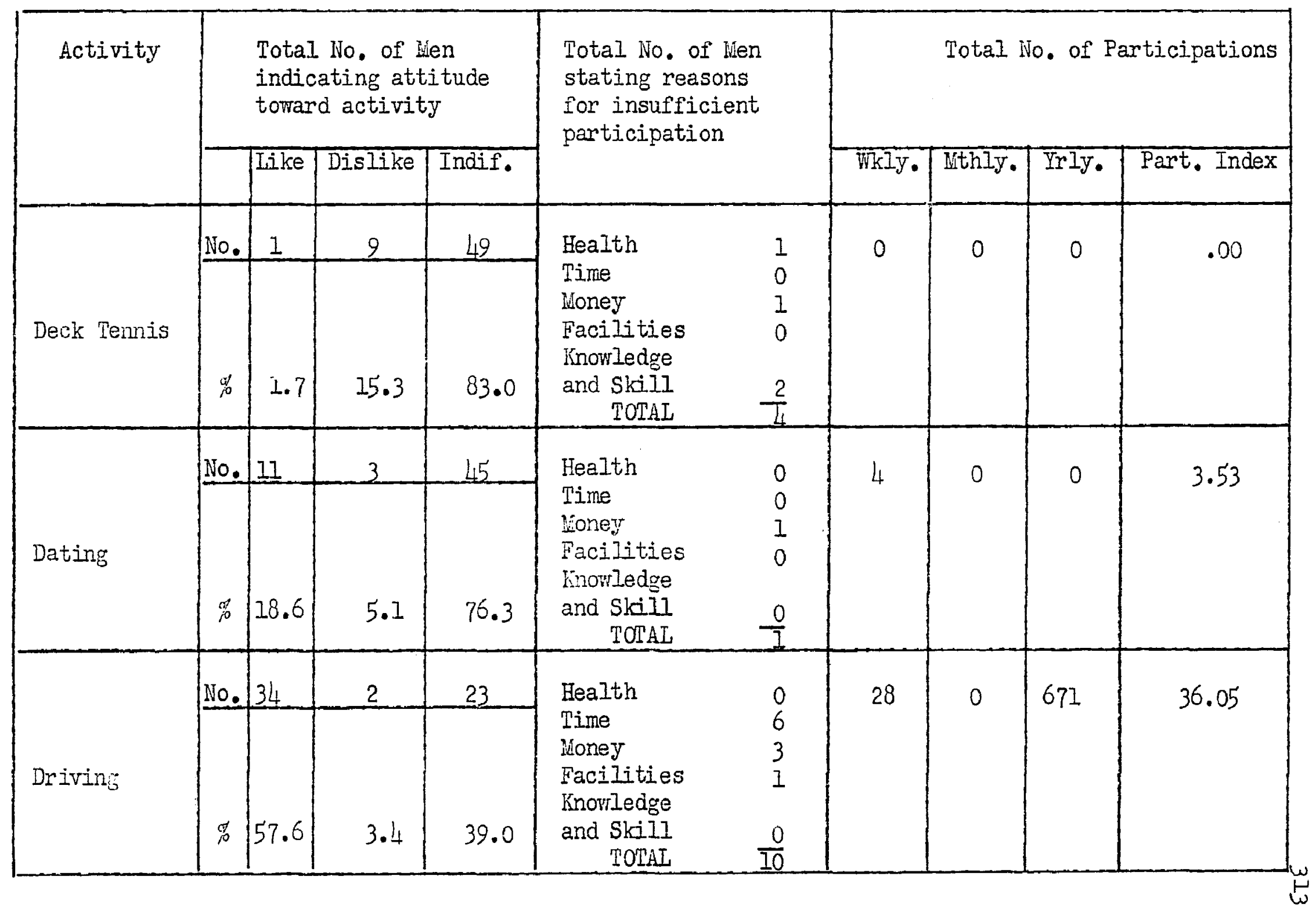


TABLE 30 (Continued)

50-59 Age Croup

\begin{tabular}{|c|c|c|c|c|c|c|c|c|c|c|}
\hline \multirow[t]{2}{*}{ Activity } & \multicolumn{4}{|c|}{$\begin{array}{l}\text { Total No. of lien } \\
\text { indicating attitude } \\
\text { toward activity }\end{array}$} & \multirow{2}{*}{\multicolumn{2}{|c|}{$\begin{array}{l}\text { Total No. of lien } \\
\text { stating reasons } \\
\text { for insufficient } \\
\text { participation }\end{array}$}} & \multicolumn{4}{|c|}{ Total No. of Participations } \\
\hline & & Tike & Dislike & Indif. & & & Wkly. & Withly. & Yrly. & Part. Index \\
\hline Fencing & No. & 4 & 13.6 & 79.6 & $\begin{array}{l}\text { Health } \\
\text { Time } \\
\text { Noney } \\
\text { Facilities } \\
\text { Knowledge } \\
\text { and Skill } \\
\quad \text { TOTAL } \\
\end{array}$ & $\begin{array}{l}1 \\
2 \\
1 \\
1 \\
1 \\
\frac{1}{6} \\
\end{array}$ & 0 & 1 & 0 & .20 \\
\hline $\begin{array}{l}\text { Field Events } \\
\text { (Track) } \\
\text { (4 Months) }\end{array}$ & No. & 22 & 1.7 & 61.0 & $\begin{array}{l}\text { Health } \\
\text { Time } \\
\text { Money } \\
\text { Faciliti es } \\
\text { Knowledge } \\
\text { and Skill } \\
\text { TOTAL } \\
\end{array}$ & $\begin{array}{l}3 \\
5 \\
1 \\
0 \\
0 \\
9 \\
\end{array}$ & 0 & 3 & $I$ & .22 \\
\hline $\begin{array}{l}\text { Bait } \\
\text { Casting } \\
\text { (6 Months) }\end{array}$ & No. & 39.0 & 6.8 & 54.2 & $\begin{array}{l}\text { Health } \\
\text { Time } \\
\text { Money } \\
\text { Facilities } \\
\text { Knowledge } \\
\text { and Skil1 } \\
\text { TOOAI }\end{array}$ & $\begin{array}{c}2 \\
6 \\
1 \\
0 \\
\frac{1}{10}\end{array}$ & 11 & 6 & 79 & 6.80 \\
\hline
\end{tabular}


TABLE 30 (Continued)

50-59 Age Group

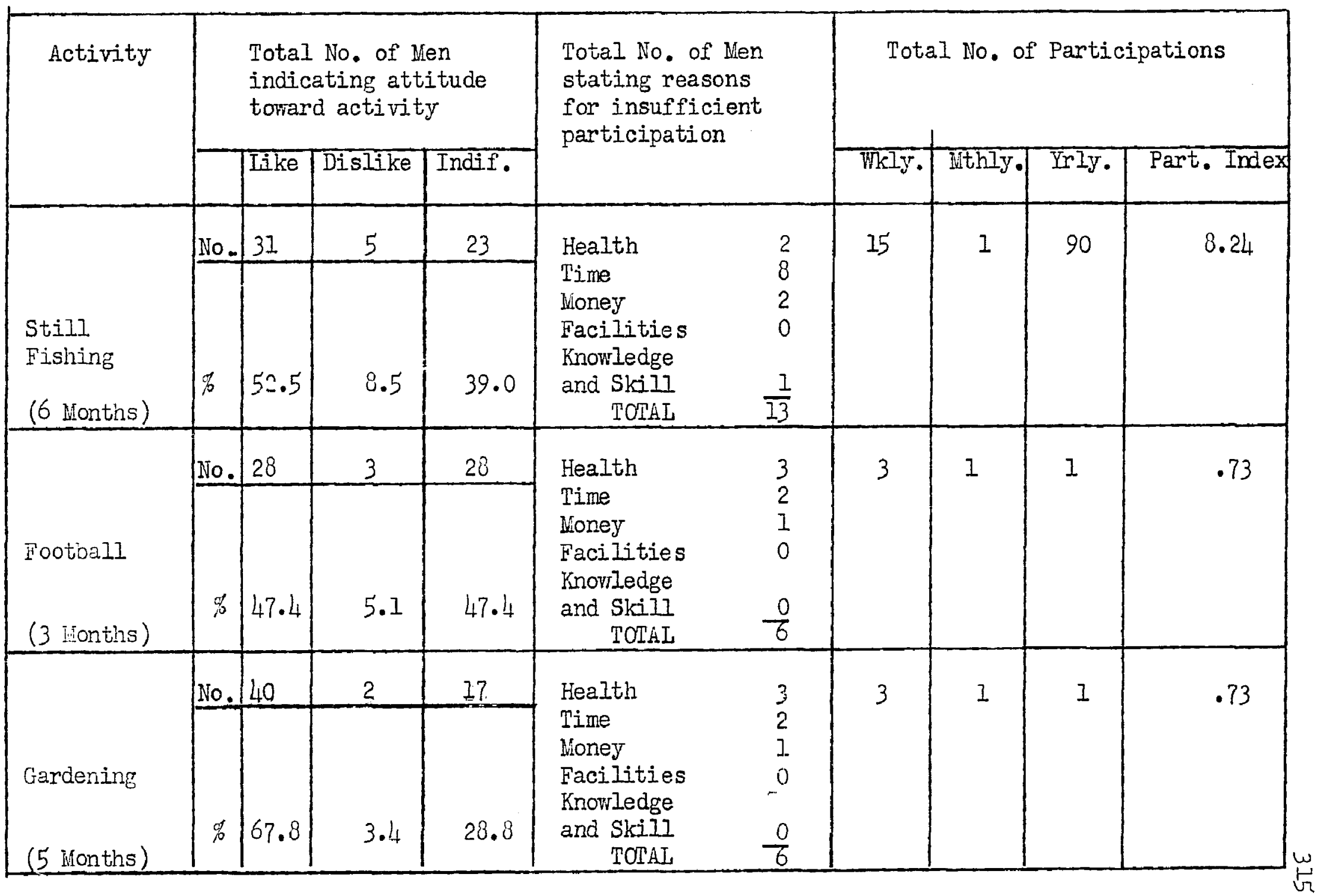


TABBLE 30 (Continued)

50-59 Age Group

\begin{tabular}{|c|c|c|c|c|c|c|c|c|c|c|}
\hline \multirow[t]{2}{*}{ Activity } & \multicolumn{4}{|c|}{$\begin{array}{l}\text { Total No. of Men } \\
\text { indicating attitude } \\
\text { toward activity }\end{array}$} & \multirow{2}{*}{\multicolumn{2}{|c|}{$\begin{array}{l}\text { Total No. of Men } \\
\text { stating reasons } \\
\text { for insufficient } \\
\text { participation }\end{array}$}} & \multicolumn{4}{|c|}{ Total No. of Participations } \\
\hline & & Like & Dislike & Indif. & & & WKIY. & Ithly. & Irly. & Part. Index \\
\hline Golf & No. & 13 & 11.9 & 39 & $\begin{array}{l}\text { Health } \\
\text { Time } \\
\text { Woney } \\
\text { Facilities } \\
\text { Knowledge } \\
\text { and Skill } \\
\text { TOTAL } \\
\end{array}$ & $\begin{array}{l}2 \\
1 \\
2 \\
0\end{array}$ & 2 & 0 & 12 & .79 \\
\hline Gymnastics & No. & 13.6 & 13.6 & 72.8 & $\begin{array}{l}\text { Health } \\
\text { Time } \\
\text { Honey } \\
\text { Facilities } \\
\text { Knowledge } \\
\text { and Skill } \\
\quad \text { TOTAL } \\
\end{array}$ & $\begin{array}{l}2 \\
2 \\
1 \\
0\end{array}$ & 2 & 0 & 6 & 1.86 \\
\hline $\begin{array}{l}\text { Handball } \\
\text { (9 Months) }\end{array}$ & No. & 9 & 7 & 43 & $\begin{array}{l}\text { Health } \\
\text { Time } \\
\text { Whoney } \\
\text { Facilities } \\
\text { Knowledge } \\
\text { and Skill } \\
\quad \text { TOTAI }\end{array}$ & $\begin{array}{l}3 \\
2 \\
2 \\
1 \\
\frac{0}{8}\end{array}$ & 0 & 0 & 1 & .02 \\
\hline
\end{tabular}


TABBLE 30 (Continued)

50-59 ige croup

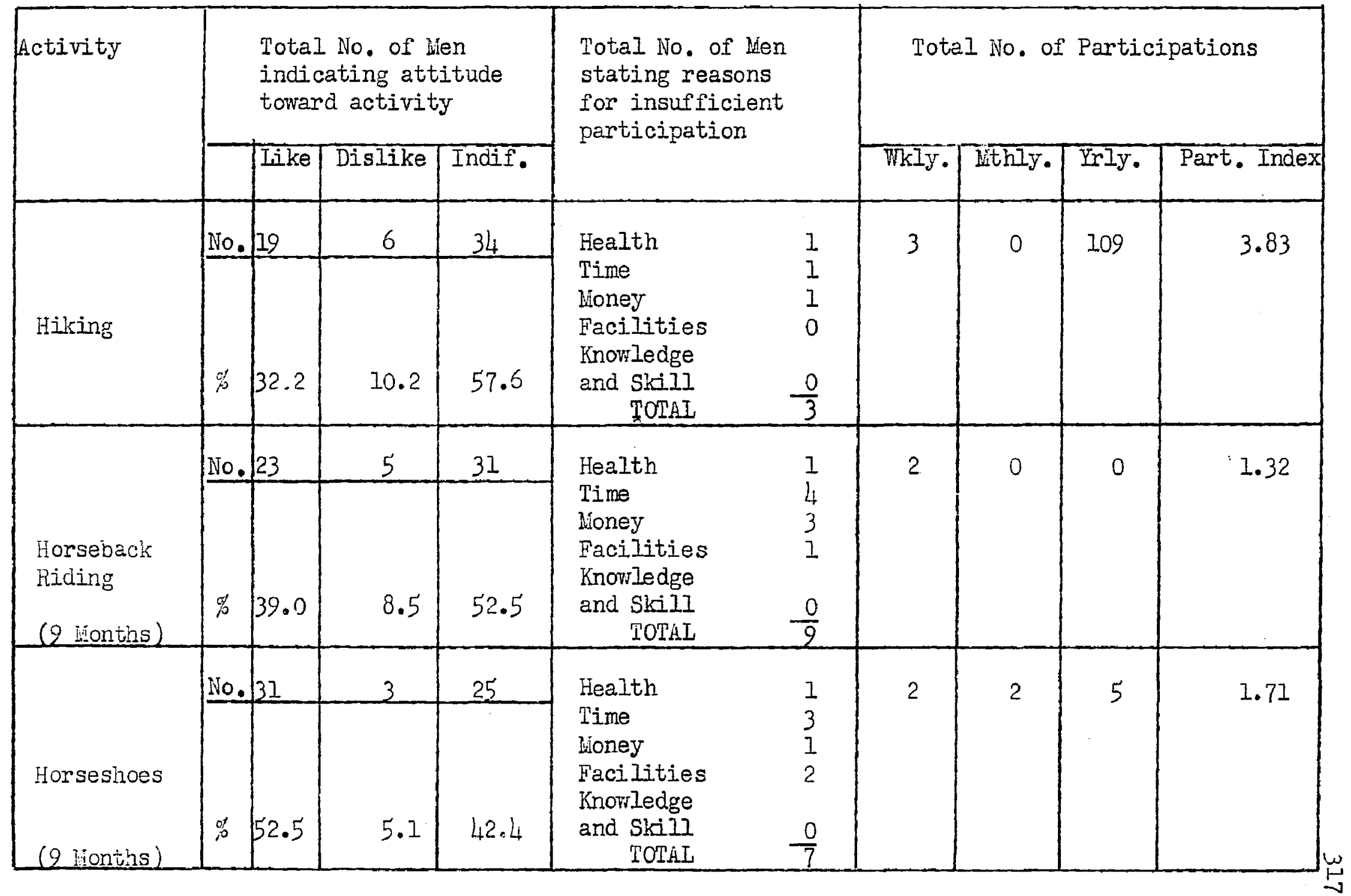


TABIE 30 (Continued)

50-59 Age Group

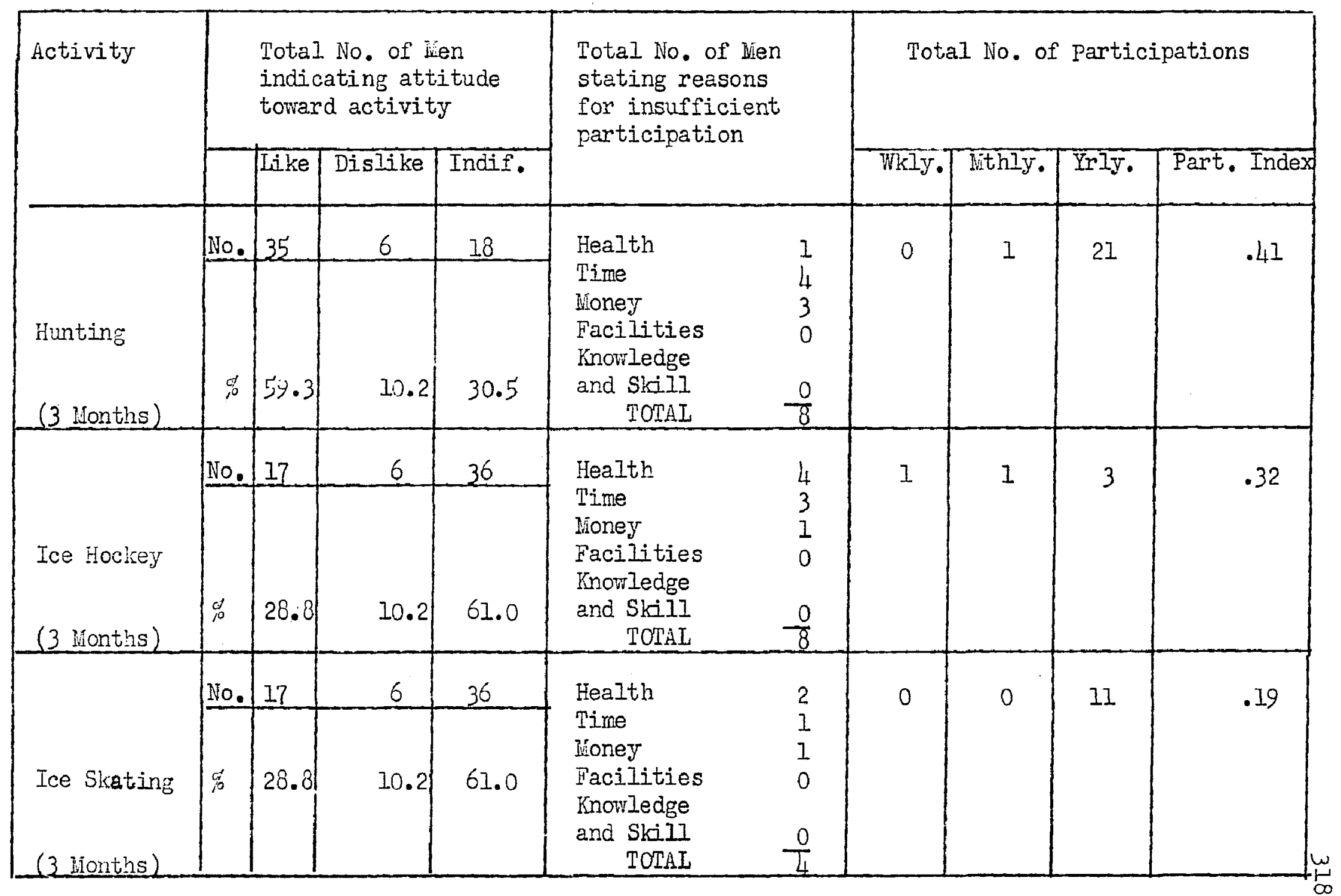


TABIE 30 (Continued)

50-59 Age Group

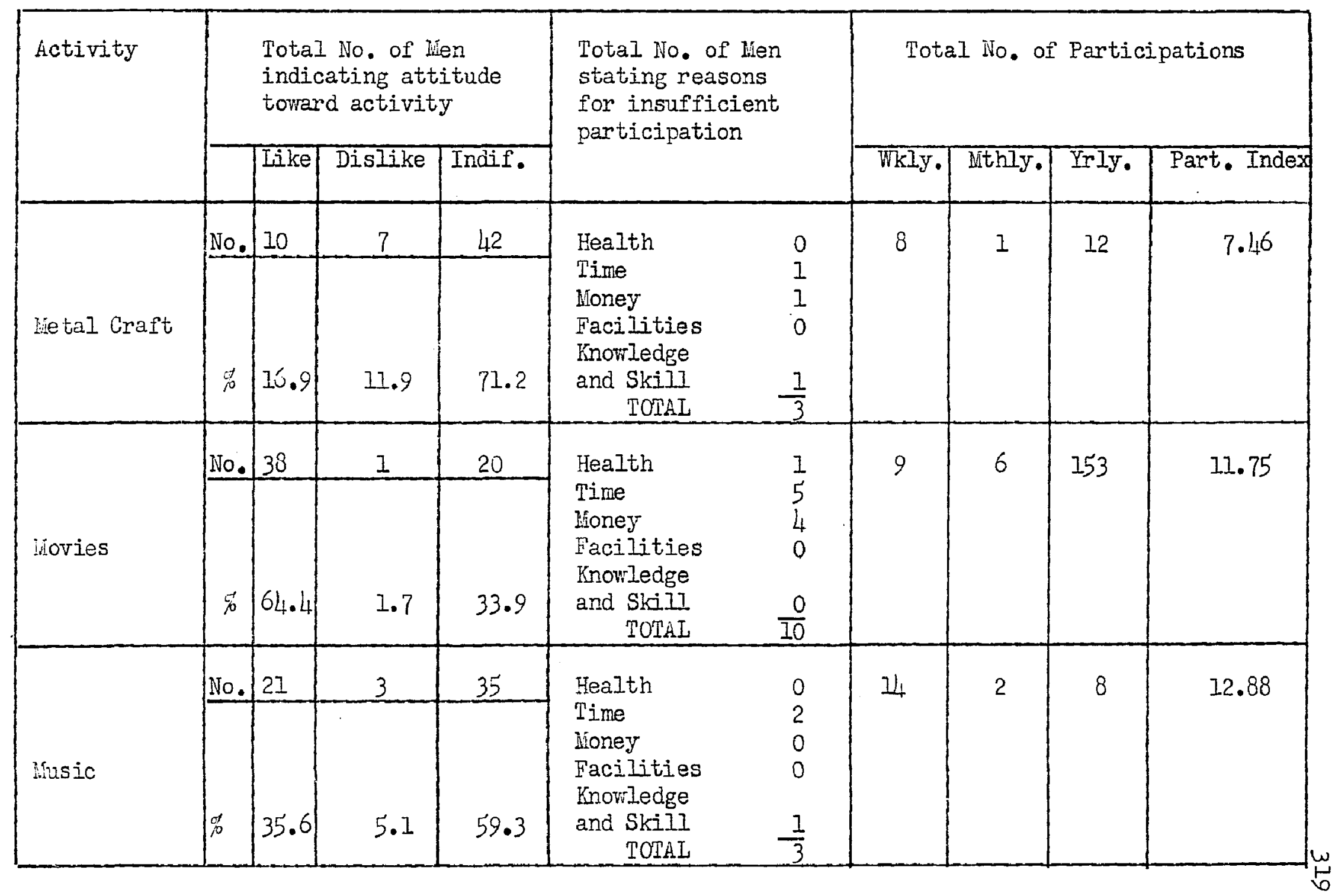




\section{TABIE 30 (Continued)}

50-59 Age Group

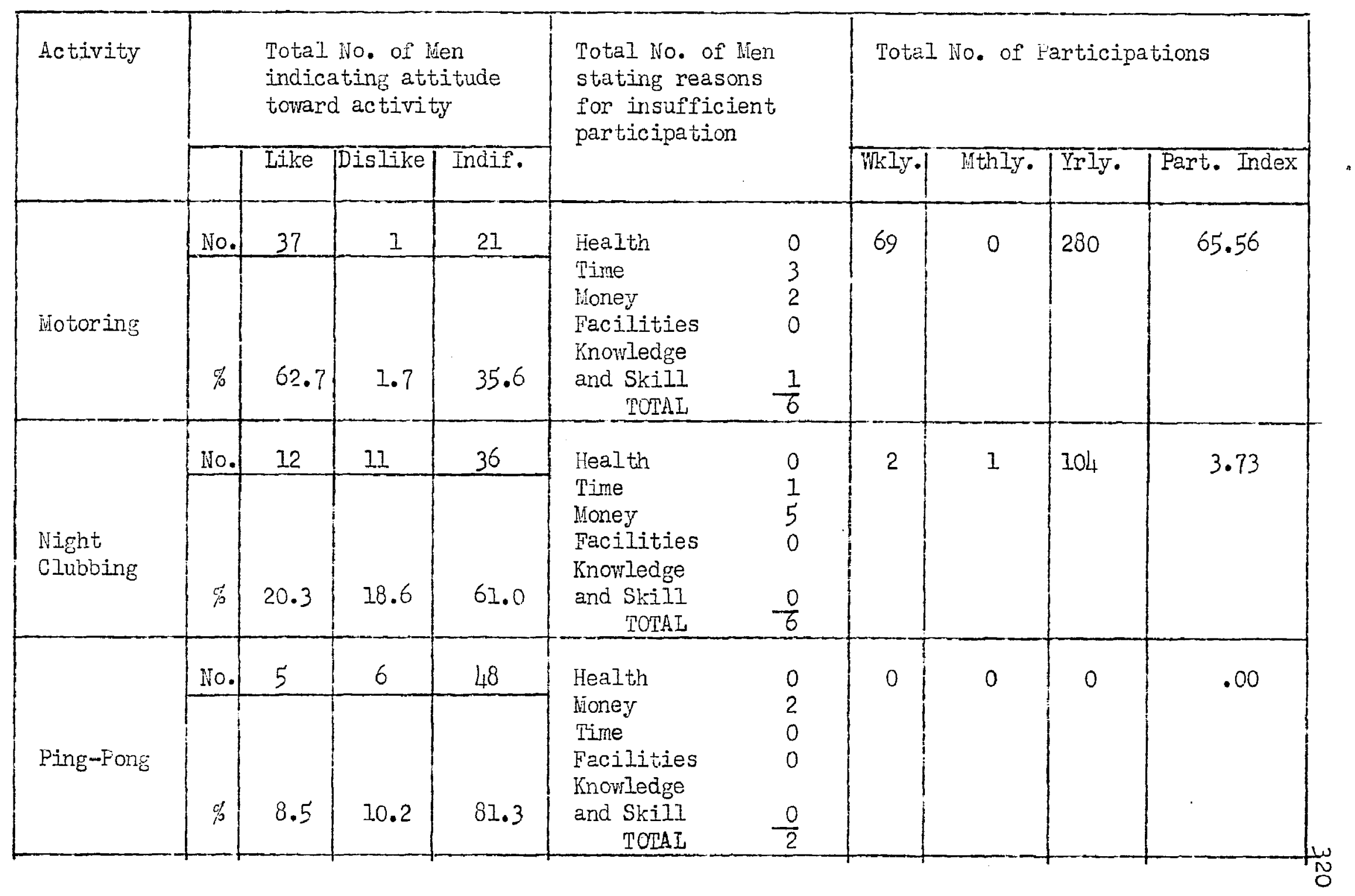


TABIE 30 (Continued)

50-59 Age Group

\begin{tabular}{|c|c|c|c|c|c|c|c|c|c|c|}
\hline \multirow[t]{2}{*}{ Activity } & \multicolumn{4}{|c|}{$\begin{array}{l}\text { Total ivo. of vien } \\
\text { indicating attitude } \\
\text { toward activity }\end{array}$} & \multirow{2}{*}{\multicolumn{2}{|c|}{$\begin{array}{l}\text { Total No. of iden } \\
\text { stating reasons } \\
\text { for insufficient } \\
\text { participation }\end{array}$}} & \multicolumn{4}{|c|}{ Total llo. of Participations } \\
\hline & & Iike & Pislike & Indif. & & & Wkly. & Mthly. & Irly. & Part. Index \\
\hline \multirow[b]{2}{*}{$\begin{array}{l}\text { Puttering, } \\
\text { Repairing, } \\
\text { etc. }\end{array}$} & No. & 35 & 5 & 19 & \multirow{2}{*}{$\begin{array}{l}\text { Health } \\
\text { Time } \\
\text { Ifoney } \\
\text { Facilities } \\
\text { Knowledge } \\
\text { and Skill } \\
\text { TOTAL } \\
\end{array}$} & \multirow{2}{*}{$\begin{array}{l}0 \\
0 \\
0 \\
1 \\
0 \\
\end{array}$} & \multirow[t]{2}{*}{23} & \multirow[t]{2}{*}{0} & \multirow[t]{2}{*}{405} & \multirow[t]{2}{*}{27.14} \\
\hline & $\%$ & 59.3 & 8.5 & 32.2 & & & & & & \\
\hline \multirow[b]{2}{*}{$\begin{array}{l}\text { Listenin } \\
\text { to Padio }\end{array}$} & Ho. & 47 & 1 & 11 & \multirow{2}{*}{$\begin{array}{l}\text { Health } \\
\text { Time } \\
\text { Money } \\
\text { Facilities } \\
\text { Knowledre } \\
\text { and Skill } \\
\quad \text { TOTAL } \\
\end{array}$} & 0 & \multirow[t]{2}{*}{43} & \multirow[t]{2}{*}{0} & \multirow[t]{2}{*}{773} & \multirow[t]{2}{*}{51.00} \\
\hline & $\stackrel{p}{p}$ & 79.6 & 1.7 & 18.6 & & $\begin{array}{l}0 \\
1\end{array}$ & & & & \\
\hline \multirow[b]{2}{*}{ Watching TV } & No. & 52 & 2 & 5 & \multirow{2}{*}{$\begin{array}{l}\text { Health } \\
\text { Time } \\
\text { lioney } \\
\text { Facilities } \\
\text { Knowledge } \\
\text { and Skill } \\
\quad \text { TOTAL }\end{array}$} & 0 & \multirow[t]{2}{*}{56} & \multirow[t]{2}{*}{0} & \multirow[t]{2}{*}{665} & \multirow[t]{2}{*}{60.63} \\
\hline & $\%$ & 88.1 & 3.4 & 8.5 & & $\frac{1}{1}$ & & & & \\
\hline
\end{tabular}


TABLE 30 (Continued)

50-59 Age Ǵroup

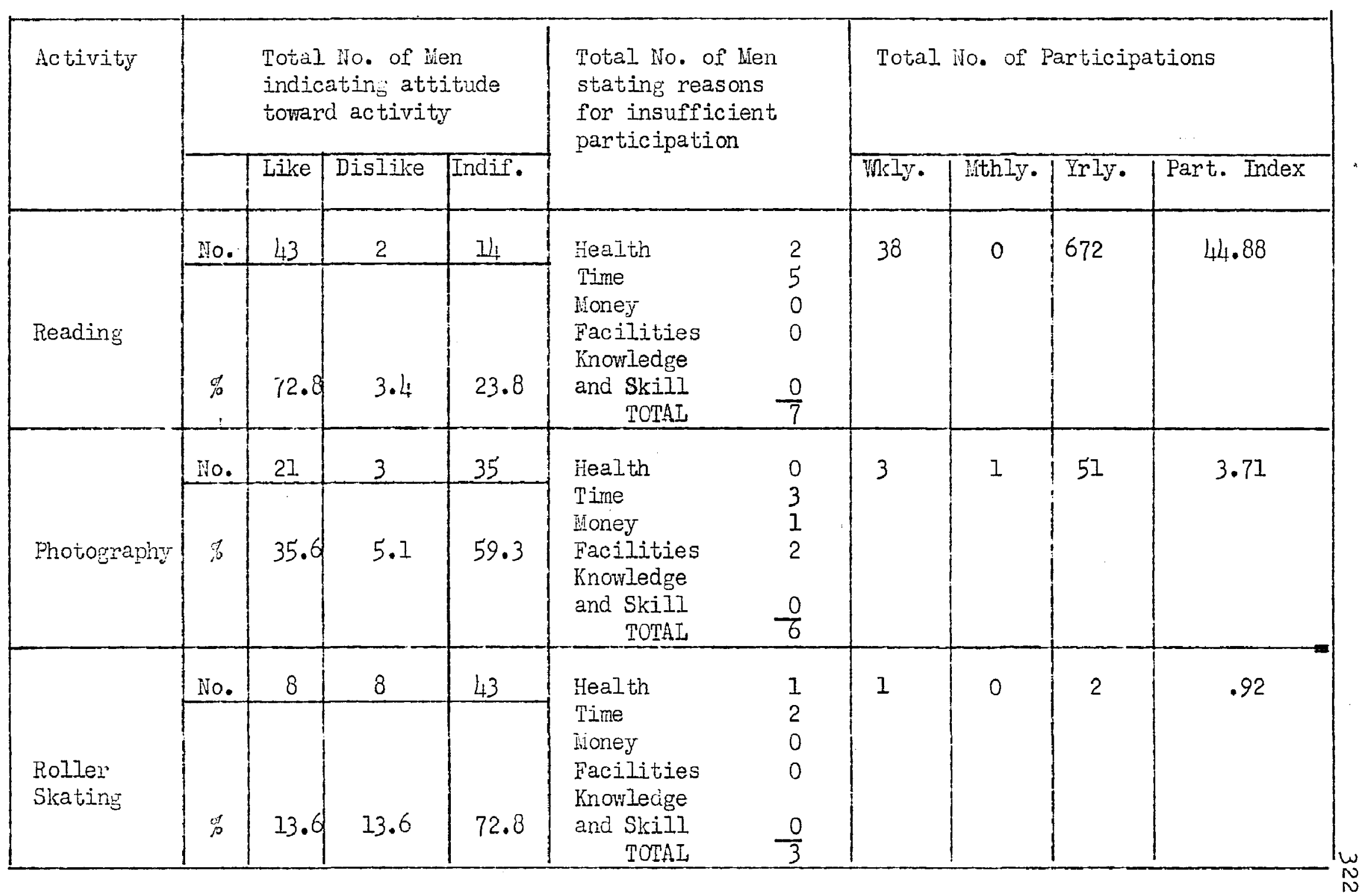


TABIE 30 (Continued)

50-59 Age Group

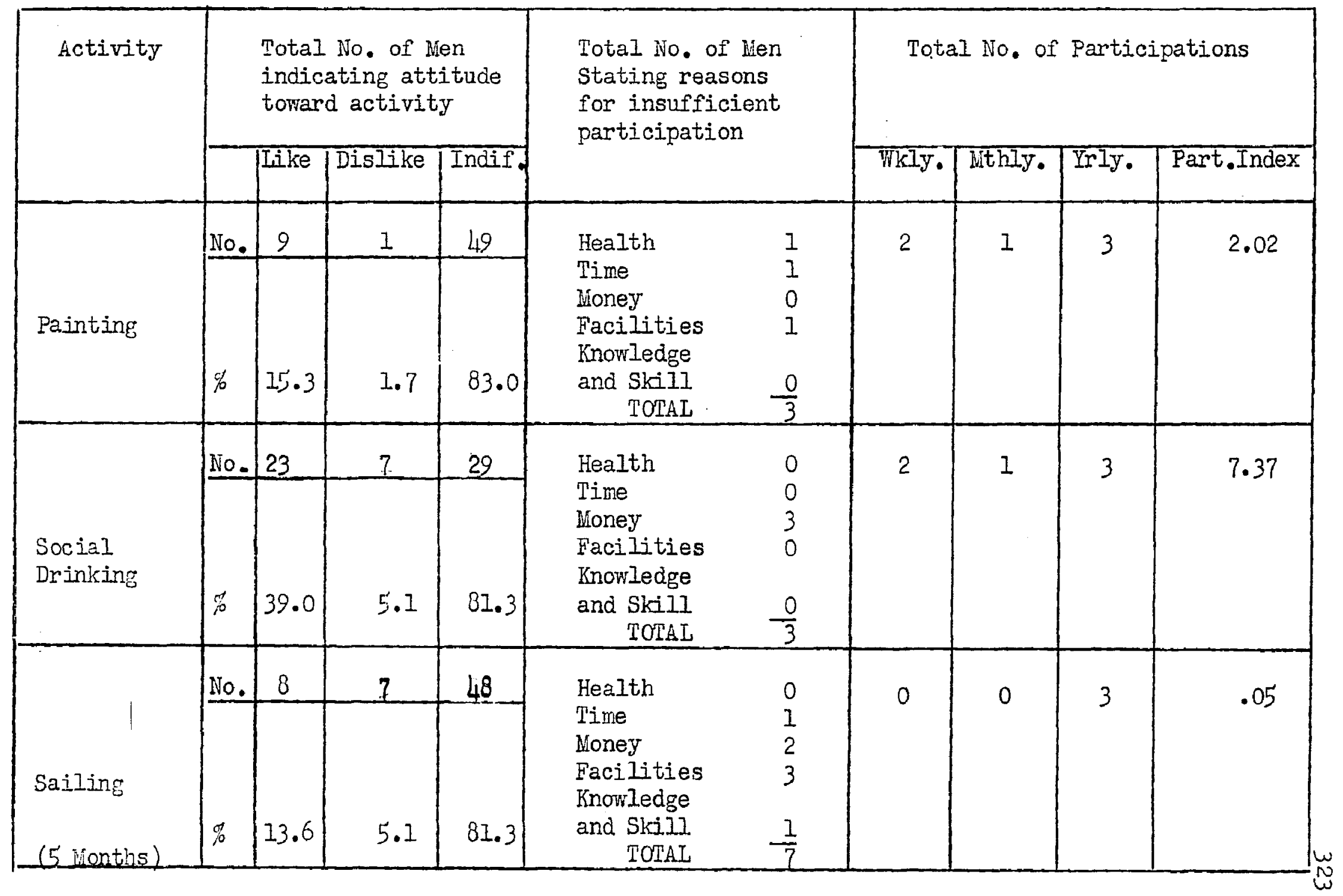


TABIE 30 (Continued) 50-59 Age Group

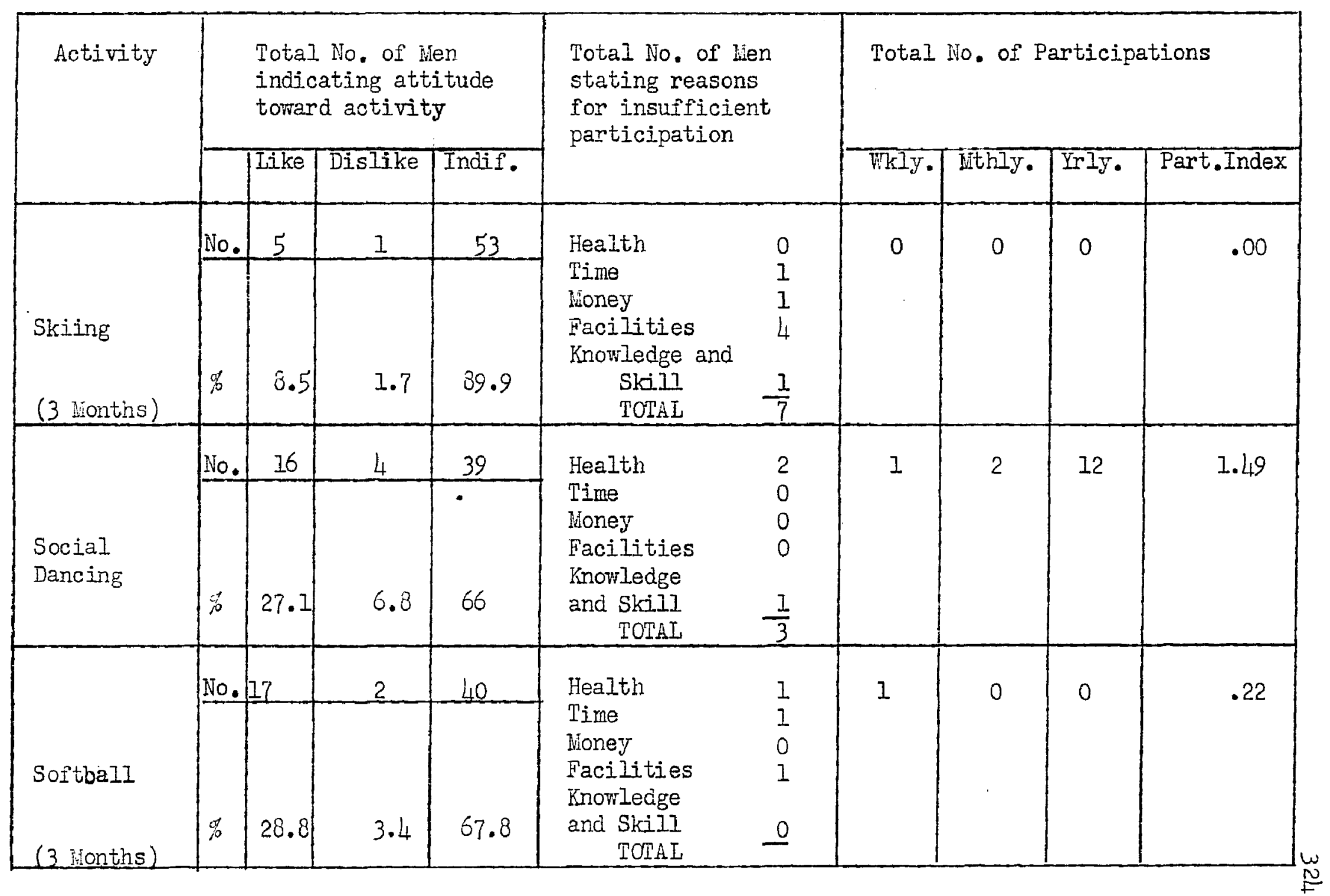


TÁBI 30 (Continued)

50-59 Age Group

\begin{tabular}{|c|c|c|c|c|c|c|c|c|c|c|}
\hline \multirow[t]{2}{*}{ Activity } & \multicolumn{4}{|c|}{$\begin{array}{l}\text { TotaI No. of Men } \\
\text { indicating attitude } \\
\text { toward activity }\end{array}$} & \multirow{2}{*}{\multicolumn{2}{|c|}{$\begin{array}{l}\text { Total No. of lien } \\
\text { stating reasons } \\
\text { for insufficient } \\
\text { participation }\end{array}$}} & \multicolumn{4}{|c|}{ Total No. of Participations } \\
\hline & & Iike & Dislike & Indif. & & & WkIy. & Mthly. & Yrly. & Part.Index \\
\hline $\begin{array}{l}\text { Speedball } \\
\text { (3 Months }\end{array}$ & No. & $11=9$ & 5.1 & 83.0 & $\begin{array}{l}\text { Health } \\
\text { Time } \\
\text { Money } \\
\text { Facilities } \\
\text { Knowledge } \\
\text { and Skill } \\
\quad \text { TOTAL } \\
\end{array}$ & $\begin{array}{l}2 \\
1 \\
0 \\
0\end{array}$ & 1 & 0 & 0 & .22 \\
\hline $\begin{array}{l}\text { Square } \\
\text { Dancing }\end{array}$ & No. & 18.6 & 13.6 & 40 & $\begin{array}{l}\text { Health } \\
\text { Time } \\
\text { lloney } \\
\text { Facilities } \\
\text { Knowledge } \\
\text { and Skill } \\
\quad \text { TOTAL } \\
\end{array}$ & $\begin{array}{l}0 \\
3 \\
1 \\
0\end{array}$ & 1 & 1 & 1 & 1.10 \\
\hline $\begin{array}{l}\text { Stamp } \\
\text { Collecting }\end{array}$ & No. & 5.1 & 15.3 & 79.6 & $\begin{array}{l}\text { Health } \\
\text { Time } \\
\text { Money } \\
\text { Facilities } \\
\text { Knowledge } \\
\text { and Skill } \\
\quad \text { TOTAL } \\
\end{array}$ & $\begin{array}{l}0 \\
1 \\
0 \\
0\end{array}$ & 0 & 1 & 1 & .22 \\
\hline
\end{tabular}


TABLE 30 (Continued)

50-59 Age Group

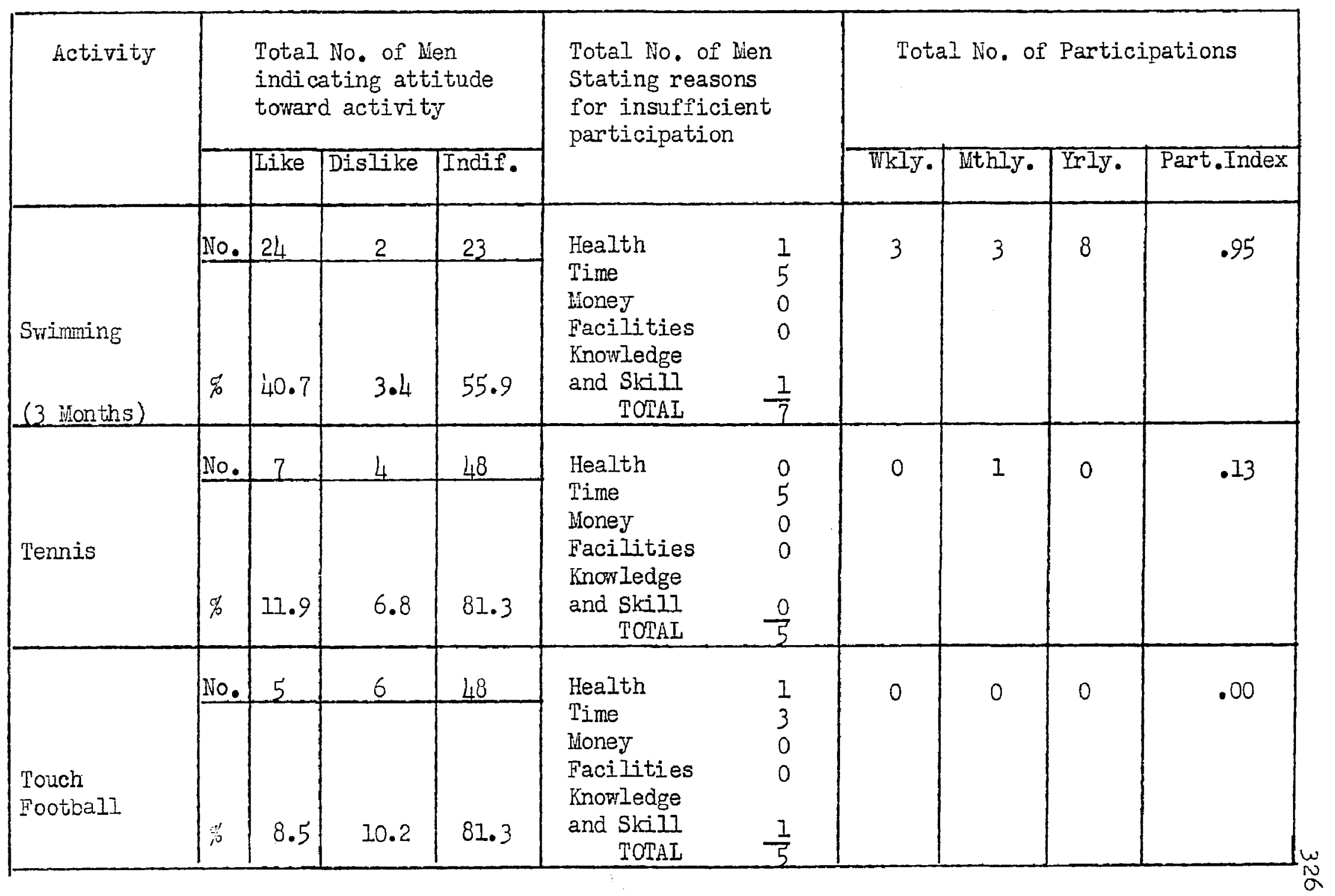


TABIE 30 (Continued)

50-59 Age Group

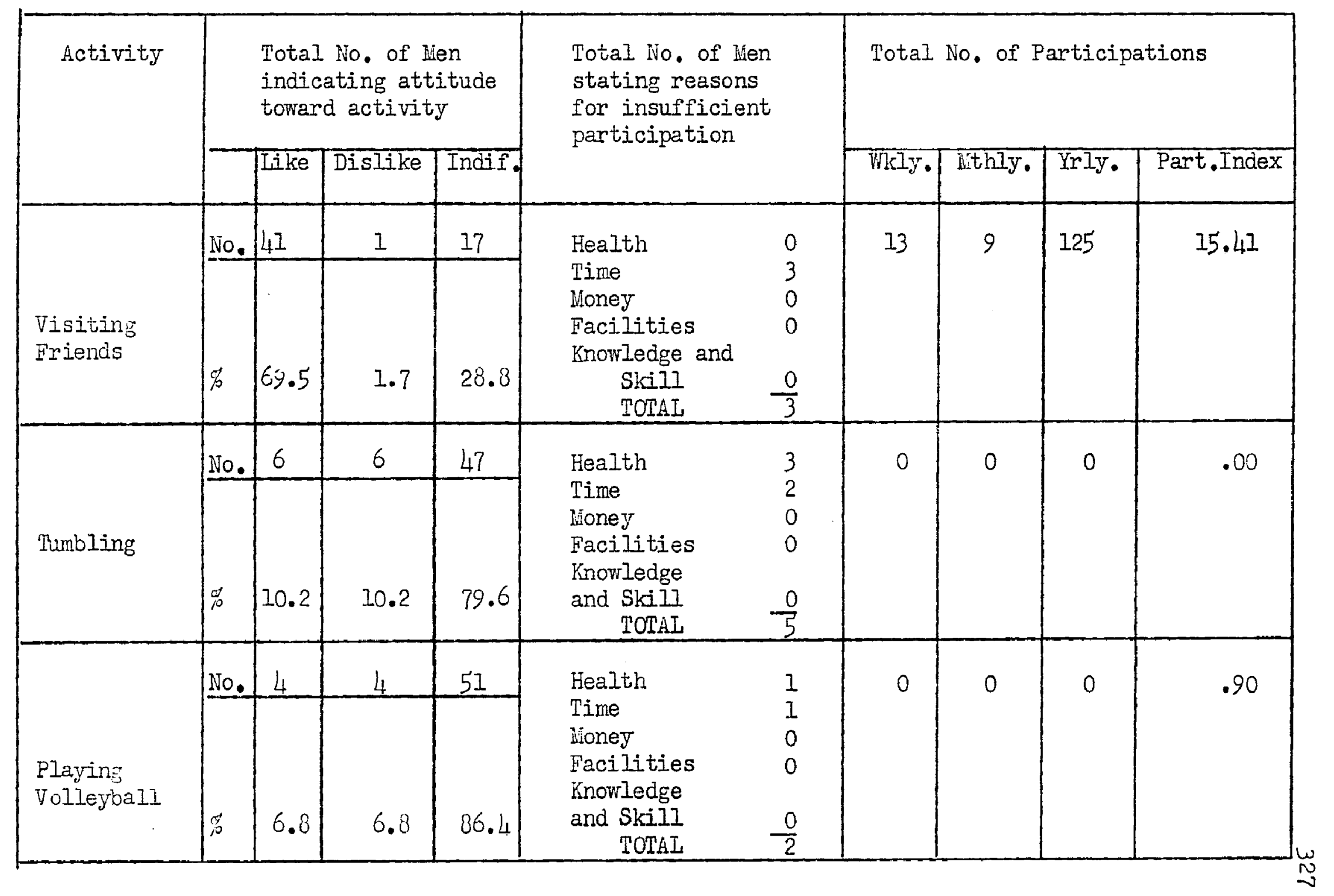


TABIE 30 (Contimued)

50-59 Age Group

\begin{tabular}{|c|c|c|c|c|c|c|c|c|c|c|}
\hline \multirow[t]{2}{*}{ Activity } & \multicolumn{4}{|c|}{$\begin{array}{l}\text { Total No. of lien } \\
\text { indicating attitude } \\
\text { toward activity }\end{array}$} & \multirow{2}{*}{\multicolumn{2}{|c|}{$\begin{array}{l}\text { Total No. of Men } \\
\text { stating reasons } \\
\text { for insufficient } \\
\text { participation }\end{array}$}} & \multicolumn{4}{|c|}{ Total No. of Participations } \\
\hline & & Like & Dislike & Indif. & & & Wkly. & withly. & Yrly. & Part.Index \\
\hline \multirow[b]{2}{*}{$\begin{array}{l}\text { Water Polo } \\
\text { (3 Mionths) }\end{array}$} & No. & 4 & 6 & 49 & \multirow{2}{*}{$\begin{array}{l}\text { Health } \\
\text { Time } \\
\text { Money } \\
\text { Facilities } \\
\text { Knowledge } \\
\text { and SkilI } \\
\quad \text { TOTAL } \\
\end{array}$} & \multirow{2}{*}{$\begin{array}{l}1 \\
1 \\
0 \\
1 \\
\frac{1}{4}\end{array}$} & \multirow[t]{2}{*}{1} & \multirow[t]{2}{*}{0} & \multirow[t]{2}{*}{1} & \multirow[t]{2}{*}{.24} \\
\hline & $\not \%$ & 0.8 & 10.2 & 83.0 & & & & & & \\
\hline \multirow[b]{2}{*}{ Woodworkins } & No. & 23 & 3 & 33 & \multirow{2}{*}{$\begin{array}{l}\text { Health } \\
\text { Time } \\
\text { lioney } \\
\text { Facilities } \\
\text { Knowledge } \\
\text { and Skill } \\
\quad \text { TOTAL }\end{array}$} & \multirow{2}{*}{$\begin{array}{l}0 \\
4 \\
2 \\
1 \\
\frac{1}{8} \\
\end{array}$} & \multirow[t]{2}{*}{7} & \multirow[t]{2}{*}{2} & \multirow[t]{2}{*}{91} & \multirow[t]{2}{*}{8.12} \\
\hline & $\%$ & 39.0 & 5.1 & 55.9 & & & & & & \\
\hline \multirow[b]{2}{*}{ "rood Carving } & No. & 8 & 5 & 46 & \multirow{2}{*}{$\begin{array}{l}\text { Health } \\
\text { Time } \\
\text { Money } \\
\text { Facilities } \\
\text { Knowledge } \\
\text { and Skill } \\
\text { TOTAL }\end{array}$} & 0 & \multirow[t]{2}{*}{1} & \multirow[t]{2}{*}{1} & \multirow[t]{2}{*}{6} & \multirow[t]{2}{*}{1.19} \\
\hline & $\stackrel{9}{\not 10}$ & 13.6 & 8.5 & $77 \cdot 9$ & & $\begin{array}{l}0 \\
0\end{array}$ & & & & \\
\hline
\end{tabular}


PABIE 30 (Continued)

50-59 Age Group

\begin{tabular}{|c|c|c|c|c|c|c|c|c|c|c|}
\hline \multirow[t]{2}{*}{ Activity } & \multicolumn{4}{|c|}{$\begin{array}{l}\text { Total No. of inen } \\
\text { indicating attitude } \\
\text { toward activity }\end{array}$} & \multirow{2}{*}{\multicolumn{2}{|c|}{$\begin{array}{l}\text { Total io. of len } \\
\text { stating reas ons } \\
\text { for insufficient } \\
\text { participation }\end{array}$}} & \multicolumn{4}{|c|}{ Total io. of Participations } \\
\hline & & Like & Dislike & Indife. & & & WkIy & Wthly. & Irly. & Part. Index \\
\hline \multirow[b]{2}{*}{ Wrestling } & No. & 22 & 6 & 31 & \multirow{2}{*}{$\begin{array}{l}\text { Health } \\
\text { Time } \\
\text { lioney } \\
\text { Facilities } \\
\text { Knowledge } \\
\text { and Skill } \\
\quad \text { TOIAL }\end{array}$} & 5 & \multirow[t]{2}{*}{7} & \multirow[t]{2}{*}{0} & \multirow[t]{2}{*}{0} & \multirow[t]{2}{*}{6.17} \\
\hline & $\not 8$ & $37 \cdot 3$ & 10.2 & 52.5 & & $\begin{array}{c}4 \\
0 \\
\frac{1}{10}\end{array}$ & & & & \\
\hline
\end{tabular}

REASONS :

$\begin{array}{lcc}\text { Health } & 94 & -20.6 \% \\ \text { Time } & 227 & -49.8 \% \\ \text { Money } & 70 & -15.4 \% \\ \text { Facilities } & 36 & -7.9 \% \\ \text { Knowledge and Skill } & 29 & -6.4 \%\end{array}$


TABIE 31

Numbers and Percentages of Men Liking, Disliking, and Indifferent to Each of Sixty-Seven Recreational Activities, Extent of Participation in Each, and Number of Men Listing Each of Five Reasons for Unsatisfactory Participation in the 0-\$2,000 Income Group

\begin{tabular}{|c|c|c|c|c|c|c|c|c|c|c|}
\hline \multirow[t]{2}{*}{ Activity } & & \multicolumn{3}{|c|}{$\begin{array}{l}\text { Total iNo. of hen } \\
\text { indicating attitude } \\
\text { toward activitor }\end{array}$} & \multirow{2}{*}{\multicolumn{2}{|c|}{$\begin{array}{l}\text { Total No. of Men } \\
\text { stating reasons } \\
\text { for insufficient } \\
\text { participation }\end{array}$}} & \multicolumn{4}{|c|}{ Total ivo. of Participations } \\
\hline & & Like & Dislike & Indif. & & & WkIy. & Ifthly. & Yrly. & Part. Index \\
\hline \multirow[b]{2}{*}{ Archery } & No. & 2 & 3 & 7 & \multirow{2}{*}{$\begin{array}{l}\text { Health } \\
\text { Time } \\
\text { Money } \\
\text { Facilities } \\
\text { Knowledge } \\
\text { and Skill } \\
\text { TOMAI } \\
\end{array}$} & \multirow{2}{*}{$\begin{array}{r}0 \\
3 \\
0 \\
2 \\
0 \\
0 \\
\end{array}$} & \multirow[t]{2}{*}{0} & \multirow[t]{2}{*}{0} & \multirow[t]{2}{*}{2} & \multirow[t]{2}{*}{.17} \\
\hline & 点 & 16.7 & 25.0 & 58.3 & & & & & & \\
\hline \multirow[b]{2}{*}{ Badminton } & I10. & 7 & $I$ & 4 & \multirow{2}{*}{$\begin{array}{l}\text { Health } \\
\text { Time } \\
\text { Honey } \\
\text { Facilities } \\
\text { Knowledge } \\
\text { and Skill } \\
\text { TOTAL }\end{array}$} & 0 & \multirow[t]{2}{*}{0} & \multirow[t]{2}{*}{4} & \multirow[t]{2}{*}{3} & \multirow[t]{2}{*}{4.25} \\
\hline & $\%$ & 58.3 & 8.3 & 33.3 & & $\begin{array}{l}2 \\
0 \\
2 \\
0 \\
\frac{0}{4}\end{array}$ & & & & \\
\hline
\end{tabular}


TABLF 31 (Continued)

0-\$2,000 Income Group

\begin{tabular}{|c|c|c|c|c|c|c|c|c|c|c|}
\hline \multirow[t]{2}{*}{ Activity } & & \multicolumn{3}{|c|}{$\begin{array}{l}\text { Total No. of lien } \\
\text { indicating attitude } \\
\text { toward activity }\end{array}$} & \multirow{2}{*}{\multicolumn{2}{|c|}{$\begin{array}{l}\text { Total No. of Men } \\
\text { stating reasons } \\
\text { for insufficient } \\
\text { participation }\end{array}$}} & \multicolumn{4}{|c|}{ Total No. of Participations } \\
\hline & & Like & Dislike & Indif. & & & Wkly. & Mthly. & Irly. & Part. Index \\
\hline Bag Punching & No. & 25.0 & 3 & 50.0 & $\begin{array}{l}\text { Health } \\
\text { Time } \\
\text { loney } \\
\text { Facilities } \\
\text { Knowledge } \\
\text { and Skill } \\
\quad \text { TOTAL }\end{array}$ & $\begin{array}{l}0 \\
2 \\
0 \\
0\end{array}$ & 0 & 2 & 1 & 2.09 \\
\hline Basebal1 & No. & 91.7 & 0 & 8.3 & $\begin{array}{l}\text { Health } \\
\text { Time } \\
\text { Noney } \\
\text { Facilities } \\
\text { Knowledge } \\
\text { and Skill } \\
\quad \text { TOIAI }\end{array}$ & $\begin{array}{l}1 \\
4 \\
0 \\
0 \\
0 \\
\frac{0}{5}\end{array}$ & 3 & 3 & 4 & 3.25 \\
\hline $\begin{array}{l}\text { Basketball } \\
\text { (6 Honths) }\end{array}$ & No. & 66.0 & 0 & 33.3 & $\begin{array}{l}\text { Health } \\
\text { Time } \\
\text { lioney } \\
\text { Faci lities } \\
\text { Knowledge } \\
\text { and Skill } \\
\quad \text { TOTAL }\end{array}$ & $\begin{array}{l}1 \\
3 \\
0 \\
0\end{array}$ & 3 & 0 & 2 & 6.70 \\
\hline
\end{tabular}


TABIE 31 (Continued)

0-\$2000 Inc ome Group

\begin{tabular}{|c|c|c|c|c|c|c|c|c|c|c|}
\hline \multirow[t]{2}{*}{ Activity } & \multicolumn{4}{|c|}{$\begin{array}{l}\text { Total No. of iven } \\
\text { indicating attitude } \\
\text { toward activity }\end{array}$} & \multirow{2}{*}{\multicolumn{2}{|c|}{$\begin{array}{l}\text { Total No. of lien } \\
\text { stating reasons } \\
\text { for insufficient } \\
\text { participation }\end{array}$}} & \multicolumn{4}{|c|}{ Total No. of Participations } \\
\hline & & Iike & Dislike & Indif. & & & Wkly. & lithly. & Irly. & Part. Index \\
\hline $\begin{array}{l}\text { Boating } \\
\text { ( } 5 \text { Months) }\end{array}$ & No. & $4 \geq .7$ & 1 & 50.5 & $\begin{array}{l}\text { Health } \\
\text { Time } \\
\text { lloney } \\
\text { Facilities } \\
\text { Knowledge } \\
\text { and Skill } \\
\text { TOTAI } \\
\end{array}$ & $\begin{array}{l}0 \\
1 \\
0 \\
2\end{array}$ & 1 & 2 & 1 & 2.70 \\
\hline Bowlin: & No. & 33.3 & $16 . ?$ & 50.0 & $\begin{array}{l}\text { Health } \\
\text { Time } \\
\text { lioney } \\
\text { Facilities } \\
\text { Inowledge } \\
\text { and Skill } \\
\quad \text { TOTAI } \\
\end{array}$ & $\begin{array}{l}0 \\
0 \\
0 \\
0 \\
. \\
0 \\
0\end{array}$ & 1 & 1 & 2 & 4.17 \\
\hline Boxing & No. & 2 & 25.0 & 58.3 & $\begin{array}{l}\text { Health } \\
\text { Time } \\
\text { Money } \\
\text { Facilities } \\
\text { Knowledge } \\
\text { and Skill } \\
\text { TOTAL } \\
\end{array}$ & $\begin{array}{l}0 \\
0 \\
0 \\
0\end{array}$ & 0 & 1 & 1 & 1.08 \\
\hline
\end{tabular}


TABL 31 (Continued)

0-, 2,000 Incone Group

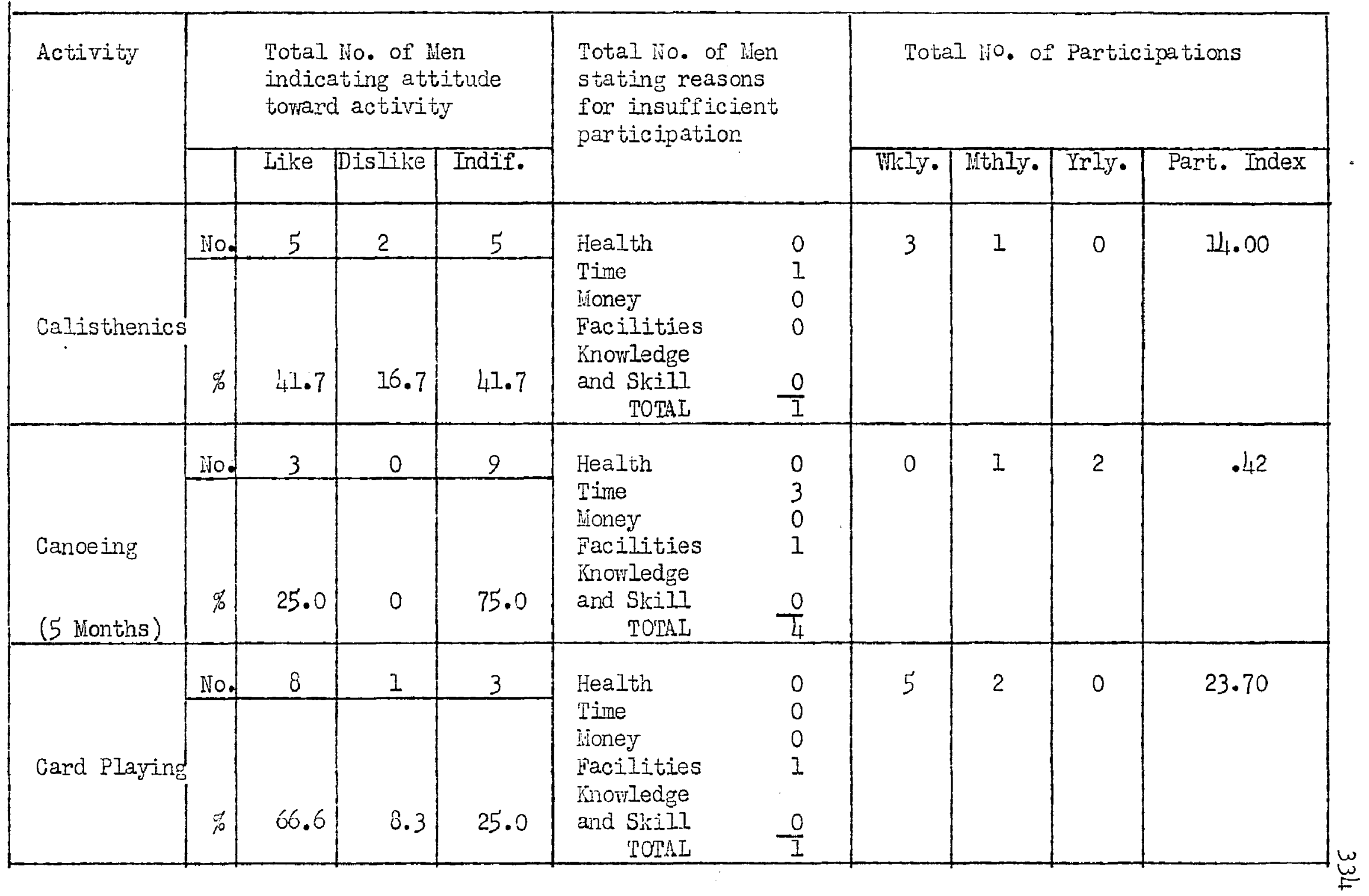


TABLE 31 (Continued)

0-\$2,000 Income Group

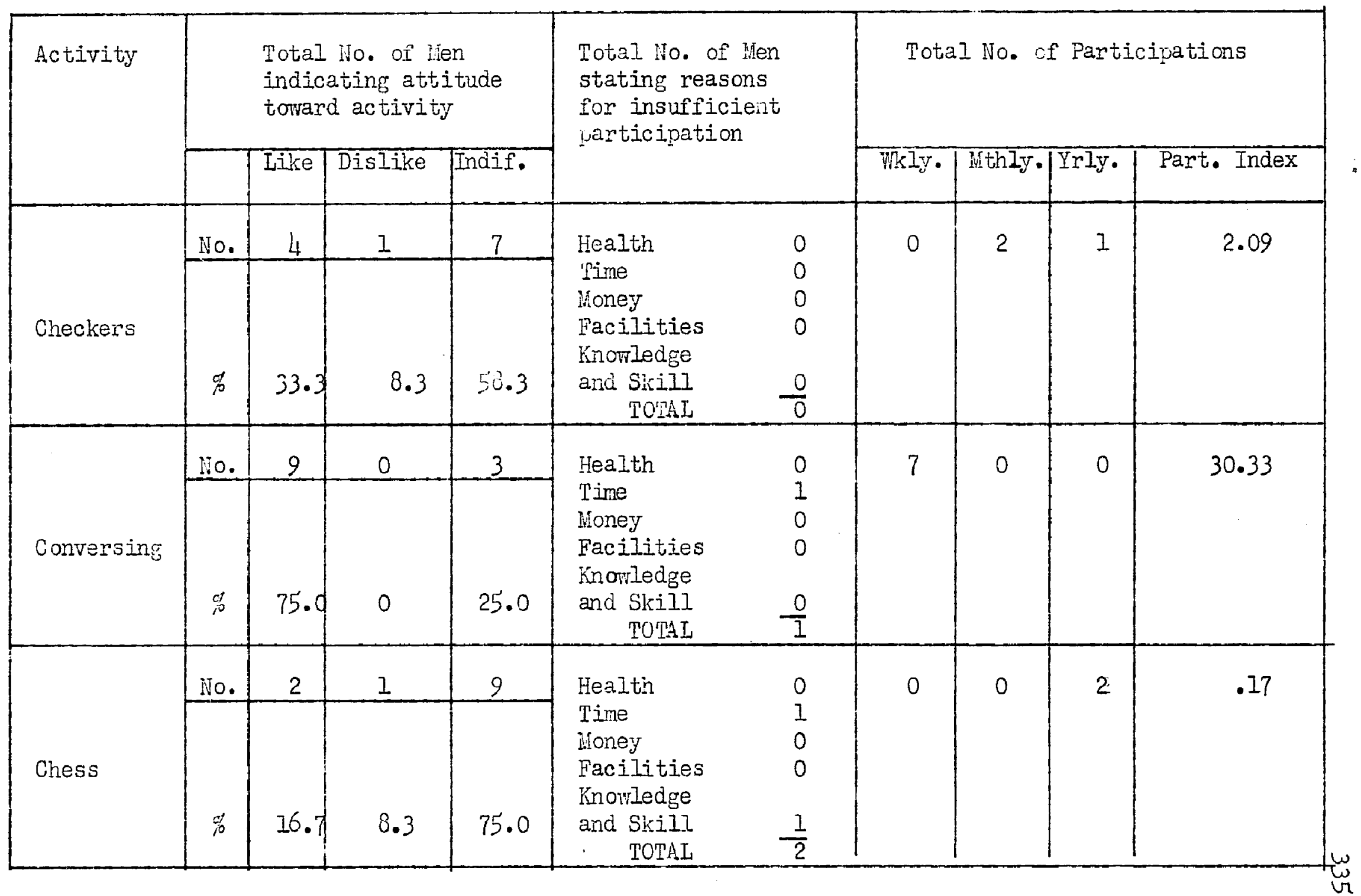


TAB: 31 (Continued)

0-\$2,000 Income Group

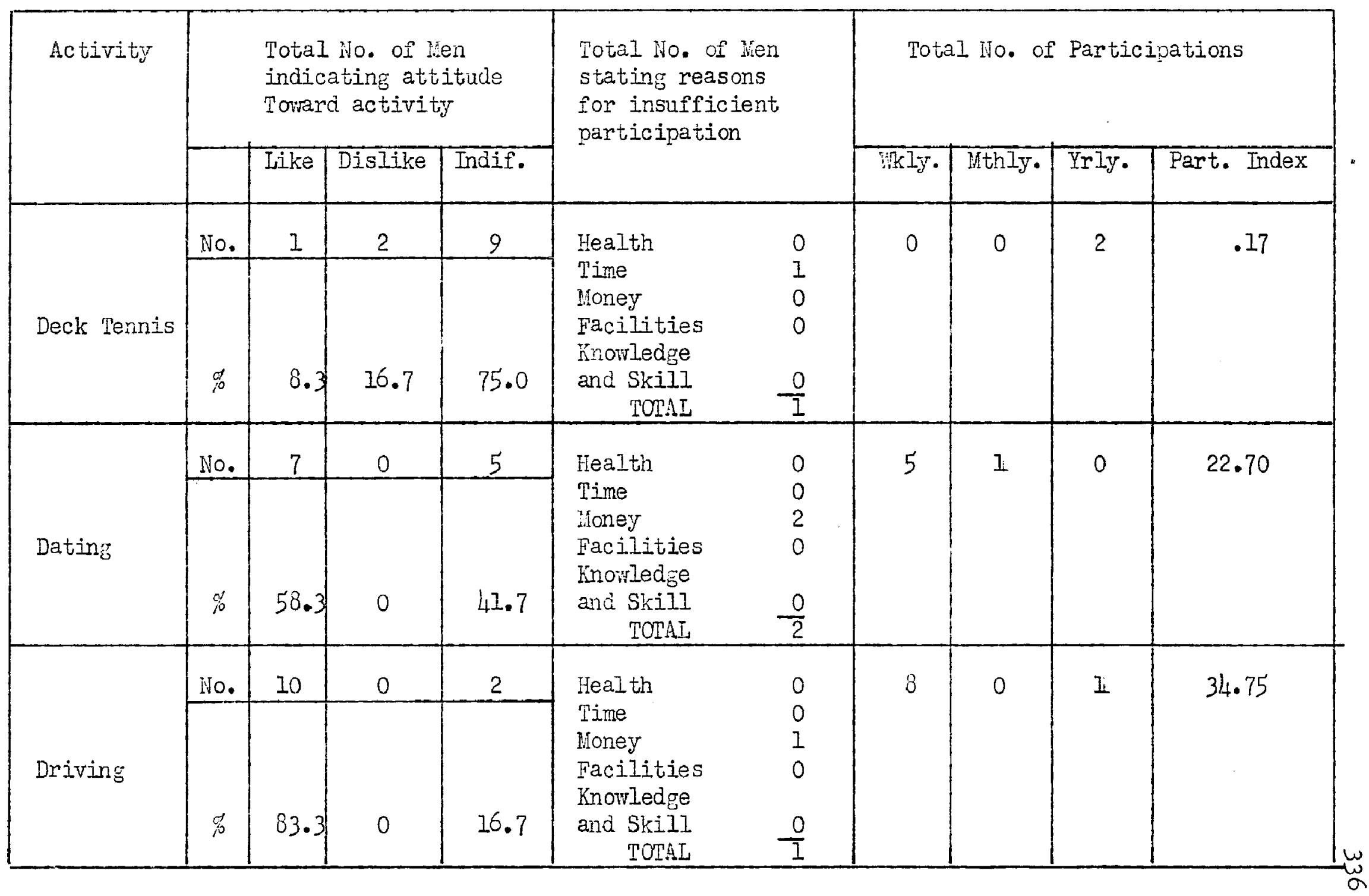


TABLE 31 (Continued)

0-\$2,000 Income Group

\begin{tabular}{|c|c|c|c|c|c|c|c|c|c|c|}
\hline \multirow[t]{2}{*}{ Activity } & \multicolumn{4}{|c|}{$\begin{array}{l}\text { Total No. of Men } \\
\text { indicating attitude } \\
\text { toward activity }\end{array}$} & \multirow{2}{*}{\multicolumn{2}{|c|}{$\begin{array}{l}\text { Total No. of Men } \\
\text { stating reasons } \\
\text { for insufficient } \\
\text { participation }\end{array}$}} & \multicolumn{4}{|c|}{ Total No. of Participations } \\
\hline & & Like & Dislike & Indif. & & & Thiky. & Mthly. & Yrly. & Part. Index \\
\hline \multirow[b]{2}{*}{ Fencing } & No. & 2 & 2 & 8 & \multirow[b]{2}{*}{$\begin{array}{l}\text { Health } \\
\text { Time } \\
\text { Honey } \\
\text { Facilities } \\
\text { Knorledge } \\
\text { and Skill } \\
\quad \text { TOTAL } \\
\end{array}$} & \multirow[b]{2}{*}{$\begin{array}{l}0 \\
1 \\
0 \\
0 \\
1 \\
\end{array}$} & \multirow[t]{2}{*}{0} & \multirow[t]{2}{*}{0} & \multirow[t]{2}{*}{1} & \multirow[t]{2}{*}{.08} \\
\hline & $\mathscr{q}$ & 16.7 & 16.7 & 66.6 & & & & & & \\
\hline \multirow[b]{2}{*}{$\begin{array}{l}\text { Pield Everts } \\
\text { (Track) } \\
\text { (4 Wonths) }\end{array}$} & No. & 3 & 3 & 6 & \multirow{2}{*}{$\begin{array}{l}\text { Health } \\
\text { Time } \\
\text { Honey } \\
\text { Facilities } \\
\text { Inowledge } \\
\text { and Skill } \\
\quad \text { TUTHL } \\
\end{array}$} & \multirow[b]{2}{*}{$\begin{array}{l}0 \\
0 \\
0 \\
0 \\
0 \\
0 \\
\end{array}$} & \multirow[t]{2}{*}{0} & \multirow[t]{2}{*}{2} & \multirow[t]{2}{*}{0} & \multirow[t]{2}{*}{.67} \\
\hline & $\%$ & 25.0 & 25.0 & 50.00 & & & & & & \\
\hline \multirow[b]{2}{*}{$\begin{array}{l}\text { Bait Casting } \\
\text { (6 inths) }\end{array}$} & Ho. & 7 & 2 & 3 & \multirow[b]{2}{*}{$\begin{array}{l}\text { Health } \\
\text { Time } \\
\text { lioney } \\
\text { Facilities } \\
\text { Knowledge } \\
\text { and Skill } \\
\text { TOTAL }\end{array}$} & 1 & \multirow[t]{2}{*}{2} & \multirow[t]{2}{*}{3} & \multirow[t]{2}{*}{0} & \multirow[t]{2}{*}{5.83} \\
\hline & $\%$ & 58.3 & 16.7 & 25.0 & & $\begin{array}{l}2 \\
0 \\
0\end{array}$ & & & & \\
\hline
\end{tabular}


TABLE 31 (Continued)

0- 2,000 Income Group

\begin{tabular}{|c|c|c|c|c|c|c|c|c|c|c|}
\hline \multirow[t]{2}{*}{ Activity } & \multicolumn{4}{|c|}{$\begin{array}{l}\text { Total No. oI Len } \\
\text { indicating attitude } \\
\text { toward activity }\end{array}$} & \multirow{2}{*}{\multicolumn{2}{|c|}{$\begin{array}{l}\text { Total No. of ken } \\
\text { stating reasons } \\
\text { for insufficient } \\
\text { participation }\end{array}$}} & \multicolumn{4}{|c|}{ Total No. of Participations } \\
\hline & & Like & Dislike & Indif. & & & Wrly. & Wthly. & Yrly. & Part. Index \\
\hline $\begin{array}{l}\text { Still } \\
\text { Fishing }\end{array}$ & No. & 75.0 & 16.7 & 8.3 & $\begin{array}{l}\text { Health } \\
\text { Time } \\
\text { Money } \\
\text { Facilities } \\
\text { Knowledge } \\
\text { and Skill } \\
\text { TOTAI } \\
\end{array}$ & $\begin{array}{l}1 \\
2 \\
0 \\
0 \\
\frac{0}{3}\end{array}$ & 2 & 3 & 2 & 6.00 \\
\hline $\begin{array}{l}\text { Football } \\
\text { (3 Ionths) }\end{array}$ & No. & 75.0 & 0 & 25.0 & $\begin{array}{l}\text { Health } \\
\text { Time } \\
\text { Woney } \\
\text { Facilities } \\
\text { Knowledge } \\
\text { and Srill } \\
\text { TOTAI }\end{array}$ & $\begin{array}{l}1 \\
2 \\
0 \\
0 \\
0 \\
\frac{3}{3}\end{array}$ & 2 & 1 & 1 & 2.42 \\
\hline $\begin{array}{l}\text { Gardening } \\
\text { (5 Honths) }\end{array}$ & No. & 58.3 & 8.3 & 33.3 & $\begin{array}{l}\text { Health } \\
\text { Time } \\
\text { lioney } \\
\text { Facilities } \\
\text { inowledge } \\
\text { and Skill } \\
\text { TOTAL }\end{array}$ & $\begin{array}{l}1 \\
1 \\
0 \\
0\end{array}$ & 2 & 1 & 2 & 4.04 \\
\hline
\end{tabular}


TABLE 31 (Continued)

0-\$2,000 Income Group

\begin{tabular}{|c|c|c|c|c|c|c|c|c|c|c|}
\hline \multirow[t]{2}{*}{ Activity } & \multicolumn{4}{|c|}{$\begin{array}{l}\text { Total io. of lien } \\
\text { indicating attitude } \\
\text { toward activity }\end{array}$} & \multirow{2}{*}{\multicolumn{2}{|c|}{$\begin{array}{l}\text { Total No. of Men } \\
\text { stating reasons } \\
\text { for insufficient } \\
\text { participation }\end{array}$}} & \multicolumn{4}{|c|}{ Total No. of Participations } \\
\hline & & Like & Dislike & Indif. & & & Wkly. & Shly. & Yrly. & Part. Index \\
\hline & No. & 4 & 0 & 8 & \multirow{2}{*}{$\begin{array}{l}\text { Health } \\
\text { Time } \\
\text { Money } \\
\text { Facilities } \\
\text { Knowledge } \\
\text { and Skill } \\
\quad \text { TOTAL } \\
\end{array}$} & \multirow{2}{*}{$\begin{array}{l}0 \\
2 \\
0 \\
0 \\
0 \\
\\
\end{array}$} & \multirow[t]{2}{*}{2} & \multirow[t]{2}{*}{0} & \multirow[t]{2}{*}{1} & \multirow[t]{2}{*}{2.97} \\
\hline $\begin{array}{l}\text { Golf } \\
\text { (4 Wonths) }\end{array}$ & g & 33.3 & 0 & 66.6 & & & & & & \\
\hline \multirow[b]{2}{*}{ Gymastics } & No. & 4 & 3 & 5 & \multirow{2}{*}{$\begin{array}{l}\text { Health } \\
\text { Time } \\
\text { Joney } \\
\text { Facilities } \\
\text { Knowledge } \\
\text { and Skill } \\
\text { TOTAL } \\
\end{array}$} & 0 & \multirow[t]{2}{*}{2} & \multirow[t]{2}{*}{1} & \multirow[t]{2}{*}{0} & \multirow[t]{2}{*}{9.70} \\
\hline & $\%$ & 33.3 & 25.0 & 41.7 & & $\begin{array}{l}0 \\
0 \\
0 \\
\\
\end{array}$ & & & & \\
\hline \multirow[b]{2}{*}{$\begin{array}{l}\text { Handbail } \\
\text { (9 Honths) }\end{array}$} & No. & 2 & 2 & 8 & \multirow{2}{*}{$\begin{array}{l}\text { Health } \\
\text { Time } \\
\text { Money } \\
\text { Facilities } \\
\text { Knowledge } \\
\text { and Skill } \\
\text { TOTAL }\end{array}$} & 0 & \multirow[t]{2}{*}{0} & \multirow[t]{2}{*}{2} & \multirow[t]{2}{*}{0} & \multirow[t]{2}{*}{1.50} \\
\hline & $\stackrel{8}{8}$ & 16.7 & 16.7 & 66.6 & & $\begin{array}{l}0 \\
0 \\
0 \\
0\end{array}$ & & & & \\
\hline
\end{tabular}


TABIE 31 (Continued)

$0-\$ 2,000$ Incume Group

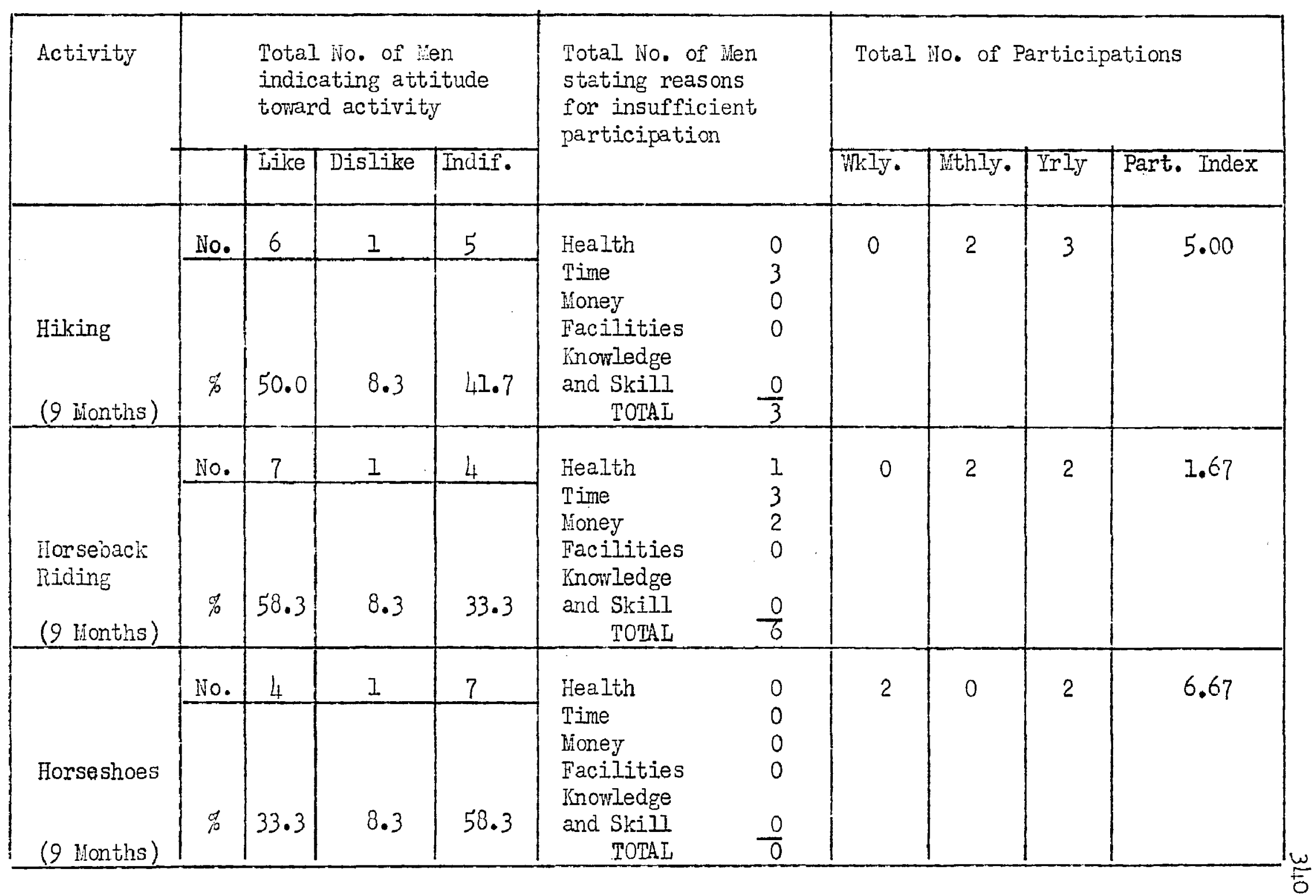


TABIE 31 (Continued)

0-\$2,000 Income Group

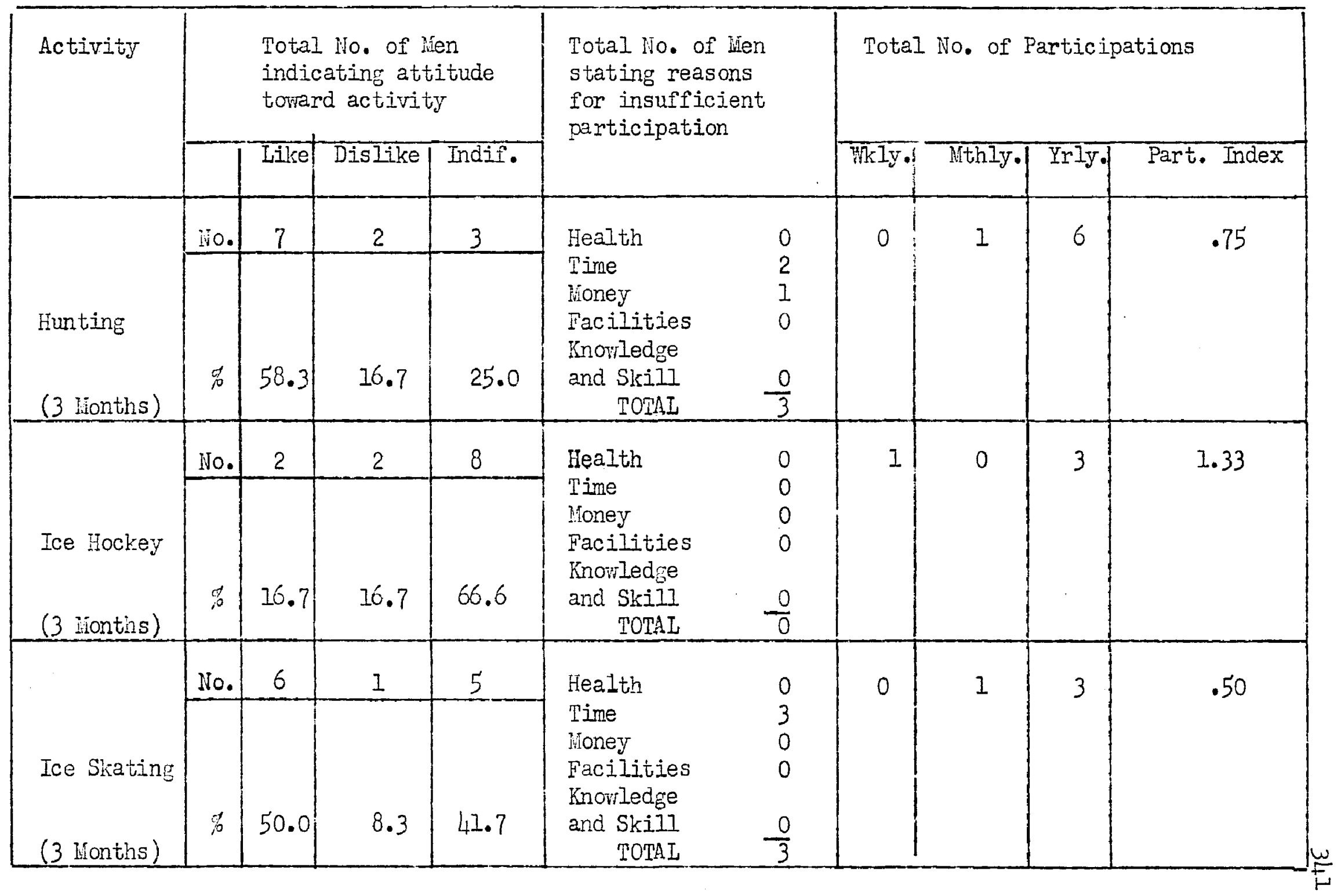




TABLA 31 (Continued)

0-\$2,000 Incone Group

\begin{tabular}{|c|c|c|c|c|c|c|c|c|c|c|}
\hline \multirow[t]{2}{*}{ Activity } & \multicolumn{4}{|c|}{$\begin{array}{l}\text { Total io. of hen } \\
\text { indicating attitucie } \\
\text { toward activity }\end{array}$} & \multirow{2}{*}{\multicolumn{2}{|c|}{$\begin{array}{l}\text { Tota. I Ho. ô iJen } \\
\text { stating reasons } \\
\text { for insufficient } \\
\text { participation }\end{array}$}} & \multicolumn{4}{|c|}{ Total No. of Participations } \\
\hline & & Iike & Dislike & Indif. & & & Wiklyd & Wthly. & Yrly.1 & Part. Index \\
\hline $\begin{array}{l}\text { Puttering, } \\
\text { Repairing, } \\
\text { etc. }\end{array}$ & No. & 91.7 & 0 & 8.3 & $\begin{array}{l}\text { Health } \\
\text { Time } \\
\text { Ioney } \\
\text { Facilities } \\
\text { Knowledge } \\
\text { and Skill } \\
\quad \text { TOrAL } \\
\end{array}$ & $\begin{array}{l}0 \\
1 \\
0 \\
0 \\
0 \\
\\
\end{array}$ & 7 & 2 & 0 & 32.30 \\
\hline $\begin{array}{l}\text { Listening } \\
\text { to Radio }\end{array}$ & iNo. & 83.3 & 0 & 16.70 & $\begin{array}{l}\text { Health } \\
\text { Time } \\
\text { Honey } \\
\text { Facilities } \\
\text { Knowledge } \\
\text { and Skill } \\
\text { TOTAL } \\
\end{array}$ & $\begin{array}{l}0 \\
1 \\
0 \\
0 \\
0 \\
\frac{0}{1} \\
\end{array}$ & 8 & 1 & 0 & 35.70 \\
\hline Watching TV & No. & 75.0 & 8.3 & 16.7 & $\begin{array}{l}\text { Health } \\
\text { Time } \\
\text { Money } \\
\text { Facilities } \\
\text { Knowledge } \\
\text { and Skill } \\
\text { TOTAL }\end{array}$ & $\begin{array}{l}0 \\
1 \\
0 \\
0 \\
0 \\
0 \\
1\end{array}$ & 6 & 2 & 0 & 28.00 \\
\hline
\end{tabular}


TABIE 31 (Continued)

0-\$2,000 Inconte Group

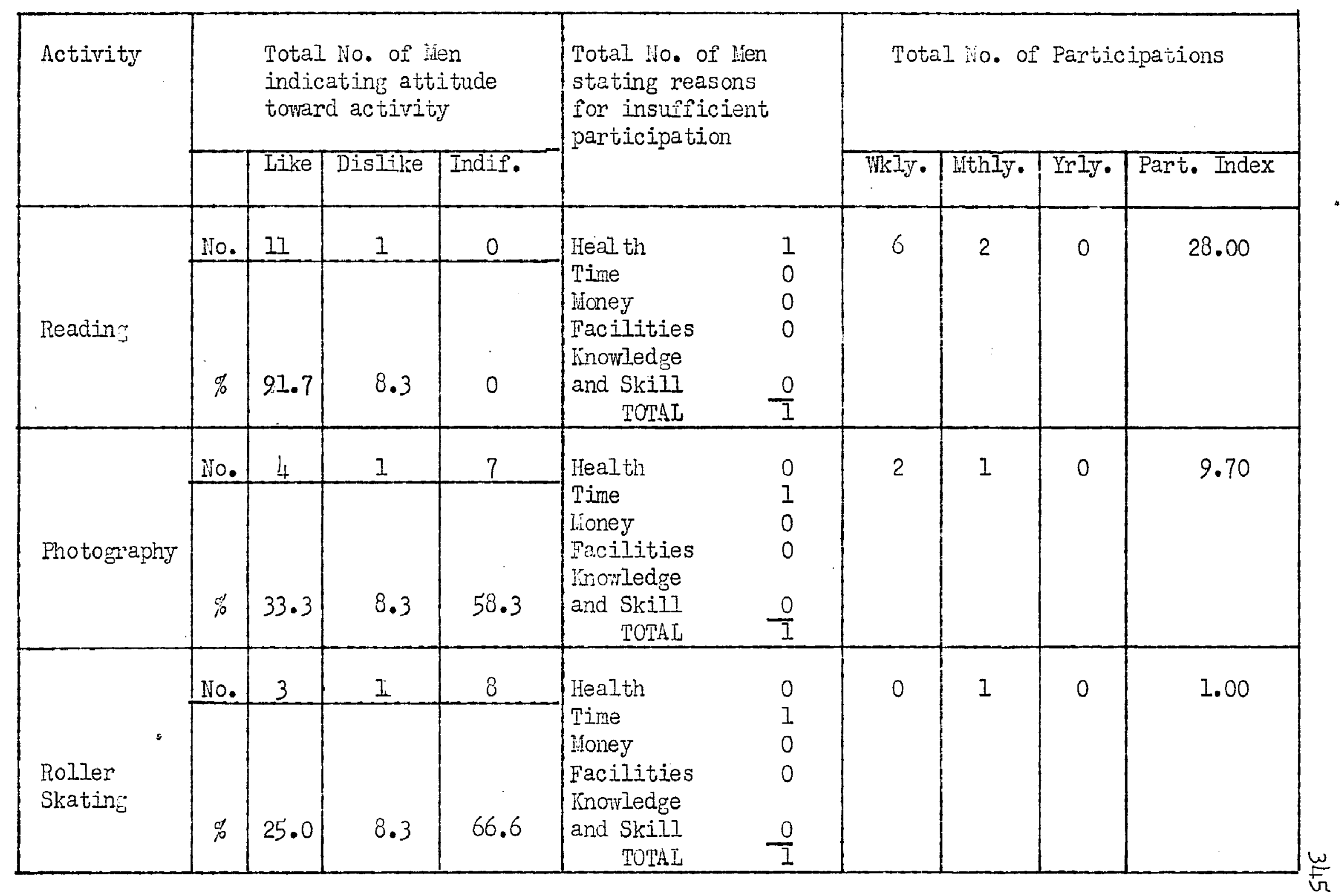


TABLE 31 (Conti nued)

0 $1,2,000$ Income Croup

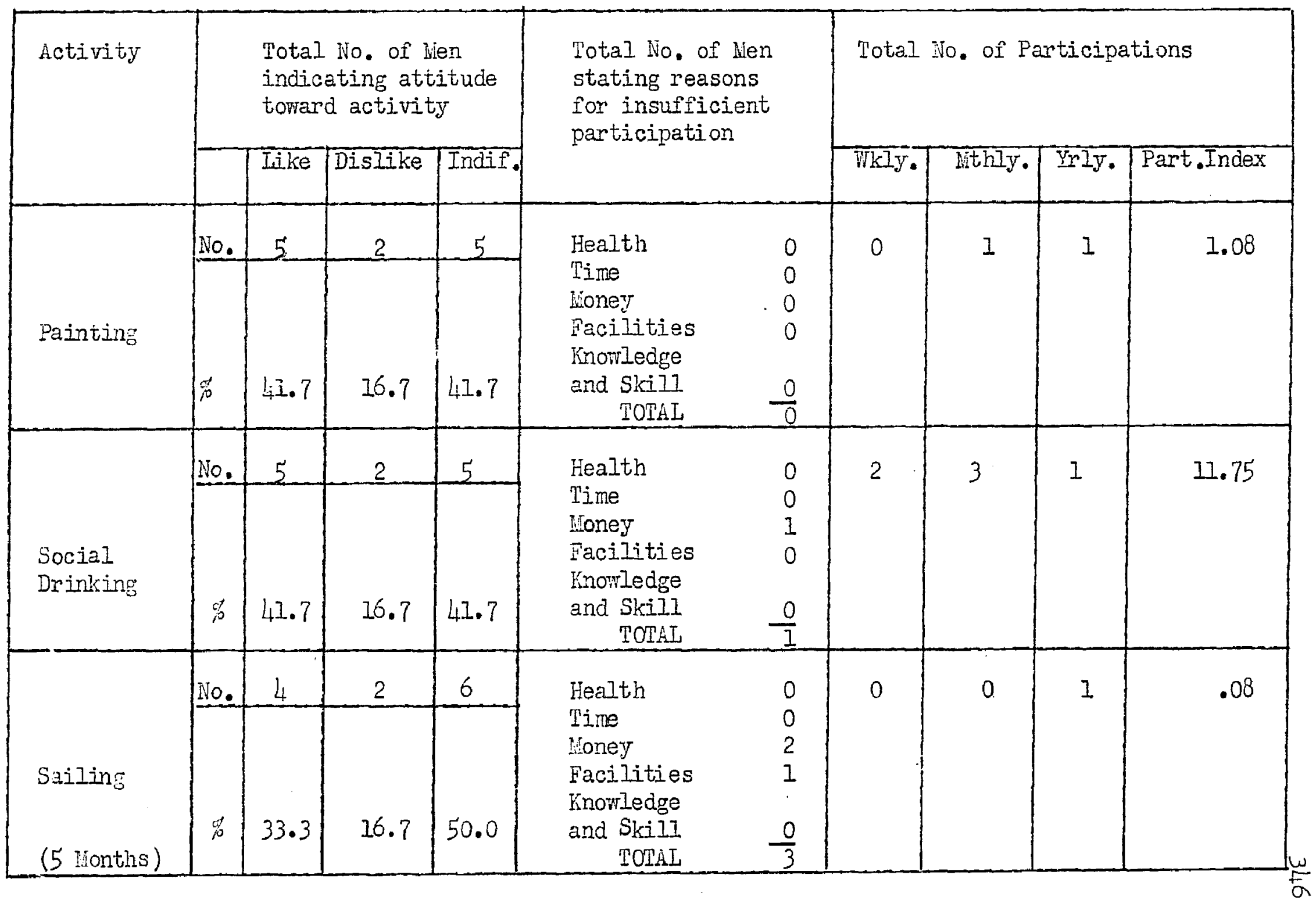


TABLE 31 (Continued)

0-\$2,000 Income croup

\begin{tabular}{|c|c|c|c|c|c|c|c|c|c|c|}
\hline \multirow[t]{2}{*}{ Activity } & \multicolumn{4}{|c|}{$\begin{array}{l}\text { Total No. of Wen } \\
\text { indicating attitude } \\
\text { toward activity }\end{array}$} & \multirow{2}{*}{\multicolumn{2}{|c|}{$\begin{array}{l}\text { Total iNo. of Men } \\
\text { stating reasons } \\
\text { for insufficient } \\
\text { participation }\end{array}$}} & \multicolumn{4}{|c|}{ Total No. of Participations } \\
\hline & & Iike & slike & Indif. & & & Wkly. & iithly. & Yrly. & Part.Index \\
\hline $\begin{array}{l}\text { Sking } \\
\text { (3 Honths) }\end{array}$ & No. & 41.7 & 8.3 & 50.5 & $\begin{array}{l}\text { Health } \\
\text { Time } \\
\text { Money } \\
\text { Facilities } \\
\text { Knowledge } \\
\text { and Skil] } \\
\text { T'OTAL } \\
\end{array}$ & $\begin{array}{l}0 \\
1 \\
0 \\
0\end{array}$ & 0 & 0 & 2 & .17 \\
\hline $\begin{array}{l}\text { Social } \\
\text { Dancing }\end{array}$ & No. & 58.3 & 8.3 & 33.3 & $\begin{array}{l}\text { Health } \\
\text { Time } \\
\text { Money } \\
\text { Facilities } \\
\text { Knowledge } \\
\text { and Skill } \\
\text { TOTAL } \\
\end{array}$ & $\begin{array}{l}0 \\
0 \\
1 \\
0\end{array}$ & 2 & 2 & 1 & 10.75 \\
\hline $\begin{array}{l}\text { Softioll } \\
\text { (3irionths) }\end{array}$ & No. & 50.0 & 0.3 & 41.7 & $\begin{array}{l}\text { Health } \\
\text { Time } \\
\text { Money } \\
\text { Facilities } \\
\text { Knowledge } \\
\text { and Skill } \\
\quad \text { TOIAL } \\
\end{array}$ & $\begin{array}{l}0 \\
2 \\
0\end{array}$ & 1 & 1 & 2 & 1.60 \\
\hline
\end{tabular}


TiBLE 31 (Continued)

0-\$2,000 Income croup

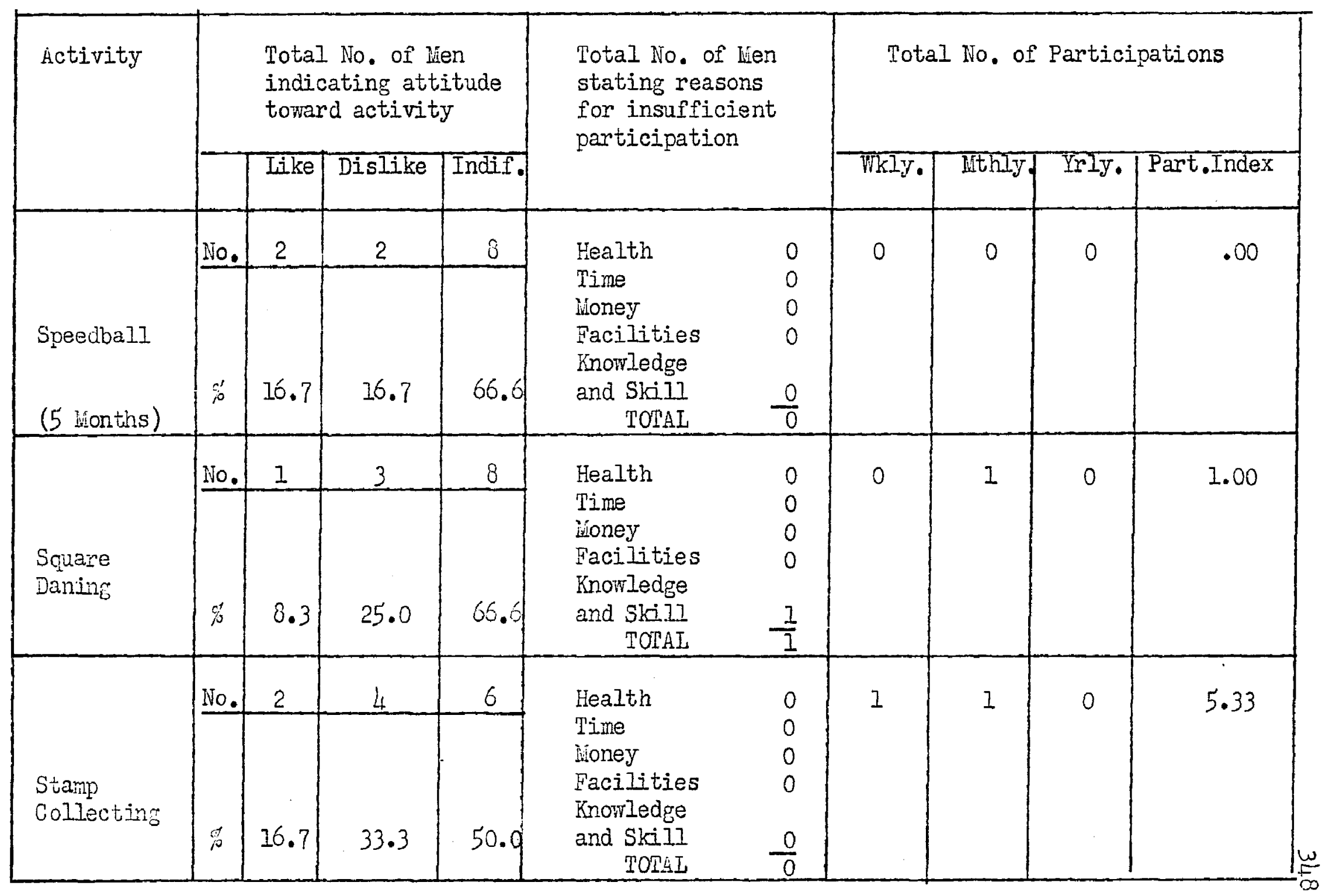


TABLE 31 (Continued)

$0-\$ 2,000$ Income croup

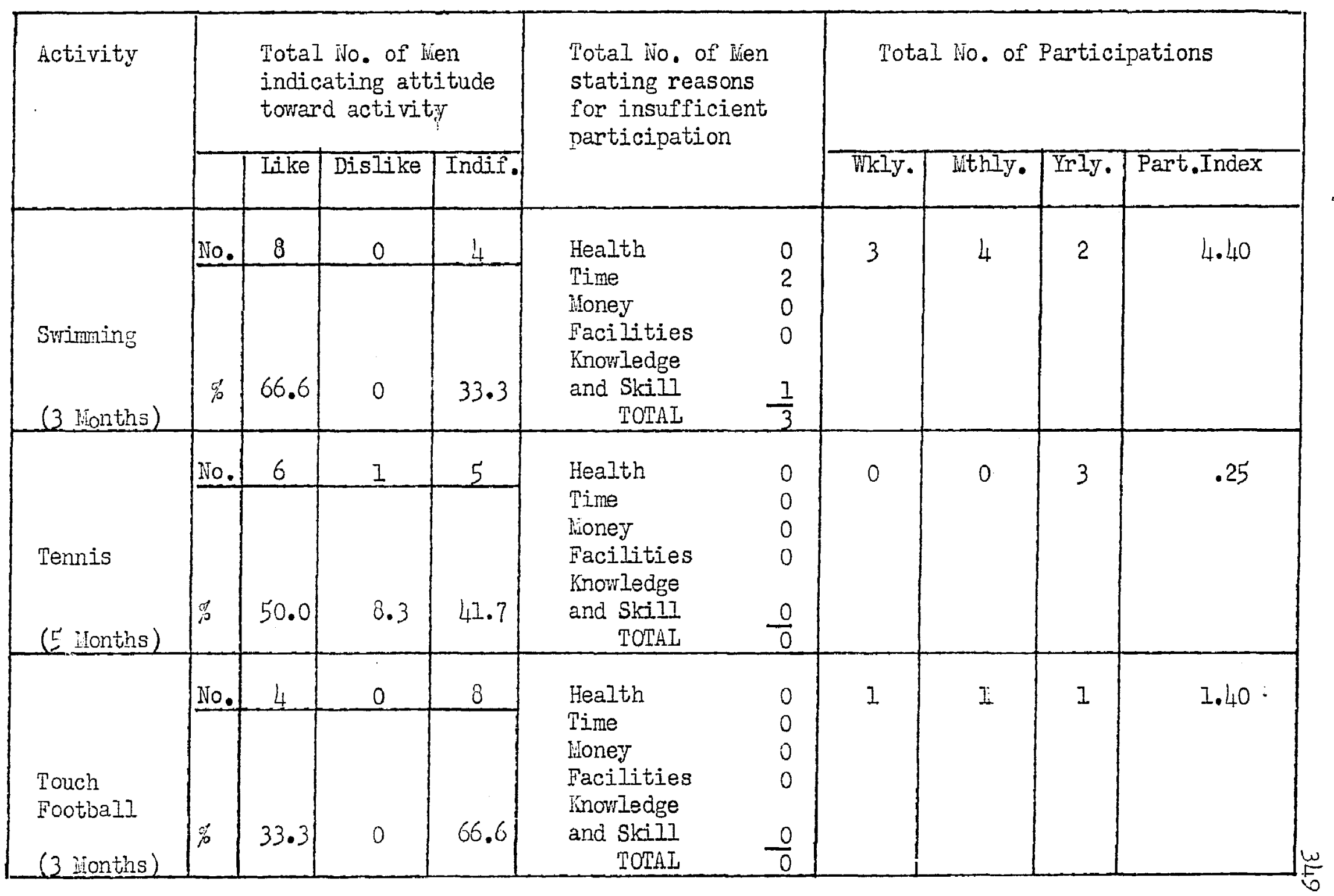


TABIS 31 (Continued)

0-\$2,000 Income Group

\begin{tabular}{|c|c|c|c|c|c|c|c|c|c|c|}
\hline \multirow[t]{2}{*}{ Activity } & & \multicolumn{3}{|c|}{$\begin{array}{l}\text { Total Ho. of iven } \\
\text { indicating attitude } \\
\text { toward activity }\end{array}$} & \multirow{2}{*}{\multicolumn{2}{|c|}{$\begin{array}{l}\text { Total No. of Mien } \\
\text { stating reasons } \\
\text { for insufficient } \\
\text { participation }\end{array}$}} & \multicolumn{4}{|c|}{ Total No. of Mien } \\
\hline & & Tike & Dislike & Indif. & & & Tikly. & Wthly. & Yrly. & Part. Index \\
\hline \multirow[b]{2}{*}{ Tumbling } & No. & 1 & 2 & 9 & \multirow{2}{*}{$\begin{array}{l}\text { Health } \\
\text { Tine } \\
\text { Money } \\
\text { Facilities } \\
\text { Mnowledge } \\
\text { and Skill } \\
\quad \text { TOTAL } \\
\end{array}$} & \multirow{2}{*}{$\begin{array}{r}0 \\
0 \\
0 \\
0 \\
-0 \\
-0\end{array}$} & \multirow[t]{2}{*}{0} & \multirow[t]{2}{*}{1} & \multirow[t]{2}{*}{1} & \multirow[t]{2}{*}{1.08} \\
\hline & $\%$ & 8.3 & 16.7 & 75.0 & & & & & & \\
\hline \multirow[b]{2}{*}{$\begin{array}{l}\text { Visiting } \\
\text { Friends }\end{array}$} & No. & 10 & 0 & 2 & \multirow{2}{*}{$\begin{array}{l}\text { Health } \\
\text { Time } \\
\text { Iioney } \\
\text { Facilities } \\
\text { Inowledge } \\
\text { and Skill } \\
\text { TOMAL } \\
\end{array}$} & 0 & \multirow[t]{2}{*}{6} & \multirow[t]{2}{*}{2} & \multirow[t]{2}{*}{0} & \multirow[t]{2}{*}{28.00} \\
\hline & p & 83.3 & 0 & 16.7 & & $\begin{array}{l}0 \\
0 \\
0 \\
0\end{array}$ & & & & \\
\hline \multirow[b]{2}{*}{ Tolleyball } & No. & 4 & $I$ & 7 & \multirow[b]{2}{*}{$\begin{array}{l}\text { Jealth } \\
\text { Tine } \\
\text { Honey } \\
\text { Facilities } \\
\text { Knowledge } \\
\text { and Skill } \\
\quad \text { TOTAL }\end{array}$} & 0 & \multirow[t]{2}{*}{0} & \multirow[t]{2}{*}{1} & \multirow[t]{2}{*}{2} & \multirow[t]{2}{*}{1.20} \\
\hline & $\%$ & 33.3 & 8.3 & 58.3 & & $\begin{array}{l}0 \\
0 \\
0 \\
0\end{array}$ & & & & \\
\hline
\end{tabular}


TABIE 31 (Continued)

$0-\$ 2,000$ Income Group

\begin{tabular}{|c|c|c|c|c|c|c|c|c|c|c|}
\hline \multirow[t]{2}{*}{ Activity } & \multicolumn{4}{|c|}{$\begin{array}{l}\text { Total No. of ien } \\
\text { indicating attitude } \\
\text { toward activity }\end{array}$} & \multirow{2}{*}{\multicolumn{2}{|c|}{$\begin{array}{l}\text { Total No. of Hen } \\
\text { stating reasons } \\
\text { for insufficient } \\
\text { participation }\end{array}$}} & \multicolumn{4}{|c|}{ Total No. of Participations } \\
\hline & & Like & Dislike & Indif. & & & Wkly. & lithly. & $\operatorname{Yr} 1 \mathrm{y}$. & Part.Index \\
\hline $\begin{array}{l}\text { Watching } \\
\text { Sports } \\
\text { Events }\end{array}$ & No. & 75.0 & 0 & 25.0 & $\begin{array}{l}\text { Health } \\
\text { Time } \\
\text { loney } \\
\text { Faci lities } \\
\text { Hinowledge } \\
\text { and Skill } \\
\text { TOTAL }\end{array}$ & $\begin{array}{l}0 \\
1 \\
1 \\
0 \\
0 \\
\frac{0}{2}\end{array}$ & 7 & 1 & 0 & 31.3 \\
\hline Walking & No. & 66.6 & 8.3 & 25.0 & $\begin{array}{l}\text { Health } \\
\text { Time } \\
\text { lioney } \\
\text { Facilities } \\
\text { Knowledge } \\
\text { and Skill } \\
\quad \text { TOTAL } \\
\end{array}$ & $\begin{array}{l}0 \\
2 \\
0 \\
0 \\
0 \\
\frac{0}{2} \\
\end{array}$ & 3 & 2 & 1 & 15.1 \\
\hline $\begin{array}{l}\text { Weight } \\
\text { Lifting }\end{array}$ & No. & 33.3 & 8.3 & 58.3 & $\begin{array}{l}\text { Health } \\
\text { Time } \\
\text { Ioney } \\
\text { Facilities } \\
\text { Ynowledge } \\
\text { and Skill } \\
\text { TOTAL }\end{array}$ & $\begin{array}{l}0 \\
0 \\
1 \\
1 \\
\frac{0}{2}\end{array}$ & 0 & 1 & 3 & 1.25 \\
\hline
\end{tabular}


TABLE 31 (Continued)

0- 2,000 Income Group

\begin{tabular}{|c|c|c|c|c|c|c|c|c|c|c|}
\hline \multirow[t]{2}{*}{ Activity } & & \multicolumn{3}{|c|}{$\begin{array}{l}\text { Total No. of ien } \\
\text { indicating attitude } \\
\text { toward activity }\end{array}$} & \multirow{2}{*}{\multicolumn{2}{|c|}{$\begin{array}{l}\text { Total No. of wen } \\
\text { stating reasons } \\
\text { for insufficient } \\
\text { participation }\end{array}$}} & \multicolumn{4}{|c|}{ Total No. of Participations } \\
\hline & & Iike & Dislike & Indif. & & & WkIy•l & Wthly. & Yrly. & Part.Index \\
\hline $\begin{array}{l}\text { Water Polo } \\
\text { (3 kionths) }\end{array}$ & No. & 16.7 & 16.7 & 66.6 & $\begin{array}{l}\text { Health } \\
\text { Time } \\
\text { Koney } \\
\text { Facilities } \\
\text { Knowledge } \\
\text { and Skill } \\
\quad \text { TOTAL } \\
\end{array}$ & $\begin{array}{l}0 \\
0 \\
1 \\
1 \\
0 \\
\frac{0}{2}\end{array}$ & 0 & 0 & 1 & .08 \\
\hline Woodworking & No. & 33.3 & 25.0 & 41.7 & $\begin{array}{l}\text { Health } \\
\text { Tine } \\
\text { Mioney } \\
\text { Facilities } \\
\text { Knowledge } \\
\text { and Skill } \\
\quad \text { TOTAL } \\
\end{array}$ & $\begin{array}{l}0 \\
0 \\
1 \\
0 \\
0 \\
\frac{0}{1}\end{array}$ & 0 & 2 & 2 & 2.17 \\
\hline Woodcarving & No. & 8.3 & 25.0 & 66.6 & $\begin{array}{l}\text { Health } \\
\text { Time } \\
\text { lioney } \\
\text { Facilities } \\
\text { Inowledge } \\
\text { and Skill } \\
\quad \text { TOTAL } \\
\end{array}$ & $\begin{array}{l}0 \\
0 \\
0 \\
0 \\
0 \\
0 \\
\end{array}$ & 0 & 0 & 0 & .0 \\
\hline
\end{tabular}


0-\$2,000 Income Group

\begin{tabular}{|c|c|c|c|c|c|c|c|c|c|c|}
\hline \multirow[t]{2}{*}{ Activity } & \multicolumn{4}{|c|}{$\begin{array}{l}\text { Total No. of Men } \\
\text { indicating attitude } \\
\text { toward activity }\end{array}$} & \multirow{2}{*}{\multicolumn{2}{|c|}{$\begin{array}{l}\text { Total No. of Men } \\
\text { stating reasons } \\
\text { for insufficient } \\
\text { participation }\end{array}$}} & \multicolumn{4}{|c|}{ Total No. of Participations } \\
\hline & & Like & Dislike & Indif. & & & Wkly. & lithly. & Irly. & Part.Index \\
\hline & No. & 5 & 2 & 5 & Health & 0 & 1 & 1 & 2 & 5.5 \\
\hline Wrestling & 若 & 41.7 & 16.7 & 41.7 & $\begin{array}{l}\text { Koney } \\
\text { Facilities } \\
\text { Knowledge } \\
\text { and Slill } \\
\text { TOTAL }\end{array}$ & $\begin{array}{l}0 \\
0 \\
0 \\
1\end{array}$ & & & & \\
\hline $\begin{array}{l}\text { Attending } \\
\mathrm{K} \text {. of } \mathrm{P} \text {. }\end{array}$ & No. & 1 & & & Total & 0 & 1 & & 52 & 4.3 \\
\hline $\begin{array}{l}\text { Attending } \\
\text { Church }\end{array}$ & No. & 1 & & & Total & 0 & 1 & & 52 & 4.3 \\
\hline Camp Heeting & No. & 1 & & & Total & 0 & 1 & & 52 & 4.3 \\
\hline $\begin{array}{l}\text { Crossword } \\
\text { Puzzles }\end{array}$ & No. & $\bar{I}$ & & & Total & 0 & $\overline{1}$ & & 52 & 4.3 \\
\hline
\end{tabular}

REASOISS :

$\begin{array}{lrrr}\text { Health } & 7 & - & 6.1 \% \\ \text { Time } & 66 & - & 57.9 \% \\ \text { Woney } & 20 & - & 17.5 \% \\ \text { Facilities } & 12 & - & 10.5 \% \\ \text { Knowledge and Skill } & 9 & - & 7.9 \%\end{array}$


TABIE 32.

Numbers and Percentages of isen Liking, Disliking, and Indifferent to Each of Sixty-Seven Recreational Activities, Extent of Participation in Each, and Number of Wen Listing Each of. Five Reasons for Unsatisfactory Participation in the $\$ 2,000-\$ 3,000$ Income Group

\begin{tabular}{|c|c|c|c|c|c|c|c|c|c|c|}
\hline \multirow[t]{2}{*}{ Activity } & & \multicolumn{3}{|c|}{$\begin{array}{l}\text { Total Ho. of ilen } \\
\text { indicating attitude } \\
\text { toward activity }\end{array}$} & \multirow{2}{*}{\multicolumn{2}{|c|}{$\begin{array}{l}\text { Total Ho. of Hen } \\
\text { stating reasons } \\
\text { for insufficient } \\
\text { participation }\end{array}$}} & \multicolumn{4}{|c|}{ Total No. of Participation } \\
\hline & & Iike & Dislike & Indif. & & & Whly. & Why. & $\overline{\text { Yrly. }}$ & Part. Index \\
\hline \multirow[b]{2}{*}{ Archery } & ijo. & 15 & 10 & 25 & \multirow{2}{*}{$\begin{array}{l}\text { Health } \\
\text { Tine } \\
\text { Honey } \\
\text { Facilities } \\
\text { Knowled } \\
\text { and Skill } \\
\quad \text { TOTAL } \\
\end{array}$} & \multirow{2}{*}{$\begin{array}{l}0 \\
5 \\
1 \\
7 \\
0 \\
13 \\
\end{array}$} & \multirow[t]{2}{*}{3} & \multirow[t]{2}{*}{1} & \multirow[t]{2}{*}{10} & \multirow[t]{2}{*}{3.56} \\
\hline & $\%$ & 30 & 20 & 50 & & & & & & \\
\hline \multirow[b]{2}{*}{ Badminton } & No. & 18 & 12 & 20 & \multirow{2}{*}{$\begin{array}{l}\text { Health } \\
\text { Time } \\
\text { Yoney } \\
\text { Facilities } \\
\text { Fnowledze } \\
\text { and Skili } \\
\text { TOTAL }\end{array}$} & 0 & \multirow[t]{2}{*}{2} & \multirow[t]{2}{*}{6} & \multirow[t]{2}{*}{9} & \multirow[t]{2}{*}{3.70} \\
\hline & $\%$ & 36 & 24 & 40 & & $\begin{array}{r}2 \\
6 \\
6 \\
\frac{0}{13}\end{array}$ & & & & \\
\hline
\end{tabular}


TABIF 32 (Continued)

$\$ 2,000-\$ 3,000$ Income Group

\begin{tabular}{|c|c|c|c|c|c|c|c|c|c|c|}
\hline \multirow[t]{2}{*}{ Activity } & & \multicolumn{3}{|c|}{$\begin{array}{l}\text { Total wo. of iten } \\
\text { indicating attitude } \\
\text { toward activity }\end{array}$} & \multirow{2}{*}{\multicolumn{2}{|c|}{$\begin{array}{l}\text { Total No. ổ Hen } \\
\text { stating reasons } \\
\text { for insufficient } \\
\text { participation }\end{array}$}} & \multicolumn{4}{|c|}{ Total Io. of Participations } \\
\hline & & Iike & Dislike & Indif. & & & Whely. & ifthly. & Yrly. & Part. Index \\
\hline \multirow[b]{2}{*}{ Bar Funchind } & nio. & 13 & 15 & 22 & \multirow{2}{*}{$\begin{array}{l}\text { Heulth } \\
\text { Time } \\
\text { Money } \\
\text { Facilities } \\
\text { Knowledge } \\
\text { and Skill } \\
\text { TOTAI } \\
\end{array}$} & \multirow{2}{*}{$\begin{array}{l}0 \\
4 \\
8 \\
2 \\
\\
\\
\end{array}$} & \multirow[t]{2}{*}{2} & \multirow[t]{2}{*}{3.} & \multirow[t]{2}{*}{5} & \multirow[t]{2}{*}{2.90} \\
\hline & $\%$ & 26 & 30 & 44 & & & & & & \\
\hline \multirow[b]{2}{*}{$\begin{array}{l}\text { Baseball } \\
\text { (3 Bonths) }\end{array}$} & No. & 40 & 2 & 8 & \multirow{2}{*}{$\begin{array}{l}\text { Health } \\
\text { Time } \\
\text { Money } \\
\text { Facilities } \\
\text { Knowledge } \\
\text { and Skill } \\
\text { TOTAI } \\
\end{array}$} & \multirow{2}{*}{$\begin{array}{r}2 \\
12 \\
1 \\
2 \\
0 \\
\frac{0}{17} \\
\end{array}$} & \multirow[t]{2}{*}{16} & \multirow[t]{2}{*}{9} & \multirow[t]{2}{*}{8} & \multirow[t]{2}{*}{4.86} \\
\hline & $\%$ & 80 & 4 & 16 & & & & & & \\
\hline \multirow[b]{2}{*}{$\begin{array}{l}\text { Basketiball } \\
\text { (6 imonths) }\end{array}$} & No. & $3 I$ & 3 & 16 & \multirow{2}{*}{$\begin{array}{l}\text { Health } \\
\text { Time } \\
\text { Honey } \\
\text { Facilities } \\
\text { Knowledge } \\
\text { and Slkill } \\
\text { roTAI }\end{array}$} & 2 & \multirow[t]{2}{*}{6} & \multirow[t]{2}{*}{4} & \multirow[t]{2}{*}{11} & \multirow[t]{2}{*}{3.82} \\
\hline & $\%$ & 62 & 6 & 32 & & $\begin{array}{l}1 \\
3 \\
\frac{1}{16}\end{array}$ & & & & \\
\hline
\end{tabular}


TABIE 32 (Continued)

$\$ 2,000-\$ 3,000$ Income Group

\begin{tabular}{|c|c|c|c|c|c|c|c|c|c|c|}
\hline \multirow[t]{2}{*}{ Activity } & \multicolumn{4}{|c|}{$\begin{array}{l}\text { Total io. of lien } \\
\text { indicating attitude } \\
\text { torrard activity }\end{array}$} & \multirow{2}{*}{\multicolumn{2}{|c|}{$\begin{array}{l}\text { Total Io. of lien } \\
\text { stating reasons } \\
\text { for insufficient } \\
\text { participation. }\end{array}$}} & \multicolumn{4}{|c|}{ Total ĩo. ô Participations } \\
\hline & & Like & Dislike & Indif. & & & Whly. & Withly. & YrIy. & Part.Index \\
\hline $\begin{array}{l}\text { Bicycling } \\
(8 \text { Months })\end{array}$ & No. & 19 & 12 & 25 & $\begin{array}{l}\text { Health } \\
\text { Time } \\
\text { lioney } \\
\text { Facilities } \\
\text { Knowledge } \\
\text { and Skill } \\
\quad \text { TOTAL } \\
\end{array}$ & $\begin{array}{c}2 \\
7 \\
1 \\
3 \\
0 \\
13\end{array}$ & 2 & 5 & 5 & 1.17 \\
\hline Boating & No. & 27 & 10 & 18 & $\begin{array}{l}\text { Health } \\
\text { Time } \\
\text { lioney } \\
\text { Facilities } \\
\text { Knomledge } \\
\text { and Skill } \\
\quad \text { TOTAL } \\
\end{array}$ & $\begin{array}{r}0 \\
6 \\
5 \\
3 \\
\\
\\
I_{1} \\
\end{array}$ & 2 & 7 & 8 & 1.73 \\
\hline $\begin{array}{l}\text { Bowling } \\
\text { ( } 9 \text { Iionths) }\end{array}$ & No. & 36 & 10 & 18 & $\begin{array}{l}\text { Health } \\
\text { Time } \\
\text { Honey } \\
\text { Facilities } \\
\text { Knowledge } \\
\text { and Skill } \\
\quad \text { ToTAL } \\
\end{array}$ & $\begin{array}{l}1 \\
7 \\
5 \\
0 \\
\frac{1}{1}\end{array}$ & 13 & 6 & 9 & 21.4 \\
\hline
\end{tabular}


TABIE 32 (Continued)

2,000-\% 3,000 Income Group

\begin{tabular}{|c|c|c|c|c|c|c|c|c|c|c|}
\hline \multirow[t]{2}{*}{ Activity } & \multicolumn{4}{|c|}{$\begin{array}{l}\text { Total Wo. of Wen } \\
\text { indicating attitude } \\
\text { toward activity }\end{array}$} & \multirow{2}{*}{\multicolumn{2}{|c|}{$\begin{array}{l}\text { Total No. of Men } \\
\text { stating reasons } \\
\text { for insufficient } \\
\text { participation }\end{array}$}} & \multicolumn{4}{|c|}{ Total No. of Participations } \\
\hline & & Iike & Dislike & Indif. & & & Wkly. & Wthly. & Yriy. & Part. Index \\
\hline \multirow[b]{2}{*}{ Boxing } & No. & 19 & 12 & 19 & \multirow{2}{*}{$\begin{array}{l}\text { Health } \\
\text { Time } \\
\text { Ioney } \\
\text { Facilities } \\
\text { rnowledge } \\
\text { and Skill } \\
\quad \text { TOTAI } \\
\end{array}$} & \multirow{2}{*}{$\begin{array}{l}2 \\
4 \\
0 \\
3 \\
0 \\
9\end{array}$} & \multirow[t]{2}{*}{3} & \multirow[t]{2}{*}{ I } & \multirow[t]{2}{*}{4} & \multirow[t]{2}{*}{3.44} \\
\hline & of & 38 & 24 & 39 & & & & & & \\
\hline \multirow[b]{2}{*}{ Calisthenics } & No. & $\mathrm{I}_{4}$ & 12 & 24 & \multirow{2}{*}{$\begin{array}{l}\text { Health } \\
\text { Time } \\
\text { Loney } \\
\text { Facilities } \\
\text { Knomledge } \\
\text { and Skill } \\
\quad \text { rutAL } \\
\end{array}$} & 1 & \multirow[t]{2}{*}{3} & \multirow[t]{2}{*}{3} & \multirow[t]{2}{*}{1} & \multirow[t]{2}{*}{3.86} \\
\hline & $g$ & 20 & 24 & 40 & & $\begin{array}{r}0 \\
1 \\
0 \\
8 \\
\end{array}$ & & & & \\
\hline \multirow[b]{2}{*}{ Canoeing } & No. & 19 & 11 & 20 & \multirow{2}{*}{$\begin{array}{l}\text { Health } \\
\text { Time } \\
\text { Ifoney } \\
\text { Facilities } \\
\text { Knowledge } \\
\text { and Skill } \\
\text { TOTAL }\end{array}$} & 0 & \multirow[t]{2}{*}{0} & \multirow[t]{2}{*}{0} & \multirow[t]{2}{*}{14} & \multirow[t]{2}{*}{.28} \\
\hline & $\stackrel{8}{0}$ & 38 & 22 & 40 & & $\begin{array}{r}3 \\
5 \\
0 \\
\frac{0}{15}\end{array}$ & & & & \\
\hline
\end{tabular}


TABIE 32 (Continued)

$\$ 2,000-\$ 3,000$ Income croup

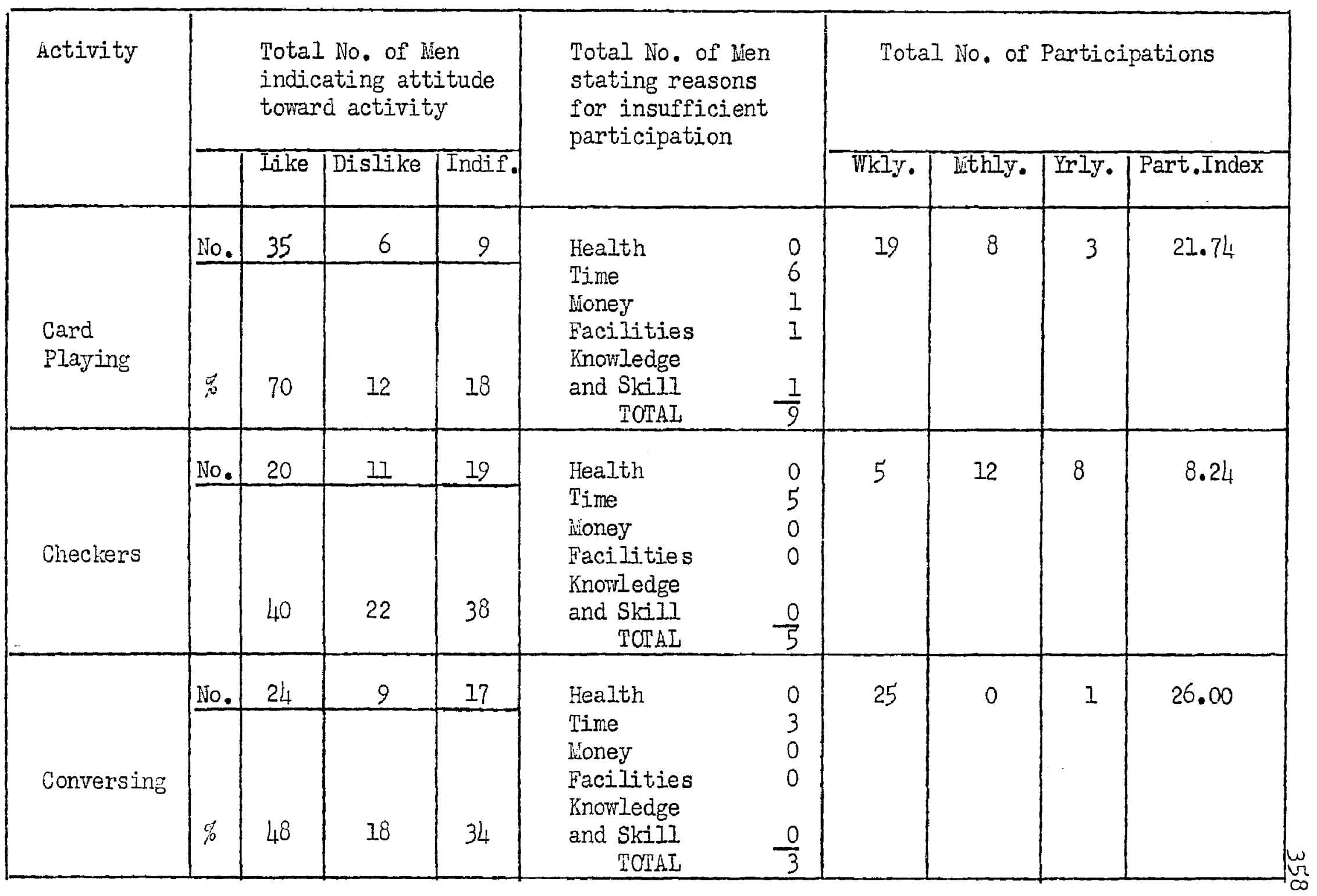


TABLE 32 (Continued)

\$2,000- 3, 3,000 Income Group

\begin{tabular}{|c|c|c|c|c|c|c|c|c|c|c|}
\hline \multirow[t]{2}{*}{ Activity } & & \multicolumn{3}{|c|}{$\begin{array}{l}\text { Total No. of wen } \\
\text { indi cating attitude } \\
\text { toward activity }\end{array}$} & \multicolumn{2}{|c|}{$\begin{array}{l}\text { Total No. of lien } \\
\text { stating reasons } \\
\text { for insufficient } \\
\text { partici pation }\end{array}$} & \multicolumn{4}{|c|}{ Total No. of Participations } \\
\hline & & like & Dislike & Inciff. & & & Wikly. & wthly. & Yriy. & Part.Index \\
\hline \multirow[b]{2}{*}{ Chess } & No. & 8 & 20 & 22 & \multirow{2}{*}{$\begin{array}{l}\text { Health } \\
\text { Time } \\
\text { Woney } \\
\text { Facilities } \\
\text { Knowledge } \\
\text { and Skill } \\
\quad \text { TOTAL } \\
\end{array}$} & \multirow{2}{*}{$\begin{array}{l}0 \\
0 \\
0 \\
1 \\
-4 \\
5\end{array}$} & \multirow[t]{2}{*}{1} & \multirow[t]{2}{*}{1} & \multirow[t]{2}{*}{2} & \multirow[t]{2}{*}{1.35} \\
\hline & $\%$ & 16 & 40 & 44 & & & & & & \\
\hline \multirow[b]{2}{*}{ Deck Tennis } & No. & 3 & 16 & 31 & \multirow{2}{*}{$\begin{array}{l}\text { Health } \\
\text { Time } \\
\text { Wioney } \\
\text { Facilities } \\
\text { Knowledge } \\
\text { and Skill } \\
\text { TOTAL } \\
\end{array}$} & \multirow{2}{*}{$\begin{array}{l}0 \\
2 \\
0 \\
0 \\
0 \\
\\
\end{array}$} & \multirow[t]{2}{*}{1} & \multirow[t]{2}{*}{0} & \multirow[t]{2}{*}{$0^{\circ}$} & \multirow[t]{2}{*}{1.04} \\
\hline & $\%$ & 6 & 32 & 62 & & & & & & \\
\hline \multirow[b]{2}{*}{ Dating } & No. & 23 & 4 & 23 & \multirow{2}{*}{$\begin{array}{l}\text { Health } \\
\text { Time } \\
\text { Money } \\
\text { Facilities } \\
\text { Knowledge } \\
\text { and Skill } \\
\text { TOTAL }\end{array}$} & \multirow{2}{*}{$\begin{array}{l}0 \\
1 \\
1 \\
0 \\
0 \\
\frac{0}{2}\end{array}$} & \multirow[t]{2}{*}{16} & \multirow[t]{2}{*}{2} & \multirow[t]{2}{*}{1} & \multirow[t]{2}{*}{17.14} \\
\hline & $\%$ & 46 & 8 & 46 & & & & & & \\
\hline
\end{tabular}


TABIE 32 (Continued)

2,000-\$3,000 Income Group

\begin{tabular}{|c|c|c|c|c|c|c|c|c|c|c|}
\hline \multirow[t]{2}{*}{ Activity } & & \multicolumn{3}{|c|}{$\begin{array}{l}\text { Total No. of Men } \\
\text { indicating attitude } \\
\text { toward activity }\end{array}$} & \multirow{2}{*}{\multicolumn{2}{|c|}{$\begin{array}{l}\text { Total No. of lien } \\
\text { stating reasons } \\
\text { for insufficient } \\
\text { participation }\end{array}$}} & \multicolumn{4}{|c|}{ Total No. of Participations } \\
\hline & & Like & Dislike & Indif. & & & WkIy. & inthly. & Frly. & Part.Index \\
\hline \multirow[b]{2}{*}{ Driving } & No. & 42 & 3 & 5 & \multirow{2}{*}{$\begin{array}{l}\text { Health } \\
\text { Time } \\
\text { honey } \\
\text { Facilities } \\
\text { Knowledge } \\
\text { and Skill } \\
\text { TOTAL } \\
\end{array}$} & \multirow{2}{*}{$\begin{array}{l}0 \\
3 \\
0 \\
2 \\
0 \\
0 \\
\end{array}$} & \multirow[t]{2}{*}{63} & \multirow[t]{2}{*}{1} & \multirow[t]{2}{*}{1} & \multirow[t]{2}{*}{65.80} \\
\hline & $c^{\prime}$ & 84 & 6 & 10 & & & & & & \\
\hline \multirow[b]{2}{*}{ Fencing } & No. & 4 & 20 & 26 & \multirow{2}{*}{$\begin{array}{l}\text { Health } \\
\text { Time } \\
\text { lioney } \\
\text { Facilities } \\
\text { Inovrledge } \\
\text { and Skill } \\
\quad \text { TOTAL } \\
\end{array}$} & \multirow{2}{*}{$\begin{array}{l}1 \\
0 \\
0 \\
1 \\
\frac{1}{3}\end{array}$} & \multirow[t]{2}{*}{1} & \multirow[t]{2}{*}{0} & \multirow[t]{2}{*}{2} & \multirow[t]{2}{*}{1.08} \\
\hline & $\%$ & 8 & 40 & 52 & & & & & & \\
\hline \multirow[b]{2}{*}{$\begin{array}{l}\text { Field Events } \\
\text { (Track) } \\
\text { (4 Eonths) }\end{array}$} & No. & 12 & 13 & 25 & \multirow{2}{*}{$\begin{array}{l}\text { Health } \\
\text { Time } \\
\text { Ioney } \\
\text { Facilities } \\
\text { Knowledge } \\
\text { and Skill } \\
\text { TOTAL }\end{array}$} & \multirow{2}{*}{$\begin{array}{l}2 \\
2 \\
0 \\
2 \\
0 \\
\frac{0}{6}\end{array}$} & \multirow[t]{2}{*}{1} & \multirow[t]{2}{*}{2} & \multirow[t]{2}{*}{3} & \multirow[t]{2}{*}{.57} \\
\hline & 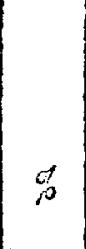 & 24 & 26 & 50 & & & & & & \\
\hline
\end{tabular}


TABT 32 (Continued)

$\$ 2,000-\$ 3,000$ Income Group

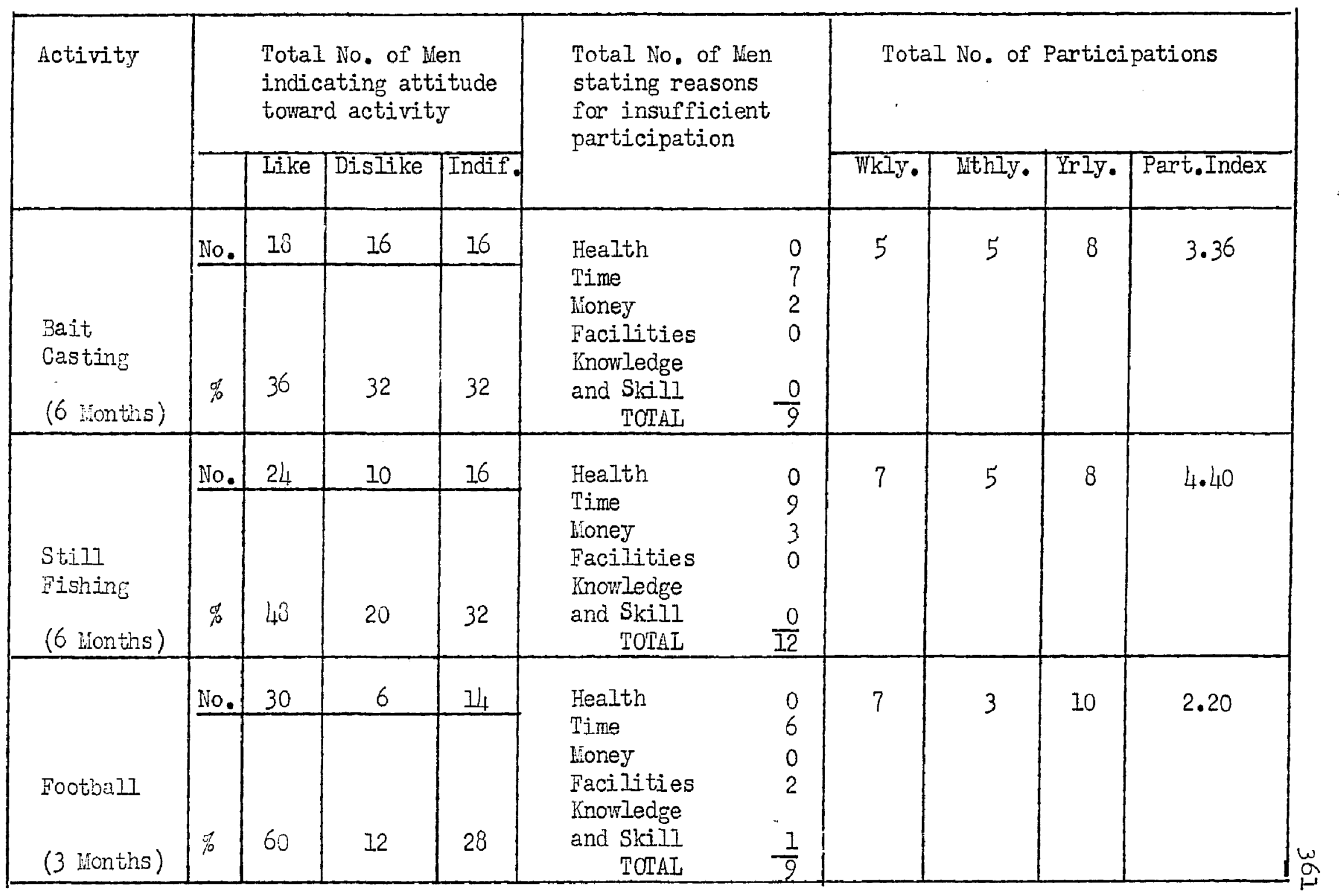


TABLE 32 (Continued)

$\$ 2,000-3,000$ income Group

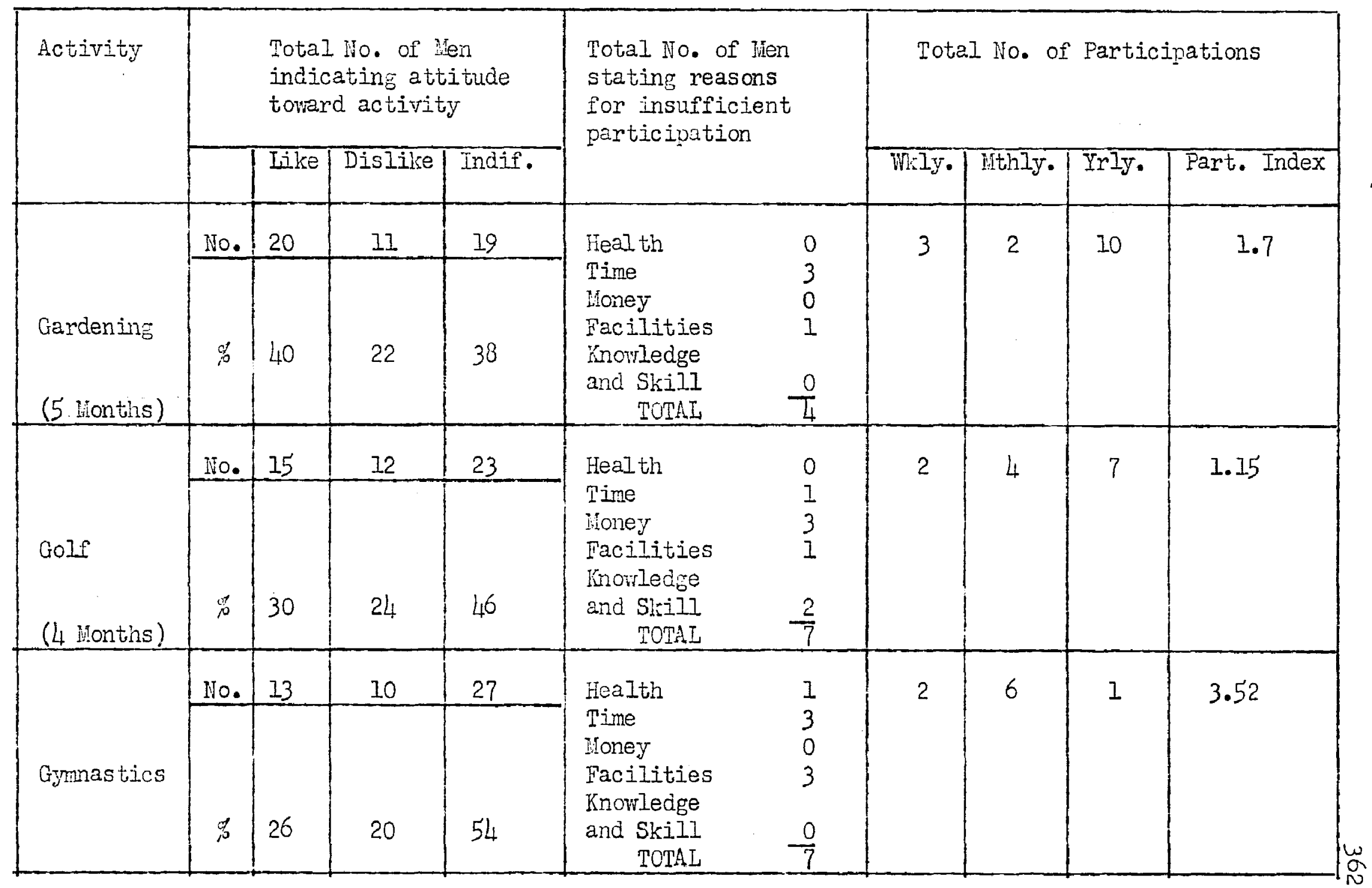


TABLE 32 (Continued)

\$2,000-3,000 Income Group

\begin{tabular}{|c|c|c|c|c|c|c|c|c|c|c|}
\hline \multirow[t]{2}{*}{ Activity } & \multicolumn{4}{|c|}{$\begin{array}{l}\text { Total iNo. of Men } \\
\text { indicating attitude } \\
\text { toward activity }\end{array}$} & \multirow{2}{*}{\multicolumn{2}{|c|}{$\begin{array}{l}\text { Total No. of Wen } \\
\text { stating reasons } \\
\text { for insufficient } \\
\text { participation }\end{array}$}} & \multicolumn{4}{|c|}{ Total No. of Participations } \\
\hline & & Tike & Dislike & Indif. & & & Vikly. & Wthly. & Yrly. & Part.Index \\
\hline $\begin{array}{l}\text { Handball } \\
\text { (9 Ionths) }\end{array}$ & No. & 13 & 12 & 25 & $\begin{array}{l}\text { Health } \\
\text { Time } \\
\text { Noney } \\
\text { Facilities } \\
\text { Knowledge } \\
\text { and Skill } \\
\quad \text { TOTAL } \\
\end{array}$ & $\begin{array}{l}1 \\
1 \\
0 \\
4 \\
1 \\
\end{array}$ & 3 & 4 & 2 & 3.10 \\
\hline $\begin{array}{l}\text { Hiking } \\
\text { (9 Honths) }\end{array}$ & No. & 16 & 12 & 44 & $\begin{array}{l}\text { Health } \\
\text { Time } \\
\text { Sioney } \\
\text { Facilities } \\
\text { Knotledge } \\
\text { and Skill } \\
\quad \text { TOISI } \\
\end{array}$ & $\begin{array}{l}1 \\
3 \\
0 \\
0 \\
0 \\
4 \\
\end{array}$ & $I$ & 3 & 6 & 1.44 \\
\hline $\begin{array}{l}\text { Horseback } \\
\text { Riding } \\
\text { (2 Months) }\end{array}$ & No. & 26 & 18 & 30 & $\begin{array}{l}\text { Health } \\
\text { Time } \\
\text { Woney } \\
\text { Facilities } \\
\text { Knowledge } \\
\text { and Skill } \\
\quad \text { TOTAL } \\
\end{array}$ & $\begin{array}{l}1 \\
5 \\
3 \\
4 \\
0 \\
13\end{array}$ & 0 & 3 & 11 & .76 \\
\hline
\end{tabular}


TABLE 32 (Continued)

$\$ 2,000-\$ 3,000$ Income croup

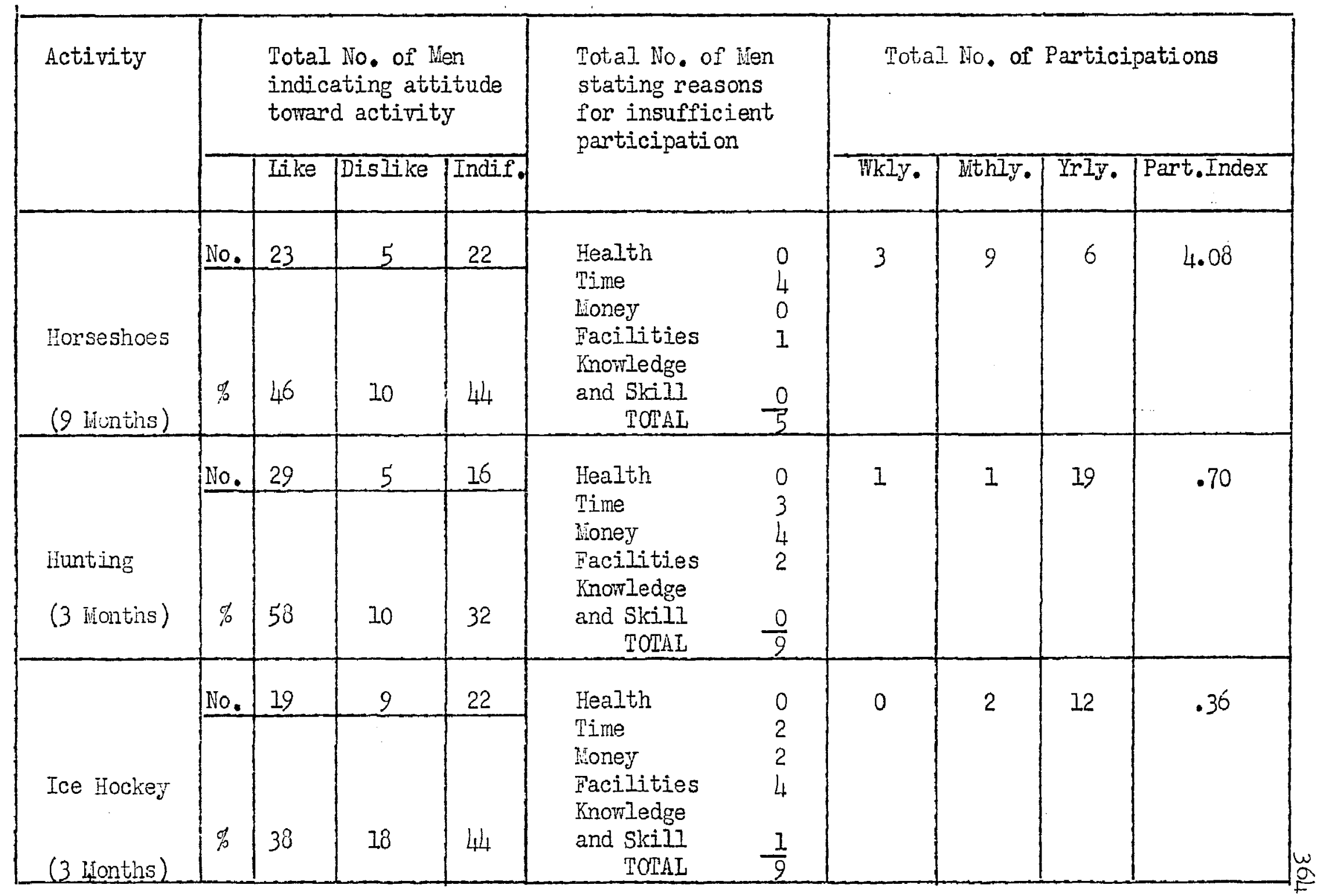


TABIL 32 (Continued)

$\$ 2,000-\$ 3,000$ Income Group

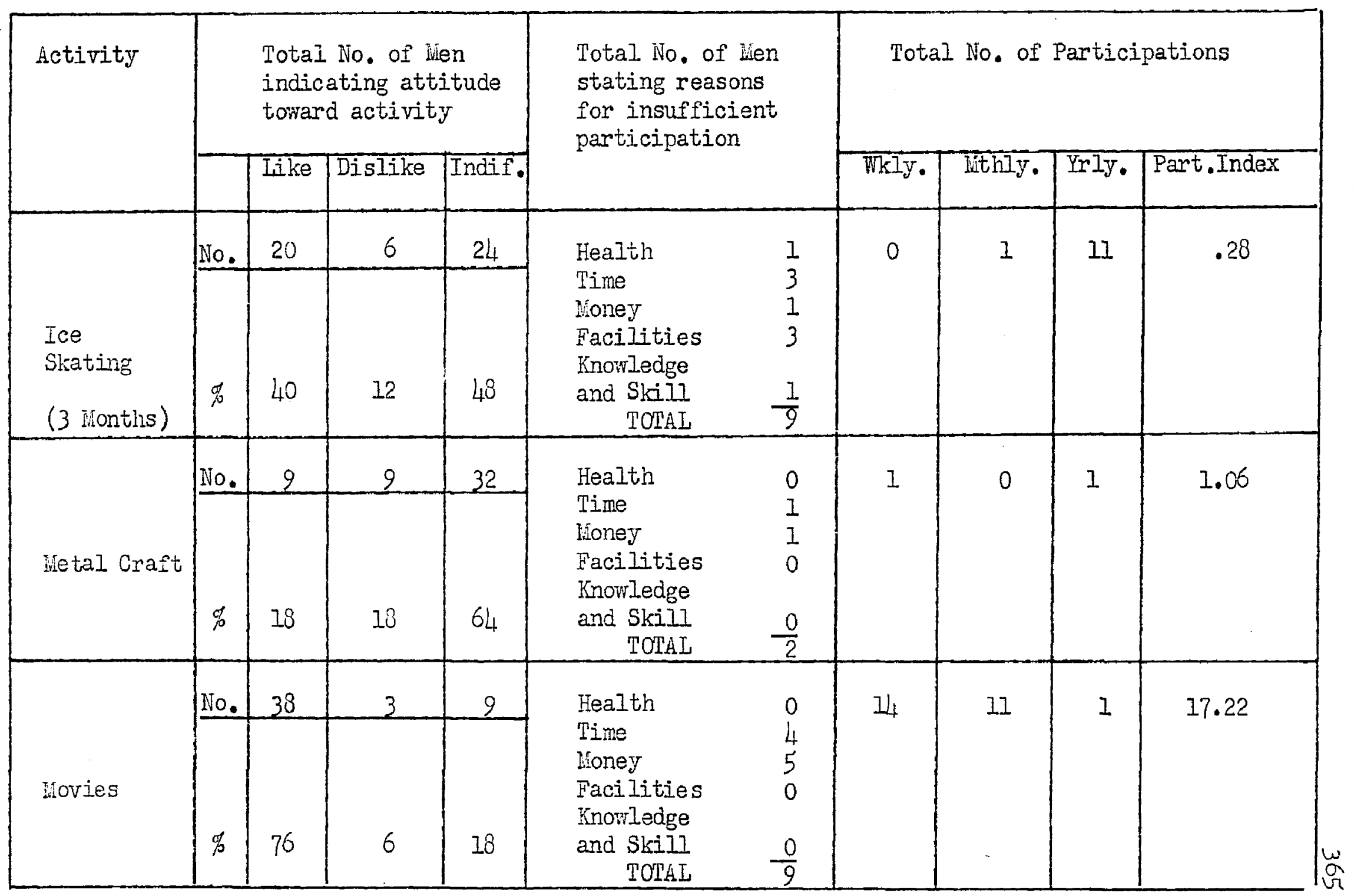


TABLi' 32 (Contimued)

32,000-33,000 Income Group

\begin{tabular}{|c|c|c|c|c|c|c|c|c|c|c|}
\hline \multirow[t]{2}{*}{ Activity } & \multicolumn{4}{|c|}{$\begin{array}{l}\text { Total No. of lien } \\
\text { indicating attitude } \\
\text { toward activity }\end{array}$} & \multirow{2}{*}{\multicolumn{2}{|c|}{$\begin{array}{l}\text { Total Ho. of riven } \\
\text { stating reasons } \\
\text { for insufficient } \\
\text { participation }\end{array}$}} & \multicolumn{4}{|c|}{ Total No. of Participations } \\
\hline & & Like & Dislike & Indif. & & & WKIy• & lithlye & Irly. & Part. Index \\
\hline \multirow[b]{2}{*}{ Music } & No. & 36 & I & 13 & \multirow{2}{*}{$\begin{array}{l}\text { Heal th } \\
\text { Time } \\
\text { Money } \\
\text { Facilities } \\
\text { Knowledge } \\
\text { and Skill } \\
\text { TomL } \\
\end{array}$} & \multirow{2}{*}{$\begin{array}{l}0 \\
1 \\
2 \\
0 \\
0 \\
3\end{array}$} & \multirow[t]{2}{*}{19} & \multirow[t]{2}{*}{0} & \multirow[t]{2}{*}{2} & \multirow[t]{2}{*}{19.80} \\
\hline & 菏 & 72 & 2 & 26 & & & & & & \\
\hline \multirow[b]{2}{*}{ Motoring } & No. & 32 & 4 & 14 & \multirow{2}{*}{$\begin{array}{l}\text { Health } \\
\text { Tine } \\
\text { Money } \\
\text { Facilities } \\
\text { Knowled } \\
\text { and Skill } \\
\text { ToTd } \\
\end{array}$} & 0 & \multirow[t]{2}{*}{25} & \multirow[t]{2}{*}{3} & \multirow[t]{2}{*}{1} & \multirow[t]{2}{*}{26.74} \\
\hline & $\%$ & 64 & 8 & 23 & & $\begin{array}{l}1 \\
2 \\
1 \\
0 \\
4 \\
\end{array}$ & & & & \\
\hline \multirow[b]{2}{*}{$\begin{array}{l}\text { Night } \\
\text { Clubbing }\end{array}$} & No. & 24 & 4 & 22 & \multirow{2}{*}{$\begin{array}{l}\text { Health } \\
\text { Tine } \\
\text { Money } \\
\text { Facilities } \\
\text { Knowledge } \\
\text { and Skill } \\
\quad \text { TOTAL } \\
\end{array}$} & 0 & \multirow[t]{2}{*}{11} & \multirow[t]{2}{*}{4} & \multirow[t]{2}{*}{4} & \multirow[t]{2}{*}{12.48} \\
\hline & $\not B$ & 48 & 8 & 44 & & $\begin{array}{r}10 \\
0 \\
0 \\
12 \\
\end{array}$ & & & & \\
\hline
\end{tabular}


TABIE 32 (Continued)

$\$ 2,000-\$ 3,000$ Income Croup

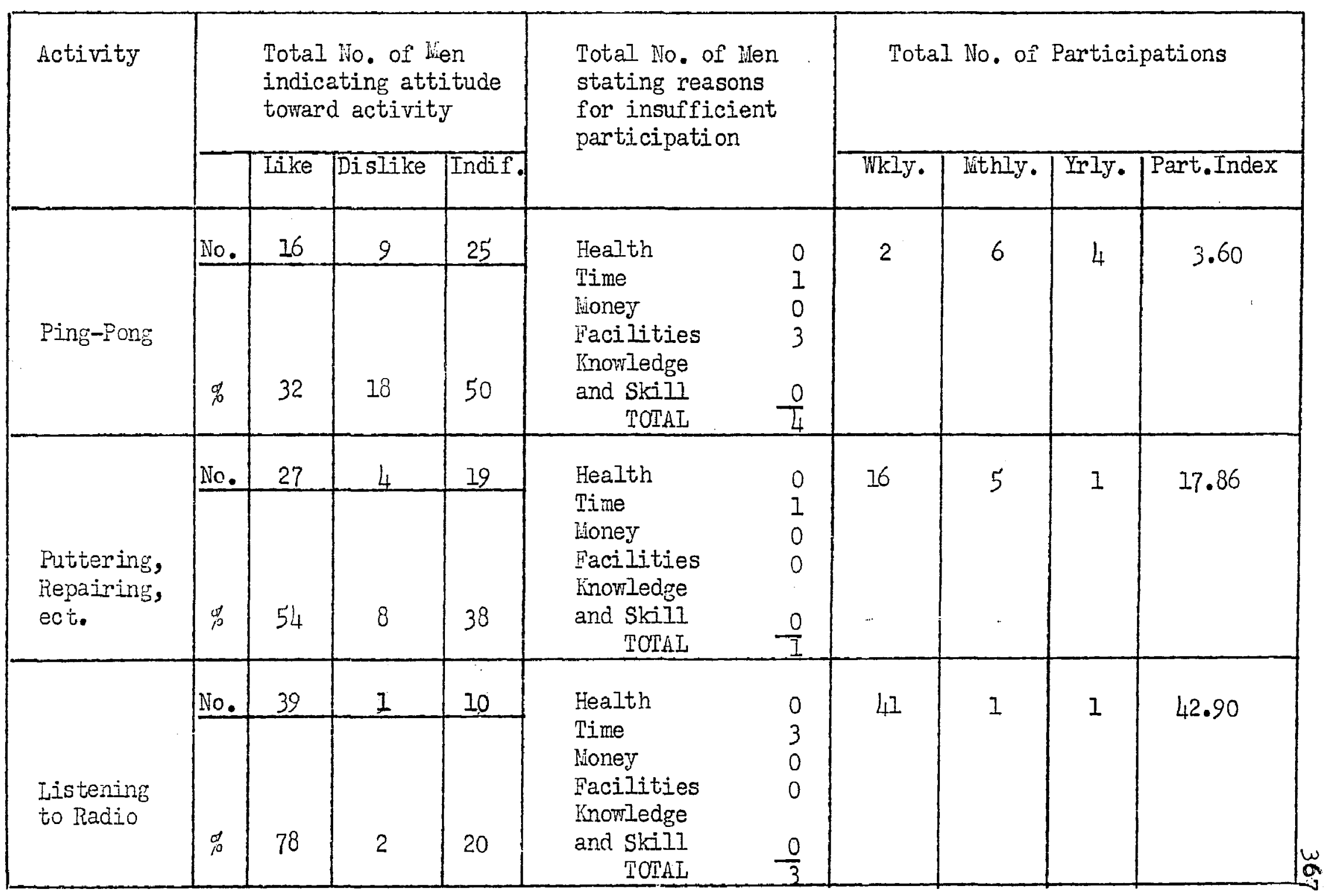


TABLE 32 (Continued)

家2,000-3,000 Income Group

\begin{tabular}{|c|c|c|c|c|c|c|c|c|c|c|}
\hline \multirow[t]{2}{*}{ Activity } & \multicolumn{4}{|c|}{$\begin{array}{l}\text { Total iNo. of lien } \\
\text { indicating attitude } \\
\text { toward activity }\end{array}$} & \multirow{2}{*}{\multicolumn{2}{|c|}{$\begin{array}{l}\text { Total No. of flen } \\
\text { stating reasons } \\
\text { for insufficient } \\
\text { participation }\end{array}$}} & \multicolumn{4}{|c|}{ Total No. of Participations } \\
\hline & & Like & Dislike & Indif. & & & Wkly. & Iithly. & Irly. & Part.Index \\
\hline Watcining TV & No. & 44 & 1 & 5 & $\begin{array}{l}\text { Health } \\
\text { Time } \\
\text { Nioney } \\
\text { Facilities } \\
\text { Knowledge } \\
\text { and Skill } \\
\quad \text { TOTAI } \\
\end{array}$ & $\begin{array}{l}0 \\
3 \\
0 \\
0\end{array}$ & 54 & 1 & 0 & 56.40 \\
\hline Reading & No. & 30 & 10 & 15 & $\begin{array}{l}\text { Health } \\
\text { Time } \\
\text { Ifoney } \\
\text { Facilities } \\
\text { Knowledge } \\
\text { and Skill } \\
\quad \text { TOTAL } \\
\end{array}$ & $\begin{array}{l}0 \\
4 \\
0 \\
0\end{array}$ & 19 & 5 & 1 & 20.98 \\
\hline Photography & No. & 23 & 4 & 64 & $\begin{array}{l}\text { Health } \\
\text { Time } \\
\text { lioney } \\
\text { Facilities } \\
\text { Knowledge } \\
\text { and Skill } \\
\quad \text { TOTAI }\end{array}$ & $\begin{array}{l}0 \\
2\end{array}$ & 5 & 6 & 5 & 6.74 \\
\hline
\end{tabular}


TABLE 32 (Continued)

$\$ 2,000-\$ 3,000$ Income Group

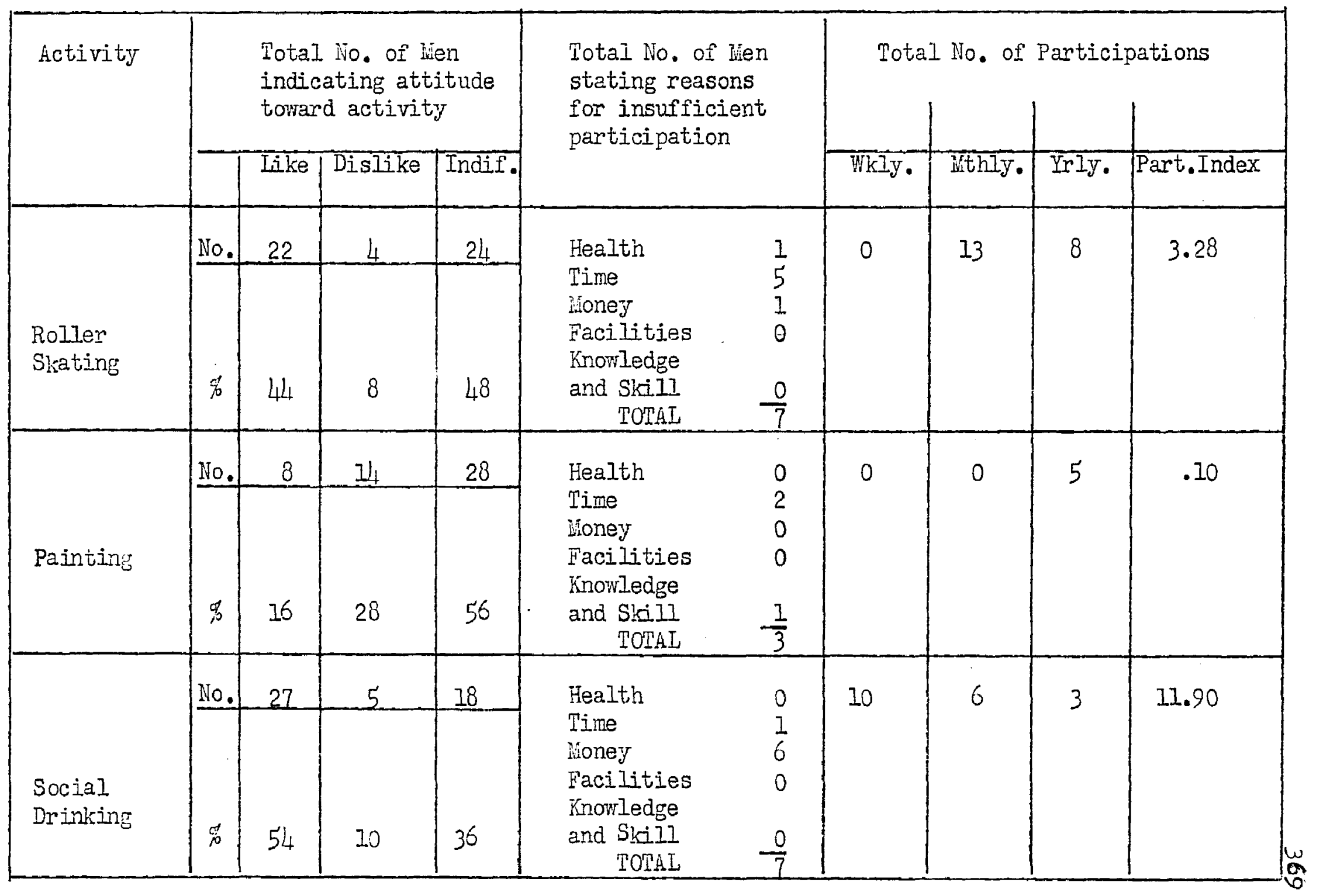


TABLE 32 (Continued)

$\$ 2,000-\$ 3,000$ Income Group

\begin{tabular}{|c|c|c|c|c|c|c|c|c|c|c|}
\hline \multirow[t]{2}{*}{ Activity } & & \multicolumn{3}{|c|}{$\begin{array}{l}\text { Total No. of lien } \\
\text { indicating attitude } \\
\text { toward activity }\end{array}$} & \multirow{2}{*}{\multicolumn{2}{|c|}{$\begin{array}{l}\text { Total io. of ben } \\
\text { stating reasons } \\
\text { for insufficient } \\
\text { participation }\end{array}$}} & \multicolumn{4}{|c|}{ Total No. of Participations } \\
\hline & & Iijke & Disilike & Indif. & & & Wkly. & lithly. & Yrly. & Part.Index \\
\hline $\begin{array}{l}\text { Sailing } \\
\text { (5 Honths) }\end{array}$ & No. & 10 & 16 & 32 & $\begin{array}{l}\text { Health } \\
\text { Time } \\
\text { Noney } \\
\text { Facilities } \\
\text { Knowledge } \\
\text { and Skil1 } \\
\quad \text { TOTAI } \\
\end{array}$ & $\begin{array}{l}0 \\
2 \\
2 \\
2 \\
0 \\
6 \\
\end{array}$ & 1 & 1 & 5 & .63 \\
\hline $\begin{array}{l}\text { Skiin: } \\
\text { (3 Honths) }\end{array}$ & No. & 18 & 12 & 58 & $\begin{array}{l}\text { Health } \\
\text { Time } \\
\text { Honey } \\
\text { Facilities } \\
\text { Knorledge } \\
\text { and Skill } \\
\quad \text { Total } \\
\end{array}$ & $\begin{array}{l}0 \\
0 \\
0 \\
4 \\
\frac{1}{5}\end{array}$ & 0 & 2 & 4 & .20 \\
\hline $\begin{array}{l}\text { Social } \\
D_{a} \text { ncing }\end{array}$ & No. & 26 & 4. & 40 & $\begin{array}{l}\text { Health } \\
\text { Time } \\
\text { Loney } \\
\text { Facilities } \\
\text { Wromledge } \\
\text { and Skill } \\
\text { TOTAL }\end{array}$ & $\begin{array}{l}0 \\
1 \\
6 \\
0 \\
0 \\
\frac{0}{7}\end{array}$ & 2 & 12 & 6 & 5.08 \\
\hline
\end{tabular}


TABLE 32 (Continued)

$\$ 2,000-\$ 3,000$ Income Group

\begin{tabular}{|c|c|c|c|c|c|c|c|c|c|c|}
\hline \multirow[t]{2}{*}{ Activity } & & \multicolumn{3}{|c|}{$\begin{array}{l}\text { Total No. of lien } \\
\text { indicating attitude } \\
\text { toward activity }\end{array}$} & \multirow{2}{*}{\multicolumn{2}{|c|}{$\begin{array}{l}\text { Total No. of ilen } \\
\text { stating reasons } \\
\text { for insufficient } \\
\text { participation }\end{array}$}} & \multicolumn{4}{|c|}{ Total No. of Participations } \\
\hline & & Iike & Dislike & Indif. & & & WkIJ. & Inthly. & Yrly. & Part.Index \\
\hline $\begin{array}{l}\text { Softball } \\
\text { (3 Wonths) }\end{array}$ & No. & 29 & 4 & 17 & $\begin{array}{l}\text { Health } \\
\text { Tine } \\
\text { lioney } \\
\text { Facilities } \\
\text { Knowledge } \\
\text { and Skill } \\
\quad \text { TOTAL } \\
\end{array}$ & $\begin{array}{l}0 \\
7 \\
1 \\
1\end{array}$ & 4 & 7 & 7 & 1.60 \\
\hline $\begin{array}{l}\text { Speedball } \\
\text { (3 lionths) }\end{array}$ & No. & 16 & 16 & 34 & $\begin{array}{l}\text { Health } \\
\text { Time } \\
\text { Ihoney } \\
\text { Facilities } \\
\text { Knowledge } \\
\text { and Skill } \\
\quad \text { TOTAI } \\
\end{array}$ & $\begin{array}{l}0 \\
5 \\
1 \\
0\end{array}$ & 1 & 3 & 3 & .50 \\
\hline $\begin{array}{l}\text { Square } \\
\text { Dancing }\end{array}$ & No. & 10 & 12 & 56 & $\begin{array}{l}\text { Health } \\
\text { Time } \\
\text { Woney } \\
\text { Facilities } \\
\text { Knowledge } \\
\text { and Slill } \\
\quad \text { TCRAL }\end{array}$ & $\begin{array}{l}0 \\
2 \\
0 \\
2\end{array}$ & 0 & 0 & 3 & .06 \\
\hline
\end{tabular}



TABIE 32 (Continued)

$\$ 2,000-33,000$ Income Group

\begin{tabular}{|c|c|c|c|c|c|c|c|c|c|c|}
\hline \multirow[t]{2}{*}{ Activity } & \multicolumn{4}{|c|}{$\begin{array}{l}\text { Total No. of lien } \\
\text { indicating attitude } \\
\text { towerd activity }\end{array}$} & \multirow{2}{*}{\multicolumn{2}{|c|}{$\begin{array}{l}\text { Total No. of lien } \\
\text { stating reasons } \\
\text { for insuficicient } \\
\text { participation }\end{array}$}} & \multicolumn{4}{|c|}{ Total No. of Participations } \\
\hline & & Lilre & Dislike & Indf. & & & Whly. & Lthy. & Irly. & Part. Index \\
\hline \multirow[b]{2}{*}{ Tumbling } & No. & 3 & 12 & 35 & \multirow{2}{*}{$\begin{array}{l}\text { Heal ih } \\
\text { Time } \\
\text { Honey } \\
\text { Facilities } \\
\text { Fnowledge } \\
\text { and Skill } \\
\quad \text { TOTAI } \\
\end{array}$} & \multirow{2}{*}{$\begin{array}{l}0 \\
1 \\
0 \\
1 \\
0 \\
\end{array}$} & \multirow[t]{2}{*}{1} & \multirow[t]{2}{*}{0} & \multirow[t]{2}{*}{2} & \multirow[t]{2}{*}{1.08} \\
\hline & $\stackrel{q}{p}$ & 6 & 24 & 70 & & & & & & \\
\hline \multirow[b]{2}{*}{$\begin{array}{l}\text { Visiting } \\
\text { Friends }\end{array}$} & No. & 35 & 1 & $\underline{I}_{4}$ & \multirow{2}{*}{$\begin{array}{l}\text { Health } \\
\text { Tine } \\
\text { Honey } \\
\text { Facilities } \\
\text { Knowledge } \\
\text { and Skill } \\
\text { TOTAL }\end{array}$} & \multirow{2}{*}{$\begin{array}{l}0 \\
3 \\
0 \\
0 \\
0 \\
3\end{array}$} & \multirow[t]{2}{*}{20} & \multirow[t]{2}{*}{5} & \multirow[t]{2}{*}{1} & \multirow[t]{2}{*}{22.02} \\
\hline & 落 & 70 & 2 & 28 & & & & & & \\
\hline \multirow[b]{2}{*}{ Volleyball } & No. & $\underline{14}$ & 7 & 29 & \multirow{2}{*}{\multicolumn{2}{|c|}{$\begin{array}{l}\text { Health } \\
\text { Time } \\
\text { Money } \\
\text { Tacilities } \\
\text { Knowledge } \\
\text { and Skill } \\
\quad \text { TOTAL }\end{array}$}} & \multirow[t]{2}{*}{0} & \multirow[t]{2}{*}{3} & \multirow[t]{2}{*}{5} & \multirow[t]{2}{*}{.82} \\
\hline & 8 & 23 & 14 & 58 & & & & & & \\
\hline
\end{tabular}


TÁBLE 32 (Continued)

$\$ 2,000-\$ 3,000$ Income Croup

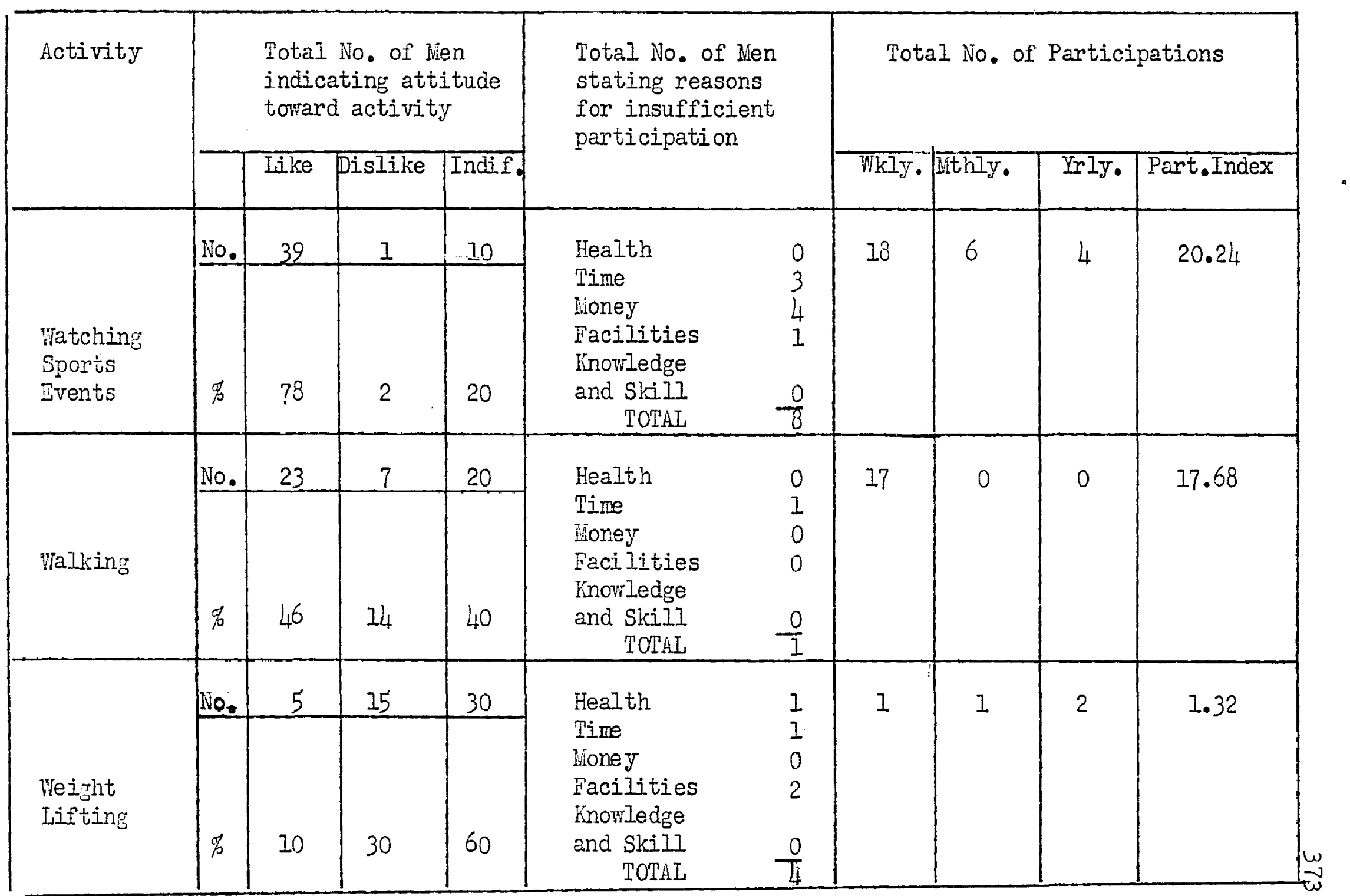


TABLA 32 (Conti nued)

$\$ 2,000-\$ 3,000$ Income Group

\begin{tabular}{|c|c|c|c|c|c|c|c|c|c|c|}
\hline \multirow[t]{3}{*}{ Activity } & & \multirow{2}{*}{\multicolumn{3}{|c|}{$\begin{array}{l}\text { Total No. of lien } \\
\text { indicating attitude } \\
\text { torard activity }\end{array}$}} & \multirow{3}{*}{\multicolumn{2}{|c|}{$\begin{array}{l}\text { Total No, of lien } \\
\text { stating reasons } \\
\text { for insufficient } \\
\text { participation }\end{array}$}} & \multicolumn{4}{|c|}{ Total No. of Participations } \\
\hline & & & & & & & \multirow[t]{2}{*}{ Wkly. } & \multirow[t]{2}{*}{ lithly. } & \multirow{2}{*}{$\operatorname{Tr} \mathrm{ly}_{0}$} & \multirow[t]{2}{*}{ Part.Index } \\
\hline & & Like & Dislike & Indif. & & & & & & \\
\hline \multirow[b]{2}{*}{ Water Polo } & No. & 1 & 13 & 36 & \multirow{2}{*}{$\begin{array}{l}\text { Health } \\
\text { Time } \\
\text { Mioney } \\
\text { Facilities } \\
\text { Inowlledge } \\
\text { and Skill } \\
\text { TOTAL }\end{array}$} & \multirow{2}{*}{$\begin{array}{l}0 \\
0 \\
0 \\
0 \\
0 \\
0\end{array}$} & \multirow[t]{2}{*}{0} & \multirow[t]{2}{*}{0} & \multirow[t]{2}{*}{0} & \multirow[t]{2}{*}{.00} \\
\hline & $\%$ & 2 & 26 & 72 & & & & & & \\
\hline \multirow[b]{2}{*}{ Woodworking } & No. & 16 & 8 & 26 & \multirow{2}{*}{$\begin{array}{l}\text { Health } \\
\text { Time } \\
\text { Honey } \\
\text { Facilities } \\
\text { Knowledge } \\
\text { and Skili } \\
\quad \text { TOTAL } \\
\end{array}$} & \multirow[b]{2}{*}{$\begin{array}{l}0 \\
3 \\
1 \\
0 \\
\\
2 \\
6 \\
\end{array}$} & \multirow[t]{2}{*}{3} & \multirow[t]{2}{*}{5} & \multirow[t]{2}{*}{2} & \multirow[t]{2}{*}{$4 \cdot 36$} \\
\hline & $\mathscr{f}_{0}$ & 32 & Ió & 52 & & & & & & \\
\hline \multirow[b]{2}{*}{$\begin{array}{l}\text { Wood } \\
\text { Carving }\end{array}$} & No. & $5-$ & 11 & 34 & \multirow{2}{*}{$\begin{array}{l}\text { Health } \\
\text { Time } \\
\text { lioney } \\
\text { Facilities } \\
\text { Inowledge } \\
\text { and Skill } \\
\quad \text { TOTAL }\end{array}$} & \multirow{2}{*}{$\begin{array}{l}0 \\
0 \\
0 \\
0\end{array}$} & \multirow[t]{2}{*}{1} & \multirow[t]{2}{*}{1} & \multirow[t]{2}{*}{0} & \multirow[t]{2}{*}{1.28} \\
\hline & $\%$ & 10 & 22 & 68 & & & & & & \\
\hline
\end{tabular}


TABIE 32 (Continued)

\$2,000-\$3,000 Income Group

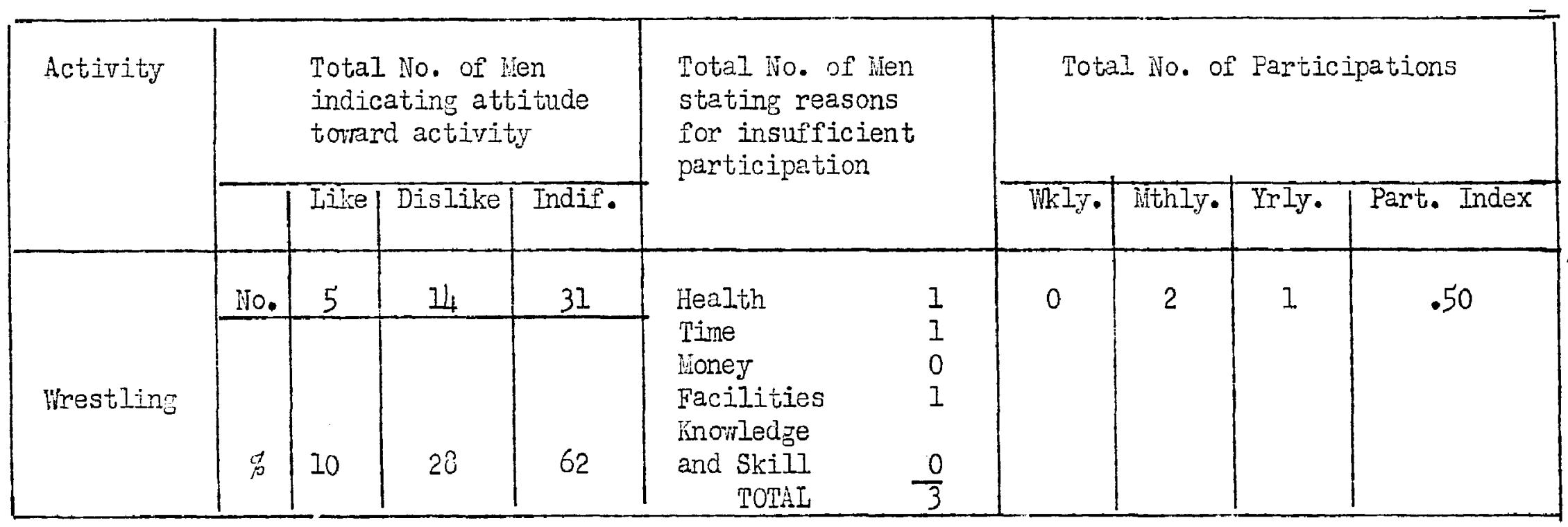

\section{REASOIS :}

$\begin{array}{lrr}\text { Health } & 21 & -4.8 \% \\ \text { Time } & 214 & -48.7 \% \\ \text { Honey } & 86 & -19.6 \% \\ \text { Facilities } & 95 & -21.6 \% \\ \text { Knowledge and Skill } & 23 & -5.2 \%\end{array}$


Numbers and Fercentages of Hen Iiking, Disliking, and Indifferent to Each of Sixty-Seven Recreational Activities, Extent of Participition in Each, and Number of Men Listing Each of Five Reasons for Insatisfactory Participation in the $\$ 3,000-\$ 4,000$ Income Group

\begin{tabular}{|c|c|c|c|c|c|c|c|c|c|c|}
\hline \multirow[t]{2}{*}{ Activity } & \multicolumn{4}{|c|}{$\begin{array}{l}\text { Total No, of Men } \\
\text { indicating attitude } \\
\text { toward activity }\end{array}$} & \multirow{2}{*}{\multicolumn{2}{|c|}{$\begin{array}{l}\text { Total No. of Men } \\
\text { stating reasons } \\
\text { for insufficient } \\
\text { participation }\end{array}$}} & \multicolumn{4}{|c|}{ Total No. of Participations } \\
\hline & & Iike & Dislike & Indif. & & & whly. & Inthly. & IrIyn. & Part. Index \\
\hline Archery & No. & $\begin{array}{l}38 \\
21.0\end{array}$ & 18.1 & $\begin{array}{l}111 \\
60.9\end{array}$ & $\begin{array}{l}\text { Health } \\
\text { Time } \\
\text { Honey } \\
\text { Facilities } \\
\text { rnowledge } \\
\text { and Skill } \\
\text { TOTAI } \\
\end{array}$ & $\begin{array}{r}0 \\
19 \\
4 \\
12 \\
\frac{4}{30} \\
\end{array}$ & 0 & 8 & 17 & .62 \\
\hline \multirow[b]{2}{*}{ Badminton } & No. & 68 & 21 & 93 & \multirow{2}{*}{$\begin{array}{l}\text { Wealth } \\
\text { Time } \\
\text { Money } \\
\text { Facilities } \\
\text { Knowledge } \\
\text { and Skill } \\
\quad \text { TOTAI } \\
\end{array}$} & 0 & \multirow[t]{2}{*}{11} & \multirow[t]{2}{*}{25} & \multirow[t]{2}{*}{43} & \multirow[t]{2}{*}{5.03} \\
\hline & $c p$ & 37.4 & 11.4 & 51.2 & & $\begin{array}{r}1 \\
15 \\
\frac{2}{40}\end{array}$ & & & & \\
\hline
\end{tabular}


TABIE 33 (Contimed)

$\$ 3,000-\$ 4,000$ Income Croup

\begin{tabular}{|c|c|c|c|c|c|c|c|c|c|c|}
\hline \multirow[t]{2}{*}{ Activity } & \multicolumn{4}{|c|}{$\begin{array}{l}\text { Total No. of lien } \\
\text { indicating attitude } \\
\text { toward activity }\end{array}$} & \multirow{2}{*}{\multicolumn{2}{|c|}{$\begin{array}{l}\text { Total No. of lien } \\
\text { stating reasons } \\
\text { for insufficient } \\
\text { participation }\end{array}$}} & \multicolumn{4}{|c|}{ Total No. of Participations } \\
\hline & & Iike & Dislike & Indif. & & & Wkly. & lithly. & Yrly. & Part.Index \\
\hline \multirow[b]{2}{*}{$\begin{array}{l}\text { Bag } \\
\text { Punching }\end{array}$} & No. & 28 & 39 & 115 & \multirow{2}{*}{$\begin{array}{l}\text { Health } \\
\text { Time } \\
\text { lioney } \\
\text { Facilities } \\
\text { Knorledge } \\
\text { and Skill } \\
\quad \text { TOTAL } \\
\end{array}$} & \multirow{2}{*}{$\begin{array}{r}1 \\
11 \\
1 \\
5 \\
\frac{1}{19}\end{array}$} & \multirow[t]{2}{*}{2} & \multirow[t]{2}{*}{7} & \multirow[t]{2}{*}{12} & \multirow[t]{2}{*}{1.09} \\
\hline & $\%$ & 15.4 & 21.3 & 63.3 & & & & & & \\
\hline \multirow[b]{2}{*}{$\begin{array}{l}\text { Baseball } \\
\text { (3 Months) }\end{array}$} & No. & 161 & 2 & 19 & \multirow{2}{*}{$\begin{array}{l}\text { Health } \\
\text { Time } \\
\text { IFoney } \\
\text { Facilities } \\
\text { Knowledge } \\
\text { and Skill } \\
\text { TOTAL } \\
\end{array}$} & \multirow{2}{*}{$\begin{array}{r}9 \\
49 \\
6 \\
2 \\
\frac{1}{67} \\
\end{array}$} & \multirow[t]{2}{*}{49} & \multirow[t]{2}{*}{29} & \multirow[t]{2}{*}{63} & \multirow[t]{2}{*}{$4 \cdot 32$} \\
\hline & $\not 8$ & 88.5 & 1.1 & 10.4 & & & & & & \\
\hline \multirow[b]{2}{*}{$\begin{array}{l}\text { Basketball } \\
\text { (6 Months) }\end{array}$} & No. & 82 & 20 & 80 & \multirow{2}{*}{$\begin{array}{l}\text { Health } \\
\text { Time } \\
\text { Woney } \\
\text { Facilities } \\
\text { Knowledge } \\
\text { and Skill } \\
\text { TOTAL } \\
\end{array}$} & \multirow{2}{*}{$\begin{array}{r}7 \\
31 \\
2 \\
7 \\
\frac{2}{49} \\
\end{array}$} & \multirow[t]{2}{*}{6} & \multirow[t]{2}{*}{11} & \multirow[t]{2}{*}{50} & \multirow[t]{2}{*}{1.49} \\
\hline & $\%$ & 45.1 & 11.0 & 43.9 & & & & & & \\
\hline
\end{tabular}


TABIE 33 (Continued)

33,000-\$, 4,000 Income Group

\begin{tabular}{|c|c|c|c|c|c|c|c|c|c|c|}
\hline \multirow[t]{2}{*}{ Activity } & & \multicolumn{3}{|c|}{$\begin{array}{l}\text { Total Ho. of lien } \\
\text { indicating attitude } \\
\text { toward activity }\end{array}$} & \multirow{2}{*}{\multicolumn{2}{|c|}{$\begin{array}{l}\text { Total No. of nen } \\
\text { stating reasons } \\
\text { for insufficient } \\
\text { participation }\end{array}$}} & \multicolumn{4}{|c|}{ Total No. of Participations } \\
\hline & & Iike & Dislike & Indif. & & & Wkly. & MithIy. & Yrly. & Part. Index \\
\hline \multirow[b]{2}{*}{$\begin{array}{l}\text { Bicycling } \\
\text { (8 Months) }\end{array}$} & Ho. & 55 & 17 & 110 & \multirow{2}{*}{$\begin{array}{l}\text { Health } \\
\text { Time } \\
\text { ironey } \\
\text { Facilities } \\
\text { Knowledge } \\
\text { and Skill } \\
\quad \text { TOTAL } \\
\end{array}$} & \multirow{2}{*}{$\begin{array}{r}3 \\
19 \\
1 \\
7 \\
1 \\
\\
\end{array}$} & \multirow[t]{2}{*}{8} & \multirow[t]{2}{*}{ I4 } & \multirow[t]{2}{*}{27} & \multirow[t]{2}{*}{2.30} \\
\hline & $\%$ & 30.3 & 9.3 & 60.4 & & & & & & \\
\hline \multirow[b]{2}{*}{$\begin{array}{l}\text { Boatins } \\
\text { (5 Honths) }\end{array}$} & No. & 84 & 13 & 85 & \multirow{2}{*}{$\begin{array}{l}\text { Health } \\
\text { Time } \\
\text { lioney } \\
\text { Facilities } \\
\text { Knowledge } \\
\text { and Skill } \\
\quad \text { TCT!L } \\
\end{array}$} & \multirow{2}{*}{$\begin{array}{r}2 \\
20 \\
11 \\
6 \\
\frac{1}{40} \\
\end{array}$} & \multirow[t]{2}{*}{17} & \multirow[t]{2}{*}{13} & \multirow[t]{2}{*}{153} & \multirow[t]{2}{*}{3.22} \\
\hline & 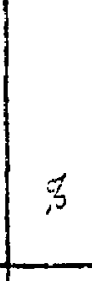 & 46.2 & 7.1 & 46.7 & & & & & & \\
\hline \multirow[b]{2}{*}{$\begin{array}{l}\text { Jorling } \\
\text { (9 Months) }\end{array}$} & No. & 125 & 16 & 41 & \multirow{2}{*}{$\begin{array}{l}\text { Health } \\
\text { Time } \\
\text { Woney } \\
\text { Facilities } \\
\text { Knowledge } \\
\text { and Skill } \\
\text { TOTAL }\end{array}$} & \multirow{2}{*}{$\begin{array}{l}1 \\
25 \\
14 \\
1 \\
\frac{1}{42}\end{array}$} & \multirow[t]{2}{*}{51} & \multirow[t]{2}{*}{32} & \multirow[t]{2}{*}{62} & \multirow[t]{2}{*}{4.51} \\
\hline & 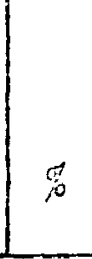 & 68.7 & 8.8 & 22.5 & & & & & & \\
\hline
\end{tabular}


TABIE 33 (Continued)

$33,000-\$ 4,000$ Income Group

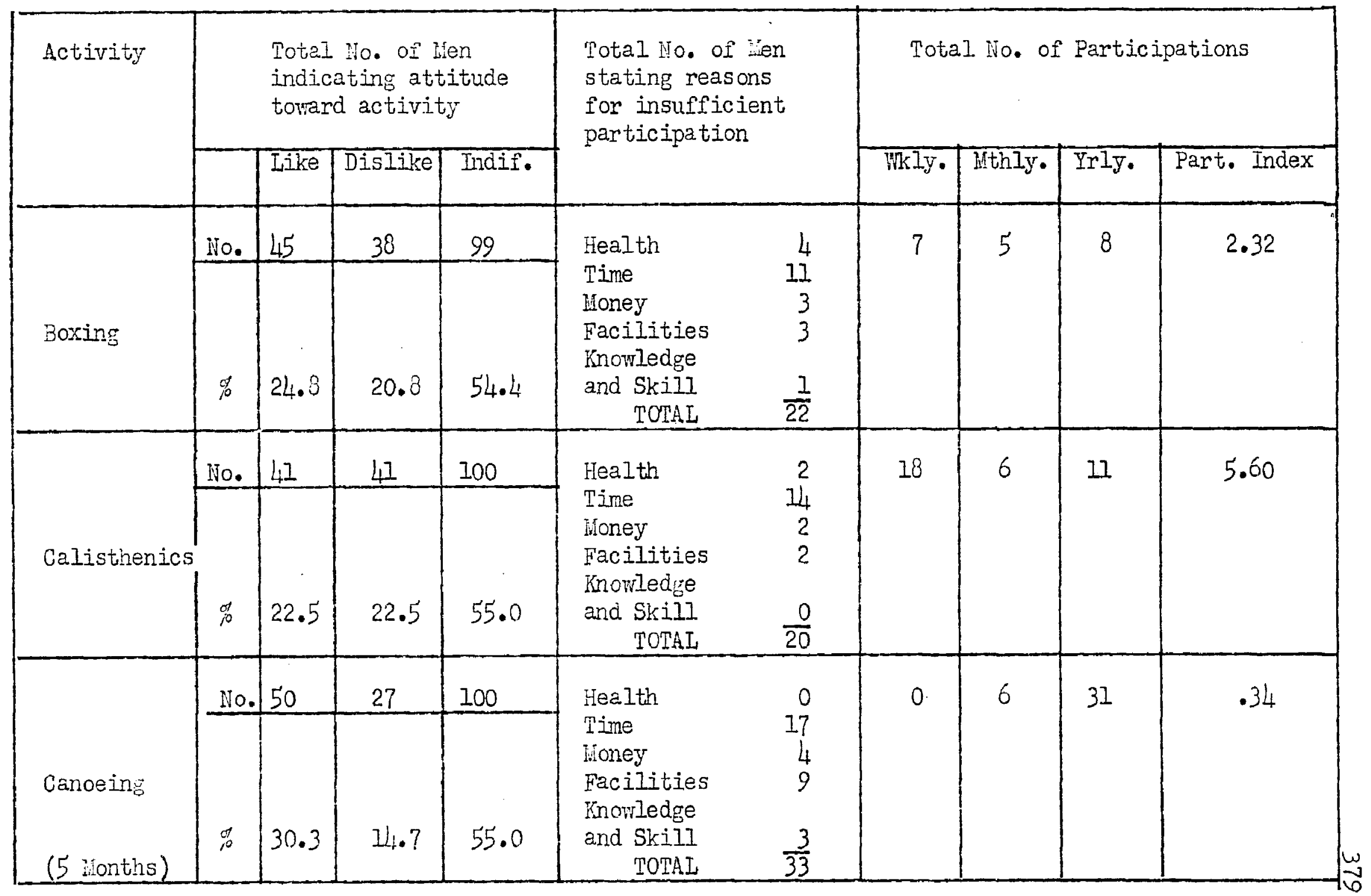


TAEIE 33 (Continued)

$\$ 3,000-\$ 4,000$ Income Group

\begin{tabular}{|c|c|c|c|c|c|c|c|c|c|c|}
\hline \multirow[t]{2}{*}{ Activity } & & \multicolumn{3}{|c|}{$\begin{array}{l}\text { Total No. of Men } \\
\text { indicating attitude } \\
\text { toward activity }\end{array}$} & \multirow{2}{*}{\multicolumn{2}{|c|}{$\begin{array}{l}\text { Total No. of lien } \\
\text { stating reasons } \\
\text { for insufficient } \\
\text { participation }\end{array}$}} & \multicolumn{4}{|c|}{ Total No. of Participations } \\
\hline & & Ijke & Dislike & Indif. & & & WkIy. & IithIy. & Yrly. & Part. Index \\
\hline \multirow[b]{2}{*}{$\begin{array}{l}\text { Card } \\
\text { Playing }\end{array}$} & No. & 138 & 12 & 32 & \multirow{2}{*}{$\begin{array}{l}\text { Health } \\
\text { Time } \\
\text { Money } \\
\text { Facilities } \\
\text { Knowledge } \\
\text { and Skill } \\
\quad \text { TOTAL } \\
\end{array}$} & \multirow{2}{*}{$\begin{array}{r}0 \\
21 \\
7 \\
1 \\
\\
0 \\
29 \\
\end{array}$} & \multirow[t]{2}{*}{66} & \multirow[t]{2}{*}{36} & \multirow[t]{2}{*}{81} & \multirow[t]{2}{*}{21.70} \\
\hline & $\stackrel{9}{0}$ & 75.8 & 6.6 & 17.6 & & & & & & \\
\hline \multirow[b]{2}{*}{ Checkers } & No. & 70 & 21 & 91 & \multirow{2}{*}{$\begin{array}{l}\text { Health } \\
\text { Time } \\
\text { joney } \\
\text { Facilities } \\
\text { Knowledge } \\
\text { and Skill } \\
\quad \text { TOTAL } \\
\end{array}$} & 0 & \multirow[t]{2}{*}{11} & \multirow[t]{2}{*}{21} & \multirow[t]{2}{*}{24} & \multirow[t]{2}{*}{4.66} \\
\hline & $\stackrel{\%}{10}$ & 38.5 & 11.5 & 50.0 & & $\begin{array}{r}1 \\
3 \\
0 \\
26 \\
\end{array}$ & & & & \\
\hline \multirow[b]{2}{*}{ Conversing } & No. & 91 & 12 & 79 & \multirow{2}{*}{$\begin{array}{l}\text { Health } \\
\text { Time } \\
\text { Money } \\
\text { Facilitie } \\
\text { Knowledge } \\
\text { and Skill } \\
\text { ToTAL }\end{array}$} & 0 & \multirow[t]{2}{*}{178} & \multirow[t]{2}{*}{2} & \multirow[t]{2}{*}{6} & \multirow[t]{2}{*}{51.02} \\
\hline & 总 & 50.0 & 6.6 & 43.4 & & $\begin{array}{l}1 \\
0 \\
\frac{2}{11}\end{array}$ & & & & \\
\hline
\end{tabular}


TABLE 33 (Continued)

$\$ 3,000-\$ 4,000$ Income Group

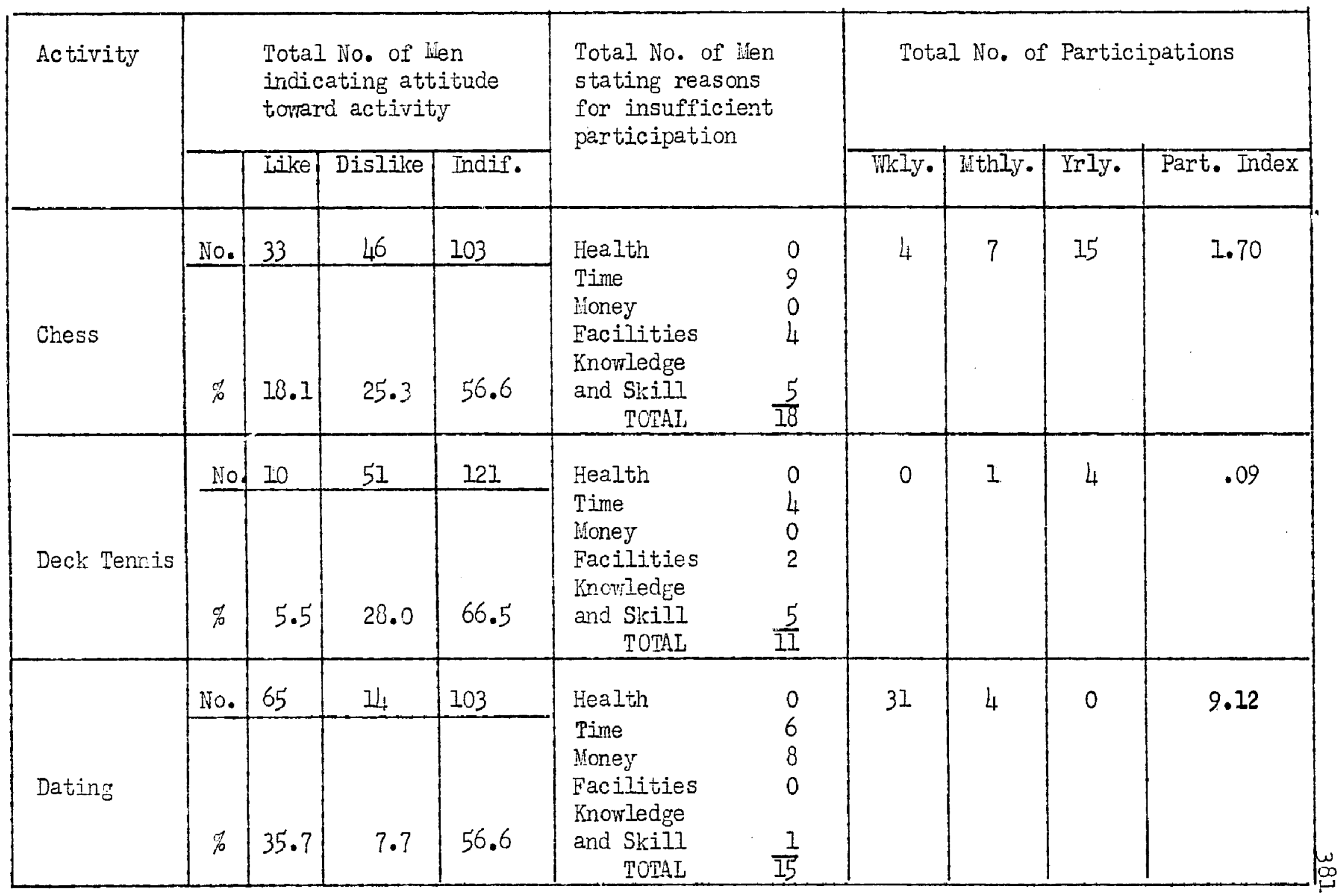


TASIE 33 (Continued)

3,000-\$4,000 Income Group

\begin{tabular}{|c|c|c|c|c|c|c|c|c|c|c|}
\hline \multirow[t]{2}{*}{ Activity } & & \multicolumn{3}{|c|}{$\begin{array}{l}\text { Total No. of inen } \\
\text { indicating attitude } \\
\text { toward activity }\end{array}$} & \multirow{2}{*}{\multicolumn{2}{|c|}{$\begin{array}{l}\text { Total No, of Wen } \\
\text { stating reasons } \\
\text { for insufficient } \\
\text { participation }\end{array}$}} & \multicolumn{4}{|c|}{ Total No. of Participations } \\
\hline & & Iike & Dislike & Indif. & & & Wkly. & listhly. & Yrly. & Part. Index \\
\hline \multirow[b]{2}{*}{ Driving } & No. & 129 & 6 & 47 & \multirow{2}{*}{$\begin{array}{l}\text { Healith } \\
\text { Tine } \\
\text { iloney } \\
\text { Facilities } \\
\text { Knowledge } \\
\text { and Skill } \\
\quad \text { TOTAL } \\
\end{array}$} & \multirow{2}{*}{$\begin{array}{l}0 \\
7 \\
5 \\
1 \\
\\
\frac{1}{14}\end{array}$} & \multirow[t]{2}{*}{166} & \multirow[t]{2}{*}{65} & \multirow[t]{2}{*}{6} & \multirow[t]{2}{*}{51.75} \\
\hline & $\not 8$ & 70.8 & 3.3 & 25.9 & & & & & & \\
\hline \multirow[b]{2}{*}{ Fencing } & No. & 16 & 52 & $171_{4}$ & \multirow{2}{*}{$\begin{array}{l}\text { Health } \\
\text { Time } \\
\text { lisoney } \\
\text { Facilities } \\
\text { Knowledge } \\
\text { and Skill } \\
\quad \text { TOTAL } \\
\end{array}$} & \multirow{2}{*}{$\begin{array}{c}0 \\
4 \\
0 \\
7 \\
\frac{5}{16}\end{array}$} & \multirow[t]{2}{*}{0} & \multirow[t]{2}{*}{1} & \multirow[t]{2}{*}{3} & \multirow[t]{2}{*}{.08} \\
\hline & $c$ & 8.3 & 28.5 & 62.7 & & & & & & \\
\hline \multirow[b]{2}{*}{$\begin{array}{l}\text { Field Events } \\
\text { (Track) } \\
\text { (4 IOnths) }\end{array}$} & No. & 50 & 24 & 108 & \multirow{2}{*}{$\begin{array}{l}\text { Health } \\
\text { Time } \\
\text { Money } \\
\text { Facilities } \\
\text { Knowledge } \\
\text { and Skill } \\
\text { TOTAL }\end{array}$} & \multirow{2}{*}{$\begin{array}{r}5 \\
12 \\
1 \\
3 \\
\frac{2}{23}\end{array}$} & \multirow[t]{2}{*}{1} & \multirow[t]{2}{*}{3} & \multirow[t]{2}{*}{21} & \multirow[t]{2}{*}{.28} \\
\hline & $\%$ & 27.5 & 13.2 & 59.3 & & & & & & \\
\hline
\end{tabular}


TABIE 33 (Continued)

$\$ 3,000-\$ 4,000$ Income Group

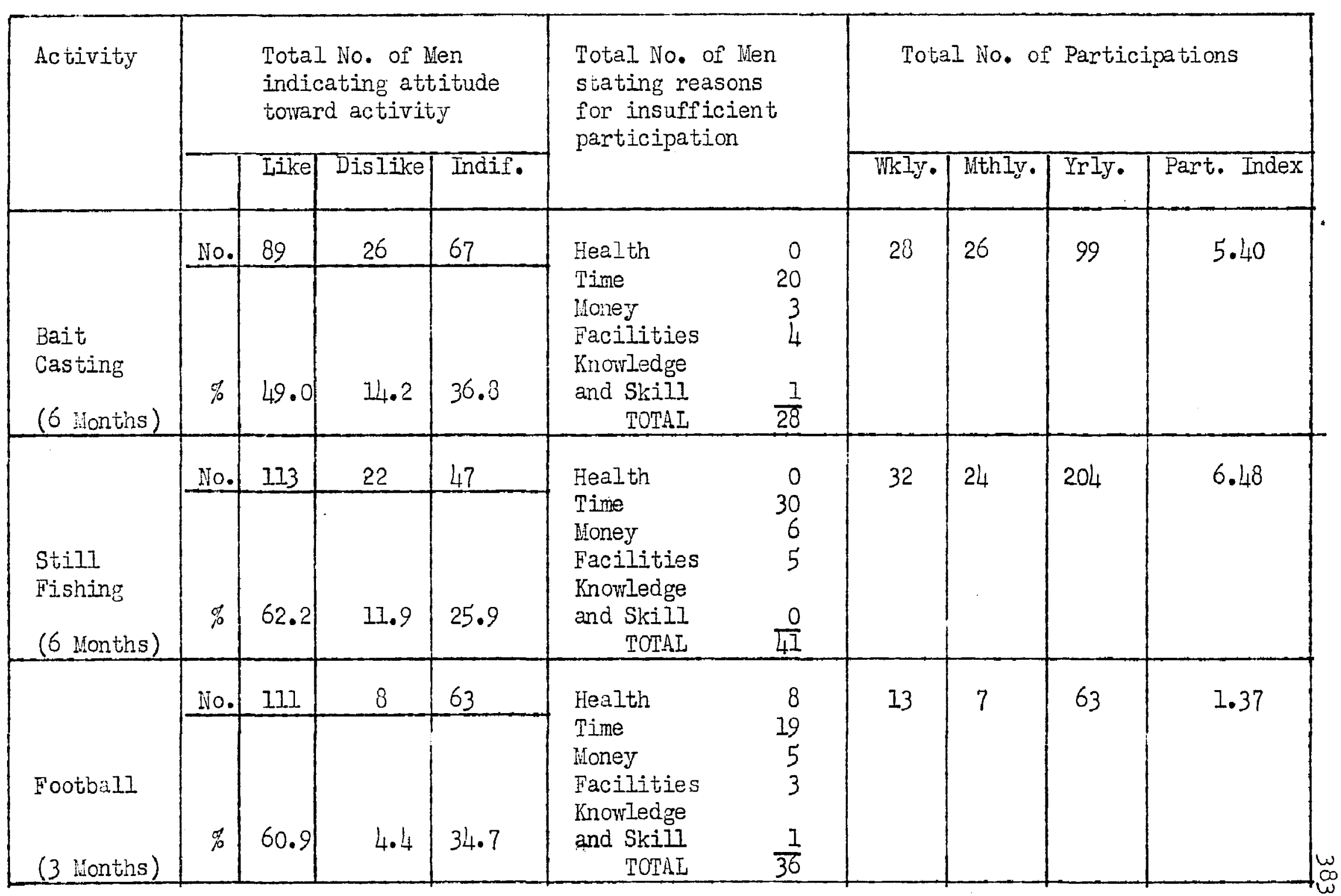


TABLE 33 (Continued)

$\$ 3,000-\$ 4,000$ Income Group

\begin{tabular}{|c|c|c|c|c|c|c|c|c|c|c|}
\hline \multirow[t]{2}{*}{ Activity } & \multicolumn{4}{|c|}{$\begin{array}{l}\text { Total No. of lien } \\
\text { indicating attitude } \\
\text { toward activity }\end{array}$} & \multirow{2}{*}{\multicolumn{2}{|c|}{$\begin{array}{l}\text { Total No. of iven } \\
\text { stating reasons } \\
\text { for insufficient } \\
\text { participation }\end{array}$}} & \multicolumn{4}{|c|}{ Total No. of Participations } \\
\hline & & Like & Dislike & Indif. & & & Wkly. & Wthly. & Irly. & Part. Index \\
\hline \multirow[b]{2}{*}{$\begin{array}{l}\text { Gardening } \\
\text { (5 Months) }\end{array}$} & No. & 108 & 20 & 54 & \multirow{2}{*}{$\begin{array}{l}\text { Health } \\
\text { Time } \\
\text { lloney } \\
\text { Tacilities } \\
\text { Knowledge } \\
\text { and Skill } \\
\quad \text { TOTAI } \\
\end{array}$} & \multirow{2}{*}{$\begin{array}{l}0 \\
9 \\
2 \\
5 \\
0 \\
16 \\
\end{array}$} & \multirow[t]{2}{*}{68} & \multirow[t]{2}{*}{5} & \multirow[t]{2}{*}{104} & \multirow[t]{2}{*}{8.76} \\
\hline & $\%$ & 59.3 & 11.0 & 29.7 & & & & & & \\
\hline \multirow[b]{2}{*}{$\begin{array}{l}\text { Golf } \\
\text { (4 Jionths) }\end{array}$} & No. & 72 & 26 & 84 & \multirow{2}{*}{$\begin{array}{l}\text { Health } \\
\text { Time } \\
\text { Money } \\
\text { Facilities } \\
\text { Knowledge } \\
\text { and Skill } \\
\quad \text { TOTAI } \\
\end{array}$} & \multirow{2}{*}{$\begin{array}{r}1 \\
\frac{14}{14} \\
2 \\
\frac{5}{36}\end{array}$} & \multirow[t]{2}{*}{21} & \multirow[t]{2}{*}{16} & \multirow[t]{2}{*}{40} & \multirow[t]{2}{*}{2.57} \\
\hline & $\%$ & 39.6 & $14 \cdot ?$ & 46.2 & & & & & & \\
\hline \multirow[b]{2}{*}{ Gymastics } & No. & 52 & 29 & 101 & \multirow{2}{*}{$\begin{array}{l}\text { Health } \\
\text { Time } \\
\text { Money } \\
\text { Facilities } \\
\text { Knowledge } \\
\text { and Skill } \\
\quad \text { TOTAI }\end{array}$} & 1 & \multirow[t]{2}{*}{7} & \multirow[t]{2}{*}{8} & \multirow[t]{2}{*}{13} & \multirow[t]{2}{*}{2.59} \\
\hline & $\%$ & 28.5 & 16.1 & 55.4 & & $\begin{array}{r}15 \\
1 \\
4 \\
\frac{1}{22}\end{array}$ & & & & \\
\hline
\end{tabular}


TABIE 33 (Continued)

\%3,000-\$4,000 Income Group

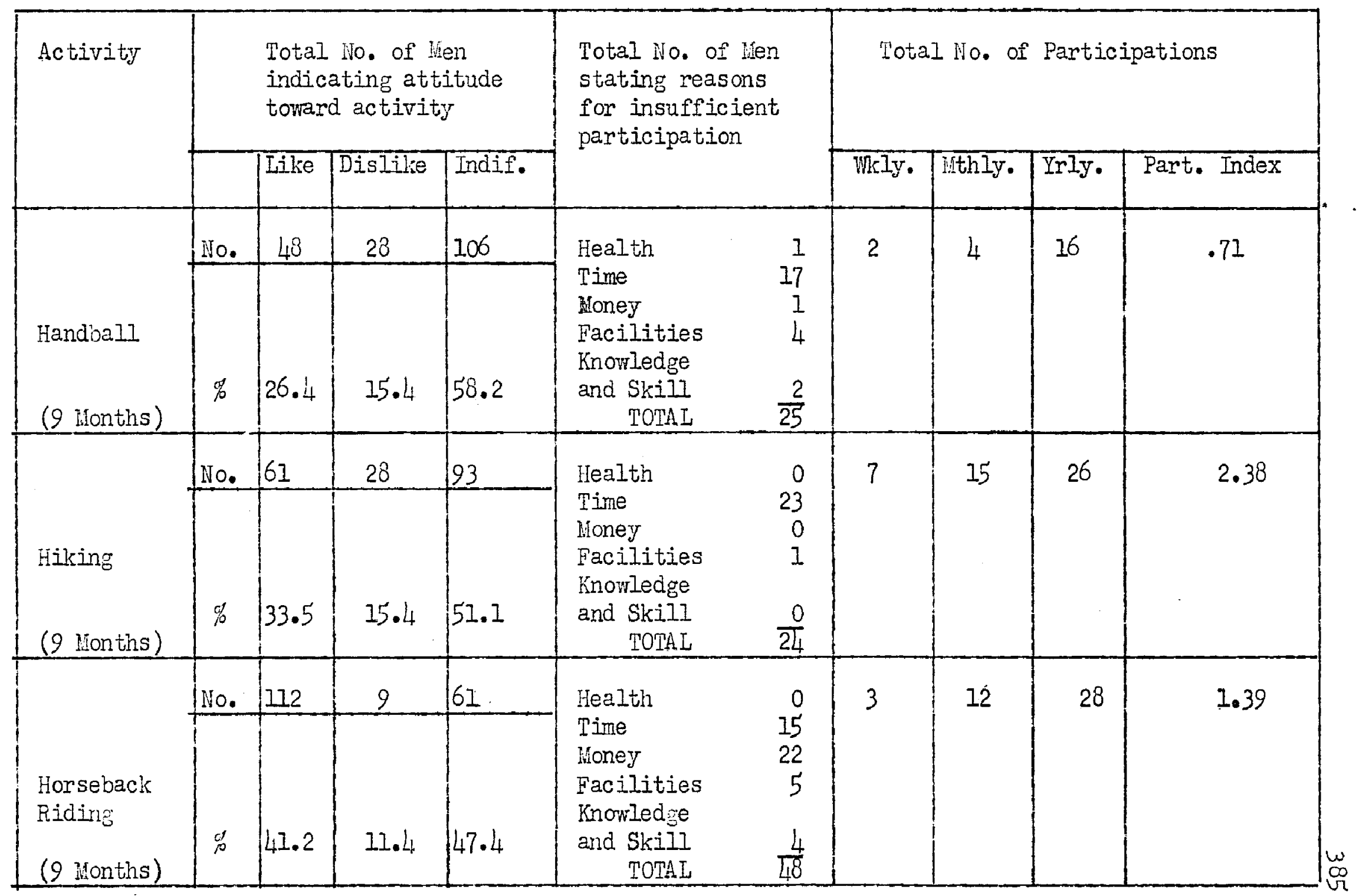


TABIE 33 (Continued)

$\$ 3,000-\$ 4,000$ Incone Group

\begin{tabular}{|c|c|c|c|c|c|c|c|c|c|c|}
\hline \multirow[t]{2}{*}{ Activity } & \multicolumn{4}{|c|}{$\begin{array}{l}\text { Total No, of Nen } \\
\text { indicating attitude } \\
\text { toward activity }\end{array}$} & \multirow{2}{*}{\multicolumn{2}{|c|}{$\begin{array}{l}\text { Total No. of liten } \\
\text { stating reasons } \\
\text { for insufficient } \\
\text { participation }\end{array}$}} & \multicolumn{4}{|c|}{ Total No. of Participations } \\
\hline & & Like & Dislike & Indif. & & & Wikly. & ifthly. & Yrly. & Part. Index \\
\hline \multirow[b]{2}{*}{$\begin{array}{l}\text { Horseshoes } \\
\text { (9 Months) }\end{array}$} & No. & 112 & 9 & 61 & \multirow{2}{*}{$\begin{array}{l}\text { Health } \\
\text { Time } \\
\text { Money } \\
\text { Facilities } \\
\text { Knowledge } \\
\text { and Skill } \\
\quad \text { TOTAL } \\
\end{array}$} & \multirow[b]{2}{*}{$\begin{array}{r}0 \\
17 \\
1 \\
17 \\
17 \\
30 \\
\end{array}$} & \multirow[t]{2}{*}{12} & \multirow[t]{2}{*}{16} & \multirow[t]{2}{*}{97} & \multirow[t]{2}{*}{3.90} \\
\hline & $\%$ & 61.5 & 15.0 & 33.5 & & & & & & \\
\hline \multirow[b]{2}{*}{$\begin{array}{l}\text { Hunting } \\
\text { (3Honths) }\end{array}$} & lNo. & 103 & 23 & 56 & \multirow{2}{*}{$\begin{array}{l}\text { Health } \\
\text { Time } \\
\text { Money } \\
\text { Facilities } \\
\text { Knorledge } \\
\text { and Skill } \\
\quad \text { TOTAI } \\
\end{array}$} & \multirow{2}{*}{$\begin{array}{r}0 \\
23 \\
5 \\
4 \\
\\
\frac{2}{34} \\
\end{array}$} & \multirow[t]{2}{*}{2} & \multirow[t]{2}{*}{8} & \multirow[t]{2}{*}{107} & \multirow[t]{2}{*}{.86} \\
\hline & $\%$ & 56.6 & 12.6 & 30.8 & & & & & & \\
\hline \multirow[b]{2}{*}{$\begin{array}{l}\text { Ice Hockey } \\
\text { (3 Honths) }\end{array}$} & No. & 62 & 24 & 96 & \multirow{2}{*}{$\begin{array}{l}\text { Heal th } \\
\text { Time } \\
\text { lioney } \\
\text { Facilities } \\
\text { Knowledge } \\
\text { and Skill } \\
\text { TOTAI }\end{array}$} & \multirow{2}{*}{$\begin{array}{r}4 \\
11 \\
4 \\
4 \\
\frac{1}{24}\end{array}$} & \multirow[t]{2}{*}{4} & \multirow[t]{2}{*}{6} & \multirow[t]{2}{*}{32} & \multirow[t]{2}{*}{.56} \\
\hline & $\not 0$ & 34.1 & 13.2 & 52.7 & & & & & & \\
\hline
\end{tabular}


TABLE 33 (Continued)

3,000-\$4,000 Income Group

\begin{tabular}{|c|c|c|c|c|c|c|c|c|c|c|}
\hline \multirow[t]{2}{*}{ Activity } & \multicolumn{4}{|c|}{$\begin{array}{l}\text { Total iNo. of ten } \\
\text { indicating attitude } \\
\text { toward activity }\end{array}$} & \multirow{2}{*}{\multicolumn{2}{|c|}{$\begin{array}{l}\text { Total No. of Men } \\
\text { stating reasons } \\
\text { for insufficient } \\
\text { participation }\end{array}$}} & \multicolumn{4}{|c|}{ Total Ho. of Participations } \\
\hline & & Like & Dislike & Indif. & & & WkIy. & Ithly. & IrIy. & Part. Index \\
\hline \multirow[b]{2}{*}{ Ice Skating } & No. & 81 & 23 & 78 & \multirow{2}{*}{$\begin{array}{l}\text { Health } \\
\text { Time } \\
\text { Inoney } \\
\text { Facilities } \\
\text { Inowledge } \\
\text { and Skill } \\
\quad \text { TOTAL } \\
\end{array}$} & \multirow{2}{*}{$\begin{array}{r}2 \\
16 \\
0 \\
5 \\
\frac{3}{26} \\
\end{array}$} & \multirow[t]{2}{*}{1} & \multirow[t]{2}{*}{8} & \multirow[t]{2}{*}{62} & \multirow[t]{2}{*}{.54} \\
\hline & $\%$ & 44.5 & 12.6 & 42.9 & & & & & & \\
\hline \multirow[b]{2}{*}{ Wetal Crait } & No. & 47 & 25 & 110 & \multirow{2}{*}{$\begin{array}{l}\text { Health } \\
\text { Time } \\
\text { Noney } \\
\text { Facilities } \\
\text { Knowledge } \\
\text { and Skill } \\
\quad \text { TOTAL } \\
\end{array}$} & 0 & \multirow[t]{2}{*}{23} & \multirow[t]{2}{*}{9} & \multirow[t]{2}{*}{14} & \multirow[t]{2}{*}{7.24} \\
\hline & $\not 8$ & 25.9 & 13.7 & 60.4 & & $\begin{array}{r}2 \\
6 \\
\quad 3 \\
\end{array}$ & & & & \\
\hline \multirow[b]{2}{*}{ Hovies } & No. & 127 & 9 & 46 & \multirow{2}{*}{$\begin{array}{l}\text { Health } \\
\text { Time } \\
\text { Money } \\
\text { Facilities } \\
\text { Knowredge } \\
\text { and Skill } \\
\quad \text { TOTAL } \\
\end{array}$} & 0 & \multirow[t]{2}{*}{42} & \multirow[t]{2}{*}{59} & \multirow[t]{2}{*}{45} & \multirow[t]{2}{*}{16.14} \\
\hline & $\%$ & 69.8 & 4.9 & 25.3 & & $\begin{array}{r}8 \\
1 \\
0 \\
20 \\
\end{array}$ & & & & \\
\hline
\end{tabular}


TABIF 33 (Continued)

33,000-4, 4,000 Income Group

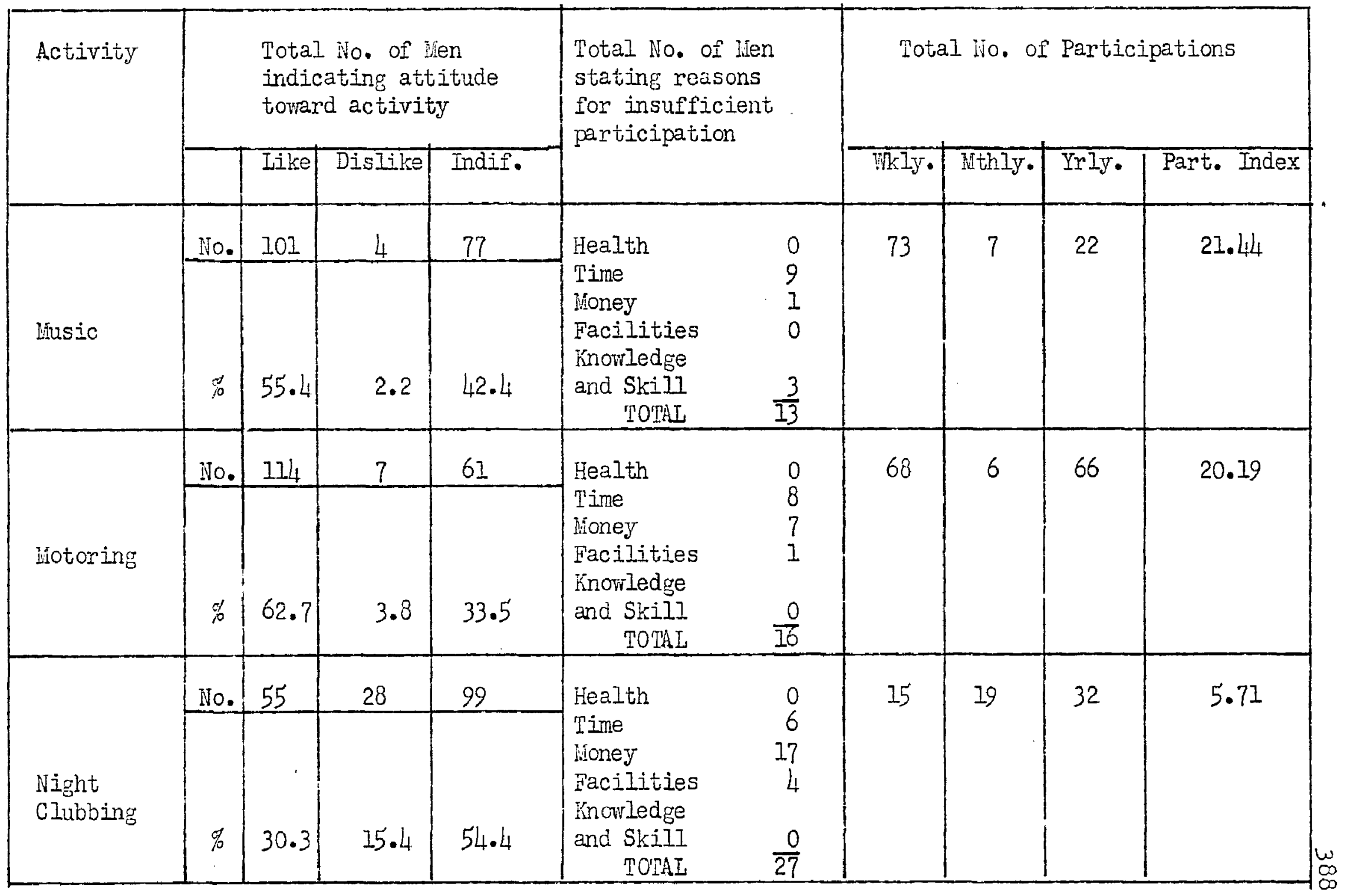


TABLE 33 (Continued)

$\$ 3,000-\$ 4,000$ Income Group

\begin{tabular}{|c|c|c|c|c|c|c|c|c|c|c|}
\hline \multirow[t]{2}{*}{ Activity } & \multicolumn{4}{|c|}{$\begin{array}{l}\text { Total No. of Men } \\
\text { indicating attitude } \\
\text { toward activity }\end{array}$} & \multirow{2}{*}{\multicolumn{2}{|c|}{$\begin{array}{l}\text { Total No. of lien } \\
\text { stating reasons } \\
\text { for insufficient } \\
\text { participation }\end{array}$}} & \multicolumn{4}{|c|}{ Total No. of Participations } \\
\hline & & Lilie & Dislike & Indif. & & & may. & Nthly. & Irly. & Part. Index \\
\hline \multirow[b]{2}{*}{$\begin{array}{l}\text { Puttering, } \\
\text { Repairing, } \\
\text { etc. }\end{array}$} & No. & 123 & 21 & 38 & \multirow{2}{*}{$\begin{array}{l}\text { Health } \\
\text { Time } \\
\text { ivoney } \\
\text { Facilities } \\
\text { Knowledge } \\
\text { and Skill } \\
\quad \text { TOTAL }\end{array}$} & \multirow{2}{*}{$\begin{array}{r}0 \\
14 \\
3 \\
0 \\
\frac{0}{17}\end{array}$} & \multirow[t]{2}{*}{45} & \multirow[t]{2}{*}{9} & \multirow[t]{2}{*}{370} & \multirow[t]{2}{*}{4.41} \\
\hline & \% & 67.6 & 11.4 & 21.0 & & & & & & \\
\hline \multirow[b]{2}{*}{ Ping-Pong } & No. & 76 & 18 & 88 & \multirow{2}{*}{$\begin{array}{l}\text { Health } \\
\text { Time } \\
\text { Money } \\
\text { Facilities } \\
\text { Knowledge } \\
\text { and Skill } \\
\text { TOTAI }\end{array}$} & 0 & \multirow[t]{2}{*}{12} & \multirow[t]{2}{*}{19} & \multirow[t]{2}{*}{28} & \multirow[t]{2}{*}{4.84} \\
\hline & $\stackrel{q f}{\rho}$ & 41.8 & 9.8 & 48.4 & & $\begin{array}{r}0 \\
11 \\
0 \\
\frac{0}{23}\end{array}$ & & & & \\
\hline \multirow[b]{2}{*}{$\begin{array}{l}\text { Listening } \\
\text { to Radio }\end{array}$} & No. & 127 & 4 & 51 & \multirow{2}{*}{$\begin{array}{l}\text { Health } \\
\text { Time } \\
\text { Money } \\
\text { Facilities } \\
\text { Knowledge } \\
\text { and Skill } \\
\quad \text { TOTAI }\end{array}$} & 0 & \multirow[t]{2}{*}{207} & \multirow[t]{2}{*}{1} & \multirow[t]{2}{*}{100} & \multirow[t]{2}{*}{59.76} \\
\hline & 范 & 69.8 & 2.2 & 28.0 & & $\begin{array}{c}1 \\
1 \\
\frac{0}{11}\end{array}$ & & & & \\
\hline
\end{tabular}


TABIE 33 (Continued)

$\$ 3,000-\$ 4,000$ Income Group

\begin{tabular}{|c|c|c|c|c|c|c|c|c|c|c|}
\hline \multirow[t]{2}{*}{ Activity } & & \multicolumn{3}{|c|}{$\begin{array}{l}\text { Total No. of hen } \\
\text { indicating attitude } \\
\text { toward activity }\end{array}$} & \multirow{2}{*}{\multicolumn{2}{|c|}{$\begin{array}{l}\text { Total No. of lien } \\
\text { stating reasons } \\
\text { for insufficient } \\
\text { participation }\end{array}$}} & \multicolumn{4}{|c|}{ Total No. of Participations } \\
\hline & & Like & Dislike & Indif. & & & WIY. & IfthIy. & $\mathrm{YrIy}$ & art. Index \\
\hline \multirow[b]{2}{*}{ Watching TV } & No. & 159 & 3 & 20 & \multirow{2}{*}{$\begin{array}{l}\text { Health } \\
\text { Time } \\
\text { Ifoney } \\
\text { Facilities } \\
\text { Knowledge } \\
\text { and Skil] } \\
\text { TOTAL }\end{array}$} & \multirow{2}{*}{$\begin{array}{l}0 \\
9 \\
1 \\
4 \\
0 \\
14\end{array}$} & \multirow[t]{2}{*}{268} & \multirow[t]{2}{*}{2} & \multirow[t]{2}{*}{103} & \multirow[t]{2}{*}{77.27} \\
\hline & $\ddot{p}$ & $87 \cdot 3$ & I.? & 11.0 & & & & & & \\
\hline \multirow[b]{2}{*}{ Reading } & No. & $\Psi_{4} .1$ & 5 & 36 & \multirow{2}{*}{$\begin{array}{l}\text { Health } \\
\text { Time } \\
\text { lioney } \\
\text { Pacilities } \\
\text { Knowled se } \\
\text { and Skill } \\
\quad \text { TOTAI }\end{array}$} & \multirow{2}{*}{$\begin{array}{r}0 \\
12 \\
0 \\
0 \\
0 \\
\frac{0}{12}\end{array}$} & \multirow[t]{2}{*}{208} & \multirow[t]{2}{*}{8} & \multirow[t]{2}{*}{265} & \multirow[t]{2}{*}{61.41} \\
\hline & $\not b$ & $77 \cdot 4$ & 2.7 & 19.9 & & & & & & \\
\hline \multirow[b]{2}{*}{ Photography } & No. & 71 & 13 & 98 & \multirow{2}{*}{$\begin{array}{l}\text { Health } \\
\text { Time } \\
\text { Woney } \\
\text { Facilities } \\
\text { Knowledge } \\
\text { and Skill } \\
\quad \text { TOTAI }\end{array}$} & 0 & \multirow[t]{2}{*}{22} & \multirow[t]{2}{*}{19} & \multirow[t]{2}{*}{14} & \multirow[t]{2}{*}{7.62} \\
\hline & $\%$ & 39.0 & 7.1 & 53.9 & & $\begin{array}{r}10 \\
5 \\
\frac{1}{23}\end{array}$ & & & & \\
\hline
\end{tabular}


TABIE 33 (Continued)

3,000-34,000 Income Group

\begin{tabular}{|c|c|c|c|c|c|c|c|c|c|c|}
\hline \multirow[t]{2}{*}{ Activityr } & \multicolumn{4}{|c|}{$\begin{array}{l}\text { Total No. of Men } \\
\text { indicating attitude } \\
\text { toward activity }\end{array}$} & \multirow{2}{*}{\multicolumn{2}{|c|}{$\begin{array}{l}\text { Total No. of len } \\
\text { stating reasons } \\
\text { for insufficient } \\
\text { participation }\end{array}$}} & \multicolumn{4}{|c|}{ Total No. of Participations } \\
\hline & & Like & Dislike & Indif. & & & Wkly• & Nthly• & Yrly. & Part. Index \\
\hline \multirow[b]{2}{*}{$\begin{array}{l}\text { Roller } \\
\text { Skatinz }\end{array}$} & No. & 61 & 29 & 92 & \multirow{2}{*}{$\begin{array}{l}\text { Healih } \\
\text { Time } \\
\text { Honey } \\
\text { Facilities } \\
\text { Knowledge } \\
\text { and Skill } \\
\quad \text { TOThL } \\
\end{array}$} & \multirow{2}{*}{$\begin{array}{r}1 \\
13 \\
1 \\
0 \\
\\
\frac{2}{17} \\
\end{array}$} & \multirow[t]{2}{*}{6} & \multirow[t]{2}{*}{9} & \multirow[t]{2}{*}{32} & \multirow[t]{2}{*}{2.43} \\
\hline & 品 & 33.5 & 16.1 & 50.6 & & & & & & \\
\hline \multirow[b]{2}{*}{ Painting } & No. & 47 & 33 & 102 & \multirow{2}{*}{$\begin{array}{l}\text { Health } \\
\text { Time } \\
\text { Tioney } \\
\text { Facilities } \\
\text { Knowledge } \\
\text { and Skill } \\
\quad \text { TOTAL } \\
\end{array}$} & 0 & \multirow[t]{2}{*}{8} & \multirow[t]{2}{*}{4} & \multirow[t]{2}{*}{62} & \multirow[t]{2}{*}{2.39} \\
\hline & $\%$ & 25.9 & 18.1 & 56.0 & & $\begin{array}{r}1 \\
0 \\
-1 \\
\end{array}$ & & & & \\
\hline \multirow[b]{2}{*}{$\begin{array}{l}\text { Social } \\
\text { Drinking }\end{array}$} & No. & 88 & 20 & 74 & \multirow{2}{*}{$\begin{array}{l}\text { Health } \\
\text { Time } \\
\text { Money } \\
\text { Facilities } \\
\text { Knowledge } \\
\text { and Skill } \\
\quad \text { TOTAL }\end{array}$} & 0 & \multirow[t]{2}{*}{37} & \multirow[t]{2}{*}{28} & \multirow[t]{2}{*}{162} & \multirow[t]{2}{*}{13.30} \\
\hline & $\%$ & 48.4 & 11.0 & 40.6 & & $\begin{array}{r}9 \\
1 \\
\frac{2}{17}\end{array}$ & & & & \\
\hline
\end{tabular}


TABIE 33 (Continued)

$\$ 3,000-\$ 4,000$ Income Group

\begin{tabular}{|c|c|c|c|c|c|c|c|c|c|c|}
\hline \multirow[t]{2}{*}{ Activity } & \multicolumn{4}{|c|}{$\begin{array}{l}\text { Total No. of lifen } \\
\text { indicating attitude } \\
\text { toward activity }\end{array}$} & \multirow{2}{*}{\multicolumn{2}{|c|}{$\begin{array}{l}\text { Total No. of hen } \\
\text { stating reasons } \\
\text { for insufficient } \\
\text { participation }\end{array}$}} & \multicolumn{4}{|c|}{ Total No. of Participations } \\
\hline & & Like & Dislike & Indif. & & & Whly. & Mthly. & Irly. & Part. Index \\
\hline \multirow[b]{2}{*}{ Sailing } & No. & 41 & 28 & 113 & \multirow{2}{*}{$\begin{array}{l}\text { Health } \\
\text { Time } \\
\text { Money } \\
\text { Facilities } \\
\text { Knowledge } \\
\text { and Skill } \\
\quad \text { TorAL }\end{array}$} & \multirow{2}{*}{$\begin{array}{r}0 \\
6 \\
5 \\
10 \\
\frac{4}{25}\end{array}$} & \multirow[t]{2}{*}{2} & \multirow[t]{2}{*}{1} & \multirow[t]{2}{*}{23} & \multirow[t]{2}{*}{$\cdot 39$} \\
\hline & $\stackrel{8}{0}$ & 22.5 & 15.4 & 62.2 & & & & & & \\
\hline \multirow[b]{2}{*}{$\begin{array}{l}\text { Skiing } \\
\text { (3 Months) }\end{array}$} & No. & 33 & 34 & 115 & \multirow{2}{*}{$\begin{array}{l}\text { Health } \\
\text { Time } \\
\text { Money } \\
\text { Pacilities } \\
\text { Knowledge } \\
\text { and Skill } \\
\quad \text { TOIAI } \\
\end{array}$} & \multirow{2}{*}{$\begin{array}{l}0 \\
7 \\
5 \\
5 \\
4 \\
21\end{array}$} & \multirow[t]{2}{*}{0} & \multirow[t]{2}{*}{2} & \multirow[t]{2}{*}{13} & \multirow[t]{2}{*}{.10} \\
\hline & of & 18.1 & 18.6 & 63.3 & & & & & & \\
\hline \multirow[b]{2}{*}{$\begin{array}{l}\text { Social } \\
\text { Dancing }\end{array}$} & iNo. & 99 & 21 & 62 & \multirow{2}{*}{$\begin{array}{l}\text { Health } \\
\text { Time } \\
\text { Honey } \\
\text { Facilities } \\
\text { Knowledge } \\
\text { and Skill } \\
\quad \text { TOTAL }\end{array}$} & 0 & \multirow[t]{2}{*}{16} & \multirow[t]{2}{*}{32} & \multirow[t]{2}{*}{24} & \multirow[t]{2}{*}{.68} \\
\hline & 粦 & $54 \cdot 4$ & 11.5 & 34.1 & & $\begin{array}{r}4 \\
2 \\
\frac{3}{23}\end{array}$ & & & & \\
\hline
\end{tabular}


TABLE 33(Continued)

$\$ 3,000-\$ 4,000$ Income Group

\begin{tabular}{|c|c|c|c|c|c|c|c|c|c|c|}
\hline \multirow[t]{2}{*}{ Activity } & & \multicolumn{3}{|c|}{$\begin{array}{l}\text { Total No. of lien } \\
\text { indicating attitude } \\
\text { toward activity }\end{array}$} & \multirow{2}{*}{\multicolumn{2}{|c|}{$\begin{array}{l}\text { Total iTo. of Nen } \\
\text { stating reasons } \\
\text { for insufficient } \\
\text { participation }\end{array}$}} & \multicolumn{4}{|c|}{ Total No. of Participations } \\
\hline & & Like & Dislike & Indif. & & & Wkly $\cdot$ & Wthly. & Yrly. & Part. Index \\
\hline \multirow[b]{2}{*}{$\begin{array}{l}\text { Softball } \\
\text { (3 Wonths) }\end{array}$} & No. & 113 & 9 & 60 & \multirow{2}{*}{$\begin{array}{l}\text { Health } \\
\text { Time } \\
\text { INoney } \\
\text { Facilities } \\
\text { Knowledge } \\
\text { and Skill } \\
\quad \text { TOTAL } \\
\end{array}$} & \multirow{2}{*}{$\begin{array}{r}4 \\
24 \\
1 \\
2 \\
\frac{1}{32} \\
\end{array}$} & \multirow[t]{2}{*}{27} & \multirow[t]{2}{*}{21} & \multirow[t]{2}{*}{29} & \multirow[t]{2}{*}{2.43} \\
\hline & 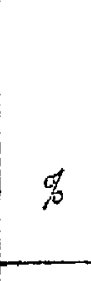 & 62.2 & 4.9 & 32.9 & & & & & & \\
\hline \multirow[b]{2}{*}{$\begin{array}{l}\text { Speedball } \\
\text { (3 Honths) }\end{array}$} & No. & 33. & 29 & 120 & \multirow{2}{*}{$\begin{array}{l}\text { Health } \\
\text { Time } \\
\text { Koney } \\
\text { Facilities } \\
\text { Knowledge } \\
\text { and Skill } \\
\text { TOTAL }\end{array}$} & \multirow{2}{*}{$\begin{array}{l}1 \\
9 \\
0 \\
0 \\
1 \\
\frac{1}{11} \\
\end{array}$} & \multirow[t]{2}{*}{4} & \multirow[t]{2}{*}{4} & \multirow[t]{2}{*}{7} & \multirow[t]{2}{*}{$\cdot 39$} \\
\hline & 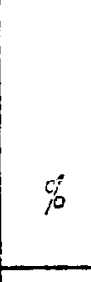 & 18.1 & 16.1 & 65.8 & & & & & & \\
\hline \multirow[b]{2}{*}{$\begin{array}{l}\text { Square } \\
\text { Dancing }\end{array}$} & No. & 50 & 32 & 100 & \multirow{2}{*}{\multicolumn{2}{|c|}{$\begin{array}{lr}\text { Health } & 0 \\
\text { Time } & 16 \\
\text { Hinney } & 1 \\
\text { Facilities } & 3 \\
\text { Knowledge } & \\
\text { and Skill } & 4 \\
\quad \text { TOTAL } & \frac{4}{24}\end{array}$}} & \multirow[t]{2}{*}{3} & \multirow[t]{2}{*}{ II } & \multirow[t]{2}{*}{16} & \multirow[t]{2}{*}{1.67} \\
\hline & $\%$ & 27.5 & 17.6 & 54.9 & & & & & & \\
\hline
\end{tabular}


2x.se 33 (Continued)

33,000-\$4,000 Income Group

\begin{tabular}{|c|c|c|c|c|c|c|c|c|c|c|}
\hline \multirow[t]{2}{*}{ Activity } & \multicolumn{4}{|c|}{$\begin{array}{l}\text { Total No, of hen } \\
\text { indicating attitude } \\
\text { toward activity }\end{array}$} & \multirow{2}{*}{\multicolumn{2}{|c|}{$\begin{array}{l}\text { Total No. of lien } \\
\text { stating reasons } \\
\text { for insufficient } \\
\text { participation }\end{array}$}} & \multicolumn{4}{|c|}{ Total No. of Participations } \\
\hline & & Like & Dislikq & Indif. & & & inkly. & litinly. & Irly• & Part. Index \\
\hline \multirow[b]{2}{*}{$\begin{array}{l}\text { Stamp } \\
\text { Collecting }\end{array}$} & No. & 15 & 49 & 118 & \multirow{2}{*}{$\begin{array}{l}\text { Health } \\
\text { Time } \\
\text { Honey } \\
\text { Facilities } \\
\text { Knowledge } \\
\text { and Skill } \\
\quad \text { TOTAL } \\
\end{array}$} & \multirow{2}{*}{$\begin{array}{l}0 \\
4 \\
0 \\
0 \\
0 \\
\frac{0}{4}\end{array}$} & \multirow[t]{2}{*}{9} & \multirow[t]{2}{*}{0} & \multirow[t]{2}{*}{2} & \multirow[t]{2}{*}{2.58} \\
\hline & 思 & 3.2 & 26.9 & 64.9 & & & & & & \\
\hline \multirow[b]{2}{*}{$\begin{array}{l}\text { Swimming } \\
\text { (3 Bionths) }\end{array}$} & Io. & $1 / 2$ & 9 & 31 & \multirow{2}{*}{$\begin{array}{l}\text { Health } \\
\text { Time } \\
\text { Money } \\
\text { Facilities } \\
\text { Inowledge } \\
\text { and Skill } \\
\quad \text { TOTAI } \\
\end{array}$} & \multirow{2}{*}{$\begin{array}{r}3 \\
17 \\
0 \\
6 \\
\frac{5}{31} \\
\end{array}$} & \multirow[t]{2}{*}{29} & \multirow[t]{2}{*}{33} & \multirow[t]{2}{*}{131} & \multirow[t]{2}{*}{3.34} \\
\hline & $\%$ & 78.1 & 4.9 & 17.0 & & & & & & \\
\hline \multirow[b]{2}{*}{$\begin{array}{l}\text { Tennis } \\
\text { (5 Months) }\end{array}$} & No. & 46 & 25 & 111 & \multirow{2}{*}{$\begin{array}{l}\text { Health } \\
\text { Time } \\
\text { Money } \\
\text { Facilities } \\
\text { Inowledge } \\
\text { and Skill } \\
\quad \text { TOTAI }\end{array}$} & \multirow{2}{*}{$\begin{array}{l}\frac{1}{11} \\
1 \\
2 \\
\frac{1}{10}\end{array}$} & \multirow[t]{2}{*}{7} & \multirow[t]{2}{*}{8} & \multirow[t]{2}{*}{42} & \multirow[t]{2}{*}{.1 .28} \\
\hline & 管 & $25 \cdot 3$ & 13.7 & 60.9 & & & & & & \\
\hline
\end{tabular}


TABLF 33 (Continued)

$33,000-34,000$ Inc one Group

\begin{tabular}{|c|c|c|c|c|c|c|c|c|c|c|}
\hline \multirow[t]{2}{*}{ Activity } & \multicolumn{4}{|c|}{$\begin{array}{l}\text { Total No. of ifen } \\
\text { indicating attitude } \\
\text { toward activity }\end{array}$} & \multirow{2}{*}{\multicolumn{2}{|c|}{$\begin{array}{l}\text { Total No. of lien } \\
\text { stating reasons } \\
\text { for insufficient } \\
\text { participation }\end{array}$}} & \multicolumn{4}{|c|}{ Total No. of Participations } \\
\hline & & Iike & Dislike & Indif. & & & WhIy. & Iithly. & Yrly. & Part. Index \\
\hline \multirow[b]{2}{*}{$\begin{array}{l}\text { Touch } \\
\text { Football } \\
\text { (3 Months) }\end{array}$} & No. & 45 & 23 & 111: & \multirow{2}{*}{$\begin{array}{l}\text { Health } \\
\text { Time } \\
\text { Money } \\
\text { Facilities } \\
\text { Knowledge } \\
\text { and Skill } \\
\quad \text { TOTAL } \\
\end{array}$} & \multirow{2}{*}{$\begin{array}{r}2 \\
8 \\
0 \\
2 \\
0 \\
12 \\
\end{array}$} & \multirow[t]{2}{*}{3} & \multirow[t]{2}{*}{6} & \multirow[t]{2}{*}{12} & \multirow[t]{2}{*}{.38} \\
\hline & of & 24.8 & 12.6 & 62.7 & & & & & & \\
\hline \multirow[b]{2}{*}{ Tumbling } & No. & 16 & 40 & 126 & \multirow{2}{*}{$\begin{array}{l}\text { Health } \\
\text { Time } \\
\text { Noney } \\
\text { Facilities } \\
\text { Knovledge } \\
\text { and Skill } \\
\text { TOIAL }\end{array}$} & 1 & \multirow[t]{2}{*}{3} & \multirow[t]{2}{*}{3} & \multirow[t]{2}{*}{6} & \multirow[t]{2}{*}{1.09} \\
\hline & $\%$ & 8.8 & 21.9 & 69.3 & & $\begin{array}{l}4 \\
3 \\
0 \\
\frac{0}{8}\end{array}$ & & & & \\
\hline \multirow[b]{2}{*}{$\begin{array}{l}\text { Visiting } \\
\text { Friends }\end{array}$} & No. & 133 & 12 & 37 & \multirow{2}{*}{$\begin{array}{l}\text { Health } \\
\text { Time } \\
\text { lioney } \\
\text { Facilities } \\
\text { Knowledge } \\
\text { and Skill } \\
\text { TOTAI }\end{array}$} & 0 & \multirow[t]{2}{*}{80} & \multirow[t]{2}{*}{18} & \multirow[t]{2}{*}{8} & \multirow[t]{2}{*}{24.09} \\
\hline & $\%$ & 72.9 & 6.6 & 20.5 & & $\begin{array}{r}1 \\
0 \\
\frac{0}{12}\end{array}$ & & & & \\
\hline
\end{tabular}


TABIE 33 (Continued)

$\$ 3,000-\$ 4,000$ Income Group

\begin{tabular}{|c|c|c|c|c|c|c|c|c|c|c|}
\hline \multirow[t]{2}{*}{ Activity } & \multicolumn{4}{|c|}{$\begin{array}{l}\text { Total No. of len } \\
\text { indicating attitude } \\
\text { toward activity }\end{array}$} & \multirow{2}{*}{\multicolumn{2}{|c|}{$\begin{array}{l}\text { Total ilo. of lien } \\
\text { stating reasons } \\
\text { for insufficient } \\
\text { participation }\end{array}$}} & \multicolumn{4}{|c|}{ Total Io. of Participations } \\
\hline & & Like & Dislike & Indif. & & & $\mathrm{W} I \mathrm{y} \cdot$ & Ithly. & Yrly. & Fart, Index \\
\hline Volleyball & No. & 30.3 & $12 . \mathrm{C}$ & 105 & $\begin{array}{l}\text { Health } \\
\text { Time } \\
\text { Money } \\
\text { Facilities } \\
\text { Knowledge } \\
\text { and Skill } \\
\quad \text { TOThI } \\
\end{array}$ & $\begin{array}{l}0 \\
8 \\
0 \\
5 \\
\frac{1}{14}\end{array}$ & 5 & 11 & 22 & 2.27 \\
\hline $\begin{array}{l}\text { Watching } \\
\text { Sport Events }\end{array}$ & No. & $87 \cdot 3$ & 2.7 & 9.9 & $\begin{array}{l}\text { Health } \\
\text { Time } \\
\text { Money } \\
\text { Facilities } \\
\text { Knowledge } \\
\text { and Skill } \\
\quad \text { TOTAL } \\
\end{array}$ & $\begin{array}{r}0 \\
18 \\
5 \\
2 \\
\\
0 \\
25 \\
\end{array}$ & 90 & 13 & 43 & 26.81 \\
\hline Walking & No. & 51.2 & 9.9 & 39.0 & $\begin{array}{l}\text { Health } \\
\text { Time } \\
\text { Honey } \\
\text { Pacilities } \\
\text { Fnowledge } \\
\text { and Skill } \\
\quad \text { ToTAL }\end{array}$ & $\begin{array}{l}1 \\
8 \\
0 \\
0 \\
0 \\
\frac{0}{9}\end{array}$ & 34 & 1 & 2 & 24.08 \\
\hline
\end{tabular}


TASIE 33 (Continued)

3,000-\$4,000 Income Group

\begin{tabular}{|c|c|c|c|c|c|c|c|c|c|c|}
\hline \multirow[t]{2}{*}{ Activity } & & \multicolumn{3}{|c|}{$\begin{array}{l}\text { Total No. of lien } \\
\text { indicating attitude } \\
\text { toward activity }\end{array}$} & \multirow{2}{*}{\multicolumn{2}{|c|}{$\begin{array}{l}\text { Total Wo. of lien } \\
\text { stating reasons } \\
\text { Ior insufficient } \\
\text { participation }\end{array}$}} & \multicolumn{4}{|c|}{ Total No. of Participations } \\
\hline & & Like & Dislike & Indif. & & & Wkly.1 & Mthly. & Yrly• & Part. Index \\
\hline \multirow[b]{2}{*}{ Wrestling } & No. & 46 & 41 & 95 & \multirow{2}{*}{$\begin{array}{l}\text { Health } \\
\text { Time } \\
\text { Honey } \\
\text { Facilities } \\
\text { Inowledge } \\
\text { and Skill } \\
\quad \text { TOTAL }\end{array}$} & 5 & \multirow[t]{2}{*}{8} & \multirow[t]{2}{*}{2} & \multirow[t]{2}{*}{9} & \multirow[t]{2}{*}{2.48} \\
\hline & $\%$ & 25.3 & 22.5 & 52.2 & & $\begin{array}{r}0 \\
0 \\
\frac{2}{1}\end{array}$ & & & & \\
\hline
\end{tabular}

REASONS :

$\begin{array}{lrrr}\text { Health } & 77 & -5.0 \% \\ \text { Time } & 886 & -57.9 \% \\ \text { Money } & 224 & -14.7 \% \\ \text { Tacilities } & 237 & -15.5 \% \\ \text { Knowledge and 8kill } & 104 & -6.8 \%\end{array}$




\section{TABLE 34}

Numbers and Percentages of Men Liking, Disliking and Indifferent to Each of Sixty-Seven Recreational Activities, Extent of Participation in Each, and Number of len Listing Each of Five Reasons for Unsatisfactory Participation in the $\$ 4,000-\$ 5,000$ Income Group

\begin{tabular}{|c|c|c|c|c|c|c|c|c|c|c|}
\hline \multirow[t]{2}{*}{ Activity } & & \multicolumn{3}{|c|}{$\begin{array}{l}\text { Total No. of Men } \\
\text { indicating attitude } \\
\text { toward activity }\end{array}$} & \multirow{2}{*}{\multicolumn{2}{|c|}{$\begin{array}{l}\text { Total No. of Wen } \\
\text { stating reasons } \\
\text { for insufficient } \\
\text { participation }\end{array}$}} & \multicolumn{4}{|c|}{ Total No. of Participations } \\
\hline & & Iike & islike & Indif. & & & $7 \mathrm{kgly}$ & WthIy. & Yrly. & Part. Index \\
\hline \multirow[b]{2}{*}{ Archery } & No. & 17 & 12 & 65 & \multirow{2}{*}{$\begin{array}{l}\text { Health } \\
\text { Time } \\
\text { ifoney } \\
\text { Facilities } \\
\text { Inowledge } \\
\text { and Skill } \\
\quad \text { TOTAL } \\
\end{array}$} & \multirow{2}{*}{$\begin{array}{l}0 \\
9 \\
2 \\
4 \\
\frac{3}{18} \\
\end{array}$} & \multirow[t]{2}{*}{1} & \multirow[t]{2}{*}{3} & \multirow[t]{2}{*}{13} & \multirow[t]{2}{*}{1.20} \\
\hline & $\%$ & 18.1 & 12.8 & 69.2 & & & & & & \\
\hline \multirow[b]{2}{*}{ Badminton } & No. & 18 & 15 & 51 & \multirow{2}{*}{$\begin{array}{l}\text { Health } \\
\text { Time } \\
\text { lioney } \\
\text { Fracilities } \\
\text { Knowledge } \\
\text { and Skill } \\
\quad \text { TOMAL }\end{array}$} & 1 & \multirow[t]{2}{*}{4} & \multirow[t]{2}{*}{8} & \multirow[t]{2}{*}{20} & \multirow[t]{2}{*}{$3 \cdot 40$} \\
\hline & 萿 & 29.8 & 16.0 & 54.3 & & $\begin{array}{l}1 \\
3 \\
\frac{1}{15}\end{array}$ & & & & \\
\hline
\end{tabular}


THIJ 34 (Continued)

$\$ 4,000-55,000$ Income Group

\begin{tabular}{|c|c|c|c|c|c|c|c|c|c|c|}
\hline \multirow[t]{2}{*}{ Activituy } & \multicolumn{4}{|c|}{$\begin{array}{l}\text { Total No. of wen } \\
\text { indicating attitude } \\
\text { tovard activity }\end{array}$} & \multirow{2}{*}{\multicolumn{2}{|c|}{$\begin{array}{l}\text { Total No. of lifen } \\
\text { stating reasons } \\
\text { for insufficient } \\
\text { participation }\end{array}$}} & \multicolumn{4}{|c|}{ Total No. of Participations } \\
\hline & & Like & Dislike & Indif. & & & Whly. & Mthly. & $\operatorname{Yr} \mathrm{Iy}_{\mathrm{v}}$ & Part. Index \\
\hline \multirow[b]{2}{*}{ Bag Funching } & No. & 28 & 20 & 56 & \multirow{2}{*}{$\begin{array}{l}\text { Feal th } \\
\text { Time } \\
\text { Money } \\
\text { Facilities } \\
\text { Inowledge } \\
\text { and Skill } \\
\quad \text { TOTAL } \\
\end{array}$} & \multirow{2}{*}{$\begin{array}{r}2 \\
8 \\
1 \\
1 \\
\frac{1}{13} \\
\end{array}$} & \multirow[t]{2}{*}{1} & \multirow[t]{2}{*}{9} & \multirow[t]{2}{*}{3} & \multirow[t]{2}{*}{1.70} \\
\hline & $\%$ & 19.9 & 21.3 & 59.6 & & & & & & \\
\hline \multirow[b]{2}{*}{$\begin{array}{l}\text { Baseball } \\
\text { (3 Hontins) } \\
\end{array}$} & No. & 78 & 1 & 15 & \multirow{2}{*}{$\begin{array}{l}\text { Health } \\
\text { Time } \\
\text { Money } \\
\text { Facilities } \\
\text { Knowledge } \\
\text { and Skill } \\
\quad \text { TorAL } \\
\end{array}$} & \multirow{2}{*}{$\begin{array}{r}12 \\
25 \\
1 \\
6 \\
\\
1 \\
15 \\
\end{array}$} & \multirow[t]{2}{*}{15} & \multirow[t]{2}{*}{10} & \multirow[t]{2}{*}{29} & \multirow[t]{2}{*}{2.70} \\
\hline & 要 & 83.0 & 1.06 & 16.0 & & & & & & \\
\hline \multirow[b]{2}{*}{$\begin{array}{l}\text { Basketiball } \\
\text { (6 Months) }\end{array}$} & No. & 33 & 13 & 43 & \multirow{2}{*}{$\begin{array}{l}\text { Health } \\
\text { Time } \\
\text { Wioney } \\
\text { Facilities } \\
\text { Ynowledge } \\
\text { and Skill } \\
\text { TOTAL }\end{array}$} & \multirow{2}{*}{$\begin{array}{l}8 \\
8 \\
0 \\
4 \\
\frac{1}{21}\end{array}$} & \multirow[t]{2}{*}{2} & \multirow[t]{2}{*}{1} & \multirow[t]{2}{*}{21} & \multirow[t]{2}{*}{.84} \\
\hline & 范 & 35.1 & 13.8 & 51.1 & & & & & & \\
\hline
\end{tabular}


TABLE 34 (Continued)

$\$ 4,000-\$ 5,000$ Income Group

\begin{tabular}{|c|c|c|c|c|c|c|c|c|c|c|}
\hline \multirow[t]{2}{*}{ Activity } & \multicolumn{4}{|c|}{$\begin{array}{l}\text { Total Ho. of wen } \\
\text { indicating attitude } \\
\text { torard activity }\end{array}$} & \multirow{2}{*}{\multicolumn{2}{|c|}{$\begin{array}{l}\text { Total No. of ilen } \\
\text { stating reasons } \\
\text { for insufficient } \\
\text { participation }\end{array}$}} & \multicolumn{4}{|c|}{ Total No. of Participations } \\
\hline & & Iike & Dislike & Indif. & & & WKIy. & Mthly. & Irly. & Part. Index \\
\hline $\begin{array}{l}\text { Bicycling } \\
\text { (8 jonths) }\end{array}$ & Mo. & 30.9 & 10.6 & 58.5 & $\begin{array}{l}\text { Health } \\
\text { Time } \\
\text { Honey } \\
\text { Facilities } \\
\text { Knowledge } \\
\text { and Skill } \\
\text { TOTAI }\end{array}$ & $\begin{array}{l}1 \\
6 \\
3 \\
3 \\
1 \\
\frac{1}{14}\end{array}$ & 3 & 5 & 16 & 1.70 \\
\hline \multirow[b]{2}{*}{$\begin{array}{l}\text { Boating } \\
\text { (5 ifonths) }\end{array}$} & No. & 45 & 9 & 40 & \multirow{2}{*}{$\begin{array}{l}\text { Health } \\
\text { Time } \\
\text { Money } \\
\text { Facilities } \\
\text { Knowledge } \\
\text { and Skill } \\
\text { TOTAL }\end{array}$} & \multirow{2}{*}{$\begin{array}{r}1 \\
10 \\
4 \\
6 \\
\frac{1}{22}\end{array}$} & \multirow[t]{2}{*}{4} & \multirow[t]{2}{*}{11} & \multirow[t]{2}{*}{36} & \multirow[t]{2}{*}{1.90} \\
\hline & $\%$ & 47.9 & 9.6 & 42.6 & & & & & & \\
\hline \multirow[b]{2}{*}{$\begin{array}{l}\text { Bowling } \\
\text { (9 Honths) }\end{array}$} & No. & 71 & 9 & $\underline{14}$ & \multirow{2}{*}{$\begin{array}{l}\text { Health } \\
\text { Time } \\
\text { Money } \\
\text { Facilities } \\
\text { Knowledge } \\
\text { and Skill } \\
\text { TOTAL }\end{array}$} & 2 & \multirow[t]{2}{*}{27} & \multirow[t]{2}{*}{10} & \multirow[t]{2}{*}{31} & \multirow[t]{2}{*}{12.50} \\
\hline & of & 75.5 & 9.6 & 14.9 & & $\begin{array}{r}7 \\
0 \\
0 \\
28\end{array}$ & & & & \\
\hline
\end{tabular}


PABLE 34 (Continued)

$\$ 4,000-35,000$ Income Group

\begin{tabular}{|c|c|c|c|c|c|c|c|c|c|c|}
\hline \multirow[t]{2}{*}{ Activity } & & \multicolumn{3}{|c|}{$\begin{array}{l}\text { Total No. Of len } \\
\text { indicating attitude } \\
\text { toward activity }\end{array}$} & \multirow{2}{*}{\multicolumn{2}{|c|}{$\begin{array}{l}\text { Total No. of Men } \\
\text { stating reasons } \\
\text { for insufficient } \\
\text { participation }\end{array}$}} & \multicolumn{4}{|c|}{ Total No. Of Participations } \\
\hline & & Ijike & Dislike & Indif. & & & Mkly. & Mthly. & Yrly. & Part. Index \\
\hline \multirow[b]{2}{*}{ Boxing } & No. & 35 & 13 & 46 & \multirow{2}{*}{$\begin{array}{l}\text { Health } \\
\text { Time } \\
\text { Money } \\
\text { Facilities } \\
\text { Knowledge } \\
\text { and Skill } \\
\quad \text { TORAL } \\
\end{array}$} & 7 & \multirow[t]{2}{*}{2} & \multirow[t]{2}{*}{1} & \multirow[t]{2}{*}{12} & \multirow[t]{2}{*}{2.40} \\
\hline & of & 37.2 & 13.8 & 48.9 & & $\begin{array}{c}0 \\
1 \\
\frac{0}{13}\end{array}$ & & & & \\
\hline \multirow[b]{2}{*}{ Calisthenics } & No. & 21 & 13 & 60 & \multirow{2}{*}{$\begin{array}{l}\text { Heal th } \\
\text { Time } \\
\text { Money } \\
\text { Facilities } \\
\text { Knowledge } \\
\text { and Skill } \\
\text { TOTAI }\end{array}$} & 4 & \multirow[t]{2}{*}{12} & \multirow[t]{2}{*}{4} & \multirow[t]{2}{*}{0} & \multirow[t]{2}{*}{$7 \cdot 20$} \\
\hline & of & 22.3 & 13.8 & 63.0 & & $\begin{array}{c}0 \\
0 \\
0 \\
10\end{array}$ & & & & \\
\hline \multirow[b]{2}{*}{$\begin{array}{l}\text { Canoeing } \\
\text { ( } 5 \text { lionths) }\end{array}$} & IIO. & 28 & 13 & 53 & \multirow{2}{*}{$\begin{array}{l}\text { Health } \\
\text { Time } \\
\text { Boney } \\
\text { Facilities } \\
\text { Inowledge } \\
\text { and Skill } \\
\quad \text { TOTAL }\end{array}$} & 1 & \multirow[t]{2}{*}{0} & \multirow[t]{2}{*}{5} & \multirow[t]{2}{*}{17} & \multirow[t]{2}{*}{.45} \\
\hline & 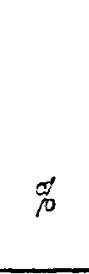 & 29.8 & 13.8 & 56.4 & & $\begin{array}{r}1 \\
10 \\
\frac{0}{18}\end{array}$ & & & & \\
\hline
\end{tabular}


TABIE 34 (Continued)

$\$ 4,000-\$ 5,000$ Income Group

\begin{tabular}{|c|c|c|c|c|c|c|c|c|c|c|}
\hline \multirow[t]{2}{*}{ Activity } & & \multicolumn{3}{|c|}{$\begin{array}{l}\text { Total lio. ồ iren } \\
\text { indicating attitude } \\
\text { toward activity }\end{array}$} & \multirow{2}{*}{\multicolumn{2}{|c|}{$\begin{array}{l}\text { Total No. of Men } \\
\text { stating reasons } \\
\text { for insufficient } \\
\text { participation }\end{array}$}} & \multicolumn{4}{|c|}{ Total No. of Participations } \\
\hline & & Like & Dislike & Indif. & & & Wkly. & Ifthly. & YrIy. & Part. Index \\
\hline \multirow[b]{2}{*}{ Card Playing } & No. & 71 & 13 & 10 & \multirow{2}{*}{$\begin{array}{l}\text { Wealth } \\
\text { Time } \\
\text { Money } \\
\text { Facilities } \\
\text { Knowledge } \\
\text { and Skili } \\
\text { TOTAL } \\
\end{array}$} & \multirow{2}{*}{$\begin{array}{r}0 \\
12 \\
4 \\
0 \\
0 \\
\frac{0}{16} \\
\end{array}$} & \multirow[t]{2}{*}{38} & \multirow[t]{2}{*}{33} & \multirow[t]{2}{*}{19} & \multirow[t]{2}{*}{25.40} \\
\hline & $\mathscr{q}$ & 75.5 & 13.3 & 10.6 & & & & & & \\
\hline \multirow[b]{2}{*}{ Checkers } & No. & $3 I$ & 16 & 47 & \multirow{2}{*}{$\begin{array}{l}\text { Health } \\
\text { Time } \\
\text { Honey } \\
\text { Facilities } \\
\text { Knowledge } \\
\text { and Skill } \\
\text { TOTAL } \\
\end{array}$} & 0 & \multirow[t]{2}{*}{13} & \multirow[t]{2}{*}{9} & \multirow[t]{2}{*}{16} & \multirow[t]{2}{*}{11.3} \\
\hline & 落 & 33.0 & 17.0 & 50.0 & & $\begin{array}{l}0 \\
0 \\
\frac{1}{9} \\
\end{array}$ & & & & \\
\hline \multirow[b]{2}{*}{ Conversing } & No. & 53 & 3 & 38 & \multirow{2}{*}{$\begin{array}{l}\text { Health } \\
\text { Time } \\
\text { Money } \\
\text { Facilities } \\
\text { Knowledge } \\
\text { and Skill } \\
\text { TOTAL } \\
\end{array}$} & 0 & \multirow[t]{2}{*}{92} & \multirow[t]{2}{*}{0} & \multirow[t]{2}{*}{365} & \multirow[t]{2}{*}{54.80} \\
\hline & 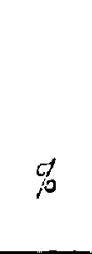 & 56.4 & 3.2 & 40.4 & & $\begin{array}{l}0 \\
0 \\
0 \\
\frac{0}{5}\end{array}$ & & & & \\
\hline
\end{tabular}


TABLE 34 (Continued)

垵4,000-\$5,000 Income Group

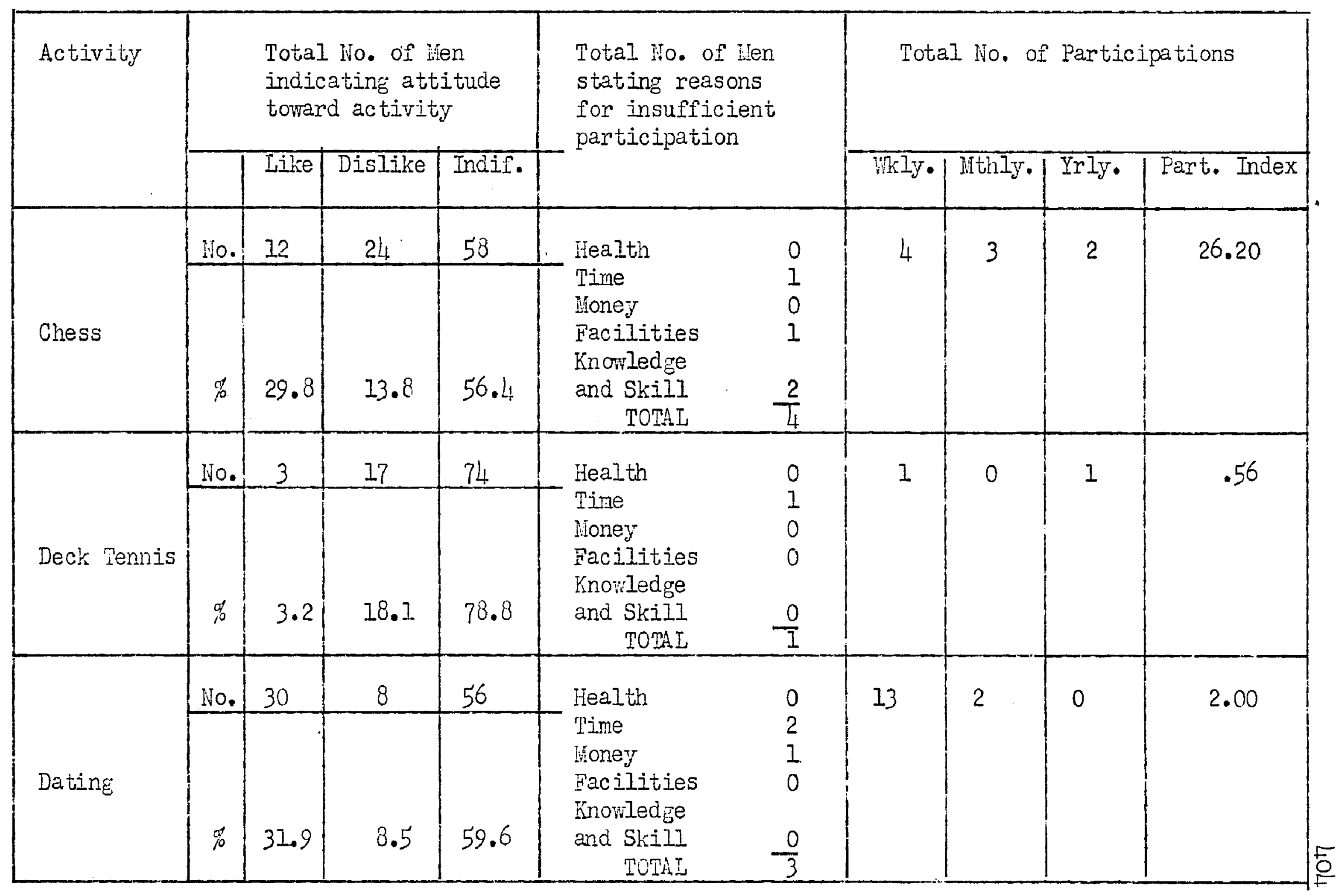


TABIE 34 (Continued)

$\$ 4,000-\$ 5,000$ Income Group

\begin{tabular}{|c|c|c|c|c|c|c|c|c|c|c|}
\hline \multirow[t]{2}{*}{ Activity } & & \multicolumn{3}{|c|}{$\begin{array}{l}\text { Total No. of Men } \\
\text { indicating attitude } \\
\text { toward activity }\end{array}$} & \multirow{2}{*}{\multicolumn{2}{|c|}{$\begin{array}{l}\text { Total No. of Jen } \\
\text { stating reasons } \\
\text { for insufficient } \\
\text { participation }\end{array}$}} & \multicolumn{4}{|c|}{ Total No. of Participations } \\
\hline & & Iike & Dislike & Indif. & & & 䎢Iy. & inthly. & $\mathrm{YrIy}$ & Part. Index \\
\hline Driving & No. & 72.4 & 7.4 & 20.2 & $\begin{array}{l}\text { Health } \\
\text { Time } \\
\text { INoney } \\
\text { Facilities } \\
\text { Knorledge } \\
\text { and Skill } \\
\quad \text { TOTAL } \\
\end{array}$ & $\begin{array}{r}0 \\
4 \\
6 \\
1 \\
0 \\
11 \\
\end{array}$ & 131 & 2 & 0 & 72.70 \\
\hline Fencing & No. & 9.6 & 20.2 & 70.3 & $\begin{array}{l}\text { Health } \\
\text { Time } \\
\text { Honey } \\
\text { Facilities } \\
\text { Knowledge } \\
\text { and Skill } \\
\quad \text { TOTAL } \\
\end{array}$ & $\begin{array}{l}0 \\
3 \\
1 \\
2 \\
2 \\
\\
\end{array}$ & 0 & 1 & 5 & .18 \\
\hline $\begin{array}{l}\text { Field Events } \\
\text { (Track) } \\
\text { (4 Honths) }\end{array}$ & No. & 23.4 & 0 & 76.6 & $\begin{array}{l}\text { Health } \\
\text { Time } \\
\text { Money } \\
\text { Facilities } \\
\text { Knowledge } \\
\text { and Skill } \\
\quad \text { TOTAL } \\
\end{array}$ & $\begin{array}{c}4 \\
8 \\
0 \\
1 \\
0 \\
\frac{0}{13}\end{array}$ & 1 & 3 & 2 & .33 \\
\hline
\end{tabular}


TABLE 34 (Continued)

$\$ 4,000-\$ 5,000$ Income Group

\begin{tabular}{|c|c|c|c|c|c|c|c|c|c|c|}
\hline \multirow[t]{2}{*}{ Activity } & \multicolumn{4}{|c|}{$\begin{array}{l}\text { Total No. of isen } \\
\text { indicating attitude } \\
\text { toward activity }\end{array}$} & \multirow{2}{*}{\multicolumn{2}{|c|}{$\begin{array}{l}\text { Total No. of hen } \\
\text { stating reasons } \\
\text { for insufficient } \\
\text { participation }\end{array}$}} & \multicolumn{4}{|c|}{ Total No. of Participations } \\
\hline & & Like & Dislike & Indif & & & Whly & Mthly. & Yrly. & Part. Index \\
\hline \multirow[b]{2}{*}{$\begin{array}{l}\text { Bait } \\
\text { Casting } \\
\text { (6 Months) }\end{array}$} & No. & $4 I$ & 10 & 43 & \multirow{2}{*}{$\begin{array}{l}\text { Health } \\
\text { Time } \\
\text { Money } \\
\text { Facilities } \\
\text { linowledge } \\
\text { and Skill } \\
\text { TOTAI }\end{array}$} & \multirow{2}{*}{$\begin{array}{r}0 \\
6 \\
1 \\
2 \\
\frac{3}{12} \\
\end{array}$} & \multirow[t]{2}{*}{13} & \multirow[t]{2}{*}{16} & \multirow[t]{2}{*}{$1_{4}$} & \multirow[t]{2}{*}{4.80} \\
\hline & & & & & & & & & & \\
\hline \multirow[b]{2}{*}{$\begin{array}{l}\text { Still } \\
\text { Fishing } \\
\text { (E Honths) }\end{array}$} & No. & 53 & 7 & 34 & \multirow[b]{2}{*}{$\begin{array}{l}\text { Health } \\
\text { Time } \\
\text { Honey } \\
\text { Facilities } \\
\text { Knowledge } \\
\text { and Skill } \\
\quad \text { TOTAL } \\
\end{array}$} & \multirow[b]{2}{*}{$\begin{array}{r}0 \\
16 \\
0 \\
3 \\
\frac{3}{22} \\
\end{array}$} & \multirow[t]{2}{*}{17} & \multirow[t]{2}{*}{28} & \multirow[t]{2}{*}{46} & \multirow[t]{2}{*}{6.98} \\
\hline & $\%$ & 56.4 & 7.4 & 36.2 & & & & & & \\
\hline \multirow[b]{2}{*}{$\begin{array}{l}\text { Football } \\
\text { (3 Honths) }\end{array}$} & No. & 50 & 8 & 36 & \multirow[b]{2}{*}{$\begin{array}{l}\text { Heal th } \\
\text { Time } \\
\text { Money } \\
\text { Facilities } \\
\text { Knowledge } \\
\text { and Skill } \\
\quad \text { TOTAL }\end{array}$} & 5 & \multirow[t]{2}{*}{2} & \multirow[t]{2}{*}{6} & \multirow[t]{2}{*}{27} & \multirow[t]{2}{*}{.75} \\
\hline & 落 & 53.2 & 0.5 & 30.3 & & $\begin{array}{l}7 \\
0 \\
3 \\
\frac{1}{16}\end{array}$ & & & & \\
\hline
\end{tabular}


TABIE 34 (Continued)

$\$ 4,000-45,000$ Income Group

\begin{tabular}{|c|c|c|c|c|c|c|c|c|c|c|}
\hline \multirow[t]{2}{*}{ Activity } & & \multicolumn{3}{|c|}{$\begin{array}{l}\text { Total Io. of Men } \\
\text { indicating attitude } \\
\text { toward activity }\end{array}$} & \multirow{2}{*}{\multicolumn{2}{|c|}{$\begin{array}{l}\text { Total No. of Men } \\
\text { stating reasons } \\
\text { for insufficient } \\
\text { participation }\end{array}$}} & \multicolumn{4}{|c|}{ Total No: of Participations } \\
\hline & & Iike & Dislike & Indif. & & & Wrky. & Ifthly. & Yrly. & Part. Index \\
\hline \multirow[b]{2}{*}{$\begin{array}{l}\text { Gardening } \\
\text { (5 Months) }\end{array}$} & No. & 57 & 10 & 27 & \multirow[b]{2}{*}{$\begin{array}{l}\text { Health } \\
\text { Tine } \\
\text { Honey } \\
\text { Facilities } \\
\text { Knowledge } \\
\text { and Skill } \\
\quad \text { TOTHL } \\
\end{array}$} & \multirow[b]{2}{*}{$\begin{array}{r}0 \\
7 \\
1 \\
3 \\
0 \\
11 \\
\end{array}$} & \multirow[t]{2}{*}{52} & \multirow[t]{2}{*}{3} & \multirow[t]{2}{*}{71} & \multirow[t]{2}{*}{12.90} \\
\hline & $\not 8$ & 60.6 & 10.6 & 20.7 & & & & & & \\
\hline \multirow[b]{2}{*}{$\begin{array}{l}\text { Golf } \\
\text { (Li Nonths) }\end{array}$} & Ho. & 43 & $\underline{14}$ & 37 & \multirow{2}{*}{$\begin{array}{l}\text { Health } \\
\text { Time } \\
\text { Honey } \\
\text { Facilities } \\
\text { Knowledge } \\
\text { and Skill } \\
\text { TOTAL } \\
\end{array}$} & 3 & \multirow[t]{2}{*}{$\mathrm{IH}_{4}$} & \multirow[t]{2}{*}{7} & \multirow[t]{2}{*}{24} & \multirow[t]{2}{*}{3.13} \\
\hline & $\not$ & 45.7 & 14.9 & $39 \cdot 4$ & & $\begin{array}{r}0 \\
3 \\
5 \\
\frac{3}{22} \\
\end{array}$ & & & & \\
\hline \multirow[b]{2}{*}{ Gymnastics } & No. & 15 & 16 & 63 & \multirow[b]{2}{*}{$\begin{array}{l}\text { Health } \\
\text { Time } \\
\text { Money } \\
\text { Facilities } \\
\text { Knowledge } \\
\text { and Skill }\end{array}$} & 4 & \multirow[t]{2}{*}{3} & \multirow[t]{2}{*}{3} & \multirow[t]{2}{*}{2} & \multirow[t]{2}{*}{2.10} \\
\hline & of & 16.0 & 17.0 & 67.0 & & $\begin{array}{r}4 \\
1 \\
1 \\
0 \\
10\end{array}$ & & & & \\
\hline
\end{tabular}


TABL 34 (Continued)

$\$ 4,000-\$ 5,000$ Income Group

\begin{tabular}{|c|c|c|c|c|c|c|c|c|c|c|}
\hline \multirow[t]{2}{*}{ Activity } & \multicolumn{4}{|c|}{$\begin{array}{l}\text { Total No. of lWen } \\
\text { indicating attitude } \\
\text { toward activity }\end{array}$} & \multirow{2}{*}{\multicolumn{2}{|c|}{$\begin{array}{l}\text { Total No. of Wen } \\
\text { stating reasons } \\
\text { for insufficient } \\
\text { participation }\end{array}$}} & \multicolumn{4}{|c|}{ Total No. of Participations } \\
\hline & & Like & Dislike & Indif. & & & Whly. & Mthly. & YrIy. & Part. Index \\
\hline \multirow[b]{2}{*}{$\begin{array}{l}\text { Handball } \\
\text { (9 Months) }\end{array}$} & INo. & 15 & 15. & 59 & \multirow{2}{*}{$\begin{array}{l}\text { Health } \\
\text { Time } \\
\text { Mroney } \\
\text { Facilities } \\
\text { Knowledge } \\
\text { and Skill } \\
\quad \text { TOTAI } \\
\end{array}$} & \multirow{2}{*}{$\begin{array}{r}3 \\
5 \\
0 \\
3 \\
\frac{1}{12} \\
\end{array}$} & \multirow[t]{2}{*}{3} & \multirow[t]{2}{*}{8} & \multirow[t]{2}{*}{2} & \multirow[t]{2}{*}{2.03} \\
\hline & $\%$ & 21.3 & 16.0 & 62.8 & & & & & & \\
\hline \multirow[b]{2}{*}{$\begin{array}{l}\text { Hiking } \\
\text { (9 Months) }\end{array}$} & No. & 22 & 10 & 62 & \multirow{2}{*}{$\begin{array}{l}\text { Health } \\
\text { Time } \\
\text { Money } \\
\text { Facilities } \\
\text { Knowledge } \\
\text { and Skill } \\
\quad \text { ToThL } \\
\end{array}$} & \multirow{2}{*}{$\begin{array}{l}3 \\
5 \\
0 \\
0 \\
0 \\
8\end{array}$} & \multirow[t]{2}{*}{2} & \multirow[t]{2}{*}{9} & \multirow[t]{2}{*}{8} & \multirow[t]{2}{*}{1.80} \\
\hline & $\%$ & 23.4 & 10.6 & 66.0 & & & & & & \\
\hline \multirow[b]{2}{*}{$\begin{array}{l}\text { Horseback } \\
\text { Riding } \\
\text { (9 Months) }\end{array}$} & No. & 35 & 9 & 50 & \multirow{2}{*}{$\begin{array}{l}\text { Iealth } \\
\text { Time } \\
\text { lloney } \\
\text { Facilities } \\
\text { Knowledge } \\
\text { and Skill } \\
\text { TOTAL }\end{array}$} & 1 & \multirow[t]{2}{*}{3} & \multirow[t]{2}{*}{4} & \multirow[t]{2}{*}{30} & \multirow[t]{2}{*}{1.95} \\
\hline & $\%$ & 37.2 & 9.6 & 53.2 & & $\begin{array}{l}6 \\
7 \\
\frac{1}{23}\end{array}$ & & & & \\
\hline
\end{tabular}


TABIE 34 (Continued)

$\$ 4,000-\$ 5,000$ Income Group

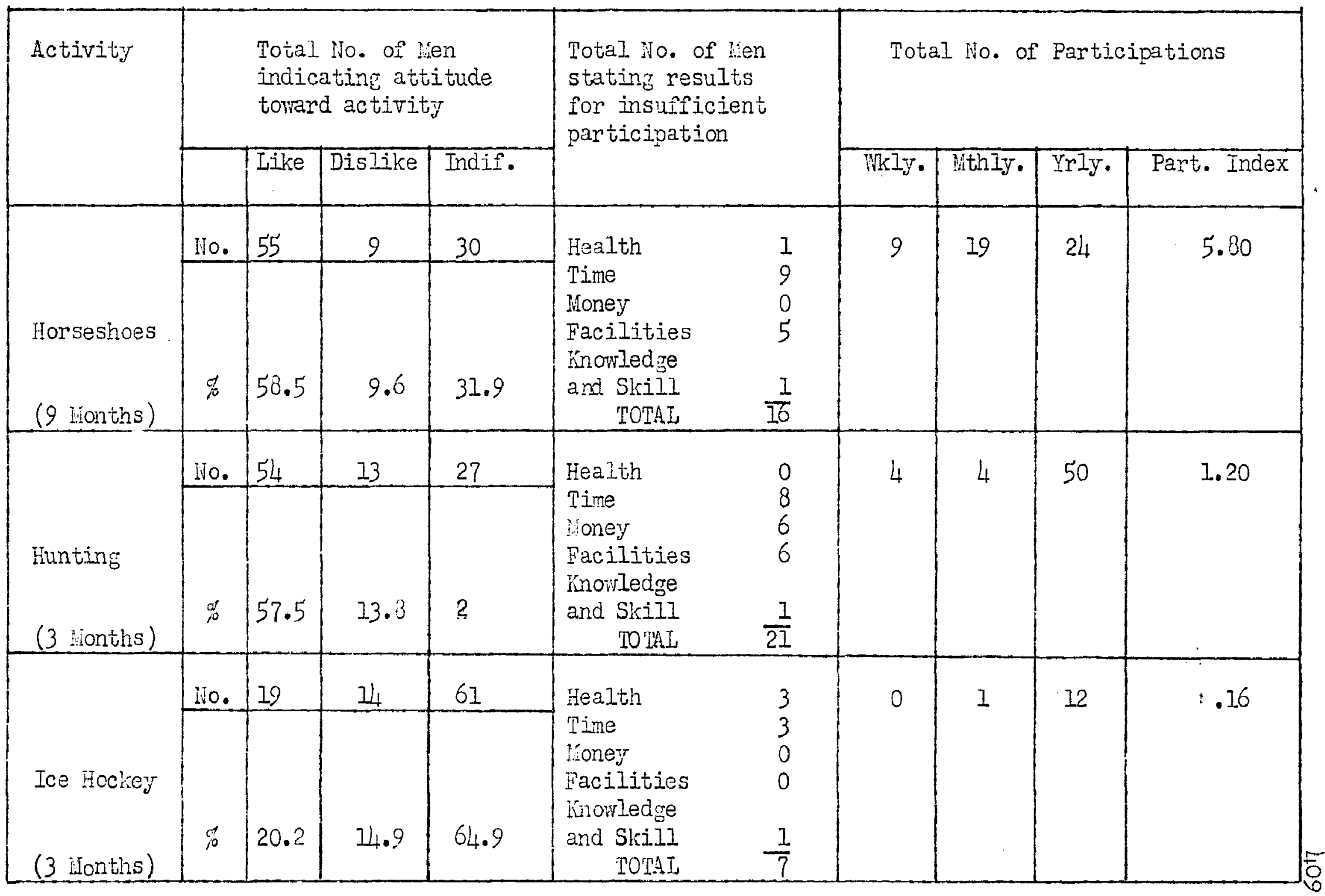


TABLE 34 (Continued)

\$4,000-\$5,000 Income Group

\begin{tabular}{|c|c|c|c|c|c|c|c|c|c|c|}
\hline \multirow[t]{2}{*}{ Activity } & & \multicolumn{3}{|c|}{$\begin{array}{l}\text { Total No. of Men } \\
\text { indicating attitude } \\
\text { toward activity }\end{array}$} & \multirow{2}{*}{\multicolumn{2}{|c|}{$\begin{array}{l}\text { Total No. of Men } \\
\text { stating reasons } \\
\text { for insufficient } \\
\text { participation }\end{array}$}} & \multicolumn{4}{|c|}{ Total No. of Participations } \\
\hline & & Iike & Dislike & Indif. & & & Whly. & Withly. & $\operatorname{Ir} \mathrm{ly}$ & Part. Index \\
\hline \multirow[b]{2}{*}{ Ice Skating } & No. & 29 & 13 & 52 & \multirow{2}{*}{$\begin{array}{l}\text { Health } \\
\text { Time } \\
\text { Lioney } \\
\text { Facilitics } \\
\text { Knowledge } \\
\text { and Skill } \\
\quad \text { TOTAL } \\
\end{array}$} & \multirow{2}{*}{$\begin{array}{l}2 \\
4 \\
0 \\
1 \\
1 \\
\frac{1}{8} \\
\end{array}$} & \multirow[t]{2}{*}{1} & \multirow[t]{2}{*}{ I } & \multirow[t]{2}{*}{28} & \multirow[t]{2}{*}{.47} \\
\hline & $\not t$ & 30.9 & 13.3 & 55.3 & & & & & & \\
\hline \multirow[b]{2}{*}{ Letal Craft } & No. & 22 & 10 & 62 & \multirow[b]{2}{*}{$\begin{array}{l}\text { Fealth } \\
\text { Time } \\
\text { Money } \\
\text { Facilities } \\
\text { Knowledge } \\
\text { and Skill } \\
\quad \text { TOTAL } \\
\end{array}$} & 0 & \multirow[t]{2}{*}{7} & \multirow[t]{2}{*}{1} & \multirow[t]{2}{*}{5} & \multirow[t]{2}{*}{$4 \cdot 10$} \\
\hline & 寉 & 23.4 & 10.6 & 66.0 & & $\begin{array}{l}3 \\
2 \\
3 \\
1 \\
9\end{array}$ & & & & \\
\hline \multirow[b]{2}{*}{ Movies } & No. & 72 & 2 & 20 & \multirow{2}{*}{$\begin{array}{l}\text { Health } \\
\text { Time } \\
\text { lioney } \\
\text { Facilities } \\
\text { Knowledge } \\
\text { and Skill } \\
\text { TOTAL }\end{array}$} & 0 & \multirow[t]{2}{*}{21} & \multirow[t]{2}{*}{35} & \multirow[t]{2}{*}{73} & \multirow[t]{2}{*}{16.90} \\
\hline & $\not 10$ & 76.0 & 2.1 & 21.3 & & $\begin{array}{r}4 \\
0 \\
0 \\
12\end{array}$ & & & & \\
\hline
\end{tabular}


TABLE 34 (Continued)

\$4,000-\$5,000 Income Group

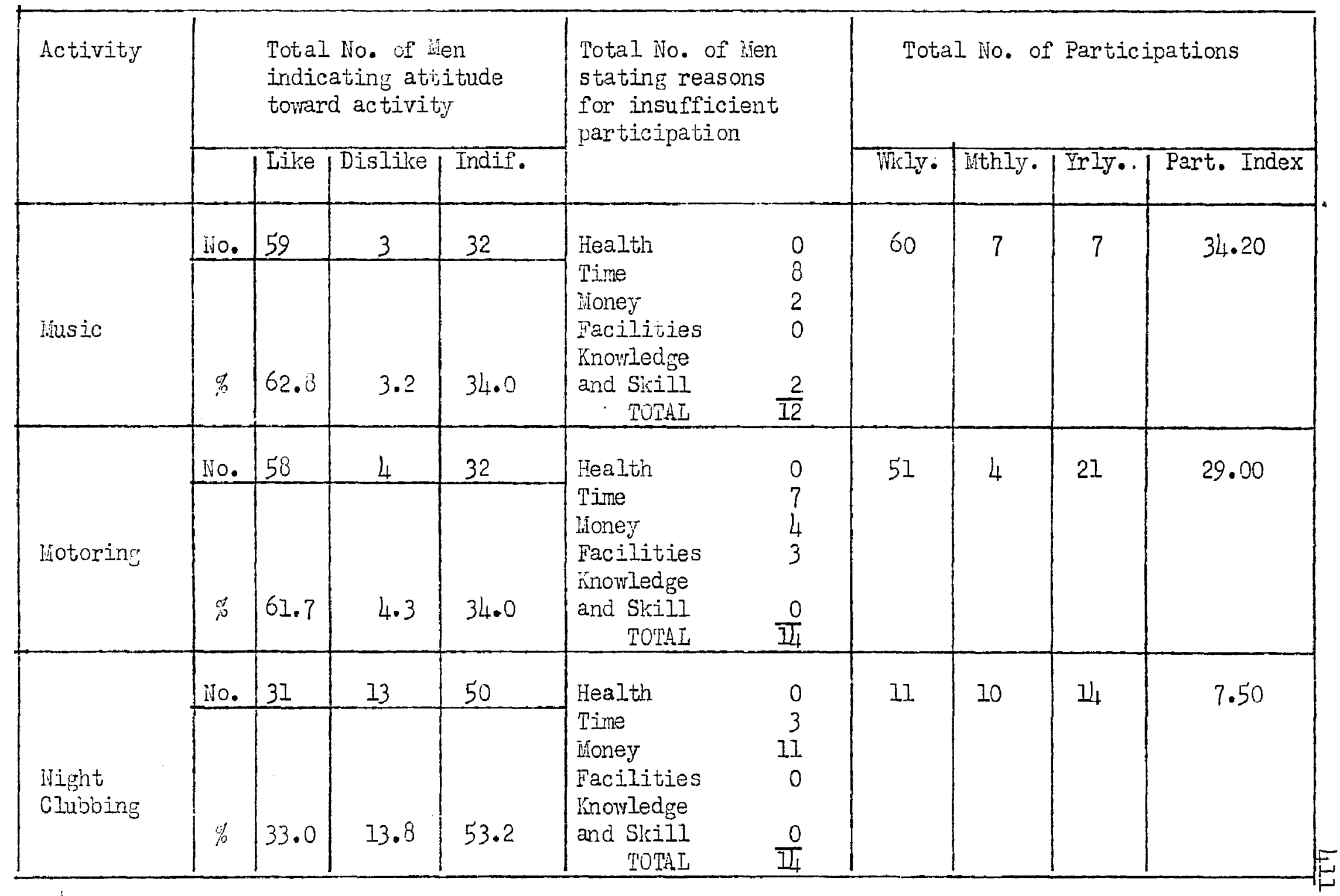


TABIE 34 (Continued)

4,000-35,000 Income Group

\begin{tabular}{|c|c|c|c|c|c|c|c|c|c|c|}
\hline \multirow[t]{2}{*}{ Activity } & & \multicolumn{3}{|c|}{$\begin{array}{l}\text { Total No. of lien } \\
\text { indicating attitude } \\
\text { toward activity }\end{array}$} & \multirow{2}{*}{\multicolumn{2}{|c|}{$\begin{array}{l}\text { Total io. of len } \\
\text { stating reasons } \\
\text { for insufficient } \\
\text { participation }\end{array}$}} & \multicolumn{4}{|c|}{ Total Ho. of Participations } \\
\hline & & Like & Dislike & Indif. & & & Wkly. & Jithly. & Yrly. & Part. Index \\
\hline \multirow[b]{2}{*}{ Ping-Pong } & No. & 33 & 15 & 46 & \multirow{2}{*}{$\begin{array}{l}\text { Health } \\
\text { Time } \\
\text { Woney } \\
\text { Facilities } \\
\text { Knorledge } \\
\text { and Skill } \\
\quad \text { TOTAL } \\
\end{array}$} & \multirow{2}{*}{$\begin{array}{r}0 \\
4 \\
0 \\
8 \\
0 \\
12 \\
\end{array}$} & \multirow[t]{2}{*}{3} & \multirow[t]{2}{*}{12} & \multirow[t]{2}{*}{15} & \multirow[t]{2}{*}{3.140} \\
\hline & $\%$ & 35.1 & 16.0 & $40 \hat{.9}$ & & & & & & \\
\hline \multirow[b]{2}{*}{$\begin{array}{l}\text { Puttering, } \\
\text { Repairing, } \\
\text { etc. }\end{array}$} & No. & 62 & 4 & 23 & \multirow{2}{*}{$\begin{array}{l}\text { ilealth } \\
\text { Time } \\
\text { Honey } \\
\text { Facilities } \\
\text { Knowledge } \\
\text { and Skill } \\
\quad \text { TOTAL } \\
\end{array}$} & 0 & \multirow[t]{2}{*}{82} & \multirow[t]{2}{*}{10} & \multirow[t]{2}{*}{11} & \multirow[t]{2}{*}{46.80} \\
\hline & $\%$ & 66.0 & $4 \cdot 3$ & 29.8 & & $\begin{array}{r}1 \\
2 \\
0 \\
\frac{1}{10} \\
\end{array}$ & & & & \\
\hline \multirow[b]{2}{*}{$\begin{array}{l}\text { Listening } \\
\text { to Radio }\end{array}$} & No. & 70 & 0 & $2 ! i_{4}$ & \multirow{2}{*}{$\begin{array}{l}\text { Health } \\
\text { rime } \\
\text { Foney } \\
\text { Facilities } \\
\text { Knowledge } \\
\text { and Skill } \\
\quad \text { TOTAL } \\
\end{array}$} & 0 & \multirow[t]{2}{*}{149} & \multirow[t]{2}{*}{0} & \multirow[t]{2}{*}{0} & \multirow[t]{2}{*}{82.40} \\
\hline & $\%$ & $74 \cdot 5$ & 0 & 25.5 & & $\begin{array}{l}0 \\
0 \\
\frac{0}{2}\end{array}$ & & & & \\
\hline
\end{tabular}


TA3LE 34 (Continued)

$\$ 4,000-\$ 5,000$ Income Group

\begin{tabular}{|c|c|c|c|c|c|c|c|c|c|c|}
\hline \multirow[t]{2}{*}{ Activity } & & \multicolumn{3}{|c|}{$\begin{array}{l}\text { Totai No. of lien } \\
\text { indicating attitude } \\
\text { toward activity }\end{array}$} & \multirow{2}{*}{\multicolumn{2}{|c|}{$\begin{array}{l}\text { Total io. of len } \\
\text { stating reasons } \\
\text { for insufficient } \\
\text { participation }\end{array}$}} & \multicolumn{4}{|c|}{ Total No. of Participations } \\
\hline & & Like & Dislike & Indif. & & & Whe & Mthly. & Irly. & Part. Index \\
\hline \multirow[b]{2}{*}{ Watching TV } & No. & 80 & 3 & 11 & \multirow{2}{*}{$\begin{array}{l}\text { Health } \\
\text { Time } \\
\text { Money } \\
\text { Facilities } \\
\text { irnowledge } \\
\text { and Skill } \\
\text { TOTAI } \\
\end{array}$} & \multirow{2}{*}{$\begin{array}{l}0 \\
3 \\
0 \\
2 \\
\\
0 \\
5 \\
\end{array}$} & \multirow[t]{2}{*}{195} & \multirow[t]{2}{*}{0} & \multirow[t]{2}{*}{0} & \multirow[t]{2}{*}{107.9} \\
\hline & $\%$ & 85.1 & 3.2 & 11.7 & & & & & & \\
\hline \multirow[b]{2}{*}{ Readinz } & iro. & 71 & 4 & 19 & \multirow{2}{*}{$\begin{array}{l}\text { Heal th } \\
\text { Time } \\
\text { Tioney } \\
\text { Facilities } \\
\text { Knowledge } \\
\text { and Skill } \\
\text { TOTAL } \\
\end{array}$} & \multirow[b]{2}{*}{$\begin{array}{l}0 \\
8 \\
0 \\
0 \\
0 \\
0 \\
\end{array}$} & \multirow[t]{2}{*}{153} & \multirow[t]{2}{*}{5} & \multirow[t]{2}{*}{0} & \multirow[t]{2}{*}{85.30} \\
\hline & $g$ & 75.5 & 4.3 & 20.2 & & & & & & \\
\hline \multirow[b]{2}{*}{ Photography } & No. & 28 & 10 & 56 & \multirow[b]{2}{*}{$\begin{array}{l}\text { Health } \\
\text { Time } \\
\text { Money } \\
\text { Facilities } \\
\text { Knomledge } \\
\text { and Skill } \\
\quad \text { TOTAI }\end{array}$} & 0 & \multirow[t]{2}{*}{7} & \multirow[t]{2}{*}{12} & \multirow[t]{2}{*}{13} & \multirow[t]{2}{*}{5.50} \\
\hline & $\ddot{t}$ & 29.8 & 10.6 & 59.6 & & $\begin{array}{l}4 \\
3 \\
2\end{array}$ & & & & \\
\hline
\end{tabular}


TABLE 34 (Continued)

4, 000-5,000 Income Group

\begin{tabular}{|c|c|c|c|c|c|c|c|c|c|c|}
\hline \multirow[t]{2}{*}{ Activity } & & \multicolumn{3}{|c|}{$\begin{array}{l}\text { Total lo. of Wen } \\
\text { indicating attitude } \\
\text { toward activity }\end{array}$} & \multirow{2}{*}{\multicolumn{2}{|c|}{$\begin{array}{l}\text { Total ino. of lien } \\
\text { stating reasons } \\
\text { for insufficient } \\
\text { participation }\end{array}$}} & \multicolumn{4}{|c|}{ Total iso. of Participations } \\
\hline & & Like & Dislike & Indif. & & & Wkly. & Wthly. & Yrly. & Part. Index \\
\hline \multirow[b]{2}{*}{$\begin{array}{l}\text { Roller } \\
\text { Skating }\end{array}$} & No. & 22 & 9 & 63 & \multirow{2}{*}{$\begin{array}{l}\text { Health } \\
\text { Time } \\
\text { Iíney } \\
\text { Facilities } \\
\text { Knowledge } \\
\text { and Skill } \\
\text { TOTAI } \\
\end{array}$} & \multirow{2}{*}{$\begin{array}{l}4 \\
9 \\
0 \\
1 \\
0 \\
I_{4} \\
\end{array}$} & \multirow[t]{2}{*}{0} & \multirow[t]{2}{*}{5} & \multirow[t]{2}{*}{24} & \multirow[t]{2}{*}{.90} \\
\hline & $\%$ & 23.4 & 9.6 & 67.0 & & & & & & \\
\hline \multirow[b]{2}{*}{ Painting } & ivo. & 21 & 12 & 61 & \multirow{2}{*}{$\begin{array}{l}\text { Health } \\
\text { Time } \\
\text { Money } \\
\text { Facilities } \\
\text { Knowledge } \\
\text { and Skill } \\
\quad \text { TOTAL } \\
\end{array}$} & 0 & \multirow[t]{2}{*}{1} & \multirow[t]{2}{*}{8} & \multirow[t]{2}{*}{12} & \multirow[t]{2}{*}{1.70} \\
\hline & $\%$ & 22.3 & 12.8 & 64.9 & & $\begin{array}{l}0 \\
0 \\
0 \\
0 \\
\end{array}$ & & & & \\
\hline \multirow[b]{2}{*}{$\begin{array}{l}\text { Social } \\
\text { Drintine }\end{array}$} & No. & 47 & 11 & 36 & \multirow{2}{*}{$\begin{array}{l}\text { Health } \\
\text { Time } \\
\text { Money } \\
\text { Facilities } \\
\text { Knowledge } \\
\text { and Skill } \\
\text { TOTAL }\end{array}$} & 0 & \multirow[t]{2}{*}{36} & \multirow[t]{2}{*}{13} & \multirow[t]{2}{*}{5} & \multirow[t]{2}{*}{21.80} \\
\hline & 总 & 50.0 & 11.7 & 38.3 & & $\begin{array}{l}5 \\
0 \\
0 \\
7\end{array}$ & & & & \\
\hline
\end{tabular}


TABIE 34 (Continued)

4h,000-6,000 Income Group

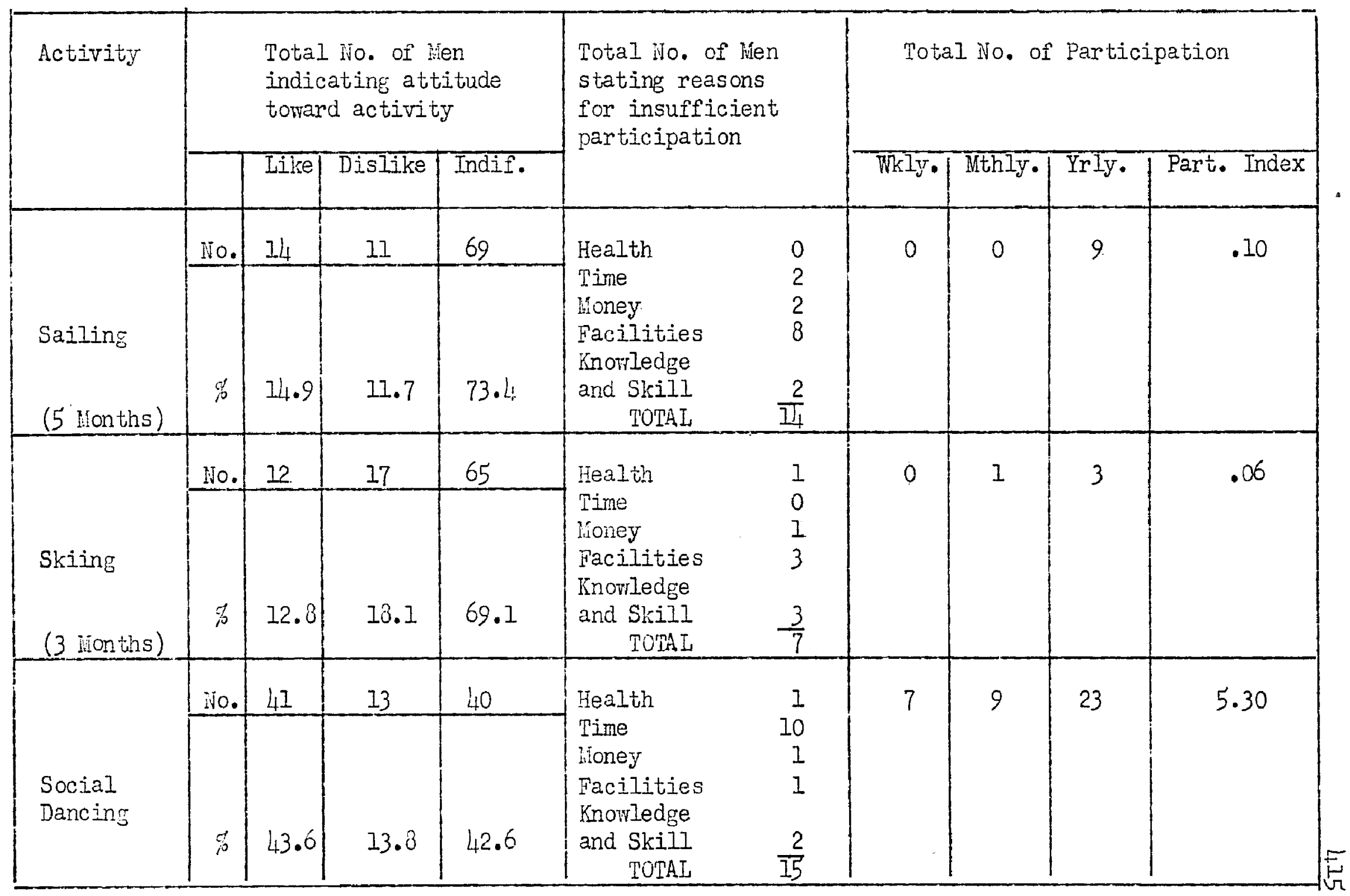


TABIE 34 (Continued)

$\$ 4,000-\$ 5,000$ Income Group

\begin{tabular}{|c|c|c|c|c|c|c|c|c|c|c|}
\hline \multirow[t]{2}{*}{ Activity } & \multicolumn{4}{|c|}{$\begin{array}{l}\text { Total iro. of Wen } \\
\text { indicating attitude } \\
\text { toward activity }\end{array}$} & \multirow{2}{*}{\multicolumn{2}{|c|}{$\begin{array}{l}\text { Total ifo. of lien } \\
\text { stiting reasons } \\
\text { for insufficient } \\
\text { participation }\end{array}$}} & \multicolumn{4}{|c|}{ Total No, of Participation } \\
\hline & & Like & Dislik & Indif. & & & W. Iy. & Wthly $\cdot 1$ & Yrly. & Part. Index \\
\hline \multirow[b]{2}{*}{$\begin{array}{l}\text { Softbali } \\
\text { (3 lionths) }\end{array}$} & $\mathrm{No}$ & 47 & 12 & 35 & \multirow{2}{*}{$\begin{array}{l}\text { Heal th } \\
\text { Time } \\
\text { Money } \\
\text { Facilities } \\
\text { Inowledge } \\
\text { and Skill } \\
\quad \text { TOTAL } \\
\end{array}$} & \multirow{2}{*}{$\begin{array}{r}1 \\
11 \\
0 \\
2 \\
\frac{0}{11}\end{array}$} & \multirow[t]{2}{*}{8} & \multirow[t]{2}{*}{9} & \multirow[t]{2}{*}{14} & \multirow[t]{2}{*}{1.50} \\
\hline & 若 & 50.0 & 12.0 & 37.2 & & & & & & \\
\hline \multirow[b]{2}{*}{$\begin{array}{l}\text { Speedball } \\
\text { (3 Honths) }\end{array}$} & ino. & 11 & 18 & 65 & \multirow{2}{*}{$\begin{array}{l}\text { Health } \\
\text { Time } \\
\text { Honey } \\
\text { Facilities } \\
\text { Knowledge } \\
\text { and Skill } \\
\text { TOTAL } \\
\end{array}$} & \multirow{2}{*}{$\begin{array}{l}0 \\
2 \\
0 \\
0 \\
1 \\
3 \\
\end{array}$} & \multirow[t]{2}{*}{1} & \multirow[t]{2}{*}{0} & \multirow[t]{2}{*}{5} & \multirow[t]{2}{*}{.20} \\
\hline & $\%$ & $11 . ?$ & 19.2 & 69.2 & & & & & & \\
\hline \multirow[b]{2}{*}{$\begin{array}{l}\text { Square } \\
\text { Dancing }\end{array}$} & No. & 19 & 13 & 57 & \multirow{2}{*}{$\begin{array}{l}\text { Health } \\
\text { Time } \\
\text { Koney } \\
\text { Facilities } \\
\text { Knowledge } \\
\text { and Skill } \\
\text { ToTAI }\end{array}$} & \multirow{2}{*}{$\begin{array}{c}0 \\
4 \\
1 \\
2 \\
\frac{4}{11}\end{array}$} & \multirow[t]{2}{*}{3} & \multirow[t]{2}{*}{1} & \multirow[t]{2}{*}{6} & \multirow[t]{2}{*}{1.30} \\
\hline & $\%$ & 20.2 & 19.2 & 60.6 & & & & & & \\
\hline
\end{tabular}


TABLIS 34 (Gontinued)

ph,000- \$5,000 Income Group

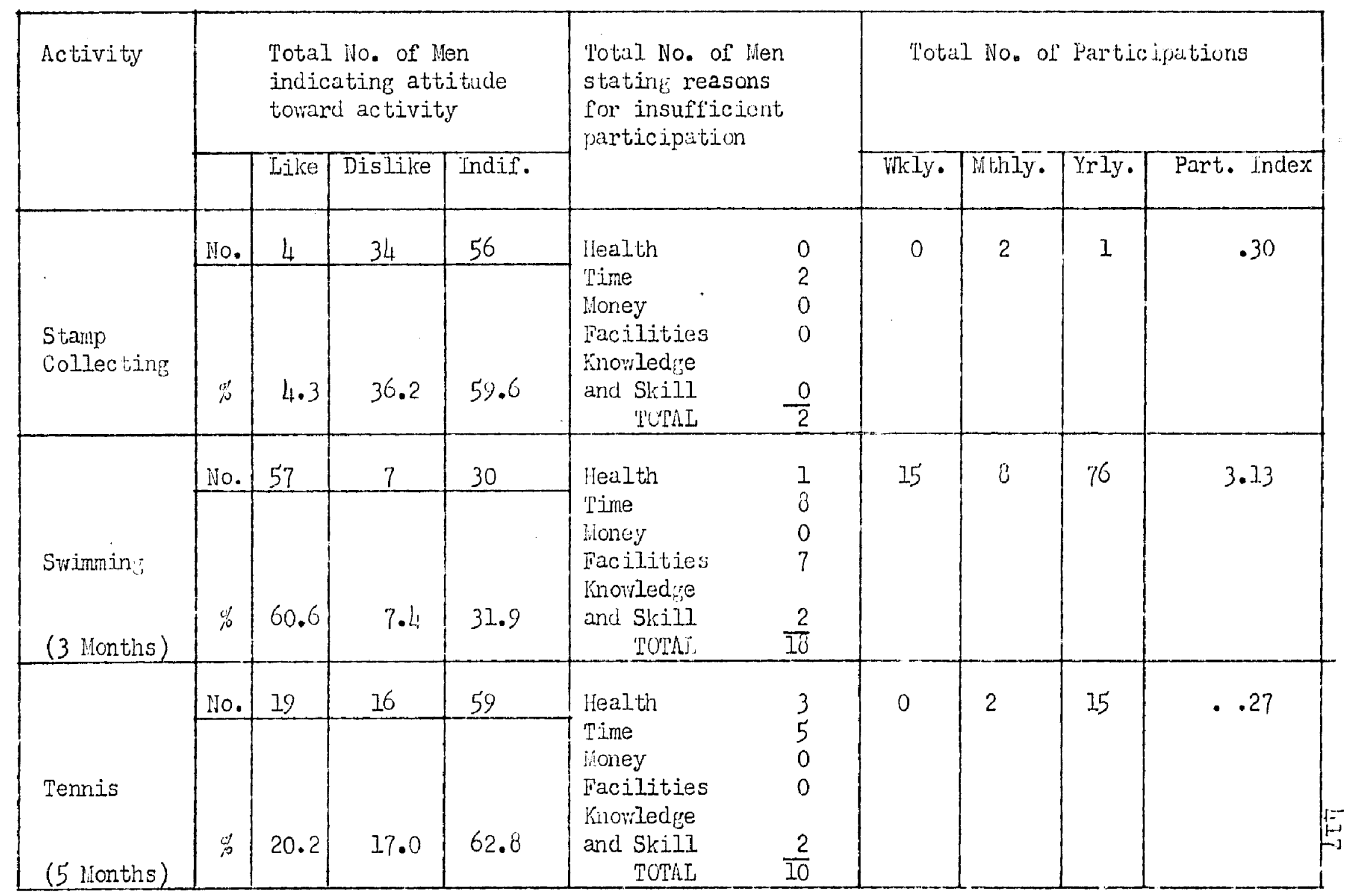


m. 3 IF 34 (Continued)

\$4,000-\$5,000 Incone Group

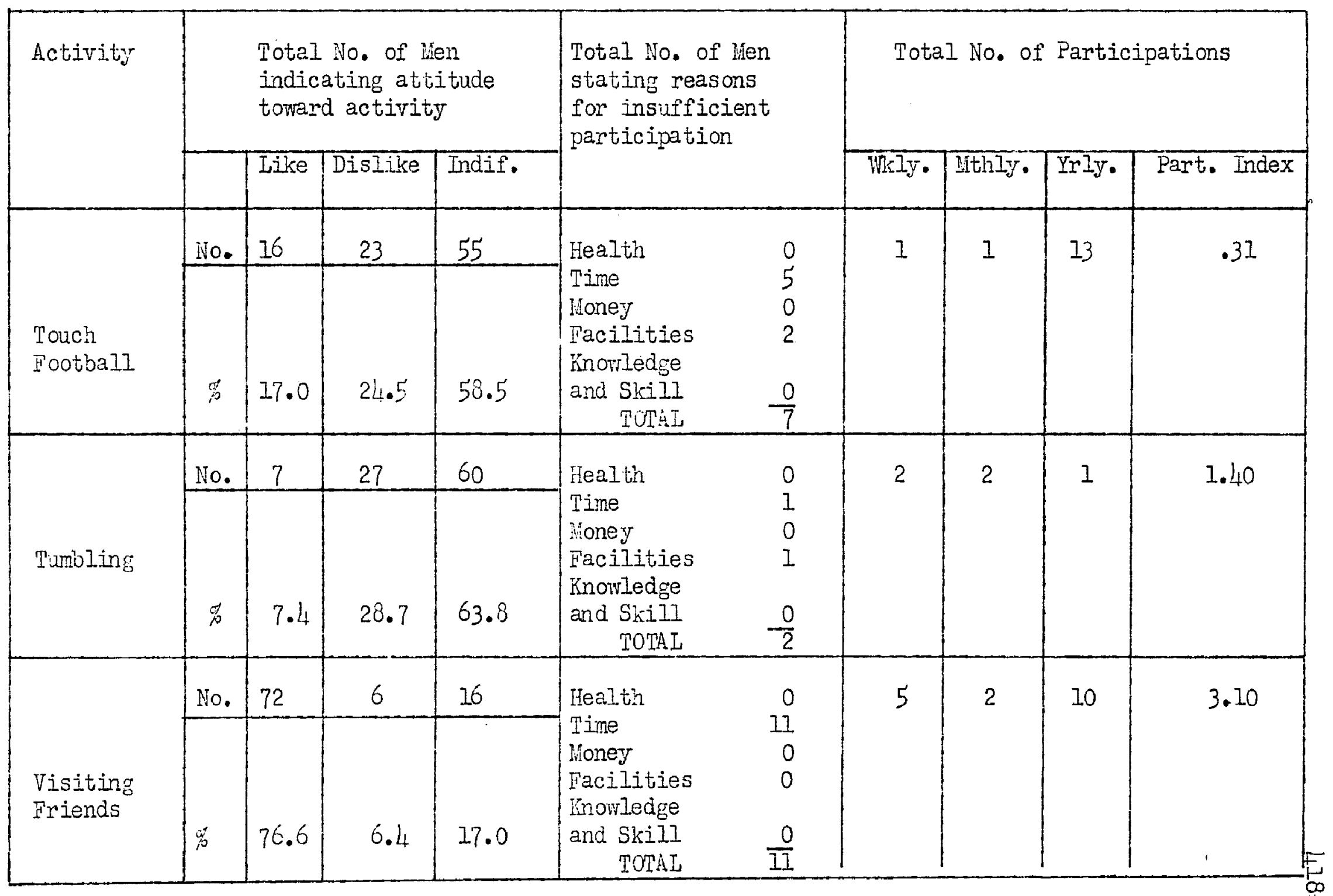


TABLE 34 (Continued)

\$4 ,000-i 5,000 Income Group

\begin{tabular}{|c|c|c|c|c|c|c|c|c|c|c|}
\hline \multirow[t]{2}{*}{ Activity } & \multicolumn{4}{|c|}{$\begin{array}{l}\text { Total iNo. of Hen } \\
\text { indicating attitude } \\
\text { Toward activity }\end{array}$} & \multirow{2}{*}{\multicolumn{2}{|c|}{$\begin{array}{l}\text { Total lio. of lien } \\
\text { stating reasons } \\
\text { for insifficient } \\
\text { participation }\end{array}$}} & \multicolumn{4}{|c|}{ Total No. of Farticipations } \\
\hline & & Like & Dislike & Indif. & & & WkIy. & lithly. & Yrly. & Part. Index \\
\hline \multirow[b]{2}{*}{ Volleyball } & No. & 16 & 17 & 61 & \multirow{2}{*}{$\begin{array}{l}\text { Health } \\
\text { Time } \\
\text { Jioney } \\
\text { Facilities } \\
\text { inowledge } \\
\text { and Skill } \\
\text { TOTAL } \\
\end{array}$} & \multirow{2}{*}{$\begin{array}{l}0 \\
2 \\
0 \\
1 \\
0 \\
\\
\end{array}$} & \multirow[t]{2}{*}{5} & \multirow[t]{2}{*}{2} & \multirow[t]{2}{*}{10} & \multirow[t]{2}{*}{3.10} \\
\hline & 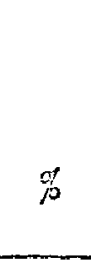 & 17.0 & 18.1 & 64.9 & & & & & & \\
\hline \multirow[b]{2}{*}{$\begin{array}{l}\text { Watching } \\
\text { Sport Event }\end{array}$} & No. & $76^{\prime}$ & 4 & $\underline{14}$ & \multirow[b]{2}{*}{$\begin{array}{l}\text { Healin } \\
\text { Time } \\
\text { Fioney } \\
\text { Facilities } \\
\text { Knowledge } \\
\text { and Skill } \\
\text { TOTAL }\end{array}$} & \multirow{2}{*}{$\begin{array}{r}0 \\
10 \\
6 \\
0 \\
0 \\
16 \\
\end{array}$} & \multirow[t]{2}{*}{41} & \multirow[t]{2}{*}{28} & \multirow[t]{2}{*}{49} & \multirow[t]{2}{*}{26.80} \\
\hline & $\%$ & 80.9 & 4.3 & 14.9 & & & & & & \\
\hline \multirow[b]{2}{*}{ Walking } & No. & 39 & 12 & 43 & \multirow{2}{*}{$\begin{array}{l}\text { Fealth } \\
\text { Time } \\
\text { Honey } \\
\text { Facilities } \\
\text { Knowledge } \\
\text { and Skill } \\
\text { TOTAI }\end{array}$} & 1 & \multirow[t]{2}{*}{53} & \multirow[t]{2}{*}{3} & \multirow[t]{2}{*}{3} & \multirow[t]{2}{*}{29.70} \\
\hline & $\not t$ & 47.5 & 12.8 & 45.7 & & $\begin{array}{l}1 \\
0 \\
0 \\
0 \\
2\end{array}$ & & & & \\
\hline
\end{tabular}


TABLE 34 (Continued)

$\$ 4,000-\$ 5,000$ Income Group

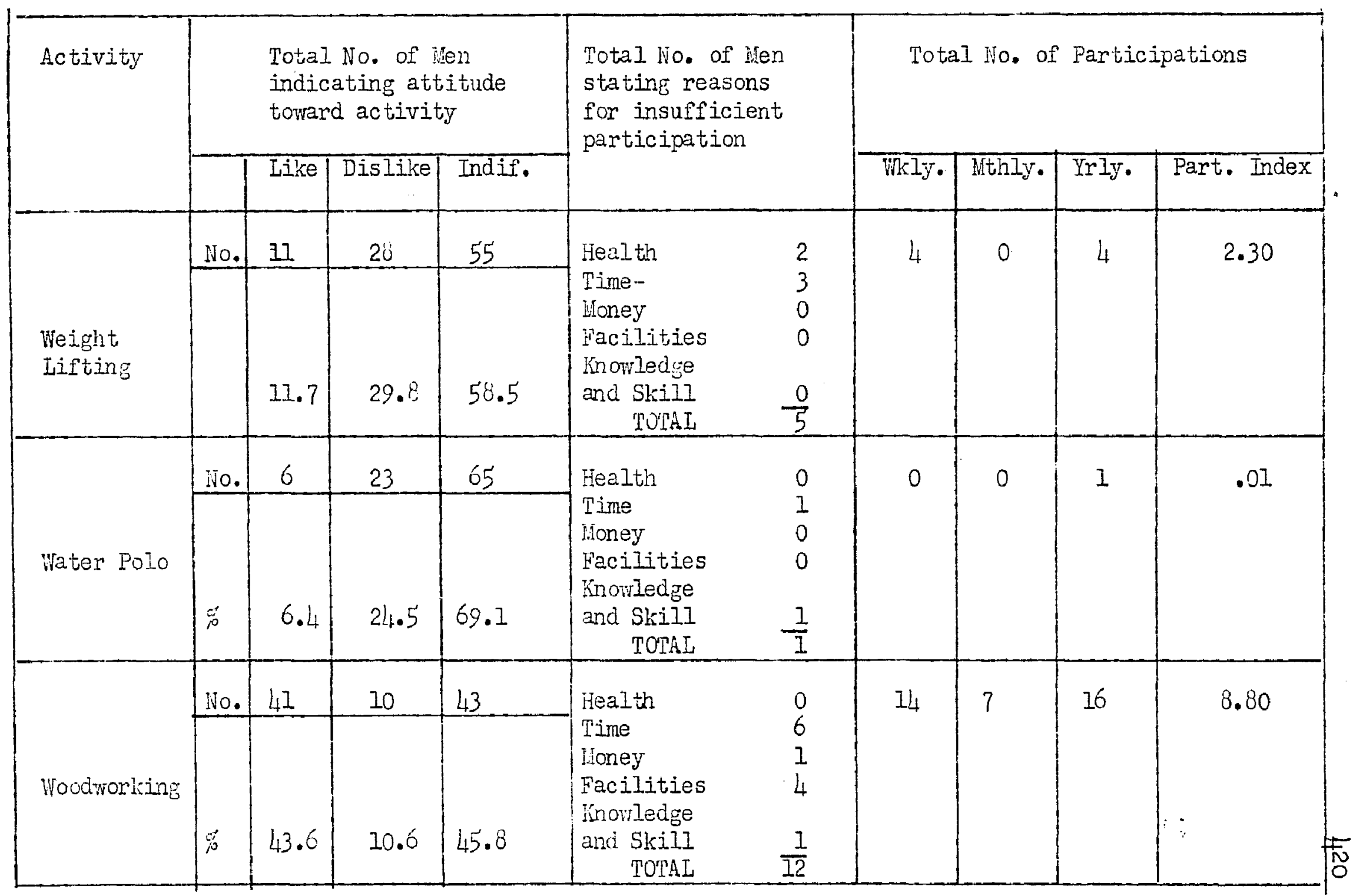


TABLE 34 (Continued)

$\$ 4,000-\$ 5,000$ Income Group

\begin{tabular}{|c|c|c|c|c|c|c|c|c|c|c|}
\hline \multirow[t]{2}{*}{ Activity } & \multicolumn{4}{|c|}{$\begin{array}{l}\text { Total No. of lien } \\
\text { indicating attitude } \\
\text { torard activity }\end{array}$} & \multirow{2}{*}{\multicolumn{2}{|c|}{$\begin{array}{l}\text { Total No. of hen } \\
\text { stating reasons } \\
\text { for insufficient } \\
\text { participation }\end{array}$}} & \multicolumn{4}{|c|}{ Total No. of Participations } \\
\hline & & Like & Dislike & Indif. & & & Wkly. & Ifthly. & Irly. & Part. Index \\
\hline \multirow[b]{2}{*}{$\begin{array}{l}\text { Wood } \\
\text { Carving }\end{array}$} & No. & 24 & 12 & 58 & \multirow{2}{*}{$\begin{array}{l}\text { Health } \\
\text { Time } \\
\text { Money } \\
\text { Facilities } \\
\text { Knowledge } \\
\text { and Skill } \\
\text { TOTAL } \\
\end{array}$} & \multirow{2}{*}{$\begin{array}{l}0 \\
3 \\
0 \\
4 \\
1 \\
1 \\
\end{array}$} & \multirow[t]{2}{*}{4} & \multirow[t]{2}{*}{3} & \multirow[t]{2}{*}{6} & \multirow[t]{2}{*}{2.70} \\
\hline & is & 25.5 & 12.5 & 61.7 & & & & & & \\
\hline \multirow[b]{2}{*}{ Wrestling } & No. & 23 & 23 & 48 & \multirow{2}{*}{$\begin{array}{l}\text { Health } \\
\text { Time } \\
\text { Money } \\
\text { Facilities } \\
\text { Knowledge } \\
\text { and Skill } \\
\text { TOTAI }\end{array}$} & 3 & \multirow[t]{2}{*}{1} & \multirow[t]{2}{*}{6} & \multirow[t]{2}{*}{3} & \multirow[t]{2}{*}{1.40} \\
\hline & 8 & $24 \cdot 5$ & $24 \cdot 5$ & 51.1 & & $\begin{array}{l}0 \\
2\end{array}$ & & & & \\
\hline
\end{tabular}

REASOIS :

Health

Tine

Honey

Pacilities

inowledge and Skill

$\begin{aligned} & 85-10.3 \% \\ & 411- \\ & 92.1 \% \\ & 14- \\ & 138-1.9 \% \\ & 60-17.5 \% \\ & 7.6 \%\end{aligned}$


Numbers and Percentages of lien Liking, Disliking and Indifferent to Each of Sixty-Seven Recreational Activities, Extent of Participation in Each, and Number of hien Listing Each of Five Reasons for Unsatisfactory Participation in the $\$ 5,000-\$ 7,000$ Income Group

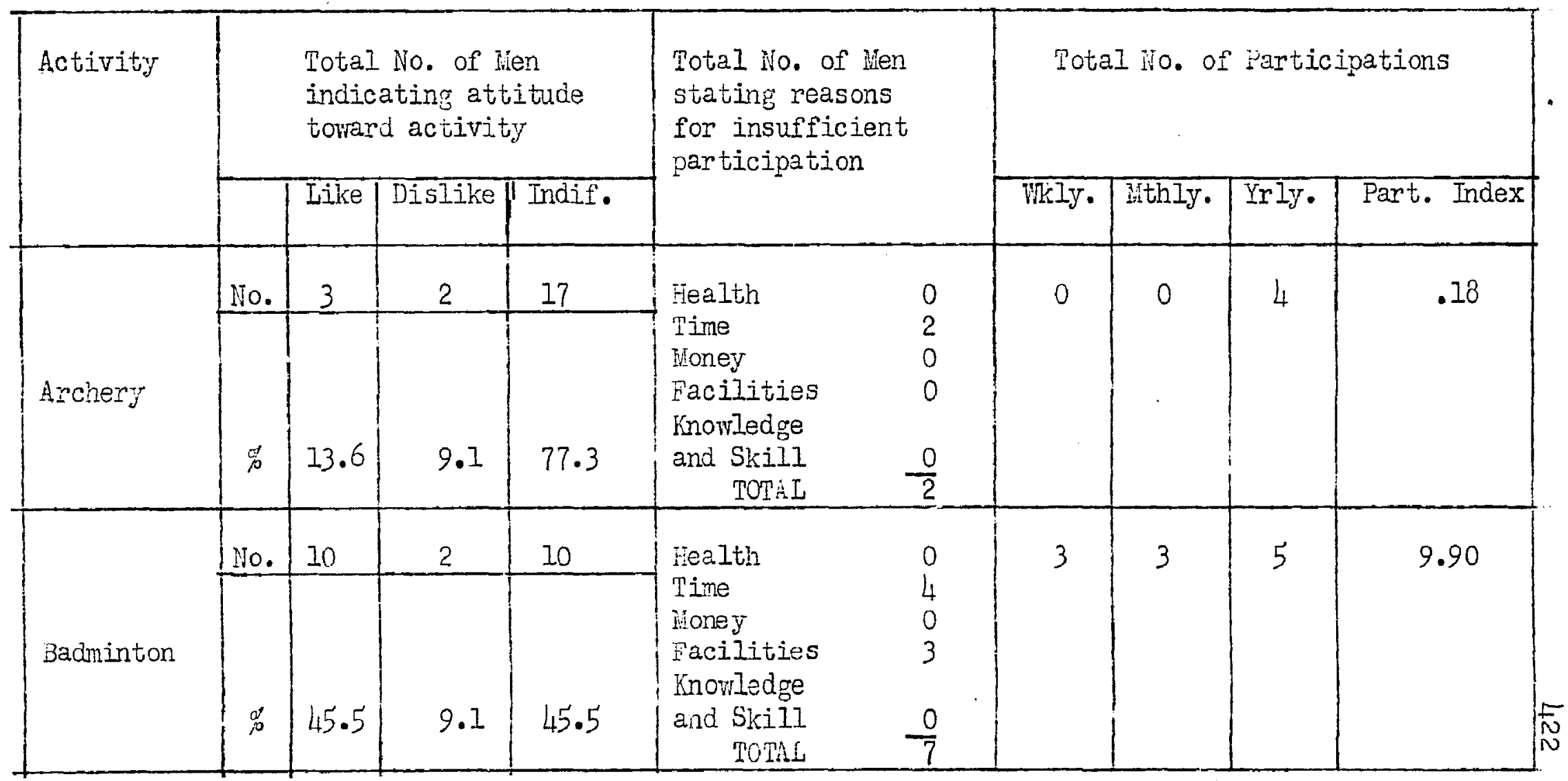


TABIE 35 (Continued)

$\$ 5,000-37,000$ Income Group

\begin{tabular}{|c|c|c|c|c|c|c|c|c|c|c|}
\hline \multirow[t]{2}{*}{ Activity } & \multicolumn{4}{|c|}{$\begin{array}{l}\text { Total lio. of lien } \\
\text { indicating attitude } \\
\text { toward activity }\end{array}$} & \multirow{2}{*}{\multicolumn{2}{|c|}{$\begin{array}{l}\text { Total No. of lien } \\
\text { stating reasons } \\
\text { for insufficient } \\
\text { participation }\end{array}$}} & \multicolumn{4}{|c|}{ Total No. of Participations } \\
\hline & & Like & Dislike & Indif. & & & WkIy. & IithIy. & Yrly. & Part.Index \\
\hline Jag Punching & to. & 4 & 36.4 & 45.5 & $\begin{array}{l}\text { Health } \\
\text { Time } \\
\text { Fioney } \\
\text { Facilities } \\
\text { Knowledge } \\
\text { and Skill } \\
\quad \text { TOTAL } \\
\end{array}$ & $\begin{array}{l}0 \\
1 \\
0 \\
3 \\
\\
0 \\
\end{array}$ & 0 & 1 & 0 & .55 \\
\hline $\begin{array}{l}\text { Baseball } \\
\text { (3. ironths) }\end{array}$ & Ho. & 72.7 & 0 & $27 \cdot 3$ & $\begin{array}{l}\text { Health } \\
\text { Tine } \\
\text { Voney } \\
\text { Facilities } \\
\text { Inowledge } \\
\text { and Skili } \\
\quad \text { TOTAI } \\
\end{array}$ & $\begin{array}{r}2 \\
10 \\
0 \\
3 \\
\\
0 \\
15 \\
\end{array}$ & 3 & 5 & 2 & 2.55 \\
\hline $\begin{array}{l}\text { Basketball } \\
\text { (6 lonths) }\end{array}$ & No. & 31.8 & 13.6 & $5 ! \cdot 5$ & $\begin{array}{l}\text { Health } \\
\text { Time } \\
\text { lioney } \\
\text { Facilities } \\
\text { Knorledge } \\
\text { and Skill } \\
\text { TOTAL }\end{array}$ & $\begin{array}{l}2 \\
2 \\
0 \\
1 \\
0 \\
5\end{array}$ & 0 & 1 & 3 & .41 \\
\hline
\end{tabular}


TABIE 35 (Continued)

$\$ 5,000-\$ 7,000$ Income Group

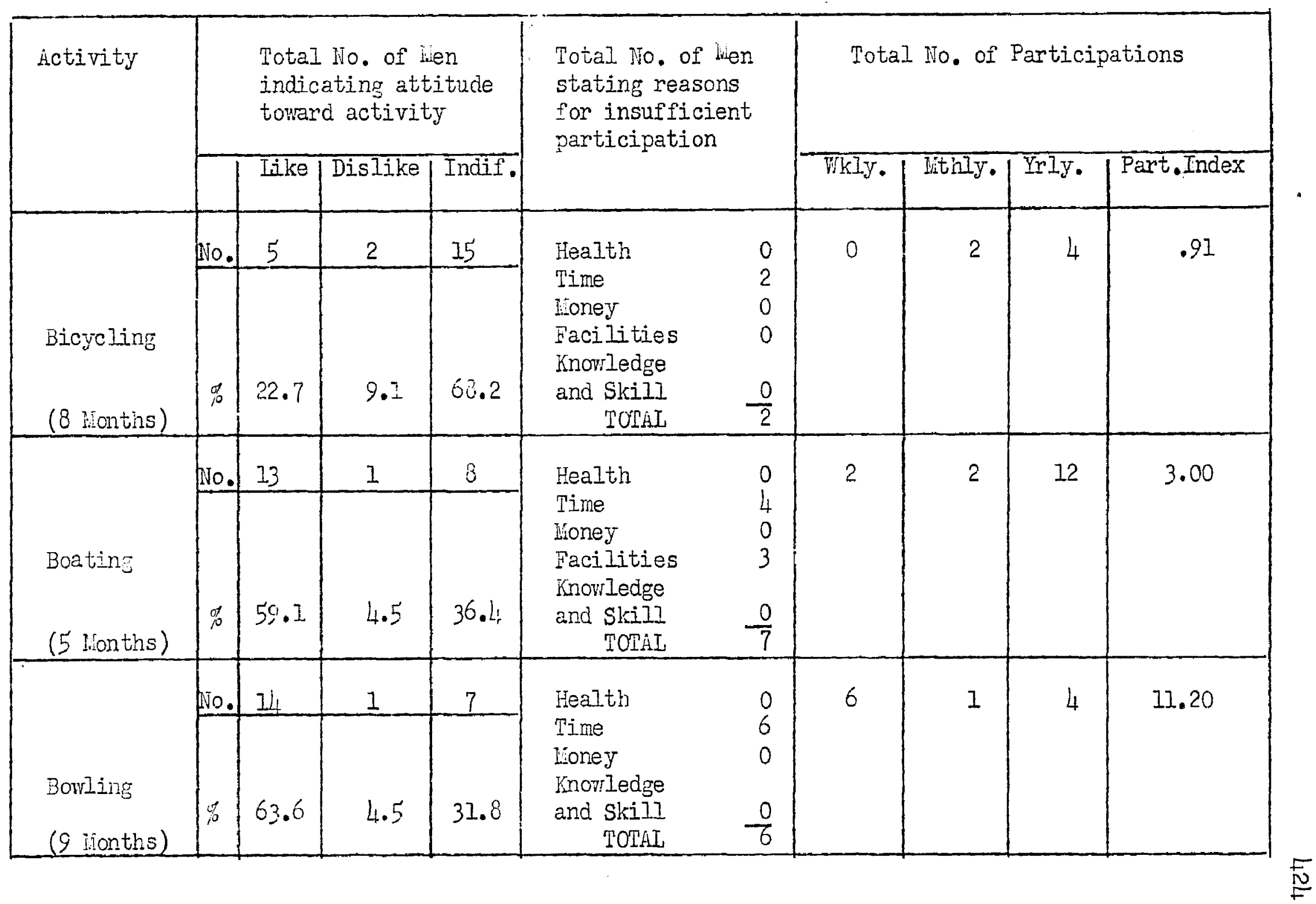



TABLE 35 (Continued)

$\$ 5,000-\$ 7,000$ Income Group

\begin{tabular}{|c|c|c|c|c|c|c|c|c|c|c|}
\hline \multirow[t]{2}{*}{ Áctivity } & \multicolumn{4}{|c|}{$\begin{array}{l}\text { Total lo. of wen } \\
\text { indicating attitude } \\
\text { toward activity }\end{array}$} & \multirow{2}{*}{\multicolumn{2}{|c|}{$\begin{array}{l}\text { Total No. of lien } \\
\text { stating reasons } \\
\text { for insufficient } \\
\text { participation }\end{array}$}} & \multicolumn{4}{|c|}{ Total ĩo. of Participations } \\
\hline & & Tike & Dislike & Indif. & & & Wkly. & Bithly. & Yrly. & Part.Index \\
\hline \multirow[b]{2}{*}{$\begin{array}{l}\text { Card } \\
\text { Playing: }\end{array}$} & No. & 17 & 1 & 4 & \multirow{2}{*}{$\begin{array}{l}\text { Health } \\
\text { Time } \\
\text { Money } \\
\text { Facilities } \\
\text { Knowledge } \\
\text { and Skill } \\
\quad \text { TOTAL } \\
\end{array}$} & \multirow{2}{*}{$\begin{array}{l}0 \\
4 \\
0 \\
0 \\
0 \\
\\
\end{array}$} & \multirow[t]{2}{*}{15} & \multirow[t]{2}{*}{9} & \multirow[t]{2}{*}{0} & \multirow[t]{2}{*}{40.40} \\
\hline & $\%$ & 77.3 & 4.5 & 18.2 & & & & & & \\
\hline \multirow[b]{2}{*}{ Checkers } & No. & 7 & 6 & 2 & \multirow{2}{*}{$\begin{array}{l}\text { Health } \\
\text { Time } \\
\text { lioney } \\
\text { Knowledge } \\
\text { and Skill } \\
\text { TOIAL } \\
\end{array}$} & \multirow{2}{*}{$\begin{array}{l}0 \\
4 \\
0 \\
0 \\
4 \\
\end{array}$} & \multirow[t]{2}{*}{2} & \multirow[t]{2}{*}{2} & \multirow[t]{2}{*}{2} & \multirow[t]{2}{*}{5.9} \\
\hline & 活 & 31.8 & 27.3 & 40.9 & & & & & & \\
\hline \multirow[b]{2}{*}{ Conversing } & rio. & 13 & 3 & 6 & \multirow{2}{*}{$\begin{array}{l}\text { Health } \\
\text { Time } \\
\text { Honey } \\
\text { Facilities } \\
\text { Knowledge } \\
\text { and Skill } \\
\text { ToTAL }\end{array}$} & \multirow{2}{*}{$\begin{array}{l}0 \\
1 \\
0 \\
0 \\
0 \\
\frac{0}{1}\end{array}$} & \multirow[t]{2}{*}{30} & \multirow[t]{2}{*}{0} & \multirow[t]{2}{*}{0} & \multirow[t]{2}{*}{89.8} \\
\hline & 䓜 & 59.1 & 13.0 & 27.3 & & & & & & \\
\hline
\end{tabular}


TABLE 35 (Continued)

\$5,000-\$7,000 Income Group

\begin{tabular}{|c|c|c|c|c|c|c|c|c|c|c|}
\hline \multirow[t]{2}{*}{ Activity } & \multicolumn{4}{|c|}{$\begin{array}{l}\text { Total No. of Men } \\
\text { indicating attitude } \\
\text { torard activity }\end{array}$} & \multirow{2}{*}{\multicolumn{2}{|c|}{$\begin{array}{l}\text { Total No, of Wen } \\
\text { stating reasons } \\
\text { for insufficient } \\
\text { participation }\end{array}$}} & \multicolumn{4}{|c|}{ Total No. of Participations } \\
\hline & & Like & Dislike & Indif. & & & Wkly. & Wthly. & Z̈rly. & Part.Index \\
\hline Chess & No. & 31.00 & 31.2 & 36.4 & $\begin{array}{l}\text { Health } \\
\text { Time } \\
\text { Loney } \\
\text { Facilities } \\
\text { Knowledge } \\
\text { and Skill } \\
\quad \text { TOTAL } \\
\end{array}$ & $\begin{array}{l}0 \\
3 \\
0 \\
1 \\
0 \\
\end{array}$ & 0 & 3 & 1 & 1.70 \\
\hline Desk Tennis & No. & 4.5 & 31.03 & 63.3 & $\begin{array}{l}\text { Health } \\
\text { Time } \\
\text { lioney } \\
\text { Facilities } \\
\text { Knowledge } \\
\text { and Skill } \\
\quad \text { TOTAI } \\
\end{array}$ & $\begin{array}{l}0 \\
1 \\
0 \\
0 \\
0 \\
1\end{array}$ & 0 & 1 & 0 & .55 \\
\hline Dating & No. & 27.3 & 9.1 & 63.6 & $\begin{array}{l}\text { Health } \\
\text { Time } \\
\text { Iioney } \\
\text { Facilities } \\
\text { Knowledge } \\
\text { and Skill } \\
\text { TOTAL }\end{array}$ & $\begin{array}{l}0 \\
0 \\
0 \\
0 \\
0 \\
0\end{array}$ & 3 & 1 & 0 & 7.60 \\
\hline
\end{tabular}


TABIE 35 (Continued)

$\$ 5,000-\$ 7,000$ Income Group

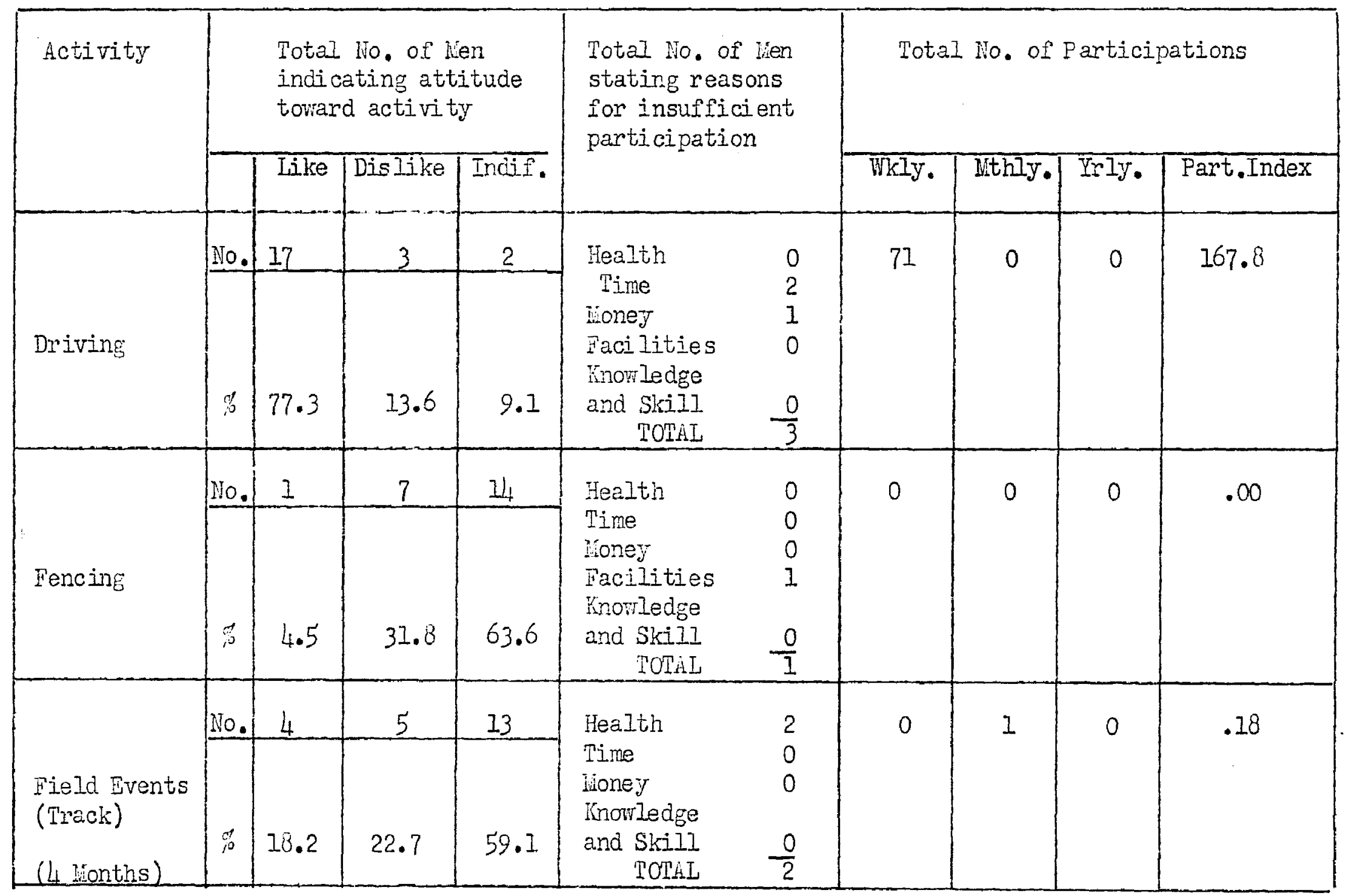


TABIE 35 (Continued)

$\$ 5,000-\$ 7,000$ Income Group

\begin{tabular}{|c|c|c|c|c|c|c|c|c|c|c|}
\hline \multirow[t]{2}{*}{ Activity } & \multicolumn{4}{|c|}{$\begin{array}{l}\text { Total No. of inen } \\
\text { indicaling attitude } \\
\text { toward activity }\end{array}$} & \multirow{2}{*}{\multicolumn{2}{|c|}{$\begin{array}{l}\text { Total No. of lien } \\
\text { stating reasons } \\
\text { for insuficicient } \\
\text { participation }\end{array}$}} & \multicolumn{4}{|c|}{ Total lvo. of Participations } \\
\hline & & Like & Dislike & Indif & & & Wkly. & Withly. & YrIy. & Part.Index \\
\hline $\begin{array}{l}\text { Bait Casting } \\
\text { (6 Months) }\end{array}$ & No. & 50.0 & 10.2 & 31.0 & $\begin{array}{l}\text { Health } \\
\text { Time } \\
\text { linoney } \\
\text { Facilities } \\
\text { Knowtedge } \\
\text { and Skili } \\
\text { TOTAL } \\
\end{array}$ & $\begin{array}{l}0 \\
3 \\
0 \\
1\end{array}$ & 3 & 3 & 27 & 5.60 \\
\hline & No. & 15 & 2 & 5 & Health & 0 & 5 & 4 & 28 & 8.3 \\
\hline $\begin{array}{l}\text { Still } \\
\text { Pishins } \\
\text { (6 ionths) }\end{array}$ & $\%$ & 68.2 & 9.1 & 22.7 & $\begin{array}{l}\text { Pime } \\
\text { Money } \\
\text { Facilities } \\
\text { Knowledge } \\
\text { and Skill } \\
\text { TOTAI }\end{array}$ & $\begin{array}{l}5 \\
0 \\
3 \\
0 \\
8 \\
\end{array}$ & & & & \\
\hline & No. & 13 & 1 & 8 & Health & 4 & 0 & 2 & 2 & .36 \\
\hline $\begin{array}{l}\text { Football } \\
\text { (3 Nonths) }\end{array}$ & $\%$ & 59.1 & 4.5 & 36.4 & $\begin{array}{l}\text { Time } \\
\text { Ioney } \\
\text { Facilities } \\
\text { Inowledge } \\
\text { and Skill } \\
\text { ToTaL }\end{array}$ & $\begin{array}{l}3 \\
0 \\
2 \\
0 \\
9\end{array}$ & & & & \\
\hline
\end{tabular}


TABLI 35 (Continued)

$\$ 5,000-\$ 7,000$ Income Group

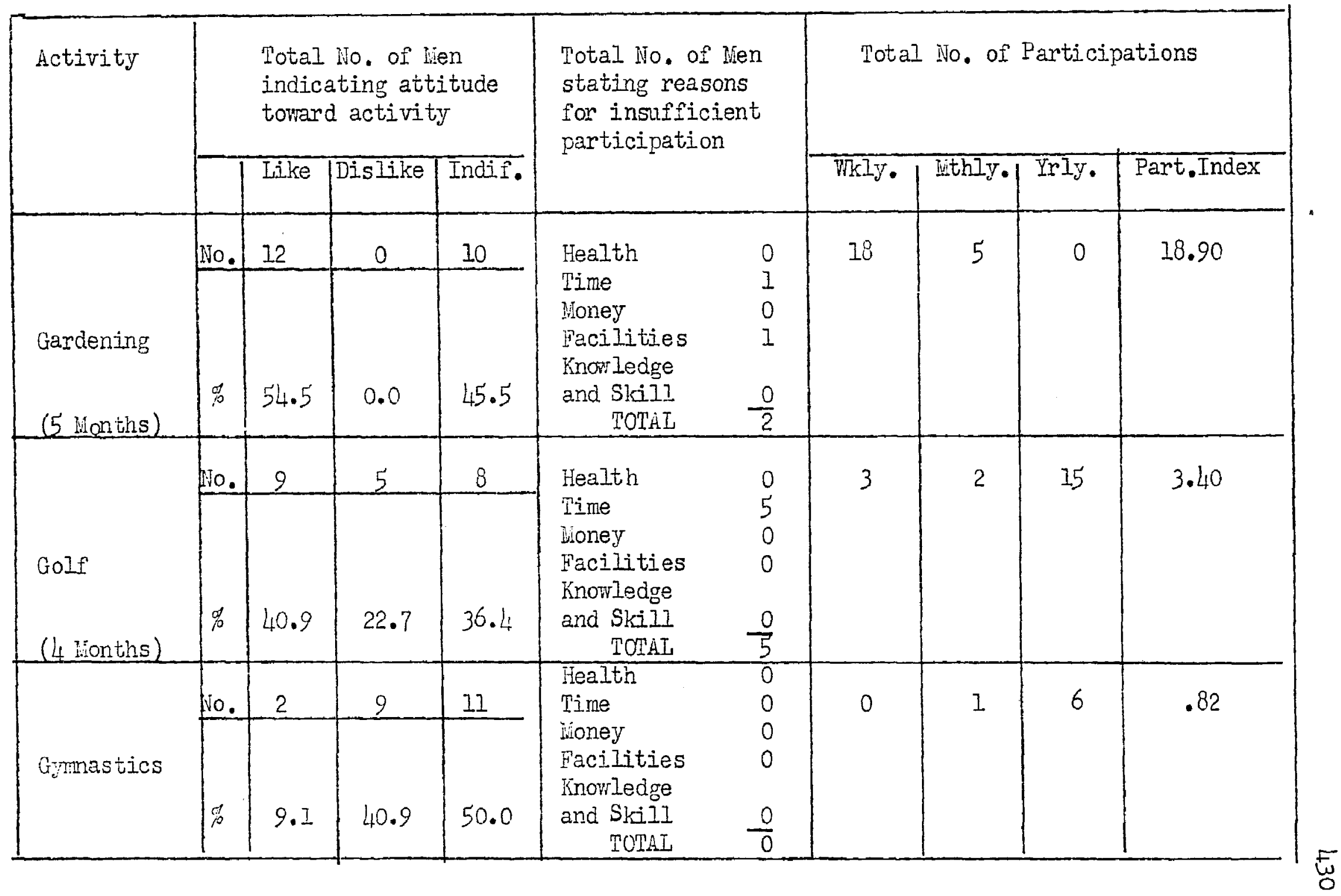


TABIE 35 (Continued)

$\$ 5.000-\$ 7,000$ Incone Group

\begin{tabular}{|c|c|c|c|c|c|c|c|c|c|c|}
\hline \multirow[t]{2}{*}{ Activity } & \multicolumn{4}{|c|}{$\begin{array}{l}\text { Total No. of Men } \\
\text { indicating attitude } \\
\text { toward activity }\end{array}$} & \multirow{2}{*}{\multicolumn{2}{|c|}{$\begin{array}{l}\text { Total No. of Men } \\
\text { stating reasons } \\
\text { for insufficient } \\
\text { participation }\end{array}$}} & \multicolumn{4}{|c|}{ Total No. of Participations } \\
\hline & & Iike & Dislike & Indif. & & & Whiy. & Iilh & Yrly. & Part Index \\
\hline \multirow[b]{2}{*}{$\begin{array}{l}\text { Handball } \\
\text { (9 Wonths) }\end{array}$} & 110. & 6 & 5 & 11 & \multirow{2}{*}{$\begin{array}{l}\text { Health } \\
\text { Time } \\
\text { Honey } \\
\text { Facilities } \\
\text { Knowledge } \\
\text { and Skill } \\
\text { TOTAL } \\
\end{array}$} & \multirow{2}{*}{$\begin{array}{l}0 \\
2 \\
0 \\
4 \\
1 \\
\\
\end{array}$} & \multirow[t]{2}{*}{0} & \multirow[t]{2}{*}{0} & \multirow[t]{2}{*}{2} & \multirow[t]{2}{*}{.09} \\
\hline & 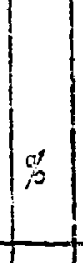 & 27.3 & 22.7 & 50.0 & & & & & & \\
\hline \multirow[b]{2}{*}{$\begin{array}{l}\text { Hiking } \\
\text { (9 inonths) }\end{array}$} & 40. & 9 & 5 & 8 & \multirow{2}{*}{$\begin{array}{l}\text { Heal th } \\
\text { Time } \\
\text { Jisoney } \\
\text { Facilities } \\
\text { Knowledge } \\
\text { and Skill } \\
\text { TOTAL } \\
\end{array}$} & \multirow{2}{*}{$\begin{array}{l}0 \\
6 \\
0 \\
0 \\
0 \\
\frac{0}{6} \\
\end{array}$} & \multirow[t]{2}{*}{1} & \multirow[t]{2}{*}{3} & \multirow[t]{2}{*}{8} & \multirow[t]{2}{*}{3.80} \\
\hline & $1 \%$ & 40.9 & 22.7 & 36.4 & & & & & & \\
\hline \multirow[b]{2}{*}{$\begin{array}{l}\text { Horseback } \\
\text { Riding } \\
\text { (9 Lonths) }\end{array}$} & 18. & 9 & 4 & 9 & \multirow{2}{*}{$\begin{array}{l}\text { Heal th } \\
\text { Time } \\
\text { Iioney } \\
\text { Facilities } \\
\text { Fnowledge } \\
\text { and Skill } \\
\text { TOIAL }\end{array}$} & \multirow{2}{*}{$\begin{array}{l}0 \\
5 \\
3 \\
1 \\
0 \\
9\end{array}$} & \multirow[t]{2}{*}{0} & \multirow[t]{2}{*}{1} & \multirow[t]{2}{*}{2} & \multirow[t]{2}{*}{.50} \\
\hline & $1 \%$ & 40.9 & 18.2 & 40.9 & & & & & & \\
\hline
\end{tabular}


TABLE 35 (Continued)

$\$ 5,000-\$ 7,000$ Income Croup

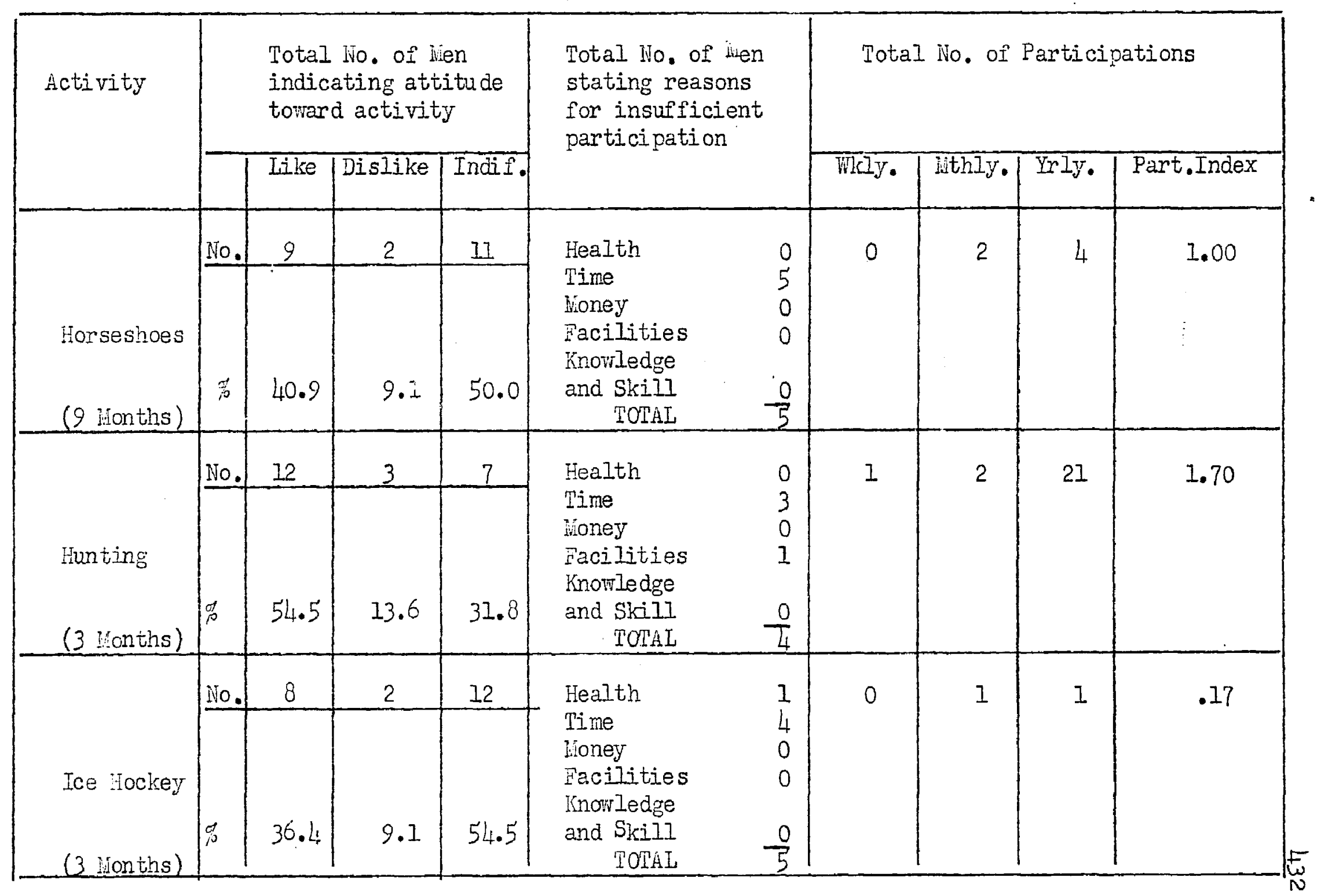


TABBL 35 (Continued)

\$5,000-\$7,000 Income Group

\begin{tabular}{|c|c|c|c|c|c|c|c|c|c|c|}
\hline \multirow[t]{2}{*}{ Activity } & \multicolumn{4}{|c|}{$\begin{array}{l}\text { Total No. of lien } \\
\text { indicating attitude } \\
\text { toward activity }\end{array}$} & \multirow{2}{*}{\multicolumn{2}{|c|}{$\begin{array}{l}\text { Total No. of lien } \\
\text { stating reasons } \\
\text { for insufficient } \\
\text { participation. }\end{array}$}} & \multicolumn{4}{|c|}{ Total No. of Participations } \\
\hline & & Like & Dislike & Indif. & & & WkIJ. & Iithly. & Yrly. & Part.Index \\
\hline $\begin{array}{l}\text { Ice Skating } \\
\text { (3 Honths) }\end{array}$ & No. & 45.5 & 22.7 & 31.8 & $\begin{array}{l}\text { Health } \\
\text { Time } \\
\text { Loney } \\
\text { Facilities } \\
\text { Knowledge } \\
\text { and Skill } \\
\quad \text { TOTAL } \\
\end{array}$ & $\begin{array}{l}0 \\
1 \\
0 \\
1 \\
0 \\
\frac{0}{2}\end{array}$ & 7 & 1 & 15 & 4.95 \\
\hline Hetal Craft & No. & 18.2 & 13.6 & 68.2 & $\begin{array}{l}\text { Health } \\
\text { Time } \\
\text { lioney } \\
\text { Facilities } \\
\text { Knowledge } \\
\text { and Skill } \\
\quad \text { TOTaL } \\
\end{array}$ & $\begin{array}{l}0 \\
1 \\
0 \\
1 \\
0 \\
\\
\end{array}$ & 0 & 1 & 13 & 1.10 \\
\hline itovies & No. & 59.1 & 4.5 & 36.4 & $\begin{array}{l}\text { Health } \\
\text { Time } \\
\text { Money } \\
\text { Facilities } \\
\text { Knowledge } \\
\text { and Skill } \\
\text { TOTAL }\end{array}$ & $\begin{array}{l}0 \\
3 \\
0 \\
0 \\
0 \\
\frac{0}{3}\end{array}$ & 5 & 8 & I & 16.2 \\
\hline
\end{tabular}


TABIE 35 (Continued)

$\$ 5,000-37,000$ Income Group

\begin{tabular}{|c|c|c|c|c|c|c|c|c|c|c|}
\hline \multirow[t]{2}{*}{ Activity } & \multicolumn{4}{|c|}{$\begin{array}{l}\text { Total No. of Len } \\
\text { indicating attitude } \\
\text { toward activity }\end{array}$} & \multirow{2}{*}{\multicolumn{2}{|c|}{$\begin{array}{l}\text { Total Wo. of lien } \\
\text { stating reasons } \\
\text { for insufficient } \\
\text { participation. }\end{array}$}} & \multicolumn{4}{|c|}{ Total lio. of Participations } \\
\hline & & Tike & Dislike & Indif: & & & WKIY & Iithiy. & $\operatorname{Irly}$ & Part.Index \\
\hline Pusic & No. & 50.0 & $4 \cdot 5$ & 45.5 & $\begin{array}{l}\text { Health } \\
\text { Time } \\
\text { lioney } \\
\text { Pacilities } \\
\text { Irnoviledge } \\
\text { and Skill } \\
\quad \text { TOTAL } \\
\end{array}$ & $\begin{array}{l}0 \\
4 \\
0 \\
0\end{array}$ & 4 & 2 & 6 & 10.80 \\
\hline Hotoring & No. & 59.1 & 13.6 & 27.3 & $\begin{array}{l}\text { Health } \\
\text { Time } \\
\text { loney } \\
\text { Faci lities } \\
\text { Knowrledge } \\
\text { and Skill } \\
\quad \text { TOTAL } \\
\end{array}$ & $\begin{array}{l}0 \\
2 \\
0 \\
0\end{array}$ & 10 & 1 & $25^{\circ}$ & 25.30 \\
\hline $\begin{array}{l}\text { Night } \\
\text { Clubbing }\end{array}$ & No. & 2.7 & 18.2 & 59.1 & $\begin{array}{l}\text { Health } \\
\text { Time } \\
\text { Woney } \\
\text { Facilities } \\
\text { Knowledge } \\
\text { and Skill } \\
\quad \text { TOTHI } \\
\end{array}$ & $\begin{array}{l}0 \\
3 \\
0 \\
0\end{array}$ & 2 & 1 & 4 & 10.00 \\
\hline
\end{tabular}


TABLE 35 (Continued)

$\$ 5,000-\$ 7,000$ Income Group

\begin{tabular}{|c|c|c|c|c|c|c|c|c|c|c|}
\hline \multirow[t]{2}{*}{ Activity } & & \multicolumn{3}{|c|}{$\begin{array}{l}\text { Total Ho. of len } \\
\text { indicating attitude } \\
\text { toward activity }\end{array}$} & \multirow{2}{*}{\multicolumn{2}{|c|}{$\begin{array}{l}\text { Total Ho. of llen } \\
\text { stating reasons } \\
\text { for insufficient } \\
\text { participation }\end{array}$}} & \multicolumn{4}{|c|}{ Total No. of Participations } \\
\hline & & Iike & Dislike & Indif. & & & WkIJ. & lithly. & Yrly. & Part.Index \\
\hline Ping-Pong & No. & 54.5 & 10.2 & $27 \cdot 3$ & $\begin{array}{l}\text { Health } \\
\text { Time } \\
\text { lioney } \\
\text { Facilities } \\
\text { Knowledge } \\
\text { and Skill } \\
\quad \text { TOTAL } \\
\end{array}$ & $\begin{array}{l}0 \\
2 \\
0 \\
4 \\
1 \\
\end{array}$ & 1 & 3 & 3 & $4 \cdot 10$ \\
\hline $\begin{array}{l}\text { Puttering, } \\
\text { Repairing, } \\
\text { etc. }\end{array}$ & No. & 68.2 & 4.5 & 27.3 & $\begin{array}{l}\text { Health } \\
\text { Time } \\
\text { Lioney } \\
\text { Facilities } \\
\text { Knowledge } \\
\text { and Skill } \\
\quad \text { TOTAL } \\
\end{array}$ & $\begin{array}{l}0 \\
1 \\
0 \\
1 \\
0 \\
2 \\
\end{array}$ & 19 & 0 & 8 & $45 \cdot 30$ \\
\hline $\begin{array}{l}\text { Listening } \\
\text { to Padio }\end{array}$ & No. & 54.5 & 4.5 & 40.9 & $\begin{array}{l}\text { Health } \\
\text { Time } \\
\text { Koney } \\
\text { Facilities } \\
\text { Knowledge } \\
\text { and Skill } \\
\text { TOMAL }\end{array}$ & $\begin{array}{l}0 \\
0 \\
0 \\
0\end{array}$ & 27 & 0 & 0 & 63.80 \\
\hline
\end{tabular}


TABIE 35 (Continued)

$\$ 5,000-3,000$ Income croup

\begin{tabular}{|c|c|c|c|c|c|c|c|c|c|c|}
\hline \multirow[t]{2}{*}{ Activity } & \multicolumn{4}{|c|}{$\begin{array}{l}\text { Total No. of lien } \\
\text { indicating attitude } \\
\text { toward activity }\end{array}$} & \multirow{2}{*}{\multicolumn{2}{|c|}{$\begin{array}{l}\text { Total Io. of lien } \\
\text { stating reasons } \\
\text { for insufficient } \\
\text { participation }\end{array}$}} & \multicolumn{4}{|c|}{ Total No. of Participations } \\
\hline & & like & Dislike & Indif. & & & WKly. & Iithly. & $\overline{\mathrm{Yr}} \mathrm{Iy} \bullet$ & Part.Index \\
\hline Watcliing TV & No. & 72.7 & 0 & 27.3 & $\begin{array}{l}\text { Health } \\
\text { Time } \\
\text { Iioney } \\
\text { Facilities } \\
\text { Inowledges } \\
\text { and Skill } \\
\quad \text { IOTAL } \\
\end{array}$ & $\begin{array}{l}0 \\
2 \\
0 \\
0 \\
0 \\
\frac{0}{2} \\
\end{array}$ & 40 & 0 & 0 & 94.50 \\
\hline Reading & No. & 90.9 & 4.5 & $4 \cdot 5$ & $\begin{array}{l}\text { Health } \\
\text { Tine } \\
\text { Jioney } \\
\text { Facilities } \\
\text { Inoviledge } \\
\text { and Skill } \\
\quad \text { TOTAL } \\
\end{array}$ & $\begin{array}{l}0 \\
4 \\
0 \\
0 \\
0 \\
\frac{0}{4}\end{array}$ & 15 & 2 & 0 & 36.50 \\
\hline Photography & No. & 40.9 & 9.1 & 50.0 & $\begin{array}{l}\text { Health } \\
\text { Time } \\
\text { lioney } \\
\text { Facilities } \\
\text { Inow ledge } \\
\text { and Skill } \\
\text { TOTAL } \\
\end{array}$ & $\begin{array}{l}0 \\
4 \\
0 \\
0 \\
0 \\
\\
\end{array}$ & 3 & 3 & 6 & 9.00 \\
\hline
\end{tabular}


TABIE 35 (Continued)

$\$ 5,000-\$ 7,000$ Income Croup

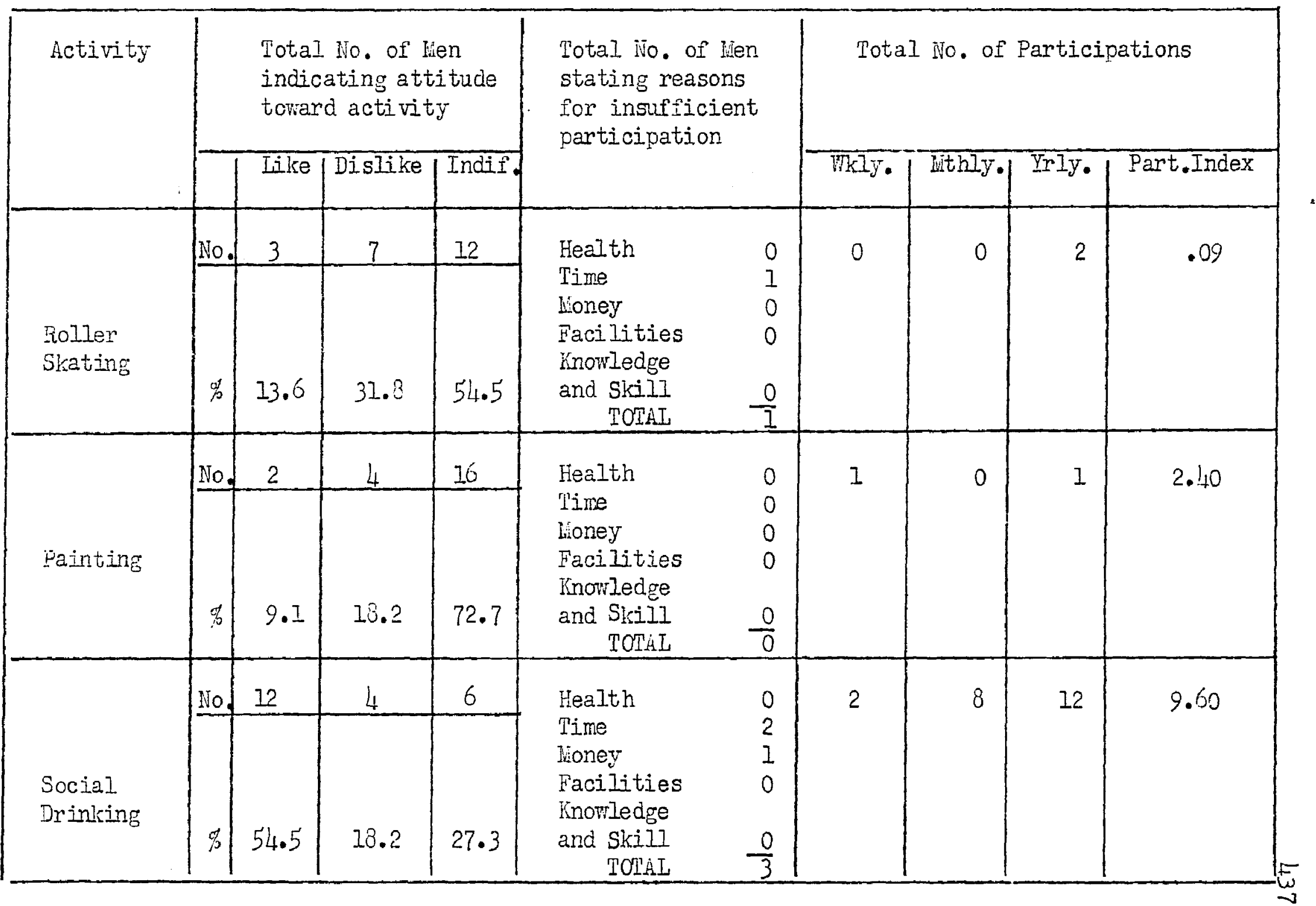


TABIE 35 (Continued)

$\$ 5,000-\$ 7,000$ Income Group

\begin{tabular}{|c|c|c|c|c|c|c|c|c|c|c|}
\hline \multirow[t]{2}{*}{ Activity } & \multicolumn{4}{|c|}{$\begin{array}{l}\text { Total No. of lien } \\
\text { indicating attitude } \\
\text { toward activity }\end{array}$} & \multirow{2}{*}{\multicolumn{2}{|c|}{$\begin{array}{l}\text { Total iNo. of hien } \\
\text { stating reasons } \\
\text { for insufficient } \\
\text { participation }\end{array}$}} & \multicolumn{4}{|c|}{ Total lo. of Participations } \\
\hline & & Like & Dislike & Indif. & & & WhIy. & lithly.| & $\mathrm{Yr}] \mathrm{y}$ & Part.Index \\
\hline $\begin{array}{l}\text { Sailins } \\
\text { (5 jionths) }\end{array}$ & No. & 40.9 & $13 . ?$ & 40.9 & $\begin{array}{l}\text { Health } \\
\text { Time } \\
\text { Honey } \\
\text { Facilities } \\
\text { Fnowledge } \\
\text { and Skill } \\
\quad \text { TOTiI } \\
\end{array}$ & $\begin{array}{l}0 \\
3 \\
2 \\
2\end{array}$ & 0 & 1 & 6 & .50 \\
\hline $\begin{array}{l}\text { Skiins } \\
\text { (3 lionths) }\end{array}$ & No. & $22 . ?$ & 27.3 & 50.0 & $\begin{array}{l}\text { Health } \\
\text { Time } \\
\text { Iíney } \\
\text { Facilities } \\
\text { Knowledge } \\
\text { and SkiII } \\
\quad \text { ToraI } \\
\end{array}$ & $\begin{array}{l}0 \\
1 \\
1 \\
2 \\
1 \\
\frac{1}{5} \\
\end{array}$ & 0 & 1 & 0 & .14 \\
\hline $\begin{array}{l}\text { Social } \\
\text { Drinking }\end{array}$ & ino. & 54.5 & 22.7 & $22 . ?$ & $\begin{array}{l}\text { Health } \\
\text { Time } \\
\text { lioney } \\
\text { Facilities } \\
\text { Knowledge } \\
\text { and Skill } \\
\quad \text { TCRAL }\end{array}$ & $\begin{array}{l}0 \\
4 \\
0 \\
0 \\
0 \\
\frac{0}{4}\end{array}$ & 2 & 8 & 2 & 9.20 \\
\hline
\end{tabular}


TABIE 35 (Continued)

\$5,000-\$7,000 Income Croup

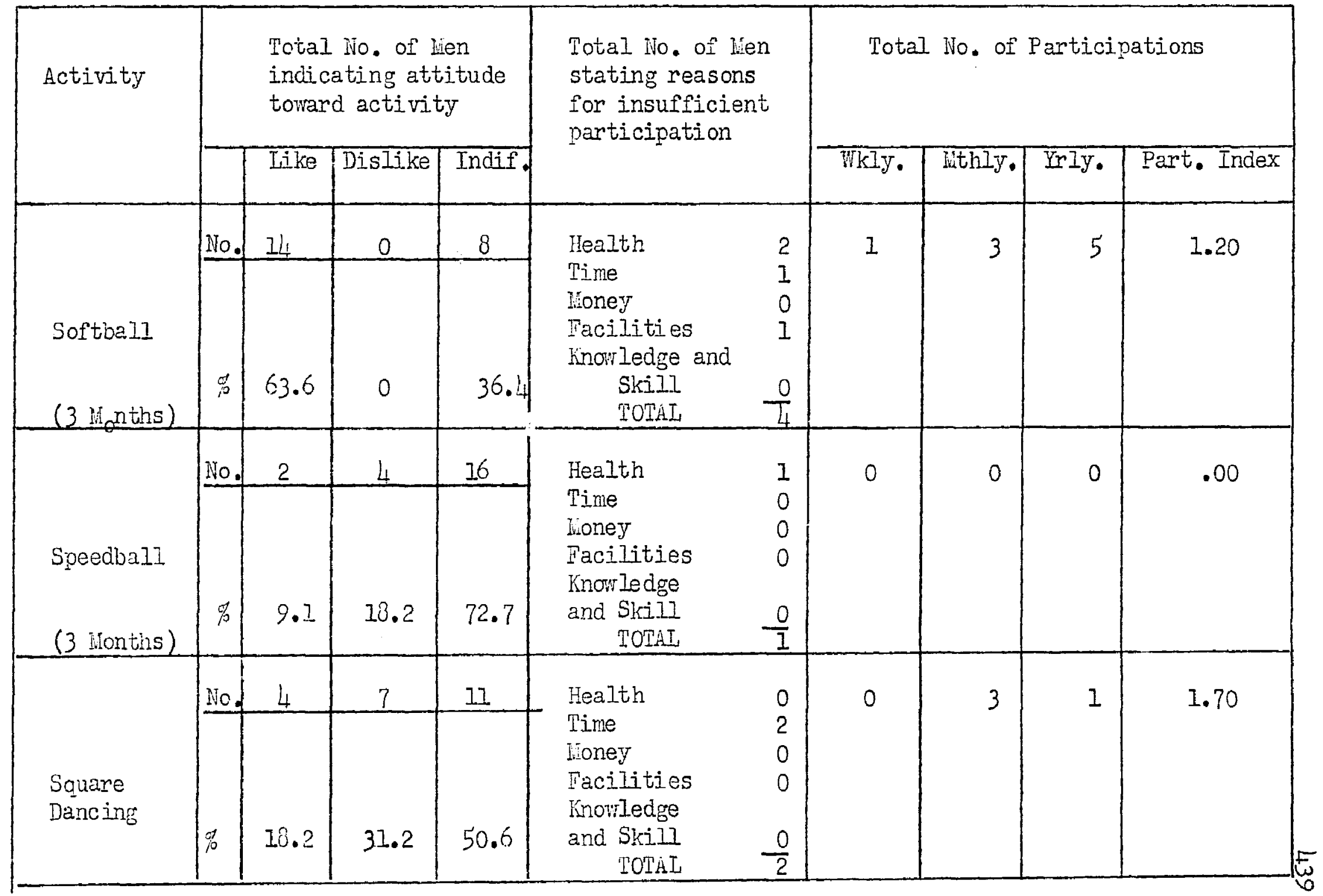


TABLE 35 (Continued)

$\$ 5,000-\$ 7,000$ Income Group

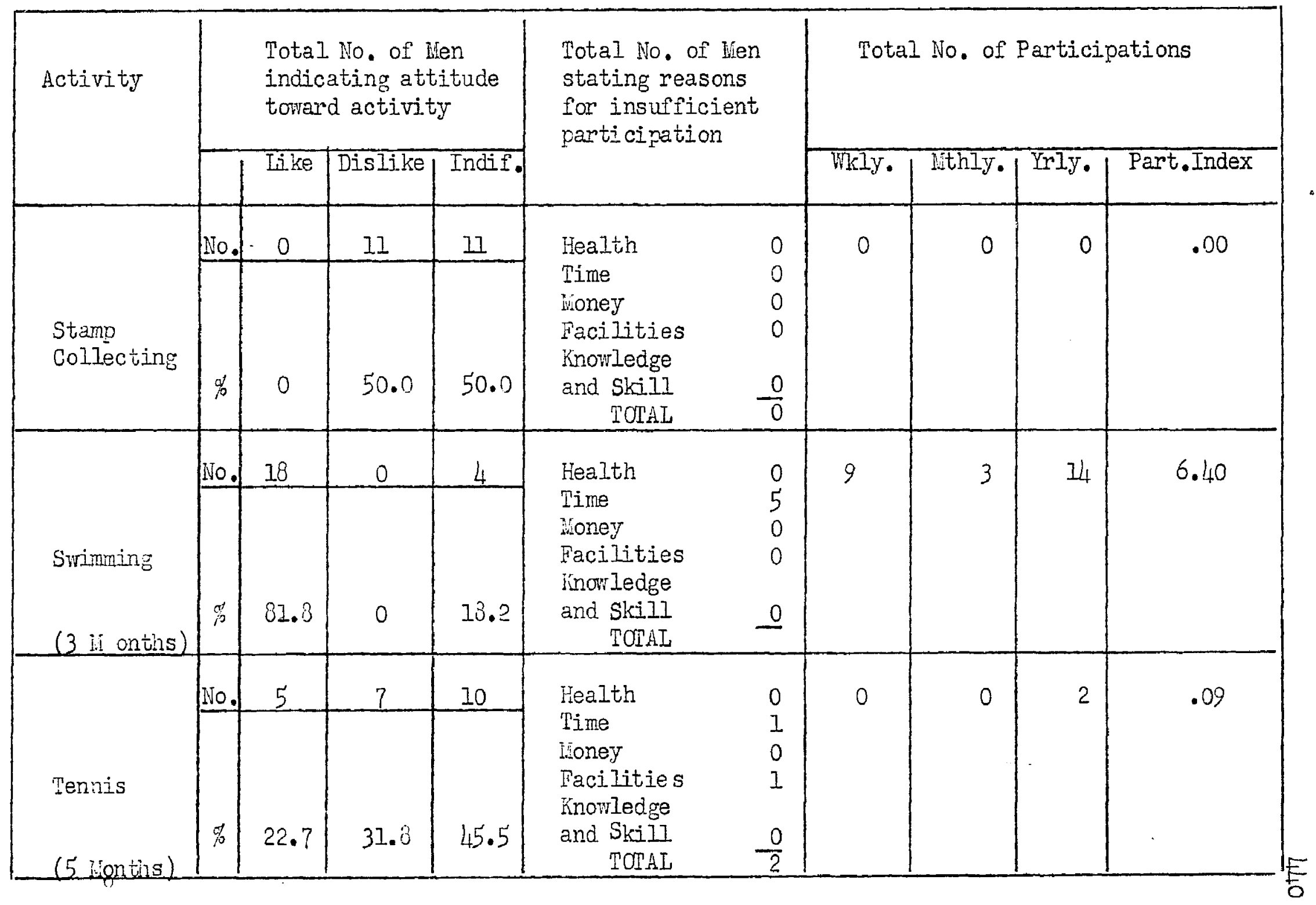


TABIS 35 (Continued)

$35,000-37,000$ Income Group

\begin{tabular}{|c|c|c|c|c|c|c|c|c|c|c|}
\hline \multirow[t]{2}{*}{ Activity } & \multicolumn{4}{|c|}{$\begin{array}{l}\text { Total lo. of lien } \\
\text { indicating attitude } \\
\text { toward activity }\end{array}$} & \multirow{2}{*}{\multicolumn{2}{|c|}{$\begin{array}{l}\text { Total Ho. of lien } \\
\text { stating reasons } \\
\text { for insufficient } \\
\text { participation }\end{array}$}} & \multicolumn{4}{|c|}{ Total io, of Participations } \\
\hline & 1 & Like & Dislike & Indif. & & & TWk & lithy.1 & Yrly. & Part.Index \\
\hline $\begin{array}{l}\text { Touch } \\
\text { Football } \\
\text { (3ironths) }\end{array}$ & 150 & 4.0 .9 & 18.2 & 9 & $\begin{array}{l}\text { Health } \\
\text { Time } \\
\text { ioney } \\
\text { Facilities } \\
\text { inow ledge } \\
\text { and Skill } \\
\quad \text { TOTAL } \\
\end{array}$ & $\begin{array}{l}1 \\
3 \\
0 \\
1 \\
0 \\
\frac{0}{5}\end{array}$ & 0 & 2 & 5 & .50 \\
\hline Tumbling & 1:. & 13.6 & 36.4 & 50.0 & $\begin{array}{l}\text { Health } \\
\text { Time } \\
\text { Eoney } \\
\text { Facilities } \\
\text { Ynorledge } \\
\text { and Skill } \\
\quad \text { TOTII } \\
\end{array}$ & $\begin{array}{l}1 \\
0 \\
0 \\
1 \\
0 \\
2\end{array}$ & 1 & 0 & 0 & 2.4 \\
\hline $\begin{array}{l}\text { Visiting } \\
\text { Friends }\end{array}$ & io. & 72.7 & 4.5 & 22.7 & $\begin{array}{l}\text { Health } \\
\text { Time } \\
\text { Loney } \\
\text { Facilities } \\
\text { Inowledge } \\
\text { and Skill } \\
\text { TOUAL }\end{array}$ & $\begin{array}{l}0 \\
2 \\
0 \\
0\end{array}$ & 9 & 8 & 6 & 25.90 \\
\hline
\end{tabular}


TABIE 35 (Continued)

\$5,000-87,000 Income Group

\begin{tabular}{|c|c|c|c|c|c|c|c|c|c|c|}
\hline \multirow[t]{2}{*}{ Activity } & \multicolumn{4}{|c|}{$\begin{array}{l}\text { Total No, of lien } \\
\text { indicating attitude } \\
\text { torard activity }\end{array}$} & \multirow{2}{*}{\multicolumn{2}{|c|}{$\begin{array}{l}\text { Total No. of Men } \\
\text { stating reasons } \\
\text { for insufficient } \\
\text { participation }\end{array}$}} & \multicolumn{4}{|c|}{ Total No. of Participations } \\
\hline & & Iike & Dislike & Indif. & & & WKIy. & lithly. & Yrly. & Part.Index \\
\hline Tolleyball & No. & 10 & 18.2 & 36.4 & $\begin{array}{l}\text { Health } \\
\text { Time } \\
\text { loney } \\
\text { Facilities } \\
\text { Fnowledge } \\
\text { and Skill } \\
\quad \text { TOTAL } \\
\end{array}$ & $\begin{array}{l}0 \\
3 \\
0 \\
1 \\
0 \\
\\
\end{array}$ & 0 & 2 & 3 & 1.20 \\
\hline $\begin{array}{l}\text { Watching } \\
\text { Sport Events }\end{array}$ & No. & 100 & 0 & $\underline{0}$ & $\begin{array}{l}\text { Health } \\
\text { Time } \\
\text { Honey } \\
\text { Facilities } \\
\text { Inowledge } \\
\text { and Skill } \\
\text { TOTAL }\end{array}$ & $\begin{array}{l}0 \\
1 \\
0 \\
0 \\
0 \\
-\frac{0}{1}\end{array}$ & 16 & 11 & 1 & 43.90 \\
\hline Walking & Wo. & 59.1 & 13.6 & $27 \cdot 3$ & $\begin{array}{l}\text { Health } \\
\text { Time } \\
\text { lioney } \\
\text { Facilities } \\
\text { Rnowledge } \\
\text { and Skill } \\
\text { TOTAI }\end{array}$ & $\begin{array}{l}0 \\
1 \\
0 \\
0 \\
0 \\
\frac{0}{1}\end{array}$ & 15 & 0 & 4 & 35.60 \\
\hline
\end{tabular}


TABLE 35 (Continued)

$\$ 5,000-\$ 7,000$ Income Group

\begin{tabular}{|c|c|c|c|c|c|c|c|c|c|c|}
\hline \multirow[t]{2}{*}{ Activity } & & \multicolumn{3}{|c|}{$\begin{array}{l}\text { Total No. of lien } \\
\text { indicating atti tude } \\
\text { toward activity }\end{array}$} & \multirow{2}{*}{\multicolumn{2}{|c|}{$\begin{array}{l}\text { Total No. of Men } \\
\text { stating reasons } \\
\text { for insufficient } \\
\text { participation }\end{array}$}} & \multicolumn{4}{|c|}{ Total No. of Participations } \\
\hline & & Like & Dislike & Indif. & & & WhIy. & Vithly 1 & Yrly.1 & Part.Index \\
\hline $\begin{array}{l}\text { Weight } \\
\text { Lifting }\end{array}$ & No. & $4 \cdot 5$ & 45.5 & 50.0 & $\begin{array}{l}\text { Health } \\
\text { Time } \\
\text { Honey } \\
\text { Facilities } \\
\text { Inowledge } \\
\text { and Skill } \\
\quad \text { TOTAL } \\
\end{array}$ & $\begin{array}{l}1 \\
0 \\
0 \\
0\end{array}$ & 0 & 0 & 0 & .00 \\
\hline Water Polo & No. & 4.5 & 40.9 & 54.5 & $\begin{array}{l}\text { Health } \\
\text { Time } \\
\text { lioney } \\
\text { Facilities } \\
\text { Knowledge } \\
\text { and Skill } \\
\quad \text { TOLAL } \\
\end{array}$ & $\begin{array}{l}0 \\
0 \\
0 \\
0\end{array}$ & 0 & 0 & 0 & .00 \\
\hline Woodworking & No. & 59.1 & 9.1 & 31.8 & $\begin{array}{l}\text { Health } \\
\text { Time } \\
\text { lioney } \\
\text { Facilities } \\
\text { Knowledge } \\
\text { and SkilI } \\
\text { TOTHL }\end{array}$ & $\begin{array}{l}0 \\
3 \\
1 \\
1\end{array}$ & 4 & 2 & 2 & 10.60 \\
\hline
\end{tabular}


TABLE 35 (Conti nued)

$\$ 5,000-\$ 7,000$ Income Group

\begin{tabular}{|c|c|c|c|c|c|c|c|c|c|c|}
\hline \multirow[t]{2}{*}{ Activity } & \multicolumn{4}{|c|}{$\begin{array}{l}\text { Total No. of llen } \\
\text { indicating atti tude } \\
\text { toryard activity }\end{array}$} & \multirow{2}{*}{\multicolumn{2}{|c|}{$\begin{array}{l}\text { Total No. of INen } \\
\text { stating reasons } \\
\text { for insufficient } \\
\text { participation }\end{array}$}} & \multicolumn{4}{|c|}{ Total No. of Participations } \\
\hline & & Iike & Dislike & Indif. & & & Whk1y. & Inthly. & Irly. & Part.Index \\
\hline $\begin{array}{l}\text { Wood } \\
\text { Carving }\end{array}$ & No. & 18.2 & 18.2 & 63.6 & $\begin{array}{l}\text { Health } \\
\text { Time } \\
\text { Woney } \\
\text { Facilities } \\
\text { Inorledge } \\
\text { and Skill } \\
\quad \text { TOTAL } \\
\end{array}$ & $\begin{array}{l}0 \\
1 \\
0 \\
0 \\
0 \\
\frac{0}{1}\end{array}$ & 0 & 0 & 6 & .27 \\
\hline Wrestling & No. & $\beta 1.8$ & 22.7 & 45.5 & $\begin{array}{l}\text { Health } \\
\text { Time } \\
\text { lioney } \\
\text { Facilities } \\
\text { Knowledge } \\
\text { and Skill } \\
\text { TOTAL }\end{array}$ & $\begin{array}{l}3 \\
1 \\
0 \\
0 \\
0 \\
0 \\
\end{array}$ & 0 & 3 & 1 & 1.70 \\
\hline
\end{tabular}

REASONS :

$\begin{array}{lrl}\text { Health } & 21 & -8.7 \% \\ \text { Time } & 155 & -64.0 \% \\ \text { Woney } & 9 & -3.7 \% \\ \text { Pacilities } & 53 & -21.9 \% \\ \text { Knomledge and Shill } & 4 & -1.6 \%\end{array}$


Numbers and Percentages of isen Liking, Disliking and Indifferent to Each of Sixty-Seven Recreational Activities, Extent of Participation in Each, and ifumber of lien Iisting Each of Five Reasons for Unsatisfactory Participation in the Over $\$ 7,000$ Income croup

\begin{tabular}{|c|c|c|c|c|c|c|c|c|c|c|}
\hline \multirow[t]{2}{*}{ Activity } & & \multicolumn{3}{|c|}{$\begin{array}{l}\text { Total Io. of lien } \\
\text { indicating attitude } \\
\text { toward activity }\end{array}$} & \multirow{2}{*}{\multicolumn{2}{|c|}{$\begin{array}{l}\text { Total ivo. of len } \\
\text { stating reasons } \\
\text { for insufficient } \\
\text { participation }\end{array}$}} & \multicolumn{4}{|c|}{ Total No. of Participations } \\
\hline & & Iike & Dislike & Indif. & & & WkIy. & ivthly. & Yrly. & Part.Index \\
\hline Archery & No. & 22.2 & 0 & 77.7 & $\begin{array}{l}\text { Health } \\
\text { Time } \\
\text { Mioney } \\
\text { Tacilities } \\
\text { Knovledge } \\
\text { and Skill } \\
\quad \text { TOTAL }\end{array}$ & $\begin{array}{l}0 \\
1 \\
0 \\
2 \\
0 \\
\frac{0}{3}\end{array}$ & 0 & 0 & 2 & .22 \\
\hline Badminton & No. & 11.1 & 22.2 & 66.6 & $\begin{array}{l}\text { Health } \\
\text { Time } \\
\text { Money } \\
\text { Facilities } \\
\text { Wnowledge } \\
\text { and Skill } \\
\text { TOTAL }\end{array}$ & $\begin{array}{l}0 \\
1 \\
0 \\
1 \\
0 \\
\frac{0}{2}\end{array}$ & 0 & 1 & 1 & 1.44 \\
\hline
\end{tabular}


RABIE 36 (Continued)

Over \$7,000 Income Group

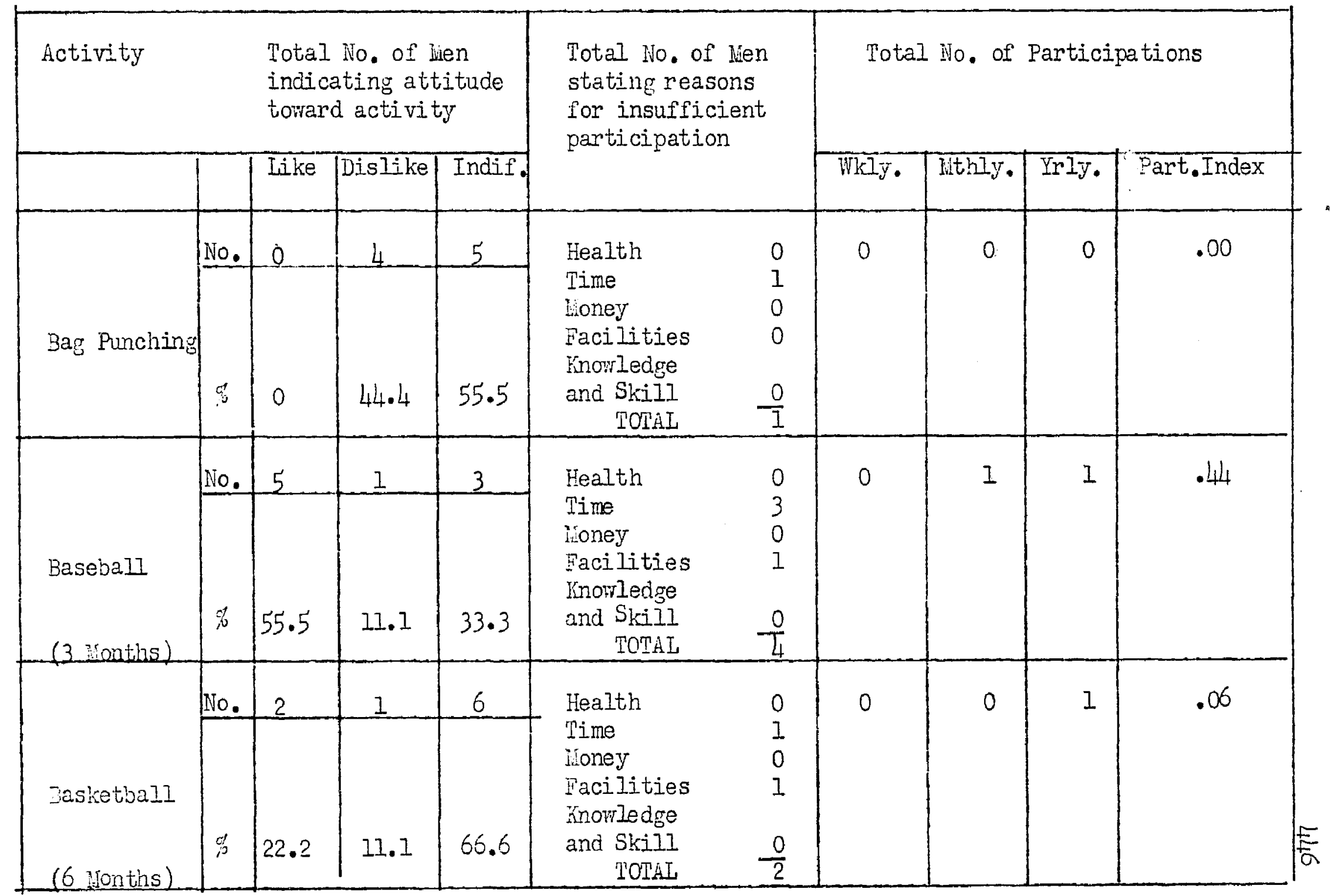


TABIF 36 (Continued)

Over $\$ 7,000$ Income Group

\begin{tabular}{|c|c|c|c|c|c|c|c|c|c|c|}
\hline \multirow[t]{2}{*}{ Activity } & \multicolumn{4}{|c|}{$\begin{array}{l}\text { Total No, of lien } \\
\text { indicating attitude } \\
\text { toward activity }\end{array}$} & \multirow{2}{*}{\multicolumn{2}{|c|}{$\begin{array}{l}\text { Total No. of lien } \\
\text { stating reasons } \\
\text { for insufficient } \\
\text { participation }\end{array}$}} & \multicolumn{4}{|c|}{ Total No. of Participations } \\
\hline & & Iike & Dislike & Indif. & & & Wkly. & Iithly. & Irly. & Part.Index \\
\hline Bicycling & No. & $44 \cdot 4$ & 11.1 & $44 \cdot 4$ & $\begin{array}{l}\text { Health } \\
\text { Time } \\
\text { inoney } \\
\text { Facilities } \\
\text { Knowledge } \\
\text { and Skill } \\
\quad \text { TOIAL } \\
\end{array}$ & $\begin{array}{l}0 \\
3 \\
0 \\
0\end{array}$ & 1 & 0 & 1 & 3.95 \\
\hline Boating & No. & 22.2 & 11.1 & 66.6 & $\begin{array}{l}\text { Health } \\
\text { Time } \\
\text { Noney } \\
\text { Facilities } \\
\text { Knowledge } \\
\text { and Skill } \\
\text { TOTiI }\end{array}$ & $\begin{array}{l}0 \\
1 \\
0 \\
1\end{array}$ & 0 & 0 & 1 & .11 \\
\hline Bowling & No. & 33.3 & 22.2 & $44 \cdot 4$ & $\begin{array}{l}\text { Health } \\
\text { Time } \\
\text { Lioney } \\
\text { Facilities } \\
\text { Knowledge } \\
\text { and Skili } \\
\text { TOTLI }\end{array}$ & $\begin{array}{l}0 \\
2 \\
0 \\
0 \\
0 \\
\frac{0}{2}\end{array}$ & 2 & 0 & 0 & 8.70 \\
\hline
\end{tabular}


TABIE 36 (Continued)

Over $\$ 7,000$ Income Group

\begin{tabular}{|c|c|c|c|c|c|c|c|c|c|c|}
\hline \multirow[t]{2}{*}{ Activity } & & \multicolumn{3}{|c|}{$\begin{array}{l}\text { Total No. of lien } \\
\text { indicating attitude } \\
\text { toward activity }\end{array}$} & \multirow{2}{*}{\multicolumn{2}{|c|}{$\begin{array}{l}\text { Total No. of len } \\
\text { stating reasons } \\
\text { for insufficient } \\
\text { participation }\end{array}$}} & \multicolumn{4}{|c|}{$\begin{array}{l}\text { Total iNo, of Participations } \\
1\end{array}$} \\
\hline & & Like & Dislike & Indif. & & & WkIy. & ithly. & Yrly. & Part, Index \\
\hline Boxing & No. & 1 & 55.5 & 33.3 & $\begin{array}{l}\text { Health } \\
\text { Time } \\
\text { hioney } \\
\text { Facilities } \\
\text { Knowledge } \\
\text { and Skill } \\
\quad \text { TOTAL } \\
\end{array}$ & $\begin{array}{l}0 \\
1 \\
0 \\
0\end{array}$ & 0 & 0 & 0 & .00 \\
\hline Calisthenic & No. & 11. & 44.4 & 44.4 & $\begin{array}{l}\text { Health } \\
\text { Time } \\
\text { honey } \\
\text { Facilities } \\
\text { inowledge } \\
\text { and Skill } \\
\text { TOTAL } \\
\end{array}$ & $\begin{array}{l}0 \\
0 \\
0 \\
1\end{array}$ & 0 & 0 & 1 & .11 \\
\hline $\begin{array}{l}\text { Canoeing } \\
(5 \text { vonths) }\end{array}$ & Wo. & 33. & 22.2 & 44.4 & $\begin{array}{l}\text { Health } \\
\text { Time } \\
\text { Loney } \\
\text { Facilities } \\
\text { Inowledge } \\
\text { and Skill } \\
\quad \text { TorAL } \\
\end{array}$ & $\begin{array}{l}0 \\
0 \\
0 \\
1\end{array}$ & 1 & 0 & 1 & 2.50 \\
\hline
\end{tabular}


PABIE 36 (Continued)

Over 7,000 Income Group

\begin{tabular}{|c|c|c|c|c|c|c|c|c|c|c|}
\hline \multirow[t]{2}{*}{ Activity } & & \multicolumn{3}{|c|}{$\begin{array}{l}\text { Total No. of Hen } \\
\text { indicating attitude } \\
\text { torard activity }\end{array}$} & \multirow{2}{*}{\multicolumn{2}{|c|}{$\begin{array}{l}\text { Total ivo. of len } \\
\text { stating reasons } \\
\text { for insufficient } \\
\text { participation }\end{array}$}} & \multicolumn{4}{|c|}{ Total ilo. of Participations } \\
\hline & & Iike & Dislike & Indif. & & & Finly. & Iithly. & Irly. & Part.Index \\
\hline & Ho. & 1 & 0 & 2 & \multirow{2}{*}{$\begin{array}{l}\text { Health } \\
\text { Time } \\
\text { Woney } \\
\text { Facilities } \\
\text { Knowledge and } \\
\quad \text { Skill } \\
\quad \text { IOTAI } \\
\end{array}$} & \multirow{2}{*}{$\begin{array}{l}0 \\
1 \\
0 \\
1\end{array}$} & \multirow[t]{2}{*}{4} & \multirow[t]{2}{*}{3} & \multirow[t]{2}{*}{0} & \multirow[t]{2}{*}{26.90} \\
\hline $\begin{array}{l}\text { Card } \\
\text { Playing }\end{array}$ & $\%$ & 77.7 & 0 & 22.2 & & & & & & \\
\hline \multirow[b]{2}{*}{ Checkers } & No. & 2 & 4. & 3 & \multirow{2}{*}{$\begin{array}{l}\text { Health } \\
\text { Time } \\
\text { Sioney } \\
\text { Facilities } \\
\text { inowledge } \\
\text { and Skill } \\
\quad \text { Ton AI } \\
\end{array}$} & \multirow{2}{*}{$\begin{array}{l}0 \\
1 \\
0 \\
1\end{array}$} & \multirow[t]{2}{*}{0} & \multirow[t]{2}{*}{0} & \multirow[t]{2}{*}{1} & \multirow[t]{2}{*}{.11} \\
\hline & $\ddot{\theta}$ & 22.2 & $44 \cdot 4$ & 33.3 & & & & & & \\
\hline \multirow[b]{2}{*}{ Conversing } & No. & 6 & 0 & 3 & \multirow{2}{*}{$\begin{array}{l}\text { Health } \\
\text { Time } \\
\text { Woney } \\
\text { Facilities } \\
\text { Knowledge } \\
\text { and SkilI } \\
\text { TOCAL }\end{array}$} & \multirow{2}{*}{$\begin{array}{l}0 \\
1 \\
0 \\
0\end{array}$} & \multirow[t]{2}{*}{6} & \multirow[t]{2}{*}{0} & \multirow[t]{2}{*}{0} & \multirow[t]{2}{*}{34.70} \\
\hline & : & 66.0 & 0 & 33.3 & & & & & & \\
\hline
\end{tabular}


TABLE 36 (Continued)

Over 7,000 Income croup

\begin{tabular}{|c|c|c|c|c|c|c|c|c|c|c|}
\hline \multirow[t]{2}{*}{ Áctivity } & & \multicolumn{3}{|c|}{$\begin{array}{l}\text { Total No. of lien } \\
\text { indicating attitude } \\
\text { toward activity }\end{array}$} & \multirow{2}{*}{\multicolumn{2}{|c|}{$\begin{array}{l}\text { Total No. of ien } \\
\text { stating reasons } \\
\text { for insufficient } \\
\text { participation }\end{array}$}} & \multicolumn{4}{|c|}{ Total No. of Participations } \\
\hline & & Like & Dislike & Indif. & & & WkIy. & ilthly.. & Frly. & Part.Index \\
\hline Chess & No. & 22.2 & $44 \cdot 4$ & 33.3 & $\begin{array}{l}\text { Health } \\
\text { Tine } \\
\text { Loney } \\
\text { Facilities } \\
\text { Inowledge } \\
\text { and Skill } \\
\quad \text { TOTAI } \\
\end{array}$ & $\begin{array}{l}0 \\
1 \\
0 \\
1 \\
0 \\
0 \\
2\end{array}$ & 0 & 0 & 1 & .11 \\
\hline Deck Tennis & INo. & 0 & 22.2 & 77.7 & $\begin{array}{l}\text { Health } \\
\text { Time } \\
\text { Loney } \\
\text { Facilities } \\
\text { Ynomledge } \\
\text { and Skill } \\
\quad \text { TOTAI } \\
\end{array}$ & $\begin{array}{l}0 \\
0 \\
0 \\
0 \\
0 \\
0 \\
\end{array}$ & 0 & 0 & 0 & .00 \\
\hline Driving & No. & 33.3 & 0 & 66.6 & $\begin{array}{l}\text { Health } \\
\text { T'ine } \\
\text { Loney } \\
\text { Facilities } \\
\text { Knowledge } \\
\text { and Skill } \\
\text { TOTAL }\end{array}$ & $\begin{array}{l}0 \\
0 \\
0 \\
0 \\
0 \\
0\end{array}$ & 0 & 0 & 0 & .00 \\
\hline
\end{tabular}


TABLE 36 (Continued)

Over ${ }_{4} 7,000$ Income Group

\begin{tabular}{|c|c|c|c|c|c|c|c|c|c|c|}
\hline \multirow[t]{2}{*}{ Activity } & \multicolumn{4}{|c|}{$\begin{array}{l}\text { Total No. of lien } \\
\text { indicating attitude } \\
\text { toward activity }\end{array}$} & \multirow{2}{*}{\multicolumn{2}{|c|}{$\begin{array}{l}\text { Total iro. of len } \\
\text { stating reasons } \\
\text { for insufficient } \\
\text { participation }\end{array}$}} & \multicolumn{4}{|c|}{ Total io. of Participations - } \\
\hline & & Iike & Dislike & Indif. & & & WkIy. & Ithly. & YrIY. & Part.Indey \\
\hline Fencing & No. & 0 & 3 & 66.9 & $\begin{array}{l}\text { Health } \\
\text { Tine } \\
\text { Eoney } \\
\text { Facilities } \\
\text { Inowledge } \\
\text { and Skill } \\
\text { TOIAL } \\
\end{array}$ & $\begin{array}{l}0 \\
0 \\
0 \\
0 \\
0 \\
0 \\
\end{array}$ & 0 & 0 & 0 & .00 \\
\hline $\begin{array}{l}\text { Field Event } \\
\text { (Track) }\end{array}$ & No. & 11.1 & 33.3 & 55.5 & $\begin{array}{l}\text { Health } \\
\text { Time } \\
\text { Loney } \\
\text { Facilities } \\
\text { Fnowledge } \\
\text { and Skill } \\
\text { TOTAL }\end{array}$ & $\begin{array}{l}1 \\
0 \\
0 \\
0 \\
0 \\
\\
\end{array}$ & 0 & 0 & 0 & .00 \\
\hline $\begin{array}{l}\text { Bait } \\
\text { Casting } \\
\text { (6 Ionths) } \\
\end{array}$ & No. & 33.3 & 22.2 & 44. & $\begin{array}{l}\text { Health } \\
\text { Tirie } \\
\text { I.oney } \\
\text { Facilities } \\
\text { inorledge } \\
\text { and Skill } \\
\text { TORAL } \\
\end{array}$ & $\begin{array}{l}0 \\
2 \\
0 \\
1 \\
0 \\
\frac{0}{3}\end{array}$ & 0 & 1 & 2 & .89 \\
\hline
\end{tabular}


TABIT 36 (Continued)

Over 37,000 Income Group

\begin{tabular}{|c|c|c|c|c|c|c|c|c|c|c|}
\hline \multirow[t]{2}{*}{ Activity } & \multicolumn{4}{|c|}{$\begin{array}{l}\text { Total No. of len } \\
\text { indicating attitude } \\
\text { toward activity }\end{array}$} & \multirow{2}{*}{\multicolumn{2}{|c|}{$\begin{array}{l}\text { Total ivo. of Hen } \\
\text { stating reasons } \\
\text { for insufficient } \\
\text { participation }\end{array}$}} & \multicolumn{4}{|c|}{ Total lio. of Participations } \\
\hline & & Like & Dislike & Indif. & & & TKly. & Sithly. & YrIy. & Part.Index \\
\hline $\begin{array}{l}\text { Still } \\
\text { Fishing } \\
\text { (o nionths) }\end{array}$ & No. & 55.5 & 22.2 & 2 & $\begin{array}{l}\text { Health } \\
\text { Time } \\
\text { Iiloney } \\
\text { Hacilities } \\
\text { Knowledge } \\
\text { and SkiIl } \\
\quad \text { TOTAI } \\
\end{array}$ & $\begin{array}{l}0 \\
2 \\
0 \\
0\end{array}$ & 0 & 3 & 1 & 2.11 \\
\hline $\begin{array}{l}\text { Football } \\
\text { (3 Months) }\end{array}$ & No. & $44 \cdot 4$ & 22.2 & 33.3 & $\begin{array}{l}\text { Health } \\
\text { Time } \\
\text { Money } \\
\text { Facilities } \\
\text { Knowledge } \\
\text { and Skill } \\
\quad \text { TOTAI } \\
\end{array}$ & $\begin{array}{l}3 \\
0 \\
0 \\
0 \\
0 \\
0 \\
\end{array}$ & 0 & 0 & 0 & .00 \\
\hline $\begin{array}{l}\text { Gardening } \\
\text { (5 Months) }\end{array}$ & Iro. & 77.7 & 11.1 & 11.1 & $\begin{array}{l}\text { Health } \\
\text { Time } \\
\text { luoney } \\
\text { Facilities } \\
\text { Knowledge } \\
\text { and Skill } \\
\text { 'POTAI } \\
\end{array}$ & $\begin{array}{l}0 \\
0 \\
0 \\
2 \\
0 \\
\frac{0}{2}\end{array}$ & 4 & 0 & 1 & $9.70^{\circ}$ \\
\hline
\end{tabular}


TÁBIE 36 (Continued)

Over $\$ 7,000$ Income Group

\begin{tabular}{|c|c|c|c|c|c|c|c|c|c|c|}
\hline \multirow[t]{2}{*}{ Activity } & \multicolumn{4}{|c|}{$\begin{array}{l}\text { Total wo. of Jien } \\
\text { indicating attitude } \\
\text { toward activity }\end{array}$} & \multirow{2}{*}{\multicolumn{2}{|c|}{$\begin{array}{l}\text { Total No. of Len } \\
\text { stating reasons } \\
\text { for insufficient } \\
\text { participation }\end{array}$}} & \multicolumn{4}{|c|}{ Total Iio. of Participations } \\
\hline & & Iike & Dislike & Indif. & & & WkIy. & Iithly. & Yrly. & Part.Index \\
\hline $\begin{array}{l}\text { Golf } \\
\text { (4 Wonths) }\end{array}$ & No. & 55.5 & 22.2 & 22.2 & $\begin{array}{l}\text { Health } \\
\text { Time } \\
\text { lioney } \\
\text { Facilities } \\
\text { Inorrledge } \\
\text { and Skill } \\
\quad \text { TOTAI } \\
\end{array}$ & $\begin{array}{l}0 \\
2 \\
0 \\
0 \\
0 \\
-\frac{0}{2} \\
\end{array}$ & 2 & $I$ & 1 & $4 \cdot 40$ \\
\hline Gymastics & No. & 11.1 & 33.3 & 55.5 & $\begin{array}{l}\text { Health } \\
\text { Time } \\
\text { lioney. } \\
\text { Facilities } \\
\text { Irnowledge } \\
\text { and Skill } \\
\text { TOTAL } \\
\end{array}$ & $\begin{array}{l}0 \\
0 \\
0 \\
0 \\
0 \\
0\end{array}$ & 0 & 0 & 0 & .00 \\
\hline $\begin{array}{l}\text { Eandball } \\
\text { (Q dionths) }\end{array}$ & INo. & 11.1 & 22.2 & 66.6 & $\begin{array}{l}\text { Health } \\
\text { Time } \\
\text { Iioney } \\
\text { Facilities } \\
\text { Inowledge } \\
\text { and Skill } \\
\text { TOTAL }\end{array}$ & $\begin{array}{l}0 \\
0 \\
0 \\
0 \\
0 \\
0\end{array}$ & 0 & 0 & 0 & .00 \\
\hline
\end{tabular}


TABIE 36 (Continued)

Over $\$ 7,000$ Income Group

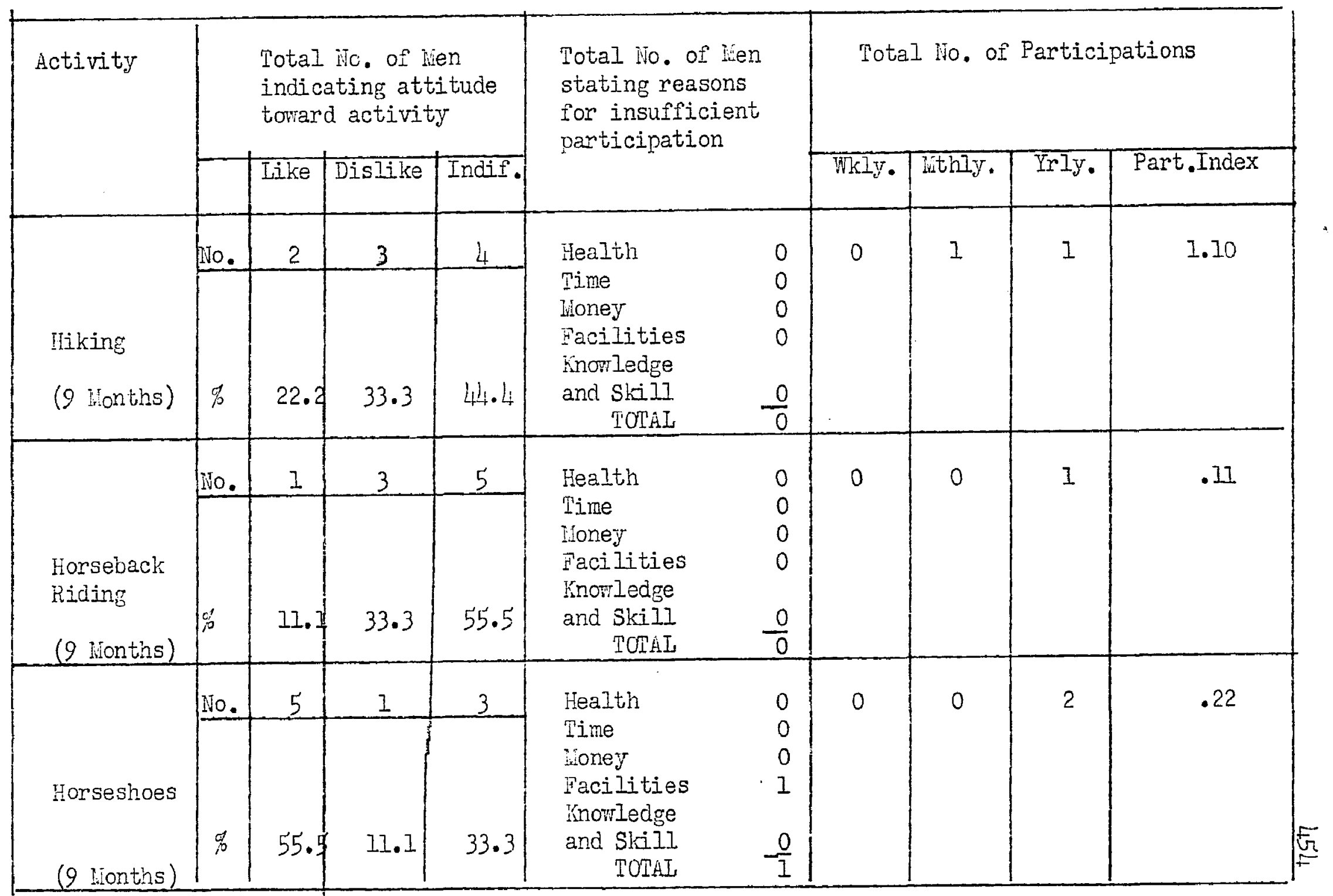


TABLE 36 (Continued)

Over $\$ 7,000$ Incone Group

\begin{tabular}{|c|c|c|c|c|c|c|c|c|c|c|}
\hline \multirow[t]{2}{*}{ Activity } & \multicolumn{4}{|c|}{$\begin{array}{l}\text { Total No. of lien } \\
\text { indicating attitude } \\
\text { toward activity }\end{array}$} & \multirow{2}{*}{\multicolumn{2}{|c|}{$\begin{array}{l}\text { Total loo of lien } \\
\text { stating reasons } \\
\text { for insufficient } \\
\text { participation }\end{array}$}} & \multicolumn{4}{|c|}{ Total iso. of Participations } \\
\hline & & Iike & Dislike & Indif. & & & $7 \mathrm{kJY}$ & lithly. & Yrly. & Part.Index \\
\hline $\begin{array}{l}\text { Huntin: } \\
\text { (3 Honths) }\end{array}$ & No. & 33.3 & 22.2 & $4.4 \cdot 4$ & $\begin{array}{l}\text { Health } \\
\text { Time } \\
\text { Woney } \\
\text { Facilities } \\
\text { Knorledge } \\
\text { and Skill } \\
\text { TOTAL } \\
\end{array}$ & $\begin{array}{l}0 \\
0 \\
0 \\
1 \\
0 \\
0\end{array}$ & 0 & 0 & 3 & .33 \\
\hline $\begin{array}{l}\text { Ice Hockey } \\
\text { (3 Honths) }\end{array}$ & No. & 22.2 & 11.1 & $44 \cdot 4$ & $\begin{array}{l}\text { Health } \\
\text { Time } \\
\text { lioney } \\
\text { Facilities } \\
\text { Inowledge } \\
\text { and Skill } \\
\quad \text { TORAL } \\
\end{array}$ & $\begin{array}{l}0 \\
0 \\
0 \\
1\end{array}$ & 0 & 0 & 1 & .1 .1 \\
\hline $\begin{array}{l}\text { Ice Skating } \\
\text { (3 Honths) }\end{array}$ & No. & 33. & 11.1 & 55.5 & $\begin{array}{l}\text { Health } \\
\text { Time } \\
\text { lioney } \\
\text { Facilities } \\
\text { Knowledge } \\
\text { and Skill } \\
\quad \text { TOTAL } \\
\end{array}$ & $\begin{array}{l}0 \\
0 \\
0 \\
1\end{array}$ & 0 & 0 & 3 & .33 \\
\hline
\end{tabular}


TABLE 36 (Continued)

Over $\$ 7,000$ Income Group

\begin{tabular}{|c|c|c|c|c|c|c|c|c|c|}
\hline \multirow[t]{2}{*}{ Activity } & \multicolumn{3}{|c|}{$\begin{array}{l}\text { Total No. of hen } \\
\text { indicating attitude } \\
\text { toward activity }\end{array}$} & \multirow{2}{*}{\multicolumn{2}{|c|}{$\begin{array}{l}\text { Total No. of hen } \\
\text { stating reasons } \\
\text { for insufficient } \\
\text { participation }\end{array}$}} & \multicolumn{4}{|c|}{ Total No. of Participations } \\
\hline & Tike! & Dislike & Indif. & & & Wkly. & lithly. & Irly. & Part.Index \\
\hline Wetal Craft & Wo. I & 2 & 66.6 & $\begin{array}{l}\text { Health } \\
\text { Time } \\
\text { Loney } \\
\text { Facilities } \\
\text { Knowledge } \\
\text { and Skill } \\
\text { TOTAL } \\
\end{array}$ & $\begin{array}{l}0 \\
0 \\
0 \\
1\end{array}$ & 0 & 0 & 0 & .00 \\
\hline Ilovies & No. 6 & 0 & 33.3 & $\begin{array}{l}\text { Health } \\
\text { Time } \\
\text { Money } \\
\text { Facilities } \\
\text { Knowledge } \\
\text { and Ski17 } \\
\quad \text { TOTAL } \\
\end{array}$ & $\begin{array}{l}0 \\
1 \\
0 \\
0\end{array}$ & 2 & 2 & 2 & 14.40 \\
\hline intus ic & $\because 44.4$ & 11.1 & 44.4 & $\begin{array}{l}\text { Health } \\
\text { Time } \\
\text { ivoney } \\
\text { Facilities } \\
\text { Knowledge } \\
\text { and Skili } \\
\quad \text { TOTAL } \\
\end{array}$ & $\begin{array}{l}0 \\
1 \\
0 \\
0\end{array}$ & 2 & 0 & 1 & 11.7 \\
\hline
\end{tabular}


TABLE 36 (Continued)

Over \$7,000 Income Group

\begin{tabular}{|c|c|c|c|c|c|c|c|c|c|c|}
\hline \multirow[t]{2}{*}{ Activity } & \multicolumn{4}{|c|}{$\begin{array}{l}\text { Total No. of lien } \\
\text { indicating attitude } \\
\text { toward activity }\end{array}$} & \multirow{2}{*}{\multicolumn{2}{|c|}{$\begin{array}{l}\text { Total No. of lien } \\
\text { stating reasons } \\
\text { for insufficient } \\
\text { participation }\end{array}$}} & \multicolumn{4}{|c|}{ Total No, of Participations } \\
\hline & & Iike & Dislike & Indif. & & & Wkly. & withly. & Irly. & Part.Index \\
\hline Notoring & No. & 44.4 & 0 & 55.5 & $\begin{array}{l}\text { Health } \\
\text { Time } \\
\text { Koney } \\
\text { Facilities } \\
\text { Knowledge } \\
\text { and SkilI } \\
\text { ToTAL } \\
\end{array}$ & $\begin{array}{l}0 \\
1 \\
0 \\
0 \\
0 \\
\frac{0}{1}\end{array}$ & 1 & 2 & 0 & 8.40 \\
\hline $\begin{array}{l}\text { Night } \\
\text { cluboing }\end{array}$ & No. & 22.2 & 55.5 & 22.2 & $\begin{array}{l}\text { Health } \\
\text { Time } \\
\text { lioney } \\
\text { Facilities } \\
\text { Inowledge } \\
\text { and Skill } \\
\quad \text { TOTAL } \\
\end{array}$ & $\begin{array}{l}0 \\
0 \\
0 \\
0 \\
0 \\
0\end{array}$ & 1 & 1 & 0 & 7.1 \\
\hline Ping-Pong & No. & 4.4 & 22.2 & 33.3 & $\begin{array}{l}\text { Health } \\
\text { Time } \\
\text { Ihoney } \\
\text { Facilities } \\
\text { Knowledge } \\
\text { and Skill } \\
\text { TOTAL }\end{array}$ & $\begin{array}{l}0 \\
0 \\
0 \\
0 \\
0 \\
0\end{array}$ & 0 & 0 & 4 & .44 \\
\hline
\end{tabular}


THBLE 36 (Continued)

Over \$7,000 Income Group

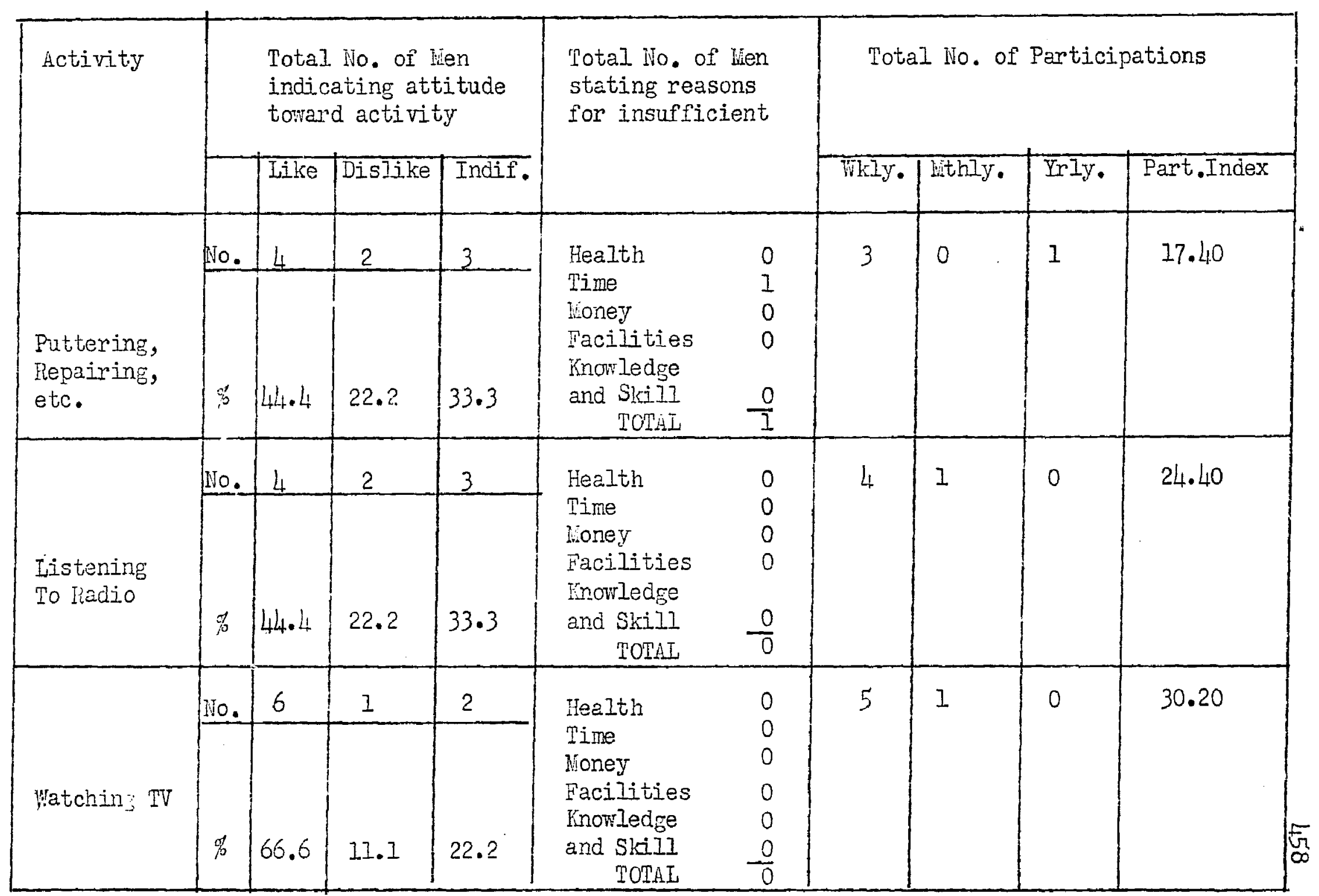


TABLE 36 (Continued)

Over $\$ 7,000$ Income Group

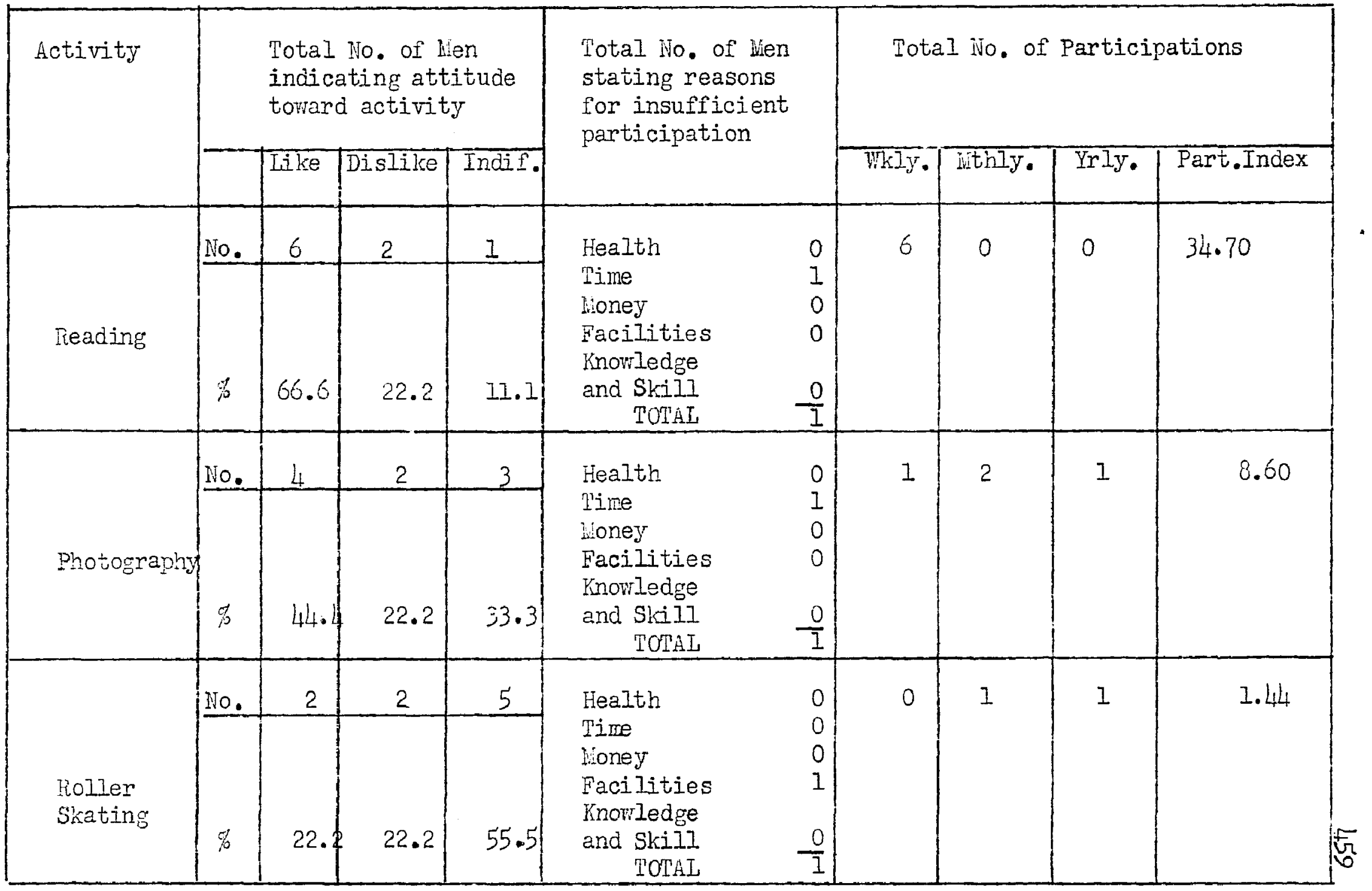


TABIE 36 (Continued)

Over $\$ 7,000$ Income croup

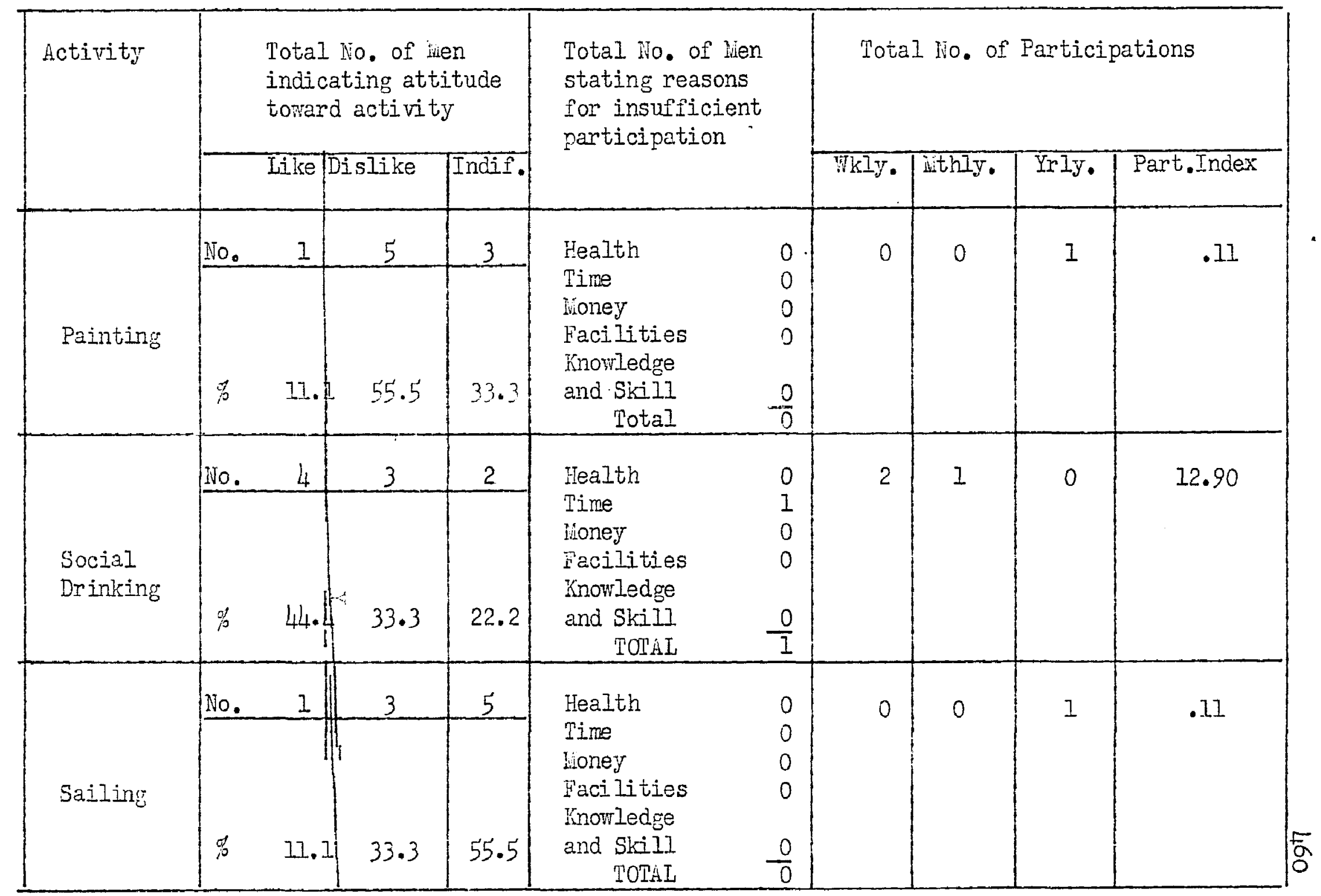


TABIE 36 (Continued)

Over \$7,000 Incorne Group

\begin{tabular}{|c|c|c|c|c|c|c|c|c|c|c|}
\hline \multirow[t]{2}{*}{ Activity } & & \multicolumn{3}{|c|}{$\begin{array}{l}\text { Total wo of Wen } \\
\text { indicating attitude } \\
\text { toward activity }\end{array}$} & \multirow{2}{*}{\multicolumn{2}{|c|}{$\begin{array}{l}\text { Total io. of lien } \\
\text { stating reasons } \\
\text { for insufficient } \\
\text { participation }\end{array}$}} & \multicolumn{4}{|c|}{ Total No. of Participations } \\
\hline & & Iike & Dislike & Indif. & & & WkIy. & Iithly. & Yrly. & Part.Index \\
\hline $\begin{array}{l}\text { Skiing } \\
\text { (3 ironths) }\end{array}$ & No. & 11.1 & 33.3 & 55.5 & $\begin{array}{l}\text { Health } \\
\text { Time } \\
\text { Honey } \\
\text { Facilities } \\
\text { Knowledge } \\
\text { and Skill } \\
\quad \text { ToTAL } \\
\end{array}$ & $\begin{array}{l}0 \\
0 \\
0 \\
1\end{array}$ & 0 & 0 & 0 & .00 \\
\hline $\begin{array}{l}\text { SociaI } \\
\text { Dancing }\end{array}$ & No. & $44 \cdot 4_{4}$ & $44 \cdot 4$ & 11.1 & $\begin{array}{l}\text { Health } \\
\text { Time } \\
\text { Ioney } \\
\text { Facilities } \\
\text { Knortledge } \\
\text { and Skili } \\
\quad \text { TOTAI } \\
\end{array}$ & $\begin{array}{l}0 \\
1 \\
0 \\
0 \\
\\
\frac{1}{2} \\
\end{array}$ & 0 & 1 & 3 & 1.70 \\
\hline Softball & No. & 11.1 & $22 . ?$ & 66.6 & $\begin{array}{l}\text { Health } \\
\text { Time } \\
\text { Loney } \\
\text { Facilities } \\
\text { Knowledge } \\
\text { and SkiII } \\
\quad \text { TOTAL } \\
\end{array}$ & $\begin{array}{l}0 \\
0 \\
0 \\
1\end{array}$ & 0 & 0 & 0 & .00 \\
\hline
\end{tabular}


TABIE 36 (Continued)

Over $\$ 7,000$ 'Income Group

\begin{tabular}{|c|c|c|c|c|c|c|c|c|c|c|}
\hline \multirow[t]{2}{*}{ Activity } & \multicolumn{4}{|c|}{$\begin{array}{l}\text { Total Ho. of Men } \\
\text { indicating attitude } \\
\text { toward activity }\end{array}$} & \multirow{2}{*}{$\begin{array}{l}\text { Total io. of wen } \\
\text { stating reasons } \\
\text { for insufficient } \\
\text { participation }\end{array}$} & & \multicolumn{4}{|c|}{ Total io. of Participations } \\
\hline & & Iike & Dislike & Indif. & & & Wkly• & Withly. & Yrly. & Part.Index \\
\hline Speedball & No. & 2 & 2 & $77 \cdot 7$ & $\begin{array}{l}\text { Health } \\
\text { Time } \\
\text { Hioney } \\
\text { Facilities } \\
\text { Knowledge } \\
\text { and. Skill } \\
\quad \text { TOIAL } \\
\end{array}$ & $\begin{array}{l}0 \\
0 \\
0 \\
0\end{array}$ & 0 & 0 & 0 & .00 \\
\hline $\begin{array}{l}\text { Square } \\
\text { Dancing }\end{array}$ & No. & 11.1 & 55.5 & 33.3 & $\begin{array}{l}\text { Health } \\
\text { Time } \\
\text { Honey } \\
\text { Facilities } \\
\text { Knowledge } \\
\text { and Skill } \\
\text { TOTAI } \\
\end{array}$ & $\begin{array}{l}0 \\
0 \\
0 \\
0 \\
0 \\
0\end{array}$ & 0 & 1 & 0 & 1.33 \\
\hline $\begin{array}{l}\text { Stamp } \\
\text { Collecting }\end{array}$ & No. & 11.1 & 33.3 & 55.5 & $\begin{array}{l}\text { Health } \\
\text { Time } \\
\text { lioney } \\
\text { Facilities } \\
\text { Knowledge } \\
\text { and Skill } \\
\text { TOTAL }\end{array}$ & $\begin{array}{l}0 \\
0 \\
0 \\
1\end{array}$ & 0 & 0 & 1 & .11 \\
\hline
\end{tabular}


IABLE 36 (Continued)

Over \$7,000 Income Group

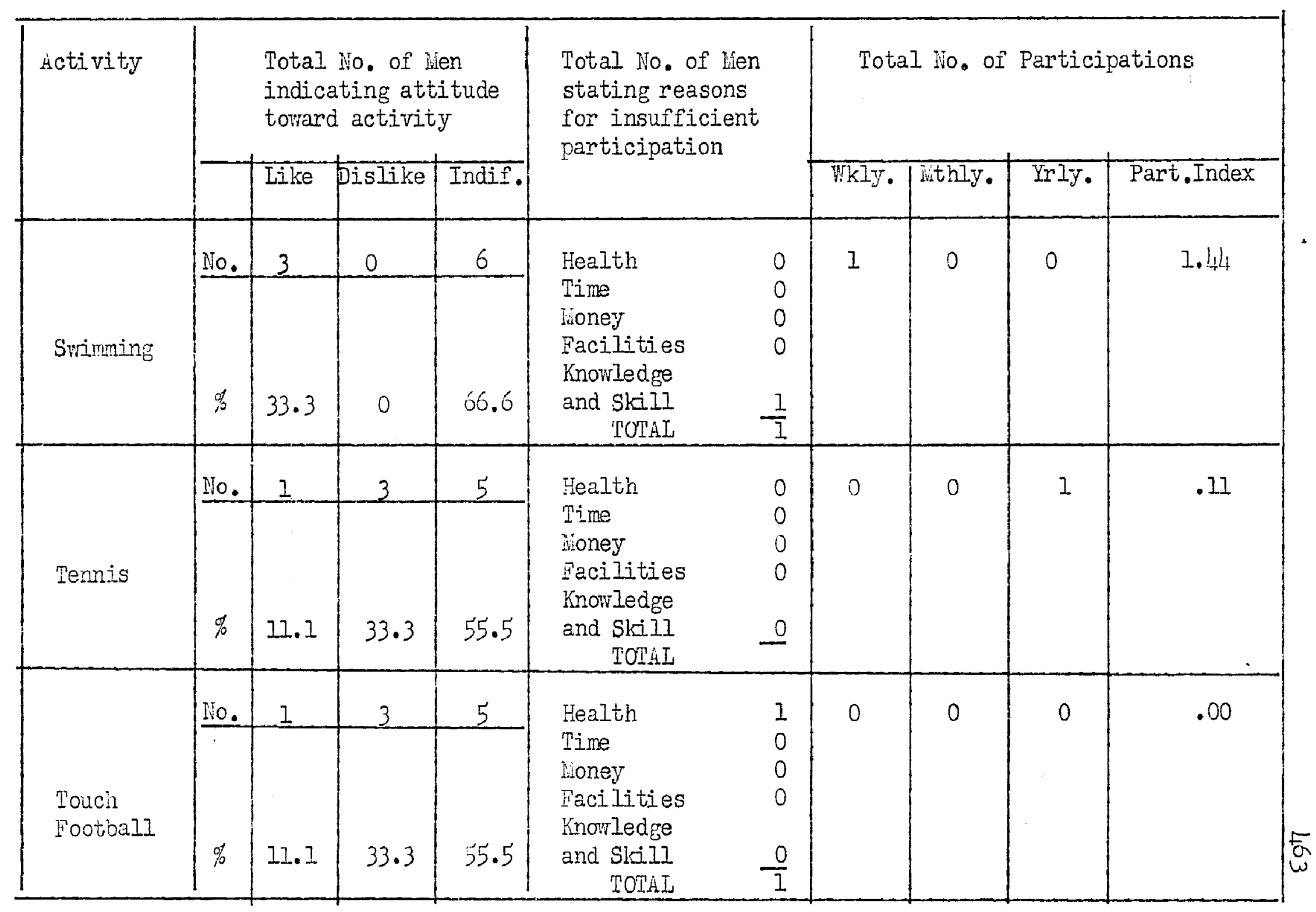


TABAL 36 (Continued)

Over 37,000 Income Croup

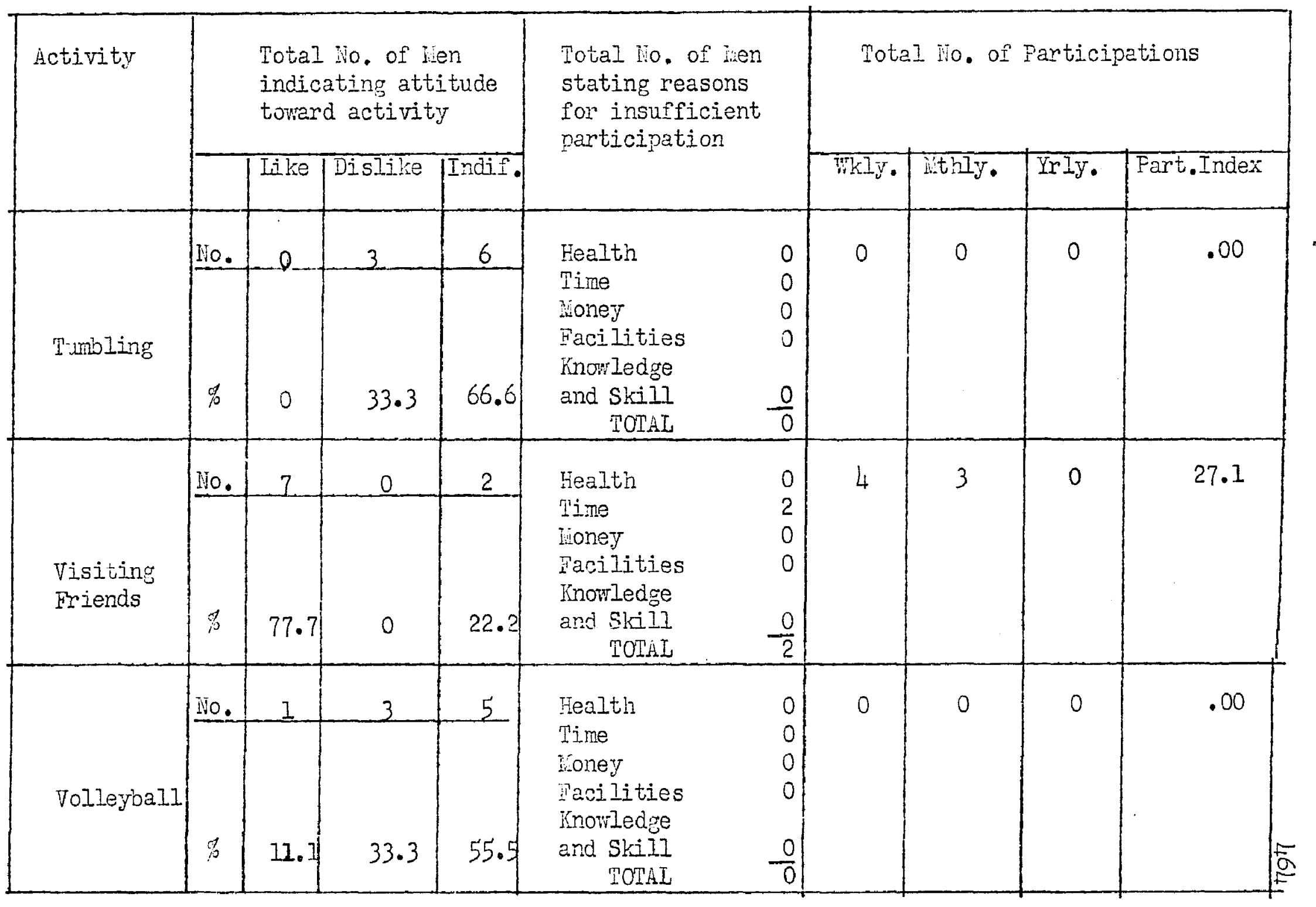


TABLE 36 (Contimued)

Over 6,000 Incone Croup

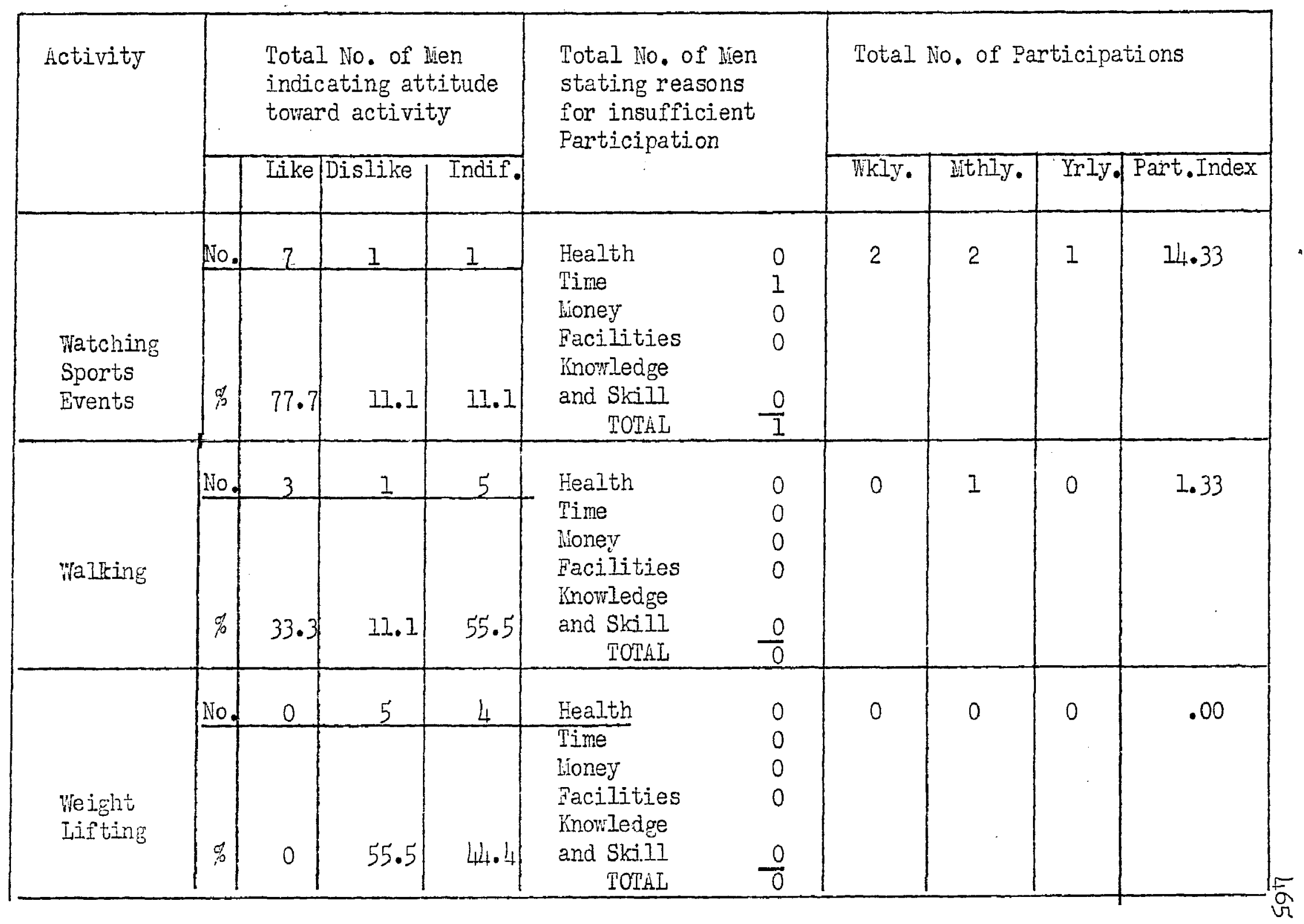


TABLE 36 (Continued)

Over $\$ 7,000$ Income Group

\begin{tabular}{|c|c|c|c|c|c|c|c|c|c|c|}
\hline \multirow[t]{2}{*}{ Activity } & \multicolumn{4}{|c|}{$\begin{array}{l}\text { Total No, of lien } \\
\text { indicating attitude } \\
\text { toward activity }\end{array}$} & \multirow{2}{*}{\multicolumn{2}{|c|}{$\begin{array}{l}\text { Total lio. of lien } \\
\text { stating reasons } \\
\text { for insufficient } \\
\text { participation }\end{array}$}} & \multicolumn{4}{|c|}{ Total io. of Participations } \\
\hline & & Iike & Dislike & Indif. & & & Wikly. & jithly. & Yrly. & Part.Index \\
\hline Water Polo & No. & 11.1 & $44 \cdot 4$ & 44.4 & $\begin{array}{l}\text { Health } \\
\text { Time } \\
\text { lioney } \\
\text { Facilities } \\
\text { Knowledge } \\
\text { and Skill } \\
\quad \text { TOTAL } \\
\end{array}$ & $\begin{array}{l}0 \\
0 \\
0 \\
0 \\
0 \\
0\end{array}$ & 1 & 0 & 0 & 1.44 \\
\hline Woodworkins & No. & $44 d_{4}$ & 22.2 & 33.3 & $\begin{array}{l}\text { Health } \\
\text { Time } \\
\text { lioney } \\
\text { Facilities } \\
\text { Inowledge } \\
\text { and Skill } \\
\text { TOTAL } \\
\end{array}$ & $\begin{array}{l}0 \\
0 \\
0 \\
0 \\
0 \\
0\end{array}$ & 2 & 1 & 0 & 12.90 \\
\hline $\begin{array}{l}\text { Wood } \\
\text { Carving }\end{array}$ & No. & 11.1 & 22.2 & 66.6 & $\begin{array}{l}\text { Health } \\
\text { Time } \\
\text { Loney } \\
\text { Facilities } \\
\text { Knorledge } \\
\text { and Skill } \\
\text { TOTAL } \\
\end{array}$ & $\begin{array}{l}0 \\
0 \\
0 \\
0 \\
0 \\
0\end{array}$ & 1 & 0 & 0 & 5.80 \\
\hline
\end{tabular}


TABIE 36 (Continued)

Over \$7,000 Income croup

\begin{tabular}{|c|c|c|c|c|c|c|c|c|c|c|c|}
\hline \multirow[t]{2}{*}{ Activity } & & \multicolumn{3}{|c|}{$\begin{array}{l}\text { Total No. of len } \\
\text { indicating attitude } \\
\text { toward activity }\end{array}$} & \multirow{2}{*}{\multicolumn{3}{|c|}{$\begin{array}{l}\text { Total ilo. of lien } \\
\text { stating reasons } \\
\text { for insufficient } \\
\text { participation }\end{array}$}} & \multicolumn{4}{|c|}{ Total No. of Participations } \\
\hline & & Tike & Dislike & Indif. & & & & ThKIY. & lithIy. & IrIy. & Part.Index \\
\hline \multirow[t]{6}{*}{ Wrestling } & No. & 1.1 .1 & .44 .4 & 44.4 & \multicolumn{2}{|c|}{$\begin{array}{l}\text { Health } \\
\text { Time } \\
\text { Doney } \\
\text { Pacilities } \\
\text { Knowledge } \\
\text { and Skill } \\
\quad \text { TOTAL }\end{array}$} & $\begin{array}{l}0 \\
0 \\
0 \\
0 \\
\frac{0}{0}\end{array}$ & 0 & 0 & 0 & .0 \\
\hline & \multirow[t]{5}{*}{ REASC } & \multicolumn{3}{|c|}{ Heal.th } & 5 & - & $7.8 \%$ & & & & \\
\hline & & \multicolumn{3}{|c|}{ Tine } & 34 & - & $53.1 \%$ & & & & \\
\hline & & \multicolumn{2}{|c|}{ Iioney } & & 0 & - & 0 & & & & \\
\hline & & \multicolumn{3}{|c|}{ Facilities } & 23 & - & $35.9 \%$ & . & & & \\
\hline & & \multicolumn{3}{|c|}{ Knowledge and Skill } & 2 & - & $3.1 \%$ & & & & \\
\hline
\end{tabular}




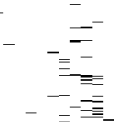

$=$

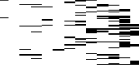

${ }_{-}=$ 
Autobiography

I, James Anton Baley, was born in Cleveland, Ohio, liarch 30 , 1918. I received my secondary school education in the public schools of Cleveland, graduating in 1937. Following graduation, I worked for one year (1937-1938) at the Sidney Hill Health Club in Cleveland, Ohio. Wy duties involved instructing members in the skills of handball, squash, and body building exercises. My undergraduate training was received at the University of Illinois which I attended from 1938 to 1941. In 1941 I enlisted in the Army Air Corps. After serving for four years in the Army Air Corps as Physical Praining Instructor, I returned to the University of Illinois to complete requirements for the degree Bachelor of Science in Physical Education in 1946.

During the school year 1946-1947 I served as Instructor in Physical Education at the University of Illinois on a full-time basis. I also started work toward the degree likster of Science in Physical Education. I completed all requirements for this degree during this year with the exception of the thesis which I wrote in absentia during my first year at Duke University.

In 1947 I accepted a position as Instructor in Physical Education at Duke University in Durham, North Carolina. Iiy major responsibilities were in teaching service classes. In addition I started, organized, and directed both a competitive gymnastics team and a physical education demonstration group called "Gymkana."

During the sumner of 1948, I initiated work toward the degree Doctor of' Philosophy in Physical Education at The Ohio State University. 
I returned to Duke University in the fall and the following summer I resigned in order to meet the residence requirement at The Ohio State University. During the school year of 1949-1950 I met the residence, course, and Ianguage requirements and passed the general examinations.

During the school year 1950-1951 I accepted a temporary position at State Teachers College in Slippery Rock, Pennsylvania. Miy duties were in teacher training. I taught courses in physiology, personal hygiene, kinesiology, first aid, corrective and preventive physical education, professional methods in physical education, and exhibition and demonstration materials. I also served as coach of tennis and as intrammal director.

In June of 1951 I enrolled again at The ohio State University to complete the dissertation. During the school year of $1951-1952$ I taught on a part-time basis at ohio wesleyan University and continued work toward the degree Doctor of Philosophy. Wy duties at Ohio Wesleyan University have included the teaching of service classes in physical education, coaching the swimming team, and teaching a professional course called Therapeutic Physical Education. 